\title{
THE DEVELOPMENT AND PRESERVATION OF TABULAR MASSIVE GROUND ICE IN PERMAFROST REGIONS
}

\author{
by \\ BRIAN JAMES MOORMAN, B.Sc., M.Sc.
A thesis submitted to
the Faculty of Graduate Studies and Research in partial fulfillment of
the requirements for the degree of

Doctor of Philosophy

Department of Earth Sciences

Carleton University

Ottawa, Ontario

(C) copyright

1998, Brian J. Moorman 
National Library

of Canada

Acquisitions and Bibliographic Services

395 Wellington Street Ottawa ON K1A ON4 Canada
Bibliothèque nationale du Canada

Acquisitions et services bibliographiques

395 , rue Wellington

Ottawa ON K1A ON4

Canada
The author has granted a nonexclusive licence allowing the National Library of Canada to reproduce, loan, distribute or sell copies of this thesis in microform, paper or electronic formats.

The author retains ownership of the copyright in this thesis. Neither the thesis nor substantial extracts from it may be printed or otherwise reproduced without the author's permission.
L'auteur a accordé une licence non exclusive permettant à la Bibliothèque nationale du Canada de reproduire, prêter, distribuer ou vendre des copies de cette thèse sous la forme de microfiche/film, de reproduction sur papier ou sur format électronique.

L'auteur conserve la propriété du droit d'auteur qui protège cette thèse. Ni la thèse ni des extraits substantiels de celle-ci ne doivent être imprimés ou autrement reproduits sans son autorisation. 


\section{Abstract}

An investigation of tabular massive ground ice was conducted to ascertain if ground ice has distinctive characteristics that could be measured and used to determine the origin of the ice.

Initial studies were conducted on Bylot Island in the eastern Canadian Arctic, where some glaciers are rapidly retreating, resulting in buried massive ground ice. The environments with the greatest potential for the burial and preservation of massive ice were first examined and the processes of burial identified. It was determined that glacier end and lateral moraines have the greatest potential for preserving massive ice.

Ground penetrating radar (GPR) methodology was developed for imaging the subsurface geometry and structure of glaciers, icing, and ground ice bodies. GPR was shown to be effective for mapping icing and glacier geometry, hydrology and subbottom structure, and possibly thermal conditions. GPR also proved effective at delineating the size and thickness of massive ground ice bodies. This revealed that the ice core in lateral and end moraines around Stagnation Glacier are continuous and extensive.

Physical property analyses indicated that some ice types could not be differentiated on their physical properties alone. A methodology was thus developed for extracting and analyzing the gaseous component of ice which would provide a differentiating technique. This method enabled the measurement of the chemical and isotopic composition of the ice and gases, and direct age determination of the ice by radiocarbon dating of the $\mathrm{CO}_{2}$ in the bubbles. In testing the technique in the proglacial environment on Bylot Island, the environmental history of the site was linked to the more extensive ice core records from Greenland and Devon Island. 
Along with the other ice property analysis techniques, the gas analysis techniques were applied to three sites across the western Canadian Arctic (Peninsula Point, North Point, and Herschel Island). It was discovered that ground ice bodies in the Tuktoyaktuk Peninsula and on Herschel Island were considerably younger than had been reported previously.

In a detailed study of the massive ground ice at Peninsula Point it was determined that the ice mass developed from the segregation of ice formed from a ground water source. The ground water probably originated as glacial meltwater, with several different sources, each with different isotopic signatures. 


\section{Acknowledgments}

This project could not have been undertaken without the aid and assistance of many individuals and institutions. First and foremost, Dr. Fred Michel provided excellent advice and guidance as well as being a great companion in the field. Drs. Alan Judge and Bill Shilts played significant roles in getting the entire research project underway. I would like to thank them for their efforts, insights and suggestions on the project.

Dr. K. Fujino is gratefully acknowledged for supplying the ice samples and photographic record from the Peninsula Point core, and for his hospitality in Japan. The efforts of Dr. Alex Wilson to extract the gases from the ice and the subsequent analysis is also greatly appreciated.

Field assistance from Lynn Moorman, Mark Elver, and Deb Kliza is greatly appreciated. Technical assistance in data manipulation and plotting was graciously provided by Vic Allen and Brenda Mottle. Thanks also go to Ron Pietsch, who ever so kindly generated some of the remote sensing images used for this research.

This research was supported by the Polar Continental Shelf Project, the Geological Survey of Canada, the Canada Centre for Remote Sensing, the Natural Sciences and Engineering Research Council, and the Department of Indian and Northern Affairs through Northern Science Training Program.

Finally, it was the discussions with many people that really made this research enjoyable. These include, but are not limited to, Drs. J. Ross Mackay, Hugh French, Chris Burn and Mr. Scott Dallimore.

The one person I owe the greatest thank-you to is my wife Lynn, for her encouragement, field assistance, editorial efforts, companionship, and all around support. 


\section{Table of Contents}

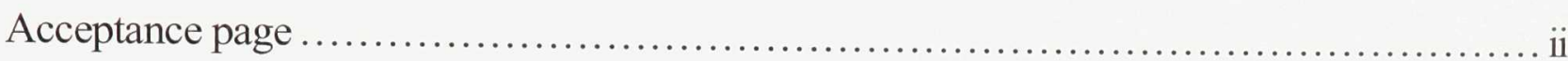

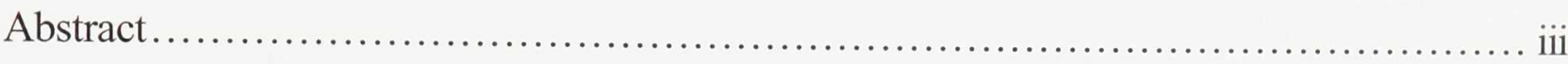

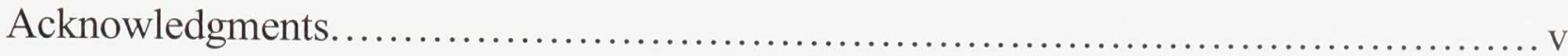

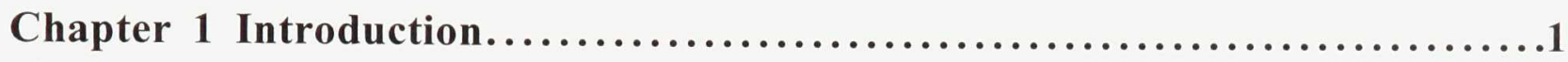

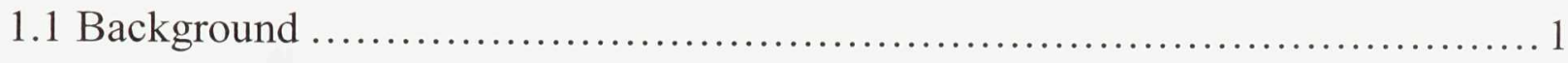

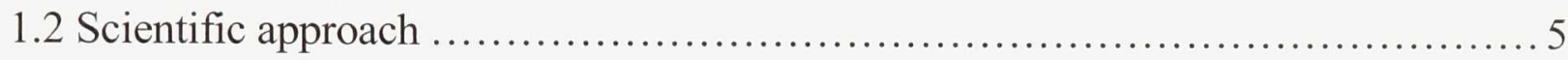

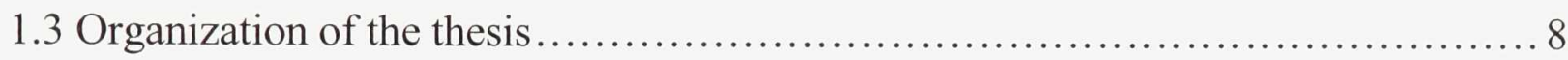

Chapter 2 The burial of ice in proglacial environments............... 10

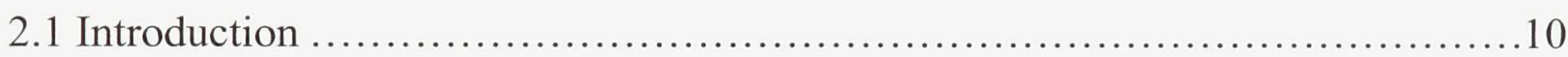

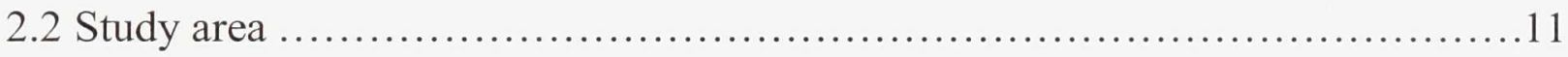

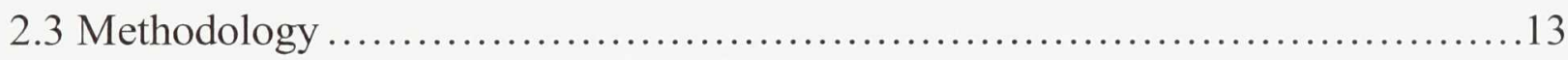

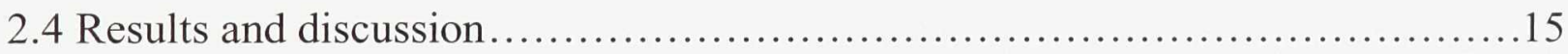

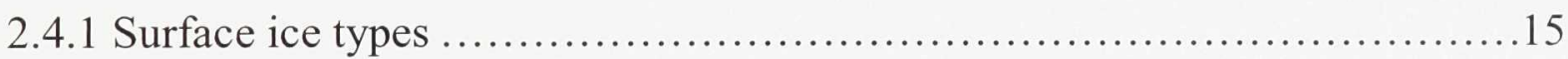

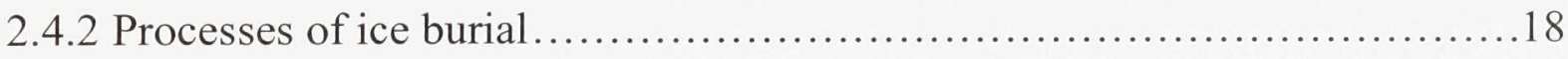

2.4.2.1 The burial of Stagnation Glacier by melt-out $\ldots \ldots \ldots \ldots \ldots \ldots \ldots \ldots \ldots \ldots \ldots \ldots \ldots \ldots$

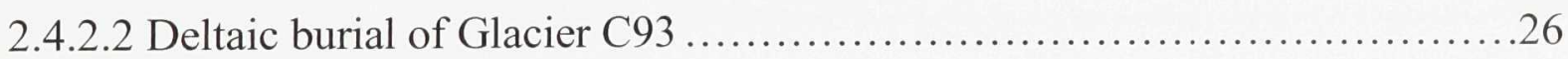

2.4.2.3 Burial of the Fountain Icing by fluvial sedimentation .................... 31

2.4.3 Processes of ground ice erosion....................................... 33

2.4.3.1 Thermokarst lake development................................... 33

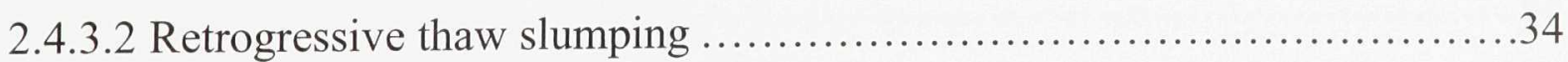

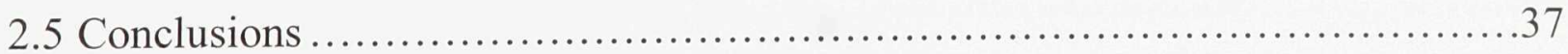


Chapter 3 Mapping surface and buried ice structures 38

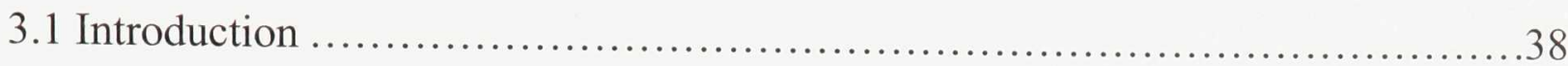

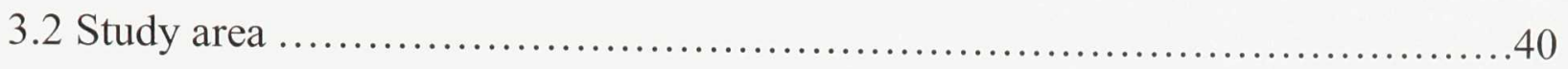

3.3 Methodology: mapping ice bodies with GPR ...............................43

3.4 Results and discussion ................................................. 50

3.4.1 Interface identification and depth determinations.........................50

3.4.2 The character of Fountain and Stagnation Glaciers ..........................54

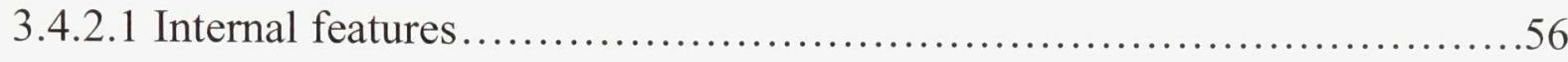

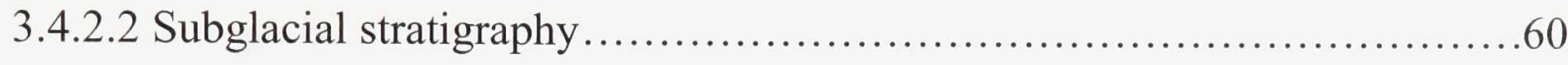

3.4.2.3 Thermal structure of Stagnation Glacier ..............................63

3.4.3 Mapping buried ice around Stagnation Glacier ...........................64

3.4.4 Mapping the structure of icings......................................66

3.4.4.1 Icing formational features........................................67

3.4.4.2 Icing erosion and stability ....................................... 74

3.4.4.3 Icing thickness and preservation.................................77

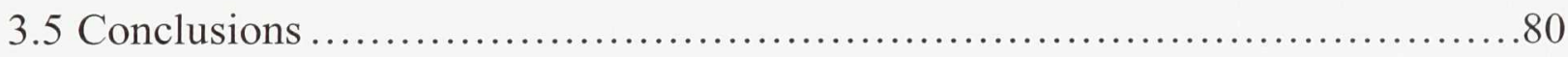

Chapter 4 Ice properties ........................................ 82

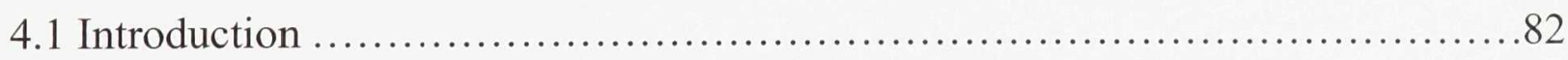

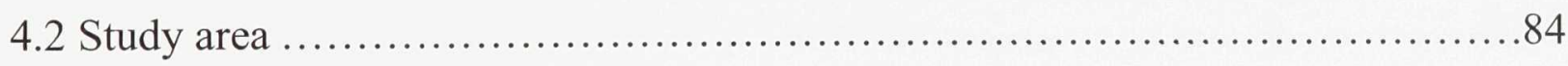

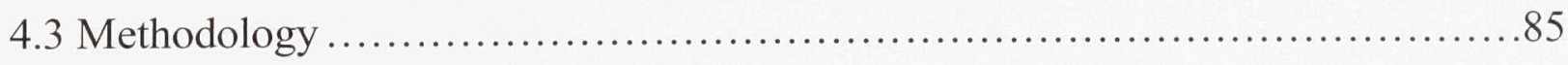

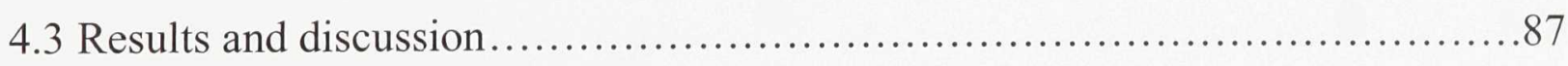

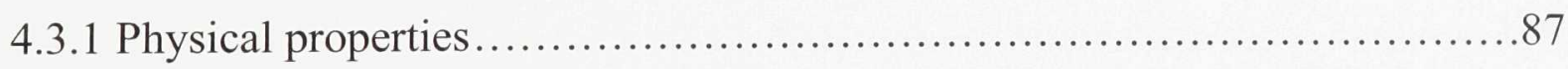

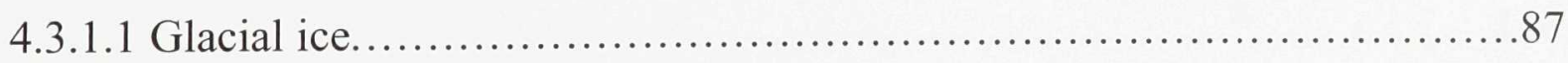

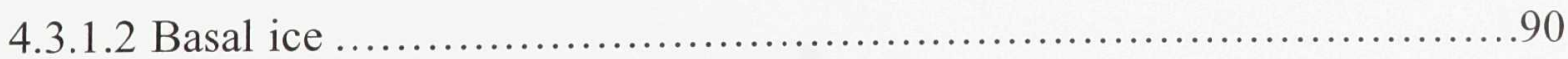

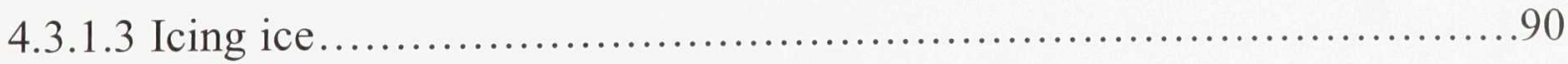

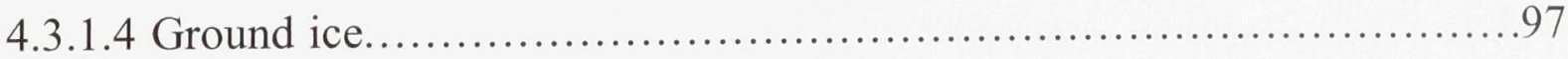


4.3.2 Chemical properties.

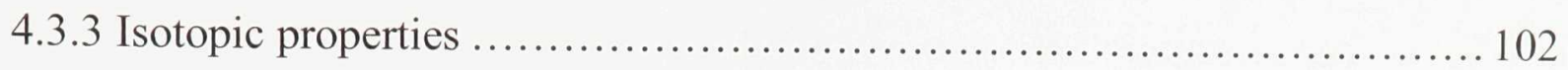

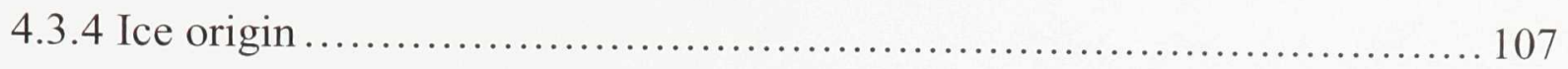

4.3.5 Development of ice bodies .......................................... 108

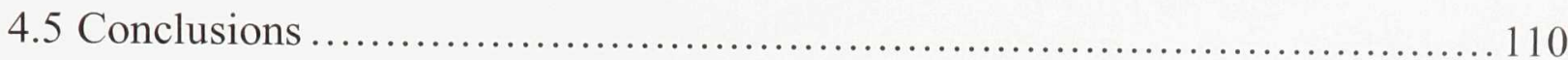

Chapter $5{ }^{14} \mathrm{C}$ dating of trapped gases in massive ground ice,

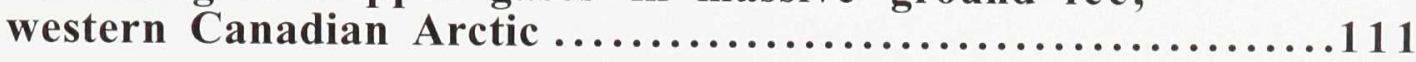

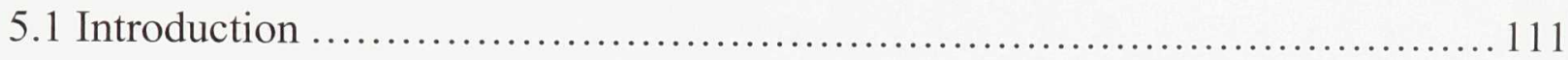

5.2 Ground-ice development in the western Canadian Arctic....................... 113

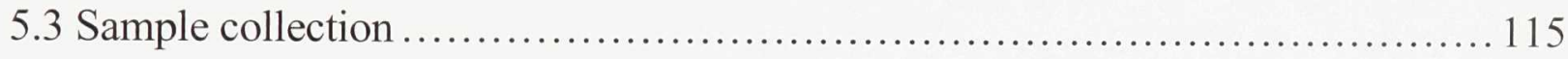

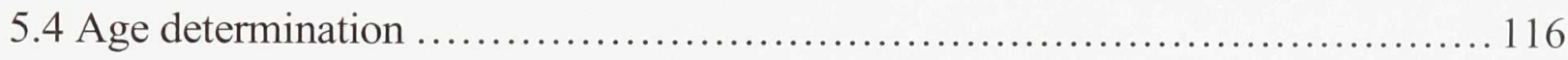

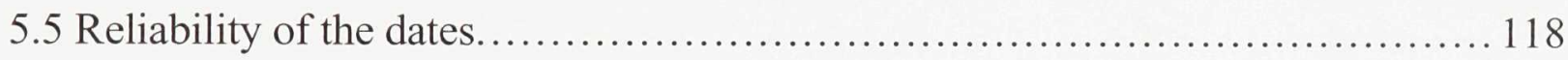

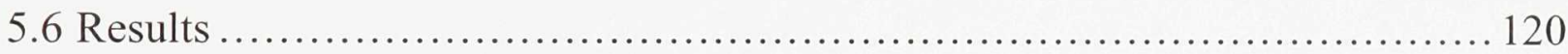

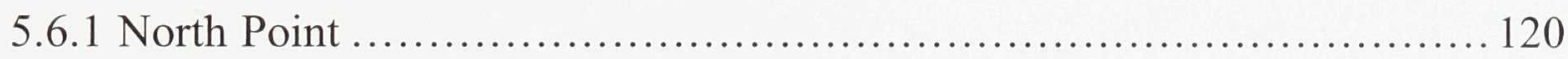

5.6.2 Peninsula Point ............................................... 120

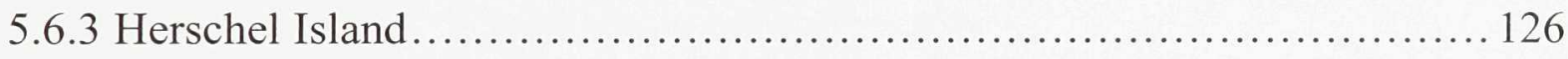

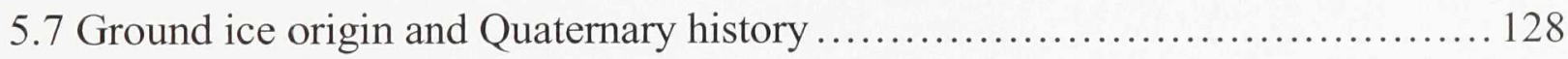

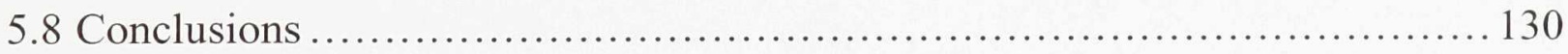

Chapter 6 The Development of Tabular Massive Ground Ice at Peninsula Point, N.W.T., Canada ........................... 1

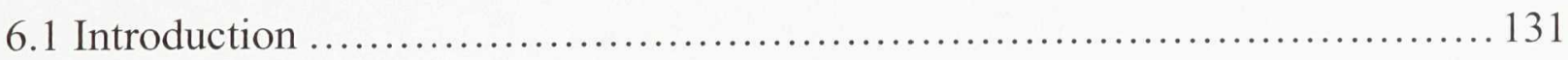

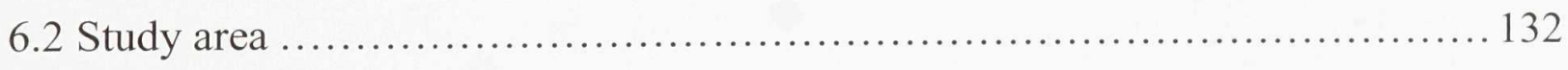

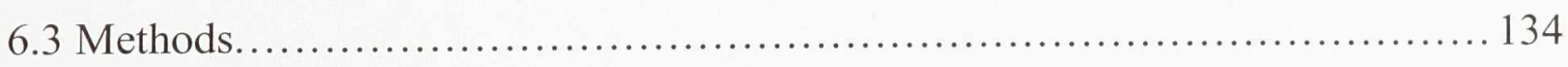

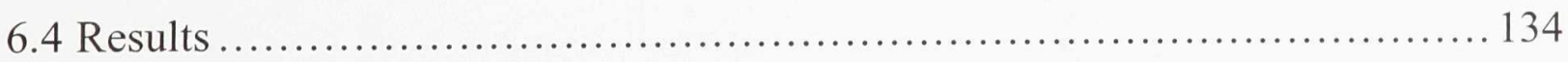

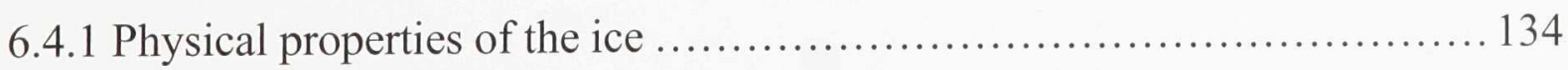

6.4.2 Chemical composition of the gas bubbles............................ 137

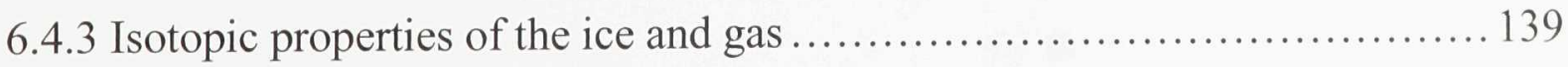




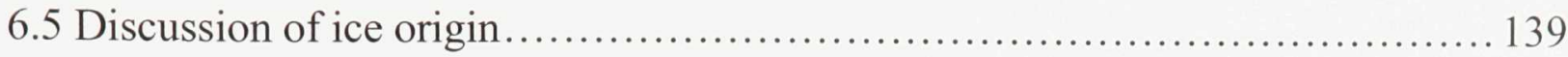

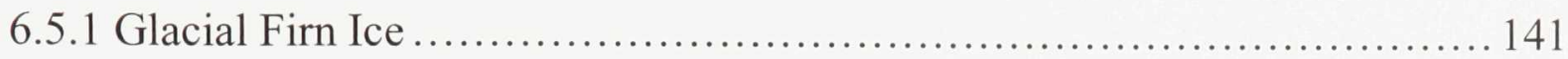

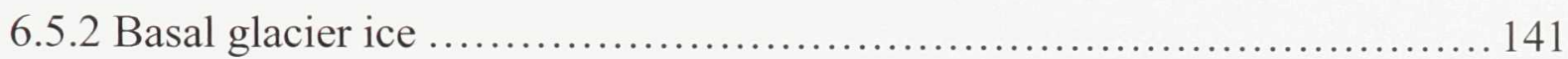

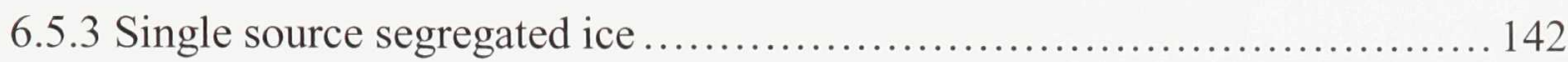

6.5.4 Multiple source segregated ice.................................... 142

6.5.5 Age of the massive ice........................................... 143

6.5.6 Massive ice development and glacial implications...................... 143

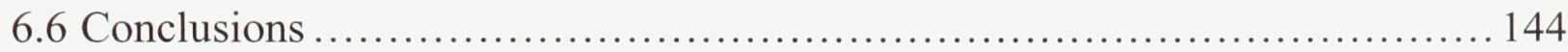

Chapter 7 Summary and Conclusions................................

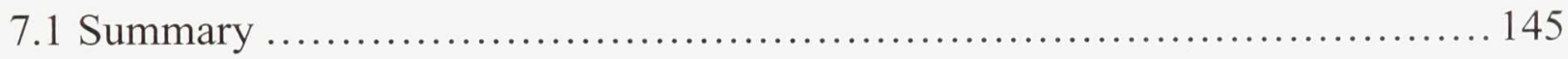

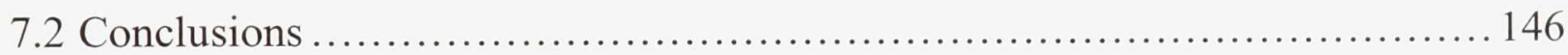

7.3 Recommendations for Further Research............................. 148

Appendix A: Ice cored delta GPR profiles

Appendix B: Accumulation area GPR profiles

Appendix C: Fountain Glacier area GPR profiles

Appendix D: Stagnation Glacier area GPR profiles

Appendix E: Peninsula Point GPR profiles 


\section{List of Tables}

Table 4.1 Chemical and isotopic data for five ice samples from Bylot Island.

Table 5.1 The gas content, $\mathrm{CO}_{2}$ concentration, ${ }^{14} \mathrm{C}$ age, and $\delta^{13} \mathrm{C}$ values of ground ice samples.

Table 5.2 Radiocarbon ages of wood and sediment found at Peninsula Point. 125

Table 6.1. Analysis of ice samples from the tabular massive ground ice at Peninsula Point. 


\section{List of Figures}

Figure 1.1 Known locations of all types of massive ground ice locations across Canada as observed by the author and others (see text for references).....

Figure 1.2 Satellite image of Bylot Island showing the Byam Martin Mountains forming the central core of the island and glaciers flowing onto the lowlands. 7

Figure 2.1 The location of the study area on Bylot Island.......................... 12

Figure 2.2 This 1985 satellite image (Landsat band 4) of the study area shows the physiography of southwestern Bylot Island. The faulted contact between the sandstone plains and the metamorphic mountainous regions of the island runs roughly down the centre of the image....................................... 16

Figure 2.3 Change detection image created by digitally subtracting a 1958 aerial photograph from a 1982 aerial photograph of the same area. The black represents areas covered by ice in 1958 but not in 1982

Figure 2.4 Map of the proglacial icing in front of Fountain Glacier in 1993 showing icing thickness in metres and the location of drainage channels within and below the icing....

Figure 2.5. Most of the shear planes present near the toe of Stagnation Glacier are void of sediment; however, some such as the one shown above carry considerable amounts of sediment up to the surface of the glacier. Up glacier is to the left. ...

Figure 2.6 Schematic section through the front of Stagnation Glacier constructed using data from a series of GPR surveys and ice exposures.

Figure 2.7 The cross profile of Stagnation Glacier shown in (a) was constructed from topographic leveling and GPR data, such as the example shown in (b). The location of this cross

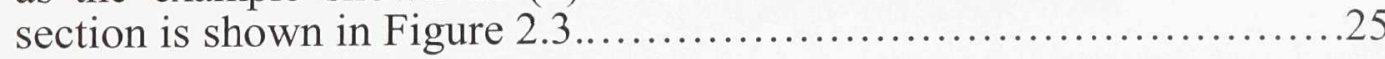

Figure 2.8 The evolution of the ice cored delta. a-c show one the growth and two erosion stages of the delta. d\&e show the spatial and stratigraphic relationships of the sediment and ice

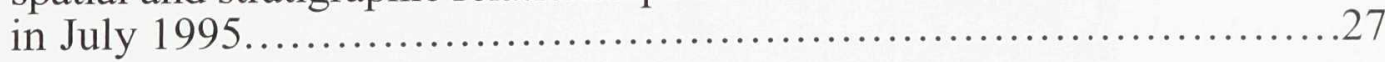

Figure 2.9 GPR profile across the delta shown in Figure 2.8. A stream cut at the left side of the profile was used for interface depth verification. 
Figure 2.10 Minimum and maximum daily temperatures from August 1994 to August 1995 at a depth of $10 \mathrm{~cm}$ below the ground surface in a low centered polygon. Data courtesy of Dr. Gilles Gauthier, Université Laval. ...

Figure 2.11 Photo of the retrogressive thaw slump on the west side of the Sermilik Valley.

Figure 3.1 Aerial photograph of the study area on Bylot Island taken in 1983 showing Fountain and Stagnation Glaciers and a portion of the icing. NAPL A26078-50.

Figure 3.2 Representative profiles of the termini of Fountain and Stagnation Glaciers

Figure 3.3 While the terminus of Fountain Glacier has remained unchanged since 1948, Stagnation Glacier has retreated almost $2 \mathrm{~km}$. The extent of the two glaciers is mapped from aerial photography taken in 1948, 1958, 1982 and 1994. The icing that originates in front of Fountain Glacier can extend for over $11 \mathrm{~km}$ some years but only a small portion of that persists from year to year.

Figure 3.4 The GPR unit is towed behind one person while the second person asses the incoming data on a laptop computer. The energy pulses generated by the transmitter (A) propagate through the ground and are reflected back to the receiver (B) whenever they encounter a dielectric interface, such as the bottom of the glacier shown on the profile. Note that the GPR data can be displayed as grey scale profiles (as shown above) or as wiggle traces (as displayed in other figures).

Figure 3.5 A comparison of the strength of returns from two different GPR configurations. While the signal to noise ratio for the deep reflections (eg. the base of the glacier) in the $200 \mathrm{MHz}$ trace is less than 1, it is greater than 2.4 in the $50 \mathrm{MHz}$ trace.

Figure 3.6 A common mid-point (CMP) velocity survey from Stagnation Glacier displaying weak reflections from internal ice layering and a strong reflection from the base of the glacier. Note that in general, few internal reflections were observed from within the glaciers.

Figure 3.7 Subsurface velocities can be determined from CMP surveys, where traces are recorded as the transmitter and receiver are separated about a common mid-point a), producing a separation vs. travel time plot as shown in b), or by profiling over a point-source reflector c), and using the geometry of the diffraction tails generated on the profile d) .........................

Figure 3.8 GPR profile up the terminus of Stagnation Glacier a), and the interpretation b). In c) a thermal model of the subsurface was used to generate reflection coefficients for the major reflectors in the profile in a) 
Figure 3.9 The basal and surface elevation of a small portion of Stagnation Glacier relative to the elevation of a benchmark at the terminus of the glacier. The location of small air filled voids and a water filled englacial tunnel are also shown. See Figure 3.3 for location

Figure 3.10 A schematic of how interpolation between multiple GPR profiles enables the determination of the 3-dimensional position of point source reflectors that generate long diffraction tails in ice.

Figure 3.11 The observed position of surface streams and position of subsurface determined from GPR surveys.

Figure 3.12 A GPR survey (a), and interpretation (b), from the side of Stagnation Glacier into its east lateral moraine, showing how the glacier ice extends out into the core of the moraine.

Figure 3.13 Photograph of an ice core taken from the icing in front of Fountain Glacier, displaying the three main types of ice present

Figure 3.14 A GPR survey (a), and interpretation (b), across the seasonal portion of the icing in front of Fountain Glacier, displaying the stratigraphy of the icing and sediments below, and the diffraction pattern generated by a water filled tunnel. See Figure 3.17 for location.

Figure 3.15 A portion of the long GPR profile a) and interpretation b) run down the seasonal portion of the icing. Note that in the down ice direction the ice stratigraphy is not flat as it is in the perpendicular direction. See Figure 3.17 for location

Figure 3.16 An exposure at a stream cut of a very large channel fill in the icing in front of Fountain Glacier.

Figure 3.17 Map of icing thickness in front of Fountain Glacier. Overall the surface of the icing was slightly domed except for a ridge surrounding a part of the seasonal portion of the icing where ice did not accumulate to the height of the perennial portion of the icing. Note that the glacier runoff stream on the east side of the valley completely disappears into the icing for

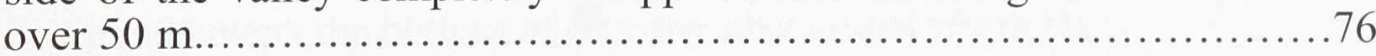

Figure 3.18 A schematic diagram of the annual cycle of ice accumulation and erosion in the only perennial icing on Bylot Island. Note that the size of the central core of ice that survives the summer melt season varies from year to year 
Figure 4.1 Sampling sites were located on Fountain and Stagnation Glaciers, at the basal ice sections at the edge of both glaciers, the lateral and end moraine surrounding Stagnation Glacier, and the retrogressive thaw slump just beyond the most recent limits of Sermilik Glacier. Note that the extent of Stagnation and Sermilik Glaciers at the time of sampling was less than on this 1982 image

Figure 4.2 The layered appearance at the terminus of Fountain Glacier is caused by small variations in the bubble concentration, crystal size, and sediment content. The horizontal layers appear to be dipping in the photograph due to the angle of the cliff face.

Figure 4.3 Examples of the ice characteristics observed on Fountain and Stagnation Glaciers. These normally (left) and cross polarized (right) thick section photographs are representative of the majority of the glacier ice observed.

Figure 4.4 Basal ice at the side of Fountain Glacier. See Figure 5.1 for location A sediment-rich layer is visible about 4-6 $\mathrm{m}$ above the base of the glacier. Note person for scale.

Figure 4.5 The deformation of Fountain Glacier basal ice. In (a) the ice flows around a bedrock knob. In (b) ice deforms around a boulder in the basal section just above the base of the glacier. In both photographs ice flow is to the left

Figure 4.6 The distinctive appearance of icings is due to the predominant beds created with each successive flooding or injection event. Most of the ice mass in the two photographs is bubbly white ice formed from slush. The layers indicated by the arrows were produced by water being injected between already existing ice layers. The discontinuous layer being pointed to in (b), is a infilled channel in the icing. The dirt on the icing in (a) is wind blown, deposited during the thaw season.

Figure 4.7 A partially melted ice crystal from within an icing blister. Note that the crystal is bent due to the changing direction of heat flow as the blister grew.

Figure 4.8 Sediment covers the bottom of recently abandoned channels. The two people in (a) are standing in an abandoned channel at a lower level, looking at the sediment at their head level. Bedrock of the valley side can be seen in the left side of the picture. In (b) a small subchannel $(20 \mathrm{~cm}$ across) is cut into the bottom of a larger channel (extends beyond the frame of the photograph) which was $3 \mathrm{~m}$ across..............................996 
Figure 4.9 Thick section photographs displaying the variability in ground ice characteristics. (a) is a cross polarized photograph of sample taken from the east lateral moraine of stagnation Glacier near the upper contact of the ice body. (b) is from a small transverse ridge in the end moraine about $20 \mathrm{~m}$ beyond the terminus of Stagnation Glacier about $20 \mathrm{~m}$ beyond the terminus of Stagnation Glacier. (c) is an example of the ice from the retrogressive slump near Sermilik Glacier

Figure 4.10 A view of the lower surface of the ice core in the east lateral moraine, from within the ice cave. The lighter portions of the wall closer to the ground are covered with frost. The darker areas above head level display the sediment dispersed throughout the ice. The arrow points to a large mass of up to cobble sized sediment in the ice.

Figure 4.11 The oxygen isotope data from glacier and ground ice on Bylot Island (dots) compared to ice core data from Devon Island and Greenland (after Paterson et al., 1977). Note that some of the ice samples are not of a firn origin and thus the radiocarbon dates represent maximum ages.

Figure 4.12 Co-isotopic plot of firn and glacier, basal, and ground ice data from Bylot Island. The open circles and triangles represent data from Glacier B7 (Figure 2.2). The solid circles and triangles represent glacier and ground ice from this study. Note that the ground ice in this study is most similar to the glacial ice and firn analyzed by Zdanowicz et al. (1996)

Figure 4.13 A spring exiting the east lateral moraine of Stagnation Glacier. A lateral stream disappeared into the moraine several hundred metres up stream. Note the person for scale (indicated by the arrow). The glacier is in the fore-ground.

Figure 5.1 Map of the western Canadian Arctic illustrating the glacial ice limits as mapped by Rampton (1988) and the sample locations discussed in the text

Figure 5.2 Flow chart illustrating the ice sublimation and analysis procedure.

Figure 5.3 Schematic diagram (a) showing general character of the thaw slump at North Point, and photograph (b) of the headwall displaying ground ice structure and sampling location (by the person at the foot of the headwall). Height of person at top of headwall is $2 \mathrm{~m}$.

Figure 5.4 Schematic diagram (a) of the structures observed in the headwall of the thaw slump at Peninsula Point, and photograph (b) of sampling location. Twig protruding from diamicton at centre of photograph was 14C dated (WAT 2685, Table 1). Height of headwall in photograph is $4 \mathrm{~m}$ 
Figure 5.5 Schematic diagram (a), and photograph (b) of the headwall of the thaw slump on Herschel Island, displaying ground ice structure and sampling location. The ice and sediment units are both highly deformed. The height of the headwall below the person is $13.75 \mathrm{~m}$.

Figure 6.1 Location of the study site in relation to the interpreted limit of the most recent glacial advance as mapped by Rampton (1988b).

Figure 6.2 A thick section photograph typical of the core from Peninsula Point. This ice came from a depth of $10.9 \mathrm{~m}$. a) normal polarization displaying bubble character, and b) cross polarization displaying crystal character.

Figure 6.3 A thick section photograph from $10.7 \mathrm{~m}$ depth in the core from Peninsula Point. This section shows the range in bubble content and character and variability in the ice crystal size present in the core. a) normal polarization displaying long vertical bubble trains as well as bubble free zones, and b) cross polarization displaying crystals varying in size from less than $0.5 \mathrm{~cm}$ to over $5 \mathrm{~cm}$ in diameter.

Figure 6.4 Core logs from Peninsula Point. The top middle and bottom sections of the core reveal quite different characters. Analytical error of $18 \mathrm{O}$ profile is $\pm 0.2 \%$ 


\section{Chapter 1}

\section{Introduction}

\subsection{Background}

Permafrost underlies over half of Canada's landmass, and massive ground ice is frequently observed throughout permafrost regions (Figure 1.1). Massive ground ice is defined as having an ice content of at least $250 \%$ (on an ice-to-dry-soil weight basis) (Permafrost Subcommittee, 1988). The size of massive ice bodies ranges from tens of cubic centimetres to thousands of cubic metres.

Massive ground ice takes several forms; pingos, ice wedges, ice lenses, and tabular massive ground ice. The development of pingos, ice wedges and small segregated ice lenses is fairly well understood (French, 1976). However, the origin and formational processes of tabular massive ice bodies are still a matter of some debate. Some tabular 


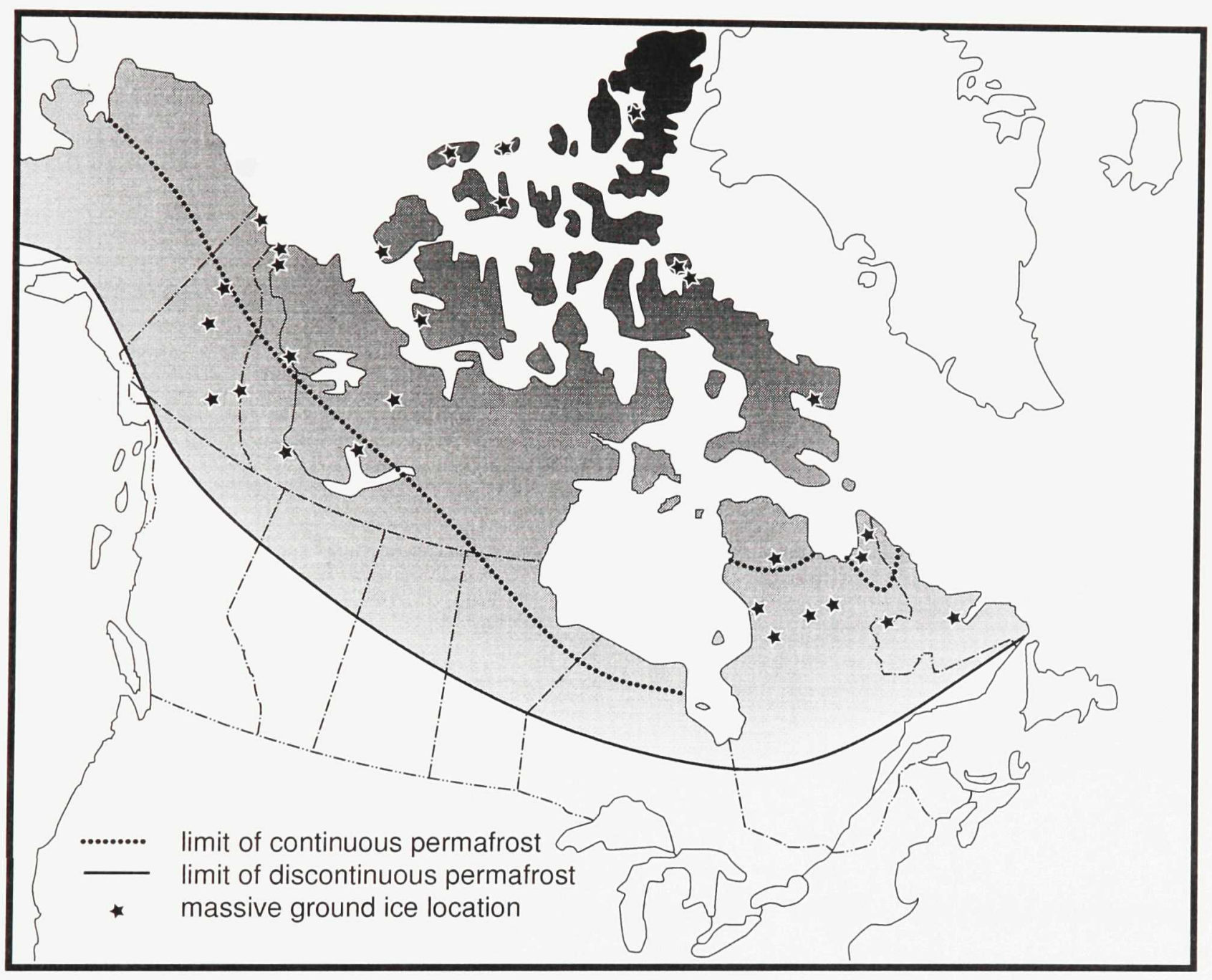

Figure 1.1 Known locations of all types of massive ground ice locations across Canada as observed by the author and others (see text for references). 
massive ice bodies have been interpreted to be of segregated origin (Mackay, 1971), while others are thought to be buried glacier ice (Dallimore and Wolfe, 1988; Robinson et al., 1993; Vaikmäe et al., 1993). Tabular massive ice bodies are distinctive in that they tend to have much larger lateral dimensions than thickness. For example, some of the largest tabular massive ice bodies that have been discovered are up to $50 \mathrm{~m}$ thick while their lateral extent is over $4 \mathrm{~km}^{2}$.

Tabular massive ground ice is prevalent throughout the Canadian Arctic. Tabular massive ground ice bodies have been observed in the interior of Yukon (French and Pollard, 1986), along the Yukon coastal plain (Harry et al., 1988; Michel, 1985; Pollard and Dallimore, 1988), throughout the Mackenzie Delta (Mackay, 1966; 1971; 1973; Gell, 1978; Fujino, 1986; Dallimore and Wolfe, 1988; Fujino et al., 1988; Rampton, 1988a, b) on Banks Island (French and Harry, 1988), on Victoria Island, (Lorrain and Demeur, 1985), on Prince Patrick and Mackenzie King Islands (Mackay, 1973), as well as on Ellesmere, Bylot, and Baffin Islands (Robinson, 1993). There has been considerably less tabular massive ground ice discovered in Alaska (Smith and Berg, 1973) and China (Cheng et al., 1978), but it is known to be extensive in Russia (Popov, 1962; 1970; Soloviev, 1973; Astakhov and Isayeva, 1988; Arkhangelov and Novgorodova, 1991; Vaikmäe et al., 1993).

Unlike other types of massive ice (eg. pingo or ice wedge), the surface expression of tabular massive ground ice is often not conspicuous and usually its genesis is not obvious. Massive ground ice has been and is currently being investigated using a limited number of different approaches. Massive ground ice was first studied using standard stratigraphic techniques (Mackay, 1971; 1973; Mackay and Black, 1973; French and Harry, 1988). The advancement of ice petrography has led to a better understanding of the complex processes at work in the genesis of massive ground ice (French and Pollard, 1986; Harry et al., 1988; Pollard and Dallimore, 1988). Recently, the examination of the 
chemical and isotopic properties of massive ground ice and the gases contained within was suggested to be very useful in genetic analysis of the ice (Michel, 1982; 1983; 1986; Kato et al., 1986a, b; Horiguchi, 1988; Arkhangelov and Novgorodova, 1991; Vaikmäe et al., 1993). Palynology is also beginning to be applied to ice cores as it has been to unconsolidated Quaternary sediments (Fujino et al., 1988). In an attempt to image the general structure of subsurface ice bodies, geophysical techniques have been employed with varying degrees of success (Scott et al., 1978). To date, the majority of research on tabular massive ground ice has focused on the stratigraphic and petrographic characteristics of tabular massive ground ice.

Often, investigations of only limited scope are undertaken, resulting in the accumulation of insufficient information for proper genetic analysis of ground ice (French and Pollard, 1986). After studying the stratigraphic and petrographic characteristics of an ice body on Banks Island it was concluded that "Additional criteria based upon water (ice) quality, especially isotopes, and crystallography need to be developed which may then be interpreted within a cryostratigraphic framework" (French and Harry, 1988).

It is proposed that a clearer understanding of the origins of tabular massive ground ice can only be gained by a more in-depth study of tabular massive ground ice bodies using a suite of techniques, including the chemical and isotopic analysis of the ice and gases trapped within it and the three dimensional internal structure of ice bodies and their stratigraphic relationship to the encompassing sediments. 


\subsection{Scientific approach}

The main purpose of this thesis is to examine the development of tabular massive ground ice and further the understanding of its origins and distribution. To this end five principal objectives are identified:

- Identify the environments in which surface ice is most likely to become buried and determine the potential for its preservation as ground ice.

- Develop a technique for imaging the stratigraphic relationships between ice bodies and the surrounding sediments.

- Develop a technique for analyzing the gases trapped within ground ice to allow their radiocarbon dating and measurement of their chemical and isotopic makeup.

- Compare the characteristics of glacier ice to those of buried ground ice in order to differentiate between the two.

- Test the hypothesis that tabular massive ground ice has measurable characteristics that are indicative of its origin, and that segregated ice can be differentiated from buried ice.

To accomplish these objectives it was determined that the processes of ice burial needed first to be examined in an environment of active ice burial. This was achieved on Bylot Island, N.W.T. where the combination of cold air temperatures (mean annual air temperature of $-15^{\circ} \mathrm{C}$ ) and rapidly retreating glaciers is resulting in the burial and preservation of large amounts of ice. Bylot Island also provides a very good modern analogy to the Laurentide ice sheet. Similar to the entire continental landmass, the centre of the island is composed of Archean crystalline rock of the Canadian Shield. This 
mountainous core is host to a large ice field (Figure 1.2). To the southwest, glaciers flow onto lowlands composed of Cretaceous/Tertiary sedimentary rock.

The development of buried massive ground ice on Bylot Island was studied using three approaches. A time series analysis of aerial photographs and satellite imagery was employed to study the retreat of glaciers over large areas, and to define the surface expression and temporal development of buried ground ice.

As only limited information on the character of massive ground ice could be gained from surface observation, ground penetrating radar (GPR) was employed to image the subsurface structural details within the ice, and the stratigraphic relationships of the ice bodies to the surrounding sediments. The recent availability of high fidelity GPR technology has enabled the development of applications for imaging surface and buried ice bodies (Moorman, 1996).

Finally, the physical, chemical, and isotopic characteristics of surface and buried ground ice were also studied in order to gain greater insight into the processes of development.

The insights acquired into ice burial on Bylot Island were then applied to decipher the origins and history of the tabular massive ground ice in the western Canadian Arctic. The western Canadian Arctic contains widespread ground ice of "complex origin" (Mackay, 1973; Michel, 1985; French and Harry, 1988; Fujino et al., 1988; Pollard and Dallimore, 1988, Dallimore and Wolfe, 1988). 


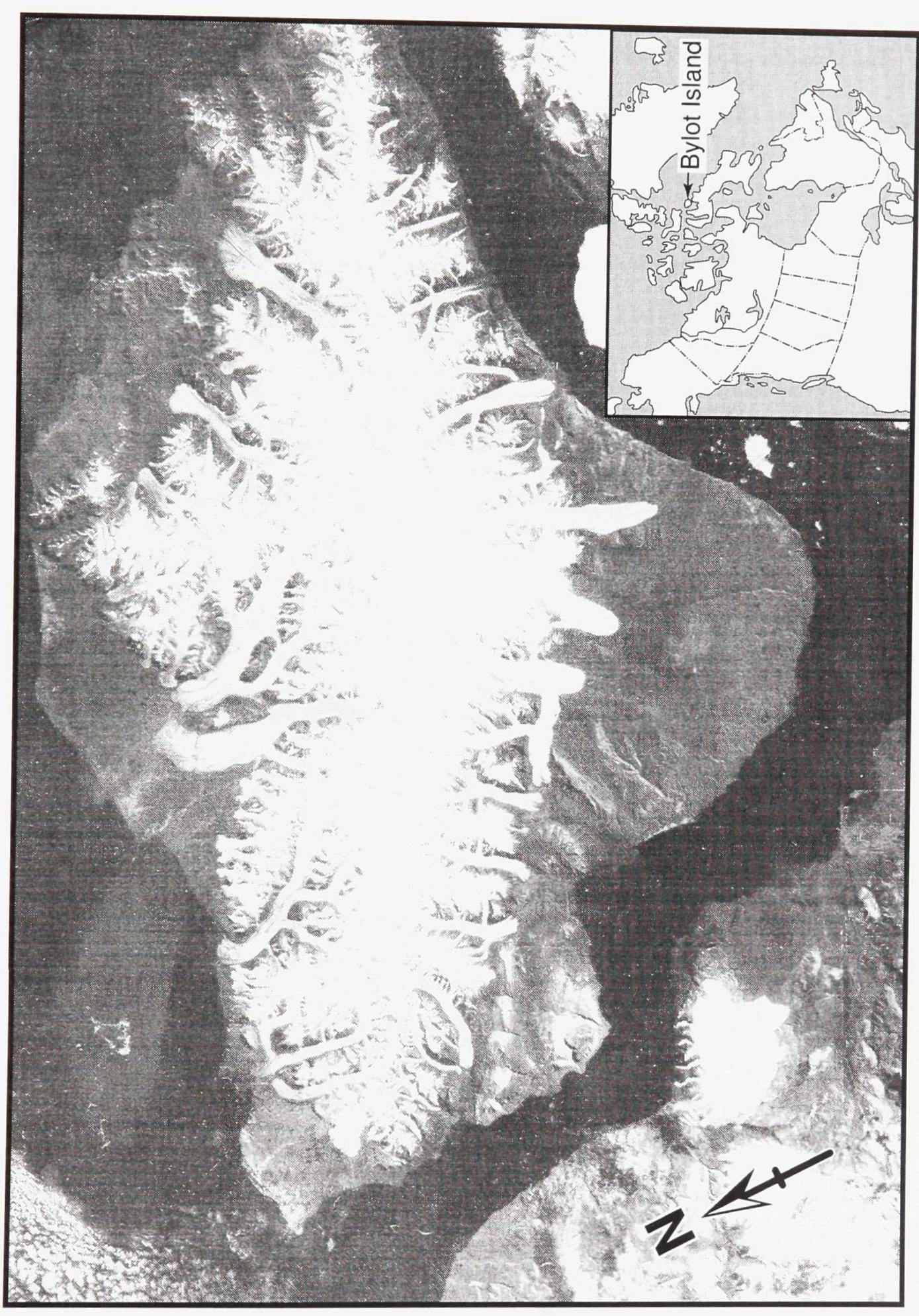

प्र 


\subsection{Organization of the thesis}

This thesis is prepared as a series of manuscripts for publication. Chapters 2-6 are designed such that they can be considered as separate entities. As a result, there is some repetition of the introductory, study area, and methodology information. There is also some division of common subject-matter for the sake of thematic organization.

Chapter 2 provides an introduction to the processes of ice burial in a proglacial setting. It also includes a discussion of the potential for preservation of the buried ice in different environments. The manuscript derived from this chapter has been submitted to the journal Permafrost and Periglacial Processes. The reviewers comments have been taken into consideration in the preparation of Chapter 2. The manuscript will be resubmitted early in 1998.

Chapter 3 is a description of ground penetrating radar (GPR) methodology and its application to the study of ground ice. This chapter contains a discussion of the application of GPR to the examination of surface and buried ice bodies in a proglacial environment. The manuscript from this chapter has yet to be submitted for publication.

Chapter 4 is a discussion of the physical, chemical and isotopic characteristics of glacier and ground ice on Bylot Island. The processes of tabular massive ground ice development in the proglacial environment and the differences between glacier, basal, icing and ground ice are the focus of this section. The manuscript from this chapter has yet to be submitted for publication.

Chapter 5 provides an introduction to the technique used for the extraction and analysis of the gases trapped in ground ice. It also contains the results from a study of three widely separated sites across the western Canadian Arctic, with implications for the 
Quaternary history of the area. The manuscript derived from this chapter has been published in the journal Permafrost and Periglacial Processes., Volume 7 pp. 257-266.

Chapter 6 contains a detailed description of the physical, chemical, and isotopic characteristics of the tabular massive ground ice located at Peninsula Point in the Mackenzie Delta, and discussion of the origin and development of the ice. The manuscript derived from this chapter has been submitted for publication in the Proceedings of the Seventh International Conference on Permafrost to be held 23-27 June, 1998, in Yellowknife, Canada.

Together these chapters demonstrate new methodologies for imaging and analyzing tabular massive ground ice, discuss of the processes of buried ice development, and provide a description of the unique properties of surface, buried, and segregated ice. The thesis also demonstrates the application of these techniques to the interpretation of the development of individual ground ice bodies and the glacial and periglacial history of a region. 


\section{Chapter 2}

\section{The burial of ice in proglacial environments}

\subsection{Introduction}

Throughout permafrost regions, tabular bodies of massive ground ice are commonly encountered. Their presence and potential instability have serious implications for terrain stability, and are thus the cause of considerable environmental and geotechnical concern. Tabular massive ground ice bodies range in size from less than $1 \mathrm{~m}$ to over $50 \mathrm{~m}$ in thickness, and from a few square metres to several square kilometres in aerial extent. Most occurrences have been discovered within a few metres of the ground surface; however, much deeper bodies have been discovered in petroleum exploration wells (Mackay, 1971; Dallimore, pers. comm., 1993). Unlike pingos and ice wedges, the origins of tabular massive ground-ice bodies are still a matter of some controversy. The purpose of this research project is to investigate the processes of ground ice development and address the potential for preservation of different types of massive ground ice on Bylot Island. 
The two main processes thought to be responsible for the development of the majority of tabular massive ground ice are the burial of surficial ice bodies (eg. glaciers) and the in situ segregation of ice as a result of frost heaving and water injection. From theoretical modeling of the segregation process, it has been suggested that it is possible to develop large tabular bodies of massive ground ice (Taber, 1929; Gorelik and Kolunin, 1993), but laboratory or field experiments have yet to verify this.

Landforms resulting from the burial of glacial ice are readily observable in many proglacial and previously glaciated settings (eg. kettle lakes). However, the precise processes of ice burial, or the potential for preservation of ground ice has not been thoroughly examined. Research in glacial sedimentology has been primarily focused on sedimentary processes related to glacial tectonics (Chinn and Dillon, 1987; Tison et al., 1993) or processes occurring at the sole of glaciers (Goodwin, 1993; Sharp et al., 1994). The research conducted on the development of supraglacial debris layers resulting from the ablation of ice, has focused on the sediment concentration processes but not on the ice preservation after stagnation (Boulton, 1967; Nakawo, 1979; Sharp, 1949).

This chapter focuses on several processes of ice burial and provides examples of the systems in an active proglacial environment. The potential for preservation of buried ice produced by these processes is also discussed.

\subsection{Study area}

The physiographic, geologic and climatic setting of Bylot Island makes it a very good miniature modern analogue of the Laurentide ice sheet that once covered most of Canada. Bylot Island is located in the eastern Canadian Arctic northeast of Baffin Island (Figure 2.1). The mountainous core of the island consists of crystalline Canadian Shield 


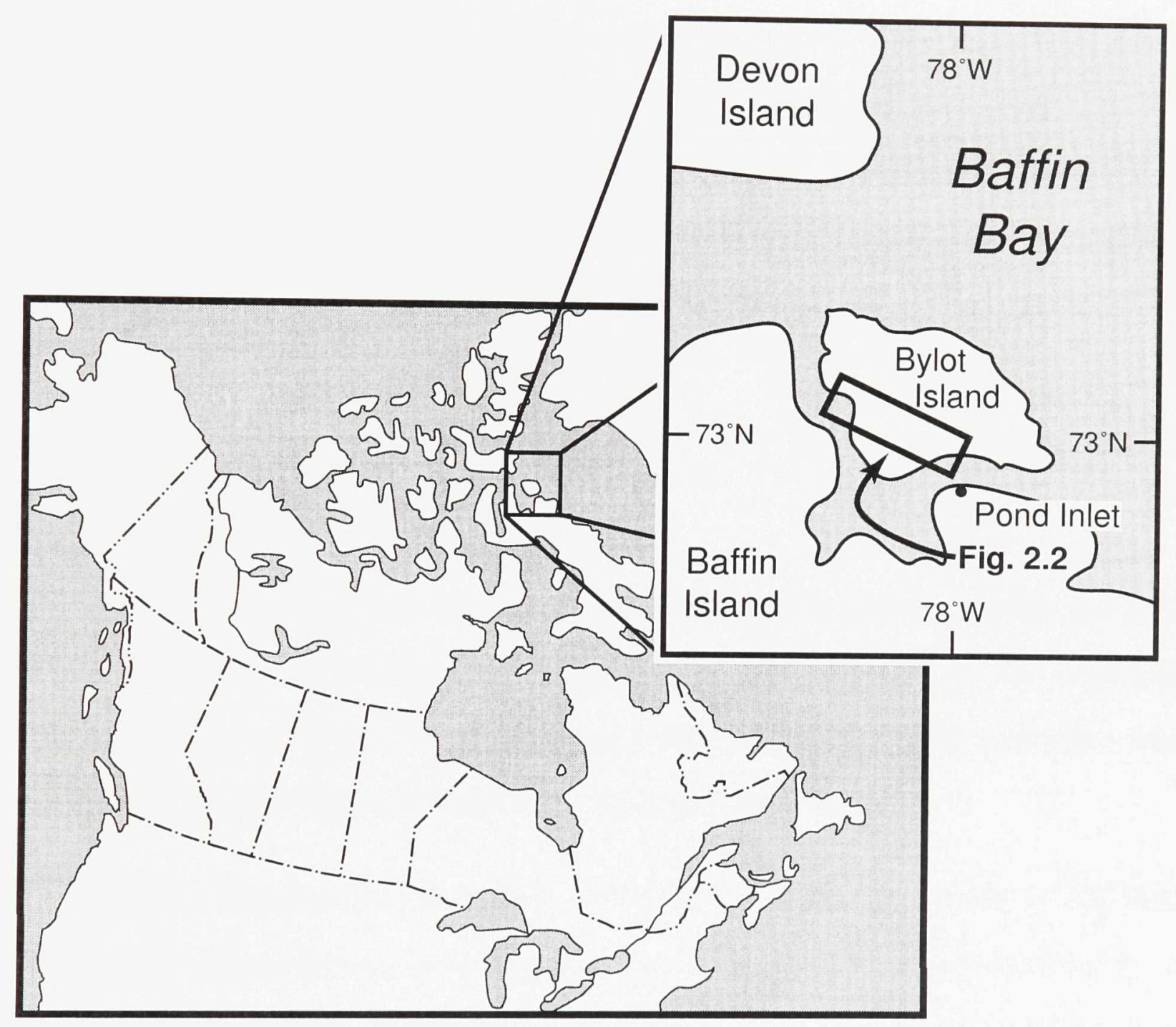

Figure 2.1 The location of the study area on Bylot Island. 
rocks and is covered by a $4500 \mathrm{~km}^{2}$ ice field. Glaciers flow from the upland accumulation areas in the centre of the island through deep valleys towards the ocean or onto the plains, which are composed of poorly consolidated sandstone and mudstone of CretaceousTertiary age. Glaciers become lobate as they flow onto the broad plains.

The climate of Bylot Island is essentially that of an arctic desert, as the mean annual air temperature is about $-15{ }^{\circ} \mathrm{C}$, and the average annual precipitation is less than $200 \mathrm{~mm}$. The island is well within the zone of continuous permafrost, and a relative lack of active thermokarst activity indicates that the permafrost is generally quite stable. The maximum active layer thickness measured on the island was less than $80 \mathrm{~cm}$.

\subsection{Methodology}

The results of previous studies on ground ice genesis indicate that the use of a single methodology or technique often leads to indefinite answers on the origin or formation process of the ice. For this reason, a suite of complementary techniques was applied to the study of the surface and buried ice bodies on Bylot Island.

Initial reconnaissance was carried out using satellite (Landsat MSS \& TM) and aerial (vertical photography \& SAR) imagery. These data sets enabled the identification of currently retreating glaciers, seasonal and perennial icings, active stream flow beneath a snow cover, and areas potentially underlain by massive ground ice. The ground ice study sites were located in areas of unvegetated moraine or where active retrogressive thaw slides were observed. Aerial photographs were also used to create detailed maps of the spatial extent of surface ice bodies such as glaciers and icings and to measure their change through time. 
Ground penetrating radar (GPR) was employed to image subsurface ice bodies. As well as being used to measure their thickness, it also provided information on the internal structure of the ice and the sedimentary structures within the basal sediments. The depth to the top of ground ice units and nature of the overlying sediments were also determined with GPR.

In front of several glaciers, the presence of hummocky moraine and many lakes suggested older ice-cored terrain. To verify that the lakes were actually ground-ice melt-out features, GPR was used to map the three dimensional geometry of the lakes and the associated lacustrine deposits using winter ice cover as a survey platform.

A pulseEKKO IV GPR system was used with $50 \mathrm{MHz}, 100 \mathrm{MHz}$, or $200 \mathrm{MHz}$ antennas employed depending on the site conditions and depth of penetration required. Surveys were conducted as single transects or in grids with the trace spacing being $2 \mathrm{~m}$ or less, enabling interpretation of detailed subsurface features. As GPR only measures the amplitude and travel time of reflected radar signals, the propagation velocity of the signal must be determined in order to calculate the depth from which reflections originated. This was accomplished by performing velocity surveys to measure the propagation velocities for conversion of travel time to depth values (Moorman, 1990). Interpretation of the GPR profiles was facilitated and verified with the aid of borehole data and nearby surface exposures.

Once the ice bodies were mapped using GPR, detailed analysis was undertaken, including stratigraphic descriptions, petrographic analysis, and sampling. Detailed descriptions were made of ground ice exposures, icings, and the basal portions of glaciers. Descriptions included ice structural features, ice crystal size, shape and orientation, bubble content, size and distribution, and sediment content, structure and distribution. Samples, $2-20 \mathrm{~kg}$ in size, were collected from glaciers, icings, and ground ice exposures for 
chemical and isotopic analysis of the ice and gaseous components, and textural and mineralogical analysis of the sediment.

\subsection{Results and discussion}

\subsubsection{Surface ice types}

Bylot Island has a wide variety of surface ice, ranging from permanent snowbanks and incipient glaciers to large valley and piedmont glaciers (Figure 2.2). The Canadian Glacier Inventory identified 98 glaciers within the study area shown in Figure 2.2 (Inland Waters Branch, 1969). Of the 18 larger glaciers, 10 are currently retreating, and 4 have marginal moraines with surficial characteristics that indicate the moraine is ice cored.

An example of the variation in glacier mass balance conditions on Bylot Island is shown in Figure 2.3. The photo map was constructed by digitally combining vertical aerial photographs taken in 1958 and 1982. The glacial extents for 1948 and 1994 were then added manually from oblique aerial photographs. As indicated on the map, Glacier B28 (informally named Stagnation Glacier) has retreated about $1.8 \mathrm{~km}$ in the last 46 years, while during the same time period adjacent Glacier B26 (informally named Fountain Glacier) has experienced no appreciable retreat. Lateral and end moraines are almost completely lacking around Fountain Glacier, while the light-coloured area surrounding Stagnation Glacier, on the map, indicates the extensive unvegetated moraines that have become exposed since the recent retreat of the glacier. The lateral moraines flanking Stagnation Glacier are up to $200 \mathrm{~m}$ high with their profile constantly changing due to melting of their ice core. 

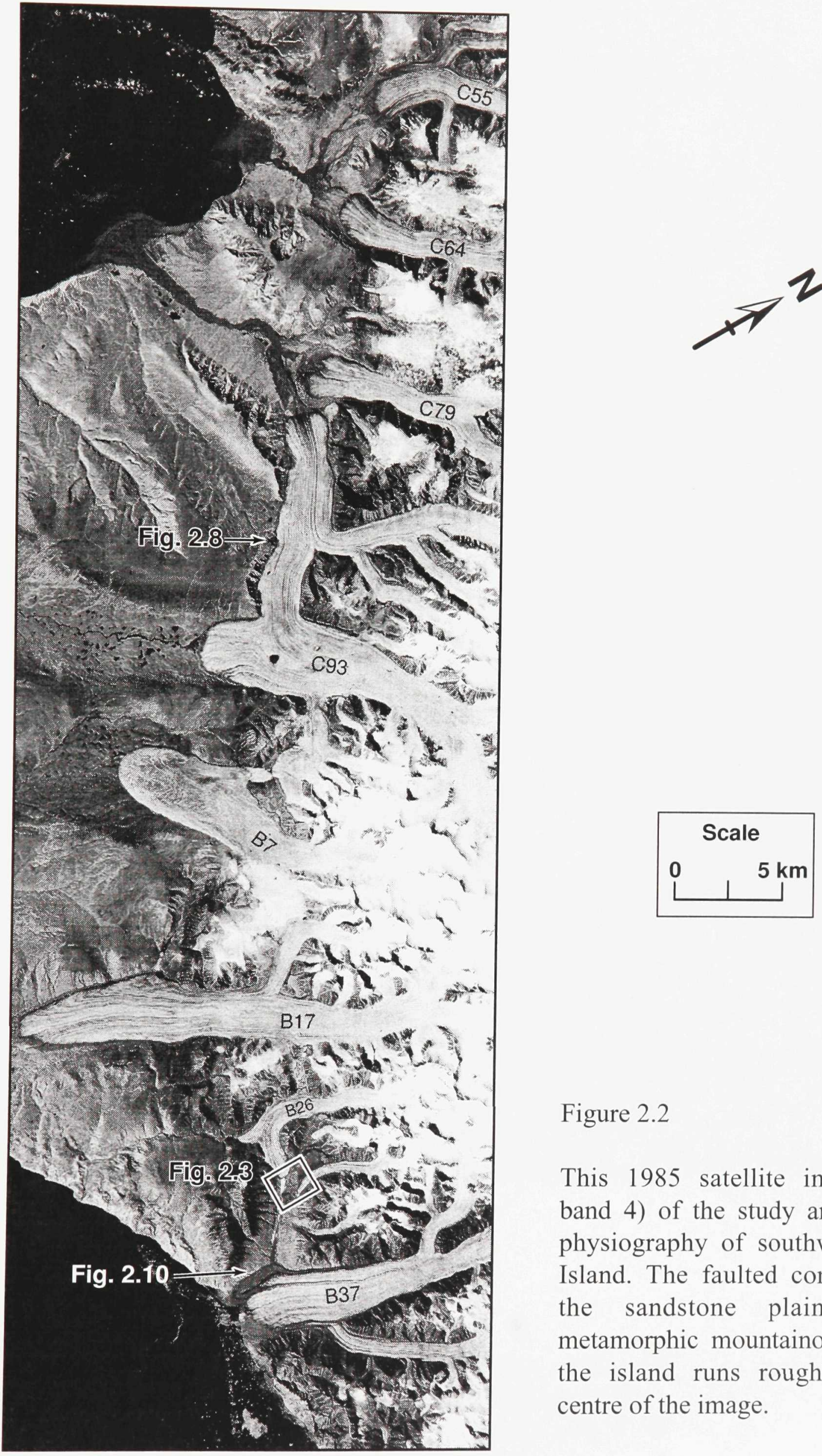

Figure 2.2

This 1985 satellite image (landsat band 4) of the study area shows the physiography of southwestern Bylot Island. The faulted contact between the sandstone plains and the metamorphic mountainous regions of the island runs roughly down the centre of the image. 


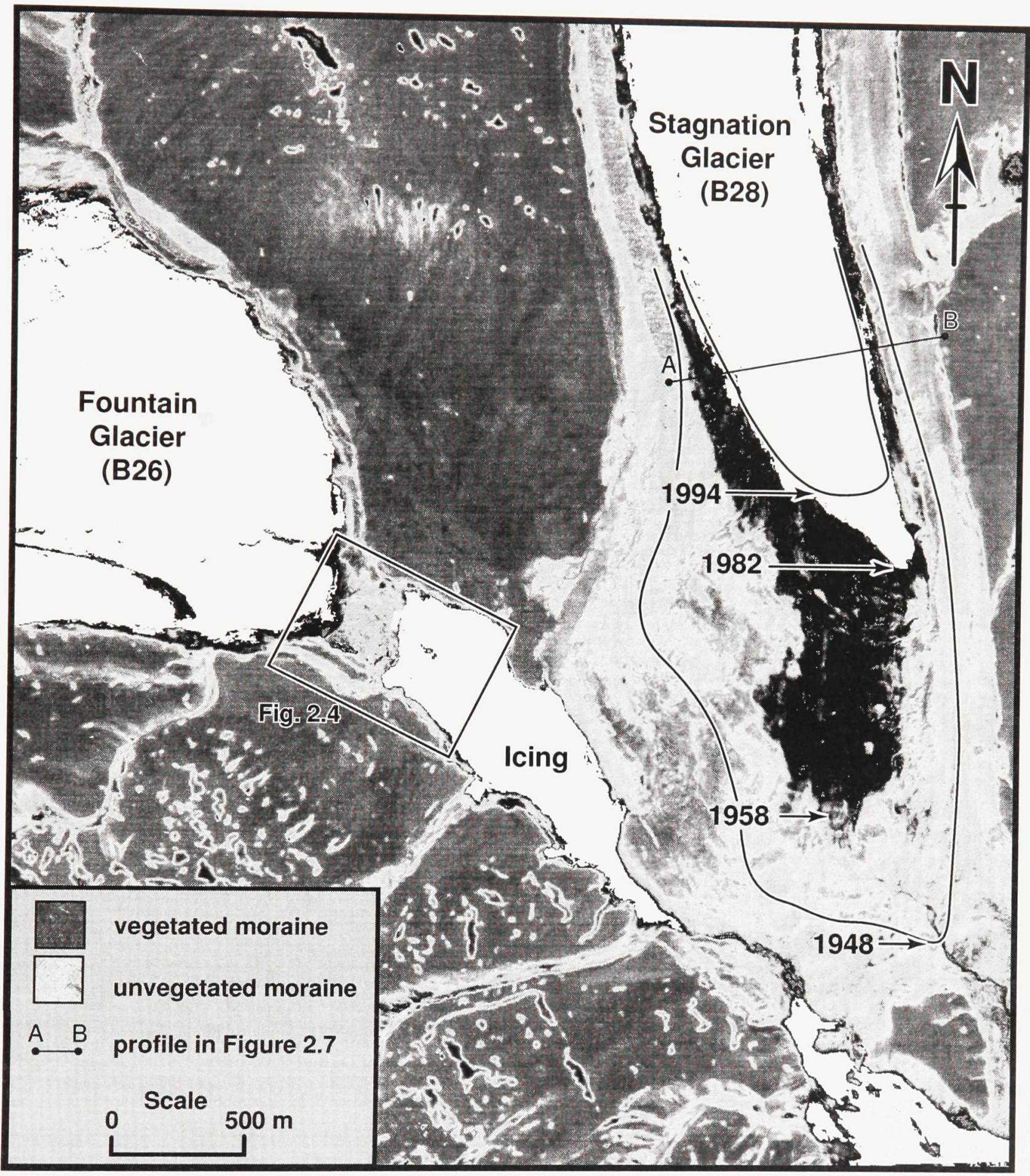

Figure 2.3 Change detection image created by digitally subtracting a 1958 aerial photograph from a 1982 aerial photograph of the same area. The black represents areas covered by ice in 1958 but not in 1982 . 
Within the study area 8 glaciers have been identified that have icings regularly developing at their snouts during the winter. Only one icing appears to persist perennially through the melt season, and is thus a possible candidate for burial. A portion of the icing at the front of Fountain Glacier (Figure 2.3) has been present in all aerial and satellite images on record since 1948. The image in Figure 2.3 shows a gap of about $200 \mathrm{~m}$ between the glacier and the icing; however, since the site was first visited in 1991, the icing has extended up to the glacier, with just the sides of the icing melting in the summer. In 1991 an artesian spring flowed up through the icing in a fountain at the icing blister (Figure 2.4). This fountain also appears on aerial photographs taken in other years when the icing did not cover that area. Since the summer of 1992 an icing blister has been observed at the site of the fountain, but high-pressure water flow has not been observed at the surface of the icing.

Numerous perennial snow banks and incipient glaciers occur within the study area, generally in stream valleys and other depressions on steep north-facing slopes. The seasonal weather patterns determine whether many of these features survive the summer. Although these surface features have the potential to develop into ground ice, the probability is very low. As they are located in erosional valley-side environments, sediment that is deposited on the snow or ice surface is normally transported further down slope soon after deposition. As well, the minimal ice flow in incipient glaciers, and thus the lack of basal erosional power, limits the incorporation of sediment into the ice mass from below. As a result there is little chance for perennial snow banks or incipient glaciers to develop into buried ice bodies.

\subsubsection{Processes of ice burial}

Two dominant processes resulting in the transformation of surface ice into tabular massive ground ice are active on Bylot Island. The first and most important is the 


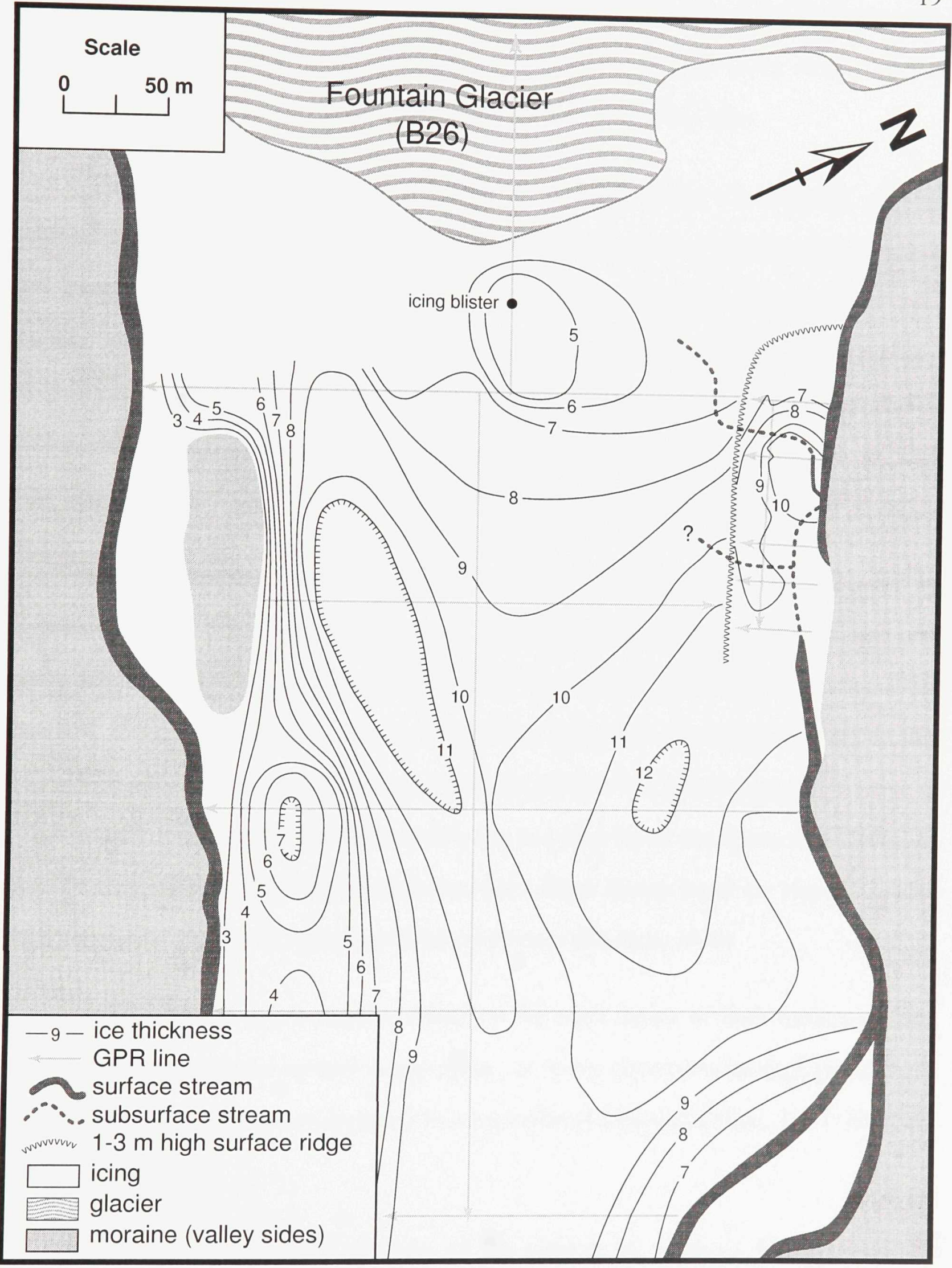

Figure 2.4 Map of the proglacial icing in front of Fountain Glacier in 1993 showing icing thickness in metres and the location of drainage channels within and below the icing. 
incorporation of subglacial sediment into a glacier and concentration of the sediment at the surface during ablation of the ice. The second is covering of surface ice bodies by land slides, scree falls, fluvial deposition, or deltaic and lacustrine deposition.

The complex environment of the base of a glacier makes investigation of basal sediment accretion processes very difficult. However, mechanical and thermal processes have been proposed as the dominant causes of sediment accretion at the base of polar glaciers. Mechanical incorporation of sediment (eg. shearing), was first suggested as a processes capable of introducing appreciable amounts of sediment into the base of glaciers (Goldthwait, 1951). This process has been used to explain several occurrences of thick dirty basal ice sequences in cold conditions (Souchez, 1967; Tison et al., 1993).

Thermal processes such as regelation and basal freezing, originally suggested by Weertman $(1959 ; 1961)$, are now thought to also be a prevalent method of sediment incorporation into glaciers (Goodwin, 1993; Gow et al., 1979; Hubbard and Sharp, 1989; Souchez, 1971; Souchez and Lorrain, 1978). The processes of melting and refreezing, causing the accretion of ice and sediment onto the bottom of a glacier, are most active in situations where the glacier undergoes both warm and cold-based conditions along its travel path. This explains why polythermal glaciers have much thicker basal ice sequences than either temperate glaciers or entirely cold based glaciers (Boulton, 1970).

Although there is considerable debate on the exact nature of both mechanical and thermal basal sediment incorporation processes, in many circumstances (eg. polythermal glaciers) both sets of processes are likely to act together (Chinn and Dillon, 1987; Hubbard and Sharp, 1989).

It has been suggested that some of the glaciers in southern Bylot Island are polythermal (Zdanowicz, 1994). As the glaciers flow onto the plains it appears that permafrost grows beneath the margins causing the formation of distinctive structural and 
sedimentological features within the basal ice sequences. Up ice, the glaciers are thought to have more variable thermal conditions with basal freezing occurring in some locations and sliding occurring in other locations.

\subsubsection{The burial of Stagnation Glacier by melt-out}

A good example of the burial of glacier ice as a result of the incorporation of basal sediments occurs at Stagnation Glacier. As a result of the recent retreat of this glacier (Figure 2.3), large ice-cored lateral and end moraines developed. Although this glacier is entirely constrained in a mountain valley, the contribution of supraglacial debris is relatively small and limited to a narrow margin along the sides of the glacier.

The basal ice observed in caves beneath the glacier has a very different appearance than the surface ice. The sediment-rich ice sequences are over $5 \mathrm{~m}$ thick. The ice has a clear brown appearance and is virtually bubble free. Sand and silt particles were observed throughout the basal ice in thin layers from one to a few grains thick. Coarse-grained sediment, ranging from sand to boulders, was also contained within the basal ice; however, it was dispersed and in lower concentrations. In general, the ice crystals were an order of magnitude smaller than those of the ice above. Although basal ice tends to be extremely variable in appearance, this ice is similar to basal freezing or regelation ice in other glaciers (Goodwin, 1993; Herron and Langway, 1979; Hubbard and Sharp, 1989). The upper contact of the basal ice zone could not be delineated.

Within $500 \mathrm{~m}$ of the terminus of Stagnation Glacier more than 50 shear planes were observed on the surface of the glacier bringing basal sediments to the surface (Figure 2.5). Most are almost void of sediment, while at their greatest thickness they contain less than a $10-\mathrm{cm}$ thick band of sediment. However, they carry enough sediment to the surface to completely cover the snout of the glacier. The shear planes cut the general layering of the glacier and show no alteration of the ice surrounding them. It appears that 


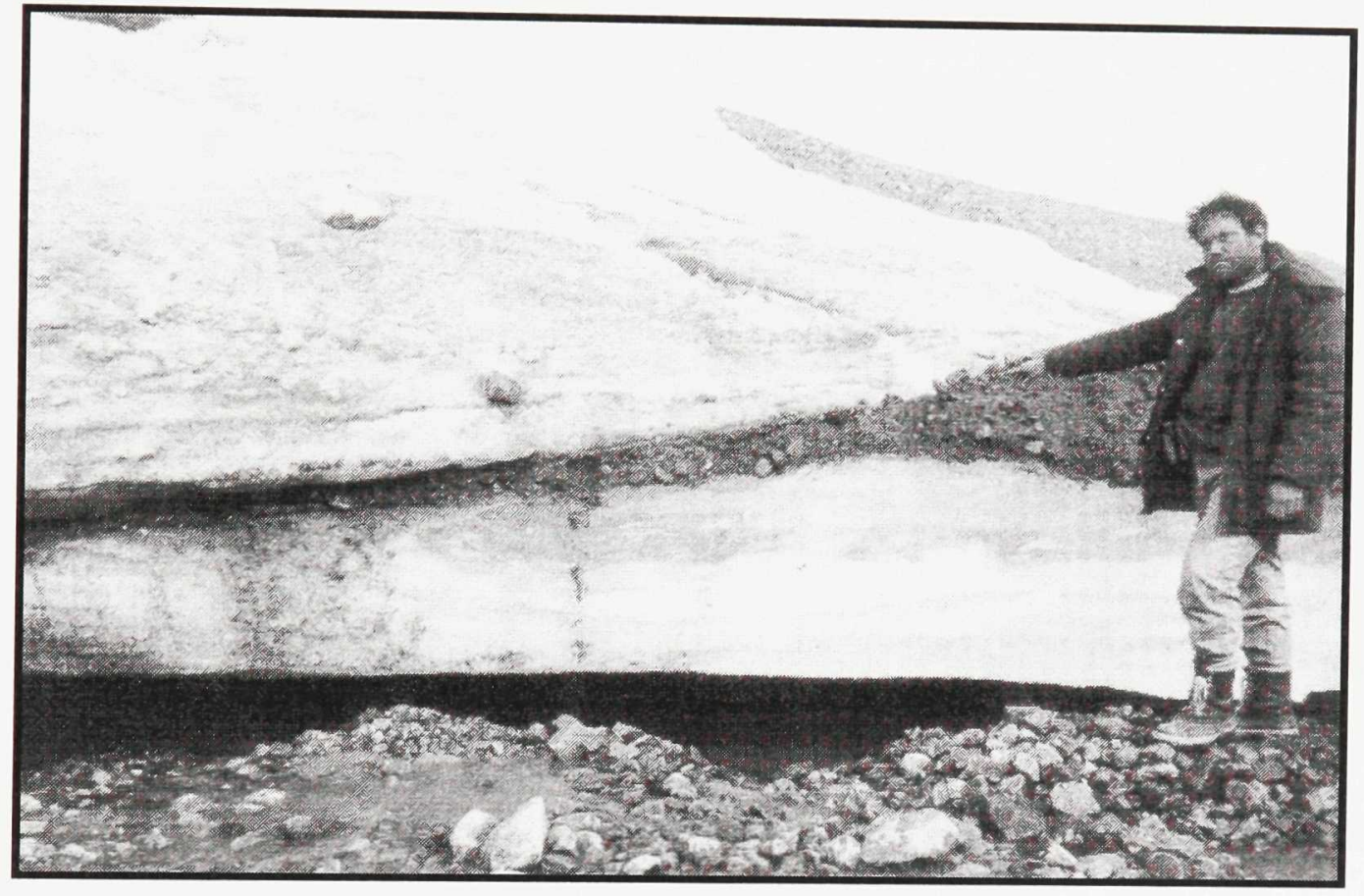

Figure 2.5 Most of the shear planes present near the toe of Stagnation Glacier are void of sediment; however, some such as the one shown above carry considerable amounts of sediment up to the surface of the glacier. Up glacier is to the left. 
subglacial sediment is either dragged or squeezed into the shear plane as the glacier decelerates near its terminus.

The implication of thermally accreted basal ice and shear planes occurring close to each other is that both mechanical and thermal basal sediment accretion processes are at work in Stagnation Glacier. Both processes can contribute to the burial of the glacier.

A series of GPR profiles revealed a buried ice body that extends $175 \mathrm{~m}$ beyond the current terminus of Stagnation Glacier (Figure 2.6). The single tabular ice body is up to $10 \mathrm{~m}$ thick and is about as wide as the glacier. From large-scale surface morphology it appears that much more of the end moraine was once underlain by ice. In the area between $175 \mathrm{~m}$ to $400 \mathrm{~m}$ beyond the front of the glacier a steep slope $\left(29^{\circ}\right)$ results in very unstable surface conditions. The unstable conditions are thought to be responsible for exposing and melting the buried ice. In its current geometry, the ice-cored end moraine is restricted to a relatively flat $100000 \mathrm{~m}^{2}$ area near the front of the glacier. The current end moraine ice core shows almost no signs of melt-out; however, the ice occasionally becomes exposed as a result of erosion of the surface cover by runoff streams. These exposures tend to be limited in extent and are quickly covered again within a few days.

Preservation of buried ice in the end moraine of glaciers depends on whether subglacial processes bring sufficient debris to the surface to provide a stable cover. Where the terrain is relatively flat this can be less than a 1-m thick layer.

Figure 2.7 shows an example of the cross section of Stagnation Glacier and its relationship to its lateral moraines. The GPR profile displays how a core of glacier ice continues beneath the lateral stream, into the lateral moraine. The ice lens inside the moraine is over $10 \mathrm{~m}$ thick in some locations. The slope of the lateral moraines ranges from $20^{\circ}$ to $30^{\circ}$, resulting in a surface cover that is susceptible to regular active layer detachments that 

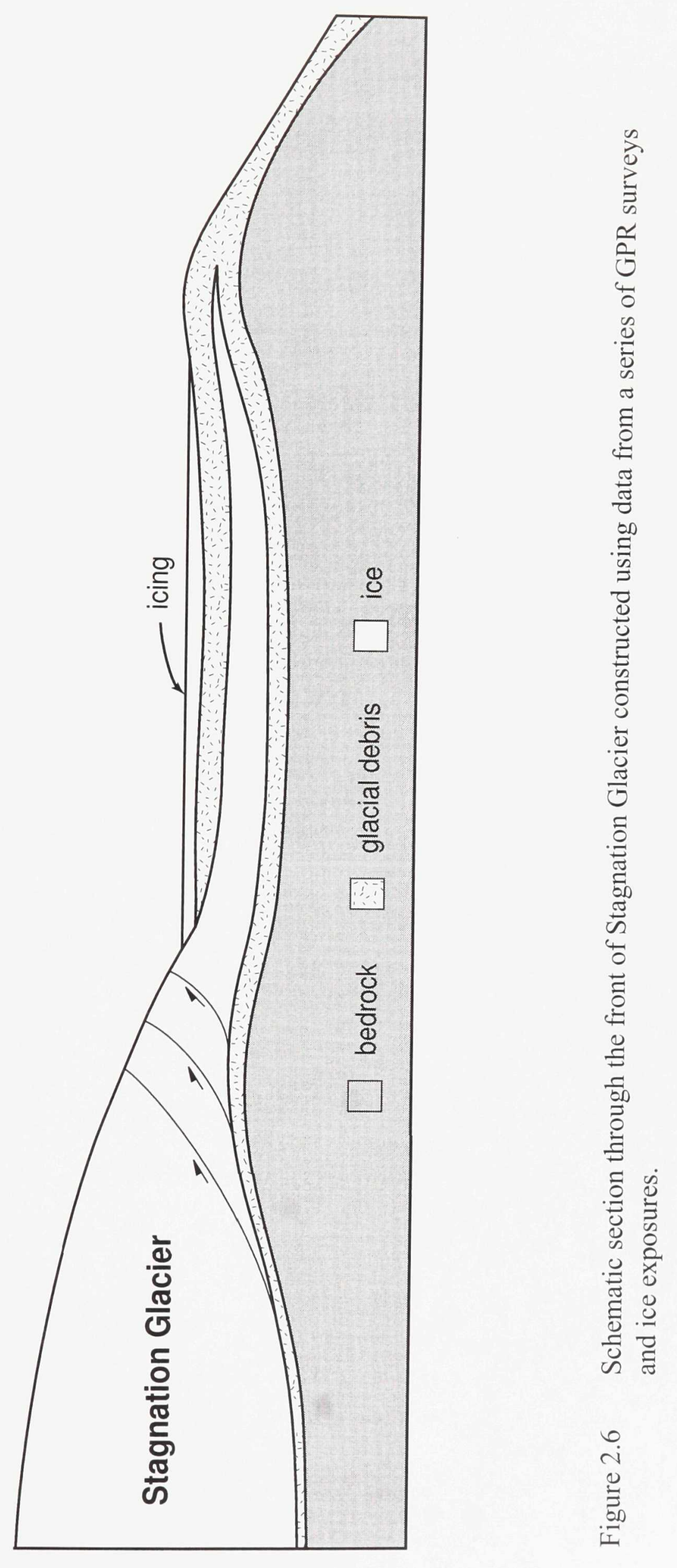


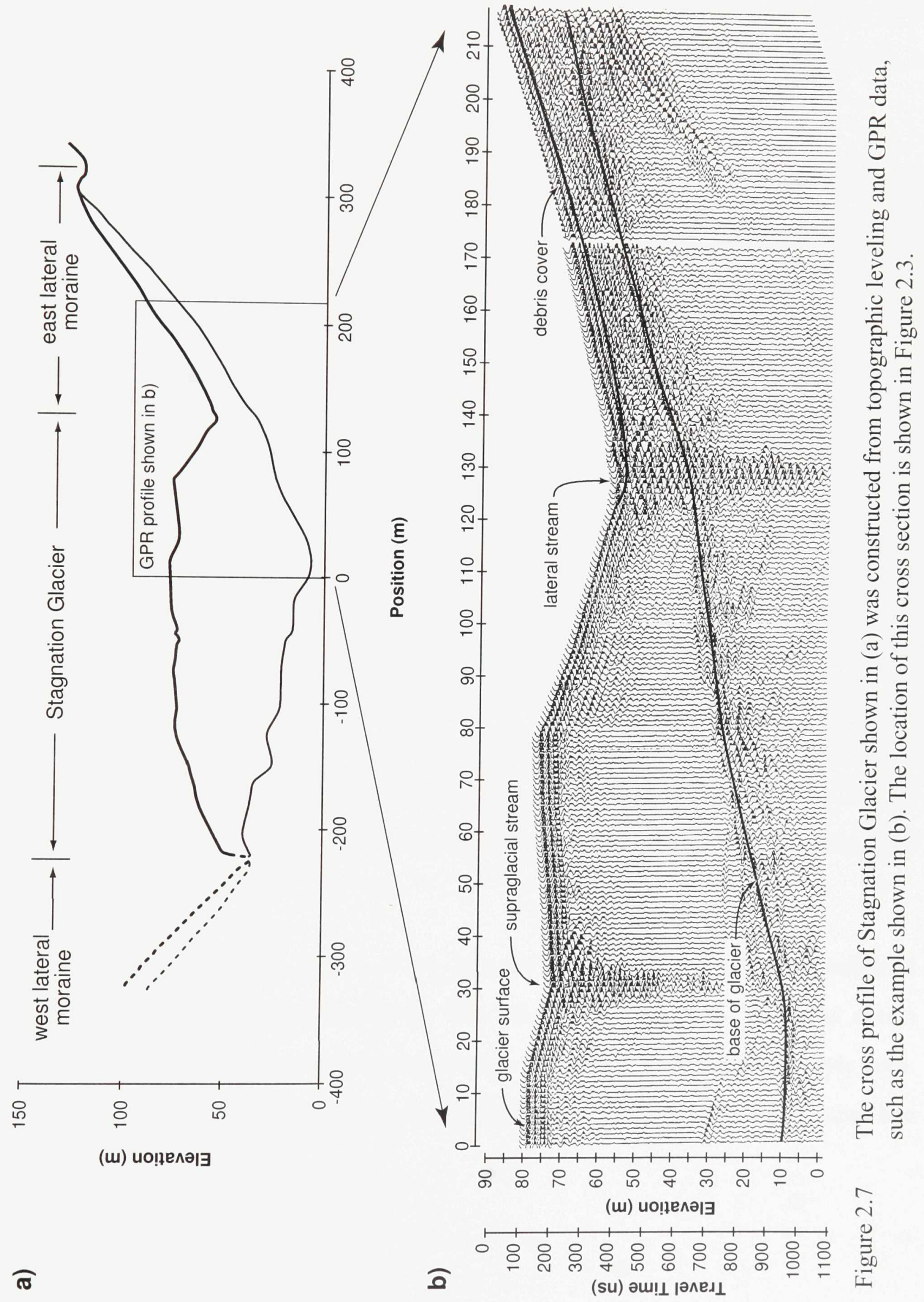


expose the ice core. These appear to melt little ice and rapidly heal within a few days. GPR measurements revealed that along the profile over the east lateral moraine shown in Figure 2.7, the debris covering the ice core did not exceed $2 \mathrm{~m}$ in thickness.

The ice core within the west lateral moraine is separated from the main glacier ice body as a result of a more active lateral stream which eroded down through the glacier ice to its base. This has not occurred between the glacier and the east lateral moraine because the surficial debris cover extends beneath the lateral stream, protecting the ice beneath.

The preservation of massive ice in lateral moraines appears to depend on whether the moraine surface stabilizes with a thick enough debris cover over the ice before the entire ice core melts.

\subsubsection{Deltaic burial of Glacier C93}

The process of ice burial by deltaic deposition was documented at the site of a lake dammed against the side of Glacier C93 (Figure 2.8). The lake was created when the northwestward-flowing arm of this glacier expanded and dammed a stream originating in an unglaciated catchment area. Aerial photographs indicate that as the lake grew, it flooded over much of the ice-cored lateral moraine and a portion of the glacier that was damming it Figure $2.8(\mathrm{a}-\mathrm{c})$.

As the unglaciated portion of the drainage basin consists of poorly consolidated sandstone, the main streams feeding the lake were laden with sand. When the stream entered the lake its sediment load was deposited in the form of a classic Gilbert style delta. Numerous lake stands are recorded by several delta levels and many strand lines etched into the valley sides. 

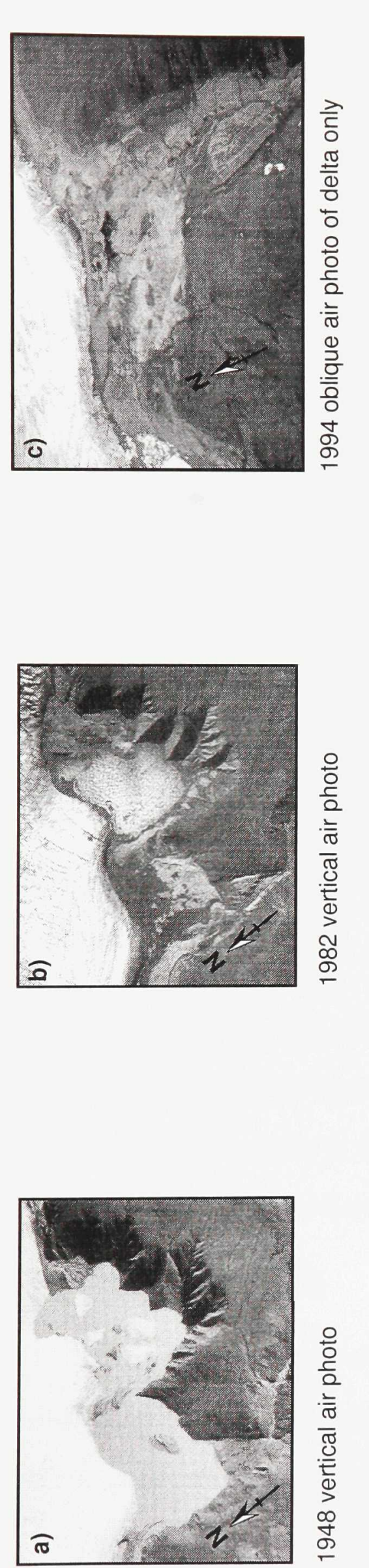

ळ

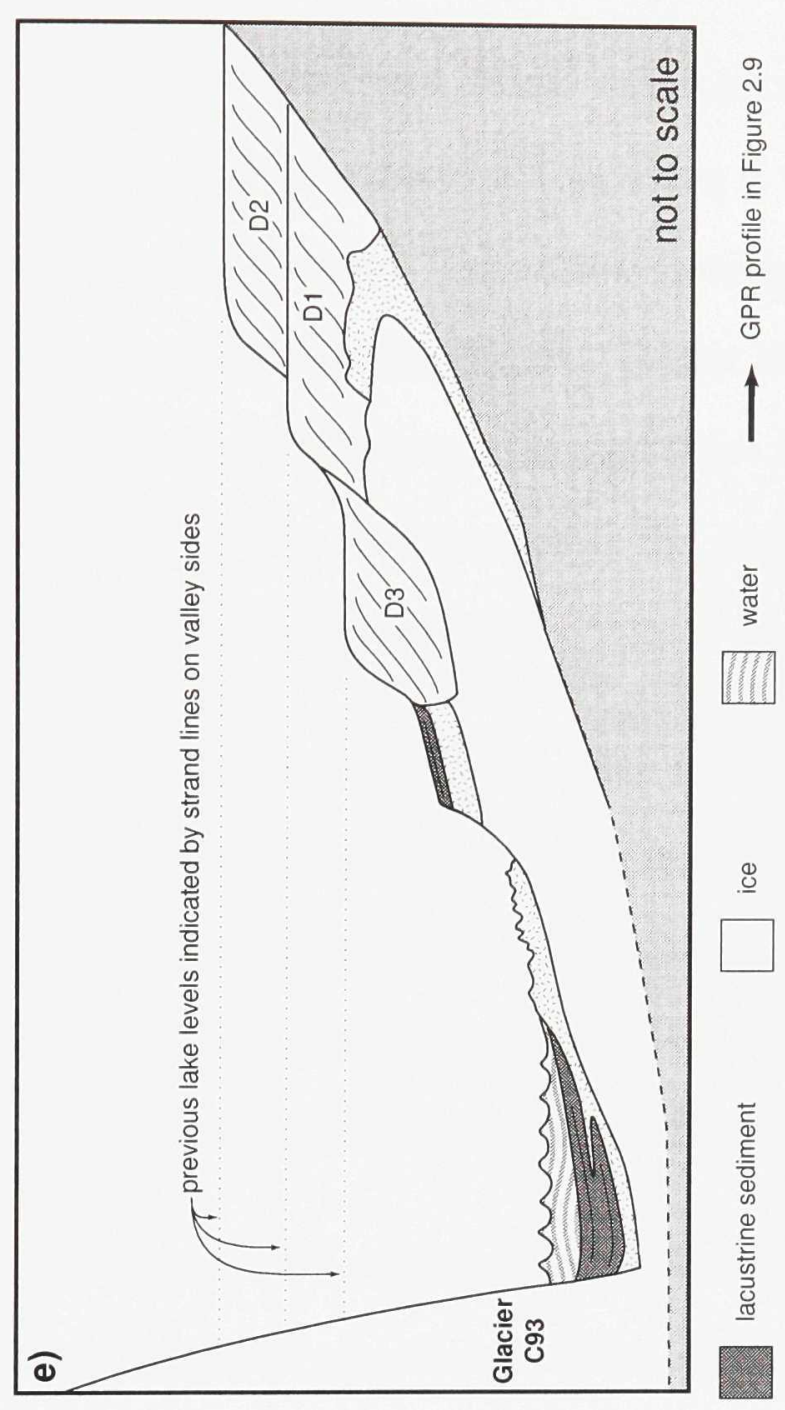

27
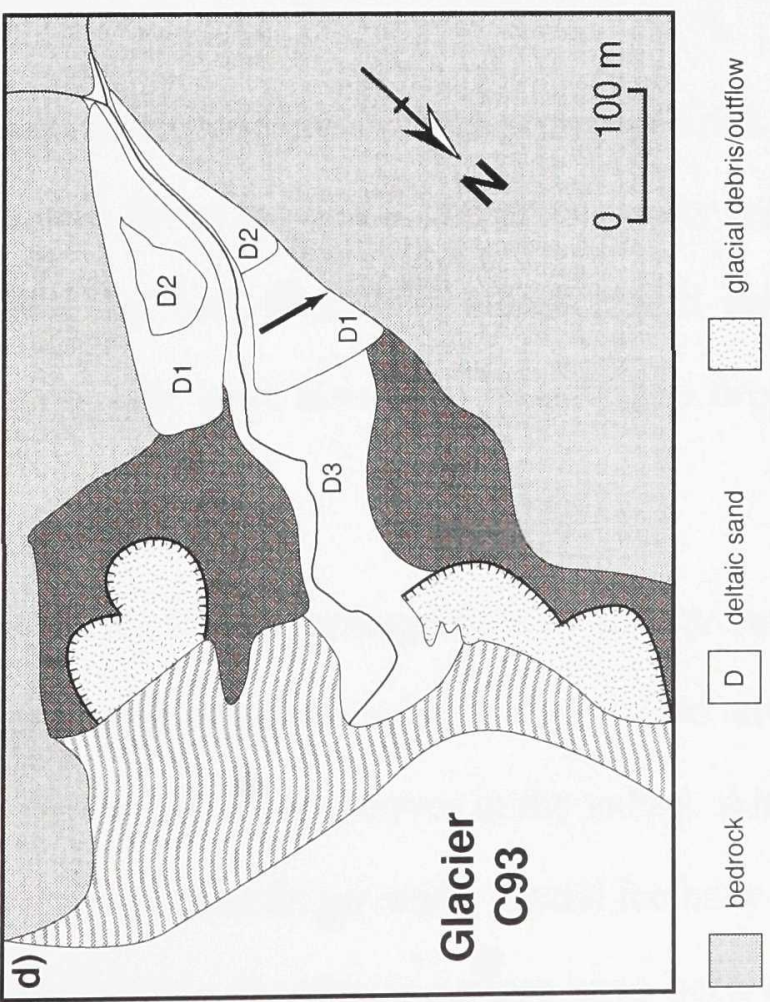

$\frac{1}{0}$
$\frac{\pi}{0}$

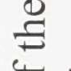

แั

$\infty$

可

으.

क \&

उ플

를

동

ธू.

$\stackrel{5}{\circ}$

ฮิ

文 $\frac{5}{0}$

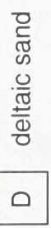

it

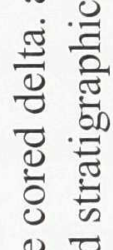

. 크

픔

4 需

क्ष

응

E

ำ 
The general history of the site as interpreted using information gleaned from surficial mapping, stream-cut exposures, and subsurface GPR profiling is that Glacier C93 retreated leaving behind an ice-cored lateral moraine. The stream flowing into the valley was later dammed by the glacier and a proglacial lake formed. Deltaic deposition on the valley side then progressed onto the moraine. A thin lacustrine mud drape was deposited on distal portions of the moraine. Lowering of lake level resulted in the stream down-cutting through the delta and into the moraine, exposing the ice core.

A subsequent rise in lake level encouraged deltaic deposition in the previous stream valley, re-covering the ice core. The delta continued to grow and progressed onto the edge of the glacier. Finally, the lake almost completely drained, encouraging down-cutting through the most recent deltaic deposits and into the underlying ice. Thermokarst was initiated on the moraine creating small ponds and retrogressive thaw flows.

The GPR profile in Figure 2.9 shows the stratigraphic relationships of the till, ice and sand. Other GPR profiles display the spatial relationships of the sediment and ice units (Appendix A).

The geometry and stratigraphic relationships of the sediment units indicate a series of fluctuations in the lake water levels. From the size of the deltaic units and the strand lines cut into the valley sides it appears that individual lake stands could have lasted years. However, water levels in the residual lake have also been observed to drop several metres in a period of two weeks.

This situation has resulted in a complex arrangement of tabular massive ice being covered by both deltaic sands and glacial debris within a restricted area. Figure $2.8 \mathrm{~b}$ schematically shows the relationships of the ice and cover in the valley. Although examples of deltaic sands, ablation till, and flow till directly covering glacial ice have been preserved, no examples of the lacustrine mud overlying the glacier surface have been discovered. This 


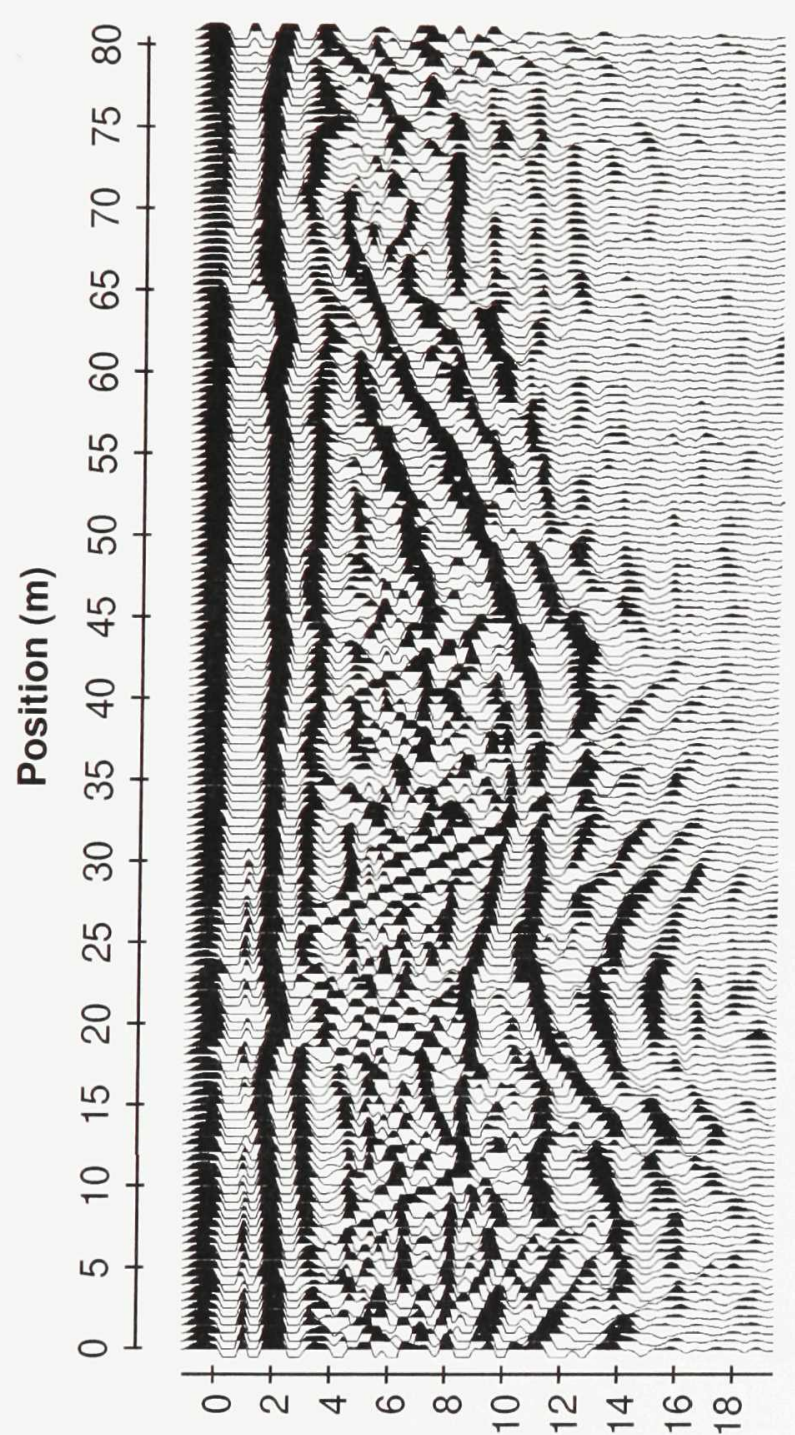

(u) प1də0

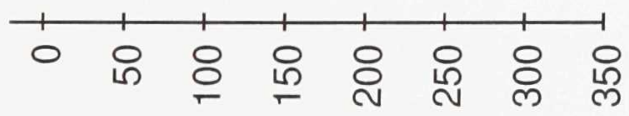

(su) әш!

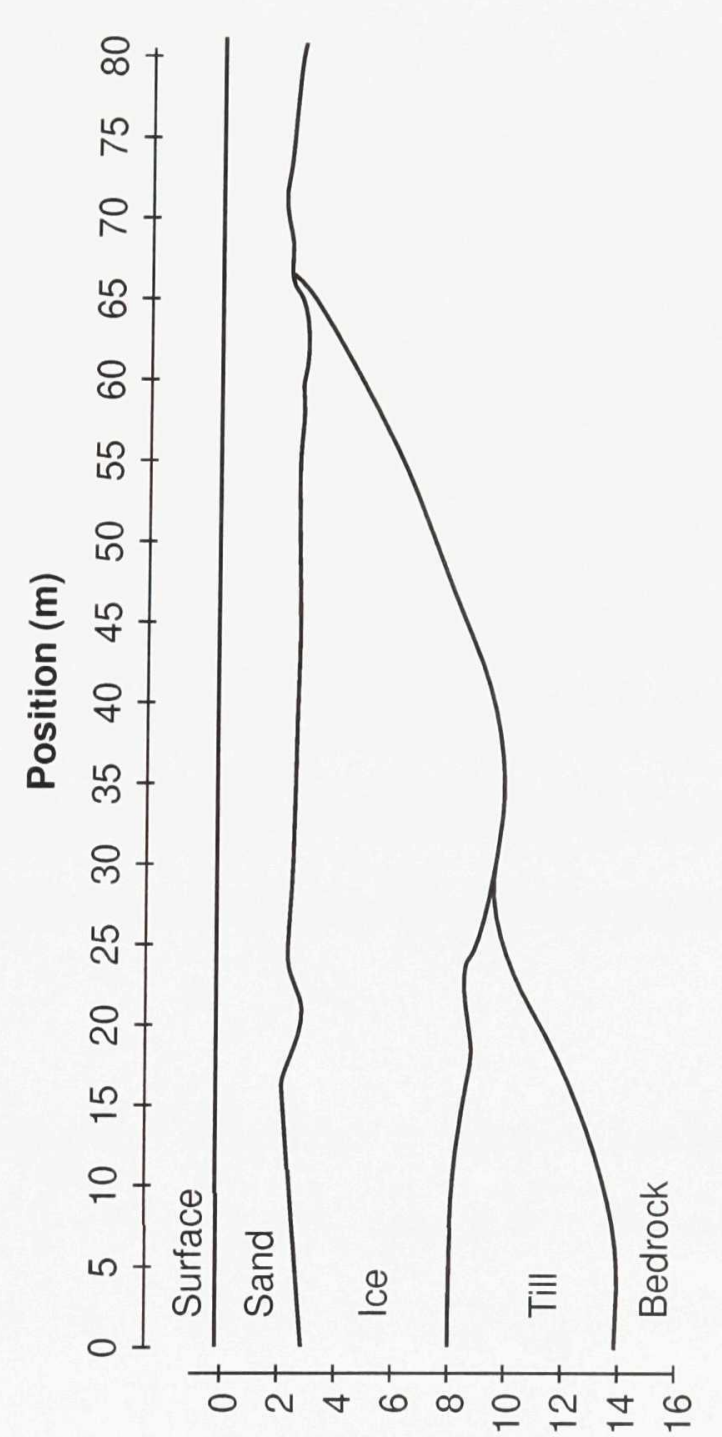

(u) पıdəa

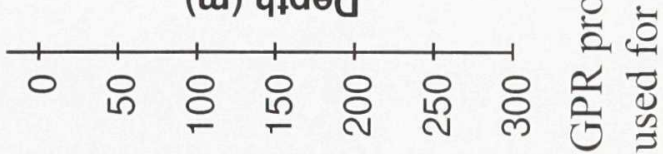

(su) әш! Іәлеג

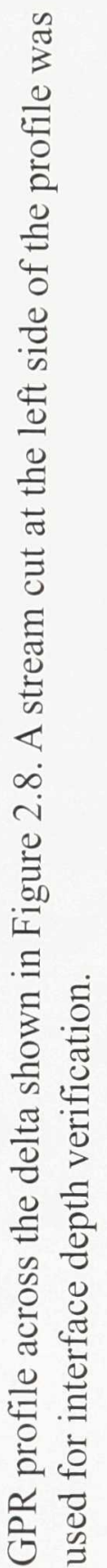


is likely because of the unstable thermal and hydrological setting of the lake and the low rate of lacustrine sediment deposition. The lacustrine mud covering the glacial debris was generally in the order of several millimetres thick and was never thicker than $3 \mathrm{~cm}$. The lack of lacustrine sediment covering the moraine indicates that either the high water level of this lake was not maintained very long or the runoff entering the lake had a low suspended sediment concentration.

The buried ice at this location varies greatly in appearance and physical properties. White bubbly sediment-free ice, similar to the exposed ice of the neighboring glacier, was discovered in many locations at this site; however, other ice types were also observed. Ice encased by the moraine ranged from being laden with very poorly sorted glacial debris, to having a sediment content less than 5\% that consisted of only sand and fines. The lowest level of exposed ice, beneath the D3 sand near the mouth of the stream, was clear, bubbleand sediment-free, with roughly $1 \mathrm{~cm}$ diameter equidimensional crystals with no preferred $\mathrm{C}$-axis orientation. Ten metres above that ice exposure, a $10 \mathrm{~cm}$ thick peat layer was incorporated into the crest of a fold in an ice-rich sandy sediment. Although the origin of all of these ice types could not be confirmed, river or lake ice was discovered buried in or beneath the delta.

Since lake drainage, the exposed moraine has been subject to frequent retrogressive thaw slumping and thermokarst subsidence. The flow material produced by the slumping has been redeposited directly on the ice, over the lake bottom sediments, and on some of the lower delta levels.

Figure 2.8d displays the July 1995 layout of the site; however, fluvial erosion and thaw slumping are currently producing rapid changes in the terrain. Over a one year period the headwalls of the retrogressive thaw slumps have retreated several metres. Changes in 
the stream course occur on a daily basis as different materials are intersected and the channel becomes blocked by scree fall or mud flows.

Preservation of the ice buried beneath the lateral moraine and deltaic sands at the side of Glacier C93 depends greatly on the erosional potential of the stream and the hydrological base level created by the glacier dam (or lack thereof). In the current configuration, retrogressive thaw slumping of the ice-rich lateral moraine continues unabated. The areas covered by sand tend to be more stable, and do not move except when undercut by fluvial erosion.

\subsubsection{Burial of the Fountain Icing by fluvial sedimentation}

Since a portion of the icing in front of Fountain Glacier persists perennially, it has a much greater chance of becoming buried than other seasonal icings located on Bylot Island. Repeated GPR surveys revealed that the perennial portion of the icing remains over $7 \mathrm{~m}$ thick from year to year. Figure 2.4 shows the icing thickness in July 1993. As the surface of the icing is planar, the topography shown is that of the bottom of the icing.

During the winter, ice is added to the top of the icing in layers $1-20 \mathrm{~cm}$ thick as subglacial groundwater flows onto the surface. The majority of the icing mass consists of vertically oriented ice crystals that are $0.1-1 \mathrm{~cm}$ in diameter and up to $10 \mathrm{~cm}$ long the result of the freezing pools of water (Elver, 1994). The randomly oriented smaller ice crystals that result from the freeze-up of slush, are less frequently observed.

In the summer, the majority of ice-melt and melt-water drainage occurs at the ice crystal boundaries. By flowing through the enlarged intracrystallar spaces, meltwater is channeled to larger conduits within or beneath the icing. Throughout the summer the largescale appearance of the icing surface remains relatively unchanged, except for the occasional collapse of the roof of a subsurface drainage tunnel. Since the water is 
effectively carried down by gravity along the intracrystallar boundaries, surficial drainage patterns do not develop. As a result, sediment that falls on the surface is not readily washed away by surface erosion.

The most likely processes of ice burial at this site are direct burial by increased fluvial activity or burial by melt-out of fluvial sediments deposited within the icing. Several streams at the edge of the icing were observed to deposit a layer of sediment in the channel they carved through the ice. However, the sediment layer left behind after the streams had abandoned their channels was always less than $10 \mathrm{~cm}$ thick, which is not great enough to provide thermal stability at the ice surface.

The possibility of sediment accumulation from multiple channel abandonment was determined to be fairly low. GPR surveys revealed that few drainage channels were present in the central perennial portion of the icing (Figure 2.4). The two streams in this area that were active, carried very little sediment, none of which was coarse enough to be deposited in moving water. There was no indication on the GPR records of other sediment accumulation within the body of the perennial icing. It appears that all of the fluvial sedimentation occurring on the icing takes place at the edges where the streams have access to the valley-side sediment source. However, by the end of the summer, the sides of the icing have completely melted, exposing the edge of the perennial icing as a vertical wall with all of the sediment-bearing streams running in the valley bottom along the side.

Due to the U-shape of the valley, burial by alluvial sediment is not likely. Slope movement on the valley sides is generally several hundred metres away from the icing. Under the current conditions deltaic sedimentation is also unlikely. The valley in which the icing resides has a slope in the order of $3-5^{\circ}$ and no glaciers flow down to or across the valley floor which could dam the drainage system. 
Thus, even though the icing in front of Fountain Glacier is a long-term surface feature with the potential for becoming buried, in the current there are no mechanisms that would enable its preservation.

\subsubsection{Processes of ground ice erosion}

The erosion of massive ground ice is generally the result of either thermokarst, due to warming of the ground, or melting from exposure to the sun due to removal of the sediment cover. Both of these mechanisms were observed on Bylot Island.

\subsubsection{Thermokarst lake development}

Regions covered by many densely spaced small lakes occur in several areas on Bylot Island. The end moraines just beyond Glaciers B7 and C93 (Figure 2.2), are good examples. GPR surveys over the ice of three lakes less than $500 \mathrm{~m}$ in diameter showed them be up to $20 \mathrm{~m}$ deep, with steeply dipping sides. Two of the lakes have portions of their bottom that is flat, while the third lake has a symmetrically concave profile (Moorman and Michel, 1997). Lacustrine sediment is only present on the flat or gently sloping bottom portions of the lakes, the steep sides consist of bouldery debris. The morphology of these lakes indicate that they are the result of the in situ melt-out of buried ground ice (i.e., thermokarst). This supports the air photo interpretation of Klassen (1993). It is not known if these lakes represent the melt-out of all of the massive tabular ground ice, or whether there are still considerable quantities preserved in other locations.

Continuing large-scale thermal erosion of massive ground ice in thermokarst terrain is difficult to measure in this region. However, several lines of evidence indicate that it is not currently eroding. The lakes and the surrounding terrain appear stable as there are no signs of surface movement and the vegetation is well established. From the thickness of sediment on the lake bottoms, and the average rate of sedimentation for other arctic lakes, it 
appears that the lakes are quite old, and thus may have formed during a warmer period sometime in the distant past (Moorman and Michel, 1997).

The current ground temperature is indicative of thick permafrost. The data displayed in Figure 2.10 were measured at a depth of $10 \mathrm{~cm}$ in a low centred polygon. From these data, the mean annual ground temperature was calculated to be $-9.6^{\circ} \mathrm{C}$. Using an estimated geothermal gradient of $42 \mathrm{~m} /{ }^{\circ} \mathrm{C}$, a permafrost thickness of $\approx 400 \mathrm{~m}$ would be expected.

Although this older thermokarst terrain covers sizable areas (eg. $30 \mathrm{~km}^{2}$ in the C93 Glacier valley), evidence of recently activated thermokarst terrain was not observed within the study area. Thus, ice that is currently in the process of being buried will likely not melt due to thermokarst under the current climate regime.

\subsubsection{Retrogressive thaw slumping}

The removal of the protective sediment cover over the ice also effectively causes melting of ground ice. This most frequently takes the form of retrogressive thaw slumping initiated by thermally-induced active-layer detachments or removal of sediment by fluvial or coastal erosion.

Several examples of retrogressive thaw slumping are currently active adjacent to Glacier B37. On the west side of the glacier valley (Figure 2.2) a sandy terrace was oversteepened by the erosional action of a lateral stream. Even though the ground ice bodies are several tens of metres above stream level, the erosion of the slope and subsequent exposure of a small portion of massive ice has led to continued retrogressive thaw of the ground (Figure 2.11). The flow material from the feature shown in Figure 2.11 has deeply cut into the unconsolidated sand below, creating a new valley and altering the local drainage patterns. 


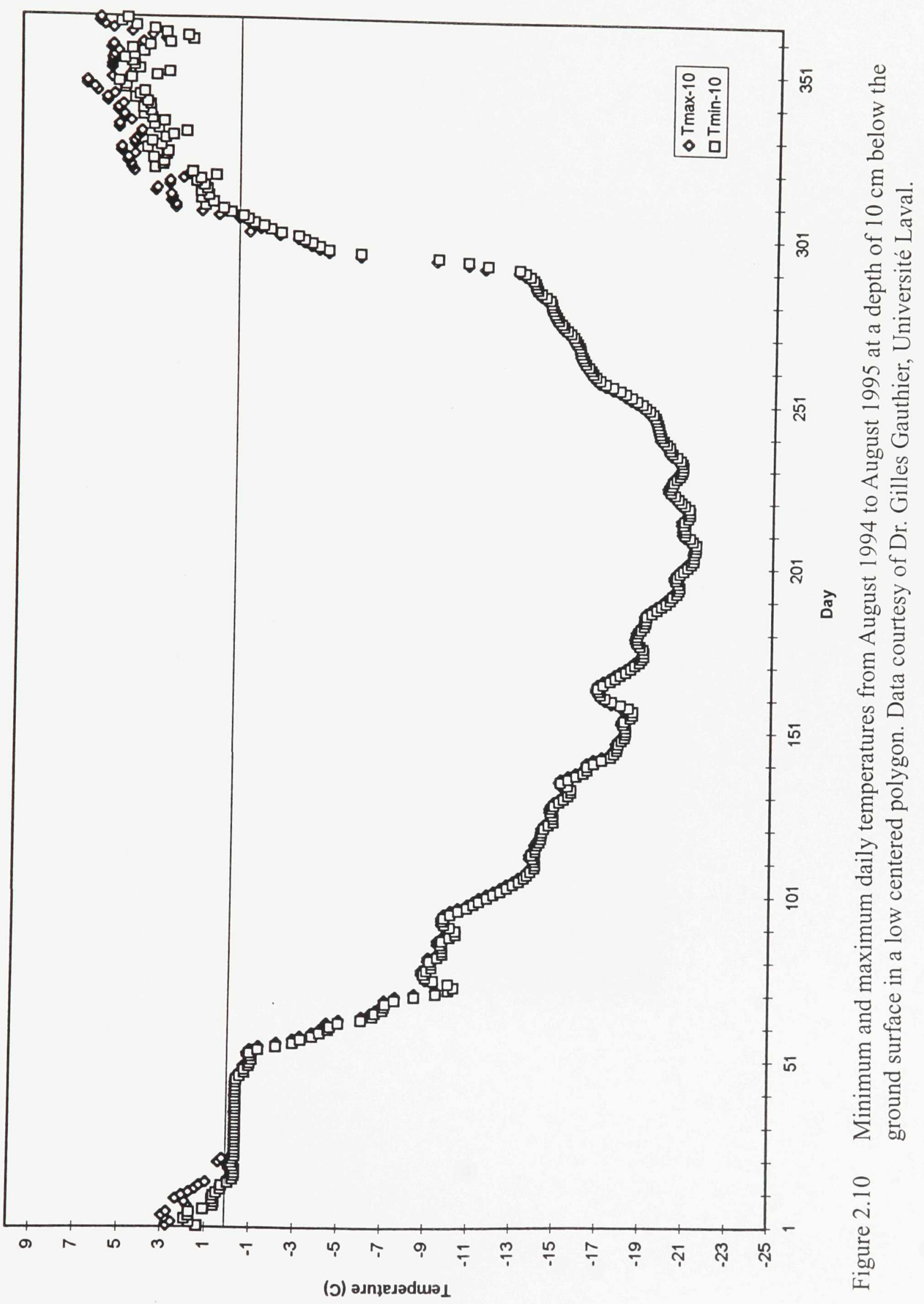




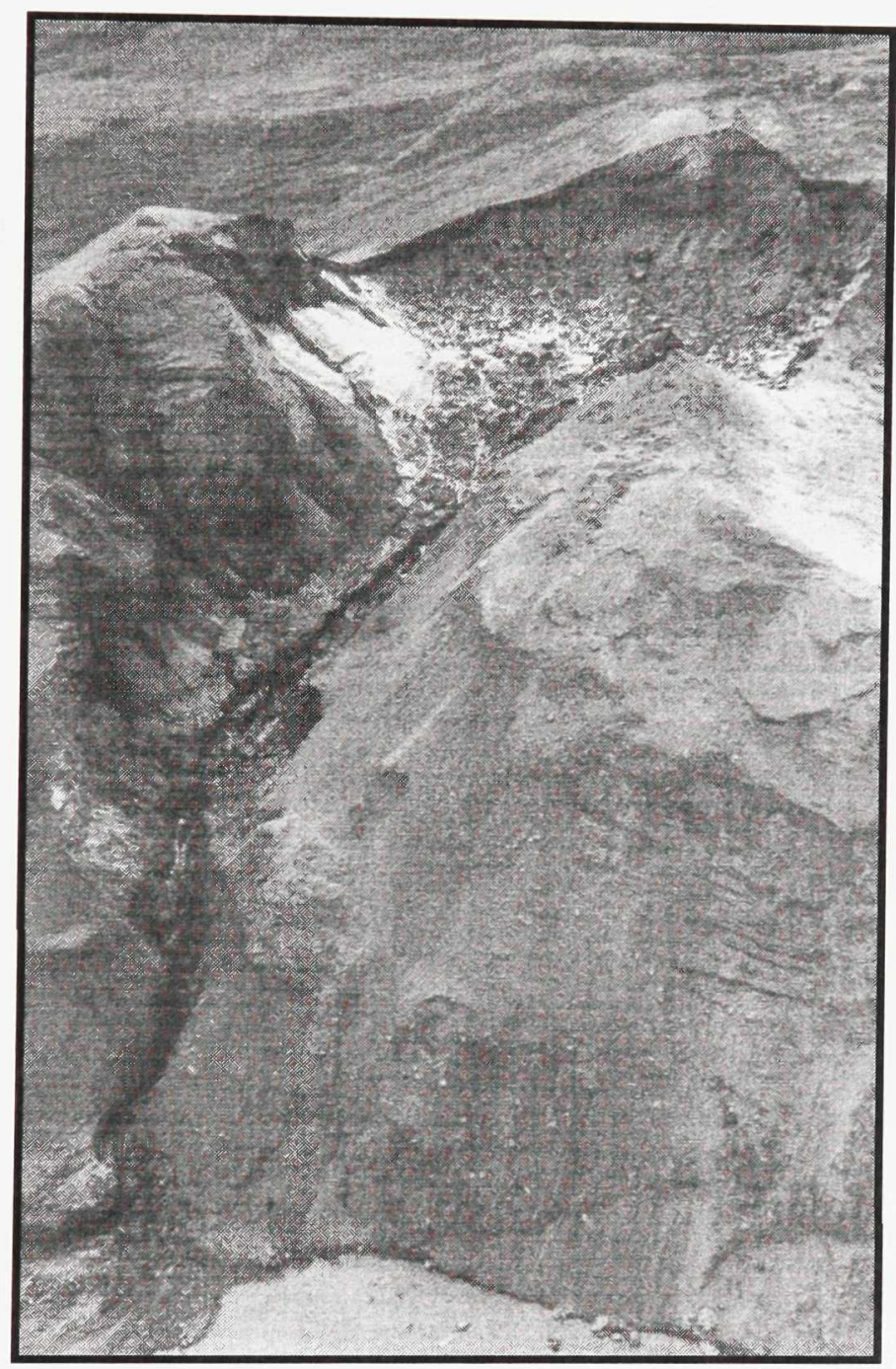

Figure 2.11 Photo of the retrogressive thaw slump on the west side of the Sermilik Valley. 
The slump shown in Figure 2.11 is still active with a headwall composed of massive ice and interbedded ice and sand varying from $1 \mathrm{~m}$ to $10 \mathrm{~m}$ high. The melt-out of the ice is anticipated to continue until the exposed portion of the ice body is so small that slumping of the overburden covers all of the exposed ice.

\subsection{Conclusions}

The use of remote sensing and aerial photography greatly simplified the search for suitable ground ice study sites. These techniques were also used to quickly determine previous glacial limits and measure the rate of glacial retreat. Ground penetrating radar was shown to be effective for mapping the geometry of surface ice, ground ice, and lacustrine and fluvial sediments. The sediment beneath the bottom of glaciers over $70 \mathrm{~m}$ thick, could easily be imaged. Where glacial debris covers the surface, the effectiveness of GPR can be limited to less than $20 \mathrm{~m}$.

From the data, it is apparent that melt-out of sediment-laden glacier ice appears to be the most effective and widespread process of ice burial on Bylot Island. With many of the glaciers on Bylot Island currently retreating, this is a optimal environment for not only the burial of glacier ice, but also its preservation as tabular massive ground ice. In some situations other processes, such as deltaic sedimentation, are also responsible for the burial of surface ice, but their occurrence was much less frequently observed.

The preservation of buried ground ice depends on climatic conditions and the stability of the terrain. The cold conditions on Bylot Island have resulted in preservation of appreciable amounts of ground ice. However, there is evidence of even more ice having been buried - and having since melted - in the kettle lakes since the last glacial maximum. 


\section{Chapter 3}

\section{Mapping surface and buried ice structures}

\subsection{Introduction}

One of the most complex sedimentary settings is found in the glacial/proglacial environment, located at and around the terminus of a glacier. In this environment a wide variety of processes are involved in sculpting the landscape, including glacial, fluvial and mass wasting activity. In some locations, permafrost development, the burial of glacier ice, and the formation of icings also play an important role in the evolution of the landscape. Studying geomorphic processes at work on the surface of the earth can be a relatively simple procedure. However, the bulk of glacial erosion and deposition occurs at the base of a glacier; surficial expressions of permafrost development are often absent, and fluvial activity in the glacial environment often involves a complex surface and subsurface network of streams. 
Over the last three decades, radio echo devices and radar systems have been developed to study a variety of large scale glaciological applications (eg. Davis et al., 1973; Weber and. Andrieux, 1970; Koerner, 1977; Bentley et al., 1979), sea ice investigations (eg. Campbell and Orange, 1974; Kovacs and Morey, 1985; Kovacs and Morey, 1992), and permafrost (eg. Annan et al., 1975; Dallimore and Davis, 1992; Robinson et al., 1992; Moorman et al., 1994). Until recently these systems tended to be bulky and operating with them in the rugged terrain at the glacier terminus was difficult or impossible. Radar systems operated from aircraft have provided some subsurface data, but the strong reflection from the air/ground interface dramatically limits the amount of energy entering the ground and thus the depth of penetration (Arcone et al., 1995). Ground-penetrating radar (GPR) can penetrate thick ice bodies, detect thermal interfaces, and image subsurface stratigraphic relationships between sedimentary units. It also offers new opportunities to explore beneath the surface of the complex environment around the terminus of a glacier.

The most recently developed GPR systems, designed for general geomorphologic and geotechnical work, are backpack portable and have technical specifications appropriate to glaciological work; however, they have yet to be extensively utilized to study the glacial/proglacial environment.

The purpose of this project was to use GPR to examine geometric and stratigraphic relationships of sediment and ice bodies in a glacial/proglacial environment. To assess the capabilities of GPR, approximately 75 lines of GPR data were acquired on glaciers, icings, and moraines. Examples from one of the glaciers and its lateral moraine, and an icing are used to illustrate the potential of GPR and to provide insights into the subsurface character in this environment and the variety of active processes which are shaping the landscape. 


\subsection{Study area}

Bylot Island lies in the eastern Canadian Arctic at the north end of Baffin Island (Figure 3.1). The core of the island is covered by a $4500 \mathrm{~km}^{2}$ ice field. The glaciers flow from the upland accumulation areas in the center of the island radially outwards down deep valleys toward the ocean or onto the south-western or northern lowland plains. The study area on Bylot Island was chosen for its wide range of glacial, proglacial, and periglacial environments.

Within the study area there are two glaciers (informally named Fountain or B26 and Stagnation Glacier or B28) of very different character (Figure 3.1). The terminus of Fountain Glacier abruptly rises from the icing covered outwash plain at angles ranging from $14^{\circ}$ to $90^{\circ}$ and generally has a convex profile (Figure 3.2). Fountain Glacier has no visible end moraines, and its lateral moraines tend to be small to non-existent. The glacier flows into a valley floored by an outwash plain that is bordered by bedrock and vegetated moraines sculpted by past glacial advances (Klassen, 1993). In the ablation zone, near horizontal planar bedding is visible in the ice with very little sediment present. Except for two main supraglacial runoff channels, the glacier surface is generally smooth. Fountain Glacier has an accumulation area of approximately $22 \mathrm{~km}^{2}$.

Stagnation Glacier has a near linear surface profile (Figure 3.2). The terminus gently emerges from an extensive highly ridged end moraine at angles ranging from $7^{\circ}$ to $40^{\circ}$. Large (up to $200 \mathrm{~m}$ high) lateral moraines flank Stagnation Glacier along much of its length. Over much of the ablation zone, debris is visible on the surface of the glacier. Near the toe of the glacier, many shear planes arc upwards to the surface. They usually contain little sediment or just appear as fractures in the ice. Near the terminus of the glacier, several large valleys in the surface of the glacier, running parallel to the flow direction, contain supraglacial runoff streams. Marginal streams generally run between the glacier and the 


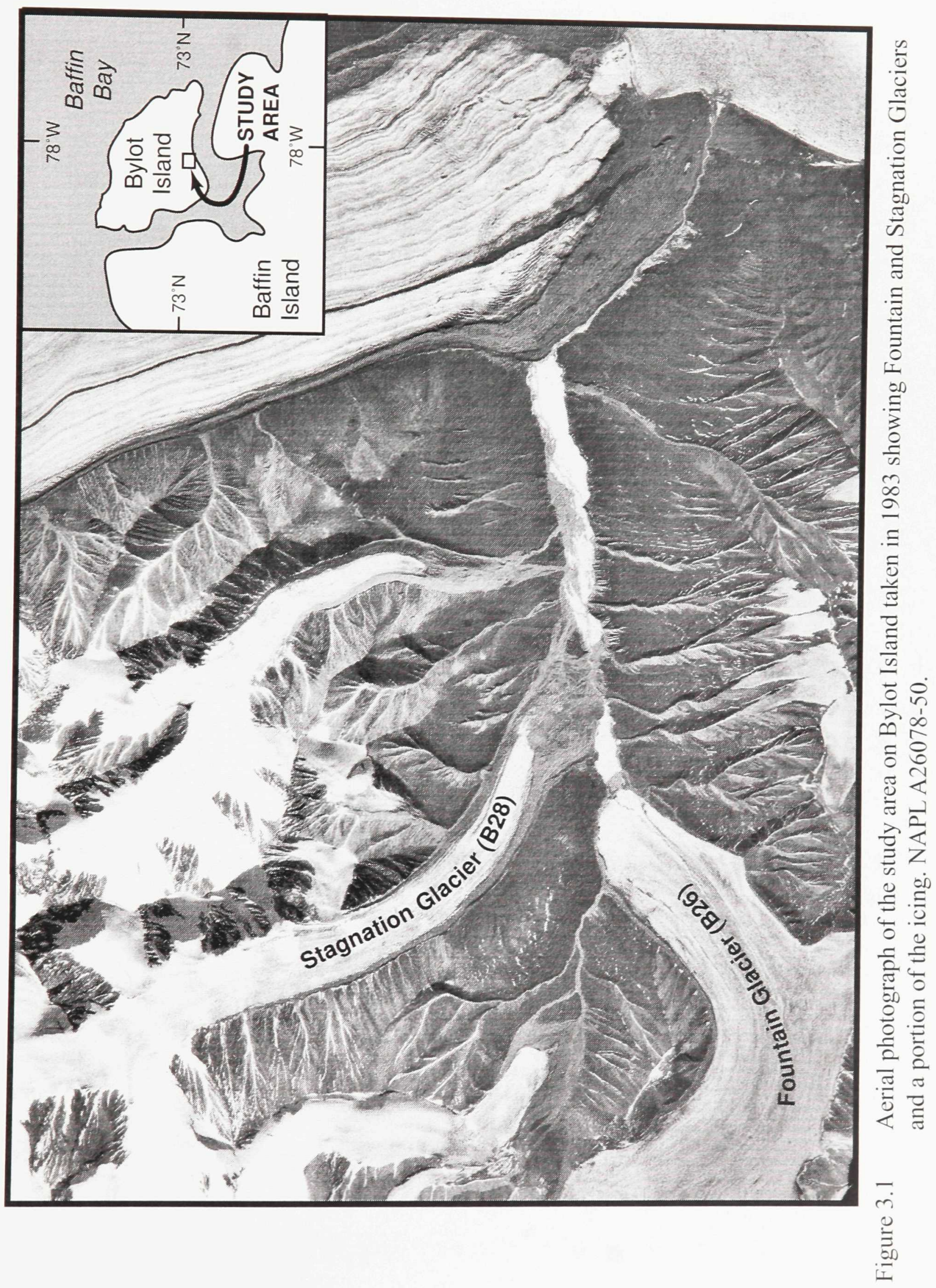




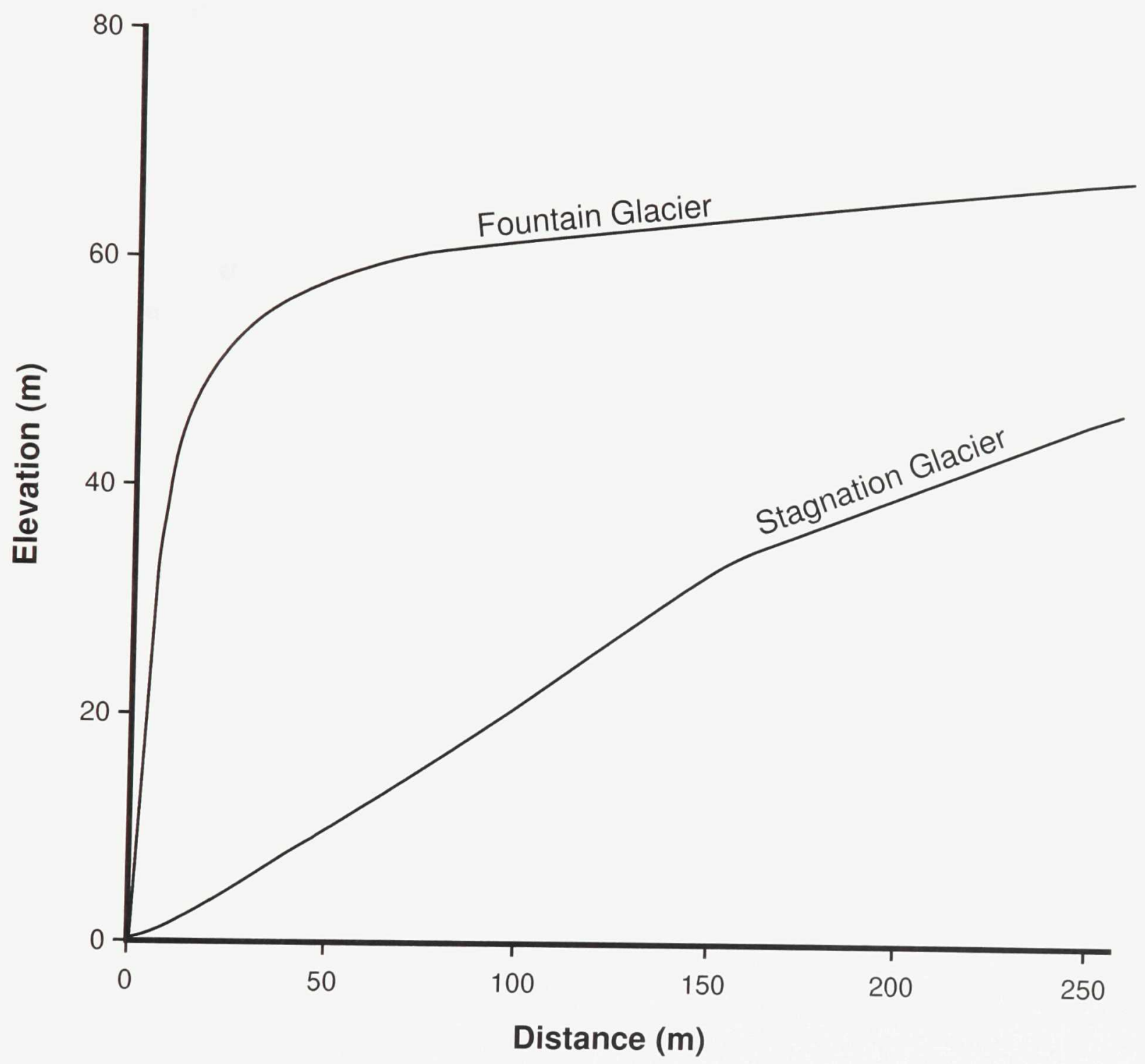

Figure 3.2 Representative profiles of the termini of Fountain and Stagnation Glaciers. 
lateral moraines; however, at several locations these streams disappear beneath the glacier or moraines. A large ice cored esker extends out from the terminus of the glacier. Stagnation Glacier has an accumulation area of about $8 \mathrm{~km}^{2}$.

Aerial photographs were used to map temporal variations in the extent of the

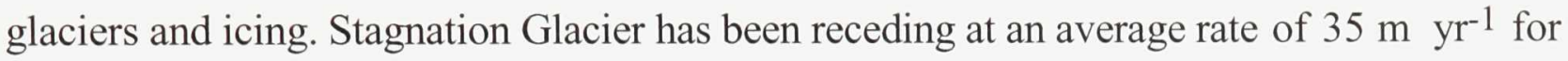
the last 46 years, while the terminus of Fountain Glacier has remained stationary (Figure 3.3).

The icing in front of Fountain Glacier currently covers the entire valley floor extending over $11 \mathrm{~km}$ down valley from the terminus of the glacier. Some sections are up to $0.5 \mathrm{~km}$ in width. Although the majority of the icing melts every summer, a portion of the icing (about $300 \mathrm{~m}$ by $1.2 \mathrm{~km}$ in extent) located between Fountain and Stagnation Glaciers appears to have existed perennially since at least 1948.

A spring has been observed to emerge from the valley bottom sediments, about $50 \mathrm{~m}$ in front of the terminus of Fountain Glacier. This appears to be one of the water sources for the ice buildup during the winter, and ice erosion during the summer. In 1993 and 1994, the spring's opening was covered by the icing and an icing blister formed on the surface above the outlet.

\subsection{Methodology: mapping ice bodies with GPR}

The large contrast in the dielectric constant between ice $(\mathrm{k}=3-4)$, water $(\mathrm{k}=80)$, sediment $(k=5-40)$, and air $(k=1)$ makes ground penetrating radar well suited for delineating ice and sedimentary units. The backpack portable digital GPR systems that are now commercially available enable GPR surveys to be quickly and easily conducted in 


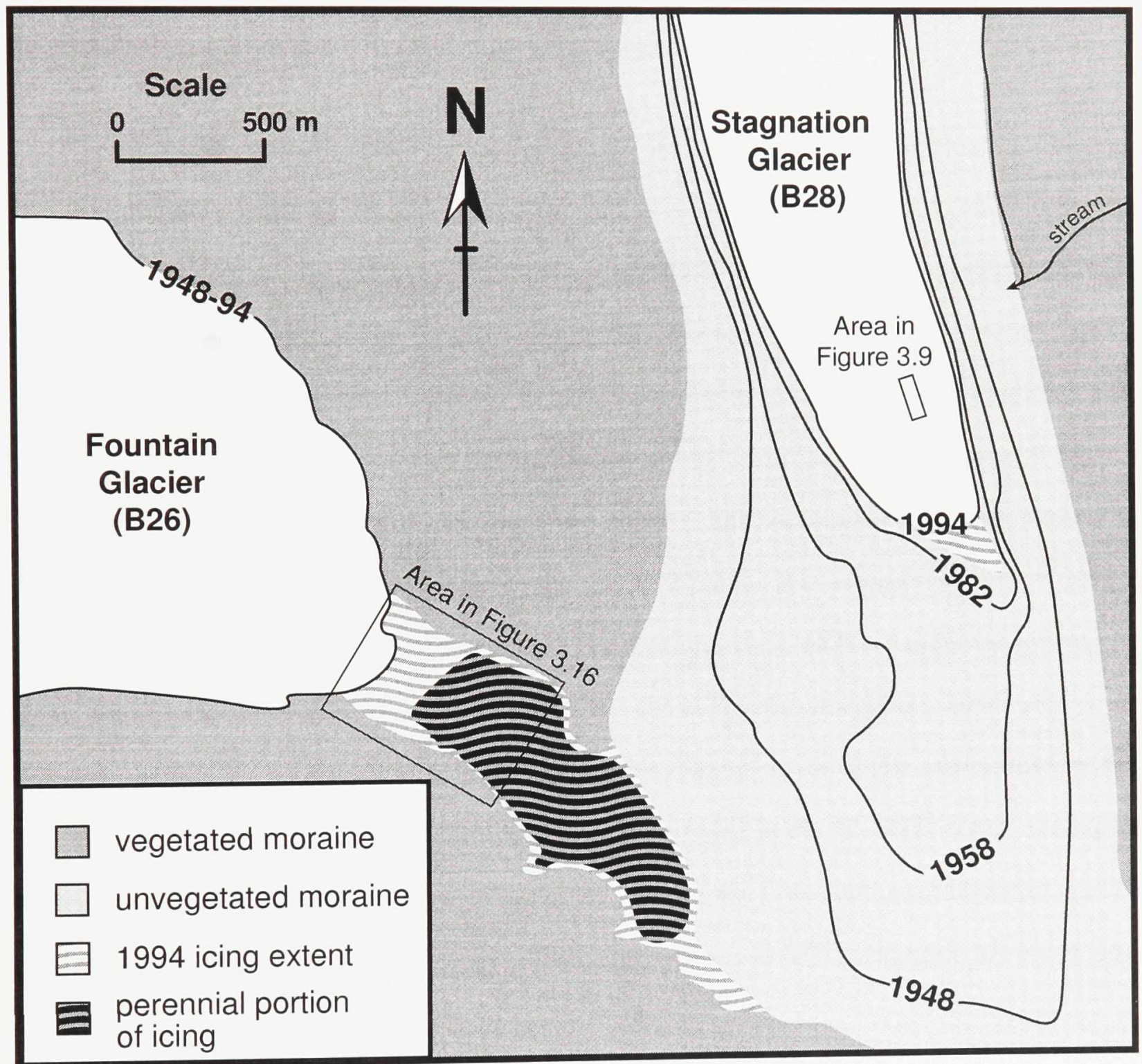

Figure 3.3 While the terminus of Fountain Glacier has remained unchanged since 1948, Stagnation Glacier has retreated almost $2 \mathrm{~km}$. The extent of the two glaciers is mapped from aerial photography taken in 1948, 1958, 1982 and 1994. The icing that originates in front of Fountain Glacier can extend for over $11 \mathrm{~km}$ some years but only a small portion of that persists from year to year. 
isolated locations with minimal logistical support, and the data to be digitally processed and enhanced. Initial studies have indicated that these GPR units can be effective for delineating the size of buried ice in permafrost to over 25 m depth (Robinson et al., 1992); however, little research has been done in glaciology with these units.

A Sensors and Software Inc, pulseEKKO IV radar system, employing antennas with center frequencies of $25,50,100$, and $200 \mathrm{MHz}$, was used with both $400 \mathrm{~V}$ and $1000 \mathrm{~V}$ transmitters. The GPR profiles were conducted with a bistatic antenna assembly with one person dragging the antenna assembly and another person following behind carrying the control unit and computer (Figure 3.4). From computer modelling and field observations it was discovered that the minimum vertical resolution in ice was $0.5 \mathrm{~m}$ at $200 \mathrm{MHz}$ and $1 \mathrm{~m}$ at $50 \mathrm{MHz}$. Although the size of objects smaller than this cannot be resolved, they can still be detected by the GPR system and appear as point source reflections on the profiles. While the $200 \mathrm{MHz}$ configuration offers better resolution, the lower frequency and higher power output of the $50 \mathrm{MHz}$ setup enables structures to be observed to greater depths. Figure 3.5 displays two traces taken at the same location and plotted at the same scale. Even though there is greater noise in the $50 \mathrm{MHz}$ trace, the signal to noise ratio is great enough to clearly make out reflections from within and beneath the 65 $\mathrm{m}$ thick glacier. The shorter pulse length produced by the $200 \mathrm{MHz}$ antennas provides finer resolution but the signal is quickly attenuated.

The optimal configuration was determined to be $200 \mathrm{MHz}$ antennas used in combination with a $400 \mathrm{~V}$ transmitter when profiling thin surface ice bodies (less than $20 \mathrm{~m}$ thick), $100 \mathrm{MHz}$ antennas with a $400 \mathrm{~V}$ transmitter when looking for structure within the sediment, and $50 \mathrm{MHz}$ antennas with a $1000 \mathrm{~V}$ transmitter when profiling thicker, or buried ice. When profiling the icings either $100 \mathrm{MHz}$ or $200 \mathrm{MHz}$ antennas were used and spaced $1 \mathrm{~m}$ apart. The $50 \mathrm{MHz}$ antennas spaced $3 \mathrm{~m}$ apart were used when surveying glaciers or moraines. When profiling on bare ice with the $50 \mathrm{MHz}$ antennas only 


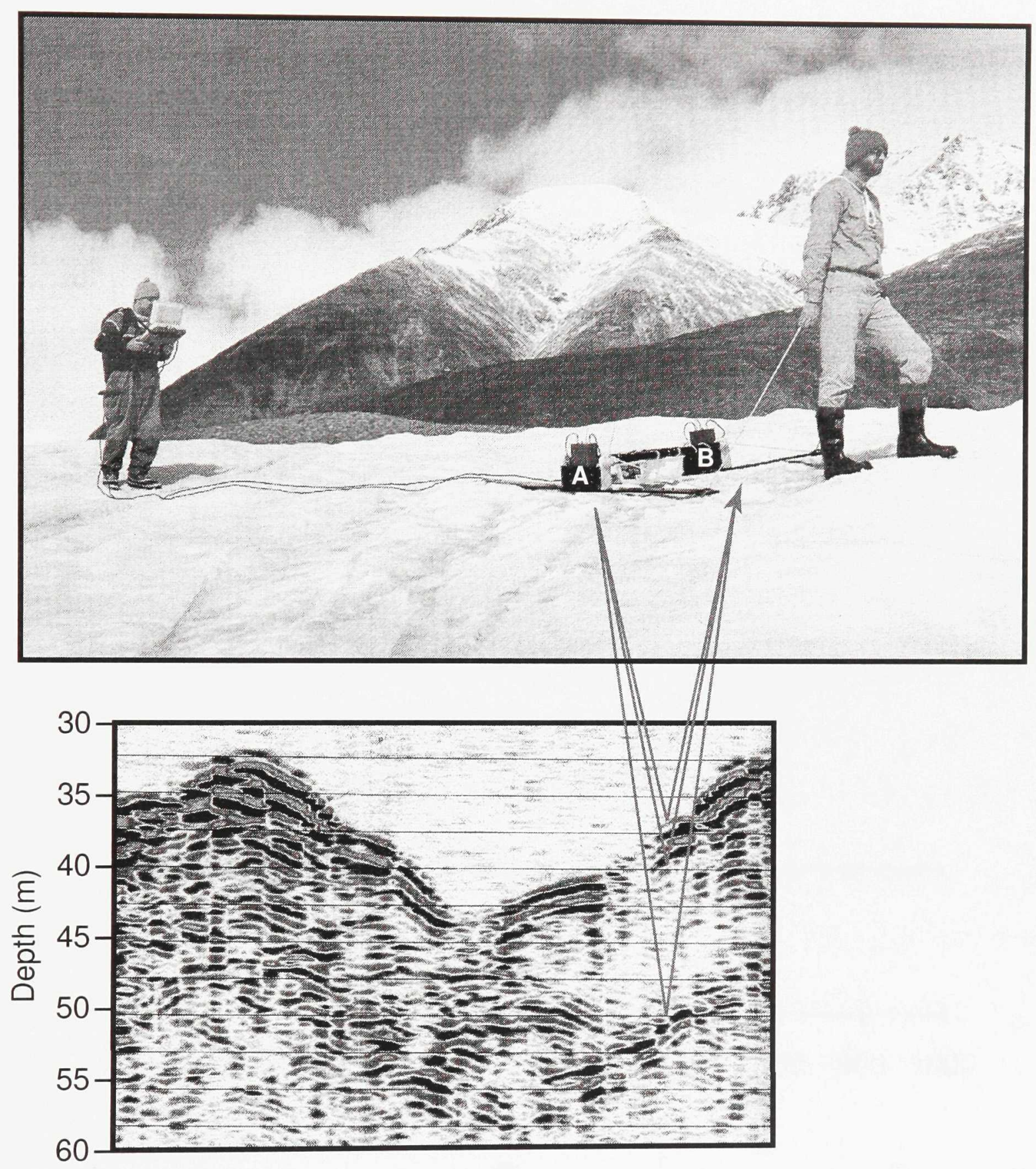

Figure 3.4 The GPR unit is towed behind one person while the second person asses the incoming data on a laptop computer. The energy pulses generated by the transmitter (A) propagate through the ground and are reflected back to the receiver (B) whenever they encounter a dielectric interface, such as the bottom of the glacier shown on the profile. Note that the GPR data can be displayed as grey scale profiles (as shown above) or as wiggle traces (as displayed in other figures). 


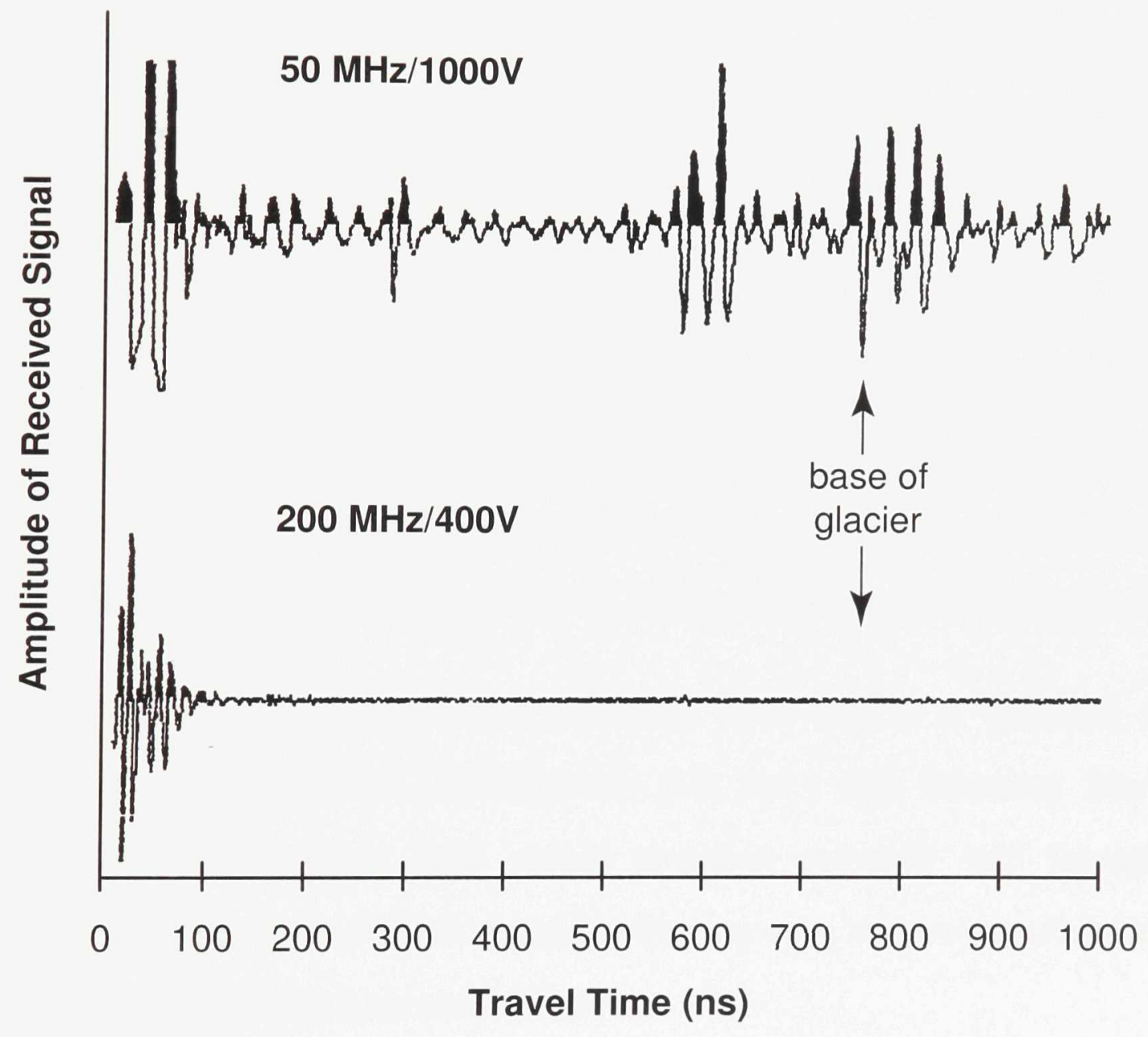

Figure 3.5 A comparison of the strength of returns from two different GPR configurations. While the signal to noise ratio for the deep reflections (eg. the base of the glacier) in the $200 \mathrm{MHz}$ trace is less than 1, it is greater than 2.4 in the $50 \mathrm{MHz}$ trace. 
$1 \mathrm{~m}$ apart, reverberations were generated through the first $100-150 \mathrm{~ns}$ of each trace. The velocity surveys demonstrate that a separation of over $10 \mathrm{~m}$ would have been required to eliminate these reverberations (Figure 3.6). This was deemed logistically very difficult and since there was little of interest in the upper few metres of the glacier ice, the near surface reverberations were disregarded in the interpretation of the GPR data.

The system was run in step mode with $1 \mathrm{~m}$ spacing between traces when doing detailed surveys of small areas, and in continuous mode when surveying larger, easily traversable areas. When running in continuous mode, the antennas were dragged at a constant walking speed and the uncertainty in the spacing between traces was verified to be less than $\pm 1 \%$.

A grid survey design was generally used such that the reflections from different profiles could be correlated where the profiles intersect, and a three dimensional model of the subsurface structure could be derived from the GPR surveys. Surface elevation was surveyed along the profile lines so that the GPR data could be corrected for topography.

The use of digital enhancement techniques were kept to a minimum in the processing of the GPR profiles. Generally only gain and a high frequency filter were applied to the data. However, GPR signals propagate extremely well through ice, producing long diffraction tails. Thus the glacier profiles were migrated to eliminate these tails and correct the dip of sloping planar reflectors.

Using the Sensors and Software Inc. GPR modelling and analysis programs, estimates were made of how the GPR would image different structures and lithologies by performing forward modelling of the different scenarios encountered. This was useful in interpreting some of the complex environments, since the models could be custom tailored to the specific subsurface structure and equipment configuration used. 


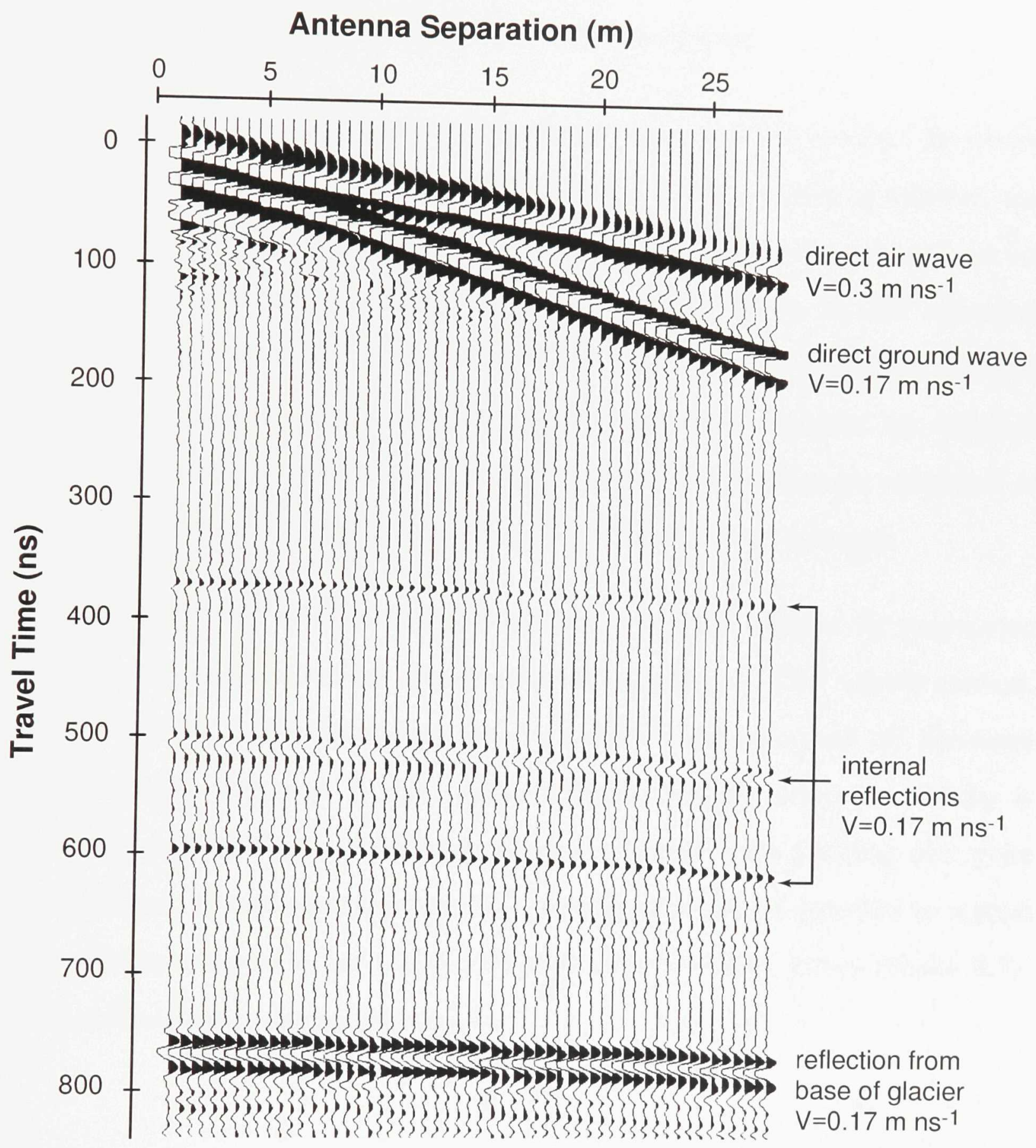

Figure 3.6 A common mid-point (CMP) velocity survey from Stagnation Glacier displaying weak reflections from internal ice layering and a strong reflection from the base of the glacier. Note that in general, few internal reflections were observed from within the glaciers. 


\subsection{Results and discussion}

\subsubsection{Interface identification and depth determinations}

As GPR transmits electromagnetic energy into the ground and measures the relative strength of energy returning to the surface and its travel time; identifying reflectors and determining their actual depth cannot be done directly. The identification of interfaces (or more precisely the materials on either side of an interface which causes the GPR reflection) was accomplished either using outcrop information or through radar stratigraphic analysis (Moorman, 1990; 1991). When employing radar stratigraphic analysis, the reflection patterns within individual units and how they intersect the interface are compared to depositional or formational models developed for various similar environments.

The conversion of the measured travel time into depth requires the propagation velocity. The propagation velocity was measured in two ways; 1) CMP velocity surveys, where the velocity is calculated from the direct arrivals and reflections off horizontal interfaces (Figure 3.6), and 2) point source reflection analysis, where the velocity is determined using the shape of reflection patterns produced when profiling over point source reflectors. The same geometry applies to the reflection patterns generated by a point source reflector in a profile, and a horizontal interface in a velocity survey (Figure 3.7). The travel time equation for normal moveout:

$$
\mathrm{t}^{2}=\frac{\mathrm{x}^{2}}{\mathrm{~V}^{2}}+\mathrm{t}_{0}^{2}
$$




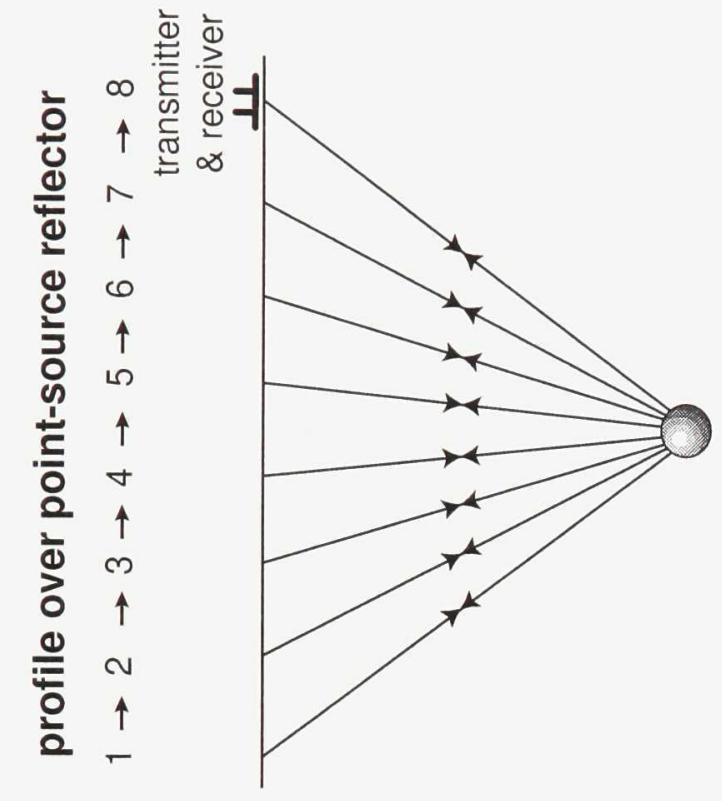

(3) 을

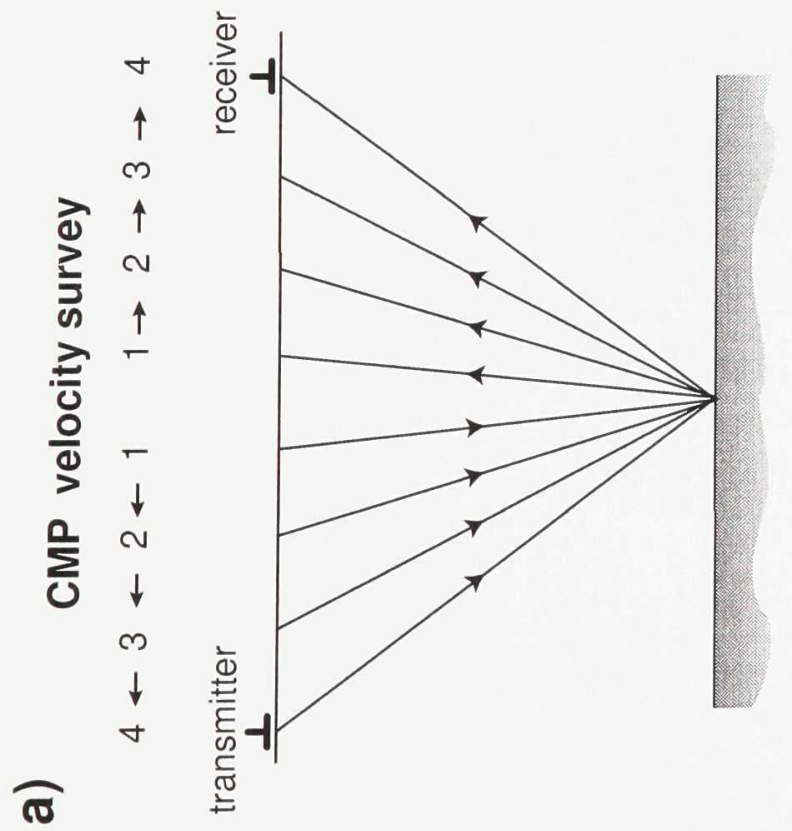

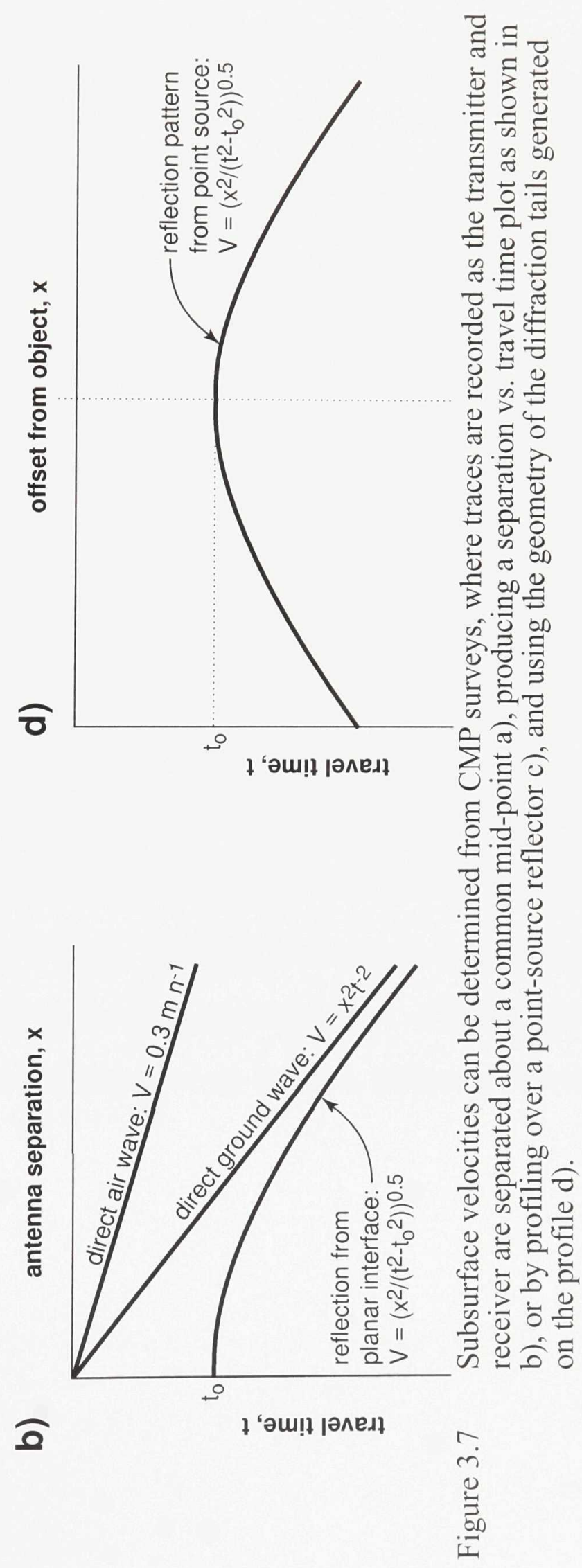


where $\mathrm{x}$ is the antenna separation in a velocity survey or the lateral offset from the point source reflector in a profile, $\mathrm{V}$ is the propagation velocity, $\mathrm{t}_{\mathrm{o}}$ is the one-way travel time at zero separation/offset (Telford et al., 1976), can be rearranged to calculate velocity:

$$
V=\sqrt{\frac{x^{2}}{t^{2}-t_{0}^{2}}}
$$

The velocity data from the icing were verified by correlation of the GPR reflections to significant interfaces in ice cores taken at the same locations. As the glaciers are too thick to easily core, the general stratigraphy was recorded at vertical sections on their sides. For the sake of simplicity, the GPR profile depth scales were constructed with the dominant velocity measured.

The range in measured velocities represents variations in the air and water content of the ice (see Table 3.1). The ice velocity measurements made near the terminus of Stagnation Glacier were uniformly $0.17 \mathrm{~m} \mathrm{~ns}^{-1}$. This is consistent with values observed by Robin (1969) and Bjornsson (1986) for glacier ice. In the accumulation area of the glaciers the firn, which was dryer and had a larger proportion of air bubbles, yielded a higher velocity of $0.19 \mathrm{~m} \mathrm{~ns}^{-1}$. 
Table 3.1. Ice velocities measured on glaciers and icings.

\begin{tabular}{|lccc|}
\hline location & $\begin{array}{c}\text { velocity } \\
\left(\mathbf{m ~ n s}^{-1}\right)\end{array}$ & $\begin{array}{c}\text { number of } \\
\text { measurements }\end{array}$ & material \\
\hline glacier accumulation area & 0.19 & 3 & hard packed snow/firn \\
glacier terminus & 0.17 & 27 & ice \\
seasonal icing & $0.12-0.17$ & 23 & wet slush to bubbly ice \\
perennial icing & $0.15-0.17$ & 12 & drained slush to bubbly ice \\
sediment under seasonal icing & $0.15-0.17$ & 5 & gravel \\
end moraine & 0.13 & 3 & till \\
\hline
\end{tabular}

The propagation velocity of a GPR signal through an electrically resistive medium, such as a glacier, is dominantly a function of the bulk dielectric constant of the material. The velocity is given by:

$$
\mathrm{V}=\frac{\mathrm{c}}{\sqrt{\varepsilon}}
$$

where $\mathrm{c}$ is the speed of light $\left(0.3 \mathrm{~m} \mathrm{~ns}^{-1}\right)$ and $\varepsilon$ is the effective (bulk) relative dielectric constant of the material. Kovacs et al. (1995) showed that:

$$
\varepsilon=(1+0.845 \rho)^{2}
$$

in polar firn (i.e., composed of ice and air with no liquid water content), where $\rho$ is the bulk density of the firn. For these conditions equations (3.3) and (3.4) can be merged and the velocity can be expressed as: 


$$
\mathrm{V}=\frac{\mathrm{c}}{1+0.845 \rho}
$$

And thus density can be determined by rearranging equation (3.5):

$$
\rho=\frac{\left(\frac{c}{V}-1\right)}{0.845}
$$

From equation (3.6), the density of the firn in the accumulation area and the glacier ice near the terminus was calculated to be $0.68 \mathrm{~g} \mathrm{~cm}^{-3}$ and $0.90 \mathrm{~g} \mathrm{~cm}^{-3}$, respectively. The bulk density of a sample of the ice from near the terminus of Stagnation Glacier was gravimetrically determined to be $0.90 \mathrm{~g} \mathrm{~cm}^{-3}$.

The velocities determined for the icing showed considerable range due to the spatial variability in the air and liquid water content of the ice (see Table 3.1). The end moraine and the sediment beneath the icing both have relatively high velocities suggesting that they are well frozen, have a high ice content, and a small proportion of clay (which has a very low velocity).

\subsubsection{The character of Fountain and Stagnation Glaciers}

A $50 \mathrm{MHz} / 100 \mathrm{~V}$ GPR profile from the accumulation area of the glaciers showed that basal reflections could be detected to depths of over $145 \mathrm{~m}$ with interface slopes up to $25^{\circ}$ (Appendix B). The thickness of Fountain and Stagnation Glaciers near their termini was generally less than $100 \mathrm{~m}$, and GPR profiles display strong reflections from the base of the glaciers (Appendices C and D). An example of the Stagnation Glacier profiles is shown in Figure 3.8. Apart from the general geometry of the glaciers, the GPR profiles provided information on the sediment inclusions and cavities within the glaciers, the subglacial stratigraphy, and indications of the thermal conditions of the glacier. 

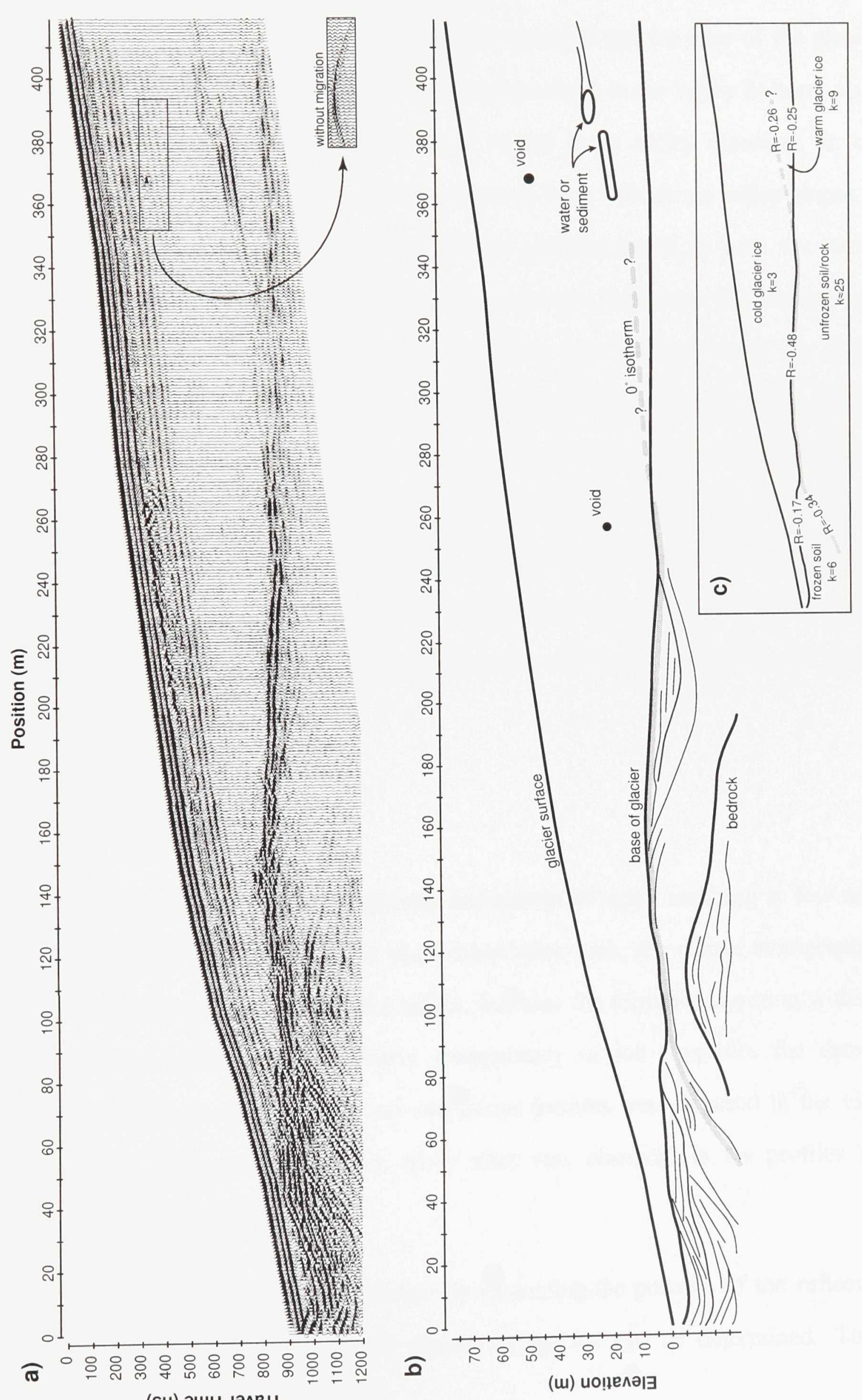

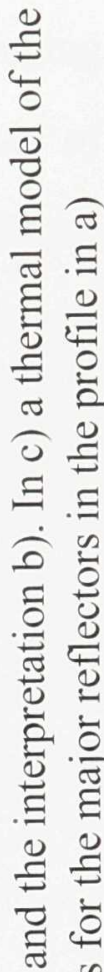

(ิ)

过

$\checkmark 0$

응

馬

政

4

芯

킹

\pm
$\mathscr{0}$

‡

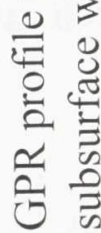

尚 
The GPR profiles from Fountain Glacier revealed that the base of the glacier has a uniform down valley slope of $2.8^{\circ}$. However, undulations in the valley bottom, up to $5 \mathrm{~m}$ in height and 10-30 $\mathrm{m}$ apart were observed in the cross valley direction. In contrast, Stagnation Glacier has a considerably more uneven base with down valley slopes ranging from $0^{\circ}$ to $22^{\circ}$. From a small 3-D GPR survey performed $400 \mathrm{~m}$ from the terminus of Stagnation Glacier, detailed ice thickness variations were measured. By subtracting the ice thickness from ice surface elevation, a topographic map for the sole of the glacier was created. As shown in Figure 3.9, the terrain beneath this portion of Stagnation Glacier slopes towards the side of the glacier, indicating that the valley is not symmetrical about its center axis. Also plotted in Figure 3.9 is elevation of the ice surface, indicating how even in thin portions of a glacier variations in the ice surface topography are not necessarily a reflection of the topography of the ground immediately beneath it. Local topography of the glacier surface near its terminus is largely the result of erosion by supra-glacial runoff.

\subsubsection{Internal features}

In general, glacier ice is relatively transparent to radar, resulting in few reflections being generated from within it. In the accumulation area, the coarse stratigraphy of the snow and firn appears on the GPR profiles, but near the terminus, layering within the ice could not be identified. The relative transparency of ice simplifies the detection of anomalous features within it. Several anomalous features were detected in the vicinity of the terminus of Stagnation Glacier, while none was observed in the profiles from the terminus of Fountain Glacier.

As Arcone et al. (1995) discuss, by examining the polarity of the reflections, the dielectric constant $(\mathrm{k})$ of the target relative to the ice can be determined. The strong 
a) glacier bottom elevation ( $\mathrm{m}$ )

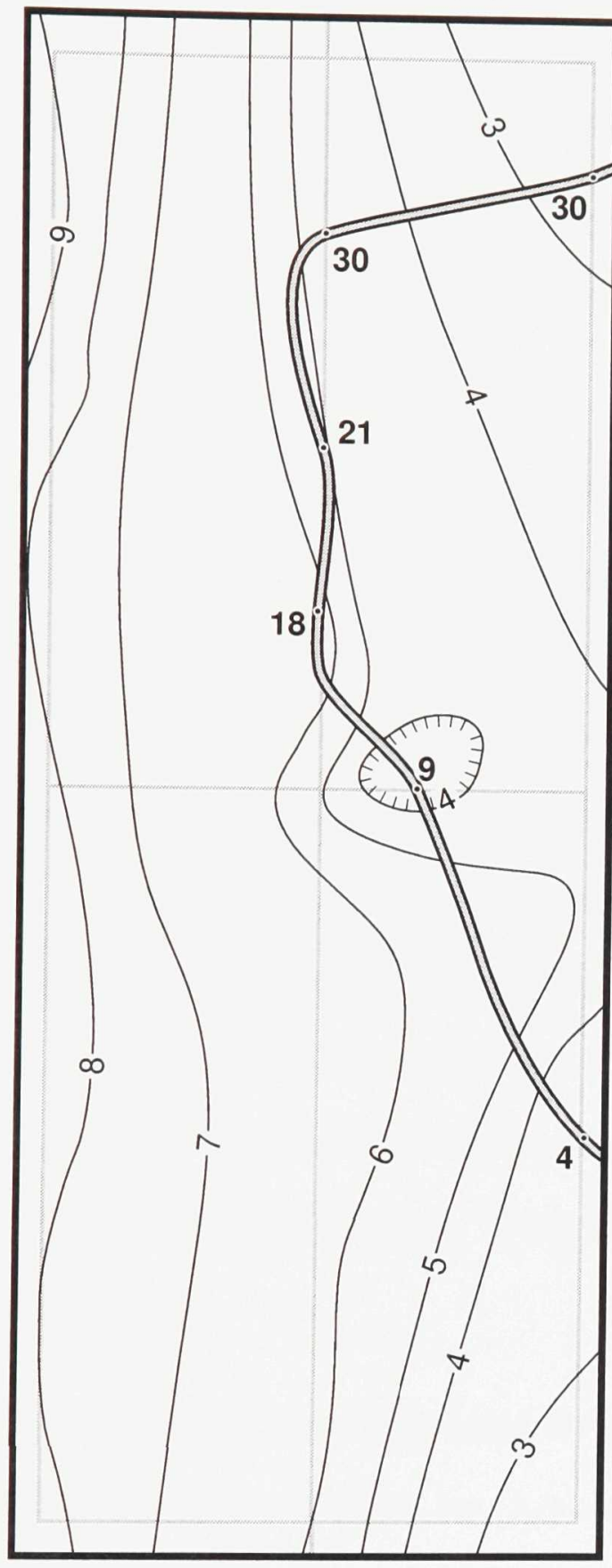

b) glacier surface elevation $(\mathrm{m})$

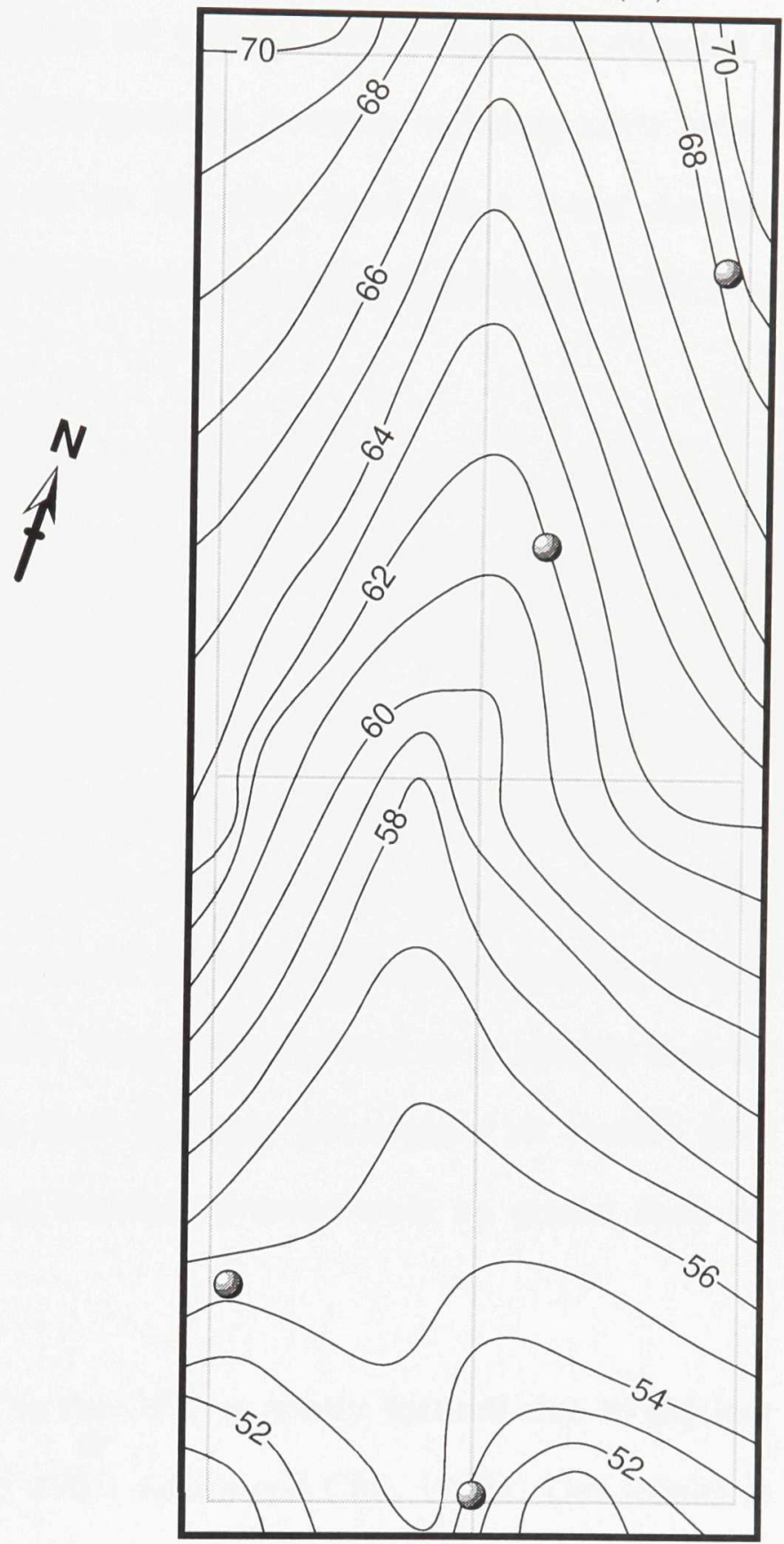

GPR survey line

= englacial tunnel

«9 englacial tunnel elevation $(\mathrm{m})$

- point source reflector (void)
Scale $20 \mathrm{~m}$

Figure 3.9 The basal and surface elevation of a small portion of Stagnation Glacier relative to the elevation of a benchmark at the terminus of the glacier. The location of small air filled voids and a water filled englacial tunnel are also shown. See Figure 3.3 for location. 
reflection from the ice $(k=3)$ to sediment $(k \approx 25)$ interface at the base of the glacier shows a distinctive +-+ polarity. Thus, targets within the ice with the same polarity are expected to have a higher dielectric constant than ice. Most geologic materials including water have a higher dielectric constant than ice, while air on the other hand has a lower dielectric constant than ice. Thus air filled voids would be expected to generate a reflection with a -+polarity.

Two anomalies, at the $255 \mathrm{~m}$ and $369 \mathrm{~m}$ positions in the GPR profile shown in Figure 3.8, have a -+- polarity and are interpreted as air filled voids. The size of these voids cannot be determined as they are smaller than the resolution of the GPR and act as simple point source reflectors. The diffraction patterns have been eliminated by migrating the data, but the inset in Figure 3.8a shows their distinctive appearance before the profile was migrated. The migration routine amplifies the return from the apex of the diffraction pattern thus enhancing the positive component of the -+- wavelet. The location of four other air filled voids are shown in Figure 3.9b. They were all found to be smaller than the resolvable size and not interconnected. It is likely that they are remnant air cavities from when crevasses closed up. There are several heavily crevassed areas up glacier from the study area.

Energy transmitted into the glacier by the GPR is poorly focused due to the low dielectric constant of the ice (Arcone et al., 1995; Annan and Chu, 1992). This results in returns coming from not just beneath the antennas, but from considerable distances off to the sides as well. This is the source of the long diffraction tails being generated by point source reflectors. The considerable length of these tails aided the determination of the three dimensional position of point source reflectors within the grid of survey lines on Stagnation Glacier. The location of the reflector was determined by interpolating the location of the apex of the reflection tails between profiles (Figure 3.10). The position and depth of the 

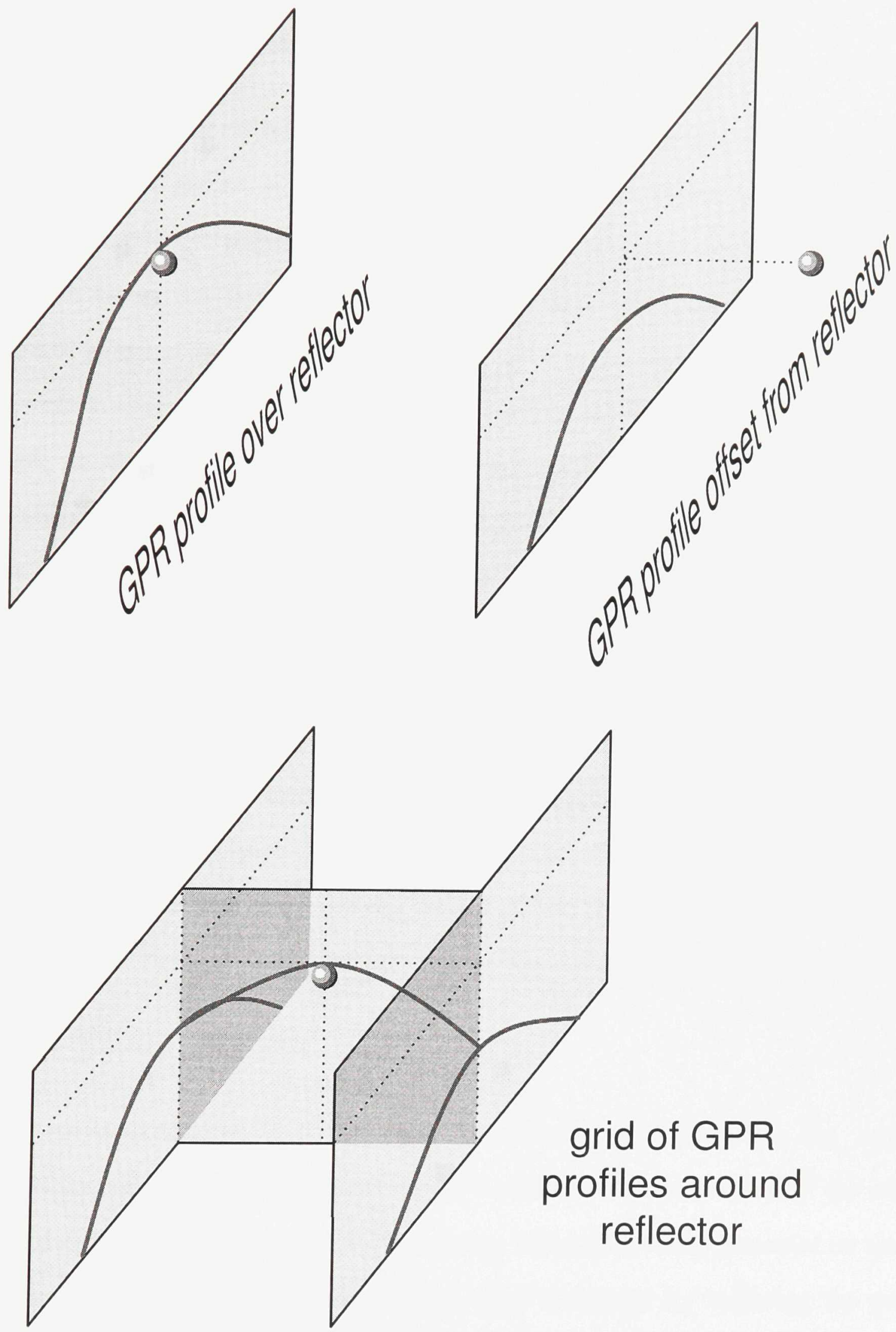

Figure 3.10 A schematic of how interpolation between multiple GPR profiles enables the determination of the 3 -dimensional position of point source reflectors that generate long diffraction tails in ice. 
reflectors are indicated in Figure 3.9.

Several of the reflections from within Stagnation Glacier have the same +-+ polarity as the base of the glacier, indicating that the reflectors have a higher dielectric constant than the ice (eg., water or sediment). The lateral extent of the two reflectors displayed on the profile in Figure 3.8 is resolved. The source of these reflections are likely either large bodies of sediment entrained within the glacier ice, or water filled englacial drainage tunnels that were crossed at acute angles by the GPR survey line. When surveying across a linear feature at an acute angle the apparent cross section dramatically increases. From interpolating between the GPR profiles in the grid on Stagnation Glacier, it appears that these two reflectors are likely part of a linear feature such as an englacial tunnel. The interpreted route of the tunnel is shown in Figure 3.9. Although the GPR profiles did not extend to the edge of the glacier at this location, the up-ice end of this feature is in direct alignment with the location of a cave where a stream running along the outside of the east lateral moraine disappears beneath it (Figure 3.11). The elevation of the englacial stream in the upper portion of Figure 3.9 is $20 \mathrm{~m}$ below that of the lateral stream that runs in a channel between the east lateral moraine and the glacier. Dye tests later revealed that there is no connectivity between the englacial and lateral streams even though they cross paths.

\subsubsection{Subglacial stratigraphy}

As demonstrated in Figure 3.8, considerable information on the subglacial stratigraphy can also be extracted from the GPR profiles. The coarse nature of the sediment at the base of Stagnation Glacier resulted in many diffractions being generated on the GPR profiles from point source reflectors. These were eliminated by migrating the profiles, producing the more realistic looking radar stratigraphic patterns shown in Figure 3.8. 


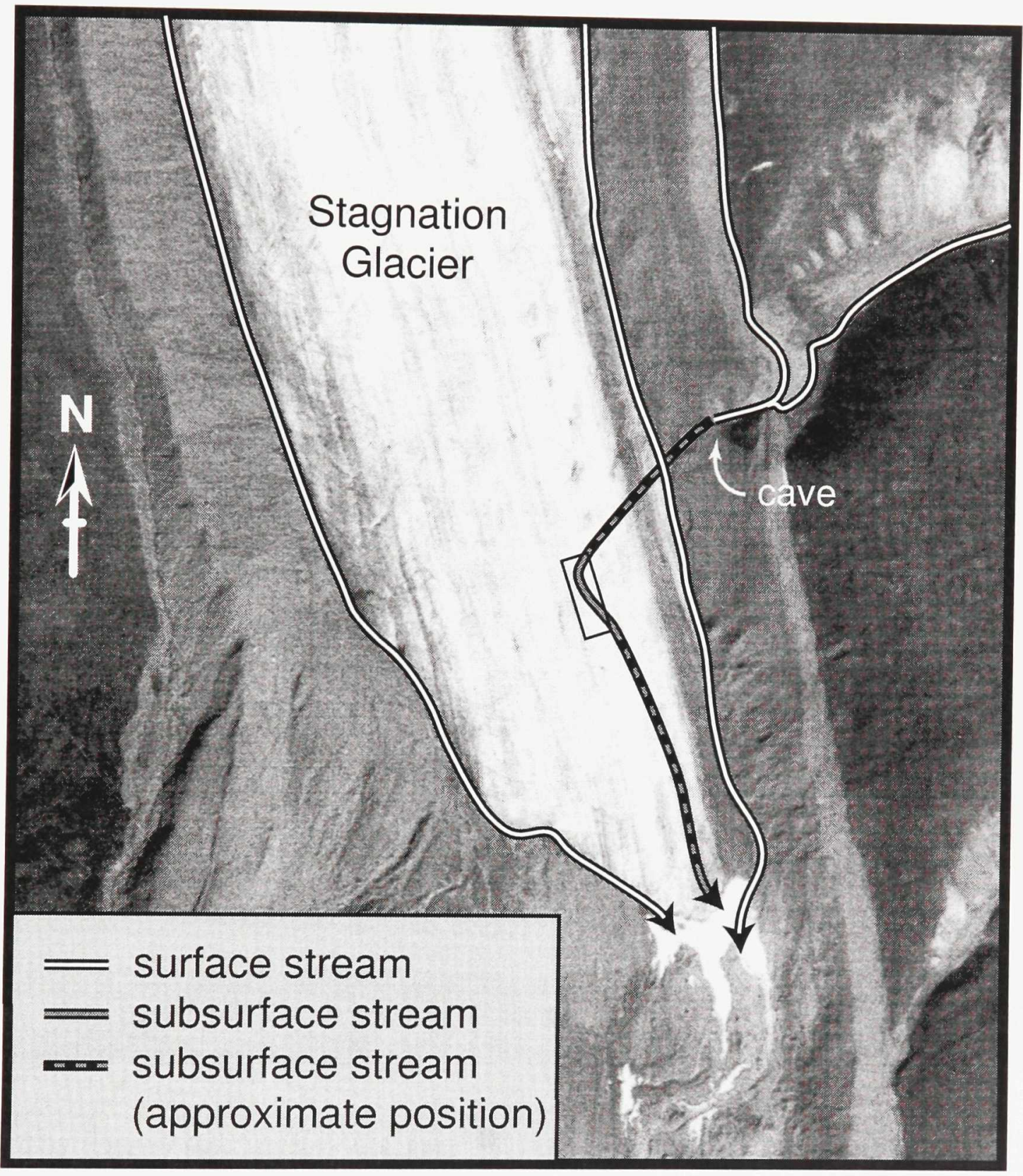

Figure 3.11 The observed position of surface streams and position of subsurface determined from GPR surveys. 
Numbering of the elevation scale stops at the base of the glacier as the velocity structure of the subglacial sediment is likely complex and direct measurement of it was not possible. However, using a bulk estimate of the velocity, the depth of penetration below the glacier ranges from $15 \mathrm{~m}$ to $25 \mathrm{~m}$. Even without information on the depth of the interfaces, their form, spatial relationships, and the radar stratigraphic character of the units on either side of each interface is informative.

Examples of the three main sedimentary structures observed beneath Stagnation Glacier are displayed in Figure 3.8. Within the first $90 \mathrm{~m}$ of the profile, numerous shingled reflections illustrate how the basal sediments are layered as they are ploughed forward and deposited by the glacier ice as it passes over the bedrock ridge. This structure is not evident on the surface of the end moraine due to the presence of a cap of sublimation till; however, it is observed at stream cuts through the end moraine and has been discovered elsewhere on the island (Klassen, 1982).

Between the positions of $90 \mathrm{~m}$ and $130 \mathrm{~m}$ in Figure 3.8, a strong subglacial reflection is present. It is continuous, but weaker at greater depths from the $70 \mathrm{~m}$ position to beyond the $200 \mathrm{~m}$ position. This appears to be a rise in the bedrock interface. Below this bedrock interface, the reflection patterns are horizontal to convex and are not shingled like the sediment at the terminus of the glacier. The reflection pattern generated from within the bedrock is most likely generated by either stratigraphy layering of the bedrock or fractures.

The feature just beneath the base of the glacier between the $150 \mathrm{~m}$ and $250 \mathrm{~m}$ positions in Figure 3.8 appears to be a depression infill. It is outlined by two separate concave reflections that encase sloping planar reflectors. This form is suggestive of a classic channel fill; however, a glacially eroded then infilled depression is also a possibility.

In contrast to Stagnation Glacier, beneath Fountain Glacier there are continuous to semi-continuous wavy reflections (see Appendix C), similar in appearance to those of the 
braided delta studied by Jol and Smith (1992). These reflections are interpreted as braided outwash sediments, such as those in the valley bottom beyond the terminus of the glacier. This indicates that Fountain Glacier has or is advancing out over its own proglacial sediments. This is supported by the lack of an end moraine beyond the terminus of the glacier.

\subsubsection{Thermal structure of Stagnation Glacier}

No direct information is known on the thermal structure of Stagnation Glacier; however, the GPR profile in Figure 3.8 does provide potential clues to the location of the zero degree isotherm. From the $90 \mathrm{~m}$ position to the $270 \mathrm{~m}$ position the reflection from the base of the glacier is strong and continuous. The reflection coefficient (R) for a planar surface such as this is given by:

$$
\mathrm{R}=\left(\mathrm{k}_{1}^{0.5}-\mathrm{k}_{2}^{0.5}\right)\left(\mathrm{k}_{1}^{0.5}+\mathrm{k}_{2}^{0.5}\right)^{-1}
$$

Where $\mathrm{k}_{1}$ is the dielectric constant of the material above the interface and $\mathrm{k}_{2}$ is the dielectric constant of the material below the interface. The strong reflection is indicative of a greater contrast in the dielectric constants in this portion of the glacier than the other areas.

The GPR data were modelled to try and reveal the cause of the observed reflection pattern. Using representative dielectric constants for the various materials, the reflection coefficients were calculated. The modelled structure shown in Figure 3.8c best replicates the GPR data. The most significant feature of the model is how the zero degree isotherm roughly follows the glacier topography, with permafrost thickening towards the glacier terminus and the thickness of isothermal ice increasing up glacier. With the zero degree isotherm positioned at the base of the glacier in the middle section of the profile an appreciably greater reflection coefficient is observed. The permafrost in the model also 
explains the greater signal penetration into the subglacial sediments at the terminus of the glacier. The presence of permafrost beneath the glacier terminus accounts for the reduction of radar signal attenuation that is caused by unfrozen pore water. The position of the zero degree isotherm within the glacier on the right side of the profile is less certain. It would require a more sophisticated system to confidently identify the zero degree isotherm within the ice (Björnsson et al, 1996). The transition from cold ice with no liquid water content, to warm ice at the pressure melting point containing intracrystallar liquid water is likely to be gradual and thus not create a strong reflection.

\subsubsection{Mapping buried ice around Stagnation Glacier}

When GPR surveys were continued off the edges of Stagnation Glacier onto the lateral and end moraines, the extent, depth, and thickness of buried ice could be seen on the profiles. At the east side of Stagnation Glacier the reflection from the base of the glacier continues under the lateral moraine (Figure 3.12). The buried ice body is roughly $20 \mathrm{~m}$ thick at the edge of the glacier and gradually pinches out towards the far edge of the moraine. At the crest of the east moraine, $180 \mathrm{~m}$ from the edge of the glacier, the ice core within the moraine is less than $1 \mathrm{~m}$ thick. The lateral stream on the east side of Stagnation Glacier flows over a thin layer of very coarse (boulder size) sediment that has rolled down to the valley bottom from the moraine above. The interference patterns beneath the stream on the GPR profile in Figure 3.12 are created by the radar signal reverberating off the coarse sediment.

A second reflection, from the overburden/ice contact also appeared on the GPR profiles. However, the reflection from this contact is often obscured by the direct ground wave, due to its proximity to the surface. The thickness of the till overburden was 


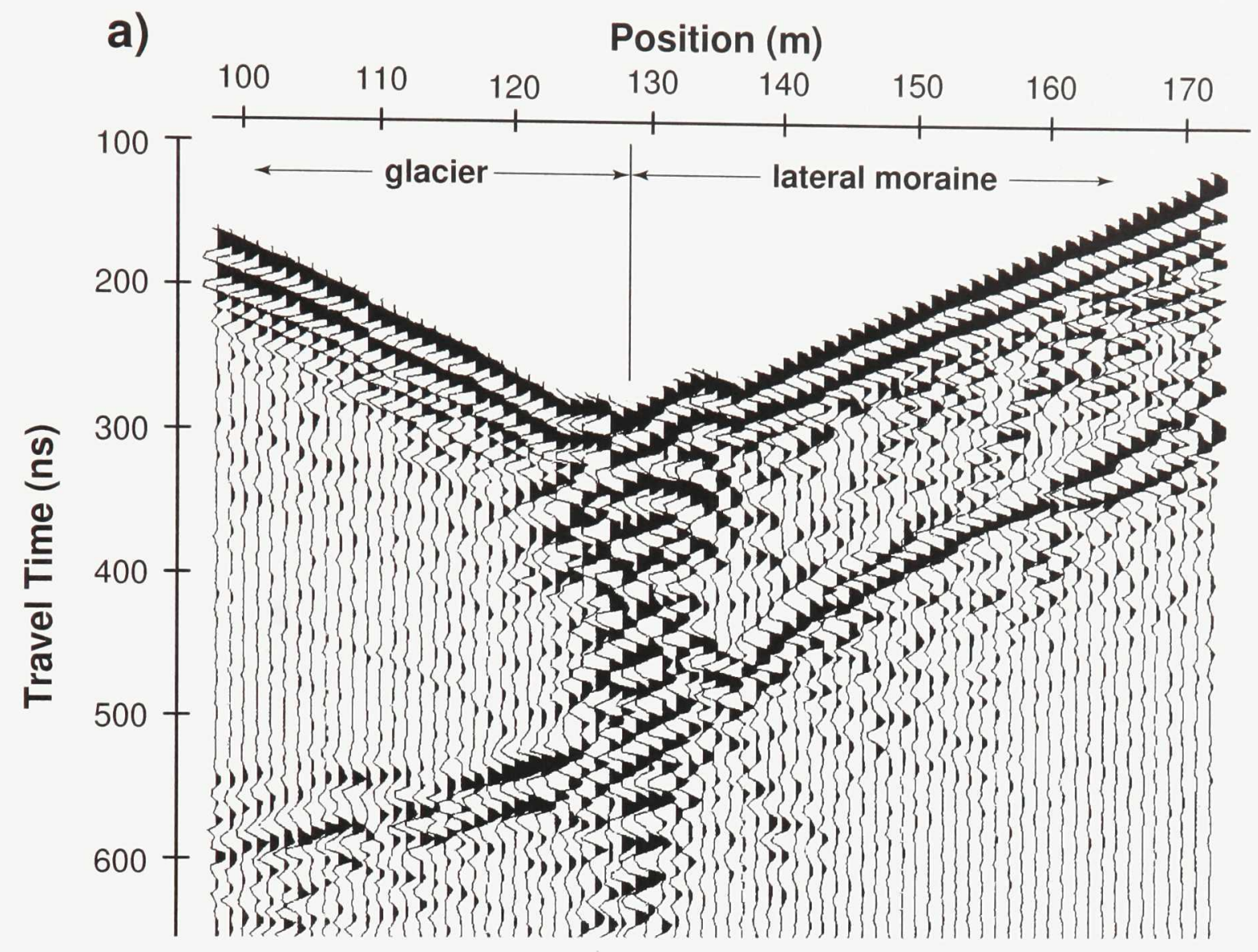

65

b)

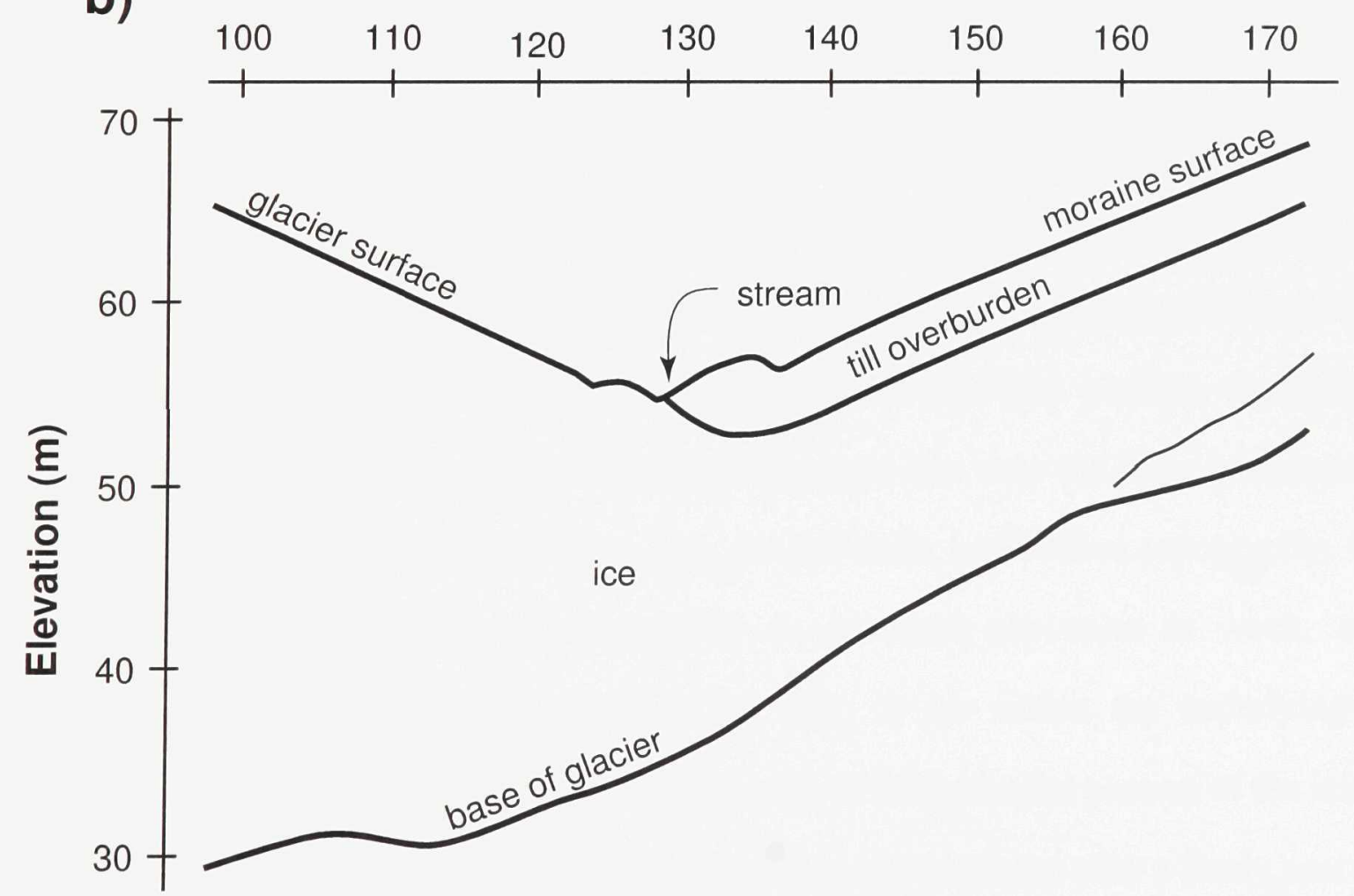

Figure 3.12 A GPR survey (a), and interpretation (b), from the side of Stagnation Glacier into its east lateral moraine, showing how the glacier ice extends out into the core of the moraine. 
measured at several exposures to range from less than $1 \mathrm{~m}$ to $3 \mathrm{~m}$. Between the measurements the overburden thickness was interpolated using the GPR data. As with the subglacial sediment, the sediment covering the lateral moraine created strong hyperbolic diffraction patterns on the GPR profiles. This sediment is extremely poorly sorted till with clay to boulder size components. Due to the number of diffractions and the variability in the velocity structure, the diffraction patterns were not as easily eliminated by migration as in the glacier ice.

Within the end moraine the buried ice extended $165 \mathrm{~m}$ beyond the terminus of the glacier, to the edge of a bedrock ridge (Figure 2.6). Down slope of the bedrock ridge layering could be seen within the till but massive ice is not evident. The thickness of the ice in the end moraine was generally less than $6 \mathrm{~m}$.

\subsubsection{Mapping the structure of icings}

One of the features that makes the study area unique on Bylot Island is the presence of the icing in front of Fountain Glacier, portions of which have existed perennially since at least 1948. Many of the other glaciers on Bylot Island generate icings in the winter but this icing is the only one that is known to have a central core that persists throughout the summer (Figure 3.3). Two grids of GPR surveys were run over the icing to determine the properties that make this icing unique, (eg. ice thickness and bottom topography, internal structural features indicative of formational or erosional processes at work, and the presence or absence of sediment within the icing or ice within the underlying gravel outwash plain). A coarse grid covered the majority of the perennial portion of the icing, and a smaller section of the seasonal portion of the icing was surveyed with a finely spaced grid of GPR lines. The depth of penetration of the GPR was considerably greater than the icing 
thickness, and strong reflections from the base of the icing and internal layering appears on all of the profiles. Since a lower powered transmitter and higher frequency antennas were used on the icing than on the glaciers, the equipment did not generate reverberations such as on the glacier profiles, and near surface ice stratigraphy could be observed on the GPR profiles. All GPR profiles from the icing are in Appendix C.

\subsubsection{Icing formational features}

Unlike glaciers, icings can be composed of ice layers with dramatically different properties. Within an icing the bubble content and liquid water content can vary dramatically with depth. Three general types of ice were identified in this icing, clearcrystalline, bubbly-massive, and interbedded ice (Figure 3.13). "Clear" ice is composed of almost pure ice with very few to no bubbles and large uniform, vertically oriented crystals that range in diameter from $0.5 \mathrm{~cm}$ to over $2 \mathrm{~cm}$, and are $1 \mathrm{~cm}$ to $20 \mathrm{~cm}$ in length. Any bubbles trapped in "clear" ice are usually located at the crystal boundaries. "Bubbly" ice consists of small randomly oriented ice crystals with many small bubbles distributed throughout the ice. The bubble content varied (up to $25 \%$ by volume), and the bubbles range from $0.5 \mathrm{~mm}$ to $2 \mathrm{~mm}$ in diameter, causing it to have a milky appearance. "Interbedded" ice is composed of alternating layers of "clear" ice and "bubbly" ice. The individual layers ranged in thickness from less than $1 \mathrm{~mm}$ to $2 \mathrm{~cm}$. The reflections from within the icing do not indicate specific ice bedding planes, which are generally thinner than the resolution of the GPR, but units which are composed of groups of beds with similar properties.

The "clear" ice forms as the result of slow freezing of a pool of calm water in which the crystals have time to orient themselves and grow large. At the same time, air bubbles are expelled ahead of the freezing front. The bubbly ice in the icing is formed when water 


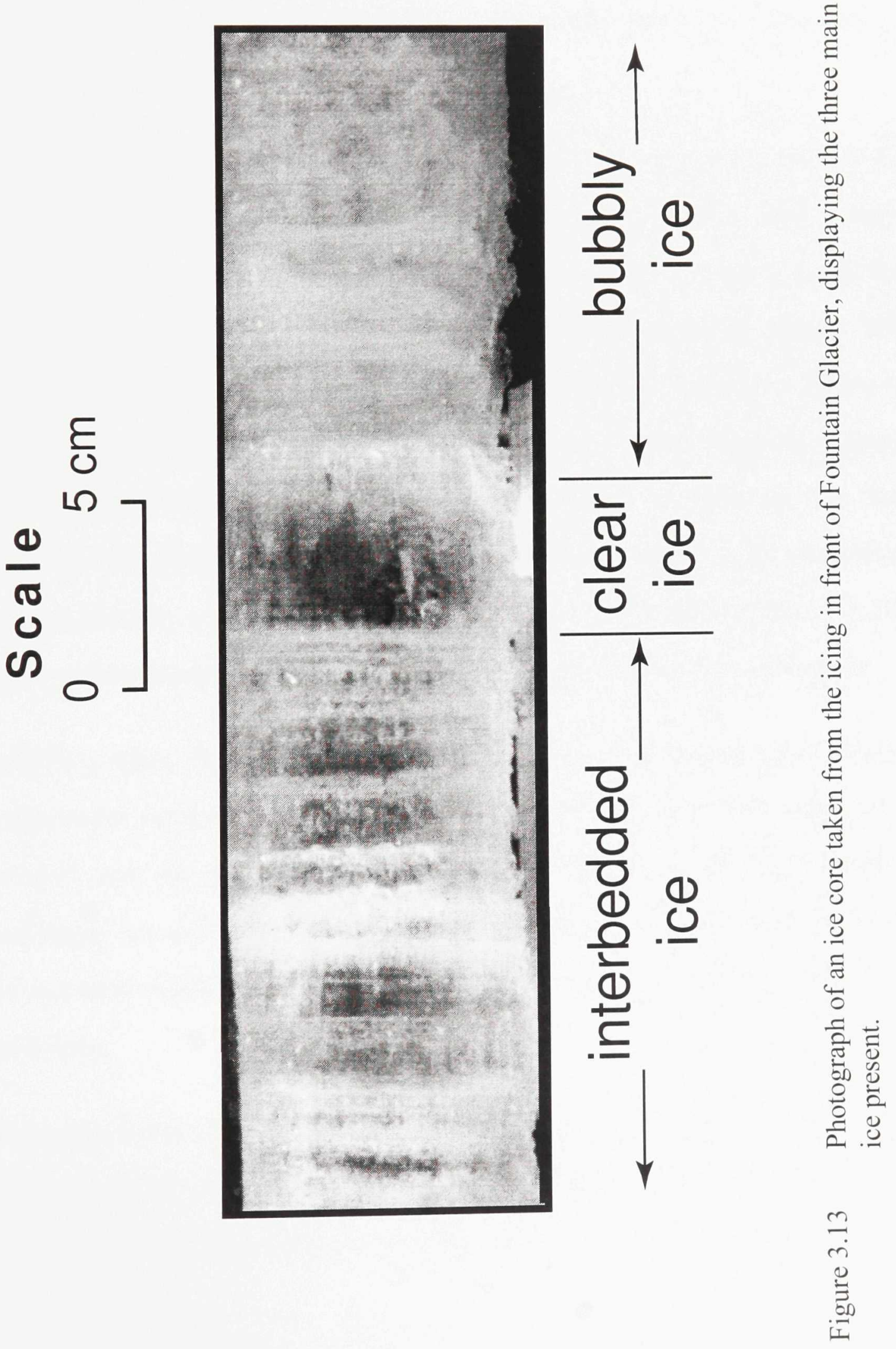


freezes quickly, resulting in the ice crystals being small and randomly oriented. "Bubbly" ice tends to have more air bubbles trapped within it because the freezing front advances faster than the air can be expelled. This often occurs when groundwater flows to the ground surface and is exposed to cold air temperatures creating frazzle ice (or slush), or when water saturates snow on the ground.

The GPR reflection patterns from within the perennial and seasonal portions of the icing differ considerably. The perennial icing is characterized by horizontal bedding planes, with very few internal reflectors, indicating no major variations or trends in the ice composition within the ice mass. Samples collected at several locations support this interpretation, showing a mixture of "bubbly" ice, and "interbedded" units from the top to the base of the icing, with few thick "clear" ice units. The lack of "clear" ice units suggests that during the formation of this portion of the icing, the water flow was generally less than or equal to the rate of freezing. Excess water flow either on the surface or in the subsurface (eg. within icing blisters) would have resulted in the pooling of water and slow "bulk" freezing, creating thick bands of clear ice, or erosional channels cut into the existing ice.

The GPR profiles from the seasonal portion of the icing contain many strong continuous reflections within the top $6 \mathrm{~m}$ of the ice (Figure 3.14). Those reflections were confirmed in drill cores which showed the upper portion of the icing containing alternating "bubbly" and "clear" ice units. Below a depth of $6 \mathrm{~m}$ within the seasonal icing, the layers were thicker and more uniformly bubble-rich. This is represented on the GPR profiles by a reflection free zone.

In the upper $6-8 \mathrm{~m}$ of the seasonal icing, the character of the internal reflections reveals information on the processes at work during the formation of the icing. In general, the returns are subparallel and roughly horizontal. This indicates that the bulk of the 

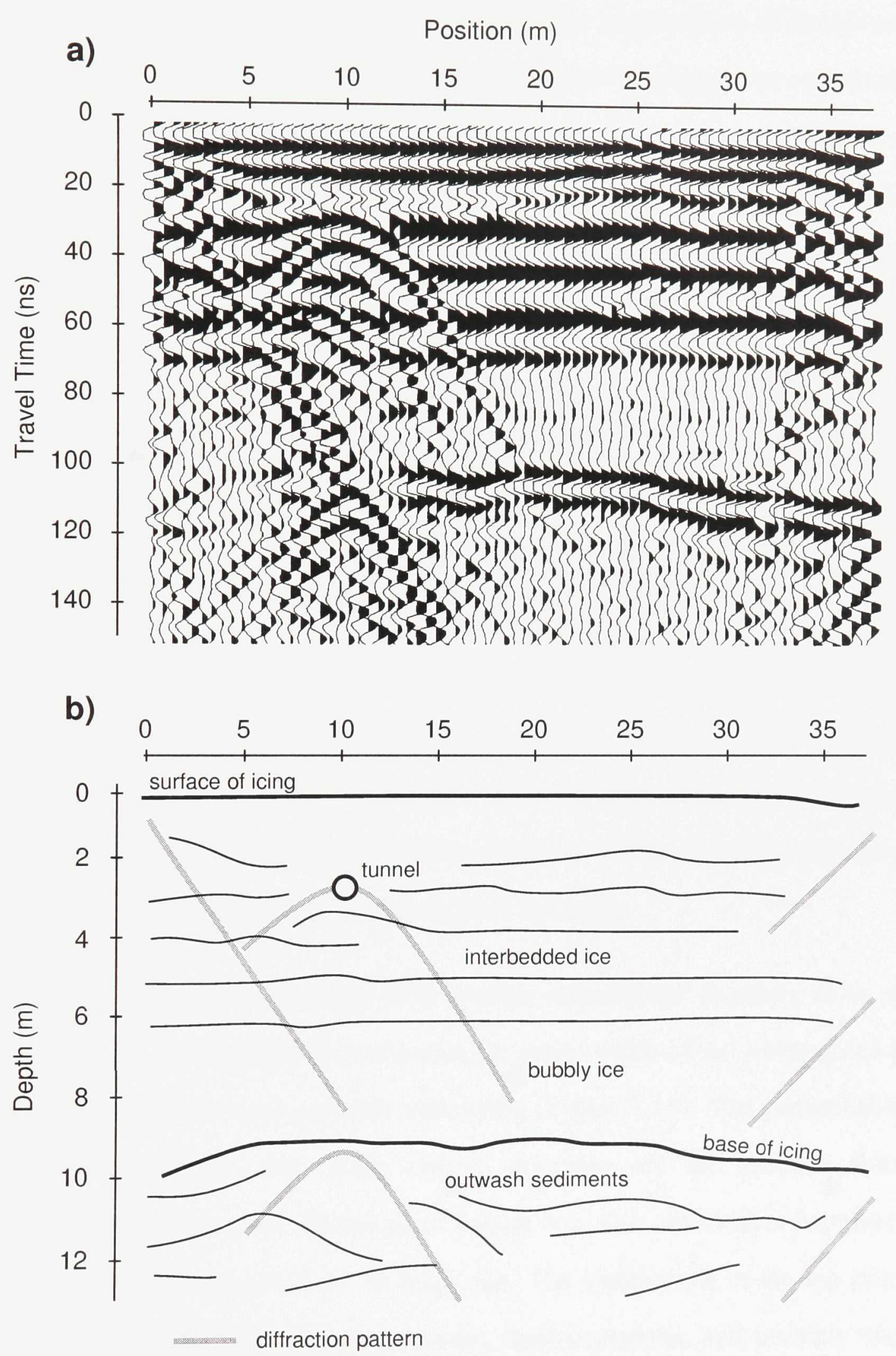

Figure 3.14 A GPR survey (a), and interpretation (b), across the seasonal portion of the icing in front of Fountain Glacier, displaying the stratigraphy of the icing and sediments below, and the diffraction pattern generated by a water filled tunnel. See Figure 3.17 for location. 
seasonally formed portion of the icing is not created by accumulation of frazzle ice flows, but by clear water which was able to flow for considerable distances over a relatively gentle slope before freezing. A system of icing formation such as this, is most likely to occur in an environment with only slightly negative air temperatures or in a regime of high but constant flow. Bylot Island experiences extremely negative temperatures throughout the winter, thus it is suggested that the water flow remains high and steady well into the winter.

Variations in the tabular structure take the form of depressions and mounded structures. The depressions were observed to be relatively localized. They were always less than $15 \mathrm{~m}$ in length and usually only a few metres wide with a depth of $1 \mathrm{~m}$ or less (Figure 3.15, 3.16). They were too small to resolve the internal character but their geometry is very similar to channels cut into the icing that were exposed at its side. They are interpreted as channel-fills, that is, abandoned drainage channels that were later filled with stagnant water that subsequently froze en-mass. Crystallographic evidence from samples collected support this theory, showing ice from within the interpreted channel-fills to be a single unit which had frozen inwards from the edges.

The mounds observed on the GPR profiles extended for distances of as much as $60 \mathrm{~m}$ in the down valley direction and across the entire width of the seasonal icing. Their top and bottom contacts were generally undulating (Figure 3.15). The conformable nature of the contacts suggests that these mound structures are ice injection features or aggradational frazzle ice units. This type of feature was also observed in exposures at the side of the icing and consisted of "bubbly" ice. The undulations in the top contact are thought to be the result of increased pressures, rapid expansion, and possibly short term ruptures, analogous to frost blisters, or the mounding of frazzle ice on the surface of the icing in the form of flows (van Everdigen 1982; Akerman, 1982). 

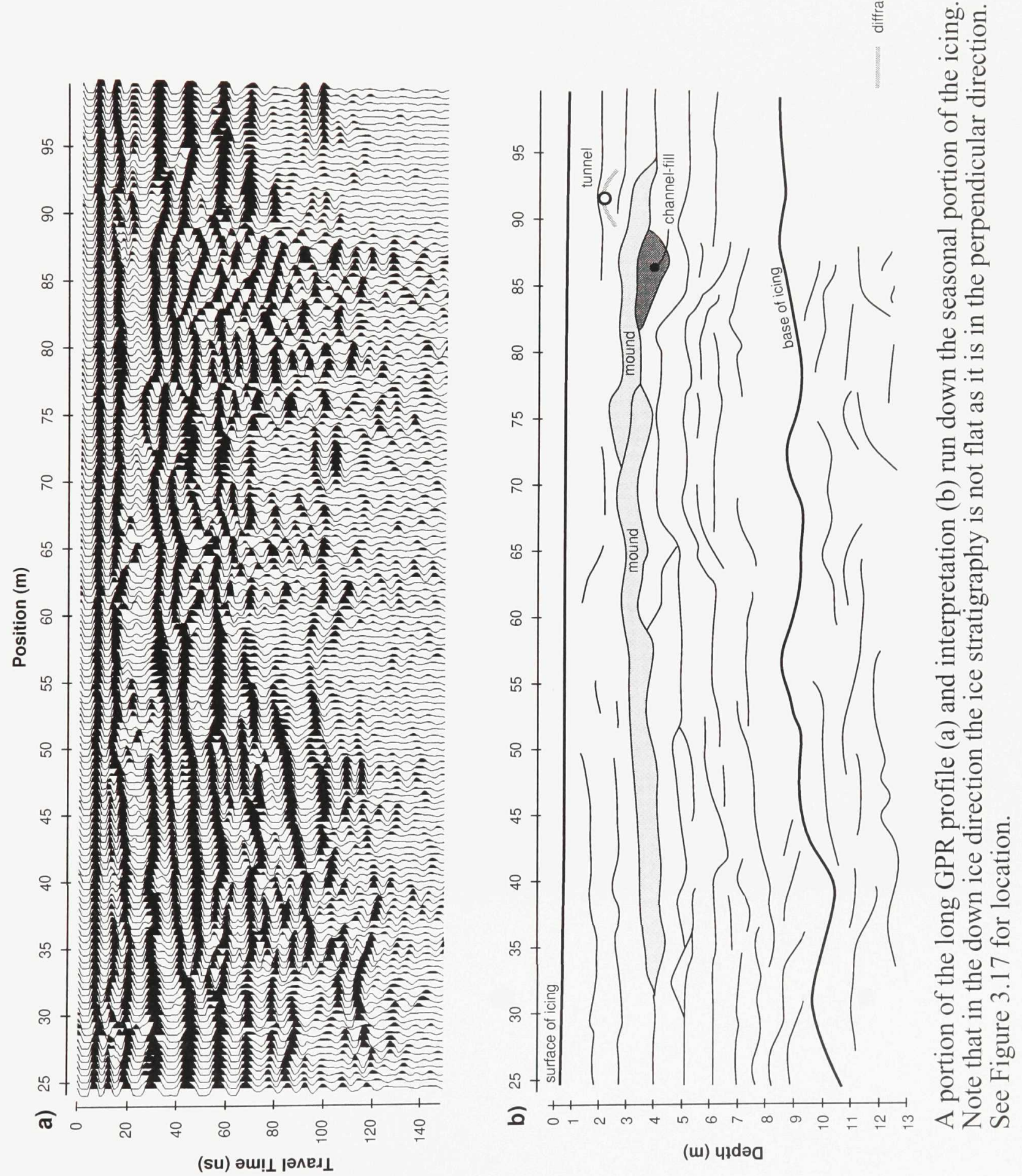

(iu) पı dəa 


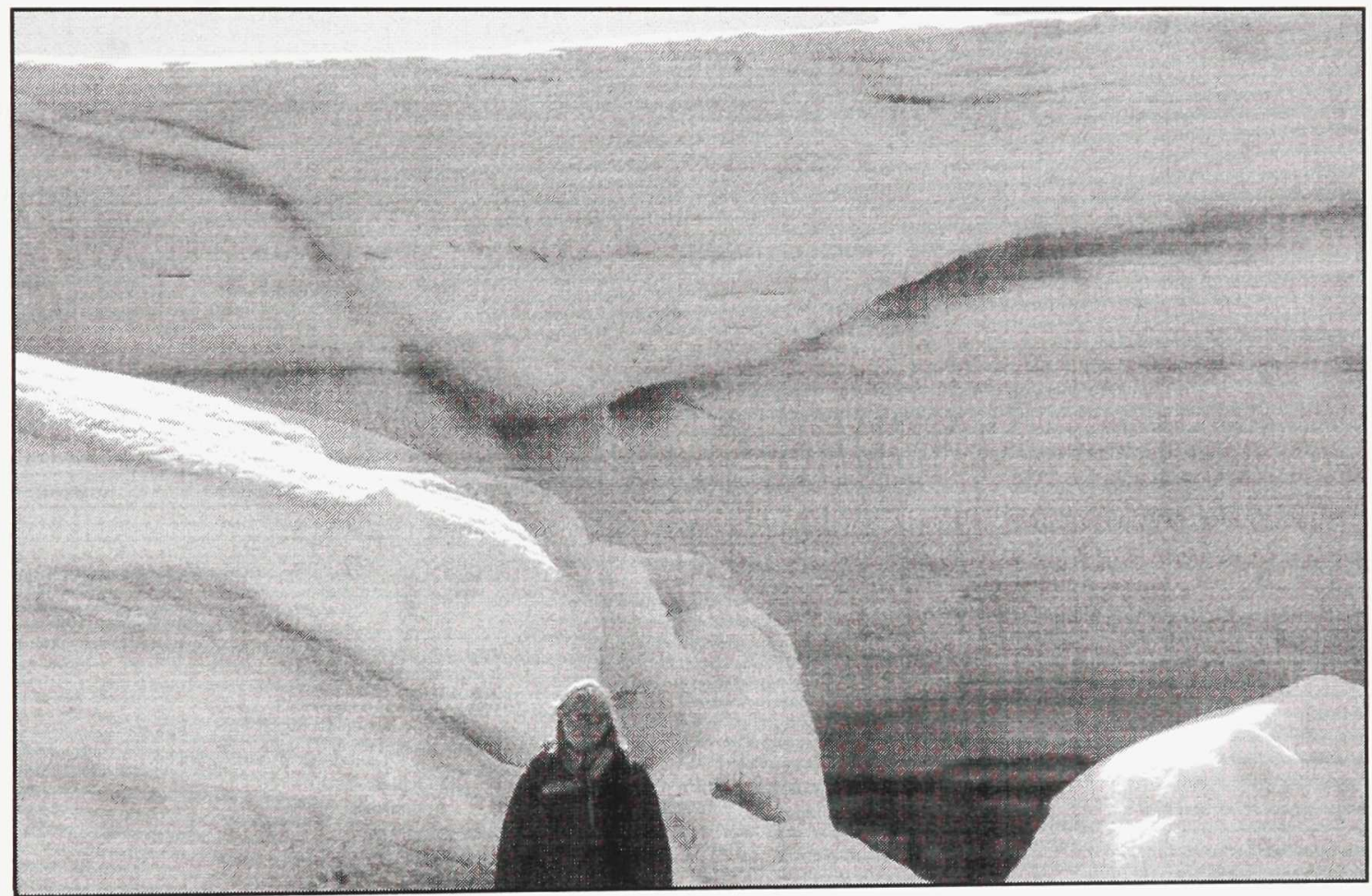

Figure 3.16

An exposure at a stream cut of a very large channel fill in the icing in front of Fountain Glacier. 
Schohl and Ettema (1990) and Lock (1990) proposed models for icing growth which have water exiting from the source onto the surface, flowing downslope, turning to slush, and freezing to produce a wedge shaped icing. Their models suggest that in cold climates such as Bylot Island, a fairly steep angled wedge of ice should develop and these are observed in other portions of the island. However, from the GPR data, the structure of this icing appears to be more complex than the models suggest. The icing actually grows in a series of stages with complex and ever-changing hydrological flow patterns. The GPR records show evidence of four different icing formation processes: 1) growth by water spreading as sheet flows over the surface for great distances before freezing, 2) water being injected into the subsurface between layers and thereby generating ice lenses, 3) the freezeup of slush flows, and 4) the infilling of small stream channels cut through the ice producing an ice stringer through the layered icing body.

Even though the icing formed over a glacial outwash plain, and the glacier and valley sides still provide sources of sediment, little sediment has been incorporated into the icing itself. Near the edges, where active valley side erosion introduces sediment to the icing, thin layers of sediment were observed in stream beds. However, the complete seasonal erosion of the sides of the icing results in the deposition and transportation of the sediment directly on the valley floor. The GPR profiles from the perennial portion of the icing indicate a complete absence of sediment within the core of the icing.

\subsubsection{Icing erosion and stability}

During the summer season, hydrothermal erosion is responsible for the majority of icing destruction. Lateral streams rapidly erode the icing edges, and streams running within the icing play a major role in cutting through and dissecting the icing. Streams flowing 
below the surface of the icing have been observed from the icing edge and from above when their roofs have collapsed.

Throughout the melt season, the streams that were observed flowing through the icing had several unique characteristics. Once a tunnel path is initiated it erodes downward rapidly with minor lateral meandering. The smallest tunnels observed were $10 \mathrm{~cm}$ high and $20 \mathrm{~cm}$ wide. As they developed throughout the summer, the tunnels could erode through the entire thickness of the icing (up to $12 \mathrm{~m}$ ) and grow to be several metres wide. By the end of the summer melt season a majority of the run off was no longer flowing through tunnels within the icing, but in streams cut down beside the icing. Tunnel location within the icing is controlled by the location of the water source, the resistance to erosion of the ice and the geometry of the water table within the icing. Many typical fluvial forms were observed in the internal icing drainage system, including rapids, waterfalls, and cut off meanders resulting in subsurface oxbow lakes.

At the time of surveying, the subsurface drainage tunnels had diameters less than $2 \mathrm{~m}$ and acted as point source reflectors (Figure 3.15). The depth and size of the drainage tunnels was determined by drilling exploratory holes at numerous locations. When their cross sectional diameter was less than about $2 \mathrm{~m}$, the exact size and cross-sectional shape could not be imaged but their depth and lateral position were consistently located to within $0.5 \mathrm{~m}$. Because of the high density of survey lines on the seasonal portion of the icing, the location of the subsurface drainage tunnels could be easily interpolated between profiles (Figure 3.17). 


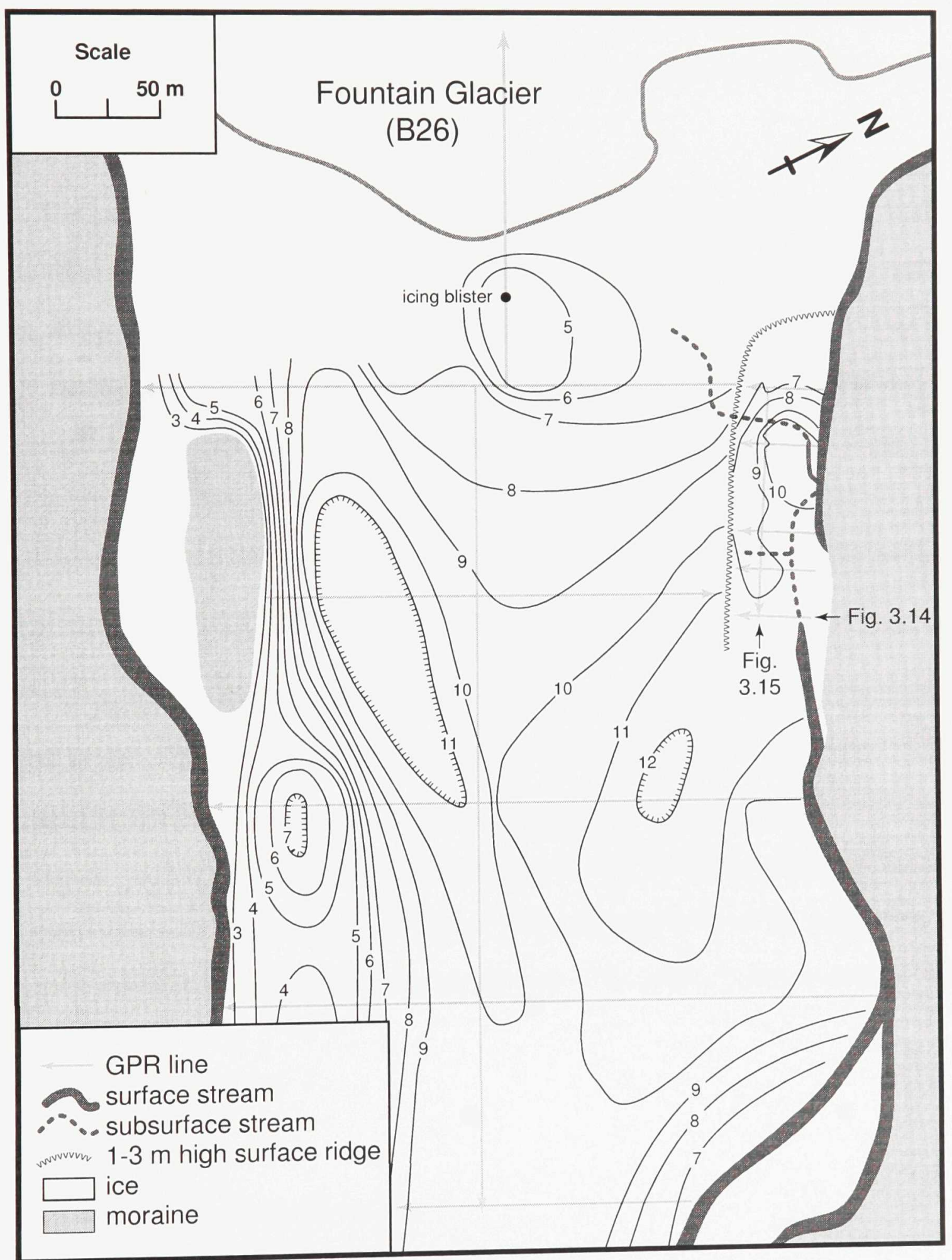

Figure 3.17 Map of icing thickness in front of Fountain Glacier. Overall the surface of the icing was slightly domed except for a ridge surrounding a part of the seasonal portion of the icing where ice did not accumulate to the height of the perennial portion of the icing. Note that the glacier runoff stream on the east side of the valley completely disappears into the icing for over $50 \mathrm{~m}$. 
Only one drainage tunnel was detected within the perennial portion of the icing, and that was leading from the icing blister directly to the seasonal portion of the icing. Three drainage tunnels were detected within the small area of the seasonal icing that was surveyed.

The long term stability of the perennial portion of the icing is the result of increased accumulation of ice over the central portion of the icing during the winter, and concentrated erosion along the edges of the icing during the summer (Figure 3.18). The two water sources feeding into the Fountain Valley bottom are the small amount of year-round flow from the groundwater spring and the great amounts of summer melt-water coming off the glacier. As the groundwater spring is centrally located in the valley, in the winter ice begins to accumulate in the central portion of the icing first. The resultant doming of the surface of the icing causes surface melt to drain towards the edges of the icing.

During the summer the majority of the melt-water runoff from Fountain Glacier is localized at the sides of the valley. This concentration of flow at the valley sides is encouraged by the doming of the ice surface and a rise in the elevation of the valley bottom in the center. As a result, the bulk of summer melt occurs along the edges of the icing, leaving the central core high and dry. Any melt of the perennial core of the icing from solar radiation or conductive heating from the air appears to be amply compensated by winter additions.

\subsubsection{Icing thickness and preservation}

The density of the data from GPR profiling enabled the generation of an isopleth map of the icing thickness. The perennial portion of the icing is over $12 \mathrm{~m}$ thick in one location but generally averages $9 \mathrm{~m}$ in thickness. The valley bottom is not planar as would 


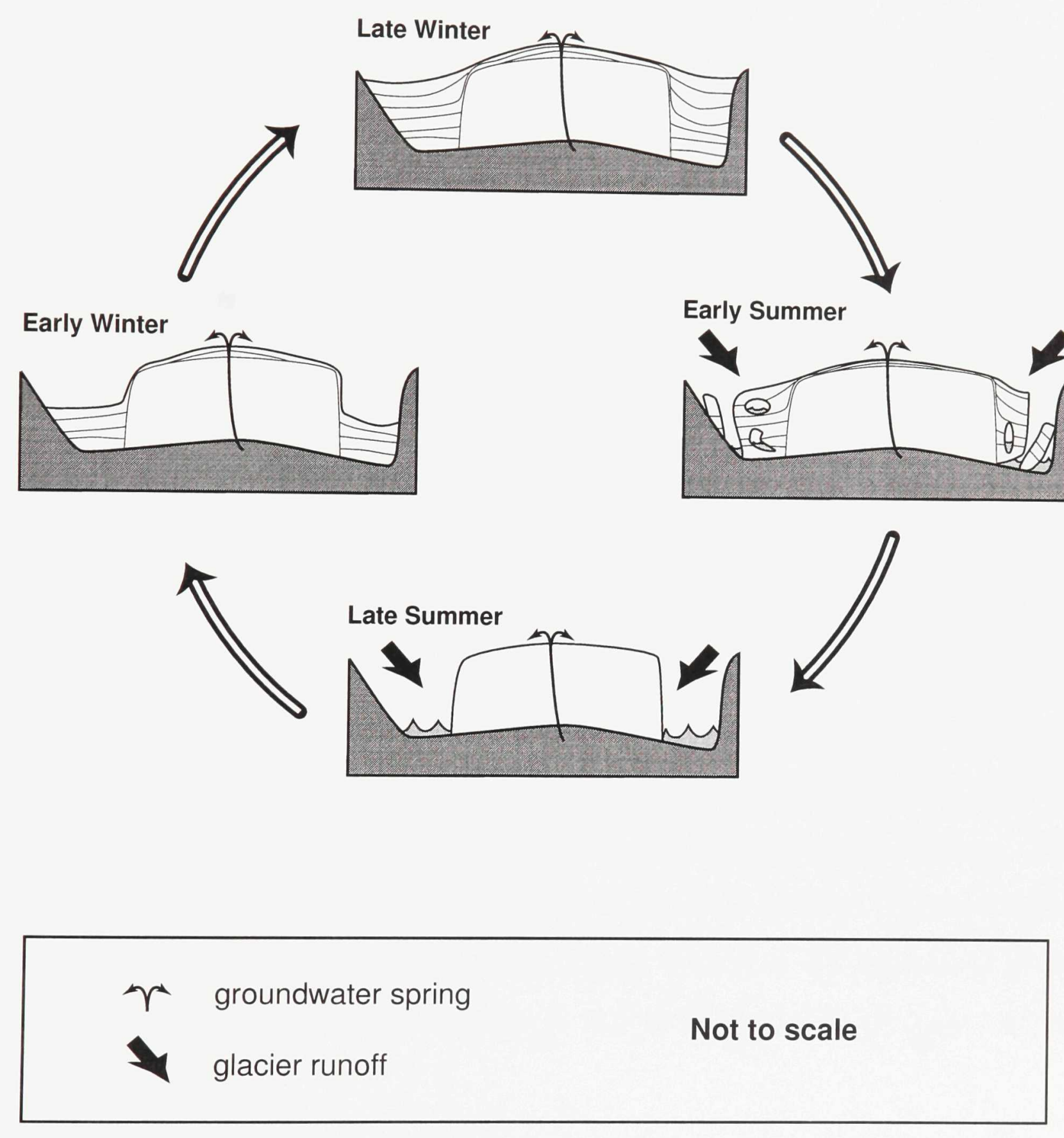

Figure 3.18 A schematic diagram of the annual cycle of ice accumulation and erosion in the only perennial icing on Bylot Island. Note that the size of the central core of ice that survives the summer melt season varies from year to year. 
be expected of a typical braided river outwash plain. It has considerable topographic variations, with the valley floor protruding up through the surface of the icing near the southern margin. Although the majority of the runoff from the glacier currently flows along the north side of the valley, it appears from the valley bottom topography that there may have been a significant channel on the south central side, just to the north of the island.

The surface of the icing was generally very smooth having a slope of $1^{\circ}$ in the down valley direction, and a slight dip (angle of less than $0.75^{\circ}$ ) towards the north and south edges away from the central dome. From the ice thickness map and the surface elevation data, the general slope of the valley floor (i.e., the ice-sediment contact) was calculated. While there is considerable local relief in the valley floor, the general downslope angle was calculated to range from $0.9^{\circ}$ to $2.4^{\circ}$.

The depth of penetration of the GPR was up to $26 \mathrm{~m}$ revealing semi-continuous, wavy, near-horizontal reflections from within the sediment below the icing. This pattern is indicative of outwash deposits (Robinson et al., 1992). Strong reflections or anomalous reflection patterns within the sub-icing sediment indicative of a buried ice body are not present in the portion of the GPR profiles below the icing. A strong continuous reflection up to $10 \mathrm{~m}$ below the ice, was interpreted as the base of the outwash sediments. This reflection from the base of the outwash sediments is generally U-shaped in the cross valley direction. The rapid attenuation of the signal beneath the base of the outwash sediments suggests that the outwash is likely underlain by unfrozen finer grained sediments, such as till. 


\subsection{Conclusions}

In summary, it was found that GPR is very effective at revealing the complex subsurface structure in the glacial/proglacial environment. Specifically it was found that:

- Using $1000 \mathrm{~V}$ transmitter and $50 \mathrm{MHz}$ antennas, GPR can image through up to $145 \mathrm{~m}$ of ice, enabling the mapping of ice thickness on the terminus of glaciers or of icings. However, when profiling over buried ice, the poorly sorted glacial sediments limit the depth of penetration to a fraction of that in pure ice.

- The propagation velocity of GPR waves through glaciers and icings can be determined from CMP soundings or modelling the shape of the long hyperbolic diffraction patterns generated by point source reflectors.

- The long diffraction patterns can also be used to interpolate the location of the source of the point source reflection between GPR profiles.

- In dry snow, firn, or ice settings an estimate of the bulk density of the material can be calculated from the velocity measurements.

- Air filled voids and sediment or water filled voids are easily differentiated in ice from the polarity of the GPR reflection.

- Using a grid of GPR profiles, the paths and depths of subsurface streams were mapped in a glacier and an icing.

- The stream flowing along the outside of the Stagnation Glacier east lateral moraine, that disappears into the moraine, appears to flow into the glacier with no hydrological 
connection to the stream running between the moraine and the glacier, even though the two streams cross paths with less than $20 \mathrm{~m}$ vertical separation.

- As the GPR energy propagates through ice very well, sedimentary structures up to $25 \mathrm{~m}$ beneath the base of the glacier could be imaged.

- Using a thermal model of Stagnation Glacier, derived from the amplitude of GPR reflections, it is suggested that the glacier is polythermal; the terminus being underlain by permafrost while further up ice the lower portion of the glacier is at the pressure melting point.

- It was discovered that the lateral moraines flanking Stagnation Glacier have a large buried glacier ice core, while there is relatively little ice incorporated into the end moraine.

- The GPR was found to be very effective at mapping the different ice types and sediment units within and beneath icings.

- The perennial persistence of the central portion of the icing appears to be the result of three factors. The majority of summer melt waters enter the valley at its edges. Both the icing and the valley bottom are domed up along the central axis of the valley, which helps to keep the melt water at the sides of the valley. A groundwater spring located in the centre of the valley provides a stable year-round source of water to rebuild the icing each winter. 


\section{Chapter 4 \\ Ice properties}

\subsection{Introduction}

The stratigraphic and physical characteristics of a ground ice body are frequently used to interpret the origin of the ice (French and Pollard, 1986; Mackay, 1989). However, relatively little research has been undertaken on the character of recently buried ice and whether it differs from the source ice. Just as the character of ice crystals are transformed as snow changes to firn and then glacial ice, the process of glacier stagnation and burial may result in changes to the ice that is being buried. A better understanding of the changes that occur during the transformation from surface to buried ice may assist in distinguishing between segregated and buried ground ice. In this chapter a description of the physical, chemical and isotopic properties of buried ice are compared to surface ice such as icing and glacier ice, and the suitability of examining different ice properties to determine the ice origin is discussed. The paleoclimatic information contained in the samples collected on Bylot Island is also discussed. 
The physical and chemical properties of glacier ice have been extensively studied in many ice cores (Paterson, 1981). However, less work has been done on basal ice, due to complications associated with sampling and its relative scarcity. It has long been identified that the bottom few metres of a glacier can be composed of ice with very different petrographic properties (usually having a much higher sediment concentration than the ice above). This is referred to as basal ice.

Initially, it was proposed that shearing near the base of a glacier was responsible for the incorporation of sediment into the lower portions of the glacier (Goldthwait, 1951; Ward, 1952). Later it was suggested that regelation (the melting, movement and refreezing of ice at the base of a glacier) could also be responsible for the incorporation of sediment into the bottom of a glacier (Gow et al., 1979; Souchez, 1971; Weertman, 1957; 1961). Weertman (1961) suggests that as the zero degree isotherm penetrates into the sediment below a glacier (such as happens in polythermal glaciers), appreciable amounts of sediment can be frozen and then incorporated into the flowing ice mass. There is now a general consensus in the literature that both of these mechanisms can operate given the appropriate conditions (Souchez et al., 1988; Tison et al., 1993)

For the purposes of this work, the term glacial ice will be used for ice that has developed from the firnification of snow. The term basal ice will be used for ice near the base of a glacier which shows dramatic alteration due to regelation, deformation or shearing, and the incorporation of basal sediment.

As a glacier retreats and ice flow stagnates, ice can become buried in moraines. In colder climates this ice can be preserved for long periods of time, protected from melting by overlying sediment (Hambrey, 1984). If the climate warms and the ice melts, a distinctive stagnant ice topography can be created. The last glaciation has resulted in many examples 
of these ice melt-out features across Canada. However, the exact processes of ice burial or characteristics of buried glacier ice are not as well known.

The burial of glacier ice can result from one or a number of different processes. The meltout or sublimation of glacier ice can result in a layer of sediment concentrating at the surface of the glacier. If this sediment layer grows thick enough, the ice core can be preserved from further melt. As a glacier retreats and its surface elevation falls below that of its lateral moraines, mass wasting can result in burial of large portions of the glacier terminus (Rains and Shaw, 1981). Shearing of basal sediments into the upper portions of a glacier can also bring enough sediment to the surface of the glacier to retard its melt. If there is still sufficient ice flow it is hypothesized that a rock glacier will form (Whalley, 1983). If the ice is essentially stagnant, the buried ice will be more stable and is termed tabular massive ground ice.

\subsection{Study area}

Bylot Island is home to a large ice field in the central mountainous core of the island. Glaciers flow down valleys on all sides of the island out towards the ocean or onto the lowlands. Of the 18 largest glaciers on southern Bylot Island, eight show no signs of retreat during the last half century, while the others are rapidly retreating. Of the three glaciers studied, Stagnation and Sermilik Glacier are retreating while the terminus of Fountain Glacier has remained stationary since at least 1948.

The mean annual ground temperature at lower altitudes on the island is in the order of $-9.5^{\circ} \mathrm{C}$, resulting in the development of thick permafrost and a thin active layer. Massive ice or indications of its presence are visible at many locations across the southern half of the Island. Ice samples were collected at various stratigraphic positions on Fountain and 
Stagnation Glaciers, and at various locations on and under the lateral and end moraines of Stagnation and from a retrogressive ground ice flow beside Sermilik Glacier (Figure 4.1).

\subsection{Methodology}

Stratigraphic descriptions included in situ description of the ice colour, bubble and sediment content, structural features, and crystal size and shape (if visible) of the ice body, as well as a description of the surrounding sediment and the contacts between the two. In some cases (eg. icing ice) these properties were so unique that no other analysis was required to characterize the ice unit. In other cases thin sections were made from ice samples for detailed petrographic analysis, and small portions of the ice samples were melted so that electrical conductivity and ${ }^{18} \mathrm{O}$ isotope measurements could be made.

Representative samples of the different ice types underwent a more extensive analysis that included the sampling of the gas bubbles contained in the ice and complete chemical and isotopic analysis of the gas was undertaken following the procedures described in Moorman et al. (1996b). Properties measured on these samples included gas content, $\mathrm{CO}_{2}$ content, $\delta^{18} \mathrm{O}$ values of the water as well as the $\mathrm{CO}_{2}, \delta^{13} \mathrm{C}$ values of the carbon in the $\mathrm{CO}_{2}$, and $\mathrm{N}_{2} \mathrm{O}$ content. Analysis of the gas bubbles also enabled ${ }^{14} \mathrm{C}$ dating of the ice. 


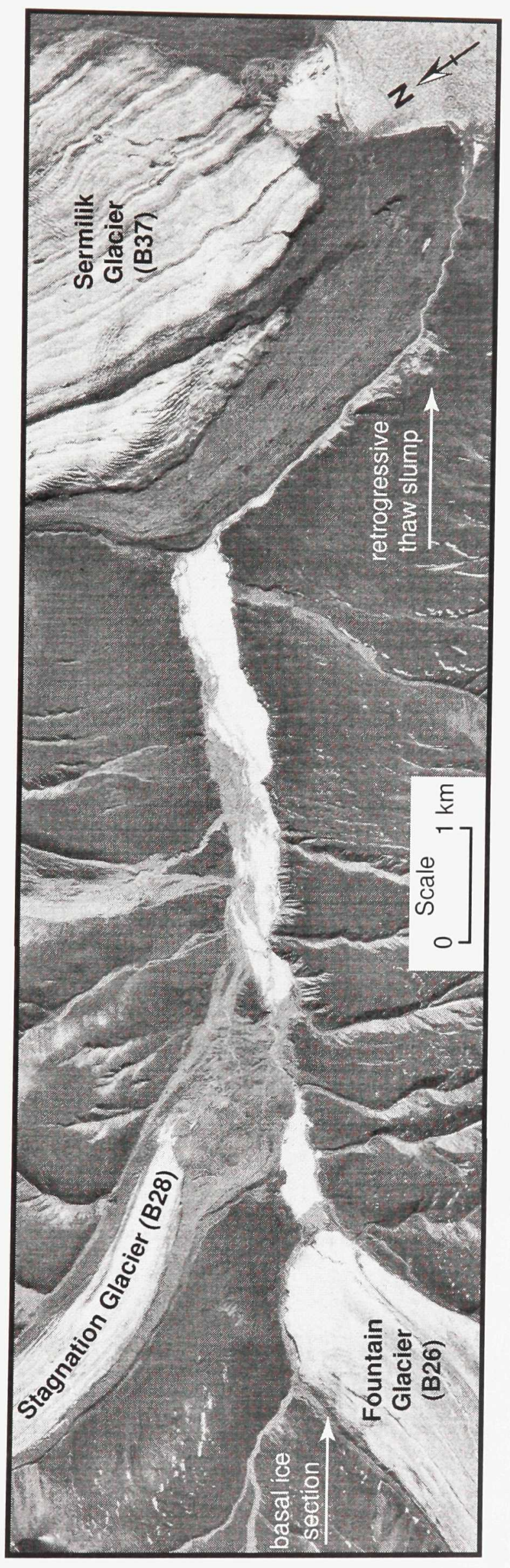

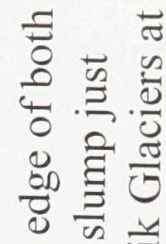

竝

.

苍式

.

तี

ठ

종

त

की

. $\frac{0}{0} \cong$

రำ

.

芯芯之

क्ष $00 . \dot{\Xi} . \Xi$

范跣

ฮี

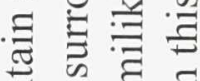

ఏ气 ฮี

○.

ธี०

రृ.

त्षु

믈

ป त

क ज के

氖

क.

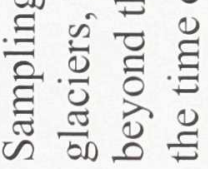

‡゙ 


\subsection{Results and discussion}

\subsubsection{Physical properties}

\subsubsection{Glacial ice}

From a distance, both Fountain and Stagnation Glaciers have a horizontally layered appearance (Figure 4.2). Slight variations in the bubble content, crystal size and particulate content are principally responsible for this appearance. On closer inspection the ice was fairly uniform with a translucent to bubbly appearance (Figure 4.3). There were numerous shear planes near the terminus of Stagnation Glacier but none in Fountain Glacier (Figure 2.5). Ice samples were collected from several locations that were spatially and stratigraphically separated on both glaciers. Oriented thick sections made from these samples revealed fairly uniform anhedral to euhedral ice crystals that were generally equidimensional and ranged from $0.5-5 \mathrm{~cm}$ in diameter, averaging $2 \mathrm{~cm}$. There was no crystallographic trend down section.

The bubbles contained in the ice were generally spherical and ranged from $0.5 \mathrm{~mm}$ to $2 \mathrm{~mm}$ in diameter. At some locations near the base of Stagnation Glacier the bubbles in the ice were slightly elongated with no preferred orientation; the long axes of these bubbles was up to $4 \mathrm{~mm}$. The gas content measured in two samples was $4.1 \mathrm{~cm}^{3} / \mathrm{kg}$ of ice and $26.8 \mathrm{~cm}^{3} / \mathrm{kg}$ of ice.

There were only small quantities of single fine sediment grains dispersed throughout the glacier ice. Sediment content measurements revealed less than $0.7 \mathrm{~g}$ of sediment per kilogram of ice. No layering or structure of the sediment was visible. 


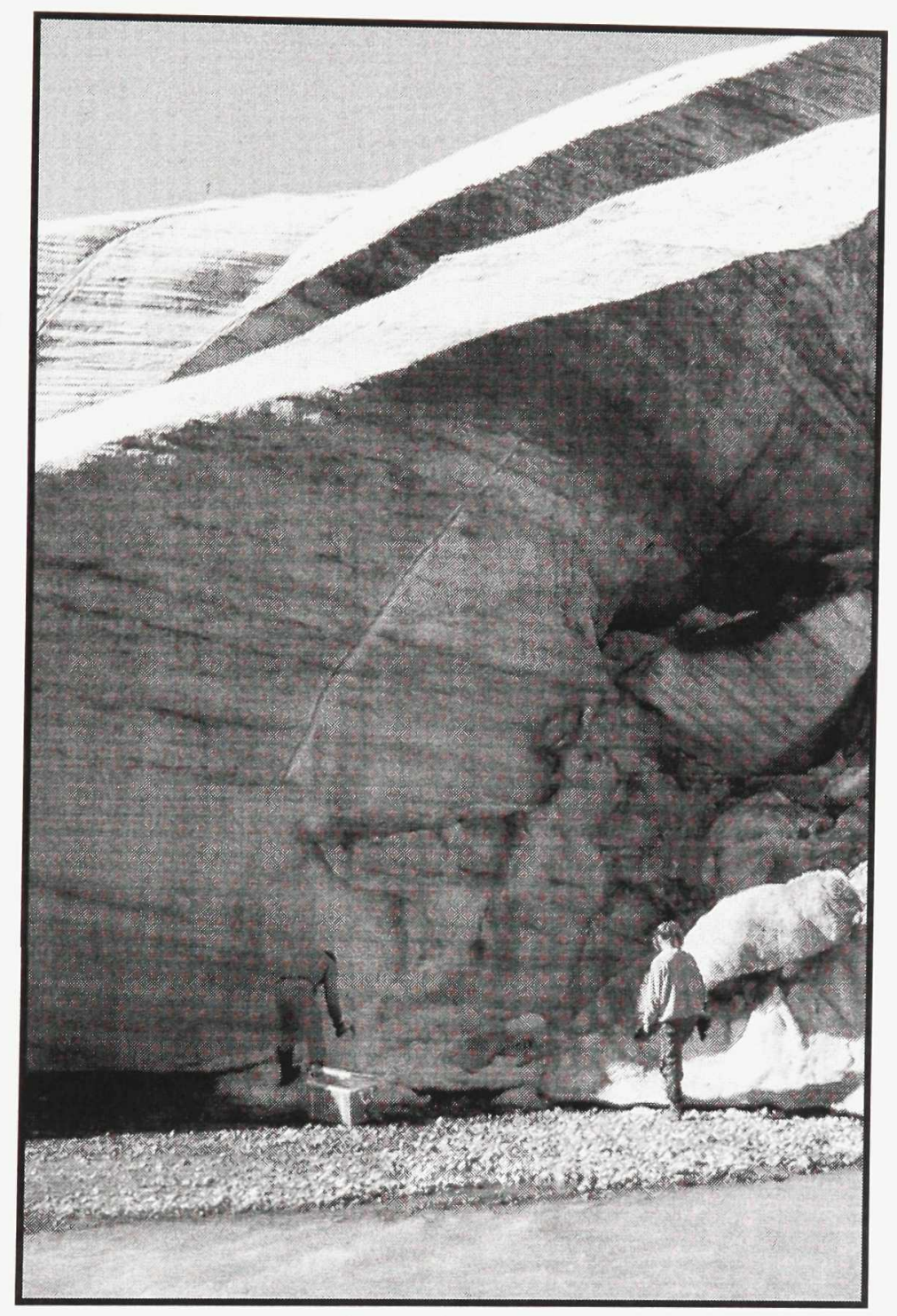

Figure 4.2 The layered appearance at the terminus of Fountain Glacier is caused by small variations in the bubble concentration, crystal size, and sediment content. The horizontal layers appear to be dipping in the photograph due to the angle of the cliff face. 

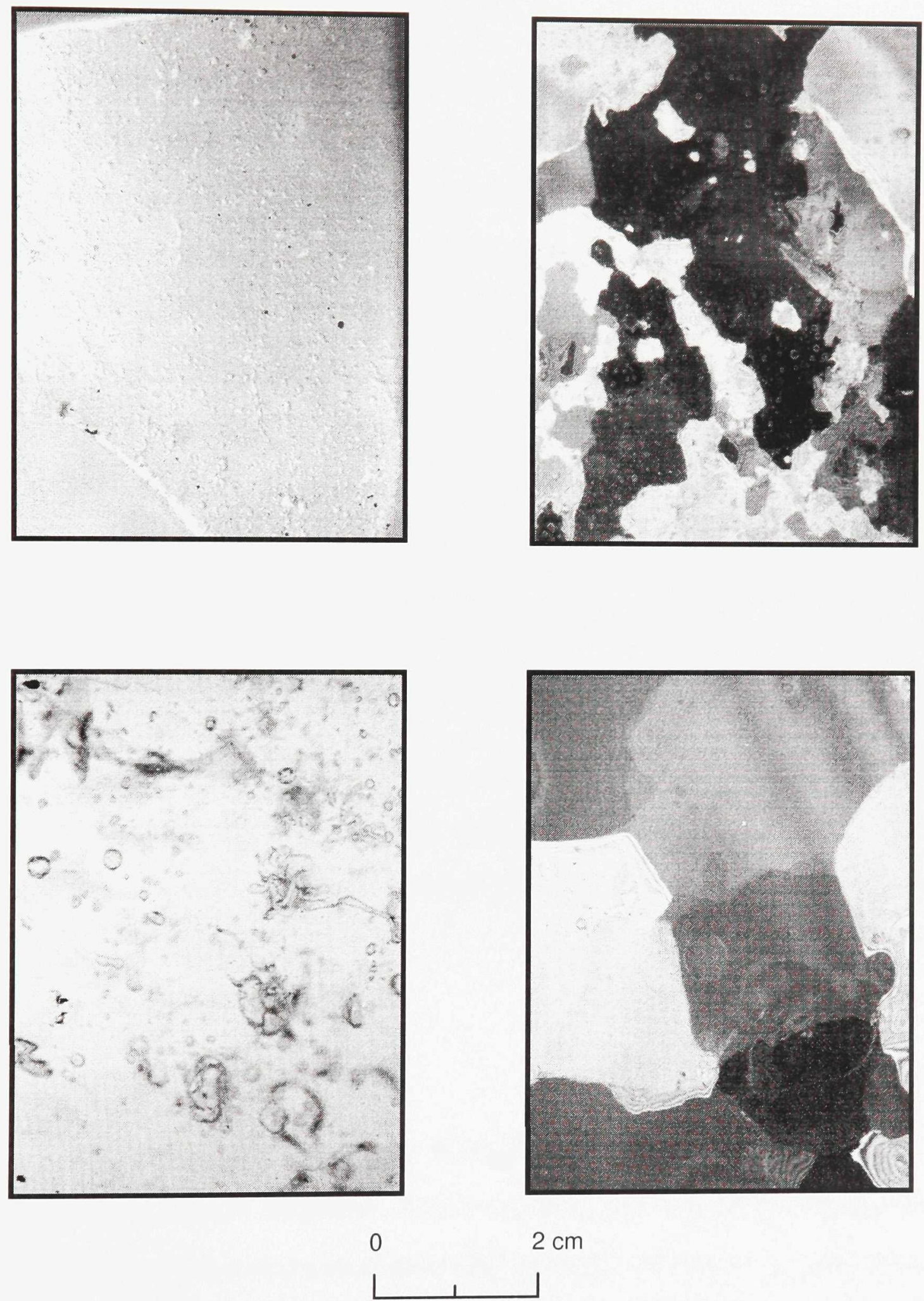

Figure 4.3 Examples of the ice characteristics observed on Fountain and Stagnation Glaciers. These normally (left) and cross polarized (right) thick section photographs are representative of the majority of the glacier ice observed. 
Several small basal ice exposures were visible along the sides of Stagnation Glacier, and one large basal ice exposure was visible at one side of Fountain Glacier. The heavy sediment load in the basal ice gave it a dark brown appearance (Figure 4.4). The sediment also enabled the easy recognition of layers, folds and faults within the ice (Figure 4.5). The folds were localized and did not propagate up into the clean glacier ice above. In some areas the sediment concentration was so high that it made up the framework of the ice-sediment mass. In other sections that were between sediment-rich layers, the ice was almost completely void of sediment.

The high sediment concentrations made it difficult to make thin sections; however, in a limited number of thin sections, the ice crystals were found to be equidimensional to irregularly shaped and up to $5 \mathrm{~cm}$ in diameter, with an average diameter of $2 \mathrm{~cm}$.

The bubble content of the basal ice also varied dramatically. Some sections contained no bubbles, but in general there was an abundance of spherical bubbles 0.5-2.0 $\mathrm{mm}$ in diameter in both the sediment-rich and sediment-poor basal ice.

\subsubsection{Icing ice}

An extensive icing is present in front of Fountain Glacier every year and a smaller icing grows in front of Stagnation Glacier intermittently. The physical properties of the icings were observed in seven cores and along several kilometres of exposed section where streams eroded down through the sides of the icing. The ice had a distinctive layered appearance with alternating bubbly and clear layers ranging in thickness from one 


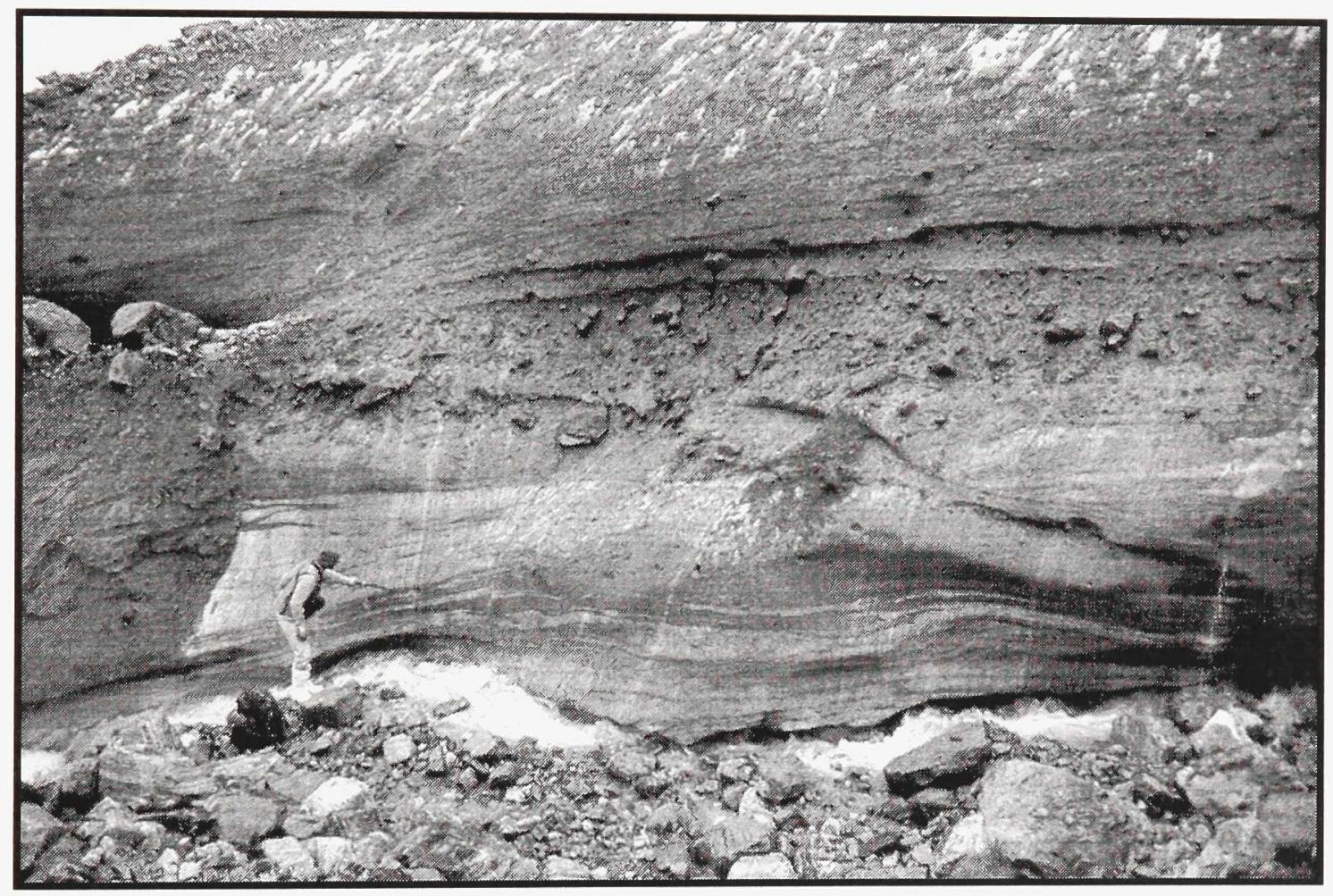

Figure 4.4 Basal ice at the side of Fountain Glacier. See Figure 5.1 for location A sediment-rich layer is visible about 4-6 $\mathrm{m}$ above the base of the glacier. Note person for scale. 

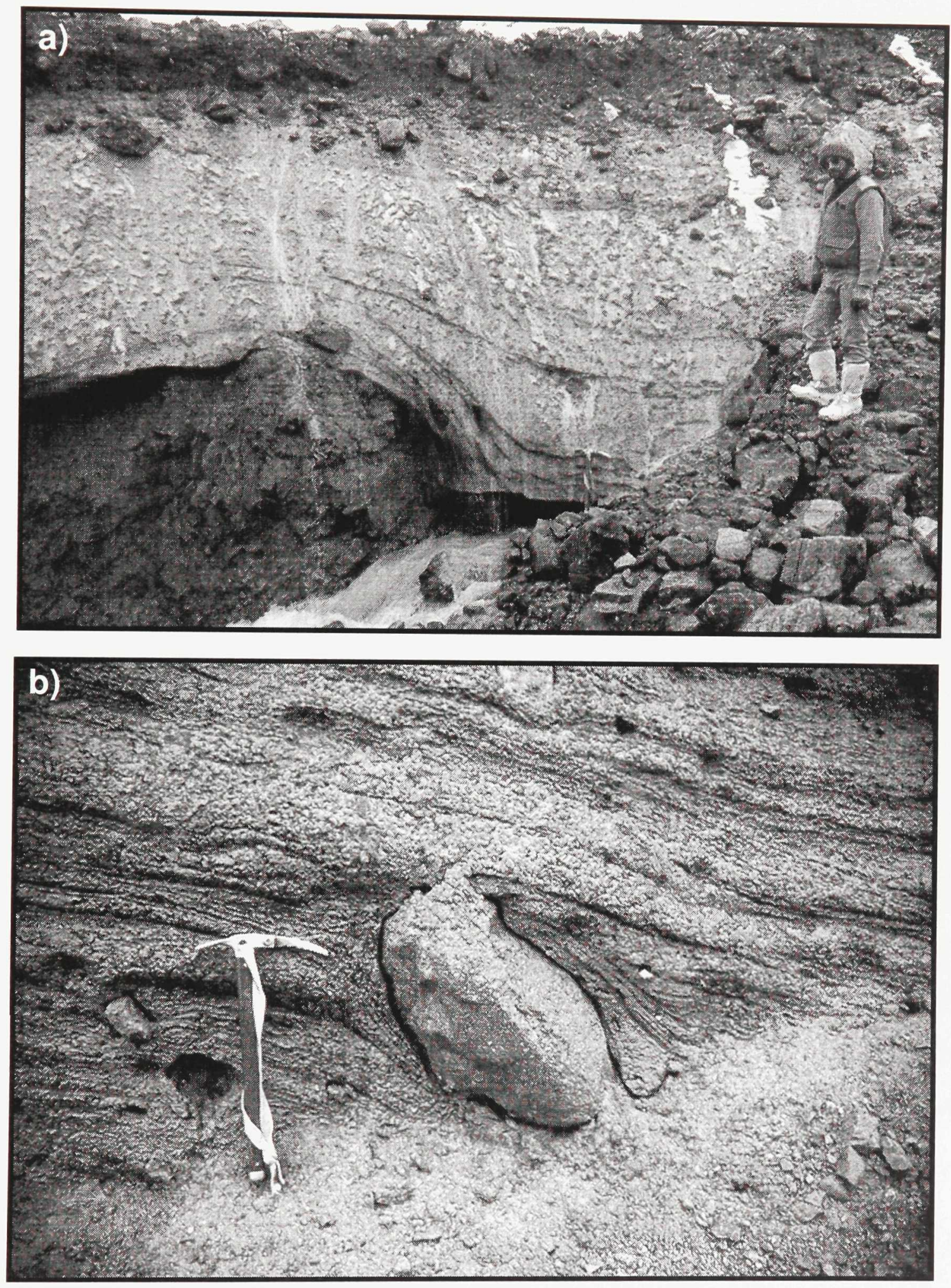

Figure 4.5 The deformation of Fountain Glacier basal ice. In (a) the ice flows around a bedrock knob. In (b) ice deforms around a boulder in the basal section just above the base of the glacier. In both photographs ice flow is to the left. 
millimetre to tens of centimetres. The layering of the icing has resulted from different flow events as indicated by dramatic changes in crystallography and bubble characteristics (Figure 4.6).

The bubbly ice results from the rapid freezing of surface water. As the water flows over the ground surface and is exposed to the cold air temperatures ice nucleation occurs quickly, ice crystals grow fast, and slush develops. The mean daily air temperature throughout February at Pond Inlet is $-34^{\circ} \mathrm{C}$ (Figure 2.1) (AES, 1980). If surface snow is present the flowing slush saturates it, and the saturated snow is incorporated into the ice mass. The characteristics of the resultant ice mass are a bubbly white layered appearance. The ice crystals in the bubbly ice were generally less than $5 \mathrm{~mm}$ in diameter, equidimensional in shape, and randomly oriented. This ice also had a high bubble content, most of the bubbles being 0.5-2 $\mathrm{mm}$ in diameter and spherical in shape. Bubbly ice layers varied in thickness from $1 \mathrm{~mm}$ to over $10 \mathrm{~cm}$.

Ice derived from water flowing within the mass of the icing also makes up an appreciable component of the icing. Water flowing through tunnels within the icing or being injected between layers of the icing tends to freeze slower than water flowing on the surface, thus enabling gas to be expelled and larger crystals to develop. As a result, this ice tends to be clear and composed of large vertically oriented ice crystals. The largest crystals (over $1 \mathrm{~m}$ long and several centimetres in diameter) were found in icing blisters (Figure 4.7). Most "clear" ice layers; however, were less than $10 \mathrm{~cm}$ thick with crystal width of $1 \mathrm{~cm}$ or less, as shown in Figure 4.6.

During the period 1993-1995 only a small amount of sediment was discovered on or within an icing. All of the observed sediment was concentrated in abandoned drainage channels at the side of the icing, having fallen down from the valley sides (Figure 4.8). 

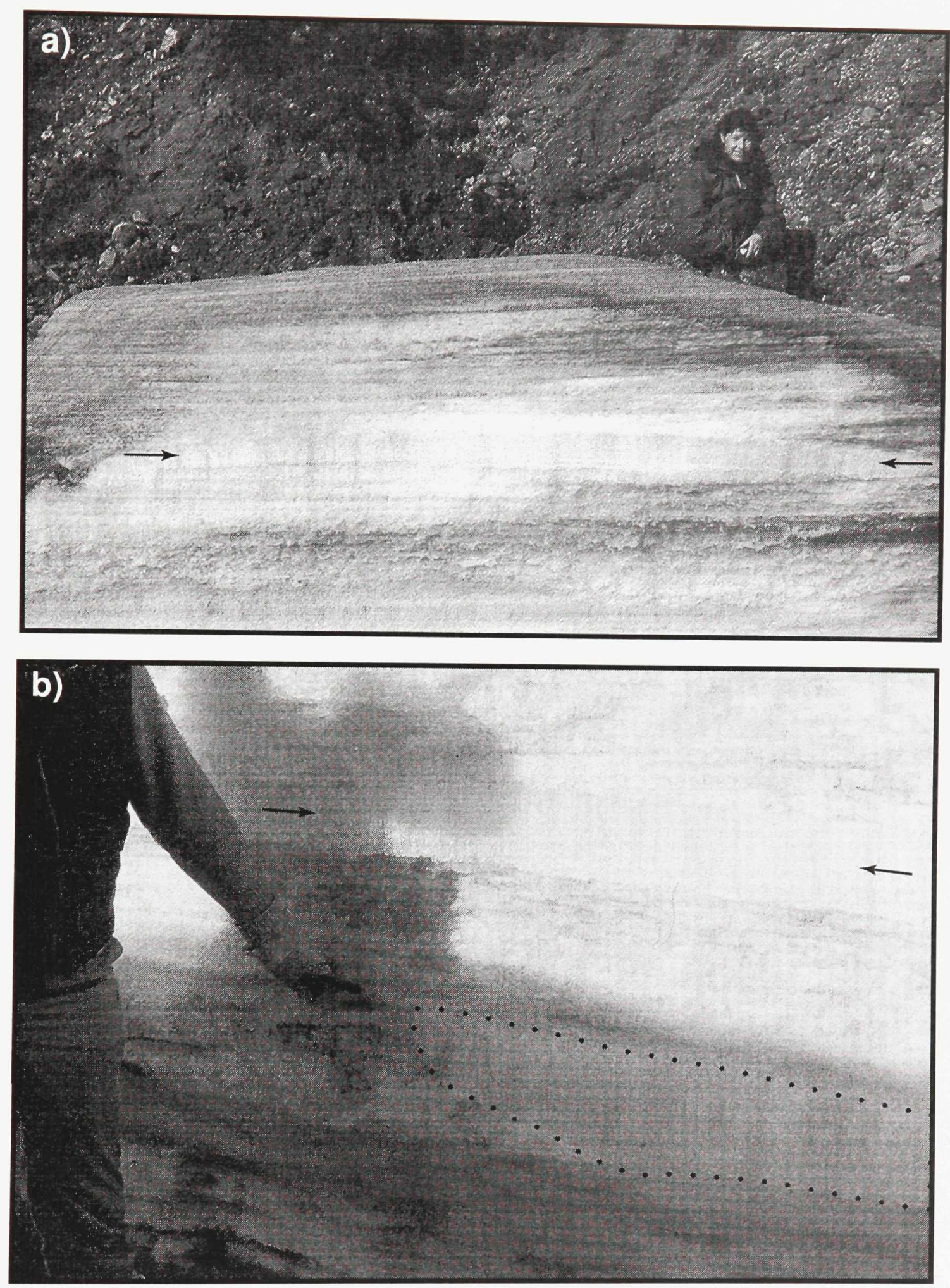

Figure 4.6 The distinctive appearance of icings is due to the predominant beds created with each successive flooding or injection event. Most of the ice mass in the two photographs is bubbly white ice formed from slush. The layers indicated by the arrows were produced by water being injected between already existing ice layers. The discontinuous layer being pointed to in (b), is an infilled channel in the icing. The dirt on the icing in (a) is wind blown, deposited during the thaw season 


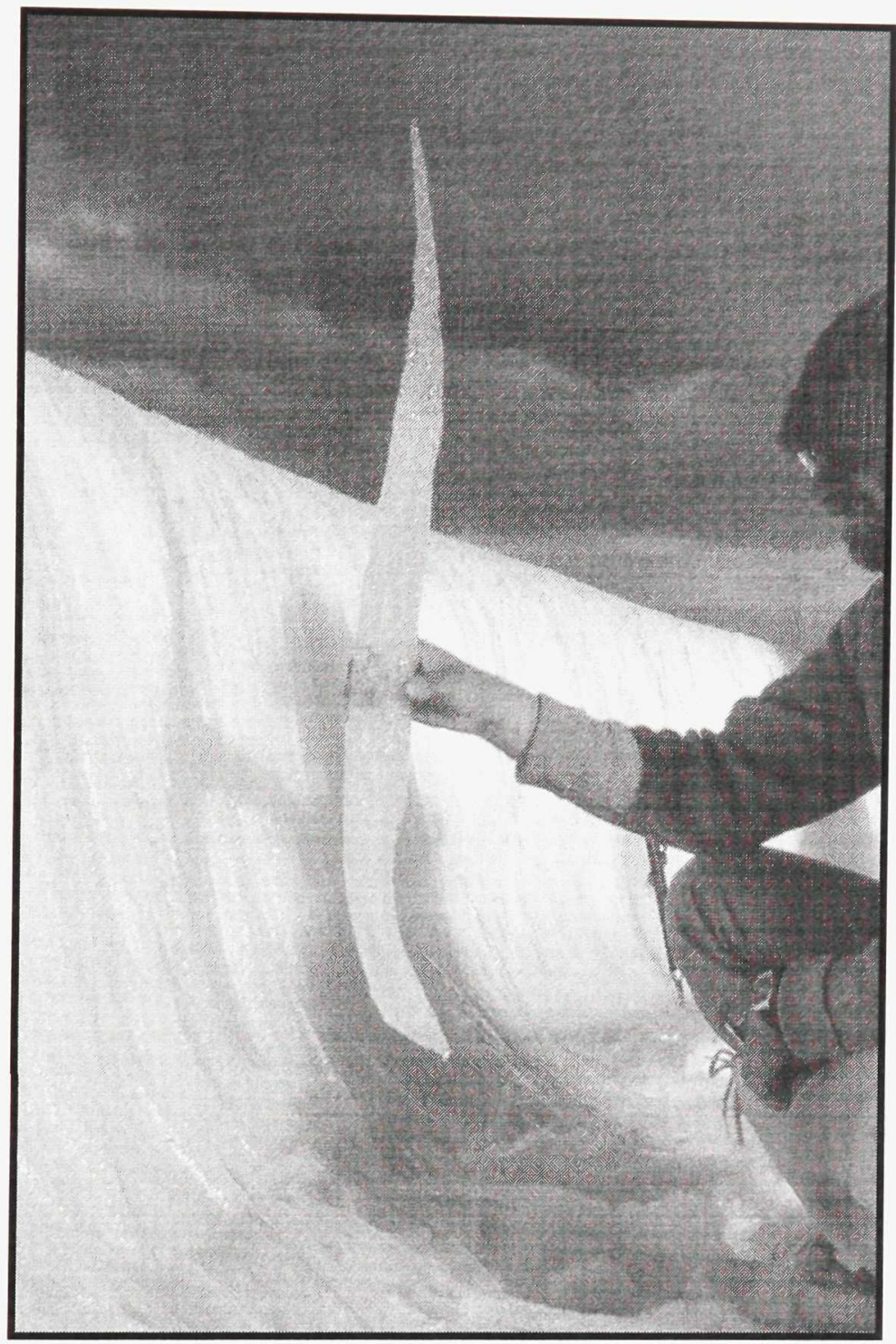

Figure 4.7 A partially melted ice crystal from within an icing blister. Note that the crystal is bent due to the changing direction of heat flow as the blister grew. 

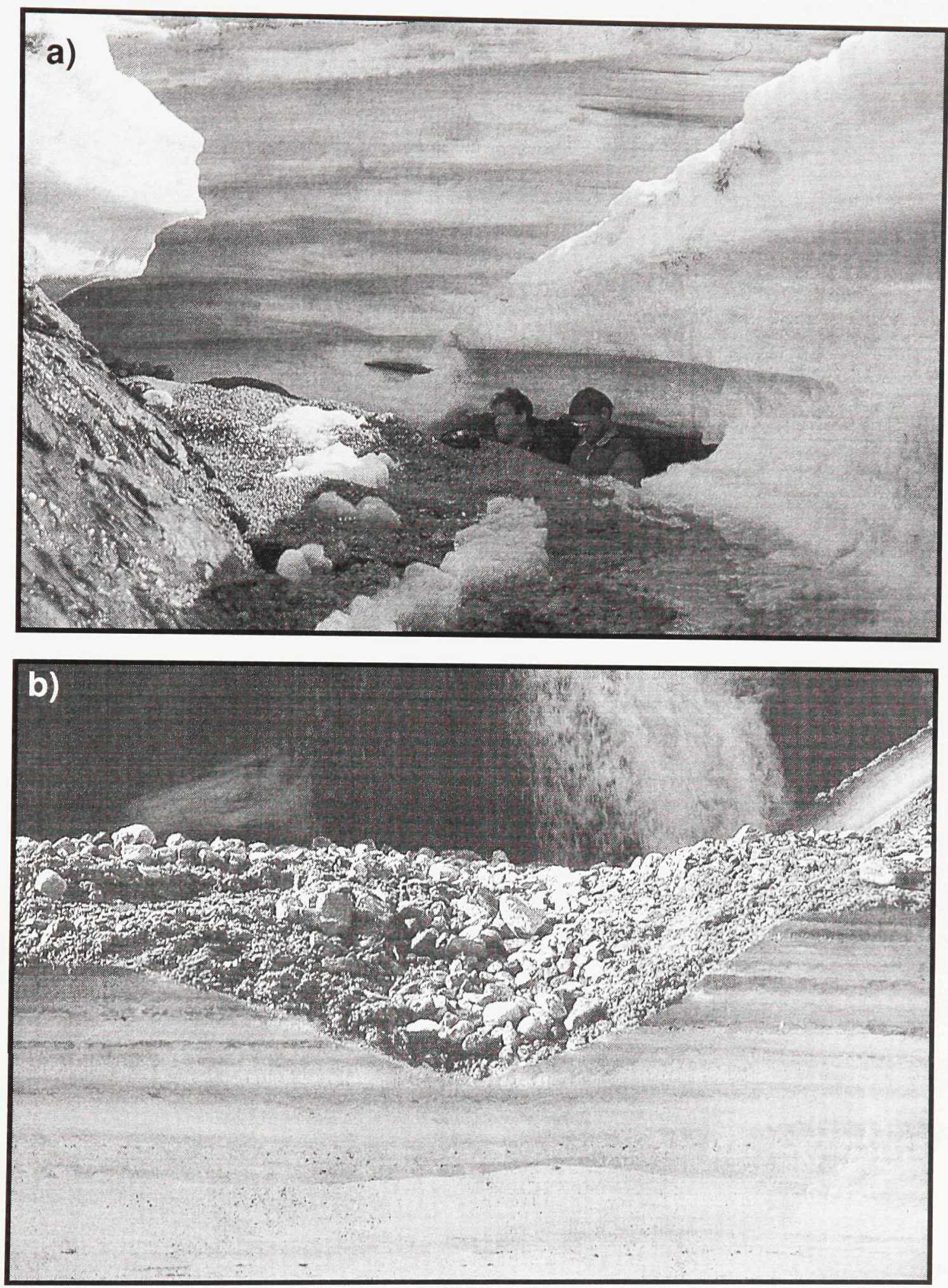

Figure 4.8 Sediment covers the bottom of recently abandoned channels. The two people in (a) are standing in an abandoned channel at a lower level, looking at the sediment at their head level. Bedrock of the valley side can be seen in the left side of the picture. In (b) a small subchannel (20 cm across)is cut into the bottom of a larger channel (extends beyond the frame of the photograph) which was $3 \mathrm{~m}$ across. 
The portions of icings where sediment was deposited were subject to rapid erosion and completely melted each summer.

As discussed in Chapter 2 it is unlikely that icing ice would become buried and preserved. However, even if it was, its very distinctive layered appearance could be used to identify its origin.

\subsubsection{Ground ice}

As discussed in Chapter 3, ground penetrating radar surveys revealed that the moraines surrounding Stagnation Glacier have a continuous core of massive ice that extends to the outside of the lateral moraines and up to $165 \mathrm{~m}$ beyond the terminus of the glacier within the end moraine. The ice core varies in thickness, but is up to $20 \mathrm{~m}$ thick within the lateral moraines.

Ten massive ground ice exposures were examined on the surface of both lateral moraines and the end moraine and a large exposure in a cave where a lateral stream flowed under the east lateral moraine (Figure 3.11). Since the layer of sediment covering the ice core was generally less than $1 \mathrm{~m}$ thick, the ground ice within these moraines was frequently exposed by active layer detachments and fluvial erosion. While the surface exposures enabled examination of the upper contact of the ice core, the cave enabled access to the lower contact.

Similar to the basal ice, the ground ice was extremely variable in its physical appearance. The ice varied from being clear and sediment and bubble free, to being sediment-rich and very bubbly (Figure 4.9). The ground ice near the upper contact of the moraine's ice core lacked very coarse grained sediment (i.e. larger than gravel). This ice 


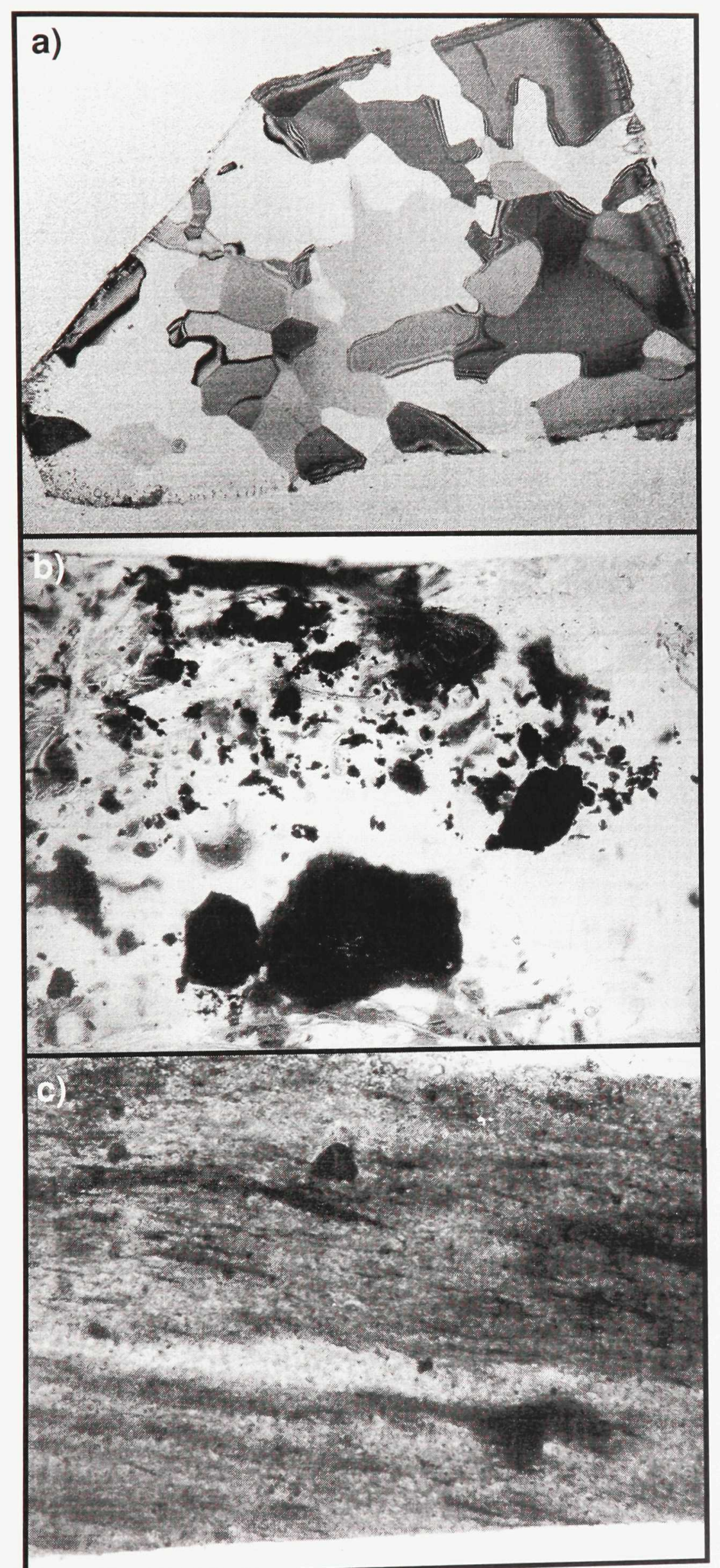

Figure 4.9

Thick section photographs displaying the variability in ground ice characteristics. (a) is a cross polarized photograph of sample taken from the east lateral moraine of Stagnation Glacier near the upper contact of the ice body. (b) is from a small transverse ridge in the end moraine about $20 \mathrm{~m}$ beyond the terminus of Stagnation Glacier. (c) is an example of the ice from the retrogressive slump near Sermilik Glacier. 
was most frequently free of sediment or contained small sediment aggregates. As displayed in Figure 4.10, the ice near the lower contact of the lateral moraine ice core had a wide variety of sediment entrained within it (from clay to boulders).

The ground ice was composed of equidimensional anhedral crystals ranging from $0.5 \mathrm{~cm}$ to $5 \mathrm{~cm}$ in diameter with an average diameter of $2 \mathrm{~cm}$. When bubbles were present they were spherical and 1-3 mm in diameter. The gas content ranged from $1.7 \mathrm{~cm}^{3} / \mathrm{kg}$ of ice to $87.9 \mathrm{~cm}^{3} / \mathrm{kg}$ of ice.

While the icing and glacier ice have distinctive properties, differentiation between basal ice and buried ice would be difficult using the physical properties alone.

\subsubsection{Chemical properties}

The conductivity of all the ice samples was found to be below measurable limits, thus indicating that both surface and ground ice had a very low dissolved solid content. The $\mathrm{CO}_{2}, \mathrm{CH}_{4}$ and $\mathrm{N}_{2} \mathrm{O}$ concentration in gas within the ice was also measured. All samples tested for $\mathrm{CH}_{4}$ had levels below the detection limit of $1 \mathrm{ppm}$. Trace amounts of $\mathrm{N}_{2} \mathrm{O}$ were measured in samples 94-2, 94-4, and 94-6. However, the levels were below quantifiable levels, and thus could be instrument noise. There was no indication of $\mathrm{N}_{2} \mathrm{O}$ in samples 943 and 94-5.

The $\mathrm{CO}_{2}$ concentration within the samples varied from $14.7 \mu \mathrm{g}$ of carbon per $\mathrm{kg}$ of ice to $286 \mu \mathrm{g}$ of carbon per $\mathrm{kg}$ of ice (Table 4.1). The range in $\mathrm{CO}_{2}$ concentrations for polar glacier ice is about 11-30 $\mathrm{g}$ of carbon per $\mathrm{kg}$ of ice (Oeschger et al., 1982). Basal ice has been found to have a much greater range (Herron and Langway, 1979; Tison et al., 1993; Yao et al., 1990). Depending on the environmental conditions, the gas in ice that has 


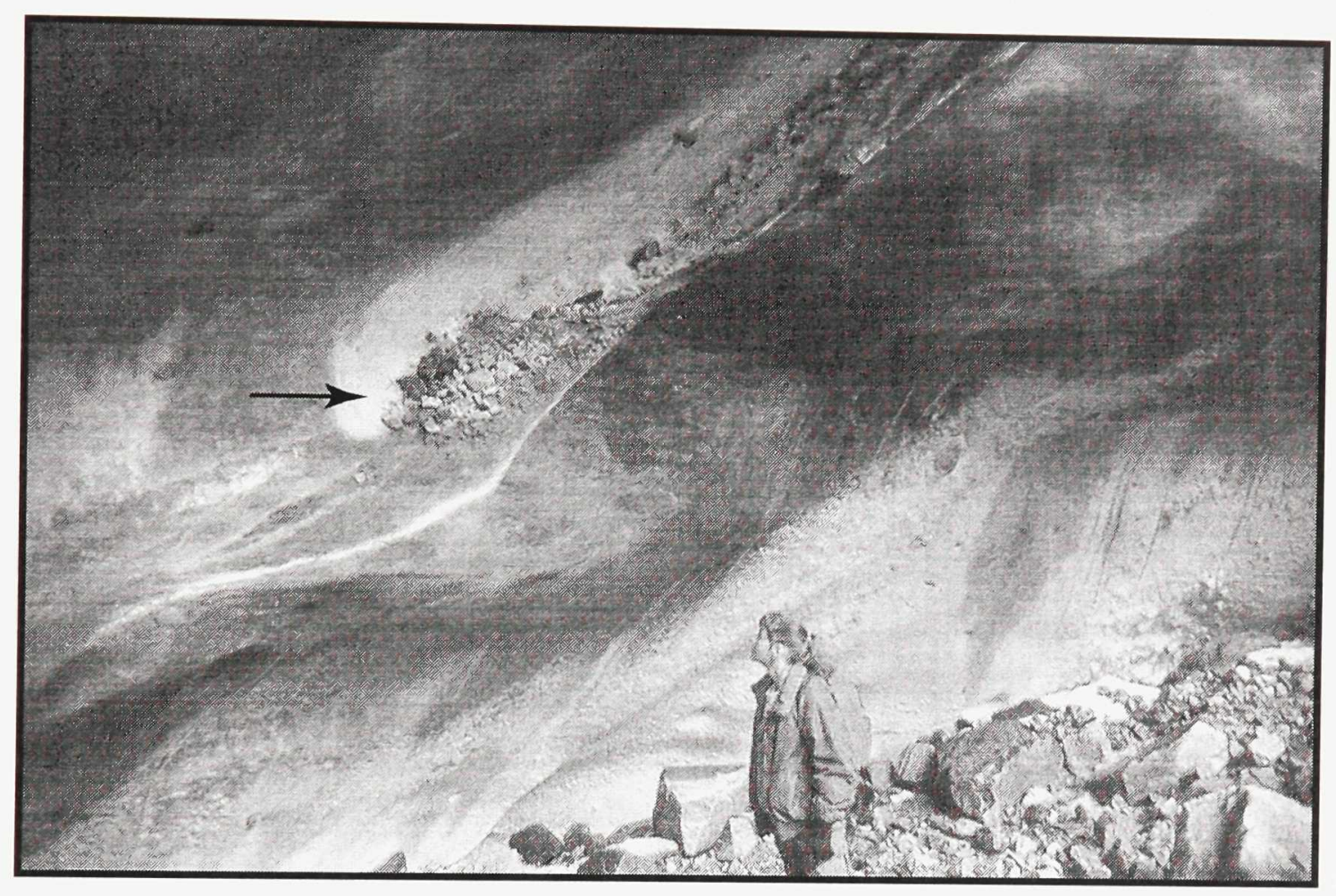

Figure 4.10 A view of the lower surface of the ice core in the east lateral moraine, from within the ice cave. The lighter portions of the wall closer to the ground are covered with frost. The darker areas above head level display the sediment dispersed throughout the ice. The arrow points to a large mass of up to cobble sized sediment in the ice. 


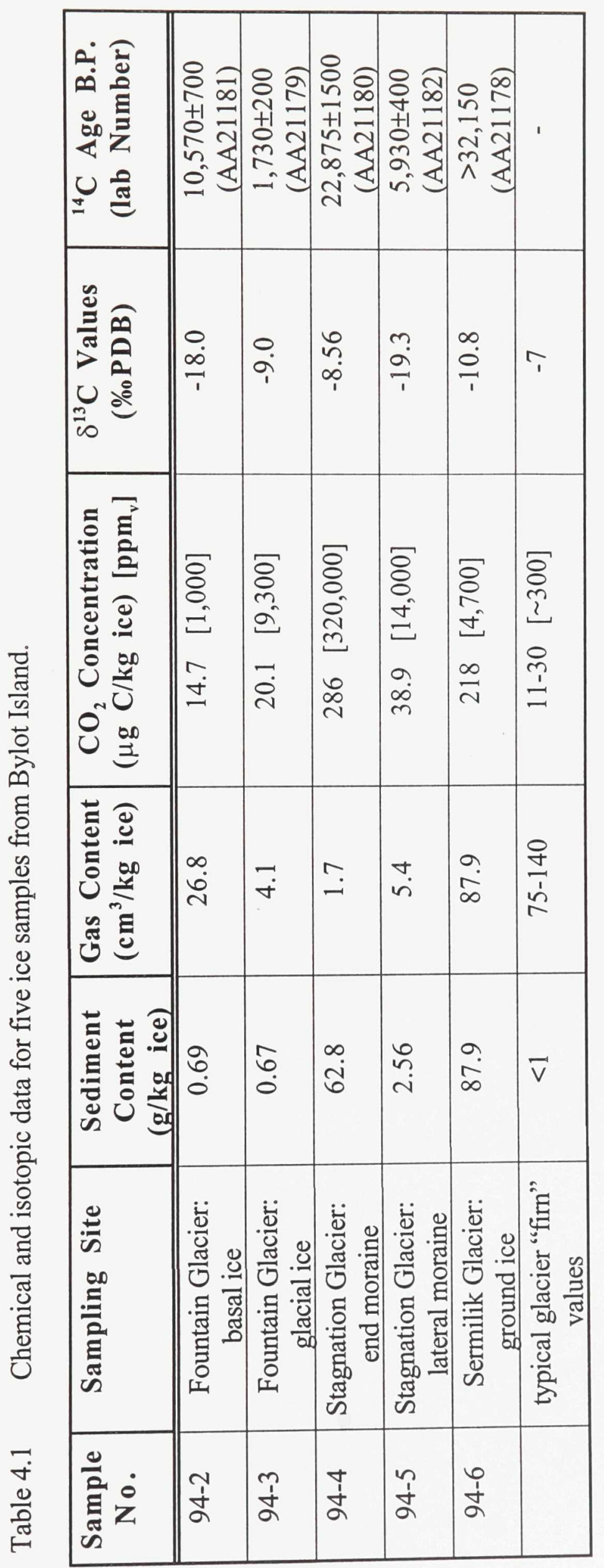


formed from ground water can also have a wide range of $\mathrm{CO}_{2}$ concentrations. Note that the total $\mathrm{CO}_{2}$ content of both the glacier and basal ice samples fall within the range of polar glacier ice, but the volumetric concentration of $\mathrm{CO}_{2}$ relative to the gas content is much higher than typical polar glacier ice in all the samples. This suggests none of the samples changed into ice from simple "dry" firnification.

\subsubsection{Isotopic properties}

The oxygen isotope ratio of the water component of ice samples was measured as it is indicative of the atmospheric temperature at the time of precipitation and the effects of freezing processes. In general, the more negative the $\delta^{18} \mathrm{O}$ ratio is, the colder the environment was at the time of precipitation. The $\delta^{18} \mathrm{O}$ ratio for 12 measurements ranged from $-16.9 \%$ to $-26.3 \%$ with an average of $-23.2 \%$. The current weighted annual average $\delta^{18} \mathrm{O}$ value for the precipitation at Pond Inlet is $-23.9 \%$ (Moorman et al., 1996a).

Radiocarbon age determination of five samples was done to enable temporal comparison of the $\delta^{18} \mathrm{O}$ values to those from other sites. The difference in gas content, $\mathrm{CO}_{2}$ concentration and $\delta^{13} \mathrm{C}$ values indicate that the samples do not contain unaltered atmospheric gases, thus the radiocarbon age determinations of the gas do not necessarily represent that of the ice, however when they are plotted beside deep ice core $\delta^{18} \mathrm{O}$ curves an interesting correlation is apparent. As indicated in Figure 4.11, the $\delta^{18} \mathrm{O}$ values for Bylot Island are appreciably less negative than those from Devon Island and Greenland, suggesting warmer temperatures. There are only a few data points but they appear to have a similar temporal signature to those of Devon Island and Greenland (i.e. cold until about 13,000 B.P., warming from 13,000 B.P. to 10,000 B.P., and then gradual cooling up to the present) (Paterson et al., 1977). 


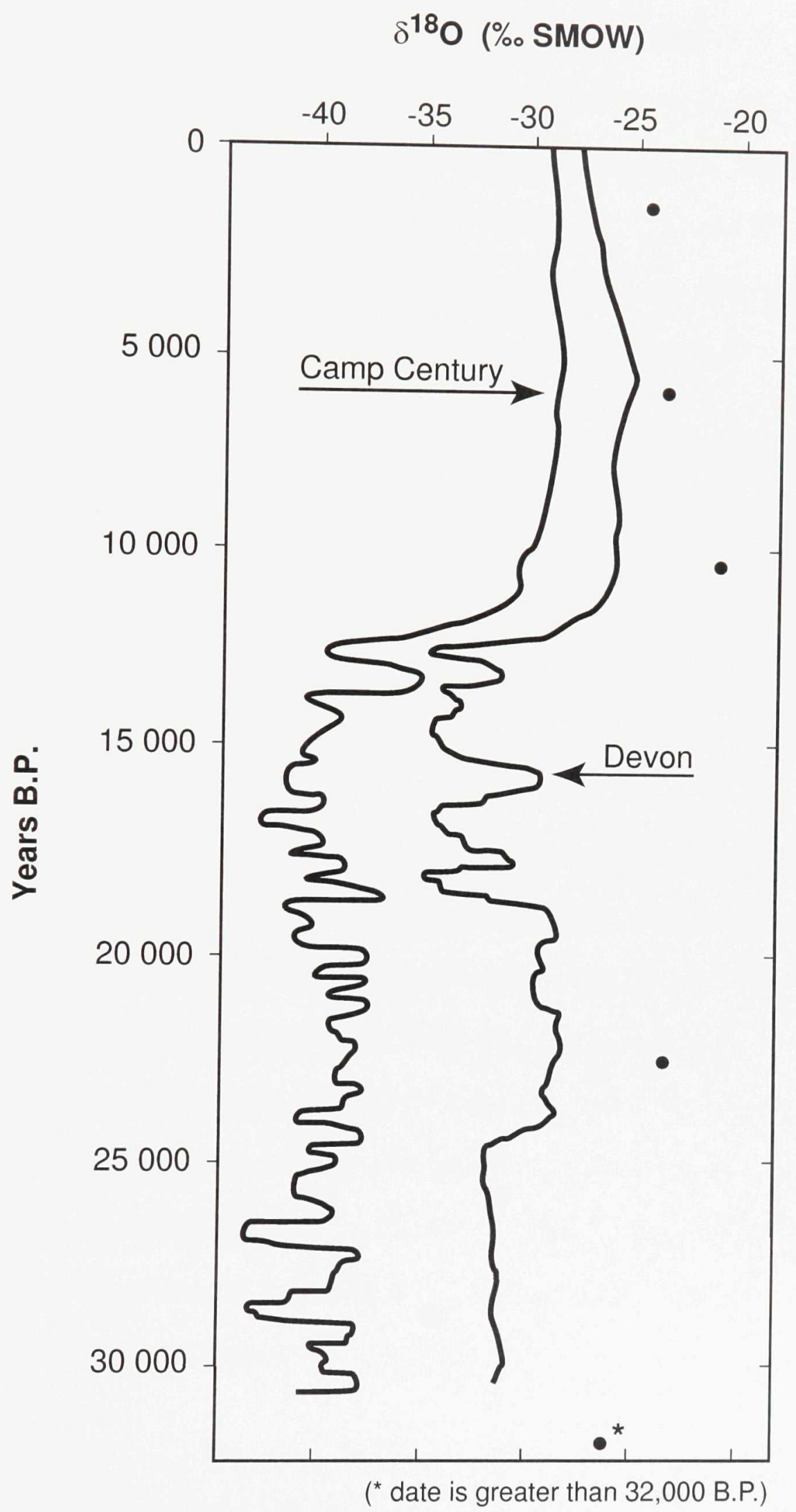

Figure 4.11 The oxygen isotope data from glacier and ground ice on Bylot Island (dots) compared to ice core data from Devon Island and Greenland (after Paterson et al., 1977). Note that some of the ice samples are not of a firn origin and thus the radiocarbon dates represent maximum ages. 
Seven of the samples were analyzed for both $\delta^{18} \mathrm{O}$ and $\delta^{2} \mathrm{H}$. The co-isotopic plot in Figure 4.12 shows the analyses from this study fall within the same general range as those from a study on Glacier B7. Although there are not a statistically significant number of data points, the ground ice from this study fall very close to the "Firn + Glacier ice" line derived by Zdanowicz et al. (1996). This suggests that the melting-refreezing action suggested by Souchez and Jouzel (1984) did not occur at this location.

The ${ }^{13} \mathrm{C}$ isotopic ratio of the gas within the ice was also measured as it is indicative of the origin of the gas (Table 4.1). As glacier ice bubbles actually represent samples of trapped atmosphere, the ${ }^{13} \mathrm{C}$ ratio is similar to the atmosphere (approximately -7\% ). Carbon dioxide derived from carbonate rocks (such as found in some ground waters) has a ratio around $0 \%$. Biogenically produced $\mathrm{CO}_{2}$ (i.e. from soil gases) can vary dramatically, but generally has a range of $-15 \%$ to $-25 \%$.

The glacial ice sample and two of the ground ice samples had $\delta^{13} \mathrm{C}$ values close to that of the atmosphere. The other two samples had much more negative $\delta^{13} \mathrm{C}$ values, indicating that there was a terrestrial component in the water that was the source for this ice. These two locations also happen to have terrestrial water sources nearby. Fountain Glacier has two terrestrially fed ice dammed lakes. These two lakes are thought to supply the ground water that produces the Fountain Icing (Elver, 1994). The east lateral moraine of Stagnation Glacier, where the high $\delta^{13} \mathrm{C}$ values were found, has a large terrestrial drainage basin that feeds a lateral stream. This stream has been observed flowing into and out of the lateral moraine and glacier (Figure 3.11 and Figure 4.13). 


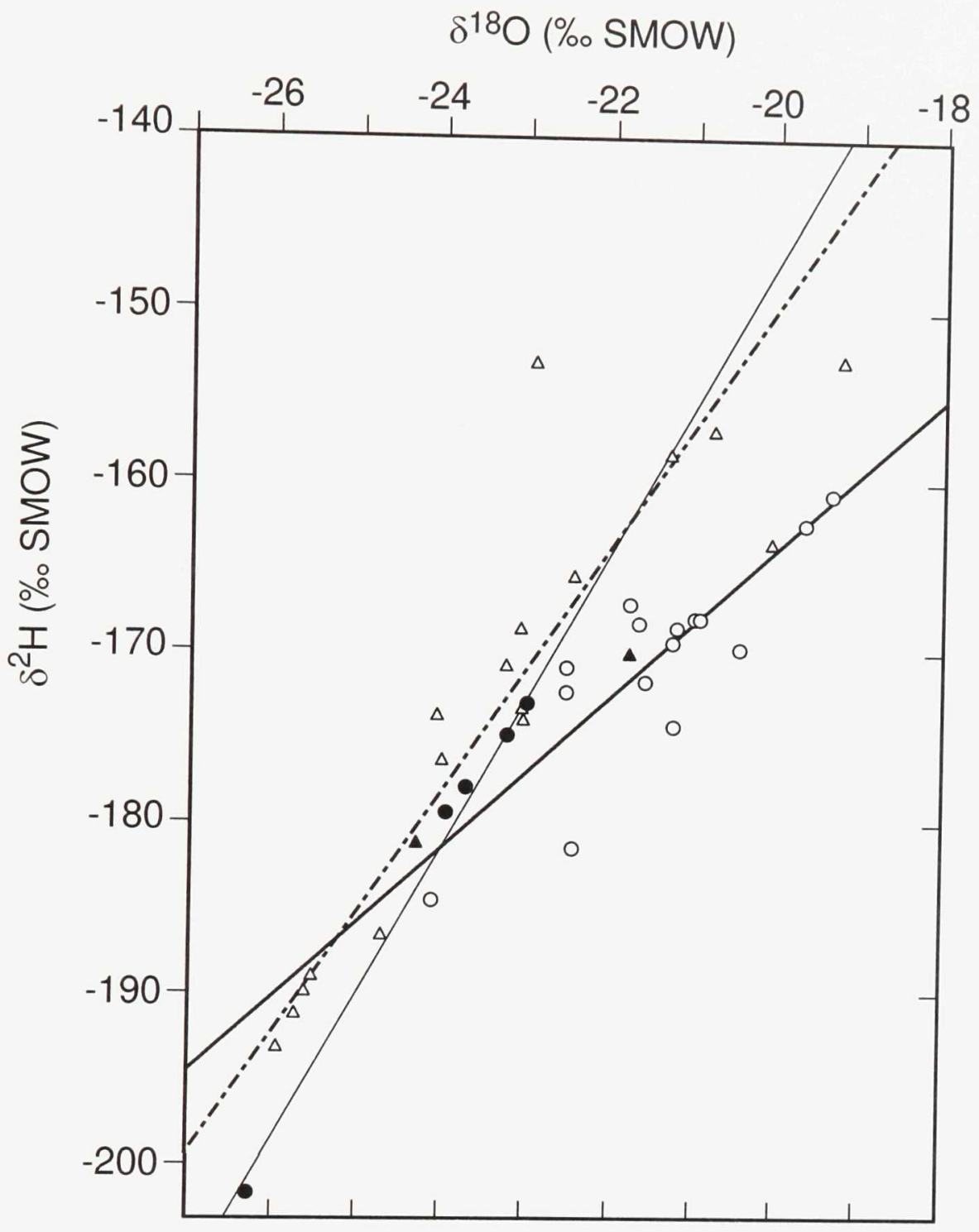

Zdanowicz et al. (1996)

$\longrightarrow$ B Basal Ice $\delta^{2} \mathrm{H}=4.4\left(\delta^{18} \mathrm{O}\right)-76.3 \quad \mathrm{r}^{2}=0.72$

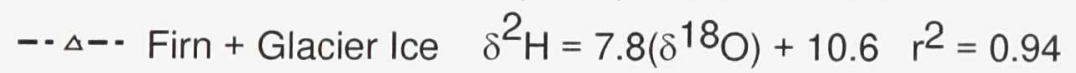

This Study

$\longrightarrow$ Ground Ice $\delta^{2} \mathrm{H}=8.6\left(\delta^{18} \mathrm{O}\right)+24.6 \quad \mathrm{r}^{2}=0.99$

- Glacial Ice

Figure 4.12 Co-isotopic plot of firn and glacier, basal, and ground ice data from Bylot Island. The open circles and triangles represent data from Glacier B7 (Figure 2.2). The solid circles and triangles represent glacier and ground ice from this study. Note that the ground ice in this study is most similar to the glacial ice and firn analyzed by Zdanowicz et al. (1996). 


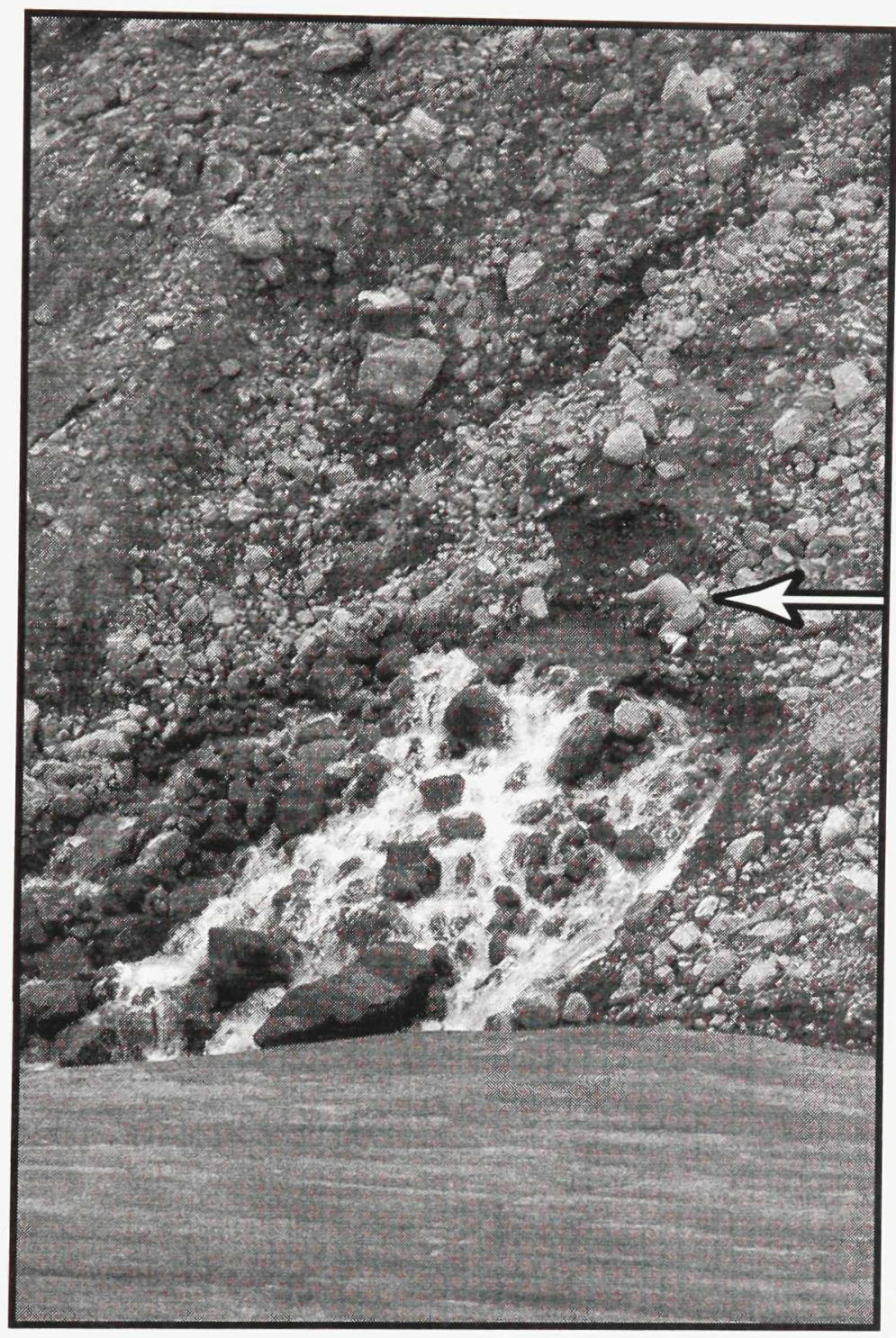

Figure 4.13 A spring exiting the east lateral moraine of Stagnation Glacier. A lateral stream disappeared into the moraine several hundred metres up stream. Note the person for scale (indicated by the arrow). The glacier is in the fore-ground. 
Using the suite of analyses described above makes it possible to identify unique characteristics for each type of ice. Of the different types of ice encountered on Bylot Island, icing and glacier ice had the most unique physical properties. Both ice types had very low sediment contents. As well, icings have a layered structure that distinguishes them from other ice types. Distinguishing basal ice and ground ice on the basis their physical properties was not as simple due to the large degree of variability in their appearance. However, the data show that using the $\mathrm{CO}_{2}$ concentration and $\delta^{13} \mathrm{C}$ values in unison is effective for differentiating basal, buried and segregated ice. High $\mathrm{CO}_{2}$ concentrations indicate the ice did not form directly from the metamorphism of firn, thus it is of a basal or segregated origin. If the $\delta^{13} \mathrm{C}$ values of a sample deviate from that of the atmosphere, another gas source is indicated (eg. soil gases or $\mathrm{CO}_{2}$ from dissolved carbonates). When there is basal melting and refreezing occurring, such as in the case of regelation, the glacier above acts as a huge source of water and provides a significant boundary controlling ground water flow. As a result, the vast majority of the water involved in the refreezing will have the glacier as its source. Thus if the $\delta^{13} \mathrm{C}$ values are very different than those found in a glacier (i.e. those of the atmosphere $\approx-7 \%$ ) then there is a good chance that the growth of the ice body did not occur at the base of a glacier. It should be noted that all these lines of evidence are negative evidence, thus determining the origin of the ice ends up being a process of elimination. 
The development of the three ice bodies studied in detail; Fountain Glacier (glacier and basal ice), Stagnation (lateral and end) moraine ice, and Sermilik ground ice, can be assessed from a spatial and temporal point of view.

The two samples from Fountain Glacier both come from the same glacial system but have a different origin. The glacier ice sample (94-3) has a sediment concentration, $\mathrm{CO}_{2}$ concentration, and $\delta^{13} \mathrm{C}$ value that are in the range to be expected in glacier ice. The gas content is lower than found in polar glaciers but this could simply be the result of summer melt filling in some of the cavities in the snow pack. The basal ice sample from Fountain Glacier (94-2) had many similar characteristics to the glacial ice sample. The sediment concentration in the sample was almost as low as the glacier ice sample; however, just above the sampling location there was a sediment rich layer. The sample was taken from roughly the level of the person's shoulders in Figure 4.4. As well, the $\delta^{13} \mathrm{C}$ value immediately indicates that the ice must have soil water at least partially as its source. Corresponding to the relative stratigraphic position of the two samples the upper one is considerably younger.

The variability in buried ground ice is shown by the two samples from the Stagnation moraines. While 94-4 has a high sediment content, 94-5 is much closer to that of the glacier ice. The gas content in both of them is low relative to the glacier and their $\mathrm{CO}_{2}$ concentrations are high. However, note that the $\mathrm{CO}_{2}$ concentration in the end moraine is an order of magnitude greater than the lateral moraine. With the $\mathrm{CO}_{2}$ concentration as high as it is in sample 94-4 the ice must have been in the liquid form at some point in its history. However, it probably doesn't have a ground water source as is indicated by the $\delta^{13} \mathrm{C}$ value. In contrast, sample $94-5$ has a lower $\mathrm{CO}_{2}$ concentration but a very negative $\delta^{13} \mathrm{C}$ value, suggesting the water came from a ground water source. Once again with these two 
samples the ages correlate with their relative stratigraphic position. Sample 94-4 came from the very center of the valley bottom, where one would expect to find the oldest ice in a glacier. The lateral moraine sample 94-5 was taken from within $50 \mathrm{~m}$ of the top of the moraine and would thus stratigraphically be much younger. However, the age of this sample more likely reflects the age of the ground water that influenced its $\delta^{13} \mathrm{C}$ value.

The ground ice sampled near Sermilik Glacier was in a terrace beyond the limit of recent moraines (Figure 4.9c). The $\mathrm{CO}_{2}$ content in the ice was measured to be $218 \mu \mathrm{g} / \mathrm{kg}$ of ice. This is approximately 20 times greater than atmospheric levels of $\mathrm{CO}_{2}$, thus indicating that the ice did not originate as glacial firn but was refrozen glacier ice (eg. basal ice) where the carbon dioxide had a chance to exchange with liquid water. The $\delta^{13} \mathrm{C}$ ratio of the $\mathrm{CO}_{2}$ in this ice is similar to that of the atmosphere suggesting that even though the ice came from a liquid source, the water was dominantly glacier meltwater. This interpretation is also supported by the fold structures that can be seen in the head wall of the exposure. Fold structure similar to these are frequently observed in the basal sections of other glaciers on the island (Zdanowicz, 1996).

An age for the ice, as determined by dating the $\mathrm{CO}_{2}$ trapped within the ice, was $>32,000$ B.P.. This agrees with other interpretations of the glacial history of the area. Klassen (1993) suggests that this bench within the Sermilik Valley has not been glaciated since the Eclipse Glaciation greater than 43,000 B.P.. Further research has indicated that this glaciation could be in the order of 60,000 B.P. (McCuaig, 1994). 


\subsection{Conclusions}

With the large suite of measurements taken on each sample a distinct signature emerged for each ice type examined. The ice types can be distinguished by:

- Icing ice can be distinguished by its unique layered structure and crystallography.

- Glacier ice can be distinguished by its low sediment concentration, $\mathrm{CO}_{2}$ concentration, and $\delta^{13} \mathrm{C}$ value that reflect the atmospheric composition.

- Basal ice can be distinguished by having some or all of these attributes; higher sediment concentration, high gas content, and high $\mathrm{CO}_{2}$ concentration. Basal ice will; however, have $\delta^{13} \mathrm{C}$ values that reflect the glacier above.

- Segregated ice may have a high sediment concentration, plus variable gas contents, $\mathrm{CO}_{2}$ concentrations, and $\delta^{13} \mathrm{C}$ values. A sample with a $\delta^{13} \mathrm{C}$ value out of the range of glacier ice distinguishes it as segregated ice.

The radiocarbon dating of the gas content enabled a comparison of the ground ice $\delta^{18} \mathrm{O}$ values to those of the continuous record derived from ice cap cores. It should be noted that the radiocarbon ages measured are those of the $\mathrm{CO}_{2}$ in the ice. In ice which is formed from processes other than firnification, the measured age may are not necessarily be that of the ice.

All except for one of the measured ages of ice are relatively young indicating rather rapidly acting glacial processes. The age determined for the massive ice beyond the limits of the Sermilik modern moraine is greater than 32,000 B.P., which supports other Quaternary history interpretations for the island. 


\section{Chapter 5}

\section{${ }^{14} \mathrm{C}$ dating of trapped gases in massive ground ice, western Canadian Arctic}

\subsection{Introduction}

The age of tabular massive ground ice is often determined from its relative stratigraphic position, with the constraining absolute ages in a sequence determined by ${ }^{14} \mathrm{C}$ dating of carbon-rich organic material encased in the ice or surrounding sediment (eg. Dallimore and Wolfe, 1988). The reliability of the ages determined from this method depend on the reliability of constraining stratigraphic information, the origin of the organic material, and the origin of the ice.

Recent developments in AMS dating have reduced the minimum required amounts of carbon to about $20 \mu \mathrm{g}$, thereby permitting direct ${ }^{14} \mathrm{C}$ dating of $\mathrm{CO}_{2}$ in the air 
trapped within ice. This may make possible not only the determination of the absolute age of ground-ice bodies, but also the formation process and the rate of growth of segregated ice bodies.

When the direct ${ }^{14} \mathrm{C}$ dating of ice was first attempted in the late 1950 's, several tons of ice had to be melted to recover enough $\mathrm{CO}_{2}$ for a single ${ }^{14} \mathrm{C}$ measurement (Coachman et al., 1958; Scholander et al., 1962). This is the equivalent of hundreds of metres of $10 \mathrm{~cm}$ diameter ice core. As a result, measurements could not be made on small ice bodies or closely spaced samples within larger ice bodies. Depending on the location within a glacier, the age of the ice within a single dated sample could vary by thousands of years. In the 1960's a method was devised to collect the required $\mathrm{CO}_{2}$ by melting a large sealed subsurface cavern in an ice body and processing the released gases through an on-site molecular sieve (Oeschger et al., 1967). However, a second problem associated with the melting procedure was that solid carbonate particles in the ice could dissolve in the water. $\mathrm{CO}_{2}$ exchange between the water and gas could take place, thereby altering the ${ }^{14} \mathrm{C}$ content of the gas.

Using AMS dating and a newly developed sublimation gas extraction technique, samples of glacier ice from deep Greenland ice cores have been successfully dated using ${ }^{14} \mathrm{C}$ age determinations on the air trapped within the ice (Wilson and Donahue, 1990; 1992).

This paper introduces the application of this technique to determine the age of massive ground ice, and the use of the chemical and isotopic composition of the gas trapped within the ice to help determine its origin. We present data from three locations in the western Canadian Arctic and discuss their implications to the regional Quaternary history. 


\subsection{Ground-ice development in the western Canadian Arctic}

Tabular massive ground-ice bodies underlie vast tracts of the arctic landscape (Mackay, 1973). Their genesis and age has often been a matter of discussion (French and Harry, 1990). In the western Canadian Arctic, the origin of the tabular massive ground ice is most often attributed to either the burial of glacier ice or superimposed ice or in situ segregation of intrasedimental ice near a glacier terminus (French and Harry, 1988; Fujino et al., 1988; Mackay, 1971; Rampton, 1988).

Two major Wisconsinan glaciations have been inferred in the Mackenzie Delta region. During the Buckland Glaciation, ice is thought to have covered most of the western Canadian Arctic some time from the Early to Middle Wisconsinan (80 000-35 000 BP) (Mackay, 1972; Rampton, 1988). During the Sitidgi Stade, glaciers are thought to have been generally restricted to the modern Mackenzie River delta and to have reached their maximum extent around 13000 BP (Rampton, 1988), although Michel (1982) suggested a more extensive Late Wisconsinan glacial advance. Since much of the massive ground ice is well beyond the interpreted ice limits of the Sitidgi Stade (Figure 5.1), the ground ice has generally been assumed to be older than $35000 \mathrm{BP}$. However, the basis for assuming an Early Wisconsinan age for glaciation in the area has been based on organic deposits, many of which yield non-finite ages. As noted by Rampton (1988), these organic samples are often reworked from older units. ${ }^{14} \mathrm{C}$ dates on material contained in the massive ground ice at Peninsula Point (Figure 5.1) suggest that it possibly may be younger than $17000 \mathrm{BP}$ (Kato et al., 1988). 


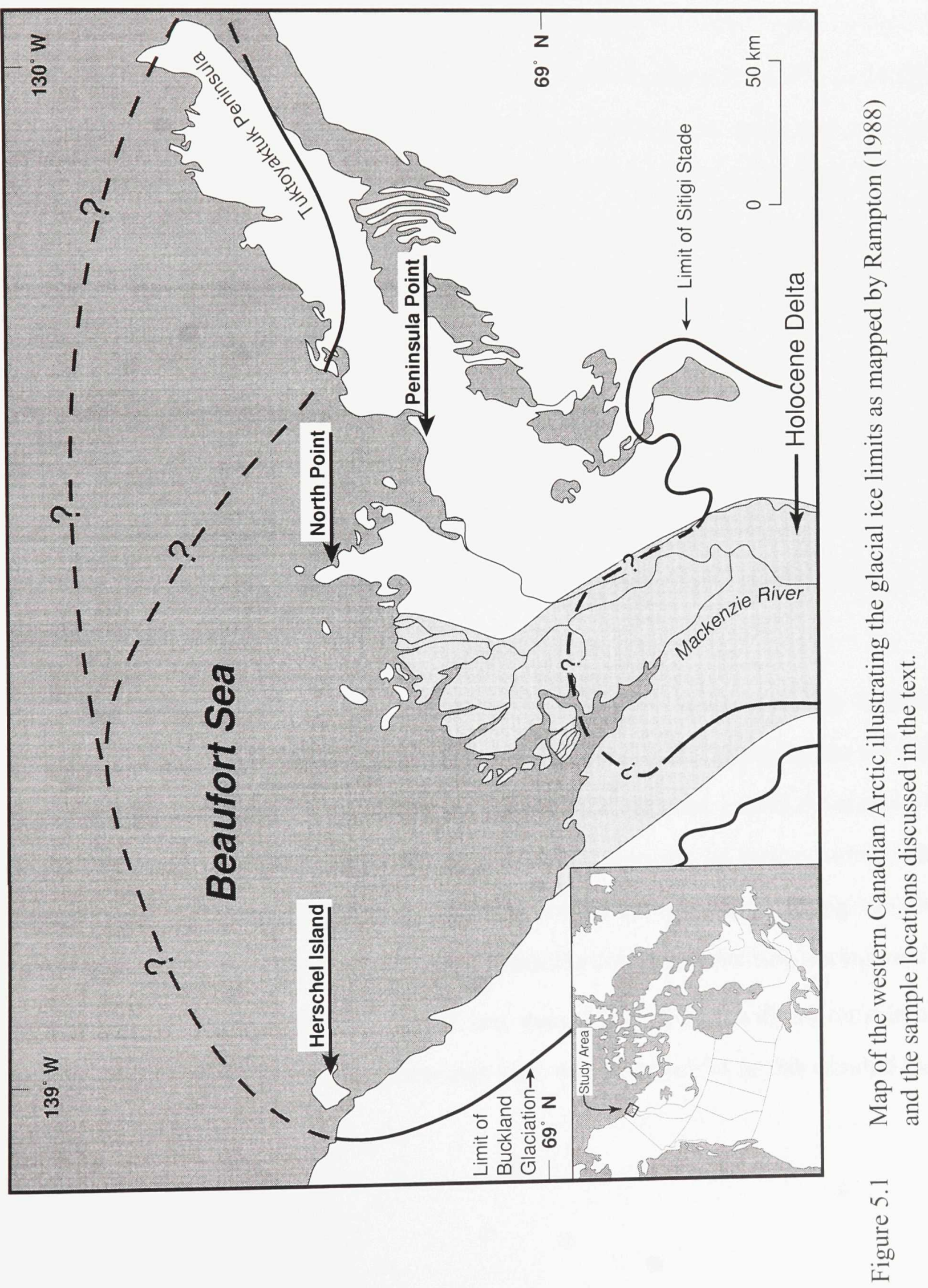




\subsection{Sample collection}

The size of ice sample required for dating depends on factors such as bubble content within the ice, the $\mathrm{CO}_{2}$ content within the bubbles, and the amount of sample removed in preparation for dating. Blocks of ice, $30 \mathrm{~cm} \times 30 \mathrm{~cm} \times 50 \mathrm{~cm}$ in size, were cut out of the headwall of retrogressive thaw slumps at the three study sites, either with an ice ax or a chainsaw. As two of the three samples were collected during a period of active melting, $10 \mathrm{~cm}$ or more of the ground-ice surface was first removed to minimize the possibility of contamination from modern $\mathrm{CO}_{2}$ within the surface ice.

To avoid contamination of the gases trapped within the ice, care was taken to ensure that the ice blocks sampled contained no cracks, sediment or ice layers that had open/connected pores, or enlarged or melting intracrystalline boundaries. As carbon dissolved in water can significantly alter the ${ }^{14} \mathrm{C}$ content of the bubble gases, it is important to prevent the melting of the ice.

The samples were placed in freezers around $-10^{\circ} \mathrm{C}$ (approximately ambient ground temperature) prior to, and any time possible during transit. Keeping the ice near its ambient ground temperature reduced the chance of contraction cracks developing in the ice as a result of rapid temperature changes, while ensuring no melt occurred. The samples were transported in heavily insulated containers (insulation rating $>\mathrm{R}-20$ ). Temperatures recorded with four dataloggers inside the shipping containers during transit showed that the ice warmed at a rate of less than $0.006{ }^{\circ} \mathrm{C} \mathrm{hr}^{-1}$ with an outside air temperature of $\approx 20{ }^{\circ} \mathrm{C}$. As the longest transit time was less than $24 \mathrm{hr}$ this ensured that melting did not occur. 


\subsection{Age determination}

Two methods have been found effective for extracting gases trapped within ice: ice sublimation (Wilson and Donahue, 1990) and cold grinding (van de Wal et al., 1990; Andree et al., 1984). We used the sublimation technique since cold grinding has a greater potential for sample contamination and incomplete gas extraction, thus resulting in greater uncertainty in the age determinations (Andree et al., 1986). The sublimation technique enables the extraction of all gases trapped within an ice block and minimizes the risk of contamination of the gas from machinery or exchange with liquid water or solid carbonate particles (Wilson and Donahue, 1992). The system used at the University of Arizona is described in detail by Wilson and Donahue $(1990,1992)$.

In preparation for gas extraction, a cylinder of ice, $10 \mathrm{~cm}$ in diameter and $\leq 50 \mathrm{~cm}$ long, was cut from the inner core of the sample and placed in a glass vacuum chamber. The system was then evacuated, and the ice was "cleaned" for five hours by sublimating an $\approx 1 \mathrm{~cm}$ outer rim from the ice. This removes from the system any modern gases trapped on the exposed surfaces of the sample and within open cracks. Once the cleaning was completed, infrared lamps were turned on and the released gas collected. The collection line starts with a pair of large ethanol traps at $-80^{\circ} \mathrm{C}$ that remove most of the water vapor (Figure 5.2). Once the water vapor was removed, the $\mathrm{CO}_{2}$ and $\mathrm{N}_{2} \mathrm{O}$ gases were collected in a multipass trap cooled by liquid nitrogen. The remaining gases (except for the lightest, eg. $\mathrm{H}_{2}$ and $\mathrm{He}$ ) were then collected in a molecular sieve held in liquid nitrogen. Once the entire ice sample was sublimated, the $\mathrm{CO}_{2}$ was transferred to an attached graphitization line where its mass was measured, and it was converted to graphite for AMS ${ }^{14} \mathrm{C}$ measurement. As liquid water cannot exist below 4.58 Torr, isotope exchange is eliminated by keeping the system at 2 Torr (this corresponds to 

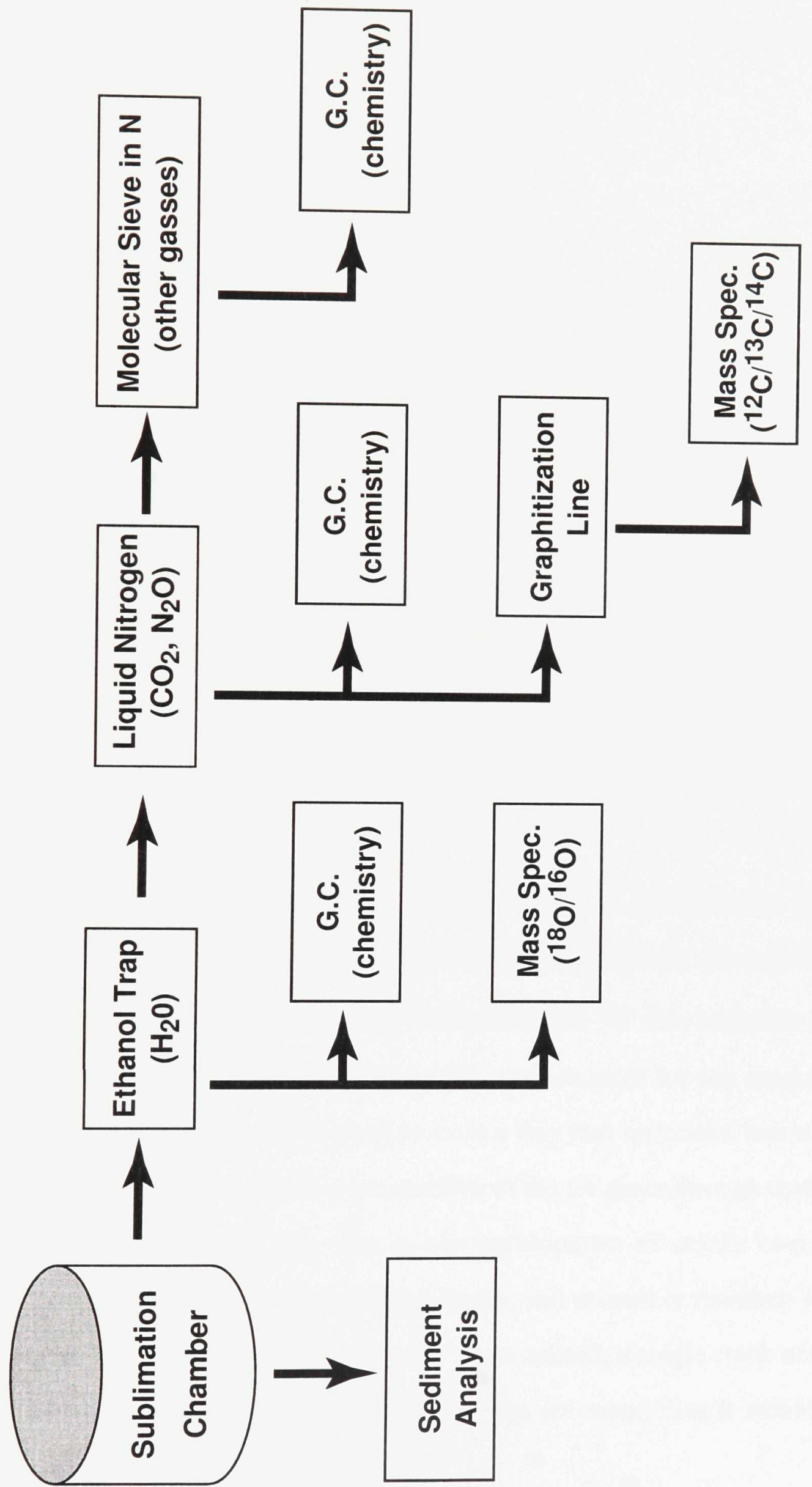
$-10^{\circ} \mathrm{C}$ ). At this temperature the infrared energy is applied without the risk of the formation of liquid water.

\subsection{Reliability of the dates}

${ }^{14} \mathrm{C}$ dating of massive ground ice provides a maximum age limit for the ice. In buried ice, the ${ }^{14} \mathrm{C}$ date represents the date when the atmospheric gases, including $\mathrm{CO}_{2}$, were sealed into the ice mass (eg. by firnification, snowpack saturation and freezing, or lake, river, ocean, or icing freeze up). Essentially this is the age of the ice. However, the actual date of burial could be more recent than the radiocarbon age of the ice. In segregated ground ice, the $\mathrm{CO}_{2}$ gas can be derived from the atmosphere, or carbonates, or organic matter within the sediments. Because all of these sources have ${ }^{14} \mathrm{C}$ ages that are older than or equal to the age of the ice, the time of formation of the ground ice could be more recent than the radiocarbon age determined.

There are two ways in which ground ice could be contaminated with younger carbon, but both can be considered negligible. Epigenetic cracks through the ice could transport younger $\mathrm{CO}_{2}$ into the ice mass, thus making the ${ }^{14} \mathrm{C}$ date of the ice mass appear younger than it really is. However, the samples were checked for any cracks at the time of extraction and analysis, and shipped in such a way that no cracks would develop en route. This only leaves the in situ contamination of the ice gases through cracking. There are several possibilities for this. The in situ development of cracks could introduce younger air into the ice mass. However the cracks, still present or resealed, would likely be noticed at the time of sampling, and even if not noticed, a single crack only comes in contact with an extremely small percentage of the ice mass, thus it would have little impact on the total ${ }^{14} \mathrm{C}$ content. 
The contamination from a resealed crack through a block of ice was modeled. For a $30 \mathrm{~cm} \times 30 \mathrm{~cm} \times 50 \mathrm{~cm}$ ice block with a gas volume of $5 \%$, and $1 \mathrm{~mm}$ diameter bubbles evenly distributed through the block, a planar crack extending through the entire length of the block would intersect approximately 10000 bubbles, and contaminate about $0.02 \%$ of the total gas volume. If the ice is 34000 years old and modern air is contaminating the bubbles intersected by the crack, the measured age would be offset by 745 years. However, if the ice is only 13000 years old, the offset will be less than 5 years. Thus, many sizable cracks would be required to produce an appreciable shift in the measured date, and these cracks would likely be noticed during visual examination of the ice. As well, any cracks that are still open or cracks that open up during the "cleaning" process are decontaminated.

A second way of contaminating the ice with younger carbon is through gas movement along intracrystalline boundaries. This is unlikely to occur unless the ice body is very close to the melting point and contains a large uniformly oriented crystal structure. Even if any of these ice bodies did approach their melting point prior to sample collection, their small (generally $<1 \mathrm{~cm}$ diameter) randomly oriented crystal structure is not conducive to intracrystalline water or gas movement. Molecular diffusion in ice also operates so slowly that its effects are insignificant over the time range of ${ }^{14} \mathrm{C}$ dating (Paterson, 1994). 


\subsection{Results}

\subsubsection{North Point}

The North Point site $\left(69^{\circ} 40^{\prime} 54^{\prime \prime} \mathrm{N}, 134^{\circ} 20^{\prime} 8^{\prime \prime} \mathrm{W}\right)$ is a retrogressive thaw slump, $<10$ masl, on the east side of Richards Island (Figure 5.1). The headwall containing the exposed ice was approximately $700 \mathrm{~m}$ long and up to $6 \mathrm{~m}$ high. At the time of sampling, in August 1992, the entire exposure consisted of a massive sandy diamicton containing various sizes of ice lenses, large massive ice beds and ice wedges (Figure 5.3). The lenses varied in thickness from $5 \mathrm{~cm}$ to $1 \mathrm{~m}$ and in length from $10 \mathrm{~cm}$ to $1 \mathrm{~m}$. The beds ranged in thickness from $30 \mathrm{~cm}$ to over $1 \mathrm{~m}$ and the largest exposed sill was over $30 \mathrm{~m}$ long. The sills and beds had sharp contacts with the surrounding sediment.

Most of the lenses were oriented horizontally; however, some had an apparent inclination of $\leq 20^{\circ}$. Even though nearby ice bodies are highly deformed (Kurfurst and Dallimore, 1991), deformation of the ice and surrounding sediment at this site was not observed.

The North Point sample was taken from a horizontal bed of structureless massive ice whose top $50 \mathrm{~cm}$ was exposed for over $5 \mathrm{~m}$ along the base of the headwall. There was a small amount of sediment dispersed throughout the ice, occurring as single grains and as small $(<1 \mathrm{~cm}$ in diameter) clods. The bubble content was estimated to be $5 \%$ and consisted of small $(<1 \mathrm{~mm}$ in diameter) spherical bubbles distributed evenly throughout the ice. The ${ }^{14} \mathrm{C}$ date of the $\mathrm{CO}_{2}$ recovered from the ice was $10500 \pm 120 \mathrm{BP}$ (Table 5.1).

\subsubsection{Peninsula Point}

This site, located on the Beaufort Sea coastline (69 $\left.24^{\prime} 35^{\prime \prime N} 133^{\circ} 8^{\prime} 29^{\prime \prime W}\right) 6 \mathrm{~km}$ southwest of Tuktoyaktuk (Figure 5.1), has been at the centre of discussion regarding the 
a)

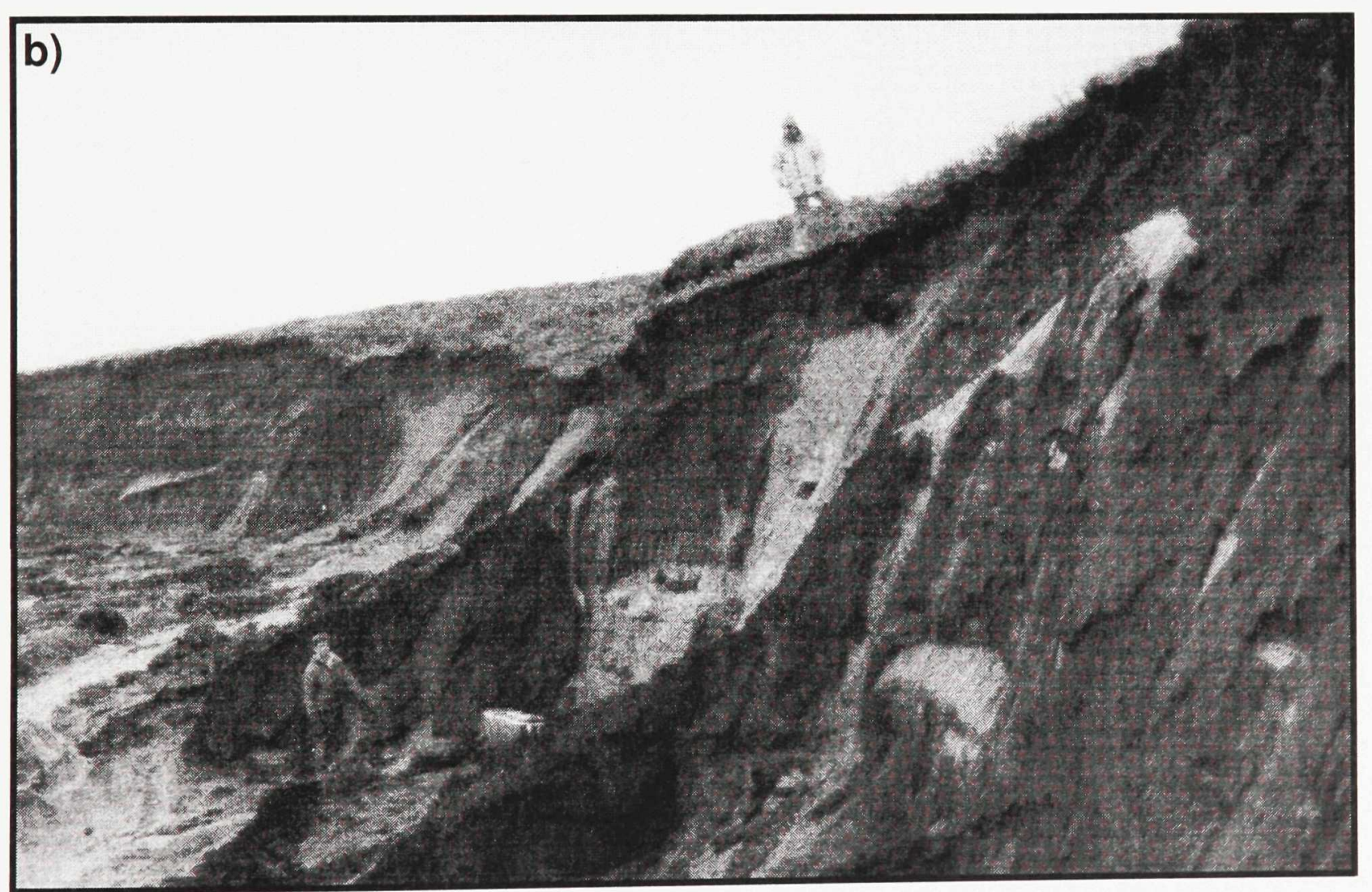

Figure 5.3 Schematic diagram (a) showing general character of the thaw slump at North Point, and photograph (b) of the headwall displaying ground ice structure and sampling location (by the person at the foot of the headwall). Height of person at top of headwall is $2 \mathrm{~m}$. 


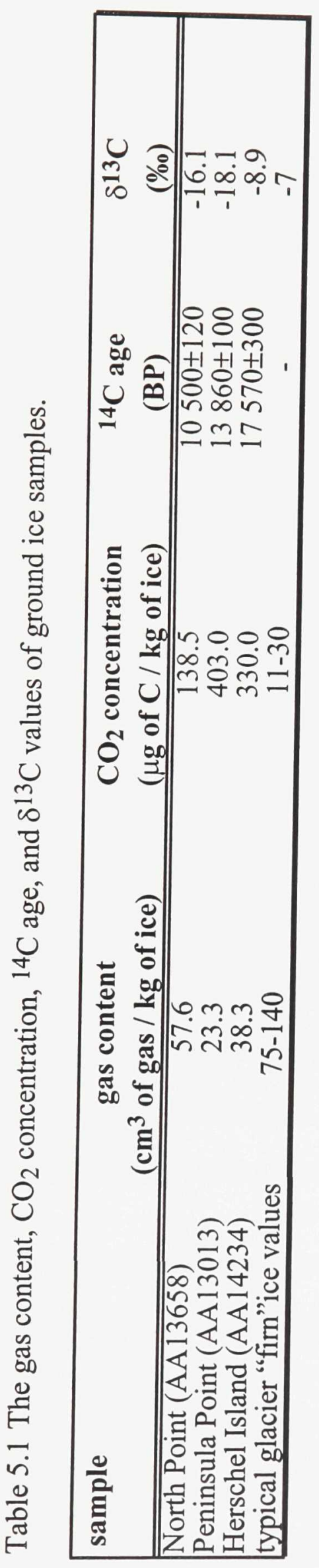


origin of tabular massive ground ice in the region (Fujino et al., 1988; Mackay, 1989; Mackay and Dallimore, 1992).

The sediment overlying the ice body is a stony clay diamicton that varies in thickness from less than $1 \mathrm{~m}$ to over $10 \mathrm{~m}$. Over much of the ice body, several generations of thaw slides have occurred, resulting in much of the upper sediment-ice contact being a thaw unconformity. The lower contact is gradational with sand (Fujino et al., 1988).

Layering within the ice body is generally flat lying to gently undulating, and is thought to have experienced only minor deformation as a result of unloading and diapirism (Mackay and Dallimore, 1992). At a few locations the beds have been upturned by ice-wedge formation.

The Peninsula Point sample was collected from a relatively undeformed section of the ice mass within $2 \mathrm{~m}$ of the top of the ice body (Figure 5.4). The ice was clear with a few sediment grains dispersed throughout. From thin section analysis the crystals were observed to be granular in shape, averaging $5 \mathrm{~mm}$ in diameter, with no significant preferred c-axis orientation. Air bubbles were estimated to make up $2 \%$ of the ice mass and were generally 1-2 $\mathrm{mm}$ in diameter and roughly spherical. The ${ }^{14} \mathrm{C}$ age of the $\mathrm{CO}_{2}$ recovered from the ice was $13860 \pm 100 \mathrm{BP}$ (Table 5.1). This date fits sequentially with the values determined for the surrounding sediment and wood fragments (Table 5.2).

Some researchers agree that the formation of this ice was possibly aided by a source of high pressure ground water, such as a glacier surrounded by permafrost (Rampton, 1988b; French and Harry, 1990; Mackay and Dallimore, 1992). However, Rampton (1988) places the Late Wisconsinan Sitidgi ice maximum (13,000 yr B.P.) 
a)

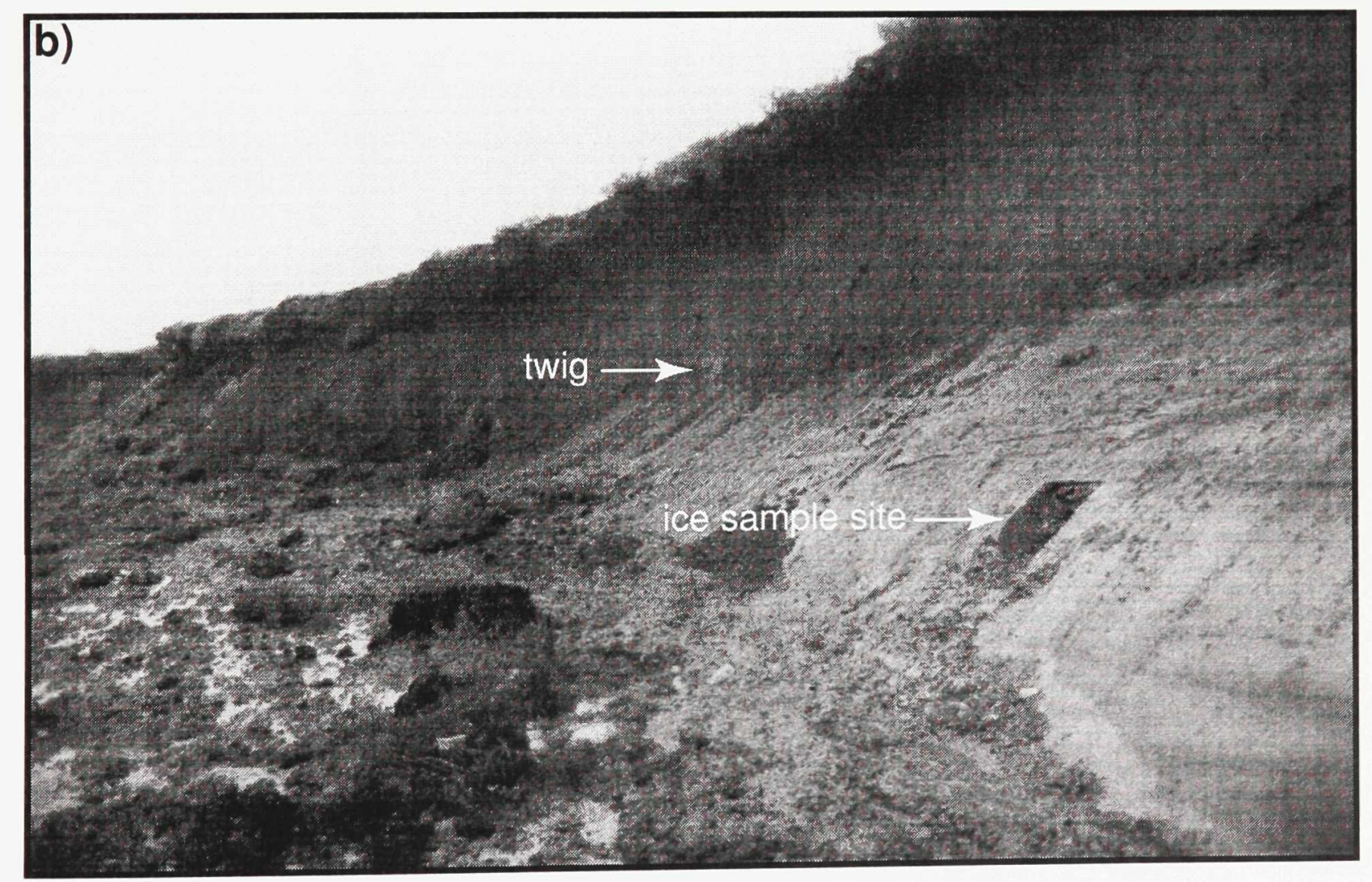

Figure 5.4 Schematic diagram (a) of the structures observed in the headwall of the thaw slump at Peninsula Point, and photograph (b) of sampling location. Twig protruding from diamicton at centre of photograph was $14 \mathrm{C}$ dated (WAT 2685, Table 5.2). Height of headwall in photograph is $4 \mathrm{~m}$. 


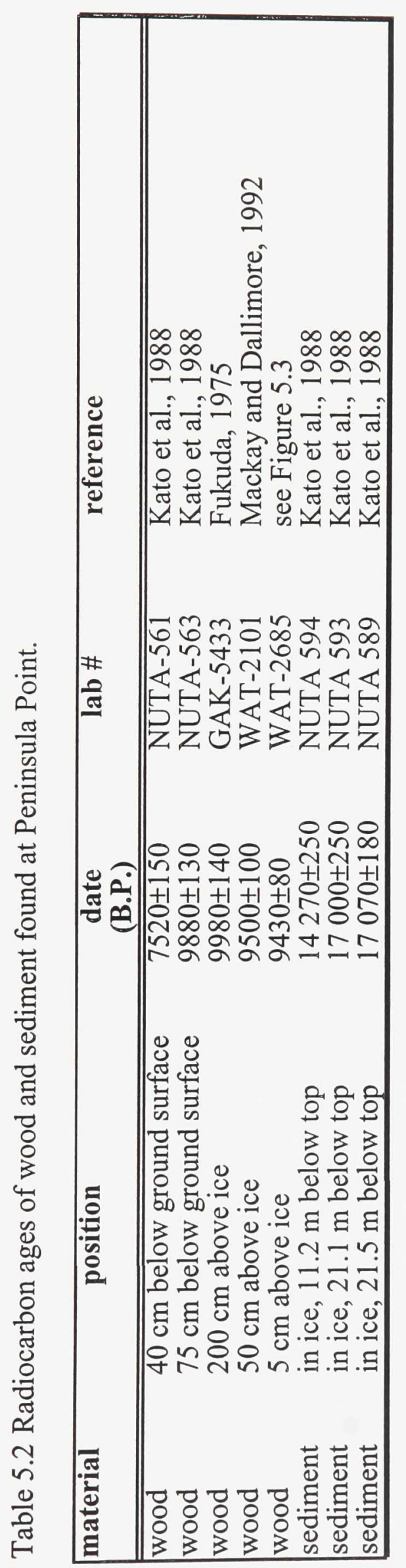


south of the Eskimo Lakes at the time of formation of the Peninsula Point ice body. The 13,860 year age of the ground ice at Peninsula Point implies that either the origin of this massive ice body was not dependent on the presence of glaciers nearby, or Rampton's placement of the maximum limit of Late Wisconsinan glaciation within the delta is too far south, and the ice actually continued further down the delta, extending at least another $100 \mathrm{~km}$ to the northeast.

\subsubsection{Herschel Island}

Massive ground ice and ice-rich sediments are widespread on Herschel Island (Figure 5.1). The most common types of massive ground ice are interpreted to be intrasedimental ice and ice wedges; however, buried snow bank ice, intrusive ice, buried glacier ice, and other unidentified ice types have been observed on the island (Michel, personal communication, 1985; Pollard, 1990). The sampling site is located at the headwall of a thaw slide $\approx 25$ masl in the southern portion of the island $\left(69^{\circ} 34^{\prime} 40^{\prime \prime} \mathrm{N}\right.$ $\left.138^{\circ} 58^{\prime} 30^{\prime \prime} \mathrm{W}\right)$. Unlike at the other two locations this sample was taken in late May before appreciable melt had begun.

At the sampling site, all of the sediments and ice in the exposure are highly deformed with well developed overturned folds and occasional shear planes, except for the modern organic layer at the surface and some of the ice wedges (Figure 5.5). The movement, as determined from the folding pattern was from southeast to northwest. The stratigraphy varies greatly along the headwall; however, in general, the modern organic sediments are underlain by a diamicton and occasionally by pods of peat that are up to $3.75 \mathrm{~m}$ thick. Radiometric dates from the peat at the sampling site, $25 \mathrm{~cm}$ and $2 \mathrm{~m}$ above the base of the peat, were determined to be $10,850 \pm 100$ (WAT-2407) and 9150 180 (WAT-2402), respectively. Below the peat, a $2 \mathrm{~m}$ thick stony-sand to clay-silt diamicton unit is present. The base of the diamicton unit is defined by an undulating thaw 

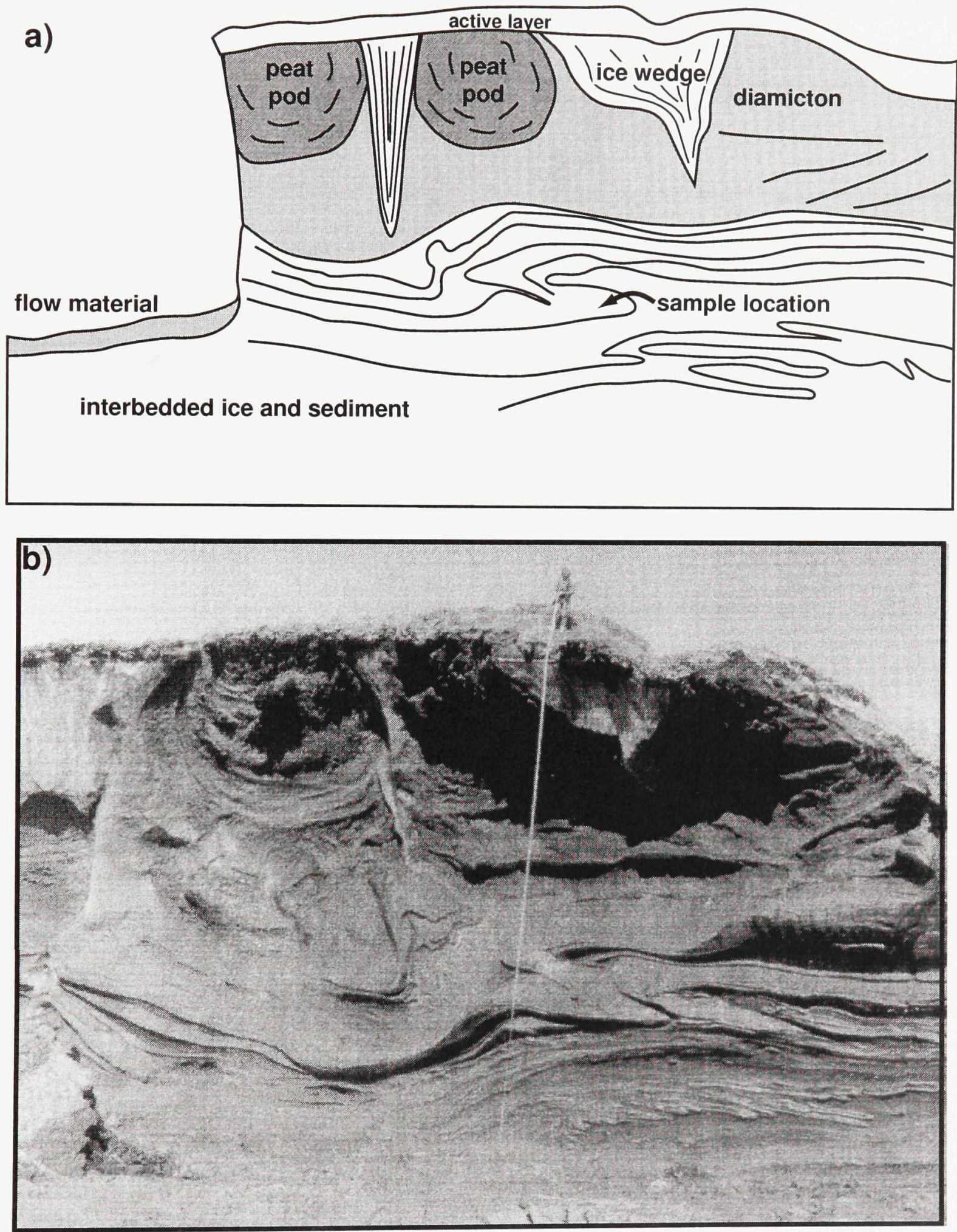

Figure 5.5 Schematic diagram (a), and photograph (b) of the headwall of the thaw slump on Herschel Island, displaying ground ice structure and sampling location. The ice and sediment units are both highly deformed. The height of the headwall below the person is $13.75 \mathrm{~m}$. 
unconformity which varies in depth between $2 \mathrm{~m}$ and $6 \mathrm{~m}$ below the ground surface. Banded ice-rich sand and massive ice, in excess of $10 \mathrm{~m}$ thick underlies the unconformity. Both the sediments and the ice of this unit are intensely folded.

The ice sample taken from Herschel Island was located in an $\approx 1.5 \mathrm{~m}$ thick ice band about $10 \mathrm{~m}$ from the top of the headwall, at the nose of a tight S-fold. In general, the ice was clear and colourless and contained about a 3\% bubble content. The bubbles were aligned into $2 \mathrm{~mm}$ wide bands spaced $1 \mathrm{~cm}$ apart. Individual bubbles were primarily spherical and less than $1.5 \mathrm{~mm}$ in diameter. Brown sand bands bounded the ice sample, but the ice itself was sediment free. The $\mathrm{CO}_{2}$ recovered from the Herschel Island ice yielded a ${ }^{14} \mathrm{C}$ age of $17570 \pm 300 \mathrm{BP}$ (see Table 5.1).

As ice must already exist before it can be deformed, and the most likely cause of deformation of this ice is glacial thrusting (Rampton 1982), this date suggests a more extensive Late Wisconsinan glaciation than previously interpreted.

\subsection{Ground ice origin and Quaternary history}

While the environments in which intrasedimental ice can form are variable, the relatively uniform surface conditions of glaciers results in a unique gaseous signature for "firn" ice ("firn" ice being that formed from the compaction of snow). The gas volume in "firn" ice depends on factors such as elevation, temperature, and wind speed. Ice core data show that its range is $75-140 \mathrm{~cm}^{3} / \mathrm{kg}$ of ice, with an average for polar ice sheets of $\approx 100 \mathrm{~cm}^{3} / \mathrm{kg}$ (Martinerie et al., 1992; Oeschger et al., 1982). With the deep burial of ice the gas bubbles can disappear as air hydrates form, but at lower pressures the hydrates are not stable, resulting in the bubbles reforming in the ice or the hydrates decomposing and 
the air being released during the gas extraction process (Paterson, 1994). The gas content of all three samples was considerably lower than that of "firn" ice (see Table 5.1).

The gases trapped in "firn" ice of polar glaciers generally have $\mathrm{CO}_{2}$ concentrations similar to that of the source air. This corresponds to a range of 11-30 $\mu \mathrm{g}$ of carbon per $\mathrm{kg}$ of ice (Oeschger et al., 1982). The development of ice in contact with water or the development of intrasedimental ice enables the incorporation of higher concentrations of $\mathrm{CO}_{2}$ resulting from the dissolution of carbonates (Raynaud et al., 1982). As shown in Table 5.1, the $\mathrm{CO}_{2}$ concentrations in the three ground ice samples are an order of magnitude greater than that of "firn" ice.

The $\delta^{13} \mathrm{C}$ values of gas in polar glacier "firn" ice would also be expected to be similar to that of the atmosphere $(\approx-7 \%$; Boutton, 1991). This value varies throughout the year and from the equator to the poles by $\approx 1 \%$ (Mook 1986; Mook et al., 1983). The depressed $\delta^{13} \mathrm{C}$ values shown in Table 5.1 indicate that the gas in the North Point and Peninsula Point ice was not solely of an atmospheric origin. The $\delta^{13} \mathrm{C}$ values for terrestrial sources of carbon such as organic matter, soil $\mathrm{CO}_{2}$, and ground water can be as low as $-30 \%$ (Boutton, 1991).

Based on the information in this paper, the origin of the three samples is not definite, except that they are likely not of a "firn" ice origin. The ages determined for the ice bodies indicate that further ground ice studies of this type may help to better define the Quaternary history of the western Canadian Arctic. With further testing of this ice dating method and a more complete understanding of the processes of ground ice development, ground-ice dating may prove to be a considerable aid in reconstructing the Quaternary history in polar regions. By dating several samples within a single ice unit the rate of ice growth can be determined from the distance and age between samples. The 
origin of ice can be determined from the relative ages of the ice within the unit, intrasedimental ice having the oldest ice on top and buried glacier ice having the oldest ice on bottom.

\subsection{Conclusions}

Using an ice sublimation gas extraction technique and AMS ${ }^{14} \mathrm{C}$ dating, the ages of the gases trapped within small ground ice samples were determined. When sampling ice that is as bubble rich as glacier ice $(\approx 10 \%)$ only $500 \mathrm{~g}$ of ice is required for ${ }^{14} \mathrm{C}$ analysis. However, in most cases it is recommended that several kilograms of ice be sampled to ensure an adequate gas volume after sample cleaning. By releasing the trapped gases by sublimating the ice, isotopic exchange between the gases and liquid water does not occur. This solves the problem of ${ }^{14} \mathrm{C}$ contamination from carbonates in the ice. The measured age of the gases thus provides a maximum age for ice body formation.

The total gas content, $\mathrm{CO}_{2}$ levels, and $\delta^{13} \mathrm{C}$ values provide evidence of the origin of ground ice. As the values for these parameters in ice of a firn origin fall within a narrow range it can be easily determined if the ice originated as firn or not.

The data reported in this paper, from samples collected in the western Canadian Arctic, indicate that some of the ground ice in the region was formed no earlier than the Late Wisconsinan, more recently than previously thought. It was also determined that none of the samples originated as firn. 


\section{Chapter 6 \\ The Development of Tabular Massive Ground Ice at Peninsula Point, N.W.T., Canada}

\subsection{Introduction}

The genesis of massive ice in the Mackenzie Delta has been the source of discussion for some time. Stratigraphic, physical property and hydrochemical analysis have offered some insights into the formational processes of ice bodies (Mackay and Dallimore, 1992), but often do not yield conclusive results on the origin of the ice. Imaging of the subsurface with ground penetrating radar has proven effective at revealing distinctive structural characteristics, when they are present (Robinson et al., 1992). In this paper the origin and development of the ground ice body at Peninsula Point in the Mackenzie Delta is discussed with the aid of data from new gas extraction and analysis techniques. 


\subsection{Study area}

In any given year, a $700 \mathrm{~m}$ long by up to $10 \mathrm{~m}$ high section of massive ice may be visible along the Beaufort Sea coast at Peninsula Point. The surficial geology of the region around Peninsula Point is characterized by a thin layer of clay-rich diamicton, generally in the order of a few metres thick, overlying very thick deltaic sands, with tabular massive ground ice frequently at or near the contact between the two units (Mackay, 1973; Mackay and Dallimore, 1992). At Peninsula Point, ground penetrating radar surveys indicate the ice is up to $20 \mathrm{~m}$ thick in some areas, but is generally between $10 \mathrm{~m}$ and $16 \mathrm{~m}$ thick (Appendix E). The radar surveys, and headwall exposures indicate that the diamicton overlying the ice is $1 \mathrm{~m}$ to over $10 \mathrm{~m}$ thick. Sand was encountered at the base of the ice in several drill holes at Peninsula Point (Fujino et al., 1983; Fujino et al., 1988; Mackay and Dallimore, 1992).

In the last 80,000 years the Mackenzie Delta region has probably been host to two glaciations. During the Buckland Glaciation, ice is thought to have covered most of the western Canadian Arctic some time during the Early to Middle Wisconsinan $(80,000$ 35,000 BP) (Mackay, 1972; Rampton, 1988b). The extent of glacial ice during the later Sitigi Stade is less certain. Rampton (1988a; b) suggests that the maximum extent was south of the $69^{\text {th }}$ parallel (about $80 \mathrm{~km}$ from Peninsula Point), when it reached its maximum around 13,000 BP (Figure 6.1), whereas Michel (1982) suggests that this glacial advance may have reached closer to the northern end of Richards Island and Moorman et al. (1996b) suggests ice extended well onto the Beaufort Sea coast. 


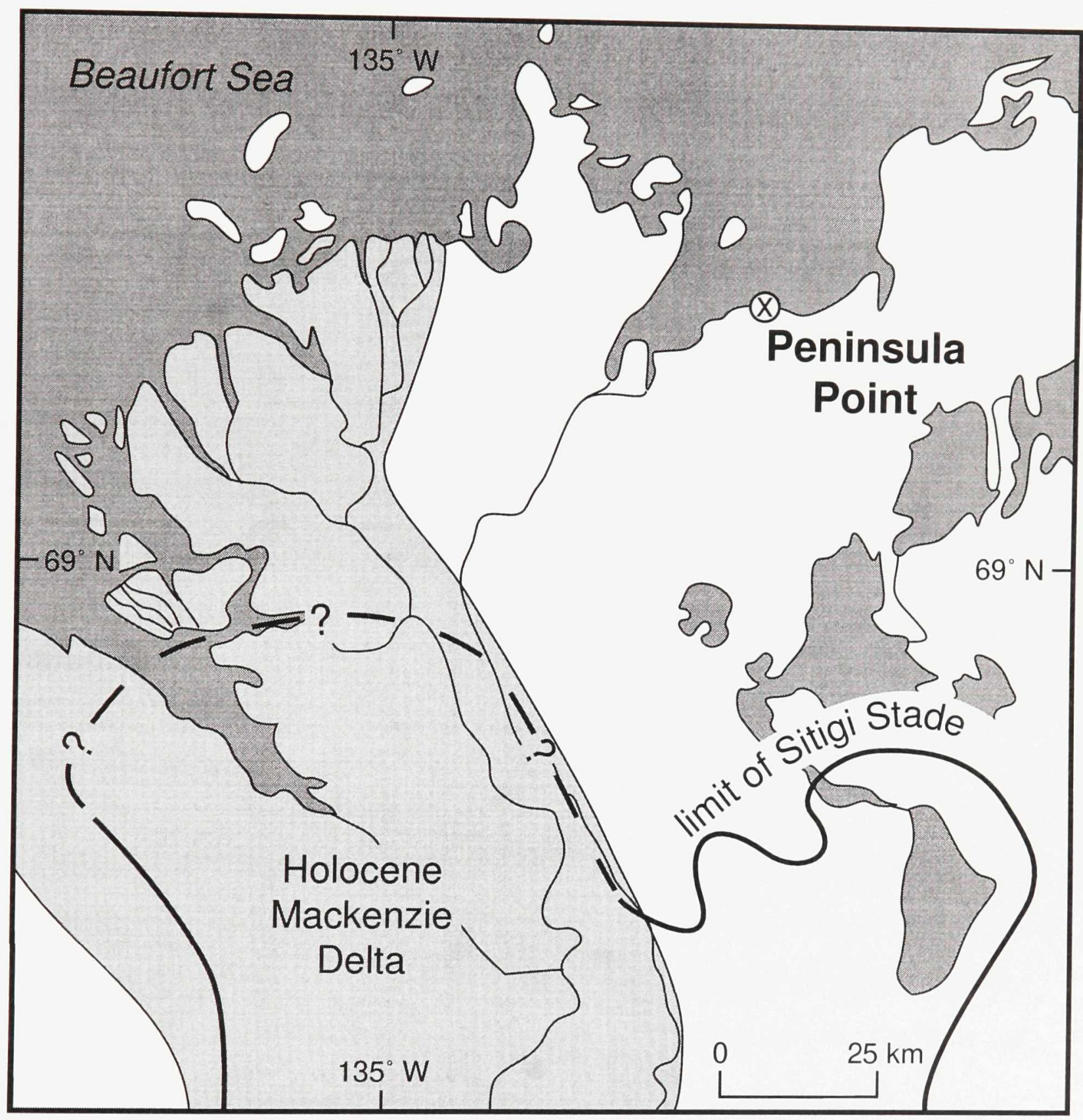

Figure 6.1 Location of the study site in relation to the interpreted limit of the most recent glacial advance as mapped by Rampton (1988b). 


\subsection{Methods}

Two expeditions to Peninsula Point examined the exposed massive ground ice. In the winter of 1989, a team of Japanese researchers, led by Dr. K. Fujino, extracted and sectioned a continuous $17.1 \mathrm{~m}$ long and $10 \mathrm{~cm}$ diameter core. A block of ice extracted from the headwall of the thaw slump is described by Moorman et al. (1996b).

Gas extraction from the ice and analysis was carried out at the University of Arizona in Tucson, USA using a recently developed ice sublimation technique (Moorman et al., 1996b; Wilson and Donahue, 1990; 1992). The analysis included the measurement of gas and sediment content, $\mathrm{CO}_{2}$ and $\mathrm{N}_{2} \mathrm{O}$ concentrations, ${ }^{13} \mathrm{C}$ and ${ }^{18} \mathrm{O}$ analysis, ${ }^{14} \mathrm{C}$ dating of the gaseous component, and ${ }^{18} \mathrm{O}$ analysis of the ice.

\subsection{Results}

\subsubsection{Physical properties of the ice}

Figure 6.2 displays typical crystal and bubble characteristics, while Figure 6.3 shows how variable these characteristics can be within some sections of the ice body. The graphs in Figure 6.4 display a correlation between the physical properties within the core. In the upper section $(0-5.5 \mathrm{~m}$ depth), the size of crystals and the concentration and character of bubbles was quite variable, and there were several sediment bands. In the middle section (5.5-13.0 m depth) the character of crystals and bubbles was much more uniform and there was a general absence of sediment. The bottom section (13.0-16.9 m depth) was similar to the top section in its variability, except the sediment bands were more abundant. 


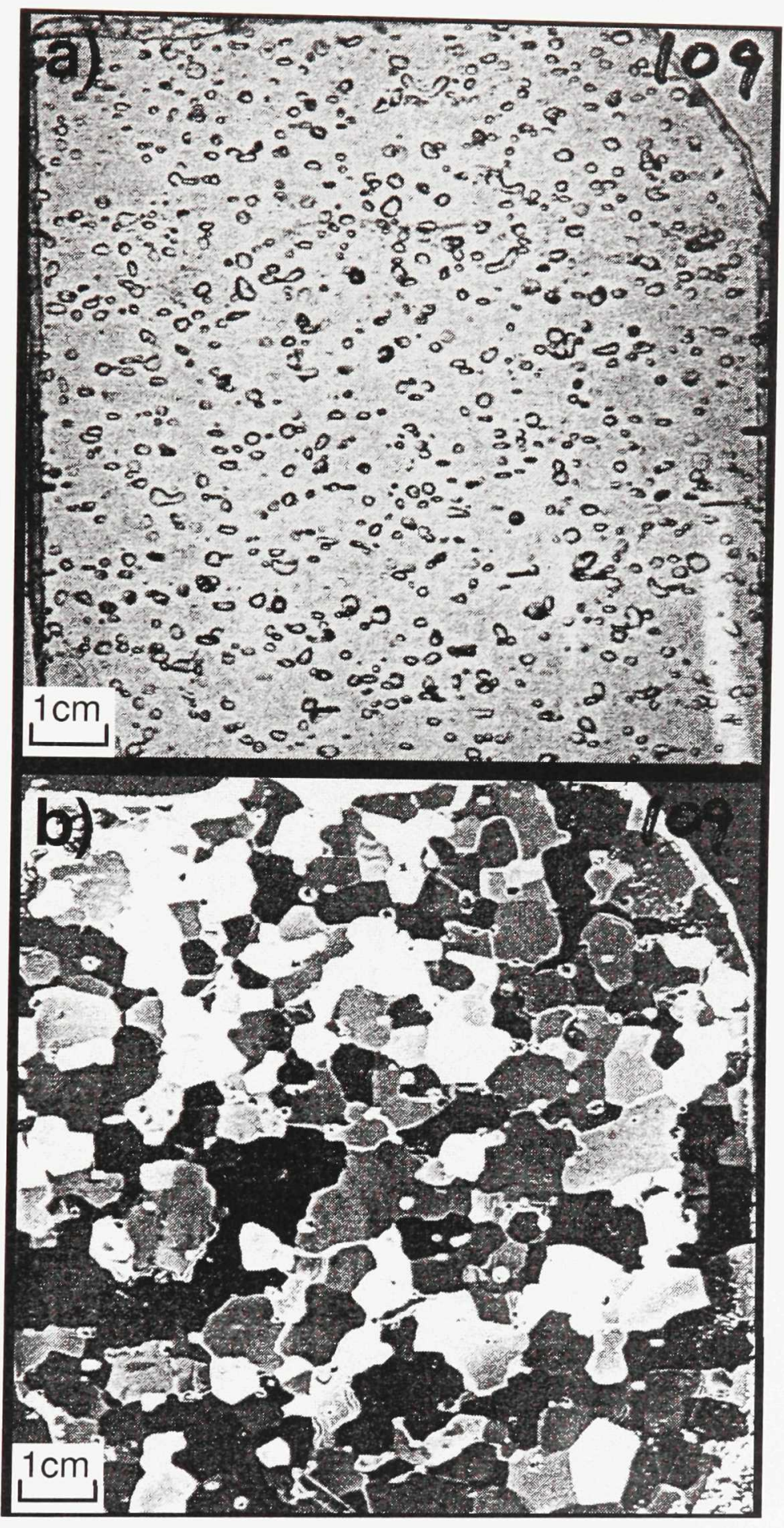

Figure 6.2 A thick section photograph typical of the core from Peninsula Point. This ice came from a depth of $10.9 \mathrm{~m}$. (a) normal polarization displaying bubble character, and (b) cross polarization displaying crystal character. 


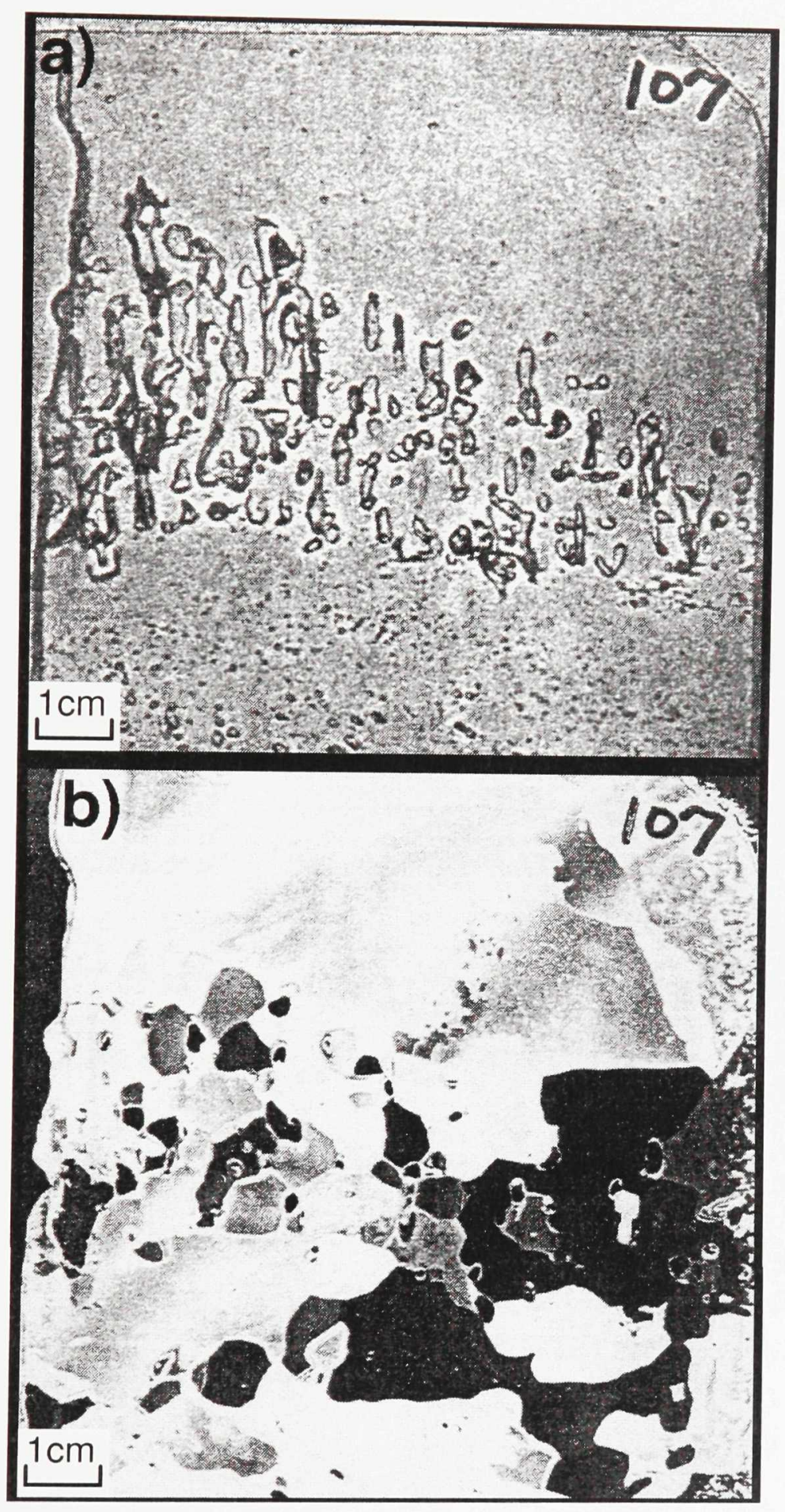

Figure 6.3 A thick section photograph from $10.7 \mathrm{~m}$ depth in the core from Peninsula Point. This section shows the range in bubble content and character and variability in the ice crystal size present in the core. (a) normal polarization displaying long vertical bubble trains as well as bubble free zones, and (b) cross polarization displaying crystals varying in size from less than $0.5 \mathrm{~cm}$ to over $5 \mathrm{~cm}$ in diameter. 
There were approximately 30 sediment inclusions in the core, ranging from $1 \mathrm{~mm}$ to $20 \mathrm{~mm}$ in thickness. In the upper third of the core the sediment inclusions tended to be fine grained and appear in layers or clods. In the bottom third of the core, the sediment was generally restricted to planar to wavy bands composed of sand. The contact at the bottom of the core consisted of interbedded ice and sand layers.

A total of 64 bedding plane indicators (eg. sediment layers, bubble planes, and bubble trains) were identified within the core. The greatest dip of a bedding plane was measured to be $20^{\circ}$, but $72 \%$ of the indicators had a dip of less than $10^{\circ}$. There was no trend in the dip angle along the core. A few indications of small scale deformation $(<1 \mathrm{~cm})$ were also evident in some of the sediment layers near the base of the core.

\subsubsection{Chemical composition of the gas bubbles}

The range in $\mathrm{CO}_{2}$ values is very large (Table 6.1). Even the lowest values are an order of magnitude greater than those found in the atmosphere, but all are within the range found in soil gases.

Extremely low levels of $\mathrm{N}_{2} \mathrm{O}$ are usually present in the atmosphere, whereas appreciable amounts can accumulate in biologically active soils (Brady and Weil, 1996). The $\mathrm{N}_{2} \mathrm{O}$ levels in three of the samples from the Peninsula Point massive ice body were below detectable limits while two of the samples had trace amounts of $\mathrm{N}_{2} \mathrm{O}$. The two samples containing some $\mathrm{N}_{2} \mathrm{O}$ also had the highest concentrations of $\mathrm{CO}_{2}$. 


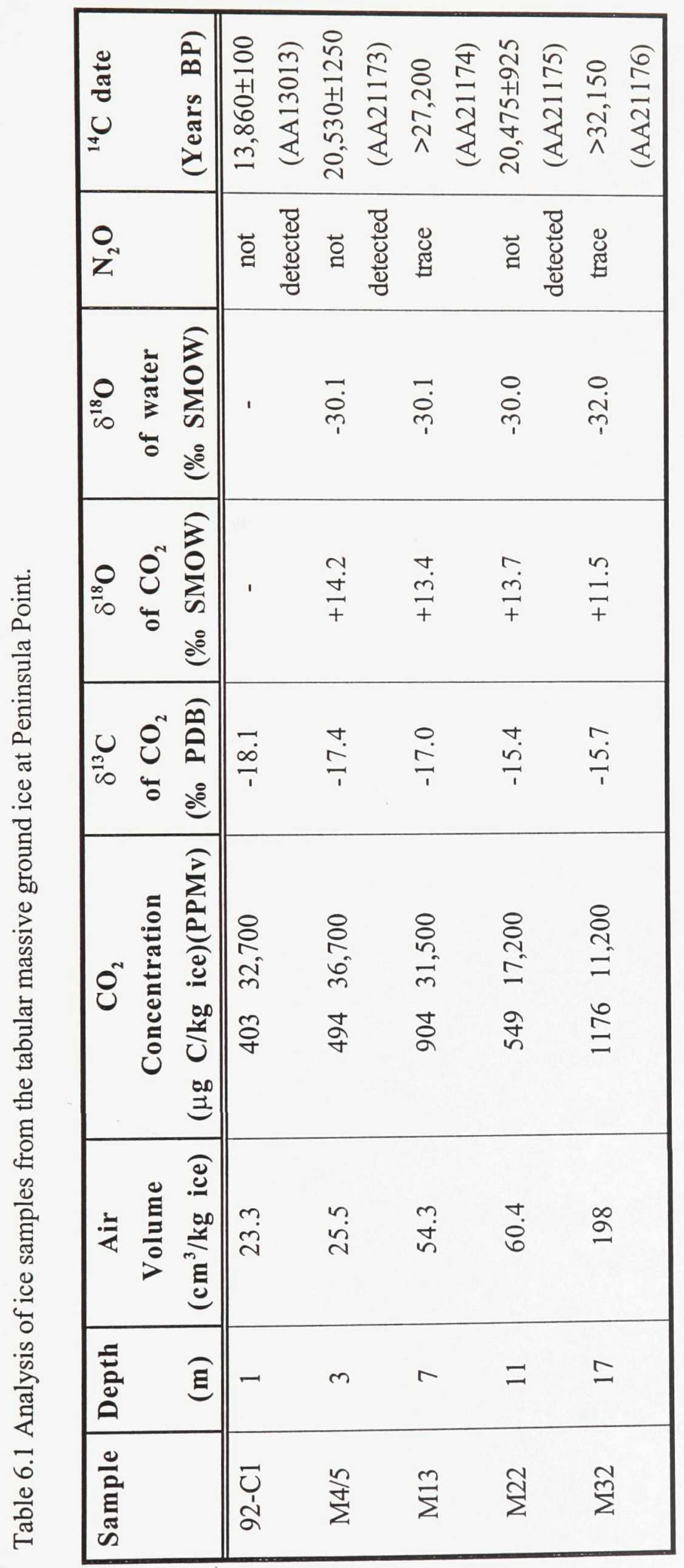




\subsubsection{Isotopic properties of the ice and gas}

The $\delta^{13} \mathrm{C}$ values of the gas trapped in the ice ranged from $-15.4 \%$ to $-18.1 \%$ (Table 6.1). These values are considerably more negative than those for atmospheric $\mathrm{CO}_{2}$ (approximately $-7 \%$ ) or $\mathrm{CO}_{2}$ derived from carbonate sources (approximately $0 \%$ ). Biogenically produced $\mathrm{CO}_{2}$ (eg. in soil gases) generally has a $\delta^{13} \mathrm{C}$ value in the range of $-15 \%$ to $-25 \%$.

The ${ }^{14} \mathrm{C}$ dates determined for the gases trapped in the ice range from $13,860 \pm 100 \mathrm{BP}$ to greater than $32,000 \mathrm{BP}$ (see Table 6.1). All of the radiocarbon ages have been normalized to $\delta^{13} \mathrm{C}=-25.0 \%$. The majority of the $\delta^{18} \mathrm{O}$ values for water (ice) fell between $-30.0 \%$ and $-32.0 \%$, similar to other samples taken from the same ice body (Kato et. al., 1986; Mackay and Dallimore, 1992). A detailed ${ }^{18} \mathrm{O}$ profile through the massive ice (Figure 6.4) displays a typical segregational pattern; however, the profile also suggests a series of discrete water pulses, rather than a continuous resupply of water. The isotopic composition of the oxygen in the $\mathrm{CO}_{2}$ and the ice indicates equilibrium between the $\mathrm{CO}_{2}$ and water at $0^{\circ} \mathrm{C}$.

\subsection{Discussion of ice origin}

Several theories have been proposed for the source of water and the formation process of the massive ground ice at Peninsula Point (Fujino et al., 1983; Fujino et al., 1988; Mackay and Dallimore, 1992; Rampton, 1988a). The strength of several theories of ice formation are assessed with consideration of the characteristics of the ice and trapped gases. 
$\|\left.\right|^{\frac{1}{2}}$ ||

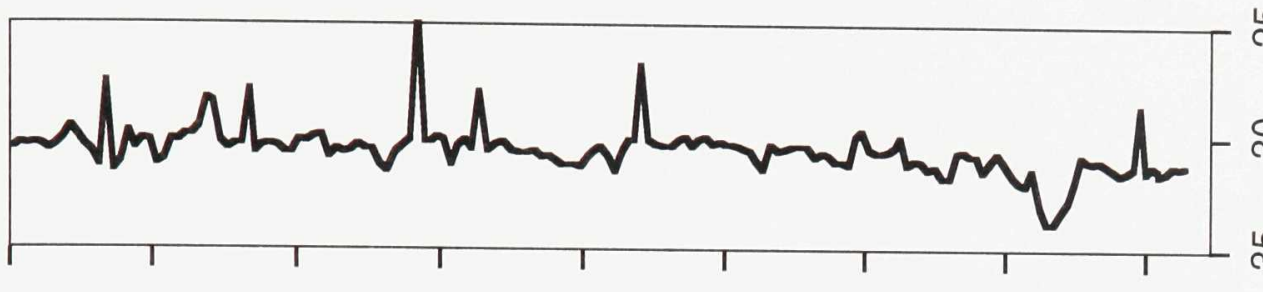

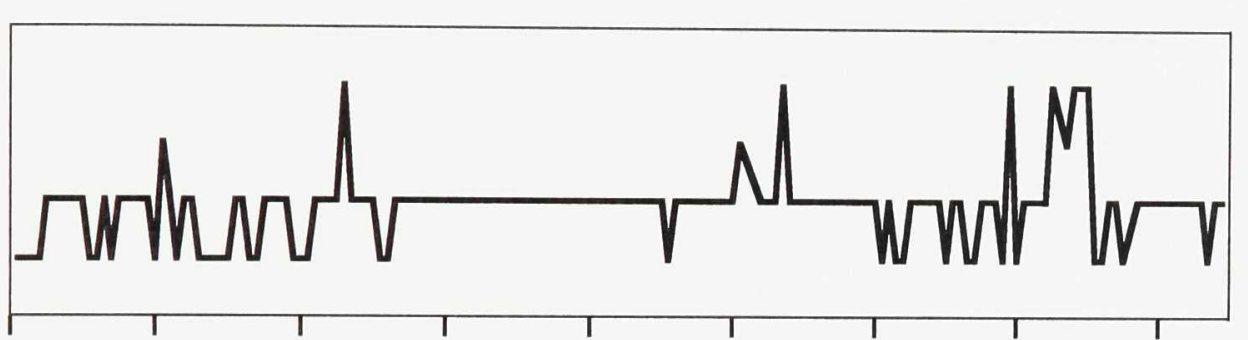

1

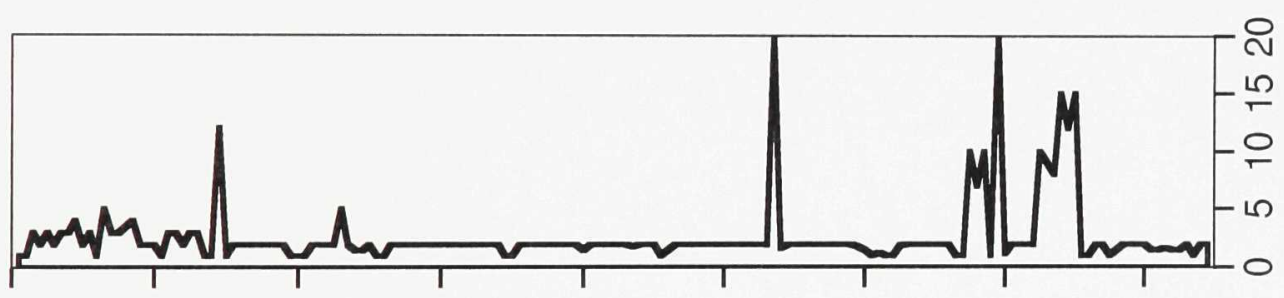

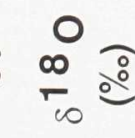

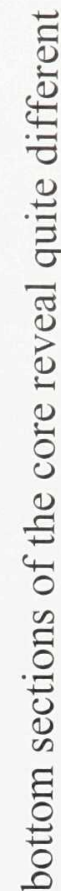

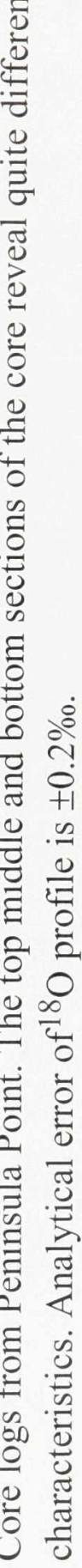

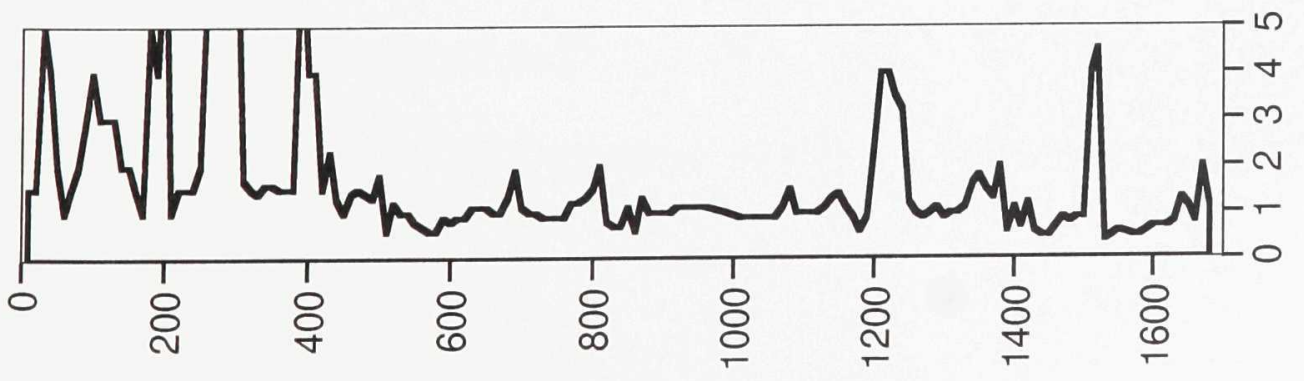

焉京

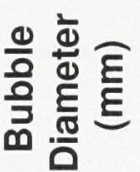

MWW

(us) पldəa 


\subsubsection{Glacial Firn Ice}

Several lines of evidence suggest this ice body did not originate as glacier ice. If the ice originated as a snow bank or glacier and was later buried, one would expect the bubbles trapped in the ice to be of similar makeup to the atmosphere. The $\delta^{13} \mathrm{C}$ values in the gases trapped in the ice are approximately $10 \%$ more negative than that of the atmosphere, and the $\mathrm{CO}_{2}$ levels are between 10 and 100 times higher than is found in the atmosphere. The $\delta^{13} \mathrm{C}$ values and $\mathrm{CO}_{2}$ concentrations are within the range of soil gases. The trace levels of $\mathrm{N}_{2} \mathrm{O}$ found in two of the samples also indicate some biogenic activity.

The radiocarbon date at a depth of $11 \mathrm{~m}$ was younger than that at $7 \mathrm{~m}$. Only complex deformation (eg. recumbent folding or thrust faulting) can result in older glacier ice being emplaced above younger ice; however, there is no evidence of this kind of deformation.

\subsubsection{Basal glacier ice}

If the origin of this ice body was basal glacier ice one would expect the bulk chemical and isotopic composition to be similar to that of the glacier as there is limited interaction with the subglacial sediments during the thawing and refreezing processes of regelation at the bottom of a glacier. The $\mathrm{CO}_{2}, \mathrm{~N}_{2} \mathrm{O}$ and $\delta^{13} \mathrm{C}$ values indicate that soil gases dominate the gas content of the ice. As well, there is very little sediment found throughout most of the Peninsula Point ice mass, unlike the high sediment concentrations usually found in basal ice. 


\subsubsection{Single source segregated ice}

In single source segregated ice (eg. closed system pingos) one would expect the radiocarbon ages to be the same throughout or to consistently decrease with depth, and the $\mathrm{CO}_{2}$ levels and $\delta^{13} \mathrm{C}$ values to be uniform or change consistently through the ice body. The ${ }^{18} \mathrm{O},{ }^{13} \mathrm{C}, \mathrm{CO}_{2}$ and age profiles do not support a single source theory.

\subsubsection{Multiple source segregated ice}

The $\delta^{18} \mathrm{O}$ values indicate that in general, the water feeding the growth of the ice body originated in a cold climate (eg. glacial or seasonal snow pack melt water). However, the $\mathrm{CO}_{2},{ }^{13} \mathrm{C}$ and ${ }^{14} \mathrm{C}$ data indicate that the water was significantly altered during its travels through the subsurface. The $\mathrm{CO}_{2}$ concentrations vary considerably throughout the ice body. The $\delta^{13} \mathrm{C}$ values are much closer to those of soil than atmospheric gases indicating that the water may have originally come from a glacier, but the $\mathrm{CO}_{2}$ in it has a biogenic source. As well, the radiocarbon ages of the $\mathrm{CO}_{2}$ do not follow a consistent trend, indicating that when the ice body was forming it was fed by a number of distinct sources of different ages.

The detailed ${ }^{18} \mathrm{O}$ profile indicates the water source and freezing history varied considerably throughout the formation of the massive ice. The data from several sections of the core display continued shifts toward more negative values with depth. In some sections, this shift is similar to what would be expected during downward freezing of a small confined water lens, while in others the shift is much more rapid. The comparison of the details of this ${ }^{18} \mathrm{O}$ profile to others (Kato et. al., 1986; Mackay and Dallimore, 1992) indicates that considerable lateral variations in the composition of the ice body also exist. 


\subsubsection{Age of the massive ice}

As the radiocarbon ages determinations use the carbon in the $\mathrm{CO}_{2}$, the dates are dependent on the source of the $\mathrm{CO}_{2}$. The ${ }^{14} \mathrm{C}$ age of biogenic $\mathrm{CO}_{2}$ is related to when the $\mathrm{CO}_{2}$ was created in the biologically active near surface zone. As this must have occurred before the formation of the massive ice, radiocarbon ages represent maximum ages for the ice. Thus, the massive ice body at Peninsula Point must have an age less than 14,000 BP. As ground water in different locations can have different residence times, it is reasonable to expect water from different source areas to have unrelated ages, thus resulting in the erratic ages throughout the ice body.

\subsubsection{Massive ice development and glacial implications}

As Rampton (1988a,b) suggests, the most likely source of water and pressure that could result in the development of the Peninsula Point ice body is a nearby glacier producing large amounts of meltwater, some of which flows through an aquifer between relict and currently aggrading permafrost. Where the pore water pressure is greater than the effective overburden pressure, there is potential for uplift of the overburden and growth of massive ice.

The zone where there are the right pressure conditions for growing ice is likely to be relatively near to the glacier front as the hydraulic head, or porewater pressure, drops off as you move away from the source.

For Rampton's model of massive ice growth to work, it is suggested that the ice front would have to be considerably closer to Peninsula Point around 13,000 BP than has previously interpreted (Figure 6.1). 


\subsection{Conclusions}

The physical characteristics of the ice crystals, air bubbles and sediment inclusions in the core from Peninsula Point can be grouped into three zones; upper, middle and lower. The upper and lower having the greatest variability in bubble and crystal properties and greater numbers of sediment inclusions.

The oxygen isotopic profile through the ice body indicates that in general, the ice body growth was likely nourished by a glacial meltwater source. The isotope data also contains evidence of segregational freezing from a number of discrete water pulses.

The chemical and isotopic data from the gases trapped within the ice body support a segregation origin, with the $\mathrm{CO}_{2}$ content and $\delta^{13} \mathrm{C}$ ratio being considerably different than that expected in buried ice. The highly negative $\delta^{13} \mathrm{C}$ values indicate strong influences from biogenic sources along the water's travel path.

The variability of the ${ }^{14} \mathrm{C}$ ages suggest the source water likely came from a number of source areas or followed different flow paths over the time period that the ice body grew. 


\section{Chapter 7 Summary and Conclusions}

\subsection{Summary}

The purpose of this thesis was to examine the development and preservation of tabular massive ground ice and determine if techniques could be developed for determining the origin and the developmental history of the ice.

Two new techniques were applied to the study of massive ground ice; GPR and sublimation gas extraction and analysis. The GPR technique was developed and evaluated for delineating the size, shape and internal structure of surface and ground ice bodies. For the first time, it has been shown that subsurface details at the scale of englacial drainage channels can be mapped in three dimensions. With GPR, cross sections can be easily generated that clearly indicate the continuity of the glacier ice into the core of moraines.

The sublimation gas extraction and analysis technique was applied to ground ice for the first time during this research. The wealth of information that the technique provides enables the interpretation of complex histories of ice body development. With the more 
comprehensive data that can be acquired with this method, differentiation among different ice types was accomplished even when the traditional methods only produced controversy.

As well as the development of new techniques, the processes of ice burial, erosion and preservation were studied, and the characteristics of ice that are linked to its developmental history were identified. Finally these analyses and the knowledge of ice properties were used to interpret the origin and thus a portion of the Quaternary history, of several bodies of massive ice on Bylot Island and in the western Canadian Arctic.

\subsection{Conclusions}

The principal conclusions made with reference to the objectives of this thesis are:

1. Areas that are optimal for the burial and preservation of massive ice can be identified by employing satellite imagery, aerial photographs and through surface examination. Under permafrost conditions, glacier ice (including basal ice), covered by end or lateral moraines was found to have the greatest potential for preservation as this is the most stable environment in the proglacial setting.

2. GPR was found to be very effective for mapping the thickness and gross internal structure of glaciers and icings. A two person portable backpack GPR system was suitable for mapping ice thicknesses up to approximately $150 \mathrm{~m}$. When surveying these ice bodies, several metres of sub-ice structure could frequently be imaged as well. For the first time, a methodology for mapping the hydrological network within a glacier was demonstrated. Depending on the thickness of sediment cover and particle size of the cover, GPR could also effectively map the extent, depth and thickness of massive ground ice bodies. 
3. The application of the sublimation gas extraction and analysis technique was developed for ground ice analysis. This enabled the determination of the chemical and isotopic composition of ground ice gases, and the direct radiocarbon dating of the gases trapped within the ice. It is no longer necessary to rely on relative dating techniques for determining the age of ground ice. The ability to directly radiocarbon date buried "firn" ice will enable the construction of an ${ }^{18} \mathrm{O}$ record for many massive ground ice bodies (less than about 50000 years old). This has the potential to considerably increase the spatial distribution of the ${ }^{18} \mathrm{O}$ record, beyond that of the present ice caps.

4. By employing a suite of techniques, measurable differences can be observed between different ice types which allows glacier, basal, icing, and segregated massive ice to be differentiated. In the case of icing ice, its origin can be determined simply from its appearance. Basal ice and segregated ice are more complicated and require more measurements such as general structure, water and gas chemistry and isotopic composition. The $\mathrm{CO}_{2}$ concentration and ${ }^{13} \mathrm{C}$ composition of the gas were found to be especially useful in determining the origin and freezing history of the ice.

5. Of the massive ground ice examined, all of it had either a segregated or buried basal ice origin. Both contain a certain amount of paleoclimatic information. However, it is hypothesized that buried glacial ice would provide a better paleoclimatic signature. 


\subsection{Recommendations for Further Research}

The development and application of the two new techniques in the process of carrying out this research has dramatically increased our ability to study massive ground ice. As such there are several key areas that should be further investigated.

1. Following up on this work and that of Robinson et al. (1992), a comprehensive GPR survey of massive ground ice bodies should be undertaken to further investigate the relationship between ice body structure and origin.

2. Now that the ${ }^{18} \mathrm{O}$ signature of any ground ice body can be directly related to the time scale, the spatial variability of precipitation over time should be analyzed throughout the Arctic. This may provide some important insights into the spatial variability of climate change. To date, most of the high resolution climatic data have come from just a few points in Antarctica, Greenland, and a couple of ice caps in the Canadian Arctic.

3. A more detailed study of the age and origin of massive ice in the western Canadian Arctic may greatly assist in the reconstruction of the glacial history of the area. Until now, working out the exact chronology and events has been complicated by the setting. With the ability to determine the origin and age of massive ground ice bodies, reconstructing the glacial history of the area should be a much easier task.

4. The search for buried glacier ice should continue to determine if further paleoclimatic information can be extracted. 


\section{References}

AES, 1980. Canadian Climate Normals (1951-1980). Atmospheric Environment Service, Environment Canada, Downsview.

Akerman, J., 1982. Studies on naled (icings) in West Spitsbergen. Fourth Canadian Permafrost Conference., pp. 189-202.

Andree, M., J. Beer, H.P. Loetscher, E. Moor, H. Oescher, G. Bonani, H.J. Hofmann, E. Morenzoni, M. Nessi, M. Suter and W. Wölfli, 1986. Dating polar ice by ${ }^{14} \mathrm{C}$ accelerator mass spectrometry. Radiocarbon, vol. 28, pp. 417-423.

Andree, M., E. Moor, J. Beer, H. Oeschger, B. Staufer, G. Bonani, H.J. Hofmann, E. Morenzoni, M. Nessi, M. Suter and W. Wölfli, 1984. ${ }^{14} \mathrm{C}$ dating of polar ice. Nuclear Instruments and Methods in Physics Research, vol. B5, pp. 385-388.

Annan, A.P. and L.T. Chu, 1992. Ground penetrating radar performance predictions. Ground Penetrating Radar.Geological Survey of Canada Paper 90-4, pp. 514.

Annan, A.P., J.L. Davis and W.J. Scott, 1975. Impulse radar profiling in permafrost. Geological Survey of Canada Report of Activities, Geological Survey of Canada Paper 75-1C, pp. 343-351.

Arcone, S.A., D.E. Lawson and A.J. Delaney, 1995. Short-pulse radar wavelet recovery and resolution of dielectric contrasts within englacial and basal ice of Matanuska Glacier, Alaska, U.S.A. Journal of Glaciology, vol. 41, pp. 68-86.

Arkhangelov, A.A. and E.V. Novgorodova, 1991. Genesis of massive ice at 'Ice Mountain', Yenesei River, Western Siberia, according to results of gas analysis. Permafrost and Periglacial Processes, vol. 2, pp. 167-170.

Astakhov, V.I. and L.L. Isayeva, 1988. The 'Ice Hill': An example of 'retarded glaciation' in Siberia. Quaternary Science Reviews, vol. 7, pp. 29-40.

Bentley, C.R., J.W. Clough, K.C. Jezek and S. Shabtaie, 1979. Ice thickness patterns and the dynamics of the Ross Ice Shelf, Antarctica. Journal of Glaciology, vol. 24, pp. 287-294.

Björnsson, H., Y. Gjessing, S.-E. Hamran, J.O. Hagen, O. Liestel, F. Pálsson and B. Erlingsson, 1996. The thermal regime of sub-polar glaciers mapped by multi-frequency radio-echo sounding. Journal of Glaciology, vol. 42, pp. 23-32.

Boulton, G.S., 1967. The development of a complex supraglacial moraine at the margin of Sørbreen, Ny Friesland, Vestspitsbergen. Journal of Glaciology, vol. 6, pp. 717-735.

Boulton, G.S., 1970. On the origin and transport of englacial debris in Svalbard glaciers. Journal of Glaciology, vol. 9, pp. 213-229. 
Boutton, T.W., 1991. Stable carbon isotope ratios of natural materials: II. Atmospheric, terrestrial, marine, and freshwater environments', In Coleman, D.C. and B. Fry (eds.), Carbon Isotope Techniques. Academic Press, Toronto, pp. 173 185.

Brady, N.C. and Weil, R.R., 1996. The nature and property of soils. Prentice-Hall, New York, $740 \mathrm{p}$.

Campbell, K.J. and A.S. Orange, 1974. A continuous profile of sea ice, lake ice and permafrost using an impulse radar. Polar Record, vol. 17, pp. 31-41.

Cheng, K., P. Tung and H. Lo, 1978. Experimental research on an embankment in an area with massive ground ice at the lower limit of alpine permafrost. Third International Conference on Permafrost, Edmonton, Alberta, National Research Council of Canada, Ottawa, pp. 199-222.

Chinn, T.J.H. and Dillon, A., 1987. Observations on a debris-covered polar glacier "Whisky Glacier", James Ross Island, Antarctic Peninsula, Antarctica. Journal of Glaciology, vol. 33, pp. 300-310.

Coachman, L.K., Enns T. and Scholander, P.F., 1958. Gas loss from a temperate glacier, Tellus, vol. 10, pp. 493-495.

Dallimore, S.R. and J.L. Davis, 1992. Ground penetrating radar investigations of massive ground ice. Ground Penetrating Radar. in Pilon, J.A. (ed.), Ottawa, Geological Survey of Canada Paper 90-4. pp. 41-48.

Dallimore, S.R. and S.A. Wolfe, 1988. Massive ground ice associated with glaciofluvial sediments, Richards Island, N.W.T., Canada. Fifth International Conference on Permafrost, Trondheim, Norway, Tapir Publishers, pp. 132-137.

Davis, J.L., J.S. Halliday and K.J. Miller, 1973. Radio echo sounding on a valley glacier in east Greenland. Journal of Glaciology, vol. 12, pp. 87-91.

Elver, M.S., 1994. The stratigraphic and isotopic characteristics of an Arctic icing, Bylot Island, N.W.T. M.Sc. thesis, Carleton University, Ottawa, 160 p.

French, H.M., 1976. The Periglacial Environment. Longman Group, London, 309 p.

French, H.M. and D.G. Harry, 1988. Nature and origin of ground ice, Sandhills Moraine, southwest Banks Island, Western Canadian Arctic. Journal of Quaternary Science, vol. 3, pp. 19-30.

French, H.M., and D.G. Harry, 1990. Observations on buried glacier ice and massive segregated ice, western Arctic Coast, Canada. Permafrost and Periglacial Processes, vol. 1, pp. 31-43.

French, H.M. and W.H. Pollard, 1986. Ground-ice investigations, Klondike District, Yukon Territory. Canadian Journal of Earth Sciences, vol. 23, pp. 550560 . 
Fujino, K. (ed.), 1986. Characteristics of the massive ground ice body in the western Canadian arctic related to paleoclimatology 1984-1985. The Institute of Low Temperature Science, Hokkaido University, Sapporo. 91 p.

Fujino, K., K. Horiguchi, M. Shinbori, and K. Kato, 1983. Analysis and characteristics of cores from a massive ice body in Mackenzie Delta, N.W.T., Canada. Fourth International Conference on Permafrost, National Academy Press, Washington, D.C., pp. 316-321.

Fujino, K., S. Sato, K. Matsuda, G. Sasa, O. Shimizu and K. Kato, 1988. Characteristics of the massive ground ice body in the western Canadian Arctic (II). Fifth International Conference on Permafrost, Trondheim, Norway, Tapir Publishers, pp. 143-147.

Gell, W.A., 1978. Thermal contraction cracks in massive segregated ice, Tuktoyaktuk Peninsula, N.W.T., Canada. Third International Conference on Permafrost, Edmonton, Alberta, National Research Council of Canada, Ottawa, pp. 278-281.

Goldthwait, R.P., 1951. Development of end moraines in east-central Baffin Island. Journal of Geology, vol. 59, pp. 567-577.

Goodwin, I.D., 1993. Basal ice accretion and debris entrainment within the coastal ice margin, Law dome, Antarctica. Journal of Glaciology, vol. 39, pp. 157166.

Gorelik, Y. and V. Kolunin, 1993. Mechanisms of layer structures growing during ground freezing. Sixth International Conference on Permafrost, South China University of Technology Press, Beijing China, pp. 879-884.

Gow, A.J., S. Epstein, and W. Sheehy, 1979. On the origin of stratified debris in ice cores from the bottom of the Antarctic ice sheet. Journal of Glaciology, vol. 23, pp. 185-192.

Haley, D., 1991. personal communication, Extensive distribution of massive ground ice in Russia. Hardy BBT Ltd., Calgary Alberta

Hambrey, M.J., 1984. Sedimentary processes and buried ice phenomina in the pro-glacial areas of Spitsbergen glaciers. Journal of Glaciology, vol. 30, pp. 116119.

Harry, D.G., H.M. French and W.H. Pollard, 1988. Massive ground ice and ice-cored terrain near Sabine Point, Yukon Costal Plain. Canadian Journal of Earth Sciences, vol. 25, pp. 1846-1856.

Herron, S. and C.C. Langway, 1979. The debris-laden ice at the bottom of the Greenland ice sheet. Journal of Glaciology, vol. 23, pp. 193-207.

Horiguchi, K., 1988. Electrical conductivity of an ice core obtained from massive ground ice. Fifth International Conference on Permafrost, Trondheim, Norway, Tapir Publishers, pp. 377-380.

Hubbard, B. and M. Sharp, 1989. Basal ice formation and deformation: a review. Progress in Physical Geography, vol. 13, pp. 529-558. 
Inland Waters Branch, 1969. Glacier Atlas of Canada: Bylot Island Glacier Inventory Area 46201. Department of Energy, Mines and Resources, Ottawa.

Jol, H.M. and D.G. Smith, 1992. Geometry and structure of deltas in large lakes: a ground penetrating radar overview. Fourth International Conference on Ground Penetrating Radar, Rovaniemi, Finland, Geological Survey of Finland, pp. 159-168.

Kato, K., K.Fujino, and K. Horiguchi, 1986a. Oxygen isotope profile in a massive ice body in Mackenzie Delta, N.W.T., Canada: preliminary report. In Fujino, K. (ed.), Characteristics of the Massive Ground Ice Body in the Western Canadian Arctic Related to Paleoclimatology 1984-1985, The Institute of Low Temperature Science, Hokkaido University, Sapporo, pp. 46-56.

Kato, K., K. Fujino, K. Horiguchi and S. Sato, 1986b. Profiles of chemical compositions in a core from a massive ice body in Mackenzie Delta, N.W.T., Canada: preliminary report. In Fujino, K. (ed.), Characteristics of the Massive Ground Ice Body in the Western Canadian Arctic Related to Paleoclimatology 1984-1985. Sapporo, The Institute of Low Temperature Science, Hokkaido University. pp. 57-70.

Kato, K., S. Sato and K. Fujino, 1988. Radiocarbon dating by accelerator mass spectrometry on sediment in a core from a massive ice body in Mackenzie Delta, N.W. T., Canada'. In Fujino, K. (ed.), Characteristics of the massive ground ice body in the western Canadian Arctic related to paleoclimatology, Institute of Low Temperature Science, Hokkaido University, Sapporo, Japan, pp. 58-69.

Klassen, R.A., 1993. Quaternary geology and glacial history of Bylot Island, Northwest Territories. Geological Survey of Canada Memoir, 429, Department of Energy, Mines and Resources, Ottawa. 93 p.

Klassen, R.A., 1982. Glaciotectonic thrust plates, Bylot Island, District of Franklin. Geological Survey of Canada Current Research, 82-1A, 369-373 p.

Koerner, R.M., 1977. Devon Island ice cap: core stratigraphy and paleoclimate. Science, vol. 196, pp. 15-18.

Kovacs, A. and R.M. Morey, 1985. Electromagnetic measurements of multi-year sea ice using impulse radar. CRREL Report 85-13, U.S. Army Cold Regions Research and Engineering Laboratory, 26 p.

Kovacs, A. and R.M. Morey, 1992. Estimating sea ice thickness from impulse radar sounding time of flight data. Ground Penetrating Radar. in Pilon, J.A. (ed.), Ottawa, Geological Survey of Canada Paper 90-4. pp. 117-124.

Kovacs, A., A.J. Gow, \& R.M. Morey, 1995. The in-situ dielectric constant of polar firn revisited. Cold Regions Science and Technology, vol. 23, pp. 245-256.

Lorrain, R.D. and P. Demeur, 1985. Isotopic evidence for relic Pleistocene glacier ice on Victoria Island, Canadian Arctic Archipelago. Arctic and Alpine Research, vol. 17, pp. 89-98. 
Mackay, J.R., 1966. Segregated epigenetic ice and slumps in permafrost, Mackenzie Delta area, N.W.T. Geographical Bulletin, vol. 8, pp. 59-80.

Mackay, J.R., 1971. The origin of massive icey beds in permafrost, western Arctic Coast, Canada. Canadian Journal of Earth Sciences, vol. 8, pp. 397-422.

Mackay, J.R., 1972. The world of underground ice. Annals, Association of American Geographers, vol. 62, pp. 1-22.

Mackay, J.R., 1973. Problems in the origin of massive icy beds, western Arctic, Canada. Second International Conference on Permafrost, North American Contribution, National Academy of Sciences, Washington, D.C., Yakutsk, U.S.S.R., pp. 223-228.

Mackay, J.R., 1979. Pingos of the Tuktoyaktuk Peninsula area, N.W.T. Geographie Physique et Quaternaire, vol. 33, pp. 3-61.

Mackay, J.R., 1989. Massive ice: some field criteria for the identification of ice types, Current Research Part G, Geological Survey of Canada Paper. 88-1G, pp. 5-11.

Mackay, J.R. and R.F. Black, 1973. Origin, composition and structure of perennially frozen ground and ground ice: a review. Second International Conference on Permafrost, Yakutsk, U.S.S.R., National Academy of Sciences, Washington, D.C., pp. 185-192.

Mackay, J.R. and S.R. Dallimore, 1992. Massive ice of the Tuktoyaktuk area western Arctic coast, Canada. Canadian Journal of Earth Sciences, vol. 29, pp. 1235-1249.

Martinerie, P., D. Raynaud, D.M. Etheridge, J.-M. Barnola, and D. Mazaudier, 1992. Physical and climatic parameters which influence the air content in polar ice. Earth and Planetary Science Letters, vol. 112, 1-13.

McCuaig, S., 1994. Glacial Chronology of the South Bylot and Salmon River Lowlands, N.W.T., using Erratic dispersial patterns, cosmodenic dating, radiocarbon dating and lichenometery. M.Sc. thesis, Carleton University, Ottawa, 140 p.

Michel, F.A., 1982. Isotope investigations of permafrost waters in northern Canada, Ph.D. thesis, University of Waterloo, Waterloo, Ontario, 424 p.

Michel, F.A., 1983. Isotope variations in permafrost waters along the Dempster Highway pipeline corridor. Fourth International Conference on Permafrost, Fairbanks, Alaska, National Academy Press, Washington, D.C., pp. 843848.

Michel, F.A., 1985. Nature and history of ground ice in the Yukon. Contract report to Energy, Mines, and Resources Canada, Ottawa., pp. 126.

Michel, F.A., 1986. Isotope geochemistry of frost-blister ice, North Fork Pass, Yukon, Canada. Canadian Journal of Earth Sciences, vol. 23, pp. 543-549. 
Mook, W.G., 1986. ${ }^{13} \mathrm{C}$ in atmospheric $\mathrm{CO}_{2}$, Netherlands Journal of Sea Research, vol. 20, pp. $211-223$.

Mook, W.G., M. Koopmans, A.F. Carter and C.D. Keeling, 1983. Seasonal, latitudinal, and secular variations in the abundance of isotopic ratios of atmospheric carbon dioxide. 1. Results from land stations. Journal of Geophysical Research, vol. 88, pp. 10915-10933.

Moorman, B.J., 1990. Assessing the ability of ground penetrating radar to delineate subsurface fluvial lithofacies. Unpublished M.Sc. thesis, Department of Geography, University of Calgary, Calgary, Alberta, 124 p.

Moorman, B.J., 1996. Unique GPR applications: Glaciology. Ekko Update, October 1996, Sensors and Software, pp. 1-2.

Moorman, B.J. and A.S. Judge, 1989. Delineating massive ice with ground penetrating radar. GAC/MAC Joint Annual Meeting, 15-17 May 1989, Montréal, Quebec, Geological Association of Canada and Mineralogical Association of Canada, pp. A76.

Moorman, B.J., A.S. Judge, M.M. Burgess and T.W. Fridel, 1994. Geotechnical investigations of insulated permafrost slopes along the Norman Wells pipeline using ground penetrating radar. GPR '94: Fifth International Conference on Ground Penetrating Radar, Kitchener, Ontario, Waterloo Centre for Groundwater Research, University of Waterloo, pp. 477-491.

Moorman, B.J., A.S. Judge and D.G. Smith, 1991. Examining fluvial sediments using ground penetrating radar in British Columbia. Current Research Part $A$, Geological Survey of Canada Paper 91-1A, pp. 31-36.

Moorman, B.J. and F.A. Michel, 1997. Bathymetric mapping and sub-bottom profiling through lake ice with ground-penetrating radar. Journal of Paleolimnology, vol. 18, pp. 61-73.

Moorman, B.J., F.A. Michel, and R.J. Drimmie, 1996a. Isotopic variability in Arctic precipitation as a climatic indicator. Geoscience Canada, vol. 23, 189194.

Moorman, B.J., F.A. Michel, and A. Wilson, 1996b. ${ }^{14} \mathrm{C}$ dating of trapped gases in massive ground ice, western Canadian Arctic. Permafrost and Periglacial Processes, vol. 7, pp. 257-266.

Nakawo, M., 1979. Supraglacial debris of G2 Glacier in Hidden Valley, Mukut Himal, Nepal. Journal of Glaciology, vol. 22, pp. 273-283.

Oeschger, H., B. Alder, and C.C. Langway, 1967. An in situ gas-extraction system to radiocarbon date glacier ice. Journal of Glaciology, vol. 6, pp. 939-942.

Oeschger, H., B. Stauffer, A. Neftel, J. Schwander and R. Zumbrunn, 1982. Atmospheric $\mathrm{CO}_{2}$ content in the past deduced from ice-core analysis. Annals of Glaciology, vol. 3, pp. 229-232. 
Paterson, W.S.B., R.M. Koerner, D. Fisher, S.J. Johnsen, H.B. Clausen, W. Dansgaard, P. Bucher, and H. Oeschger, 1977. An oxygen isotope climatic record from the Devon Island Ice Cap, Arctic Canada. Nature, vol. 266, pp. 508-511.

Paterson, W.S.B., 1994. The Physics of Glaciers. Pergamon, New York. 480 p.

Permafrost Subcommittee, 1988. Glossary of permafrost and related ground-ice terms. Associate Committee on Geotechnical Research, National Research Council of Canada, Ottawa, $156 \mathrm{p}$.

Pollard, W.H., 1990. The nature and origin of ground ice in the Herschel Island area, Yukon Territory, Canada. Fifth Canadian Permafrost Conference, Université Laval, Quebec City, pp. 23-30.

Pollard, W.H. and S.R. Dallimore, 1988. Petrographic characteristics of massive ground ice, Yukon Coastal Plain, Canada. Fifth International Conference on Permafrost, Trondheim, Norway, Tapir Publishers, pp. 224-229.

Popov, A.I., 1962. The Origin and Development of Massive Fossil Ice. Academy of Sciences of the USSR, V.A. Obruchev Institute of Permafrost Studies, Moscow. National Research Council of Canada, Technical Translation 1006, vol. 11, pp. 5-24.

Popov, A.I., 1970. Underground ice of northern Eurasia. Acta Geographica Lodziensia, vol. 24, pp. 365-370.

Rains, R.B. and J. Shaw, 1981. Some mechanisms of controlled moraine development, Antarctica. Journal of Glaciology, vol. 27, pp. 113-128.

Rampton, V.N., 1982. Quaternary geology of the Yukon Coastal Plain, Canada. Geological Survey of Canada Bulletin 317, Geological Survey of Canada, $42 \mathrm{p}$.

Rampton, V.N., 1988a. Origin of massive ground ice on Tuktoyaktuk Peninsula, Northwest Territories, Canada: a review of stratigraphic and geomorphic evidence. Fifth International Conference on Permafrost, Tapir Publishers, Trondheim, Norway, pp. 850-855.

Rampton, V.N., 1988b. Quaternary geology of the Tuktoyaktuk coastlands, Northwest Territories. Geological Survey of Canada Memoir, 423, Geological Survey of Canada, $98 \mathrm{pp}$.

Raynaud, D., R. Delmas, J.M. Ascencio and M. Legrand, 1982. Gas extraction from polar ice cores: a critical issue for studying the evolution of atmospheric $\mathrm{CO}_{2}$ and ice-sheet surface elevation. Annals of Glaciology, vol. 3, pp. 265-268.

Robin, G.de.Q., E. Evans and J.T. Bailey, 1969. Interpretation of radio echo sounding in polar ice sheets. Philosophical Transactions of the Royal Society of London Ser. A, vol. 265, pp. 437-505. 
Robinson, S.D., 1991. Ground penetrating radar studies, North Head, Richards Island, Northwest Territories. Unpublished B.E.S., Department of Geography, University of Waterloo, Waterloo, Ontario, 89 p.

Robinson, S.D., 1993. Geophysical and Geomorphological investigations of massive ground ice on the Froshiem Penninsula, Ellesmere Island. Unpublished M.Sc. Thesis, Queen's University, Kingston, Ontario, 171p.

Robinson, S.D., B. J. Moorman, A.S. Judge, S.R. Dallimore, and J.W. Shimeld, 1992. The application of radar stratigraphic techniques to the investigation of massive ground ice at Yaya Lake, Northwest Territories. Muscox, vol. 39, pp. 39-49.

Robinson, S.D., B.J. Moorman, A.S. Judge, and S.R. Dallimore, 1993. The characterization of massive ground ice at Yaya Lake, N.W.T. using radar stratigraphy techniques, Current Research 93-1B. Geological Survey of Canada, pp. 23-32.

Schohl, G.A. and R. Ettema, 1990. Two-dimensional spreading and thickening of aufeis. Journal of Glaciology, vol. 36, pp.

Scholander, P.F., W. Dansgaard, D.C. Nutt, H.D. Vries, L.K. Coachman, and E. Hemmingsen, 1962. Radio carbon age and oxygen-18 content of Greenland icebergs. Meddelelser on Grømland, vol. 165, pp. 1-26.

Scott, W.J., P.V. Sellmann and J.A. Hunter, 1978. Geophysics in the study of permafrost. Third International Conference on Permafrost, Edmonton, Alberta, National Research Council of Canada, Ottawa, pp. 93-115.

Sharp, M., J. Jouzel, B. Hubbard and W. Lawson, 1994. The character, structure and origin of the basal ice layer of a surge-type glacier. Journal of Glaciology, vol. 40, pp. $327-340$.

Sharp, R.P., 1949. Studies of superglacial debris on valley glaciers. American Journal of Science, vol. 247, pp. 289-315.

Smith, N. and R. Berg, 1973. Encountering massive ground ice during road construction in central Alaska. Second International Conference on Permafrost, Yakutsk, U.S.S.R., National Academy of Sciences, Washington, D.C., pp. 730736.

Soloviev, P.A., 1973. Thermokarst phenomena and landforms due to frost heaving in Central Yakutia. Biuletyn Peryglacjalny, vol. 23, pp. 135-155.

Souchez, R.A., 1967. The formation of shear moraines: an example from south Victoria Land, Antarctica. Journal of Glaciology, vol. 6, pp. 837-843.

Souchez, R.A., 1971. Ice-cored moraines in south-western Ellesmere Island, N.W.T., Canada. Journal of Glaciology, vol. 10, pp. 245-54.

Souchez, R.A. and J. Jouzel, 1984. On the isotopic composition in $\delta \mathrm{D}$ and $\delta^{18} \mathrm{O}$ of water and ice during freezing. Journal of Glaciology, vol. 30, pp. 369-372. 
Souchez, R.A. and R.D. Lorrain, 1978. Origin of the basal ice layer from Alpine glaciers indicated by its chemistry. Journal of Glaciology, vol. 20, pp. 319-328.

Souchez, R.A., R. Lorrain, J.-L. Tison, and J. Jouzel, 1988. Co-isotopic signature of two mechanisms of basal-ice formation in Arctic outlet glaciers. Annals of Glaciology, vol. 10, pp. 163-166.

Taber, S., 1929. Frost heaving. Geology, vol. 37, pp. 428-461.

Telford, W.M., L.P. Geldart, R.E. Sheriff and D.A. Keys, 1976. Applied Geophysics. Cambridge University Press, Cambridge. 455 p.

Tison, J., J. Petit, J. Barnola and W.C. Mahaney, 1993. Debris entrainment at the icebedrock interface in sub-freezing temperature conditions (Terre Adélie, Antarctica). Journal of Glaciology, vol. 39, pp. 303-315.

Vaikmäe, R., F.A. Michel, \& V.I. Solomatin, 1993. Morphology, stratigraphy and oxygen-isotope composition of fossil glacier ice at ledyanaya gora, northwest Siberia, Russia. Boreas, vol. 22, pp. 205 - 213.

van de Wal, R.S., K. Borg, H. Oeter, N. Reeh, A. Jong and J. Oerlemans, 1990. Progress in ${ }^{14} \mathrm{C}$ dating of ice at Utrecht. Nuclear Instruments and Methods in Physics Research, vol. B52, pp. 469-472.

van Everdingen, R.O., 1982. Frost blisters of the Bear Rock Spring area near Fort Norman, N.W.T. Arctic, vol. 35, pp. 243-265.

Ward, W. H., 1952. The glaciological studies of the Baffin Island Expedition, 1950. Part II. the Physics of glaciation in central Baffin Island. Journal of Glaciaology, vol. 2, pp. 33-38.

Weber, J.R. and P. Andrieux, 1970. Radar soundings on the Penny Ice Cap, Baffin Island. Journal of Glaciology, vol. 9, pp. 49-54.

Weertman, J., 1957. On the sliding of Glaciers. Journal of Glaciology, vol. 3, pp. 3338.

Weertman, J., 1961. Mechanism for the formation of inner moraines found near the edge of cold ice caps and ice sheets. Journal of Glaciology, vol. 3, pp. 965978.

Whalley, W.B., 1983. Rock glaciers-permafrost features or glacial relics? Fourth International Conference on Permafrost, National Academy Press, Washington, D.C., Fairbanks, Alaska. pp. 1396-1401.

Wilson, A.T. and D.J. Donahue, 1990. AMS carbon-14 dating of ice: progress and future prospects. Nuclear Instruments and Materials in Physics Research, vol. B52, pp. 473-476.

Wilson, A.T. and D.J. Donahue, 1992. AMS radiocarbon dating of ice: Validity of the technique and the problem of cosmogenic in situ production in polar ice cores. Radiocarbon, vol. 34, pp. 431-435. 
Yao, T. D., J. R. Petit, J. Jouzel, C. Lorius, and P. Duval, 1990. Climatic record from an ice margin area in East Antarctica. Annals of Glaciology, vol. 14, pp. 323-327.

Zdanowicz, C.M., 1994. A sedimentological and glaciological study of basal debris entrainment and transport in polar glaciers or southwest Bylot Island, N.W.T. M.Sc. Thesis, Carleton University, Ottawa, 225 p.

Zdanowicz, C.M., F.A. Michel, and W.W. Shilts, 1996. Basal debris entrainment and transport in glaciers of southwestern Bylot Island, Canadian Arctic. Annals of Glaciology, vol. 22, pp. 107-113. 


\section{Appendix A:}

Ice cored delta GPR profiles 


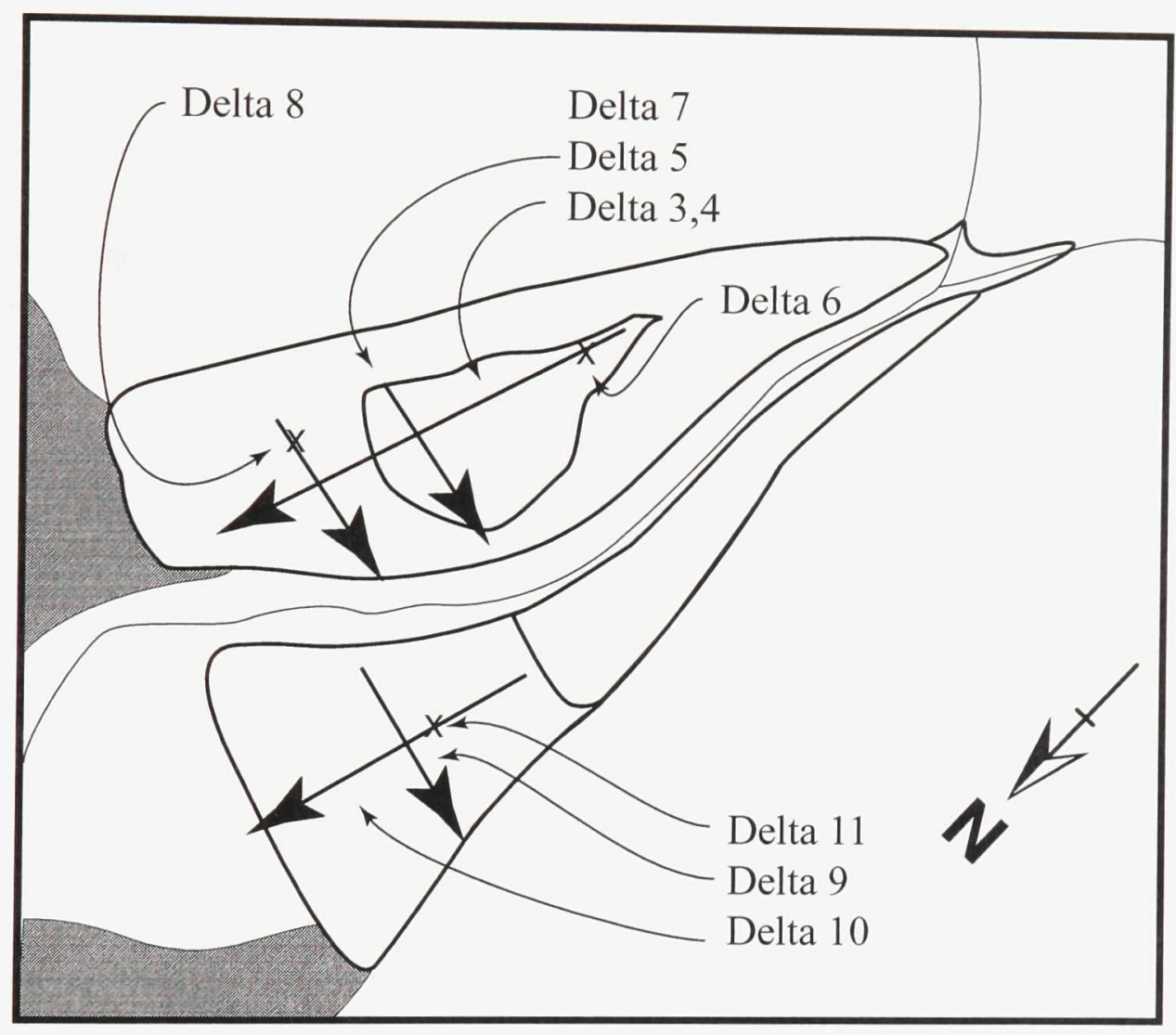

GPR profile locations. Arrows indicate direction of profile. Numbers indicate the file number. Velocity profile mid points are indicated by an " $x$ ". Some files may also end with the letter "a" indicating some modifications have been made (eg. polarity reversal or trace deletion). 


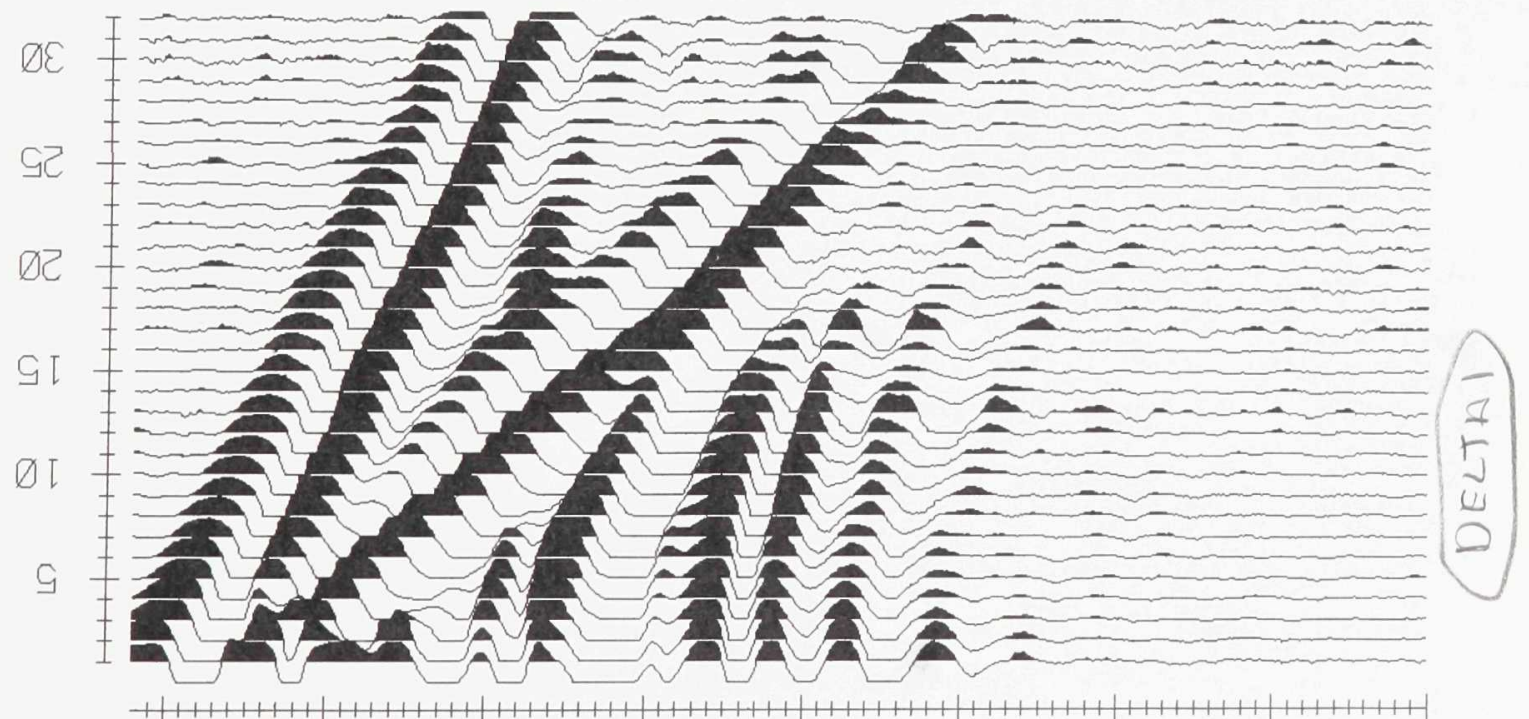

$\varnothing$

Q $\quad Q \quad \square$

$\mathbb{Q}$

Q

त

ए) 


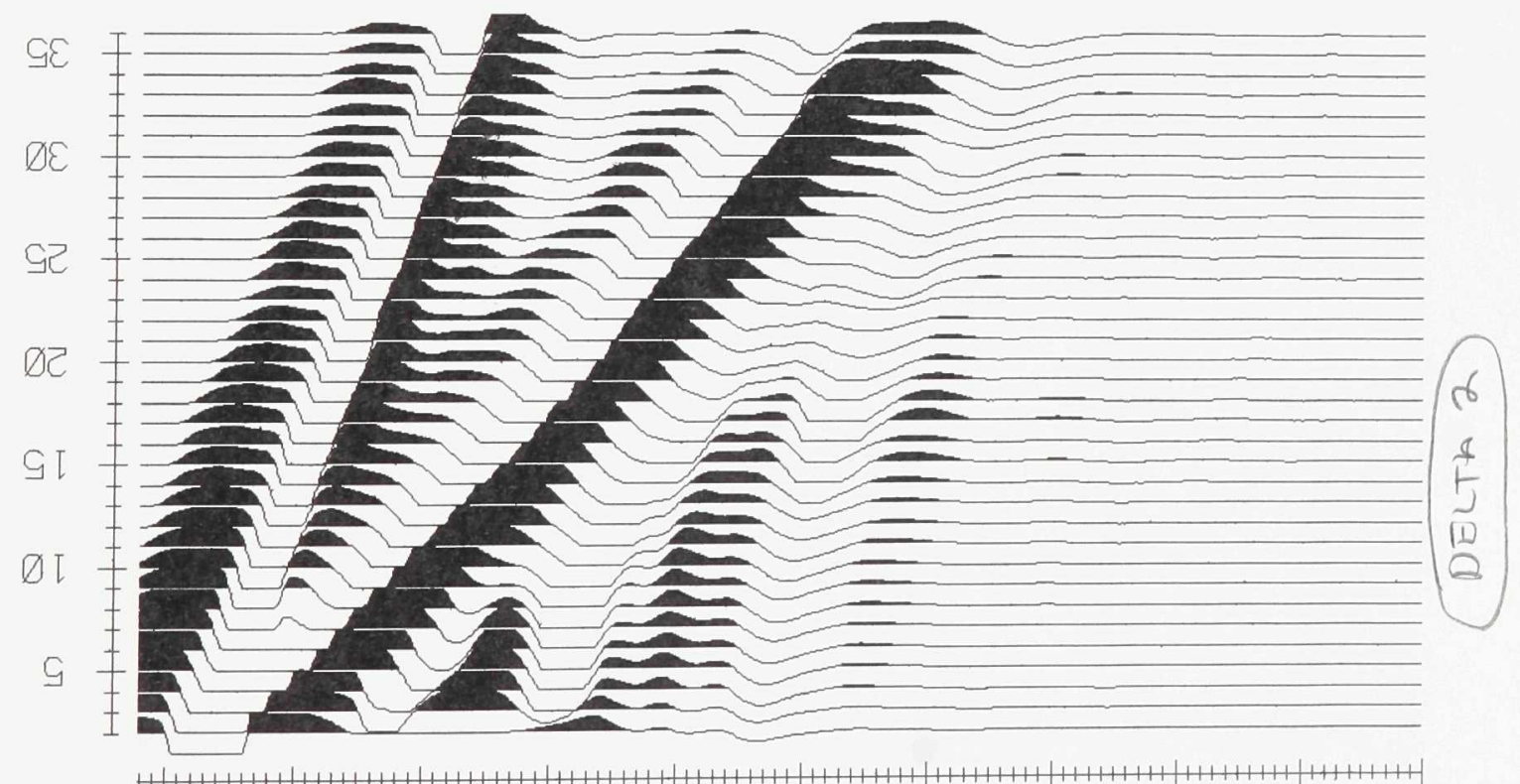

H11111111111111111111111111111111111+1111111111111111111111111111111111111111111111111111
Q Q $\quad$ Q
Q एिं एि
Q
लि बे
$\frac{\pi}{\square} \quad$ की
(SU) Diid $T \perp$ 


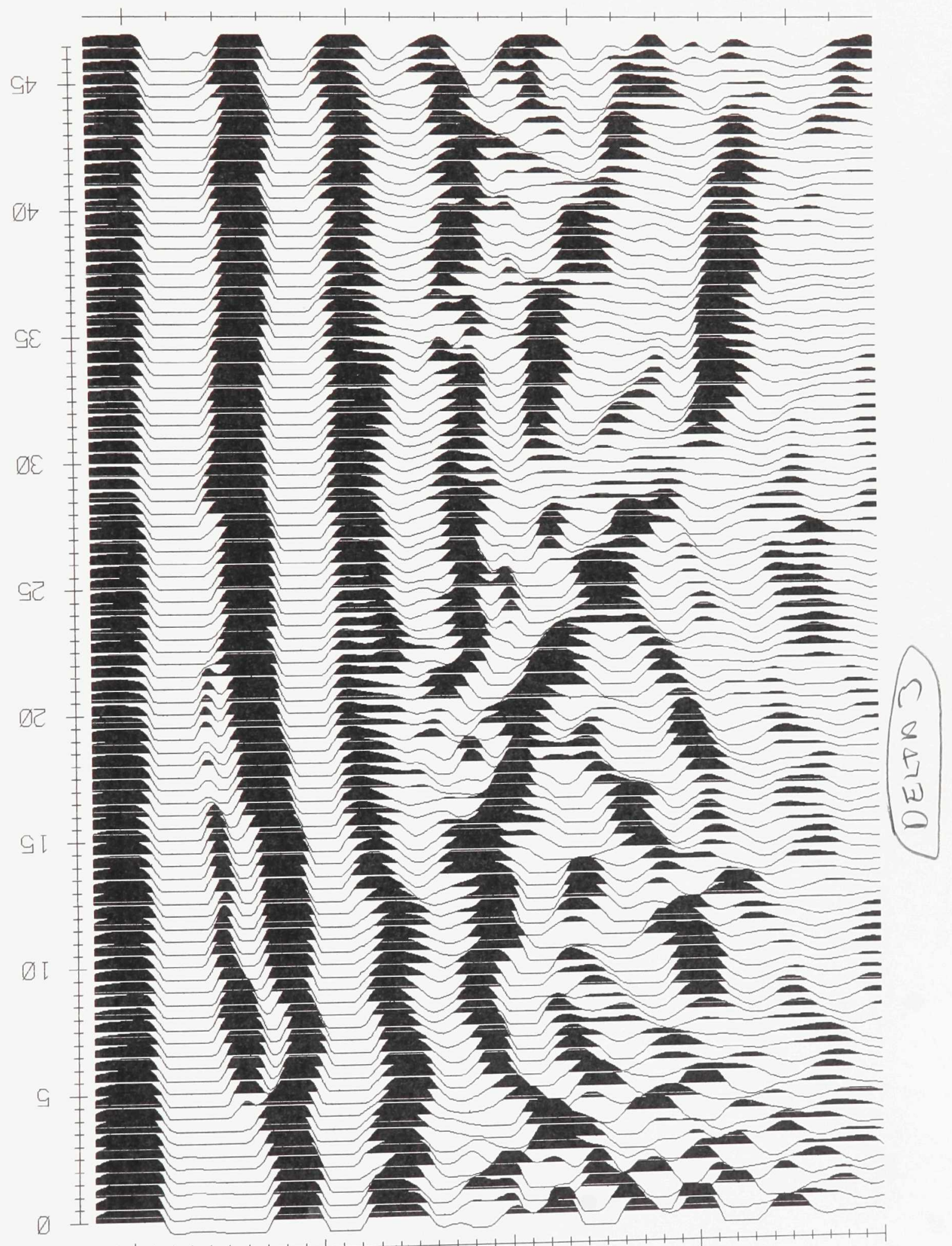


$Q$

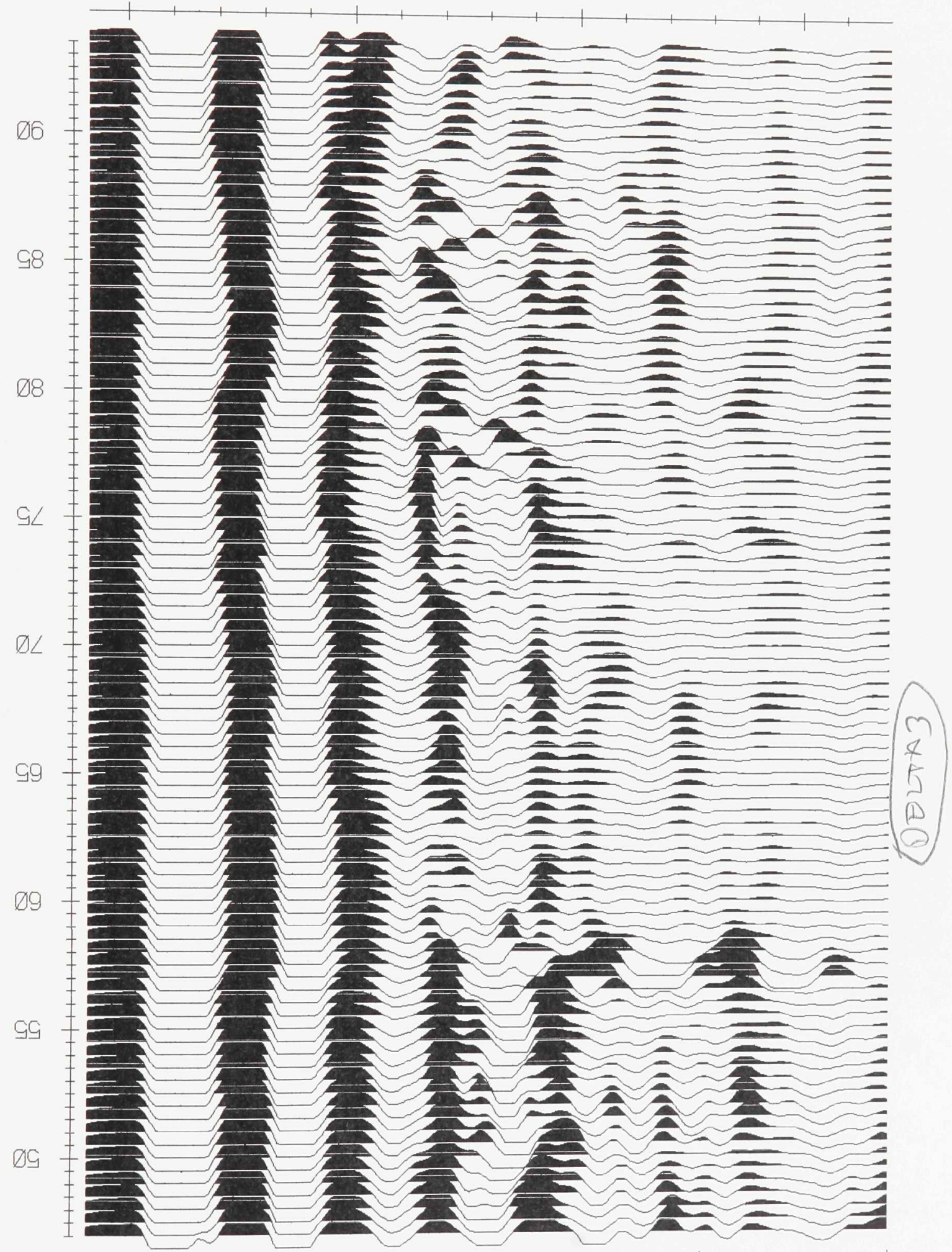

Q

$\mathbb{Q}$

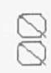

Q

$Q$ 
su/w $\varnothing \angle I D D=\wedge$ (w) $47 d \partial \square$

$Q$

เ)

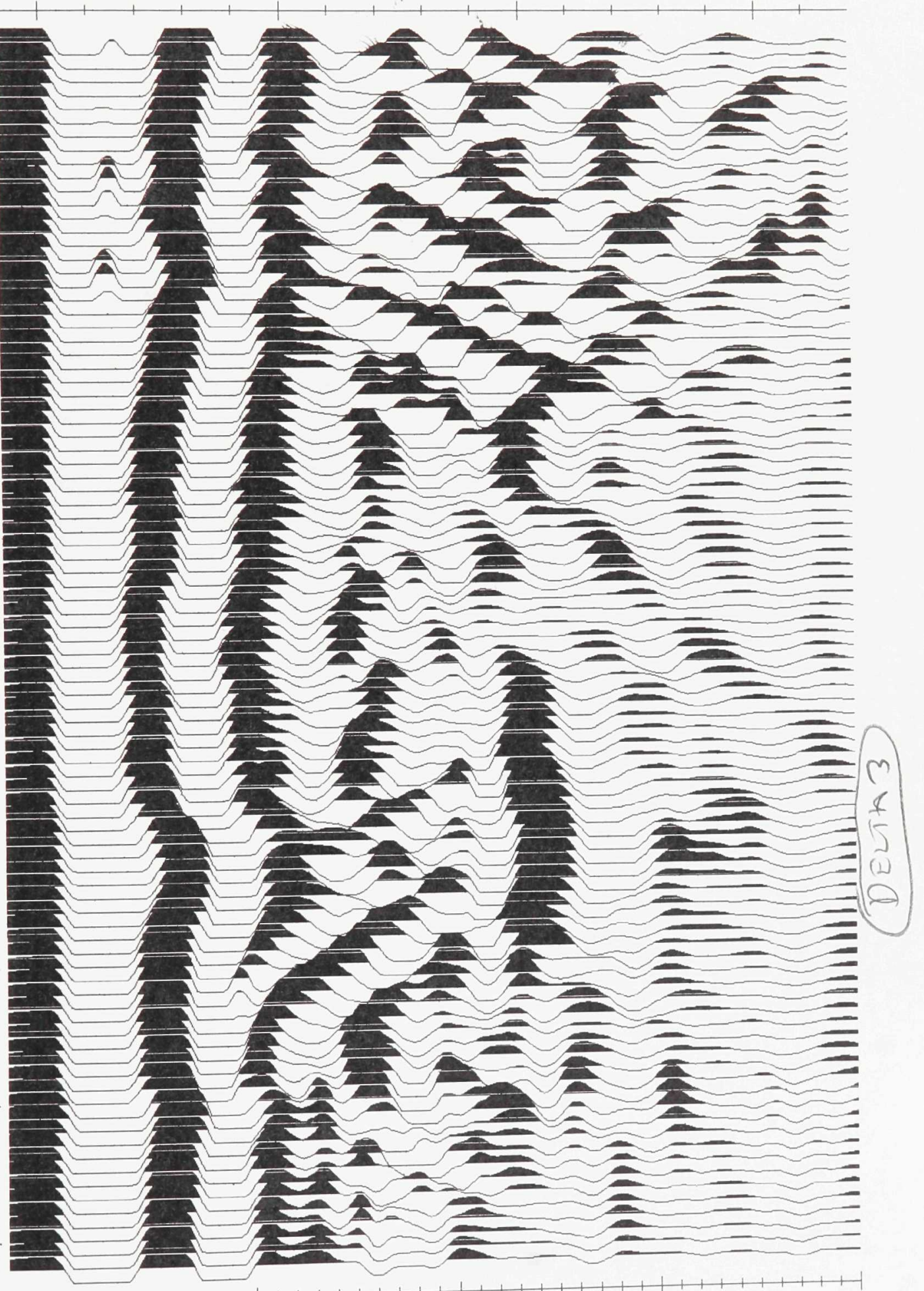

$Q$

(1)

$Q$

ถ 
su/m $\varnothing \angle[\square=\wedge$ (M) $47 d \partial \square$

$Q$

$Q$

10

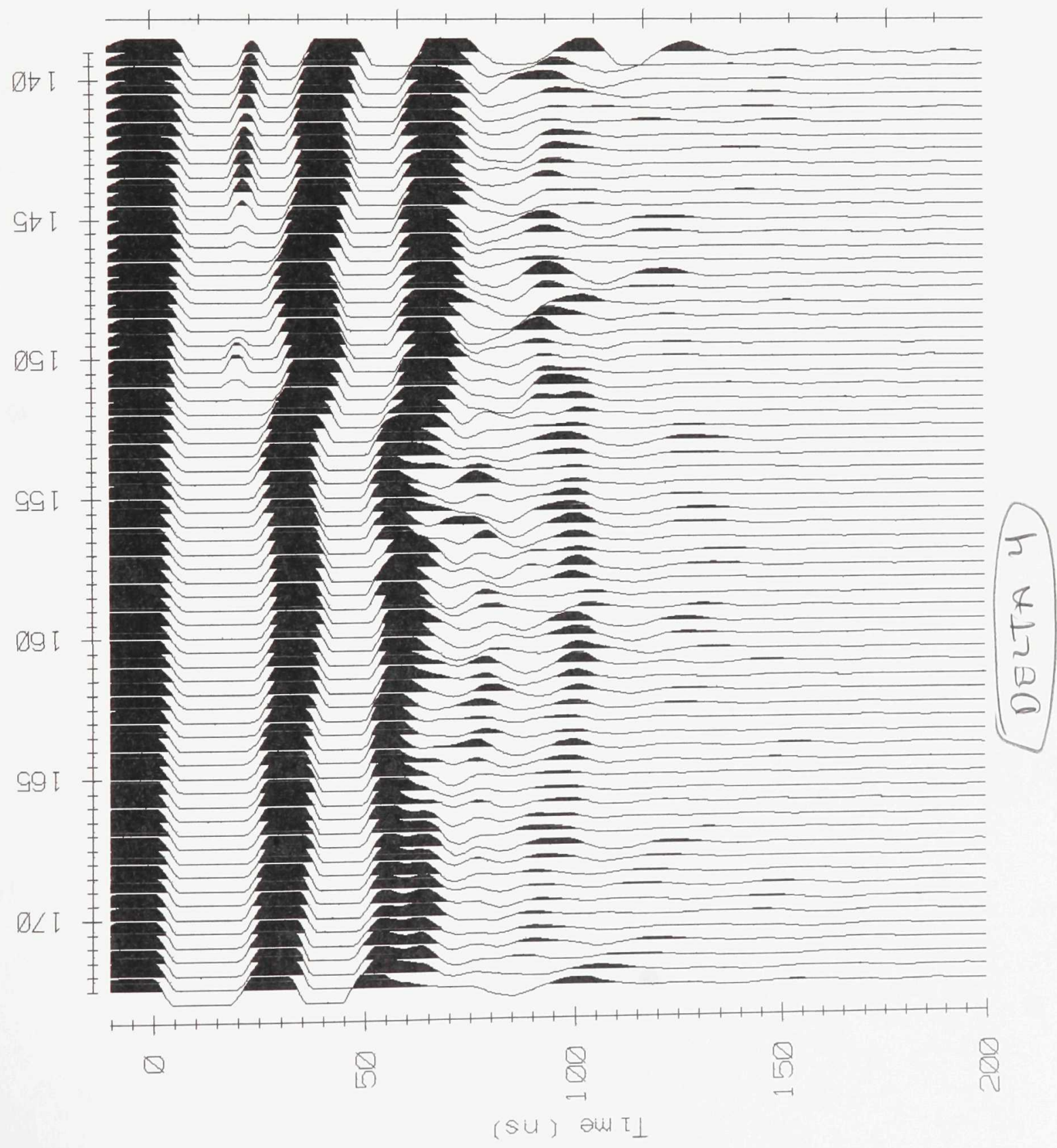




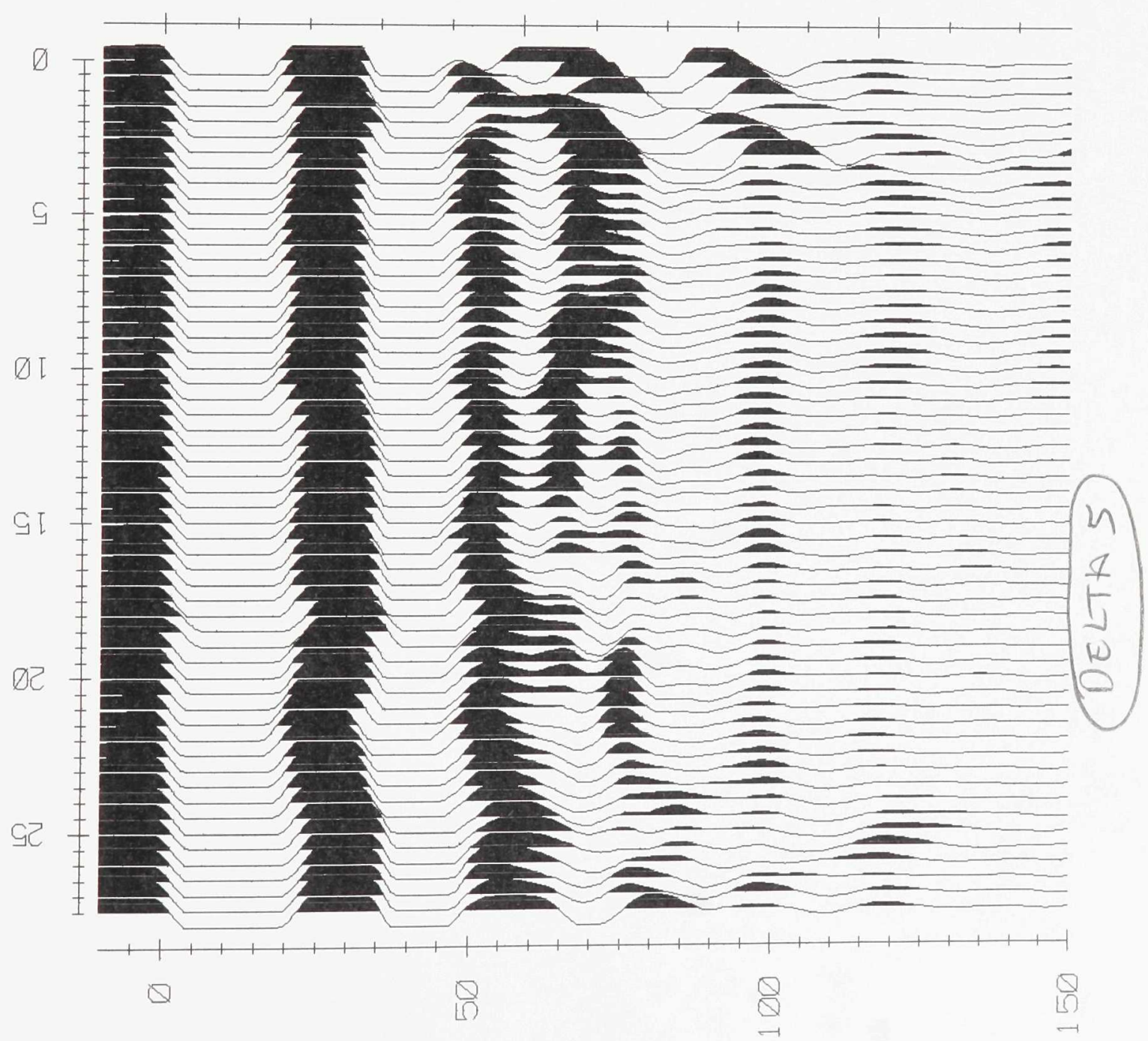

(sU) Diut $I \perp$ 


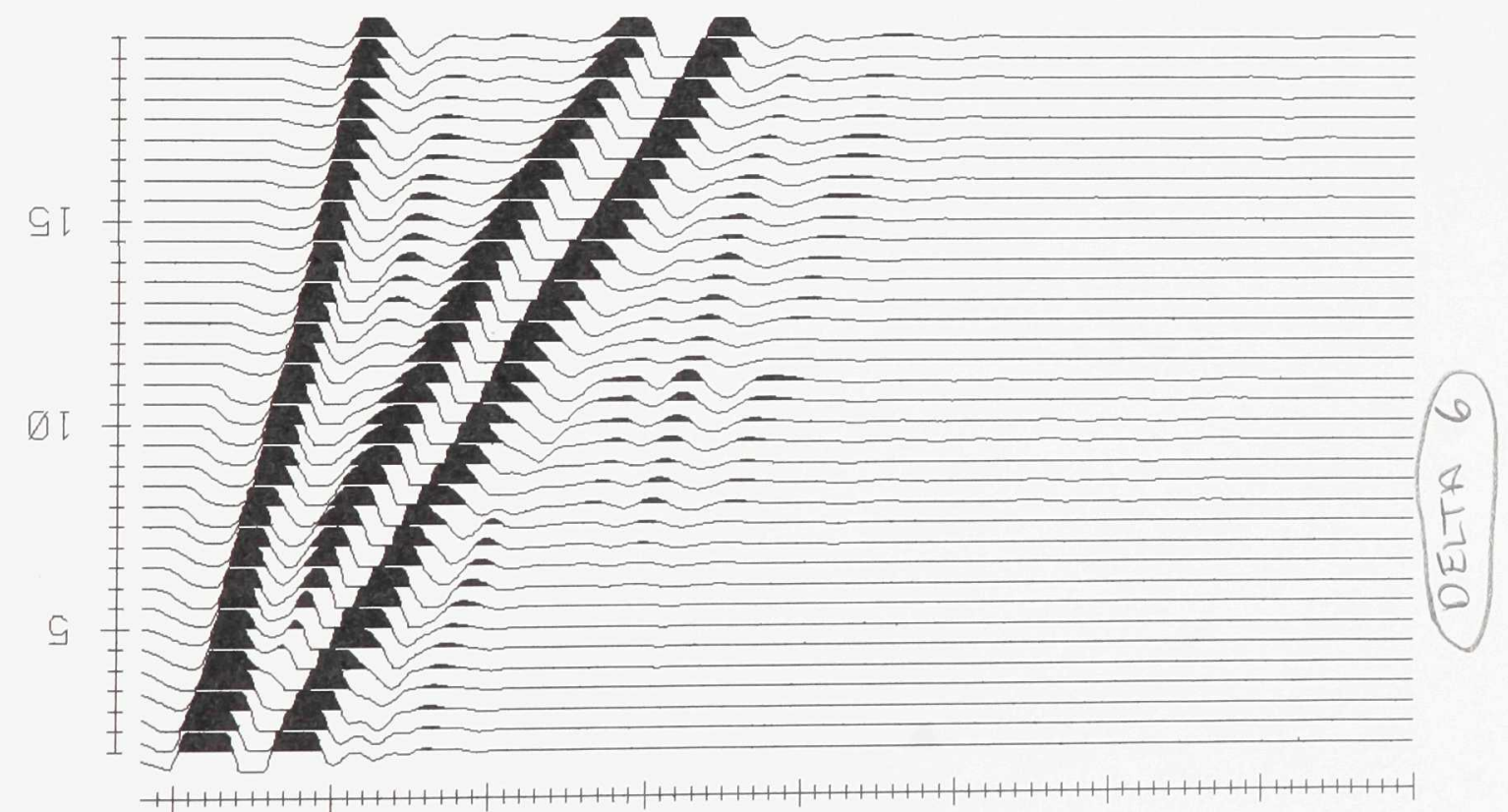
$Q \quad Q$
(1) Q
$\underset{\square}{\square} \quad \frac{Q}{\square}$
पि
ले
त) ब

$(s u)$ bu $T \perp$ 
su/m $\varnothing \angle I^{\circ} \varnothing=\wedge$ (w) $47 d \partial \square$

$Q$

$Q$

15

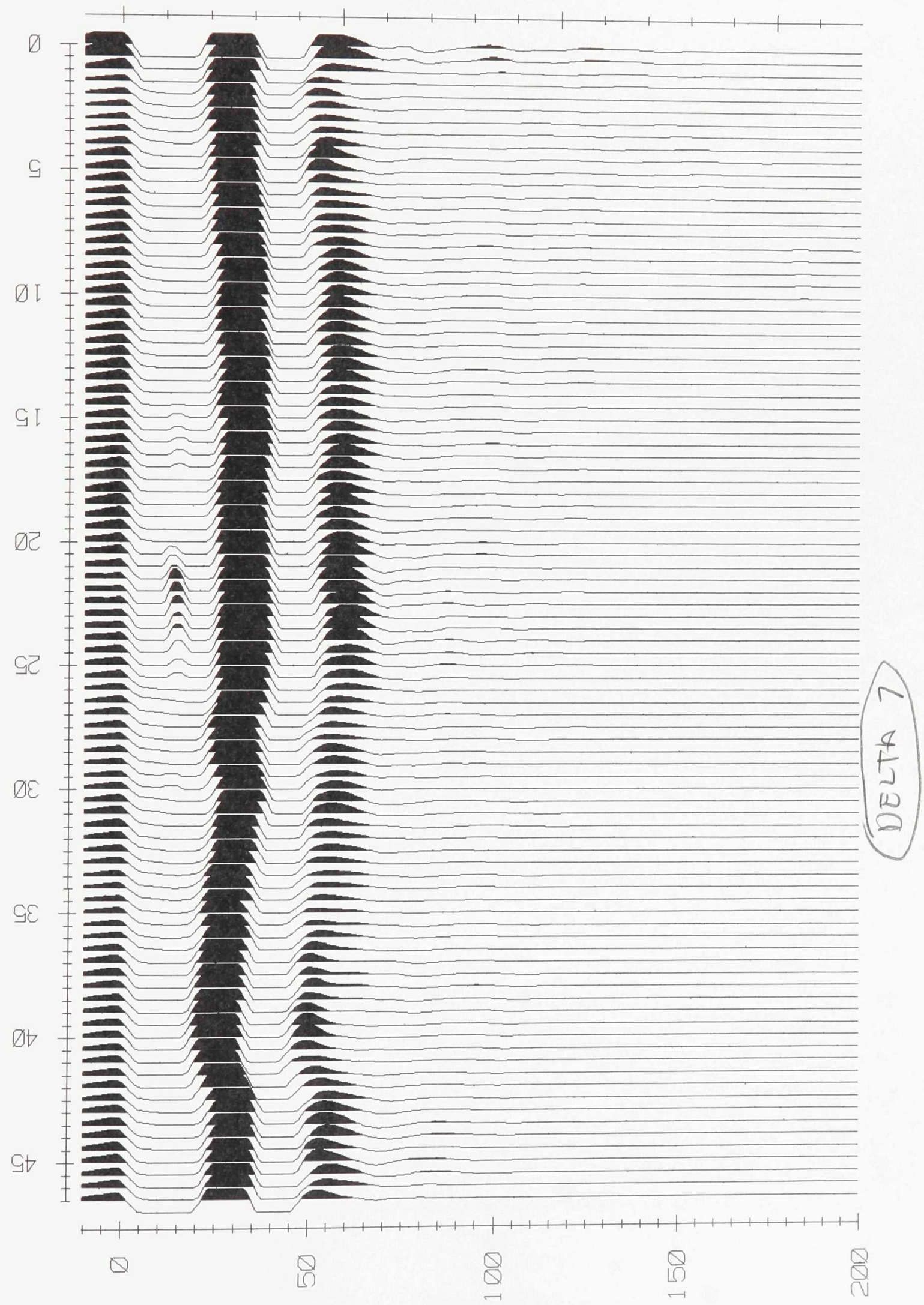

$(s u)$ bW $\tau_{\perp}$ 
su/w $\square \angle I^{\circ} \emptyset=\wedge$ (w) $47 d \partial \square$

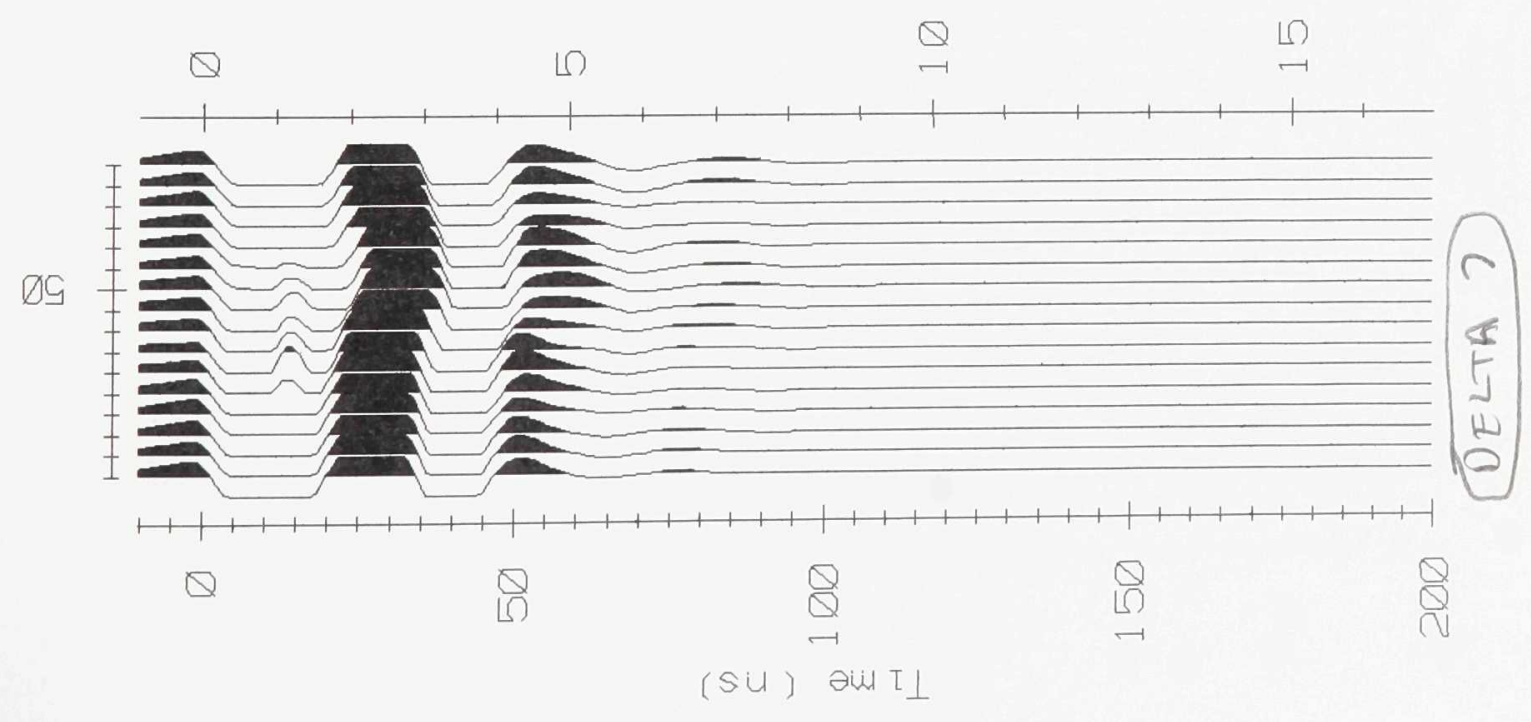


IVI: 
su/m $\square \angle I D=\wedge \quad$ (w) $47 d \partial \square$

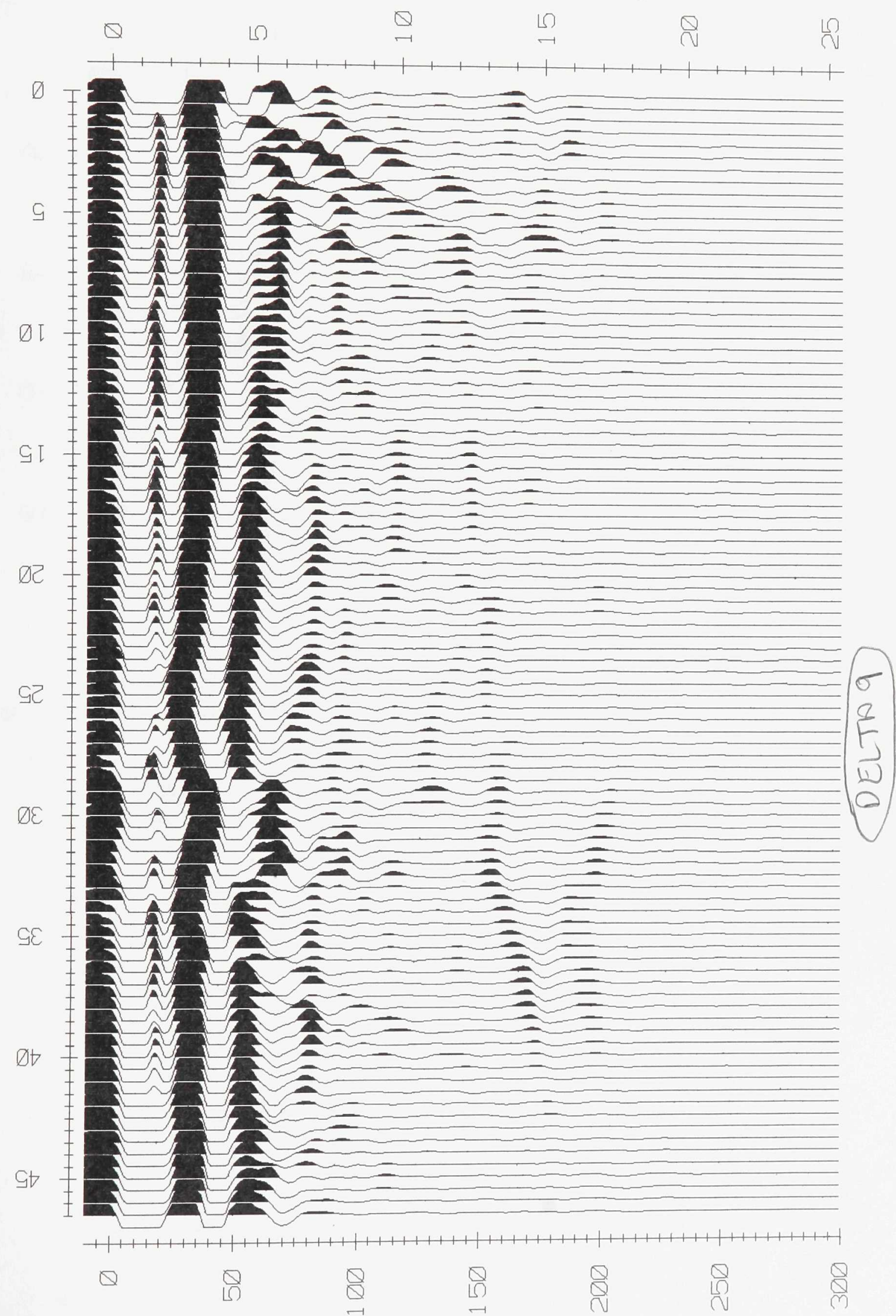


su/w $\varnothing \angle I^{\circ} \varnothing=\wedge$ (w) 47d

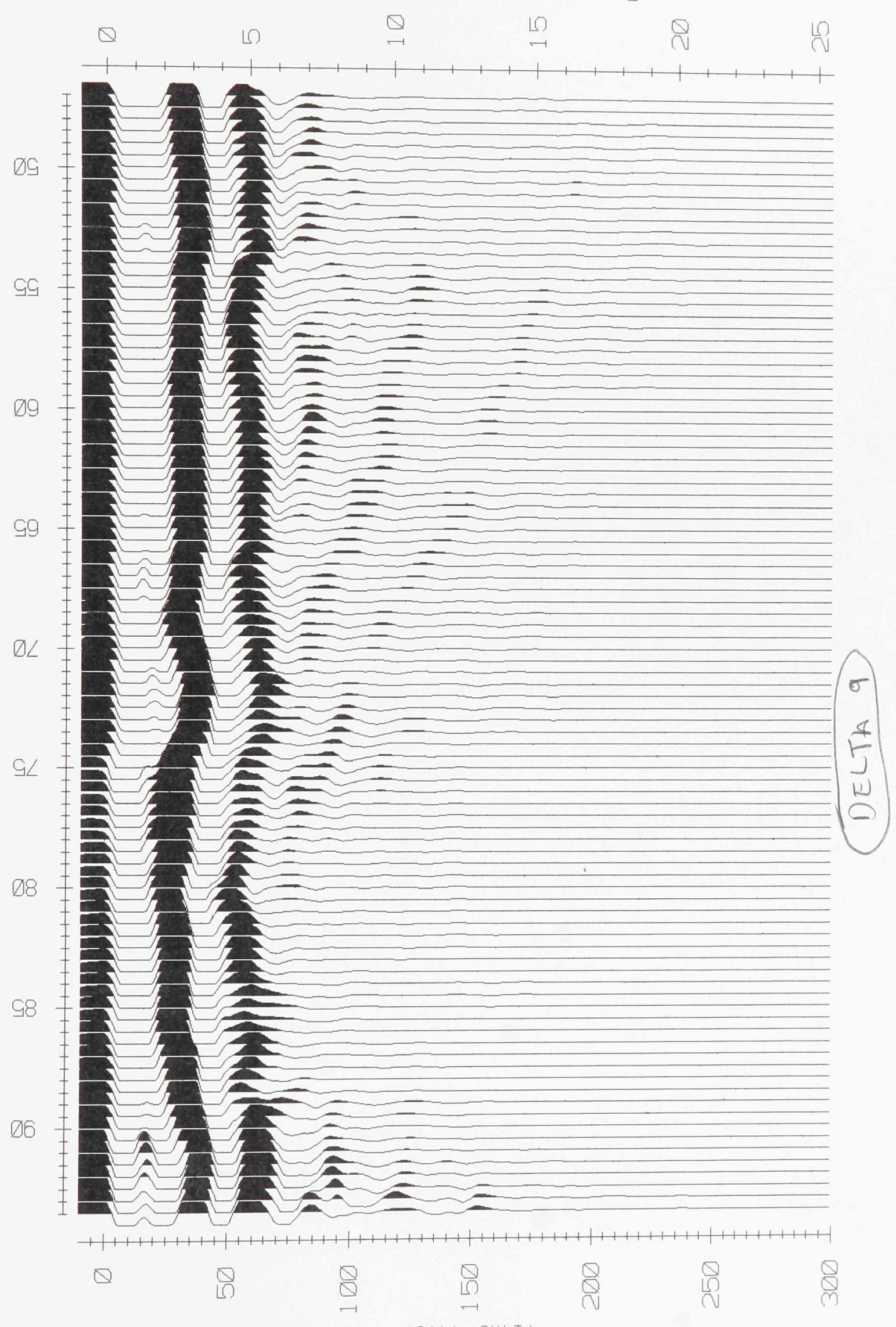




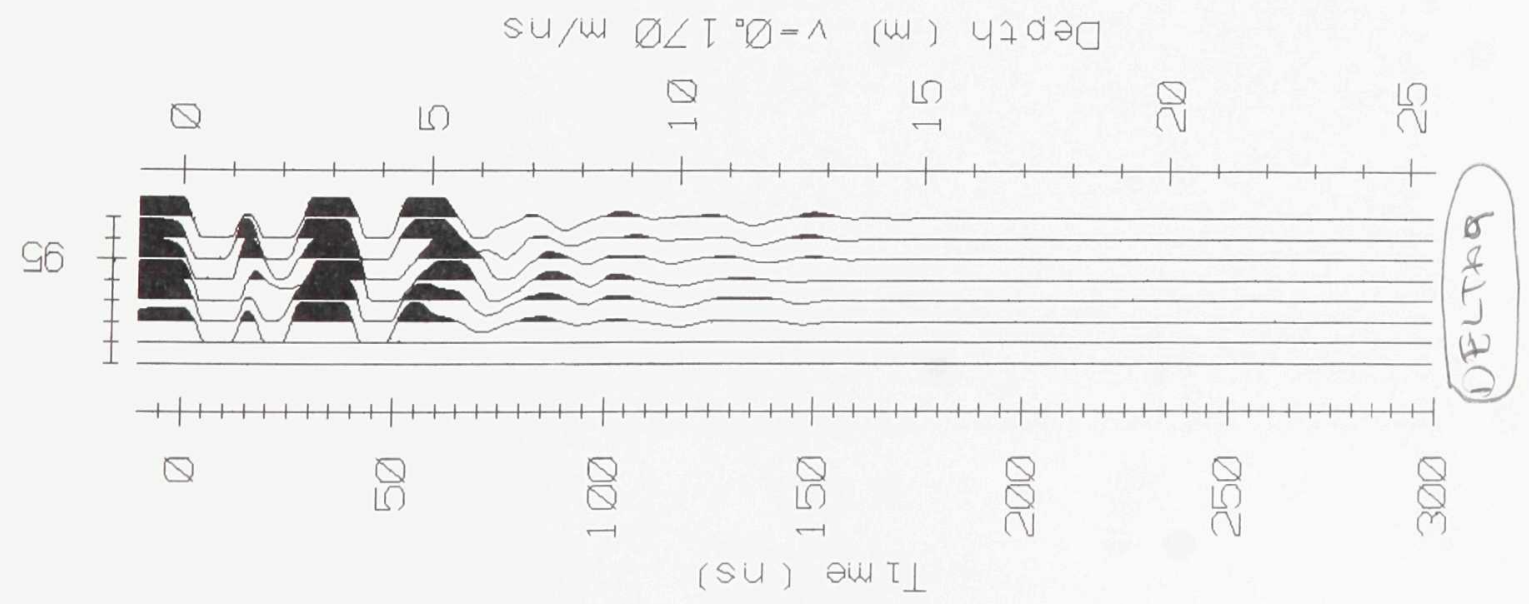


su/w $\varnothing \angle I^{\circ} \varnothing=\wedge \quad$ (w) $47 d \partial \square$

$Q$

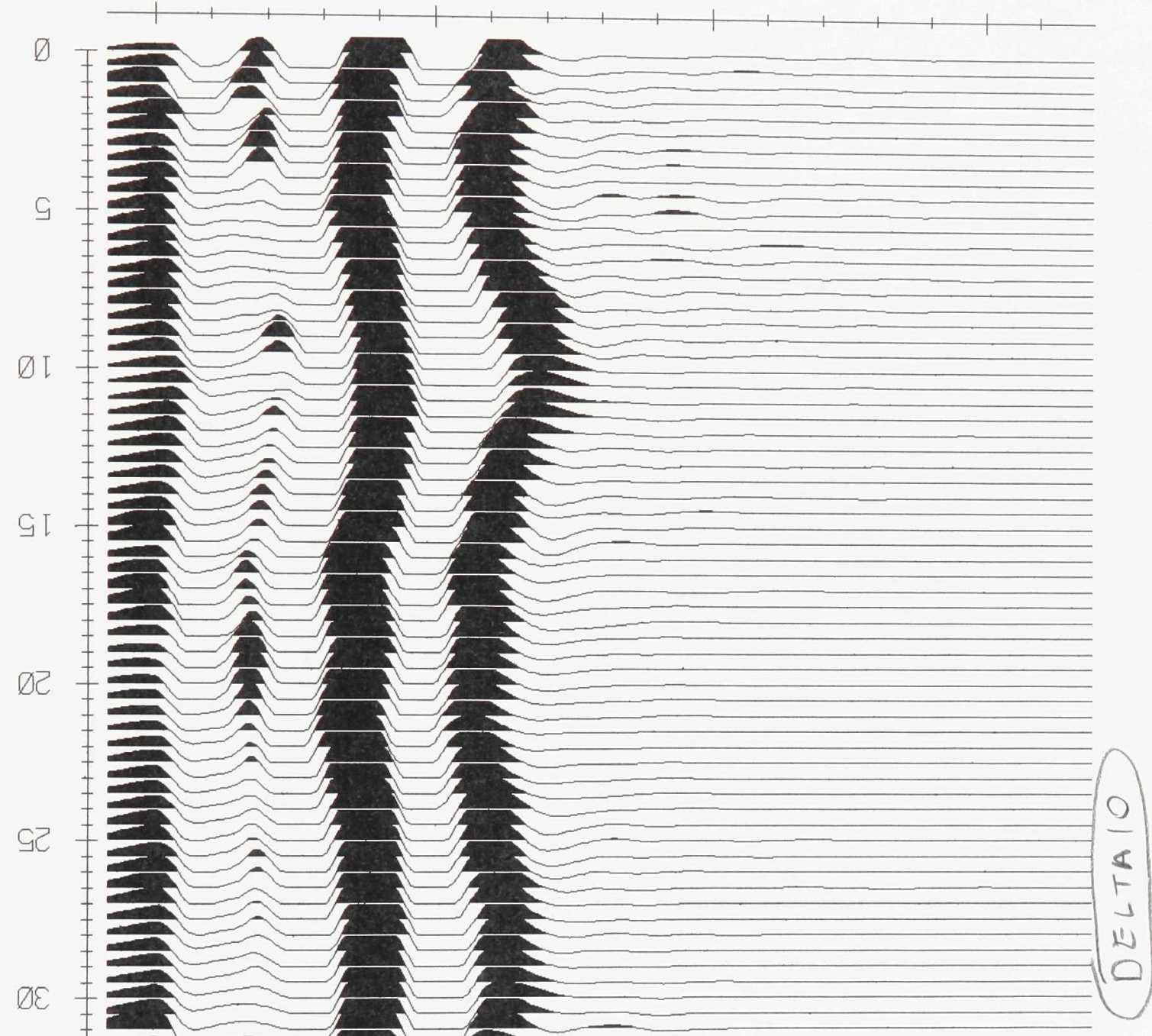

唹年

唹年

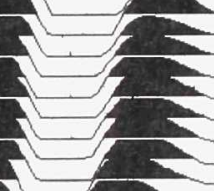

$\sum_{1}$

-

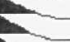

$9 \varepsilon$

$Q$

ถ

$Q$

(1) 
su/w $\varnothing \angle T^{\circ} \not=\wedge$ (w) $47 d \partial \square$

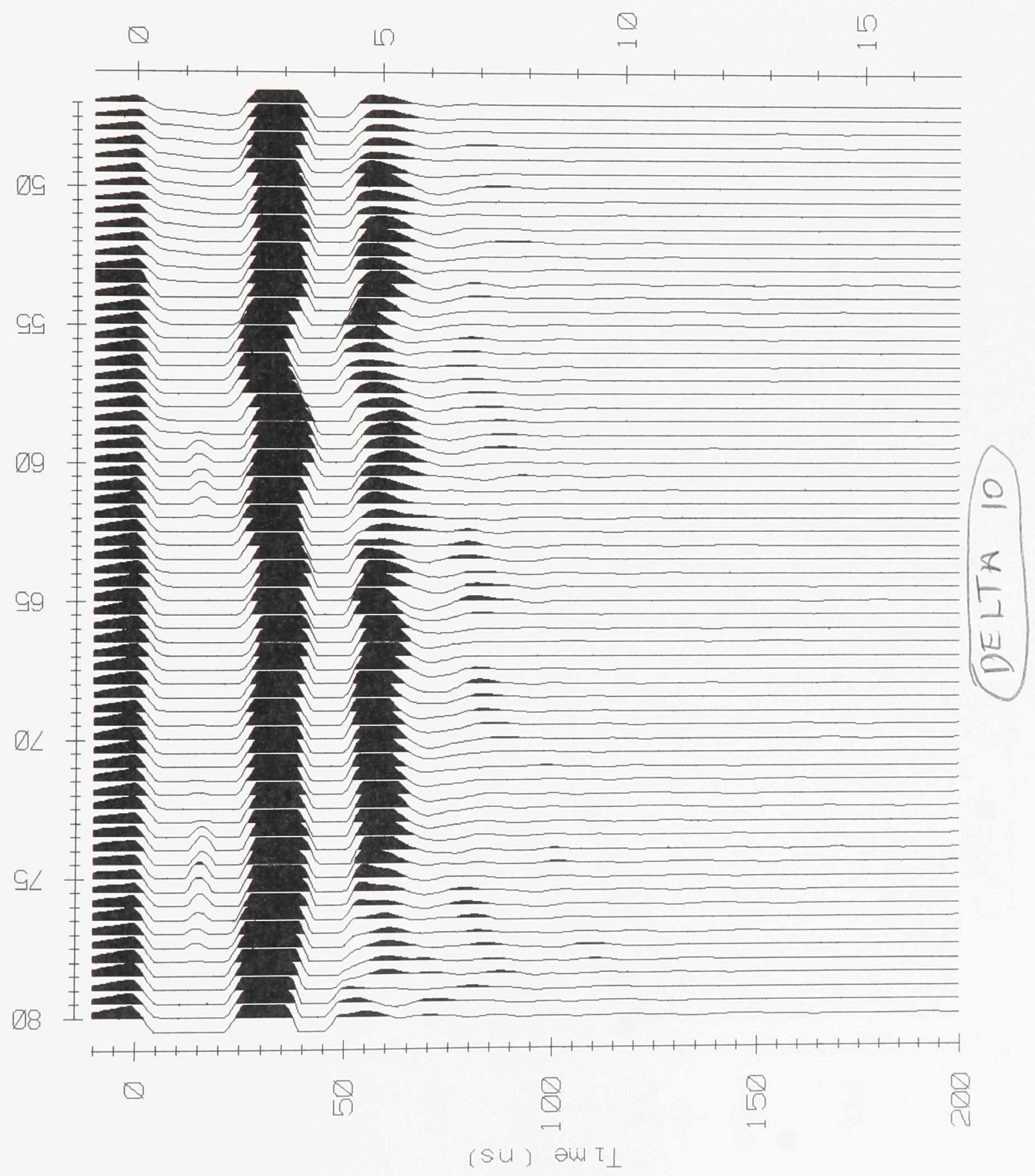




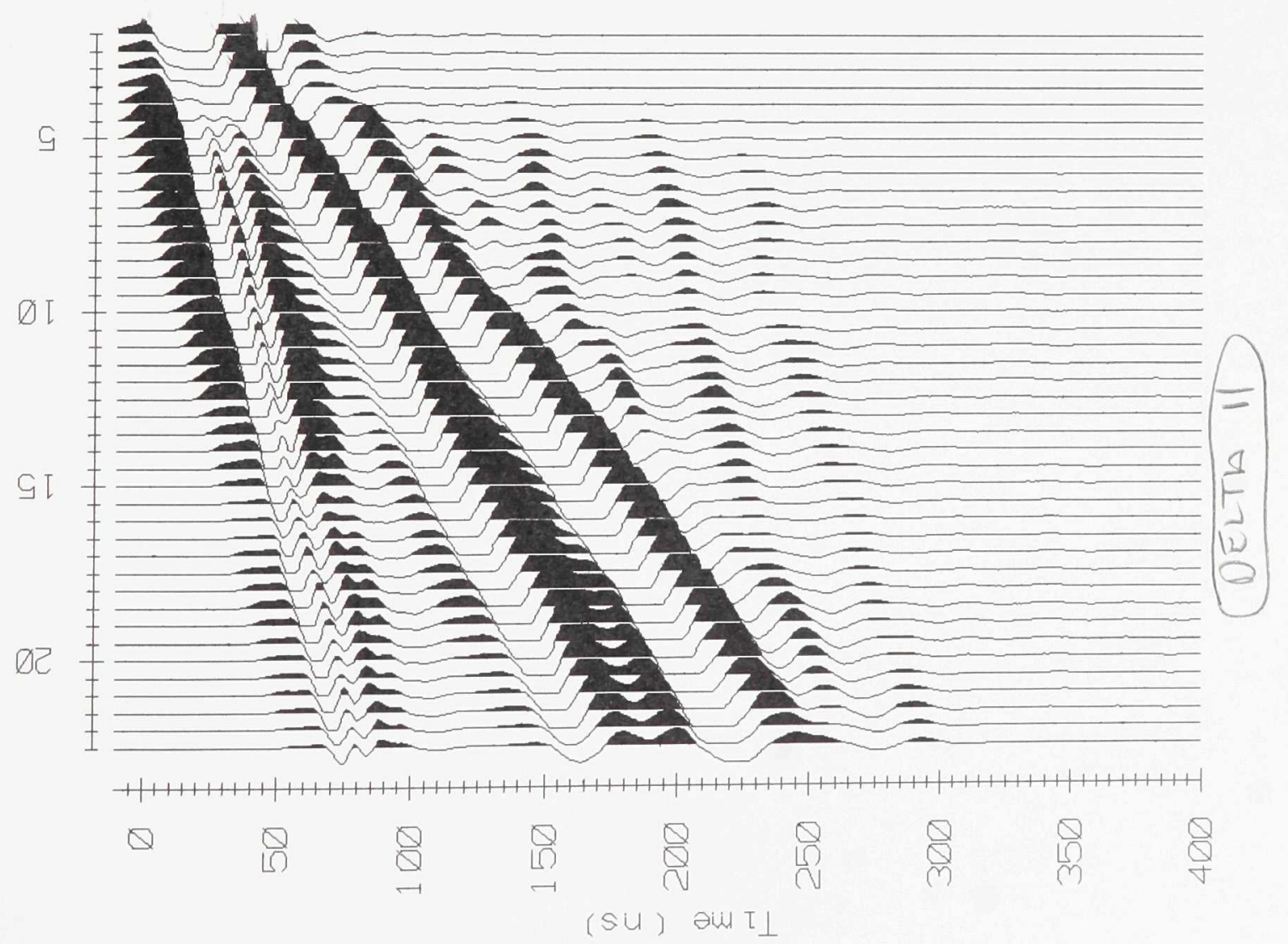




\section{Appendix B:}

Accumulation area GPR profiles 


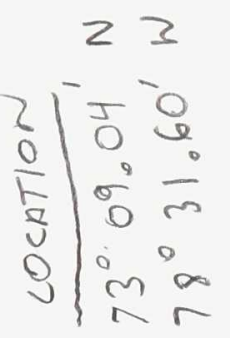

su/w $\square \angle \tau^{\circ} \emptyset=\wedge \quad$ (w) $47 d \partial \square$

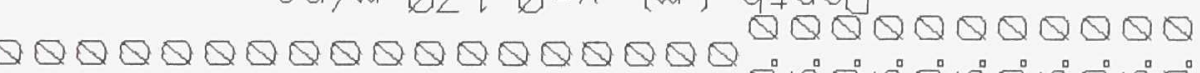

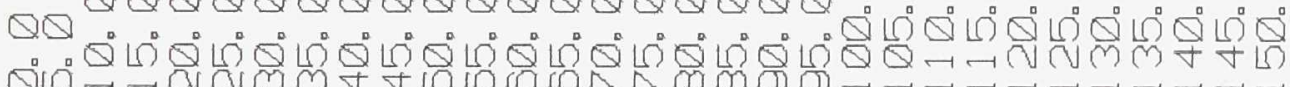

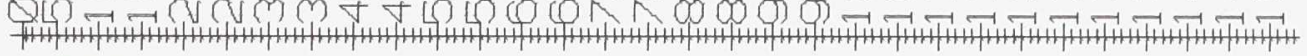

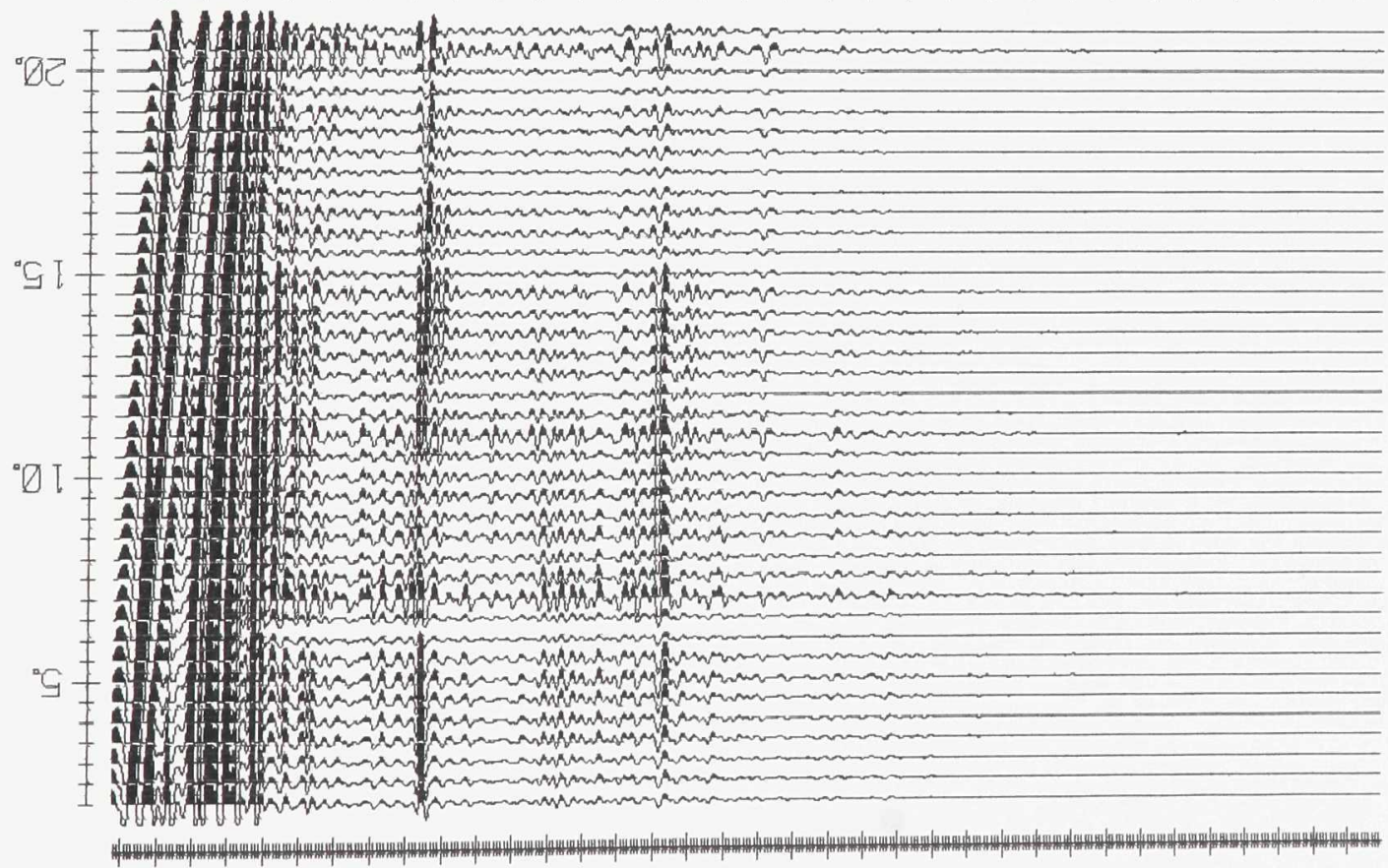

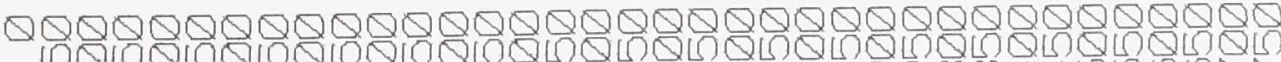

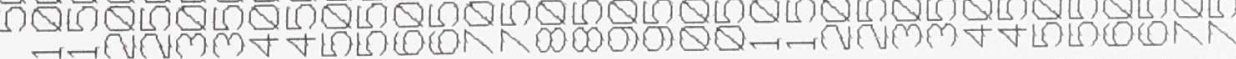


$\operatorname{su} /$ W $\varnothing \angle\left[{ }^{\circ} \varnothing=\wedge\right.$ (W) " $\wedge \theta T \exists$

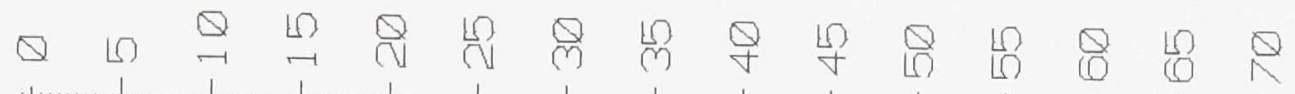

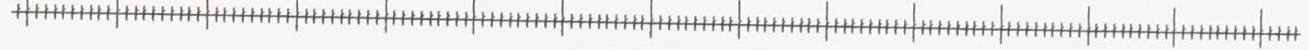

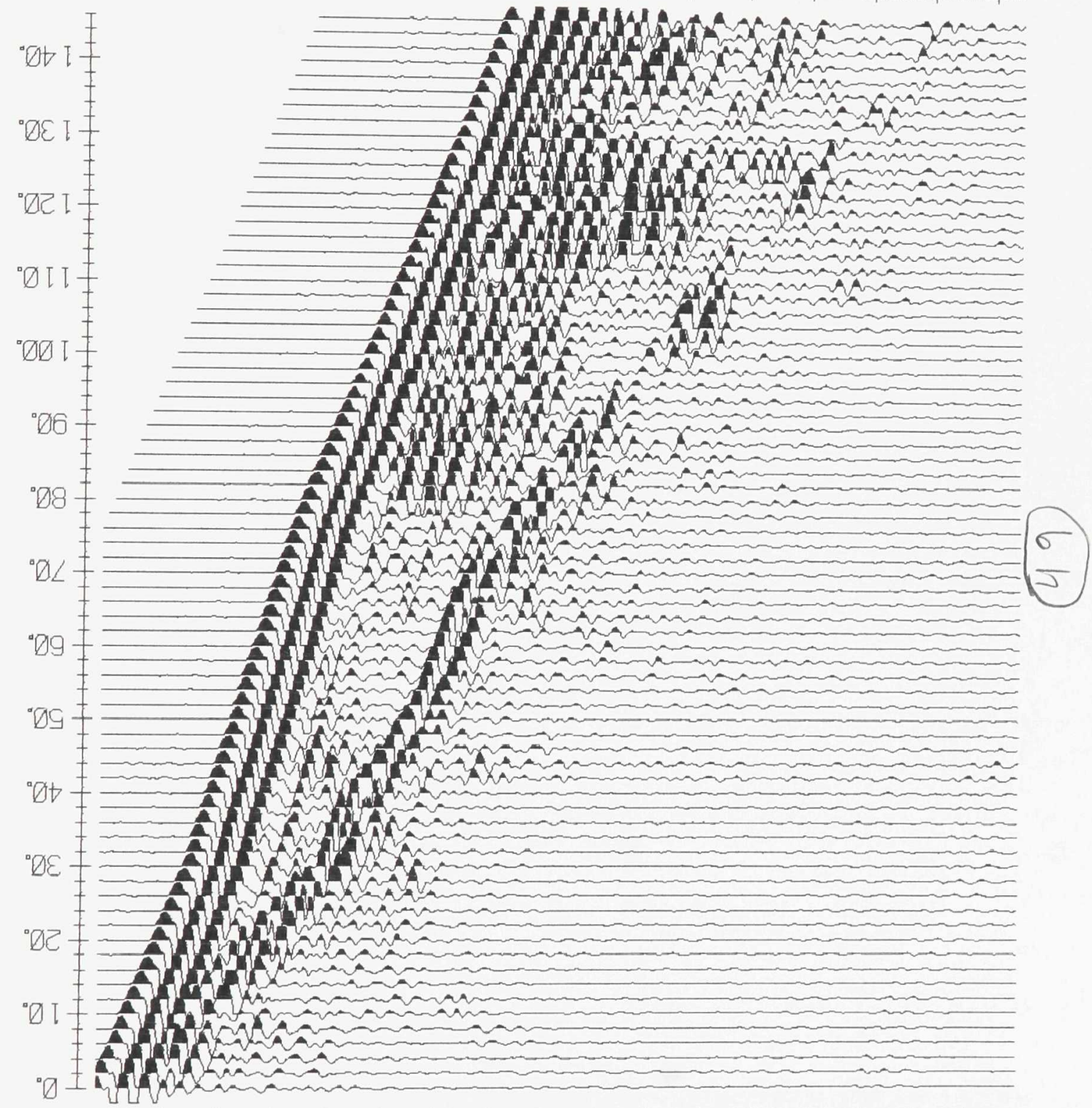

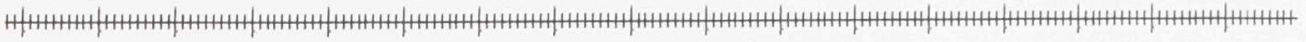

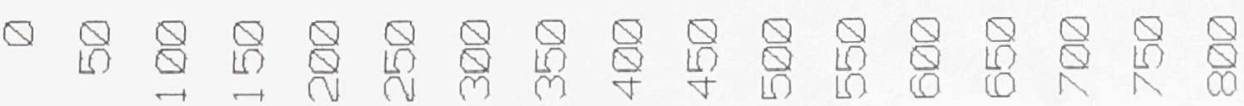




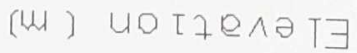

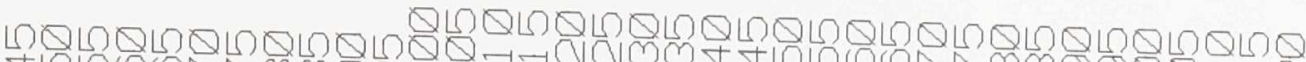

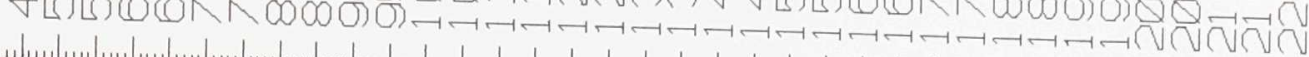

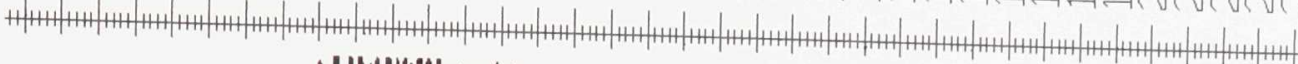

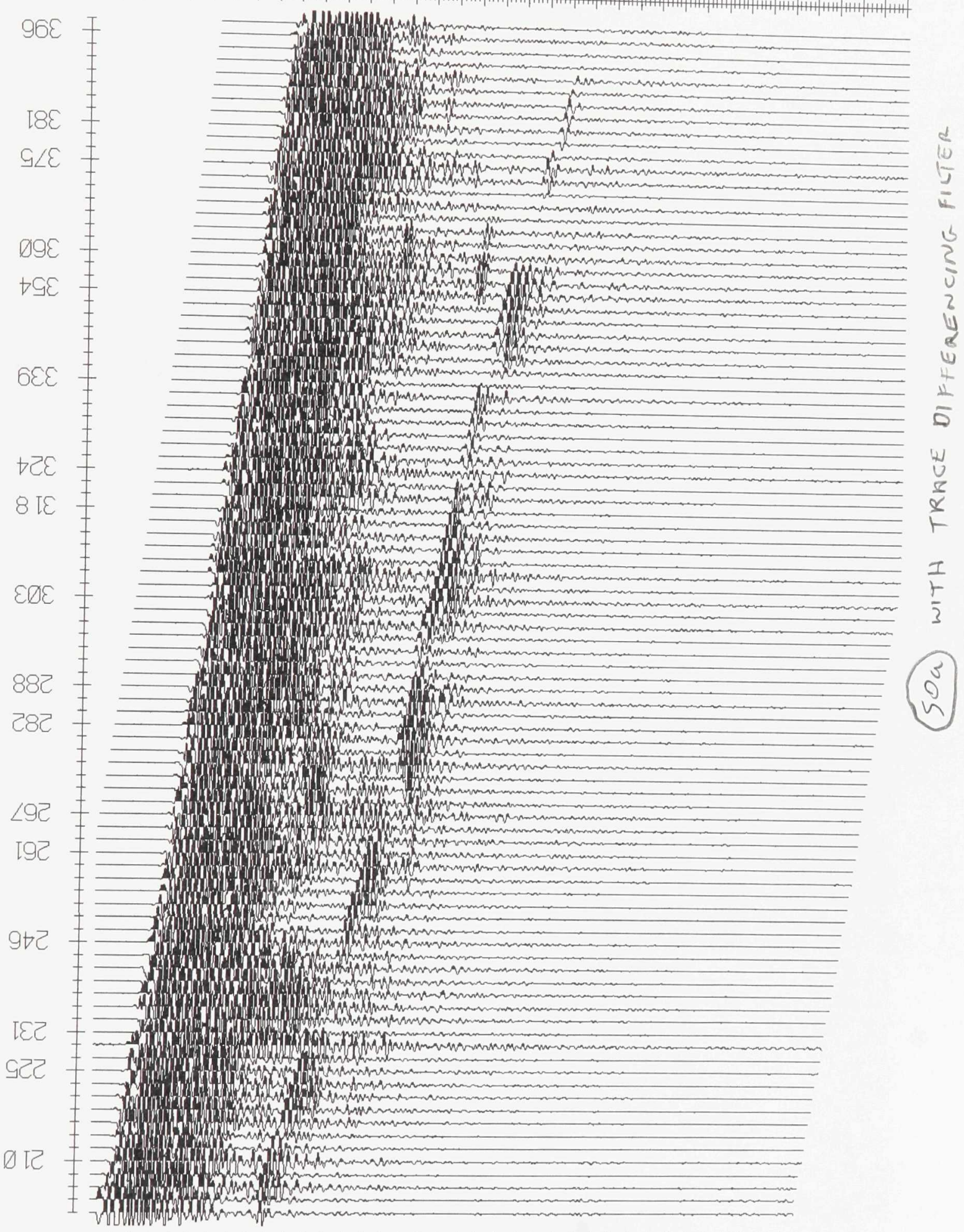

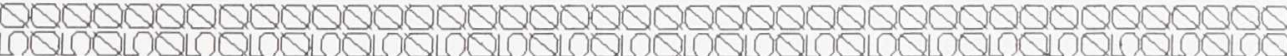

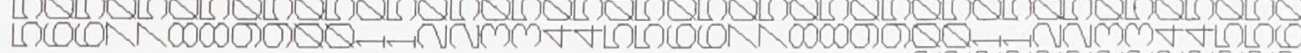
(su) Din $T \perp$ 


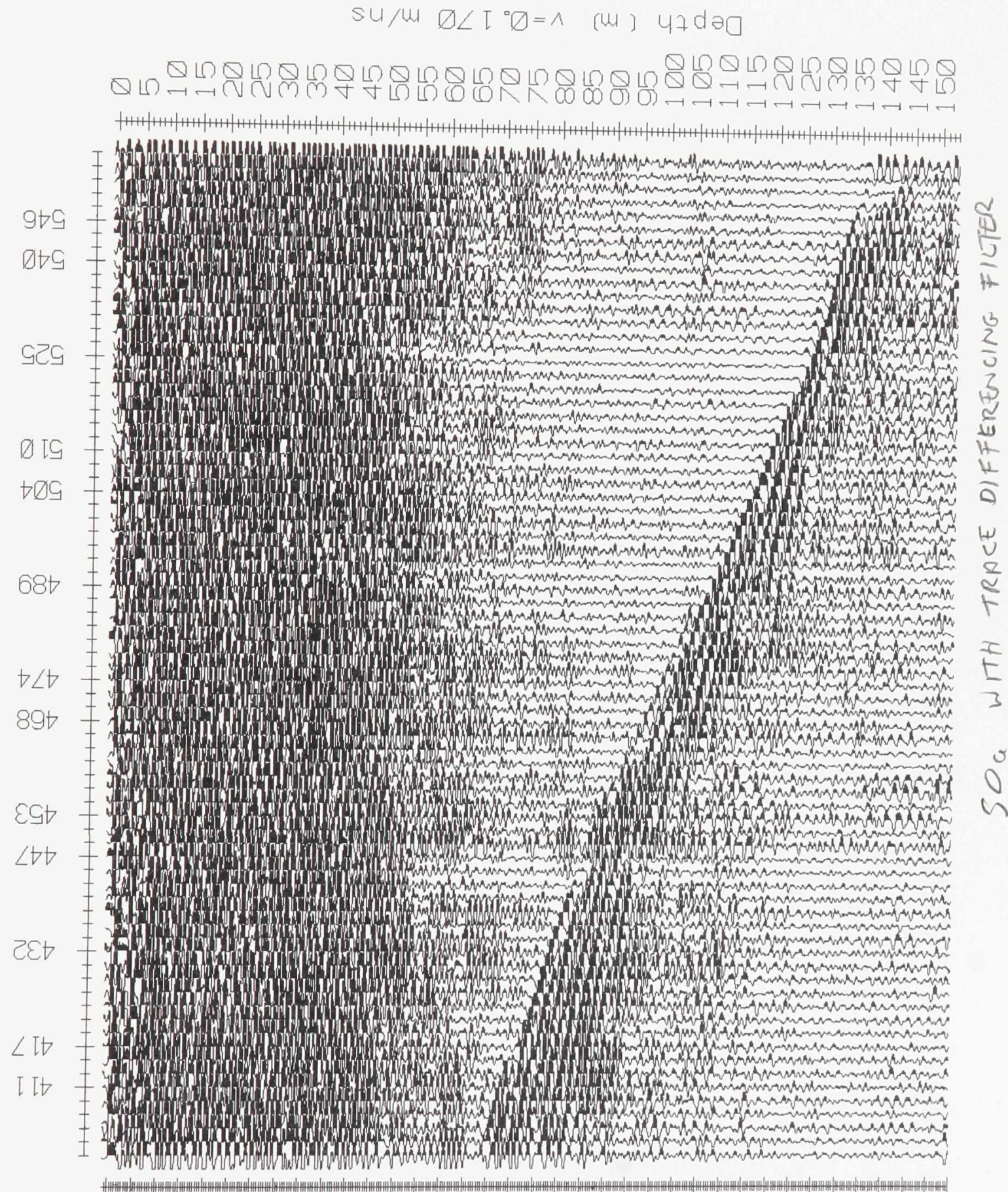

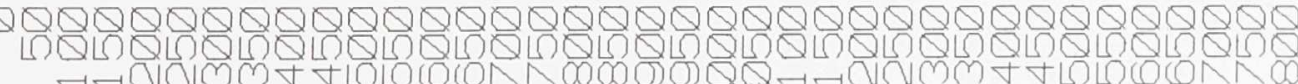




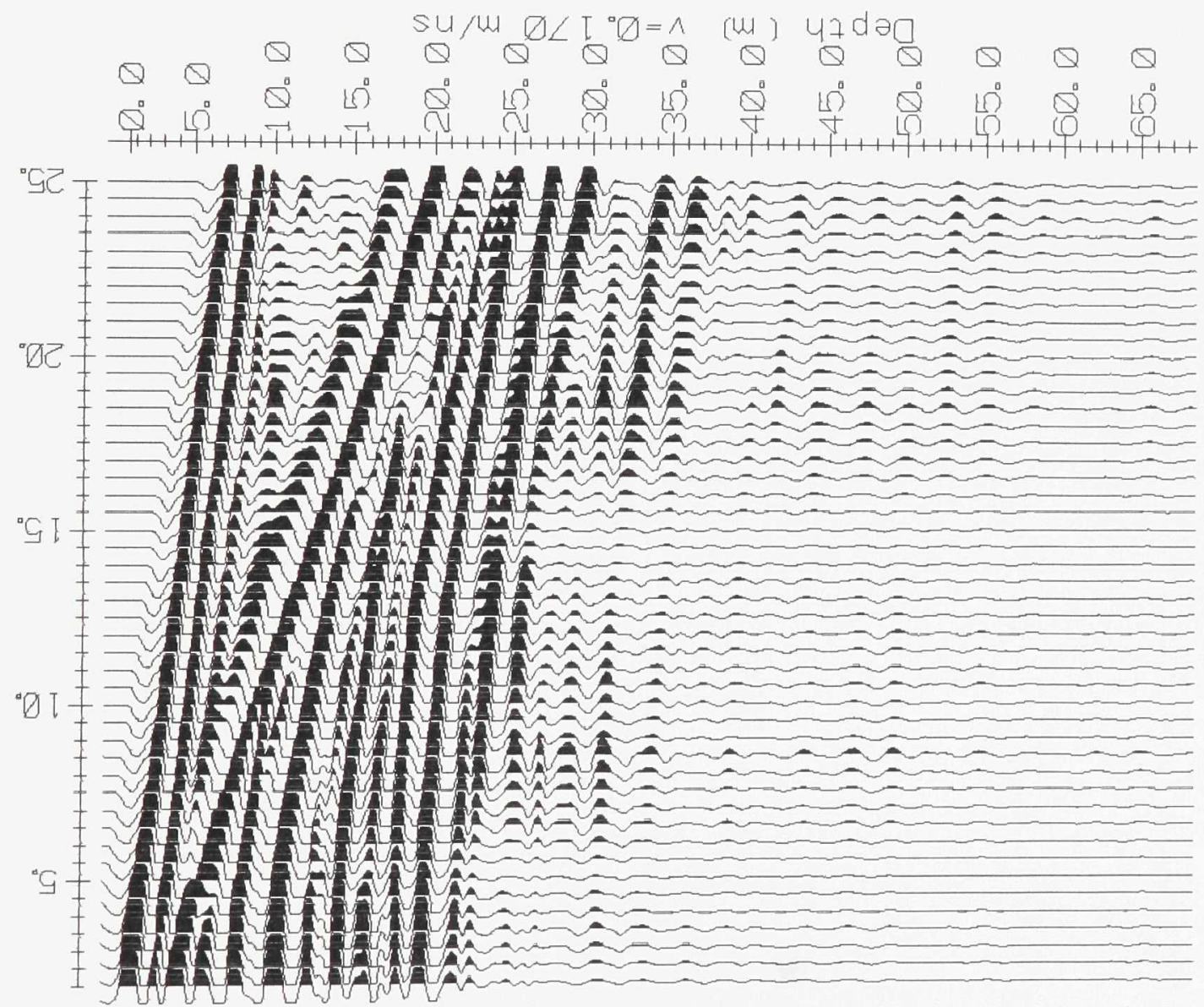

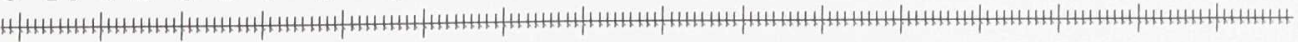

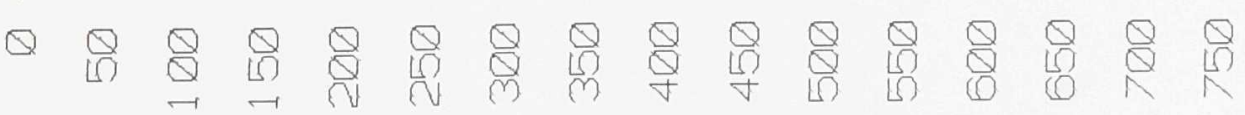

$$
(s u) \text { ow } T \perp
$$




\section{Appendix C:}

Fountain Glacier area GPR profiles 


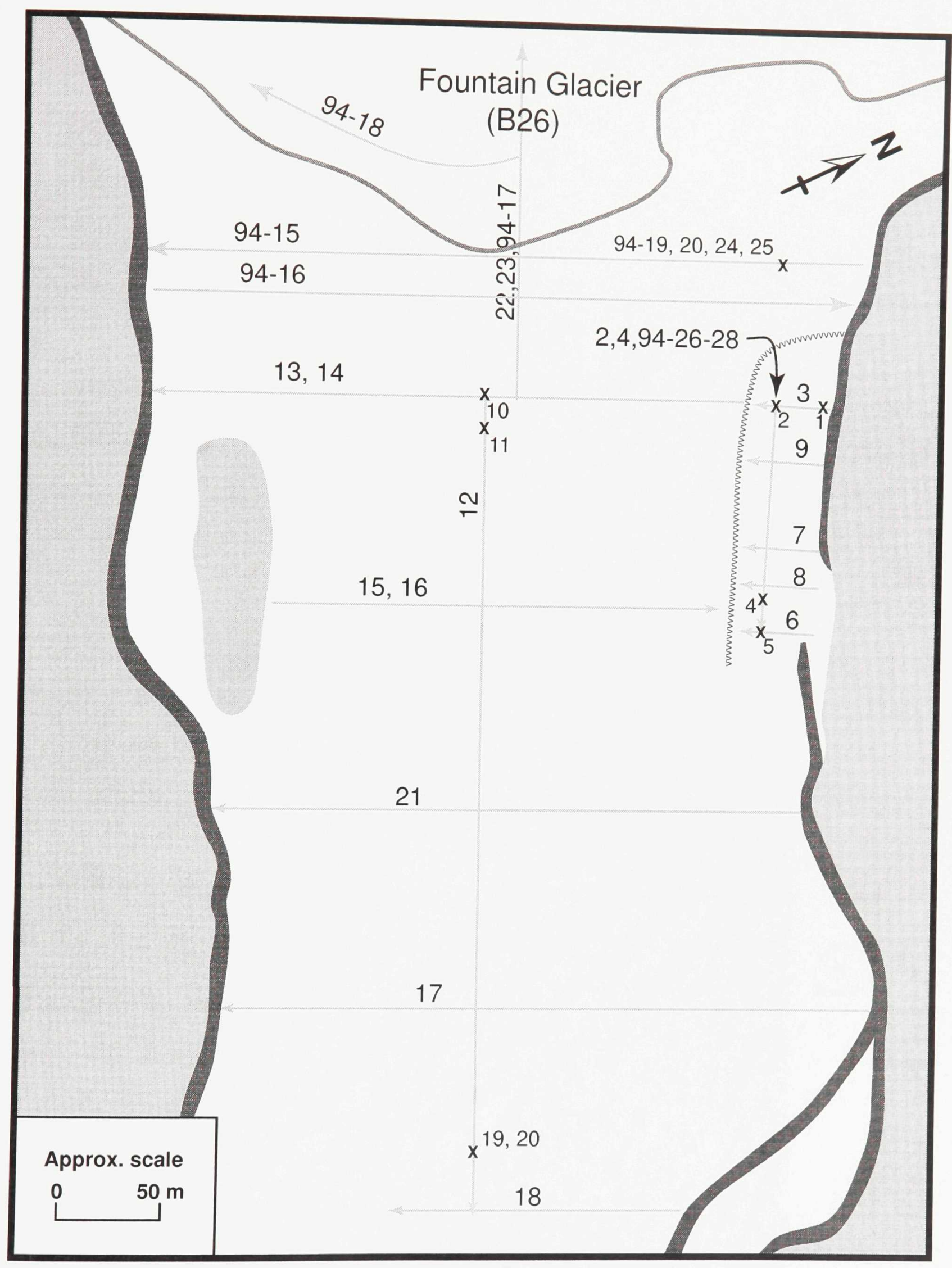

GPR profile locations. Arrows indicate direction of profile. Numbers indicate the file number. Velocity profile mid points are indicated by an " $x$ ". Some files may also end with the letter " $a$ " indicating some modifications have been made (eg. polarity reversal or trace deletion). 


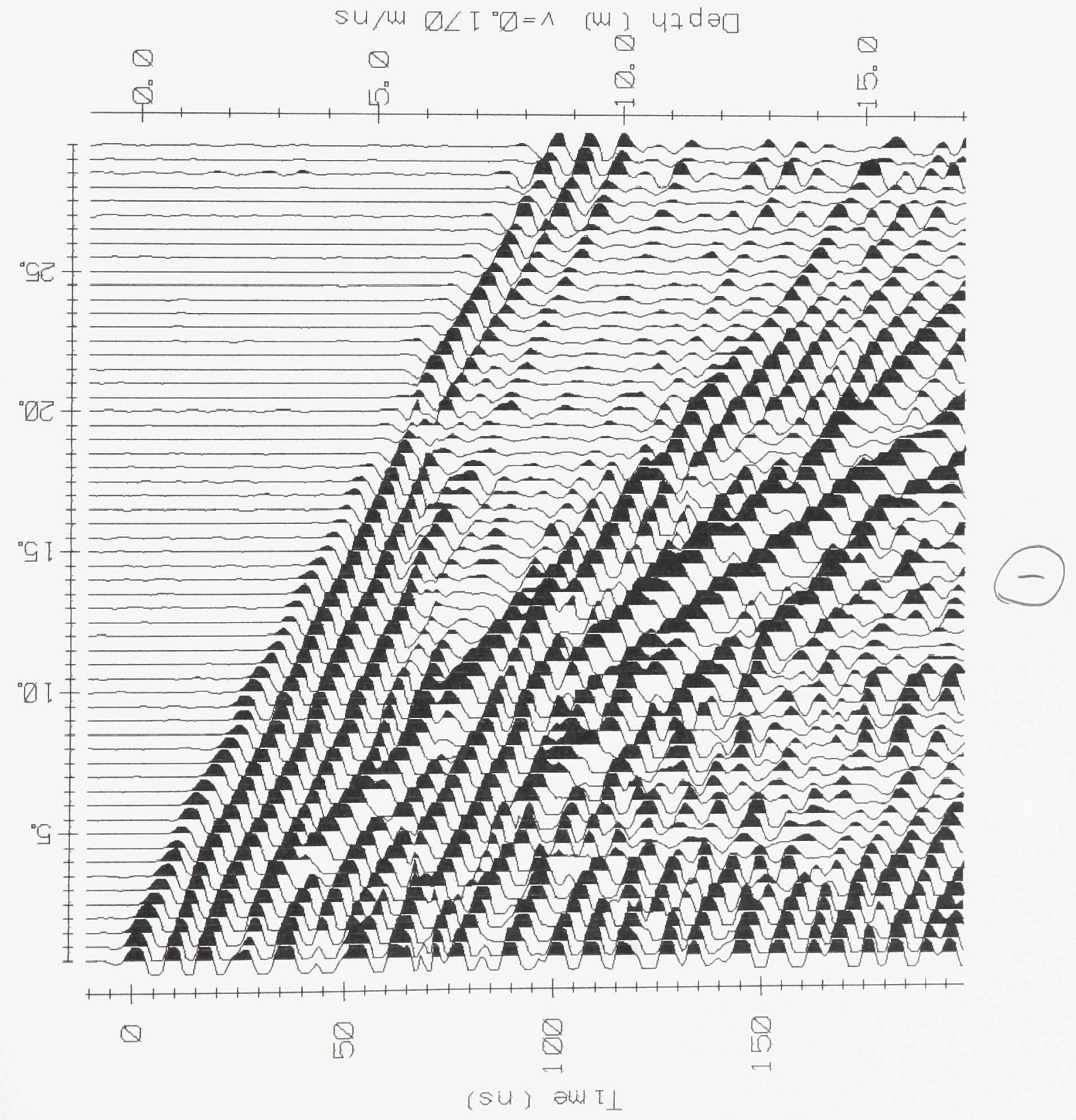


su/w $\triangle \angle I \square=A$ (w)
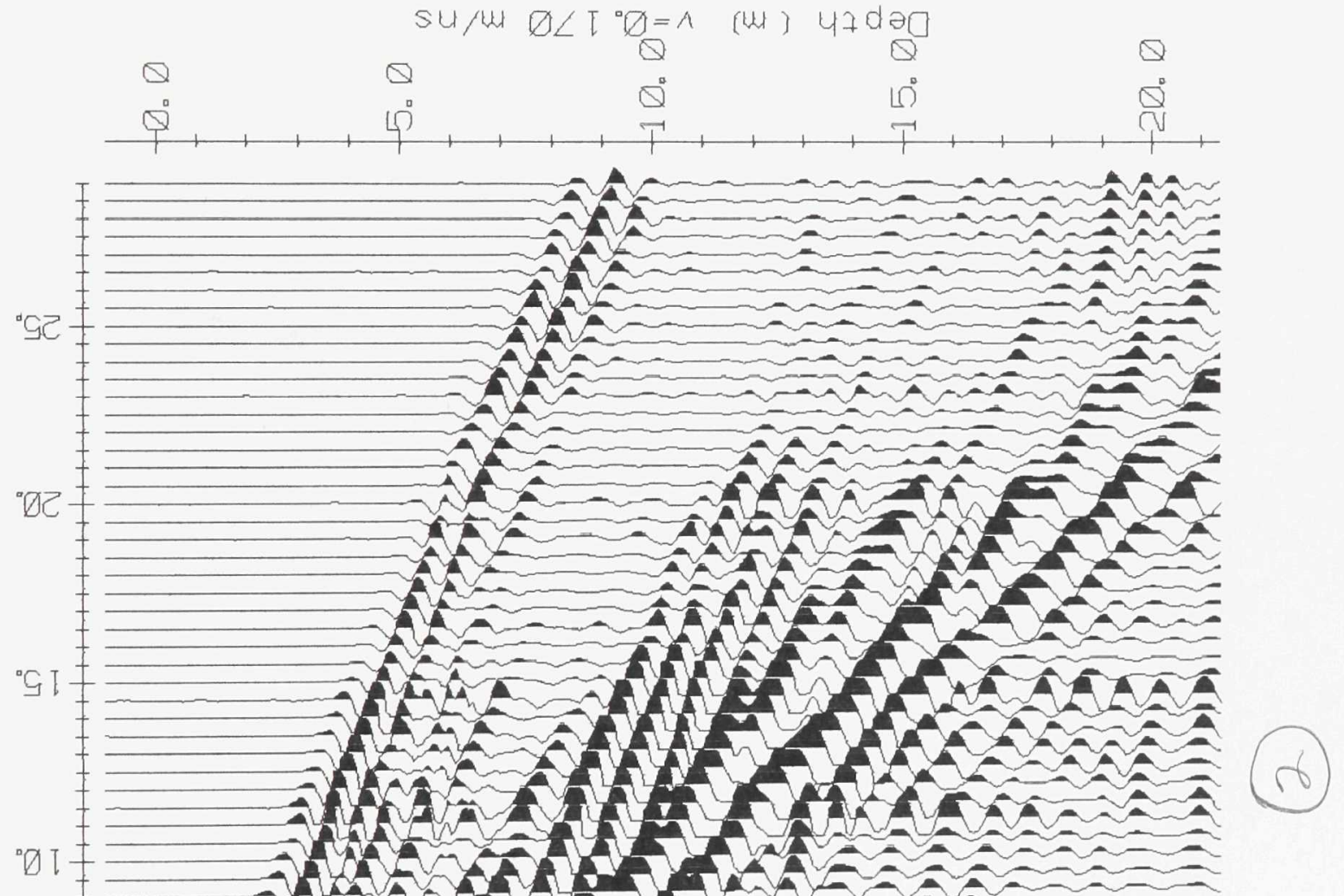

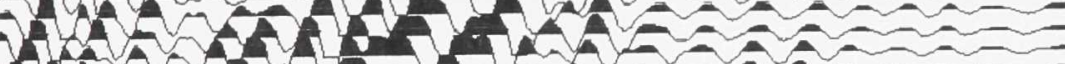

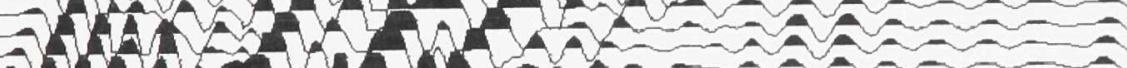

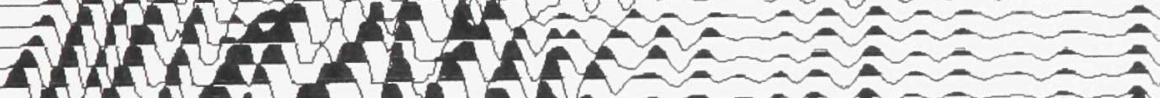

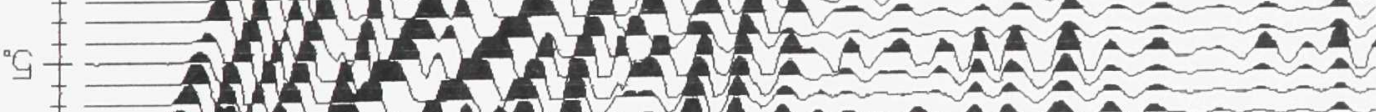

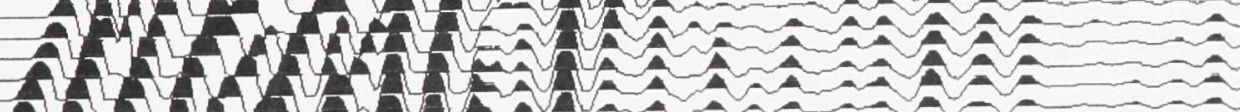

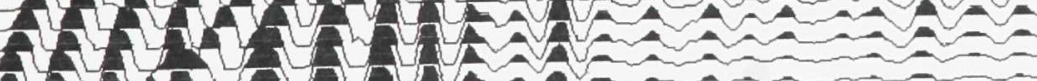
$Q$
8
$Q$
$\stackrel{Q}{\square}$
Q 
su/w $\varnothing \angle T^{\circ} \varnothing=\wedge$ (m) 47dag

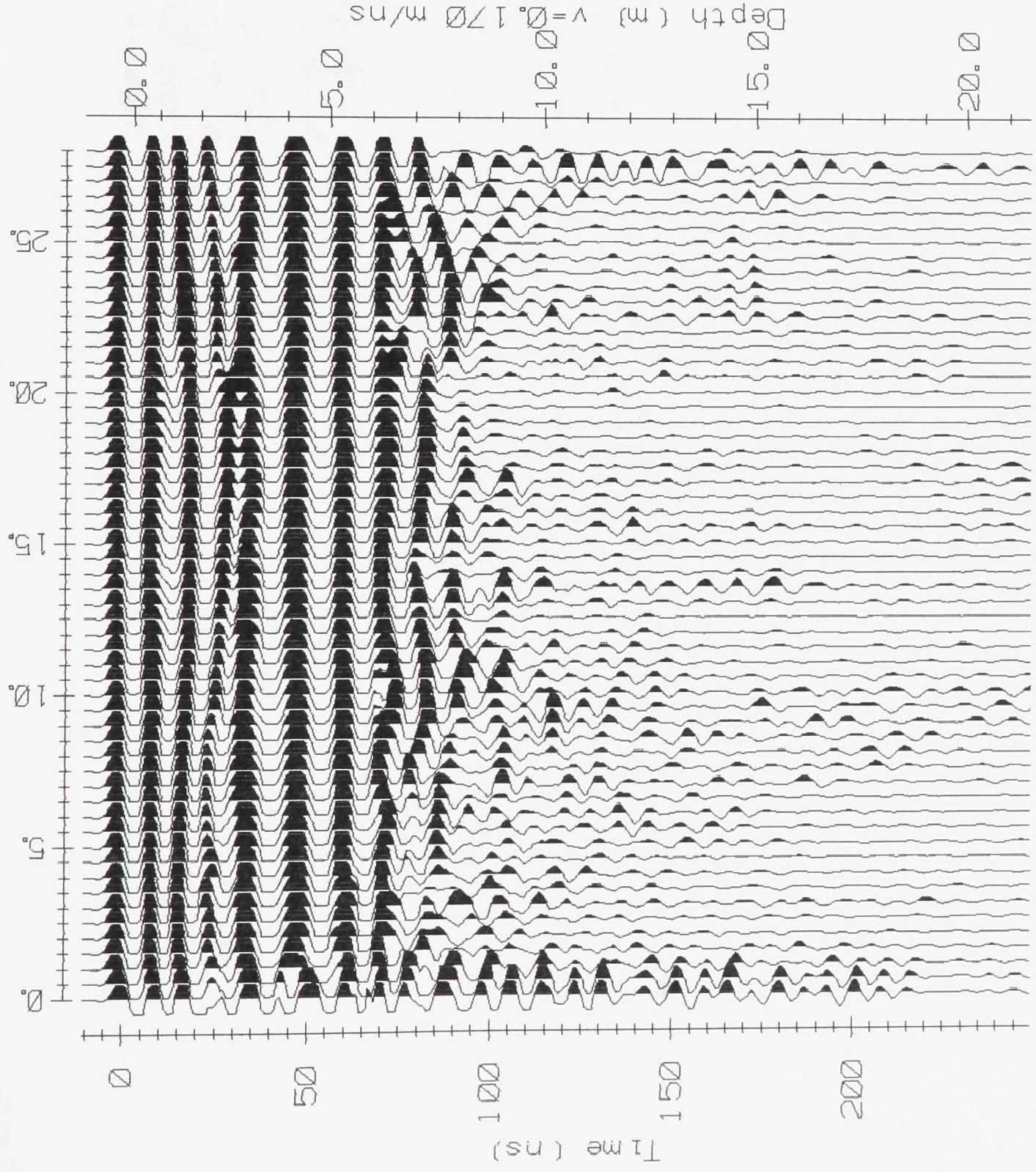


SU/W $\square \angle I{ }^{\circ} D=\wedge$ (W) $\triangle \triangle \theta 丁 \exists$

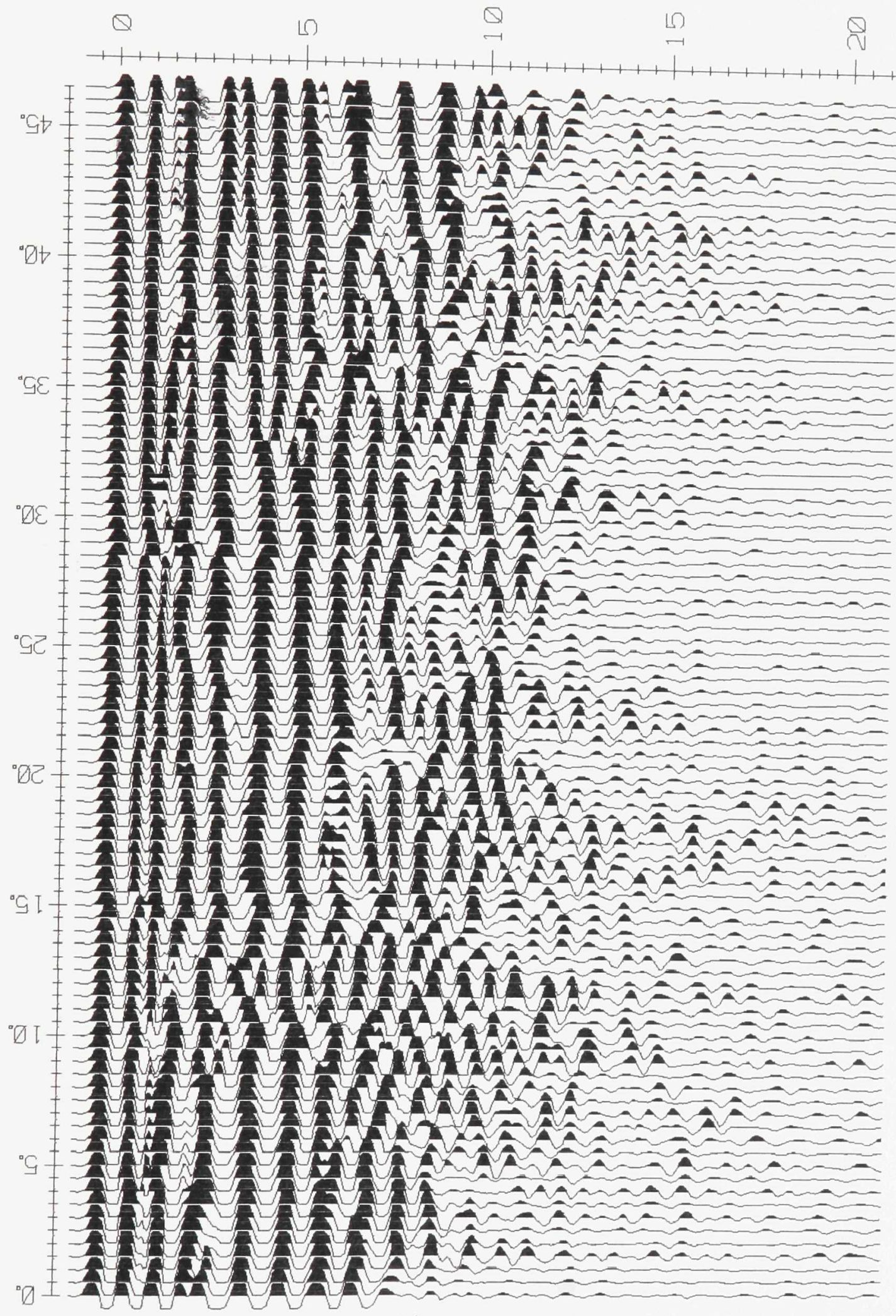




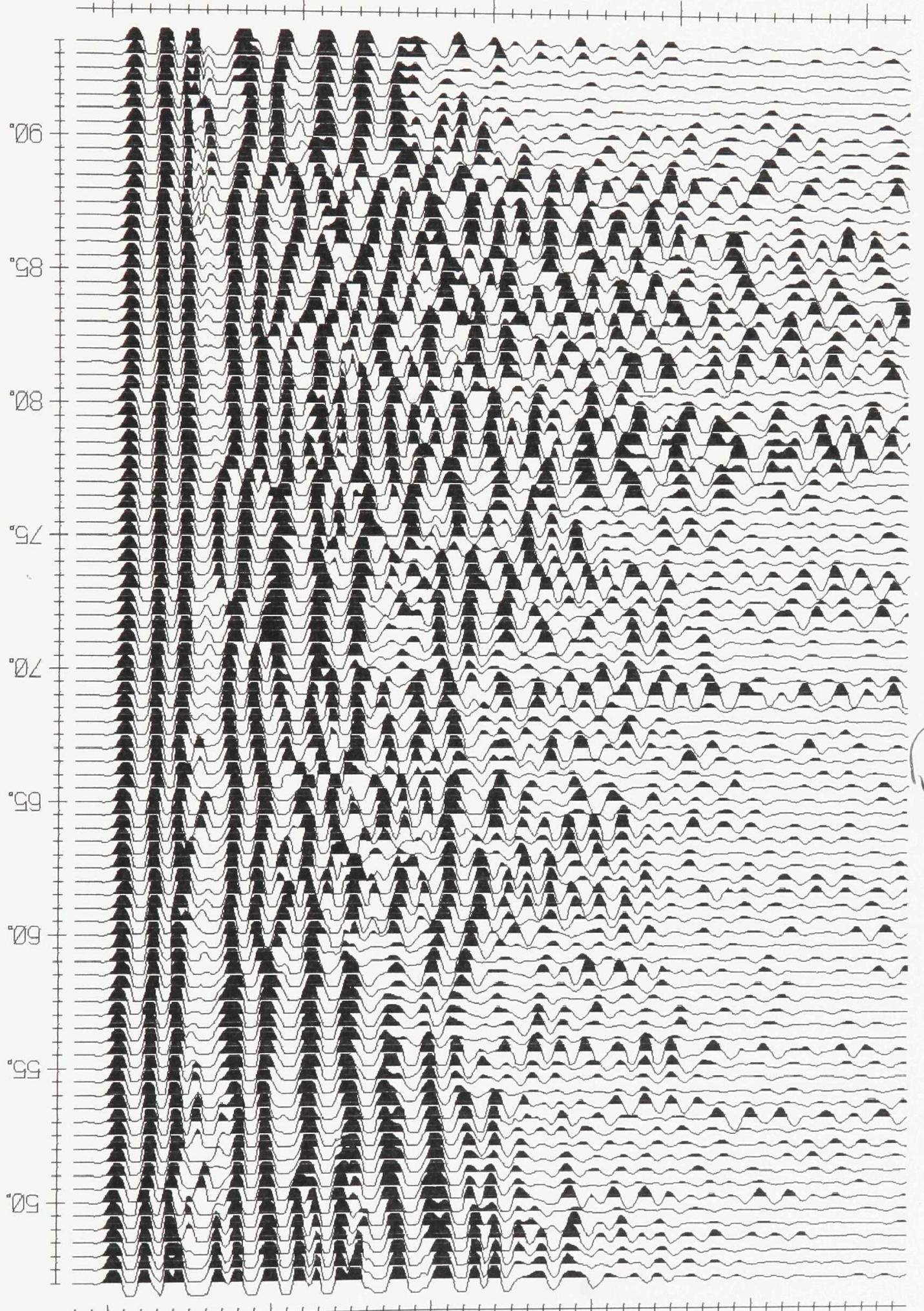


$S U / M \quad D \angle E D=\wedge \quad[M] \cdot A \partial T \exists$

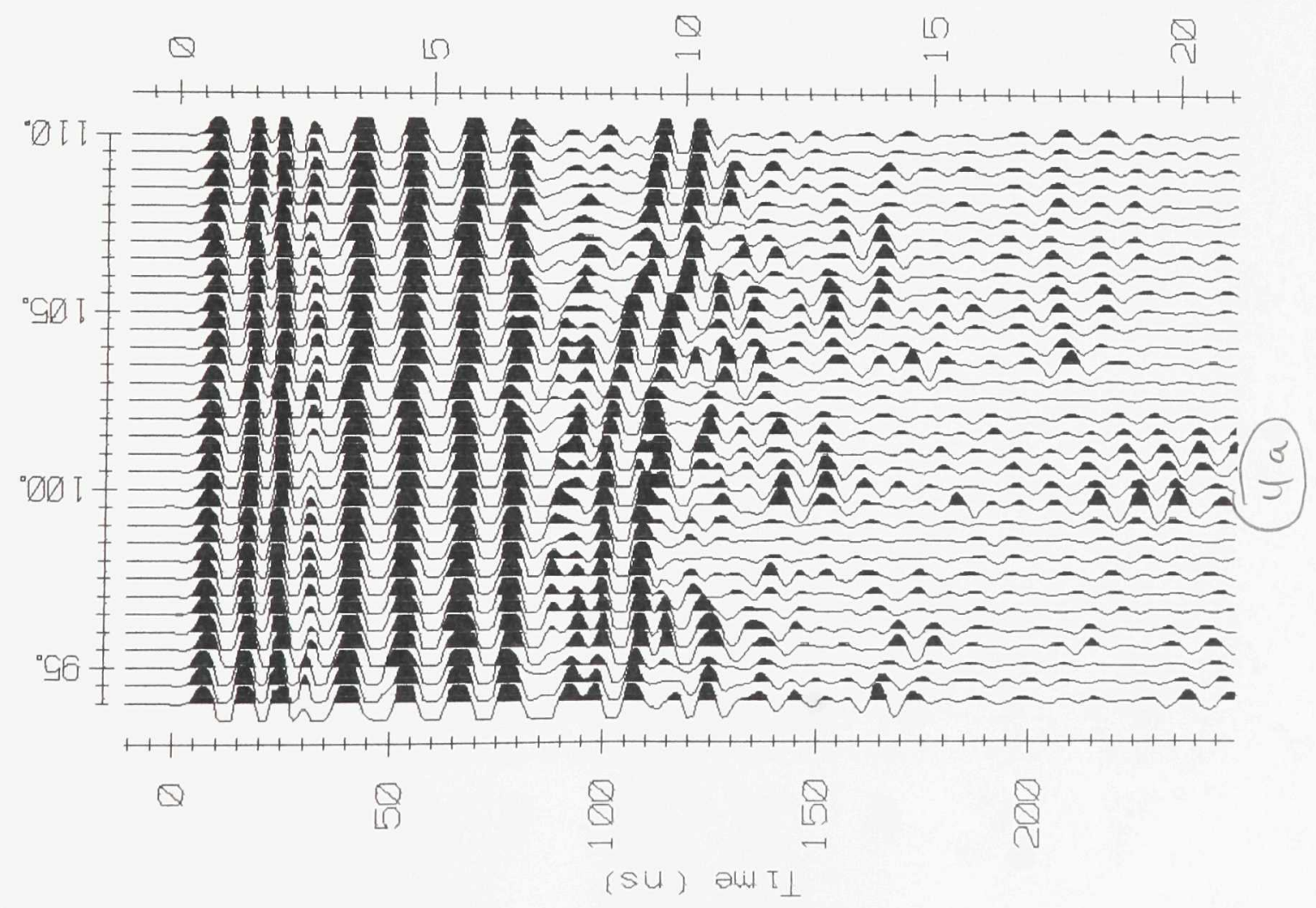



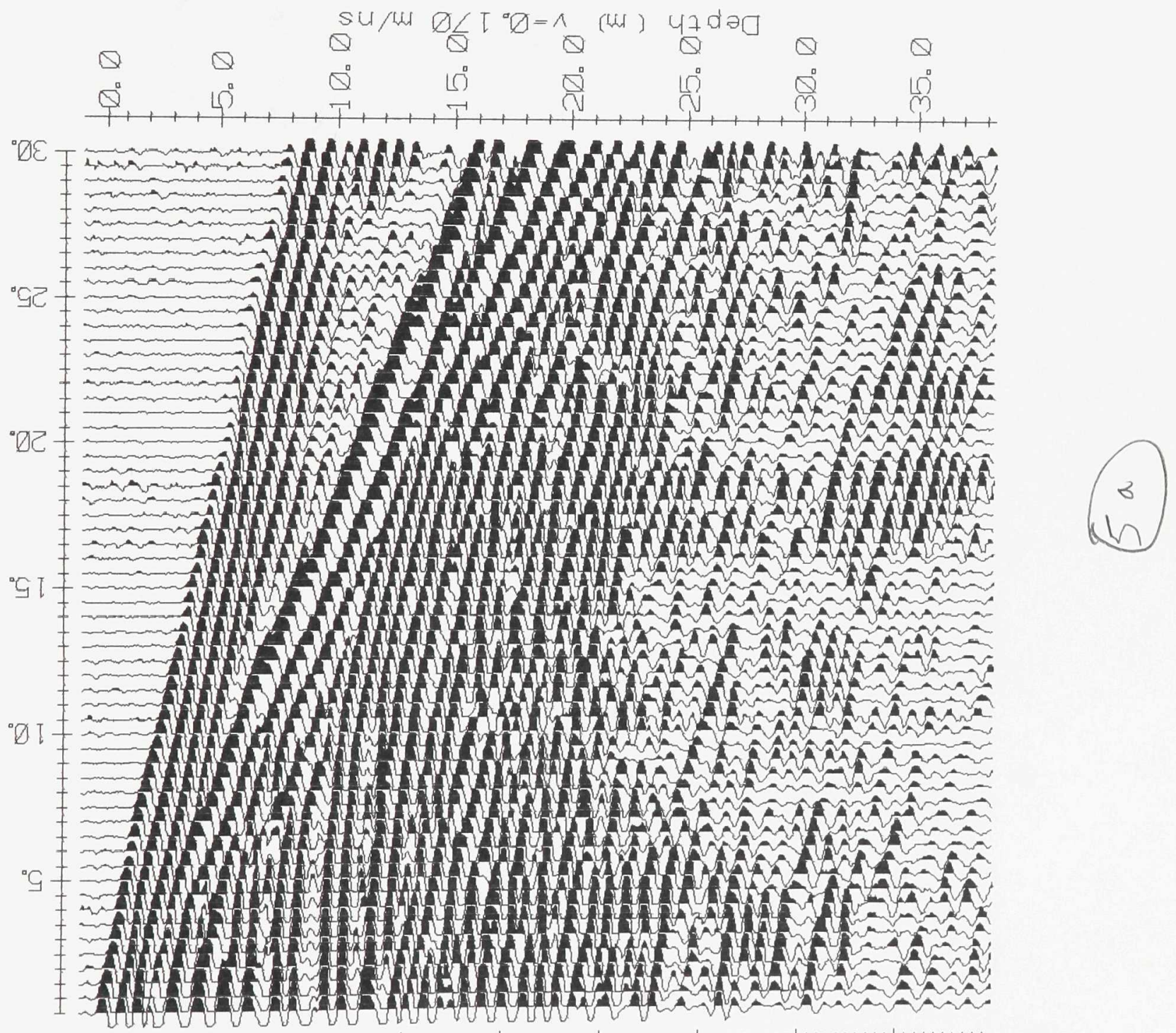

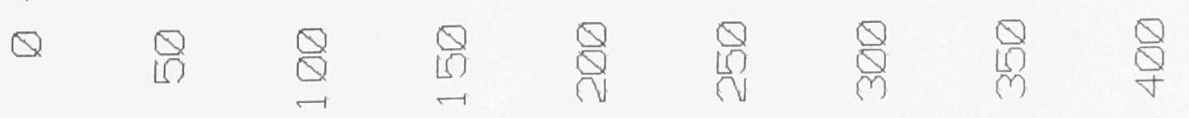


su $/ M \angle I D=\wedge$ (w) $47 d a$

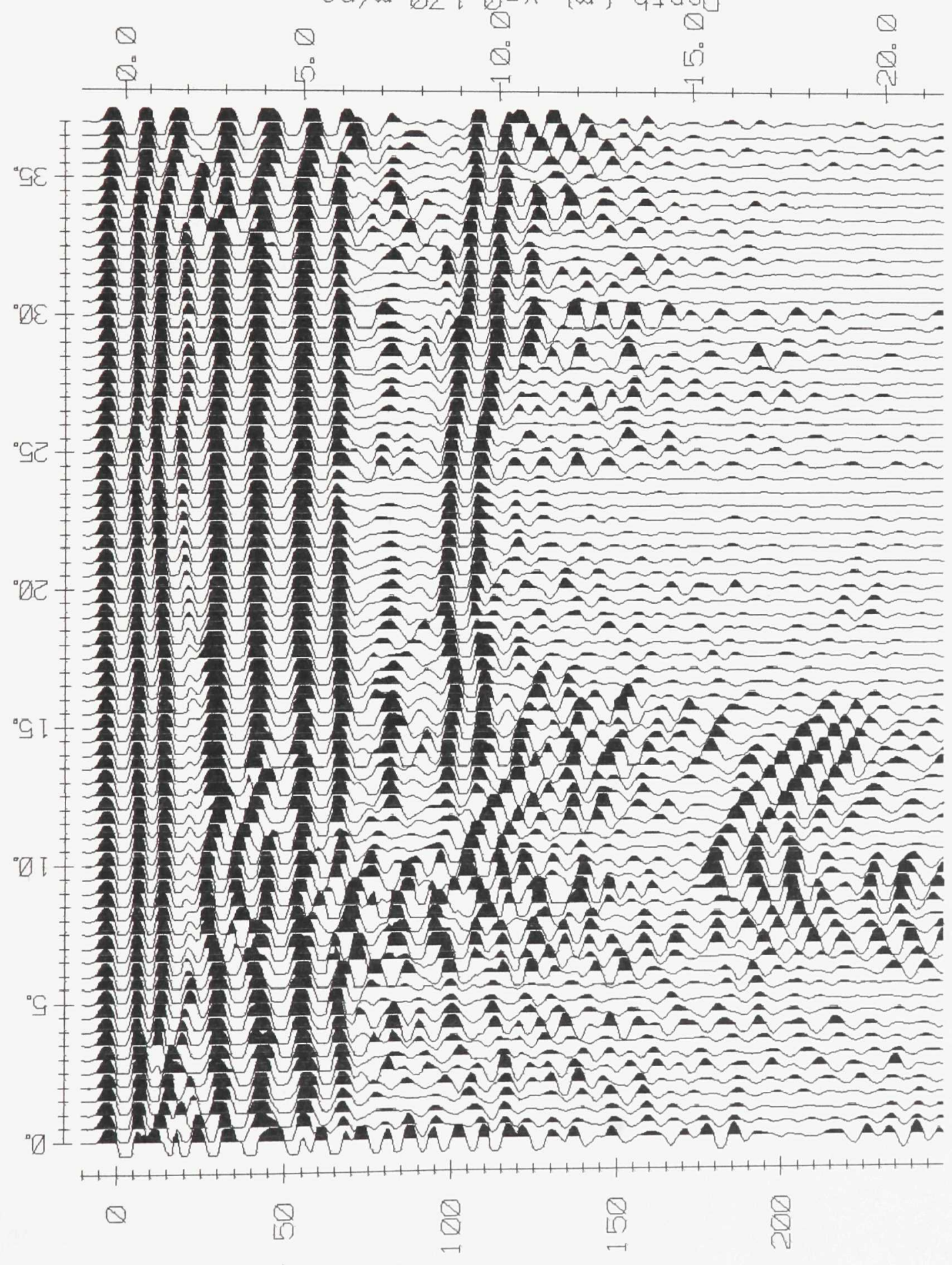




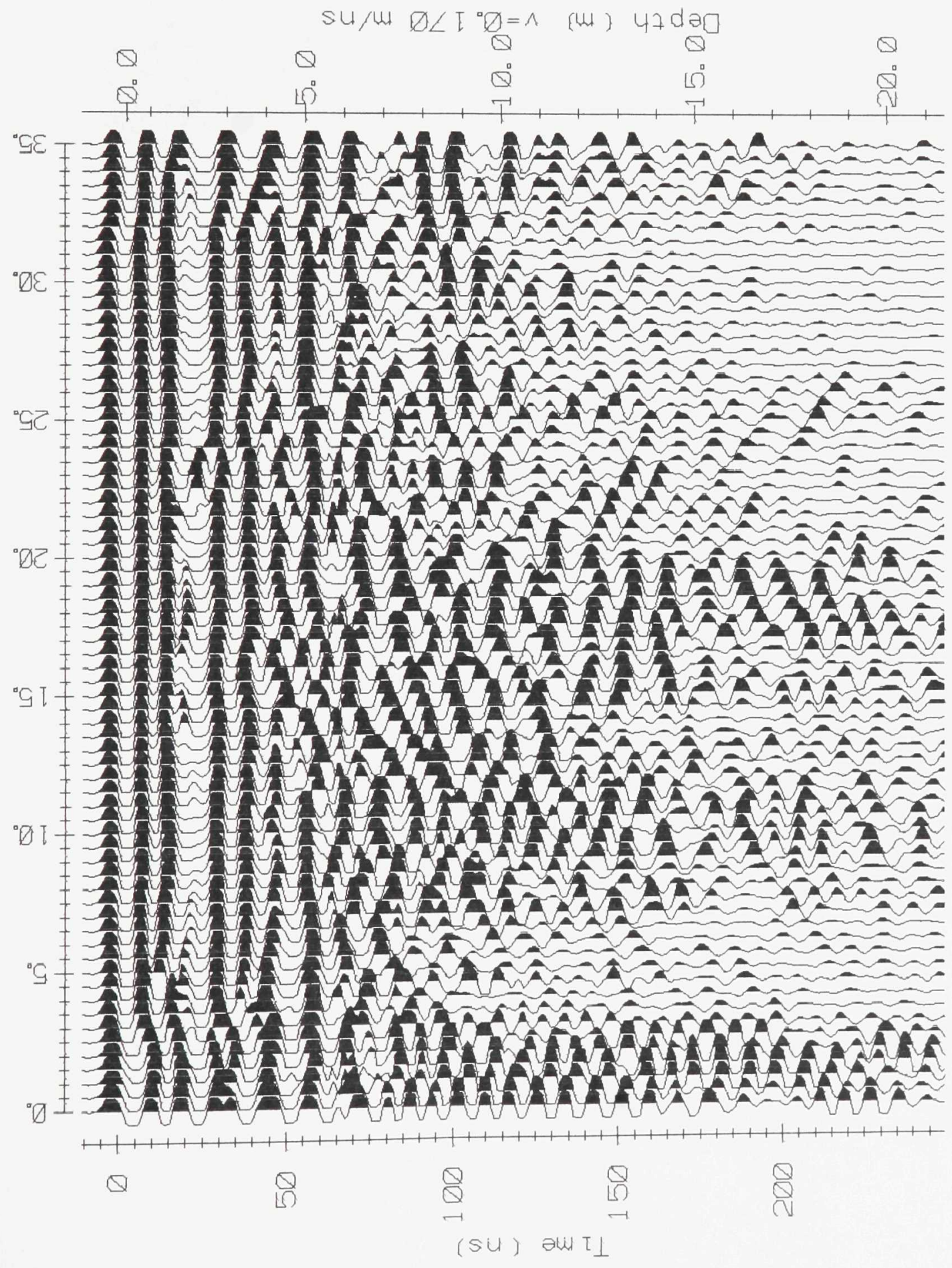


su/M $\square \angle I \square=\wedge$ [w] 47dכ0
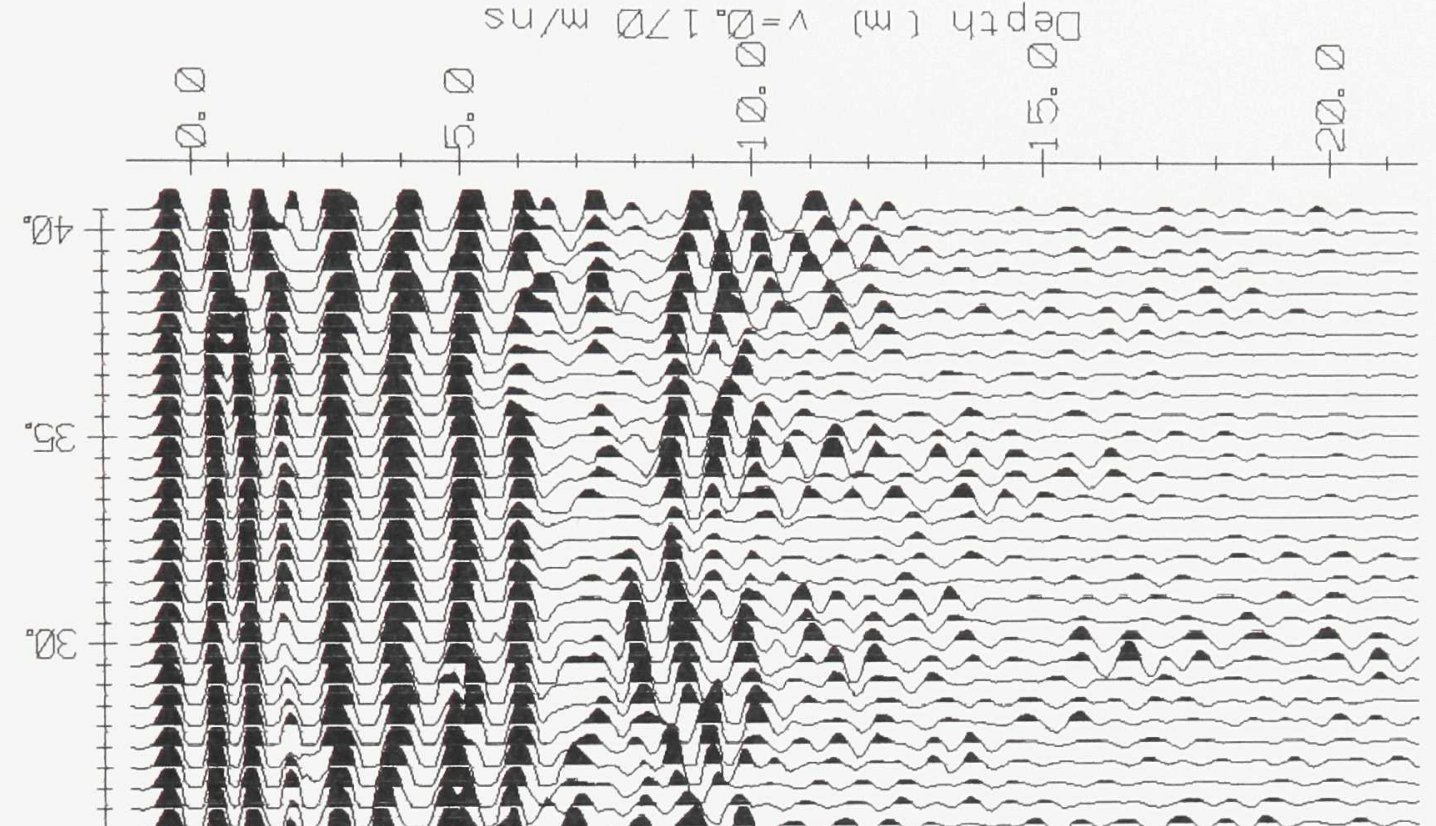

GC N NA

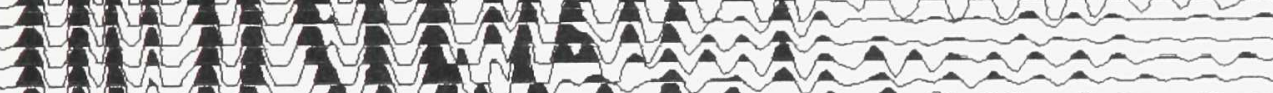

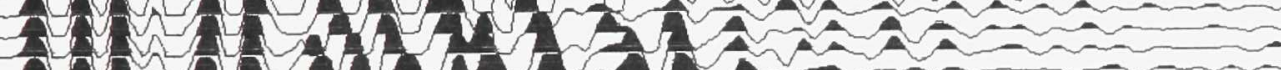

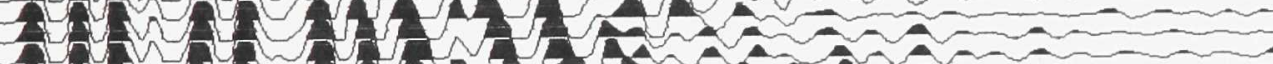

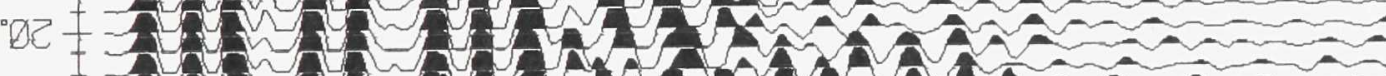

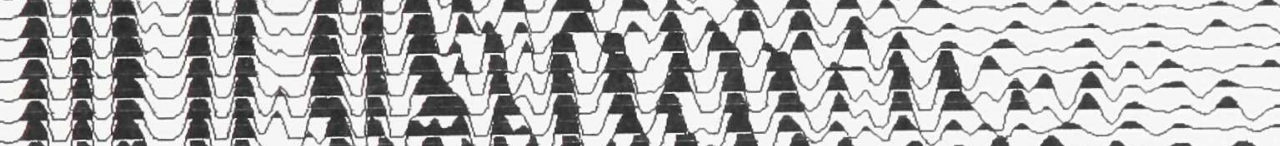

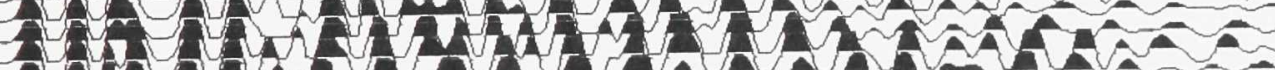

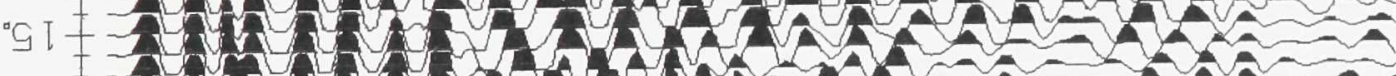

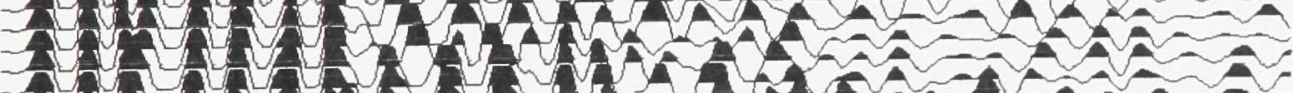

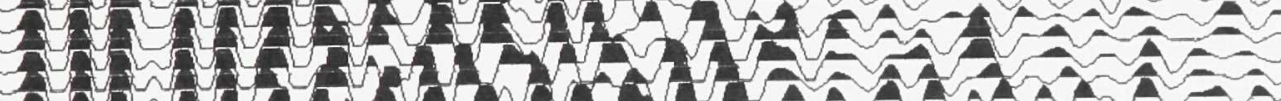

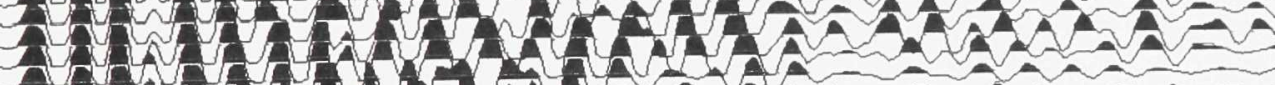
QI $=$ IN N 1 S

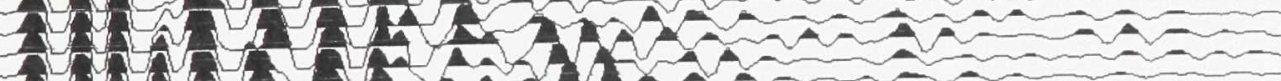

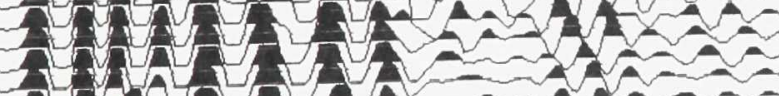

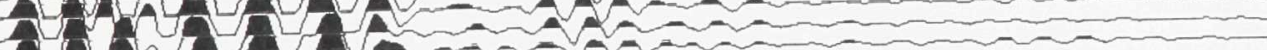

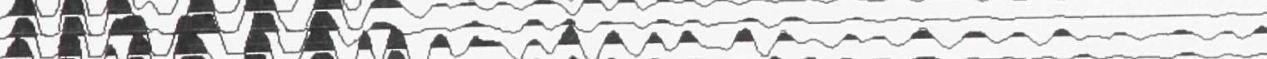
$)$ H $142=$ "Ø

Q

Q 


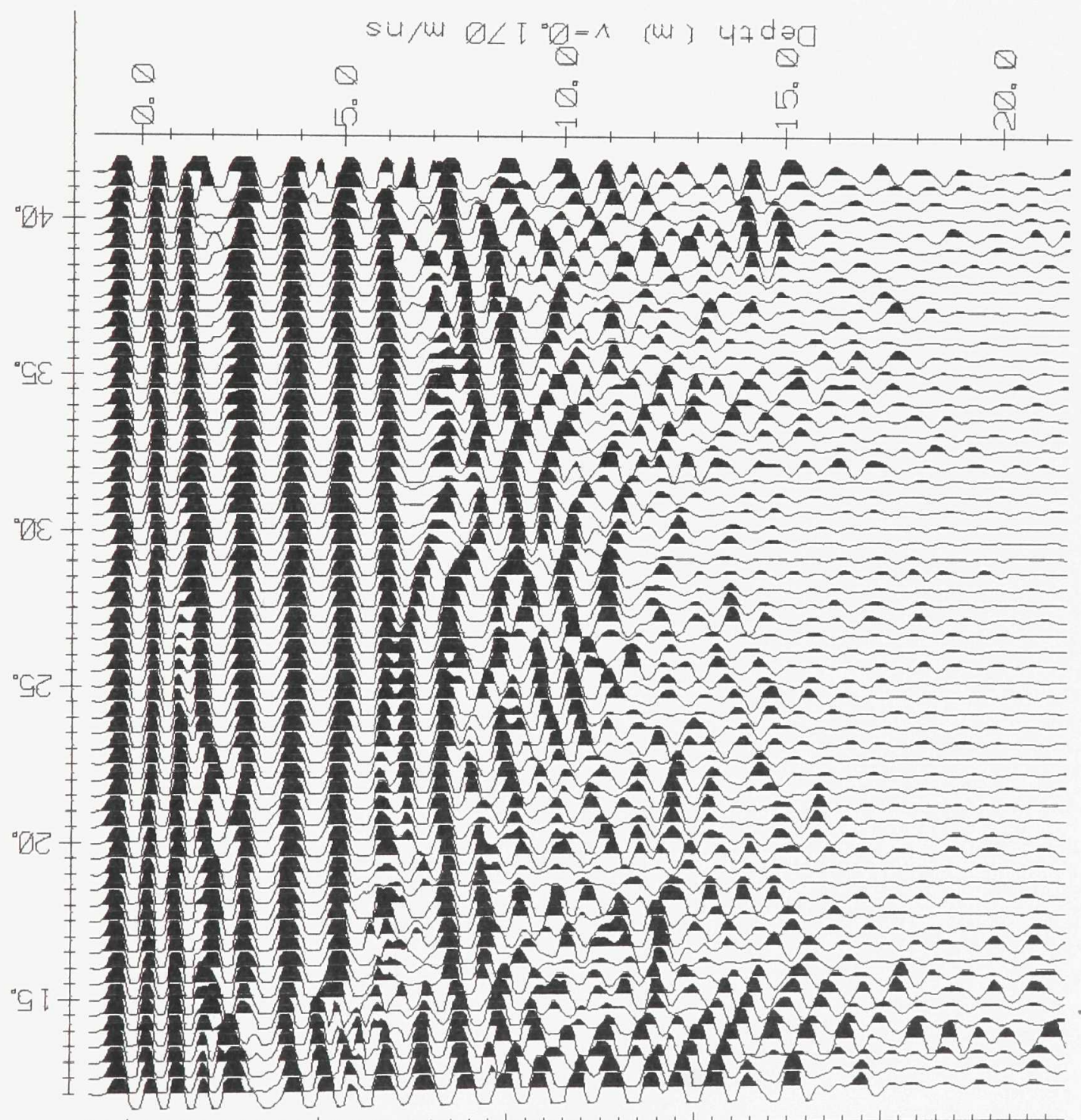

$Q$

Q

$Q$

Q

$\mathrm{Q}$ 


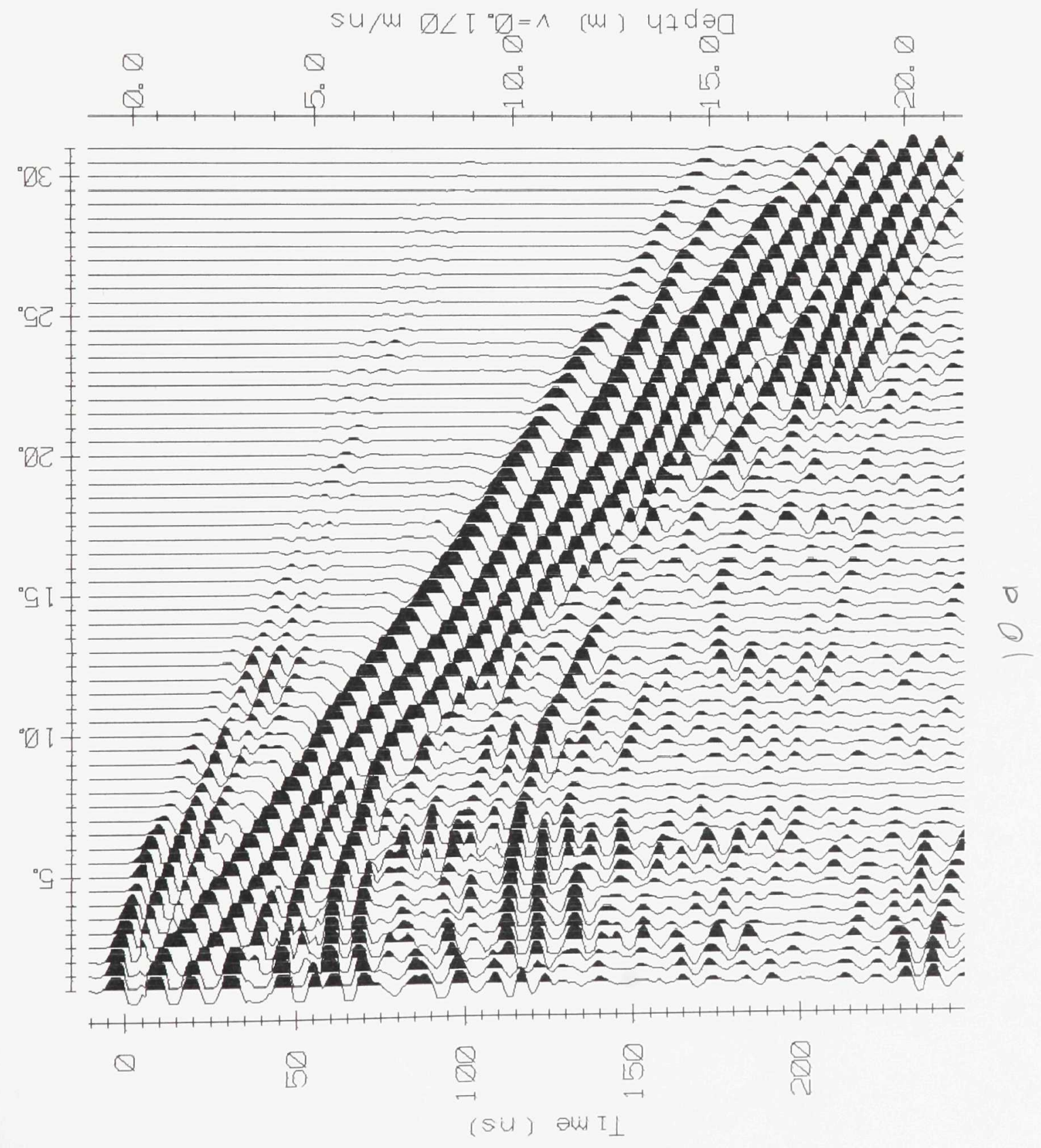




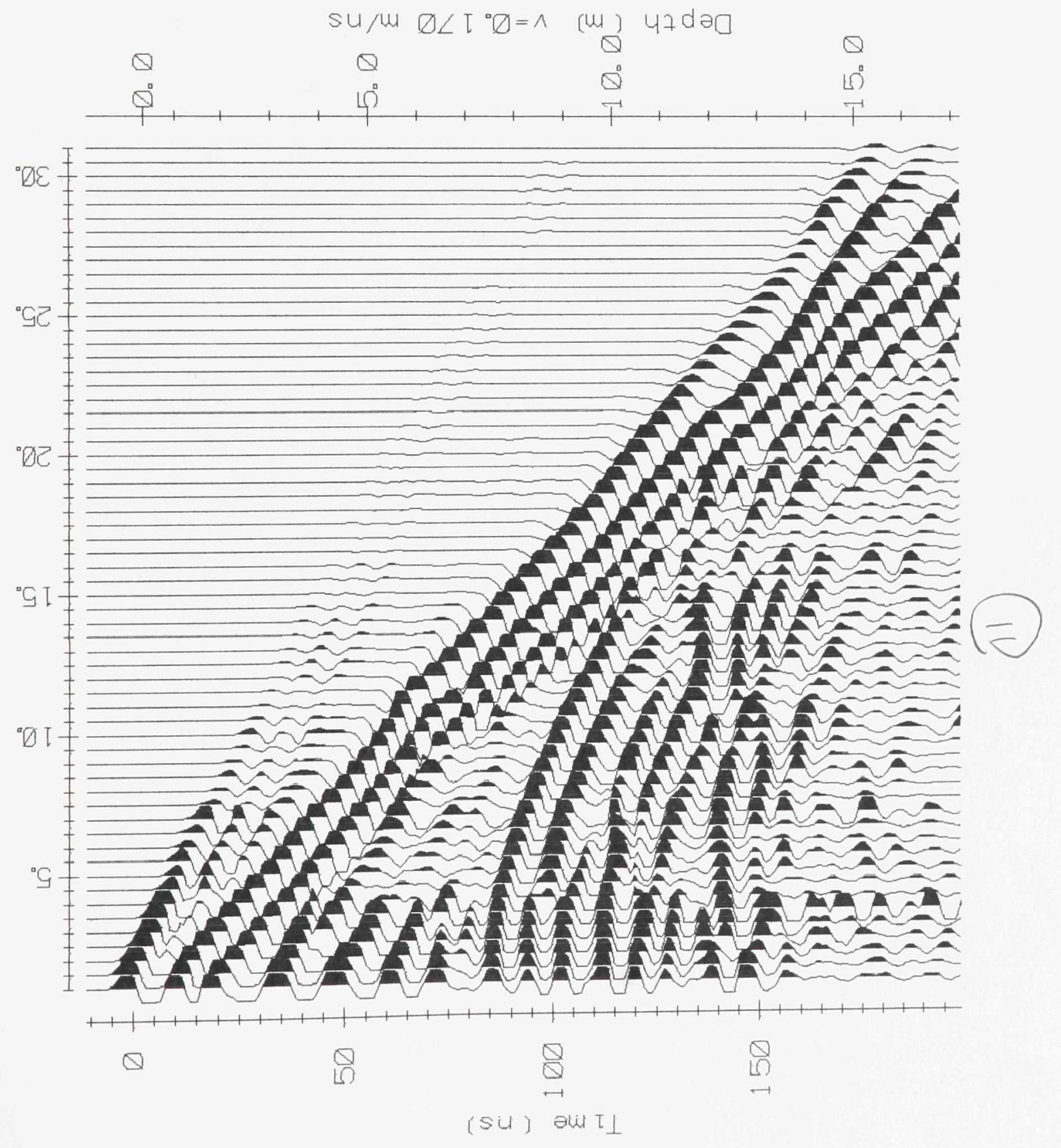




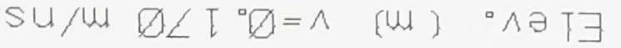

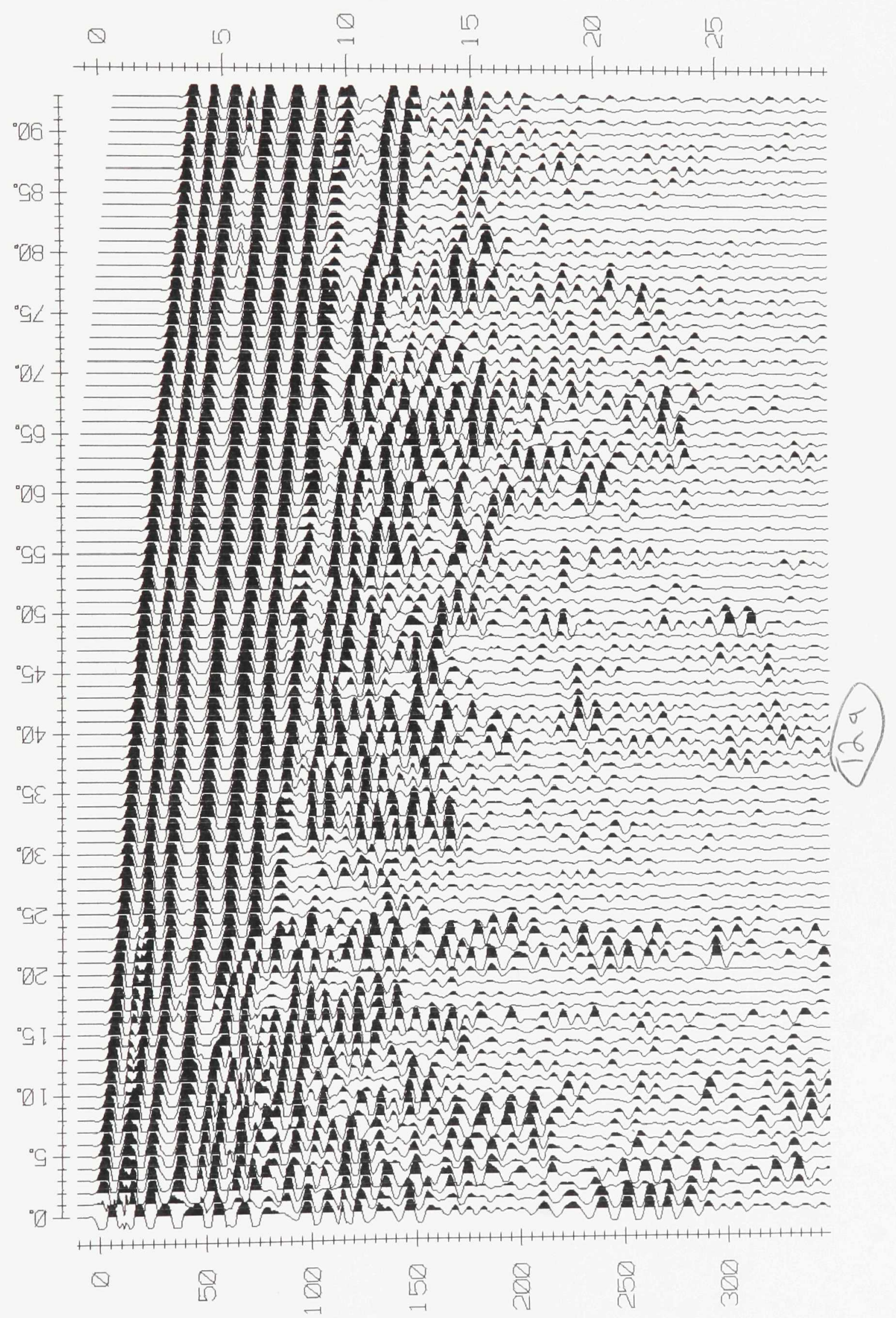




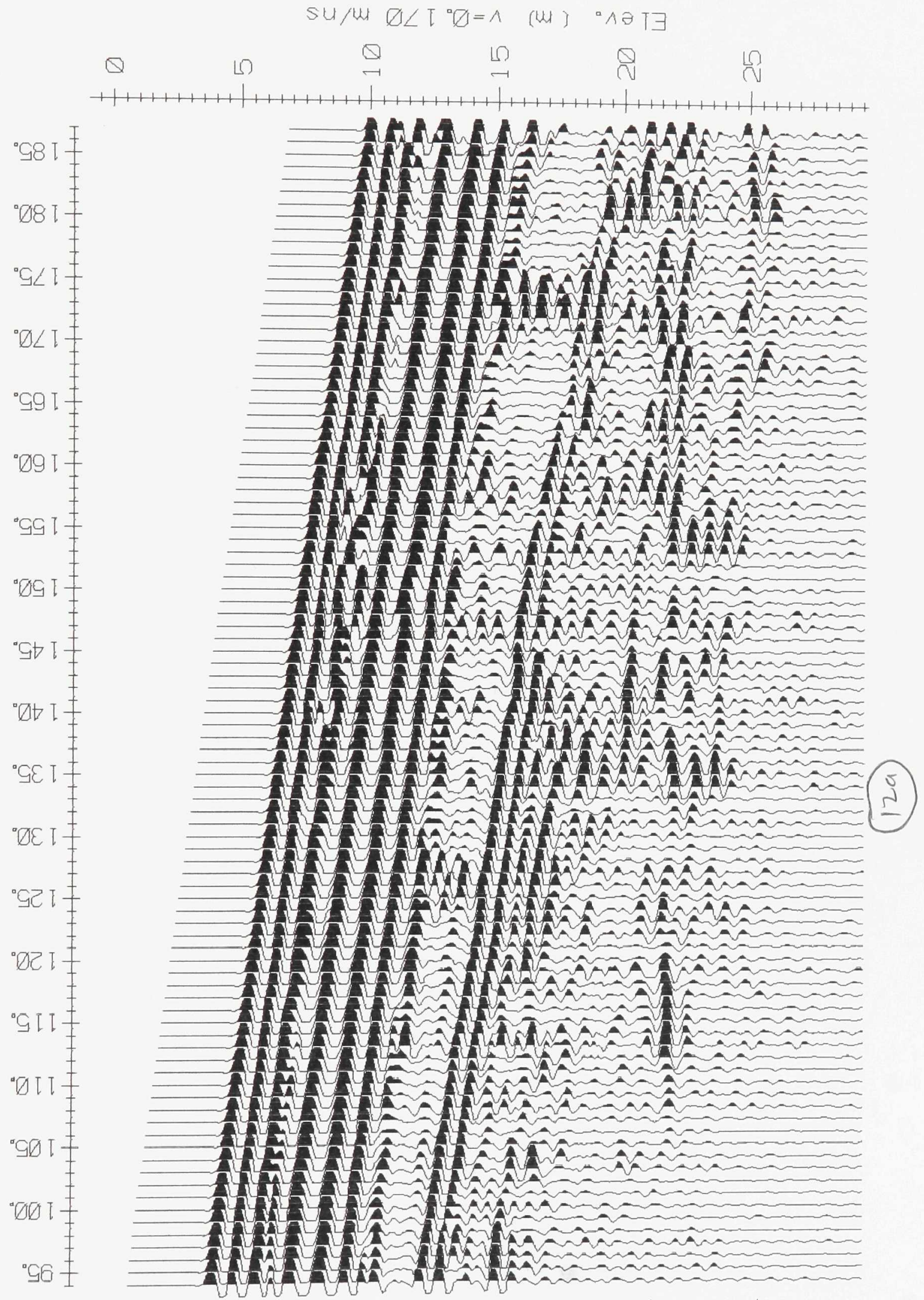

Q
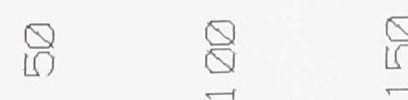

ए

पि बे 


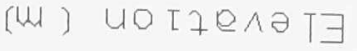

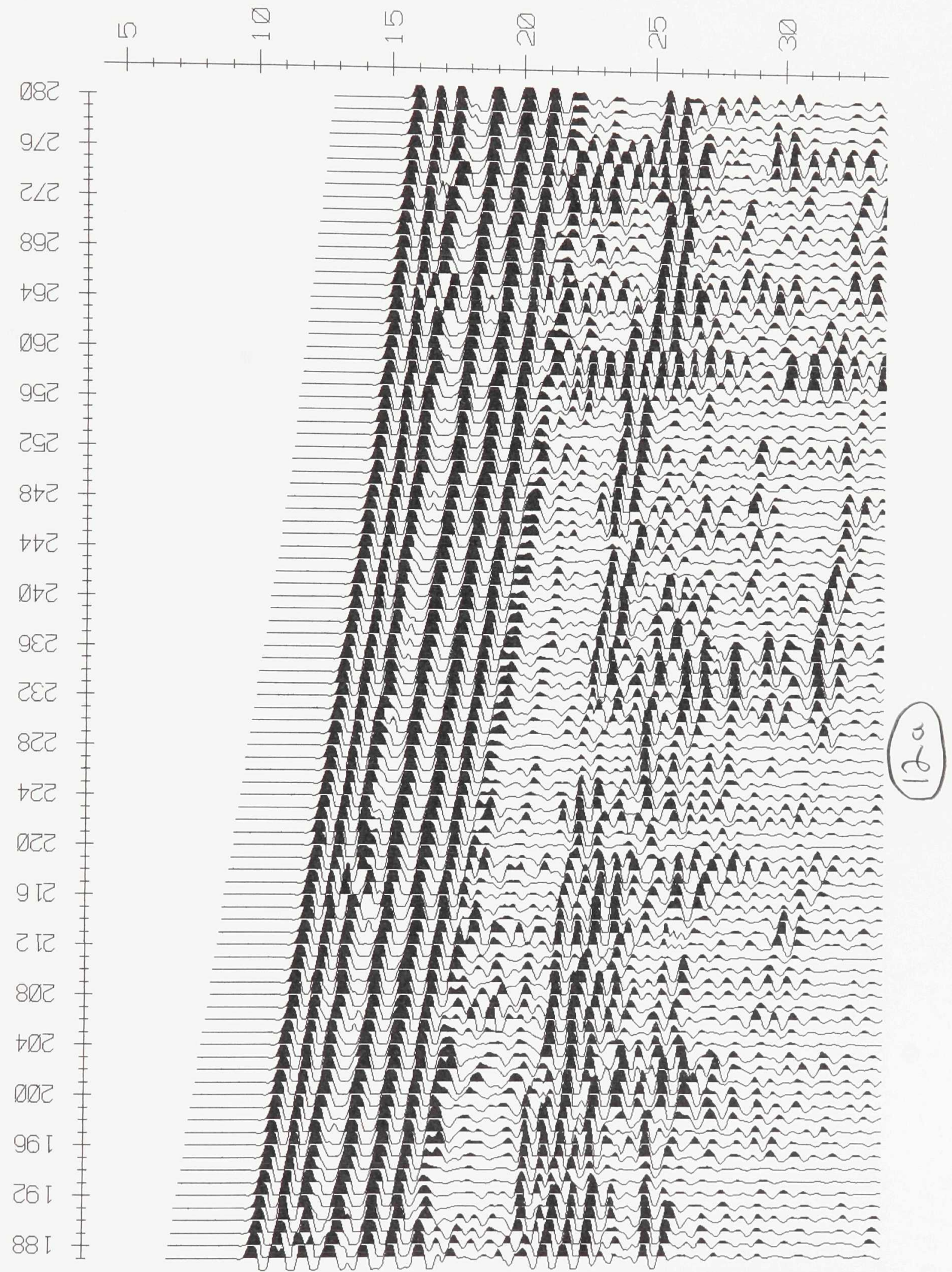

$\mid 1111111$

$\begin{array}{ll}Q & Q \\ \square & \square\end{array}$
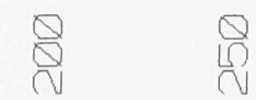

ले

ल ब 
(w) Uo ta사

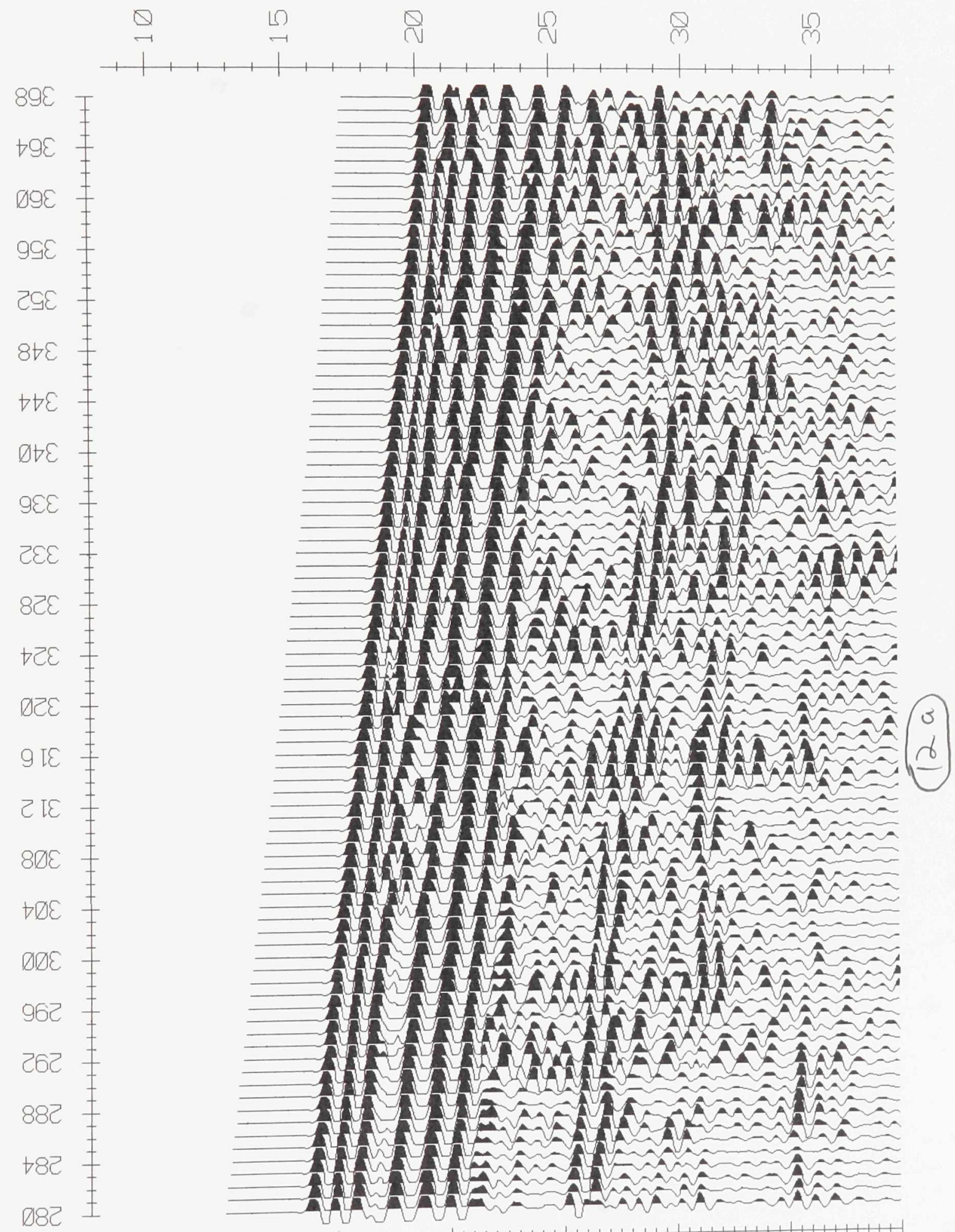

(D) 


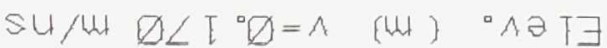

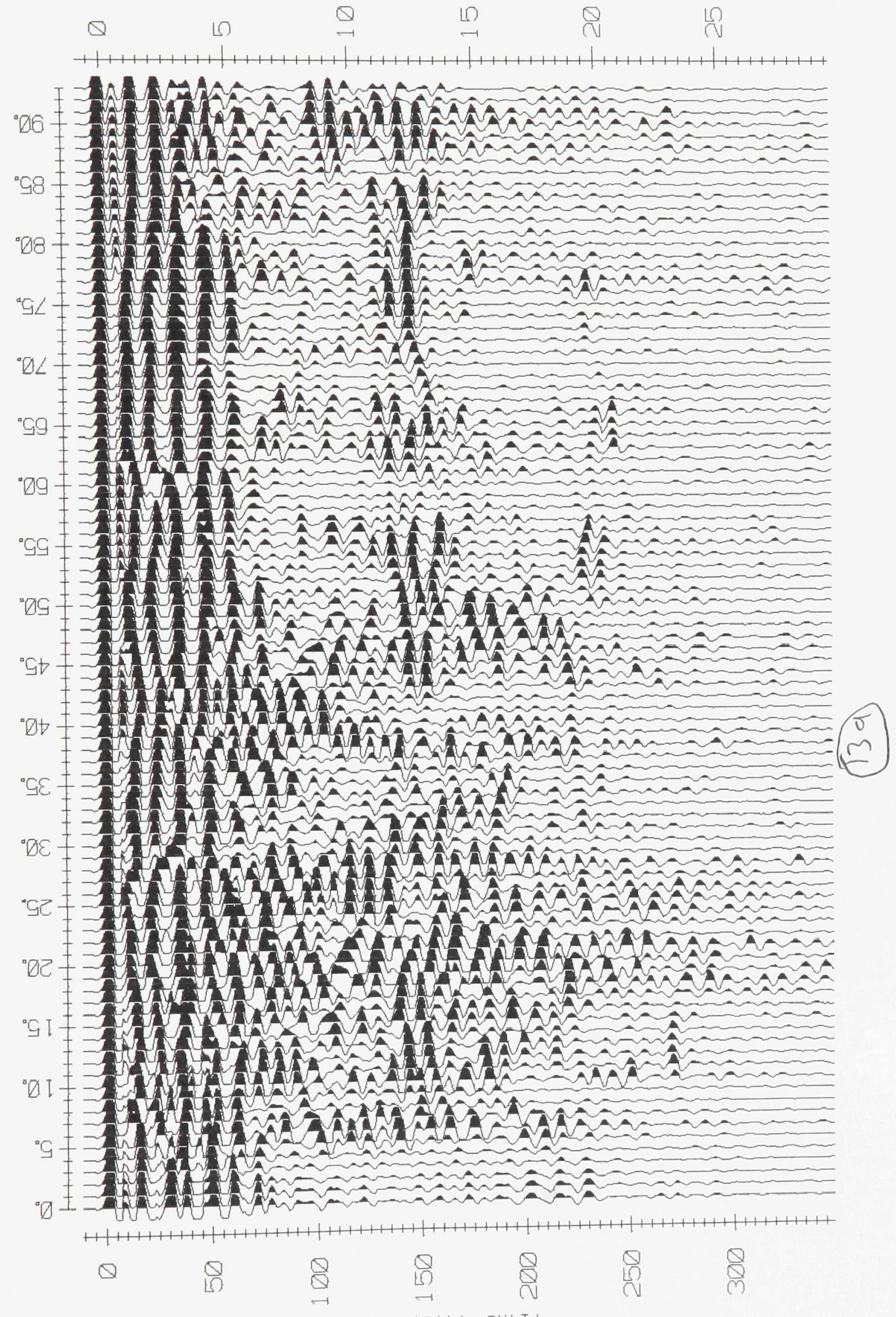




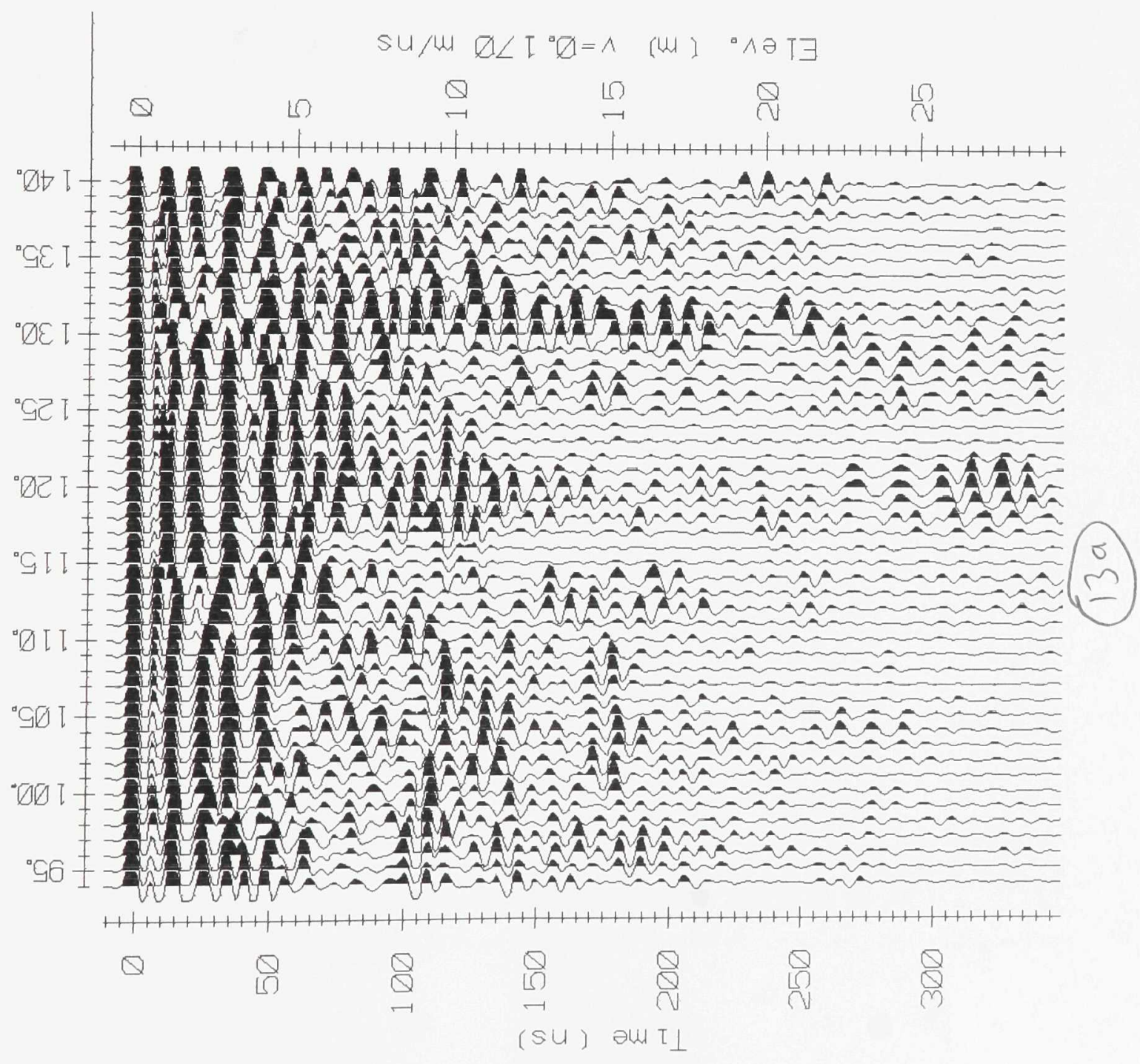




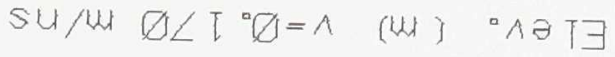

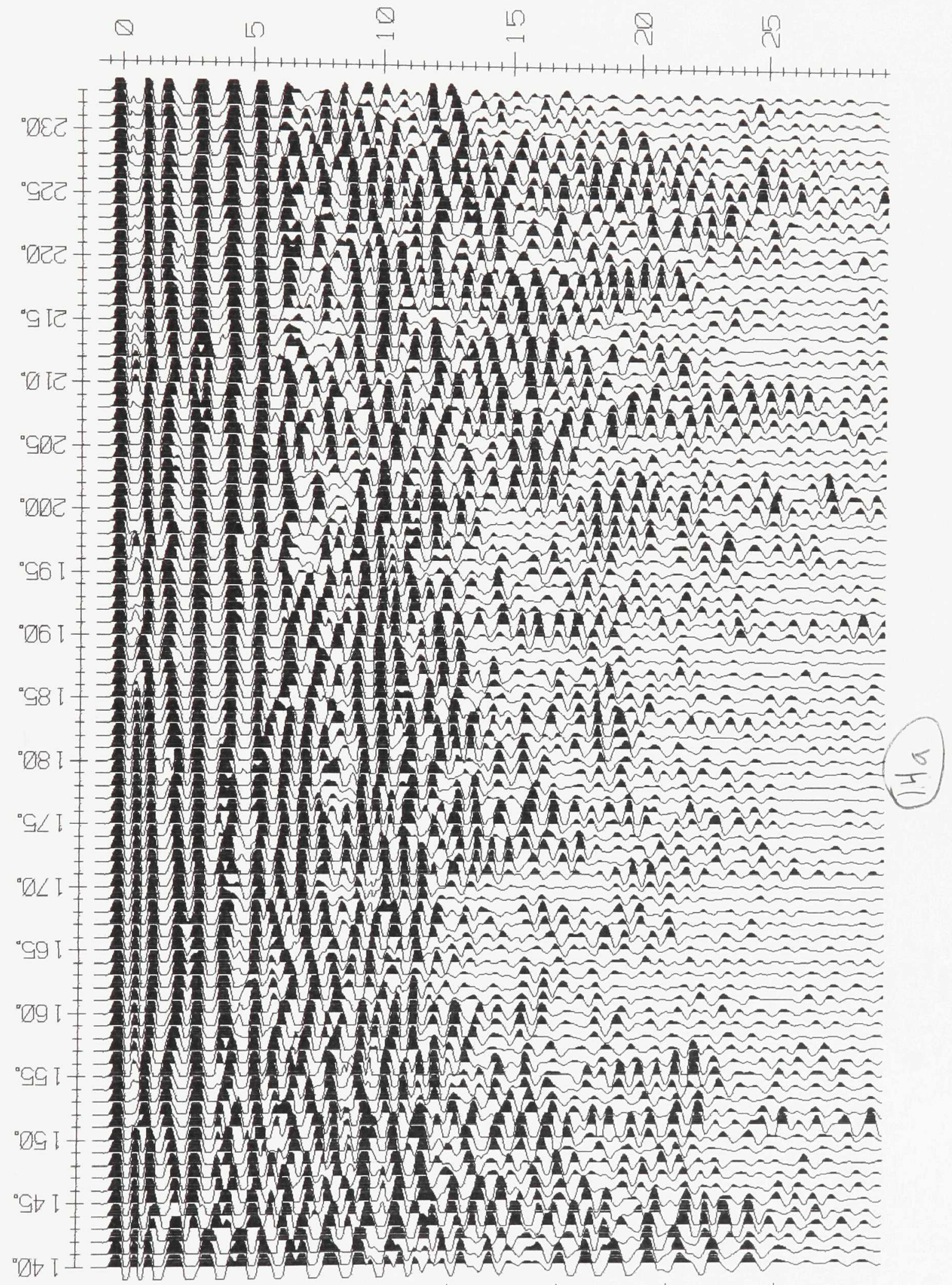


su/M $D \angle\left[{ }^{\circ} D=\wedge \quad\right.$ (WH ) ${ }^{\circ} \wedge \supset T \exists$

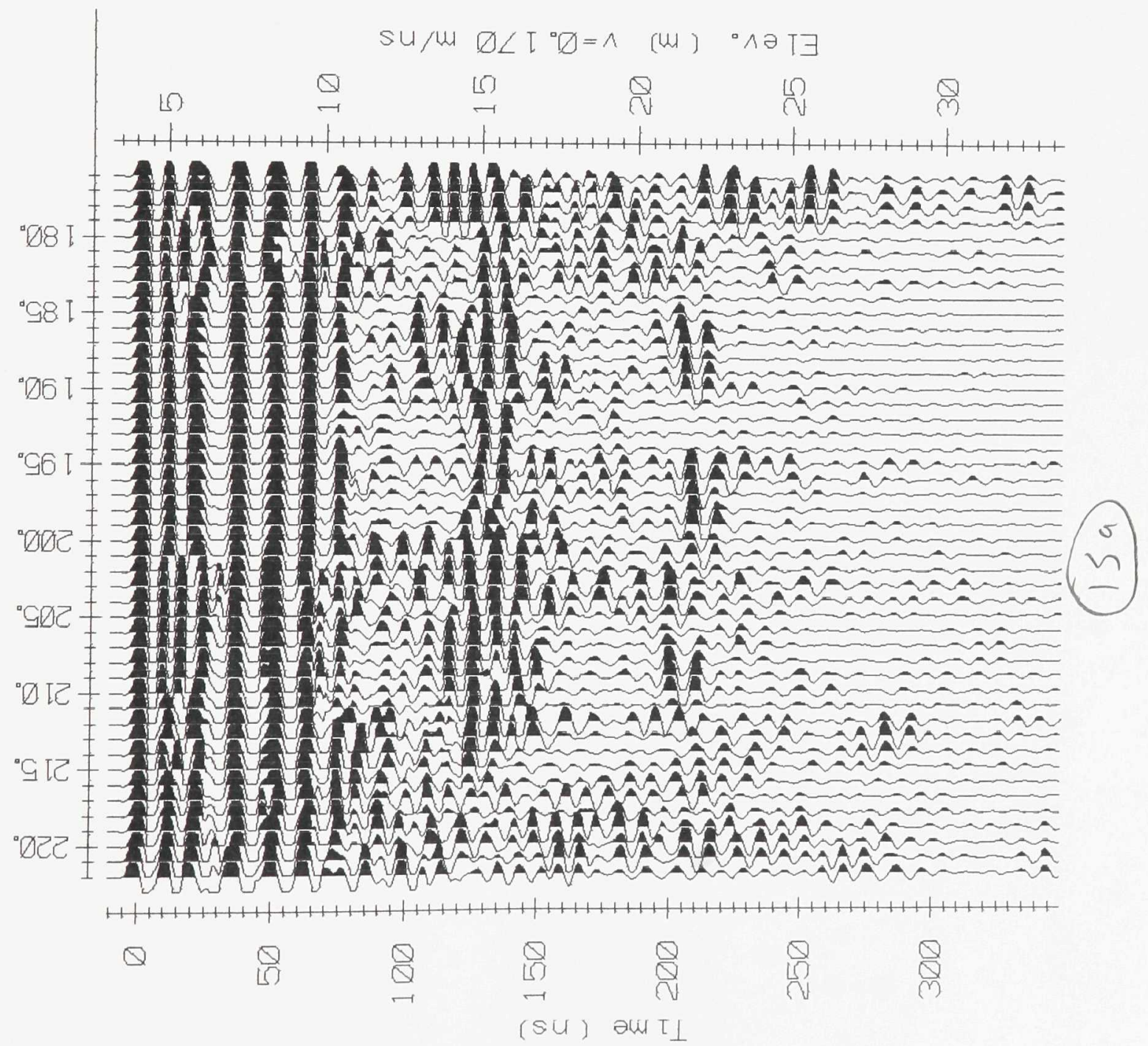




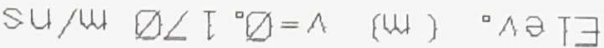

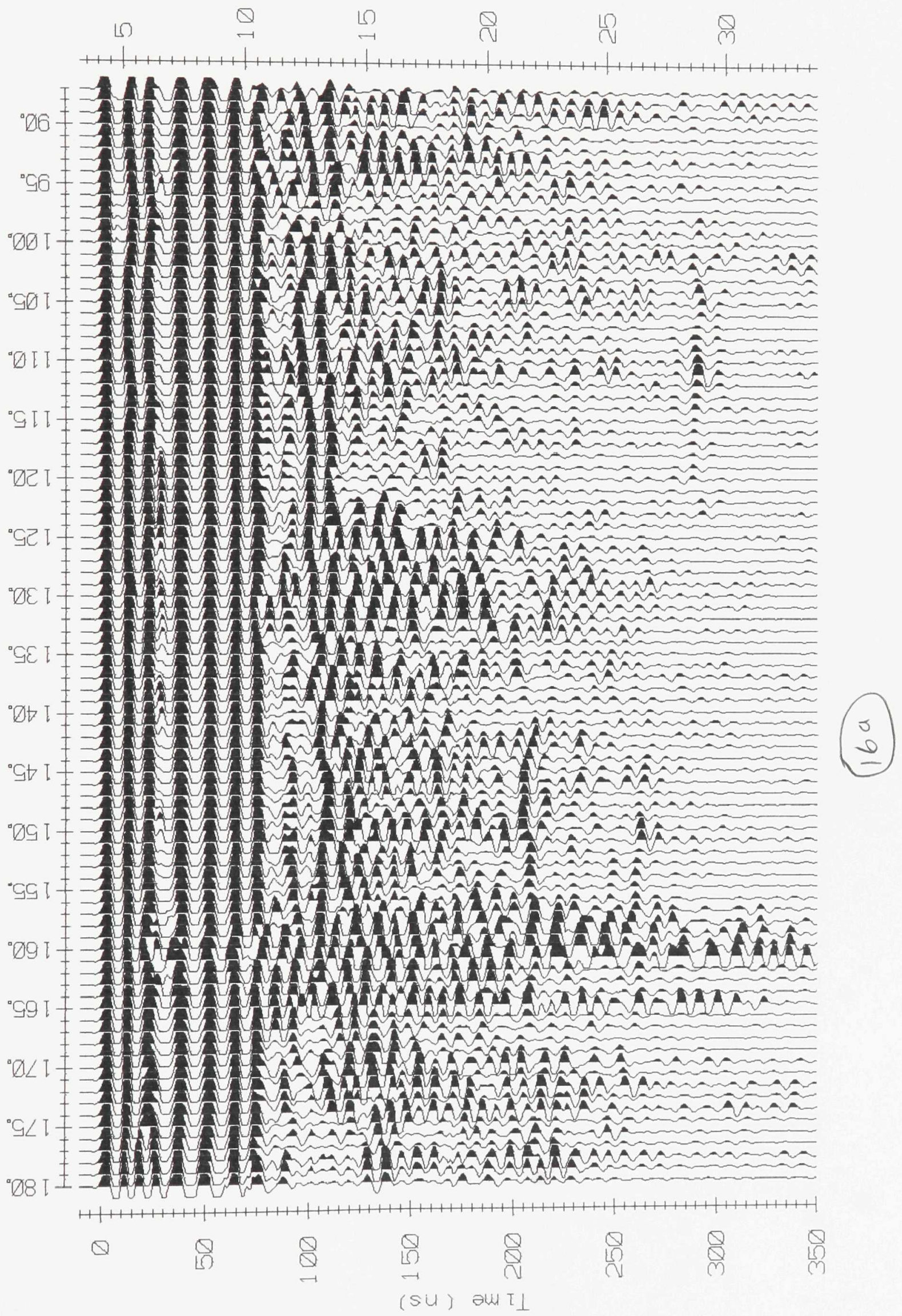




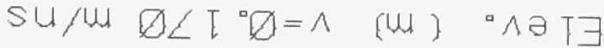

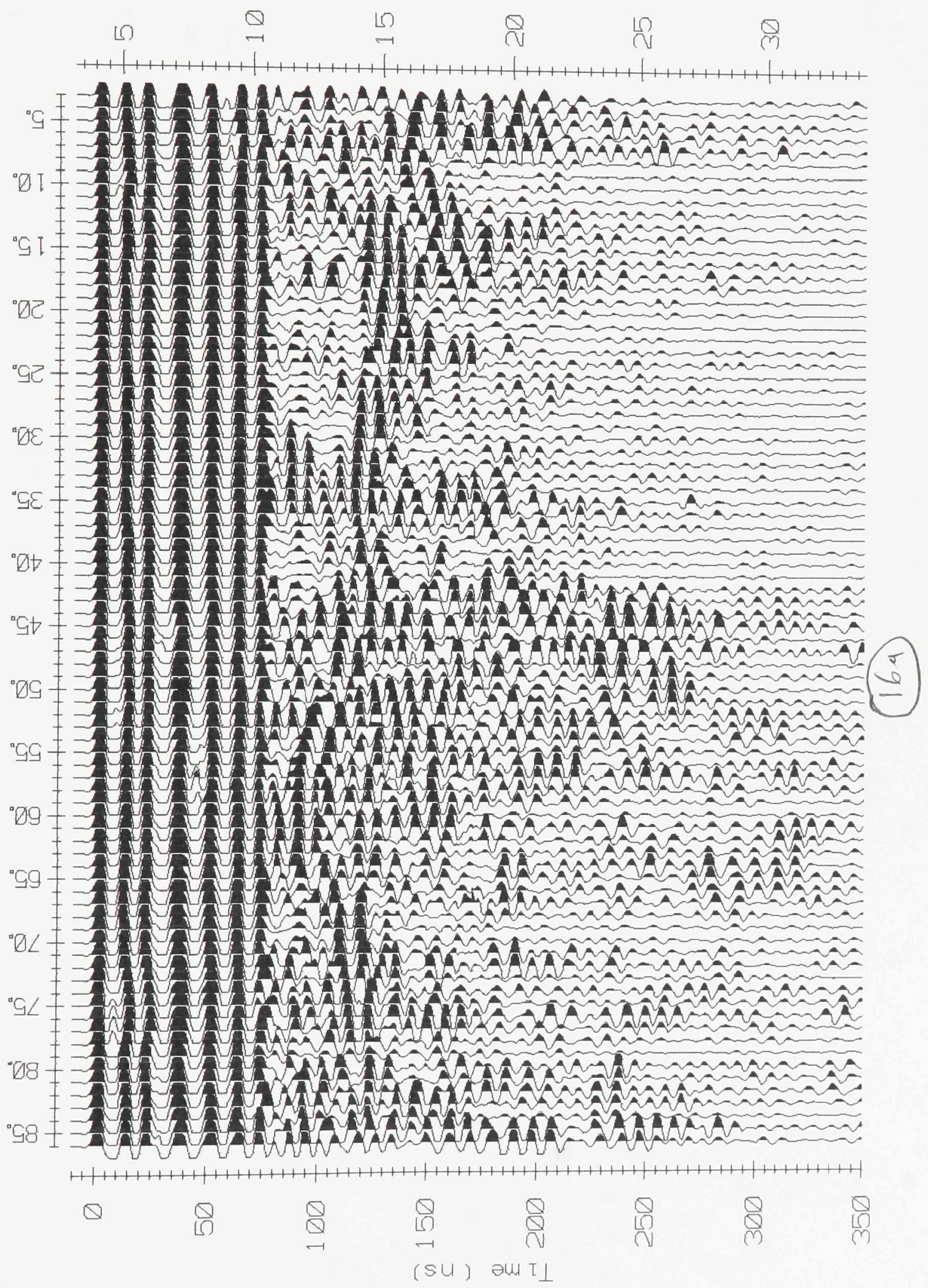




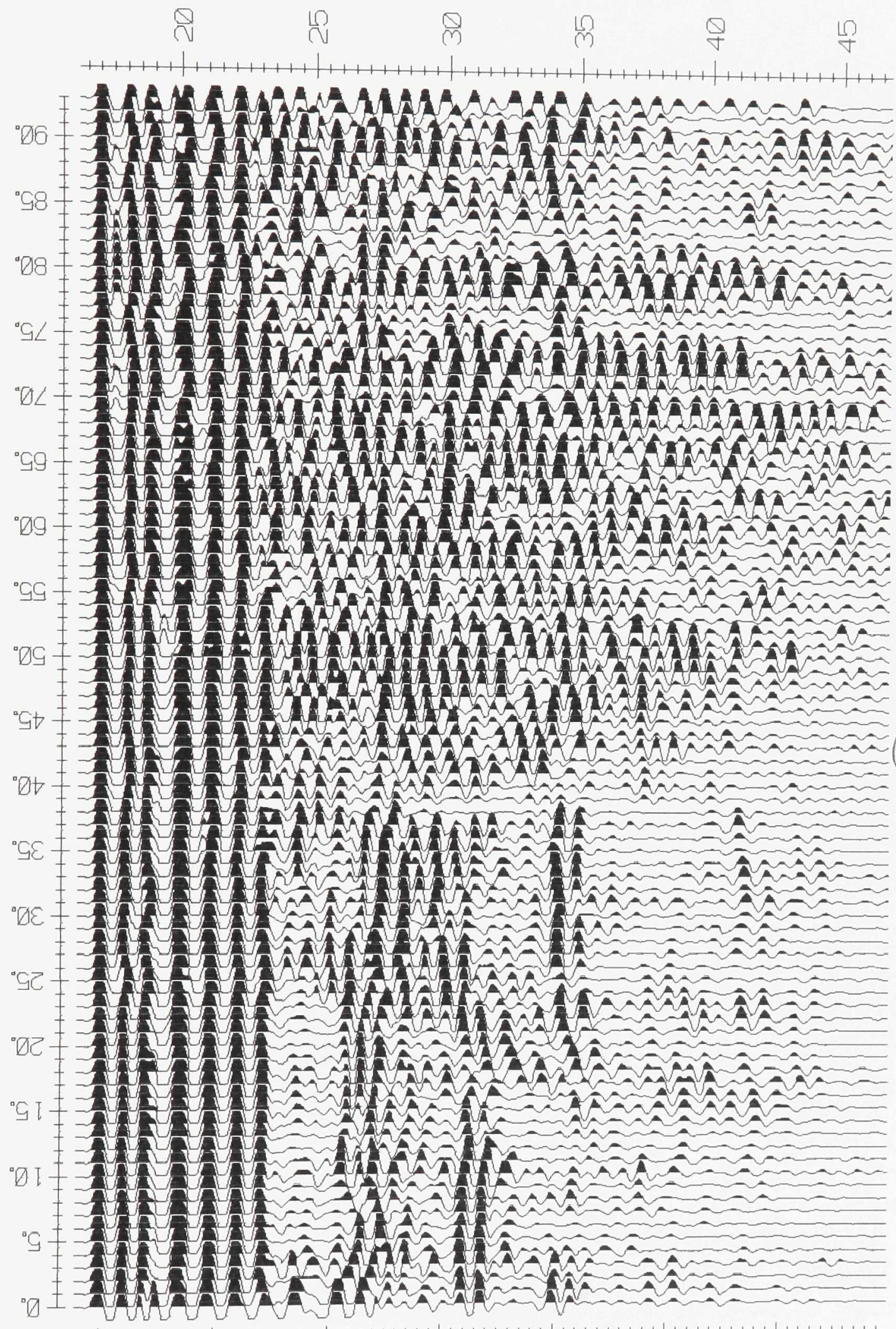



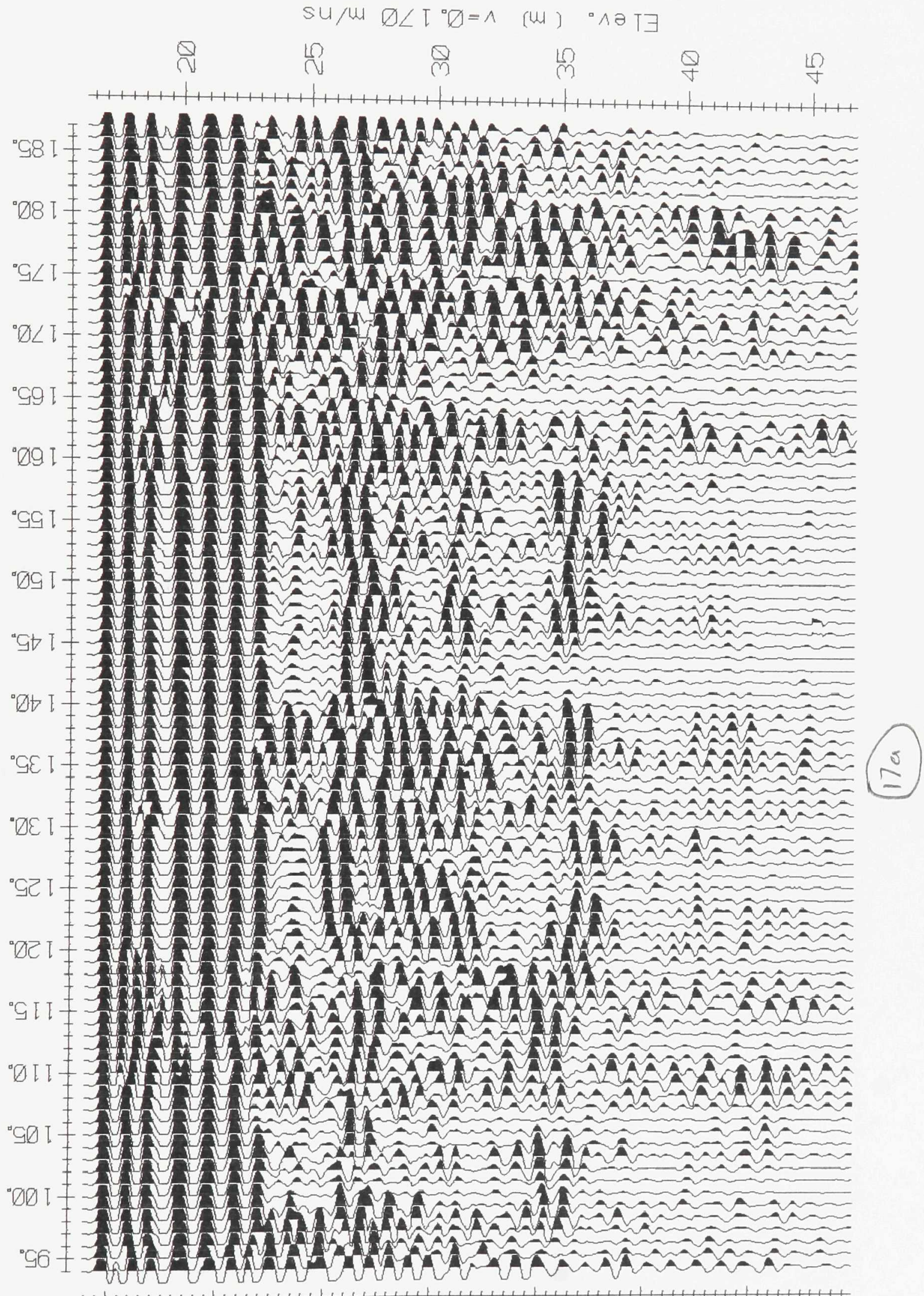
su/M $\varnothing \angle T{ }^{\circ} \oslash=\wedge$ (w) ${ }^{\circ} \wedge \partial T \exists$

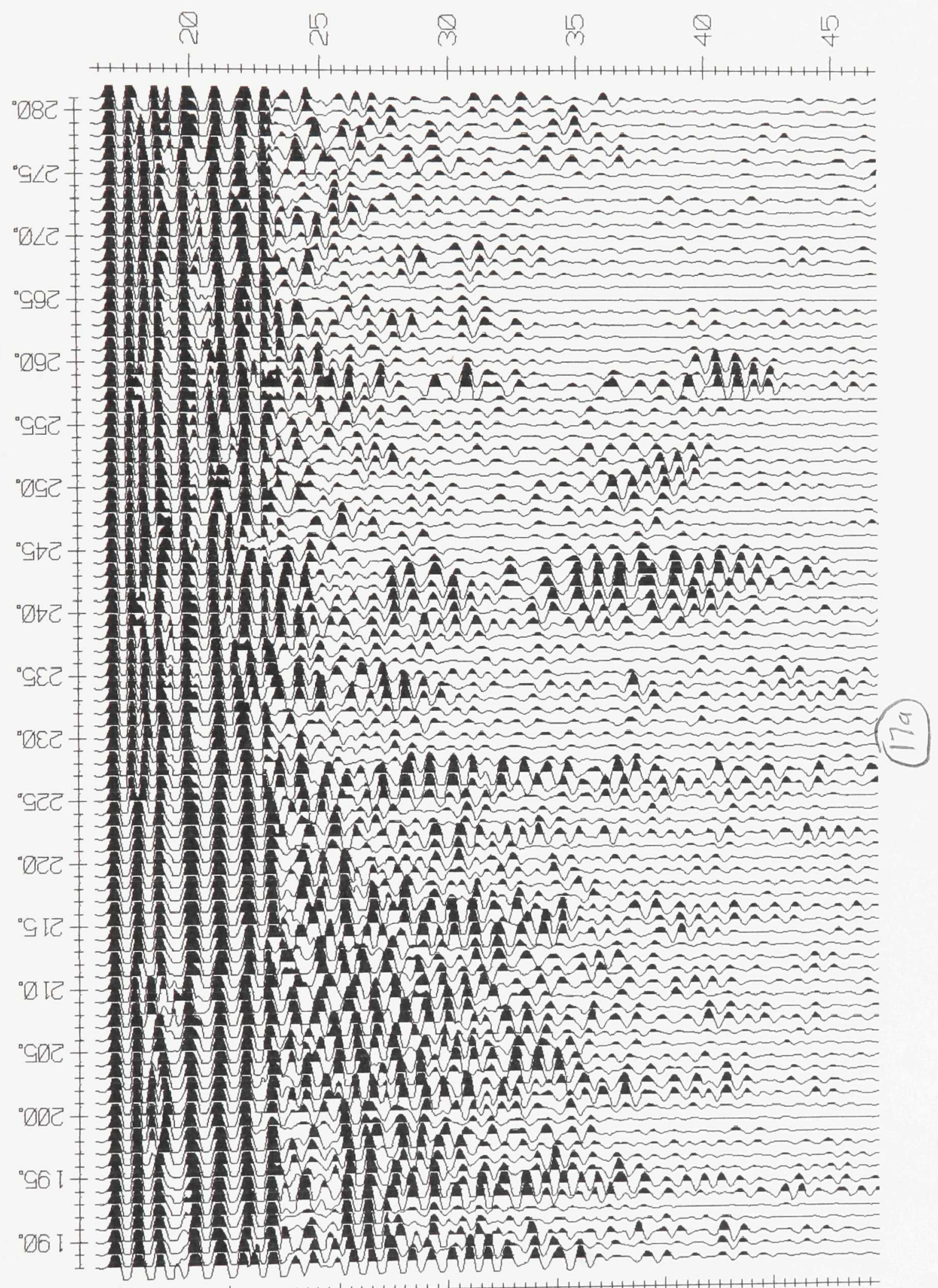

Q

है

8

这

8

遏

\& 


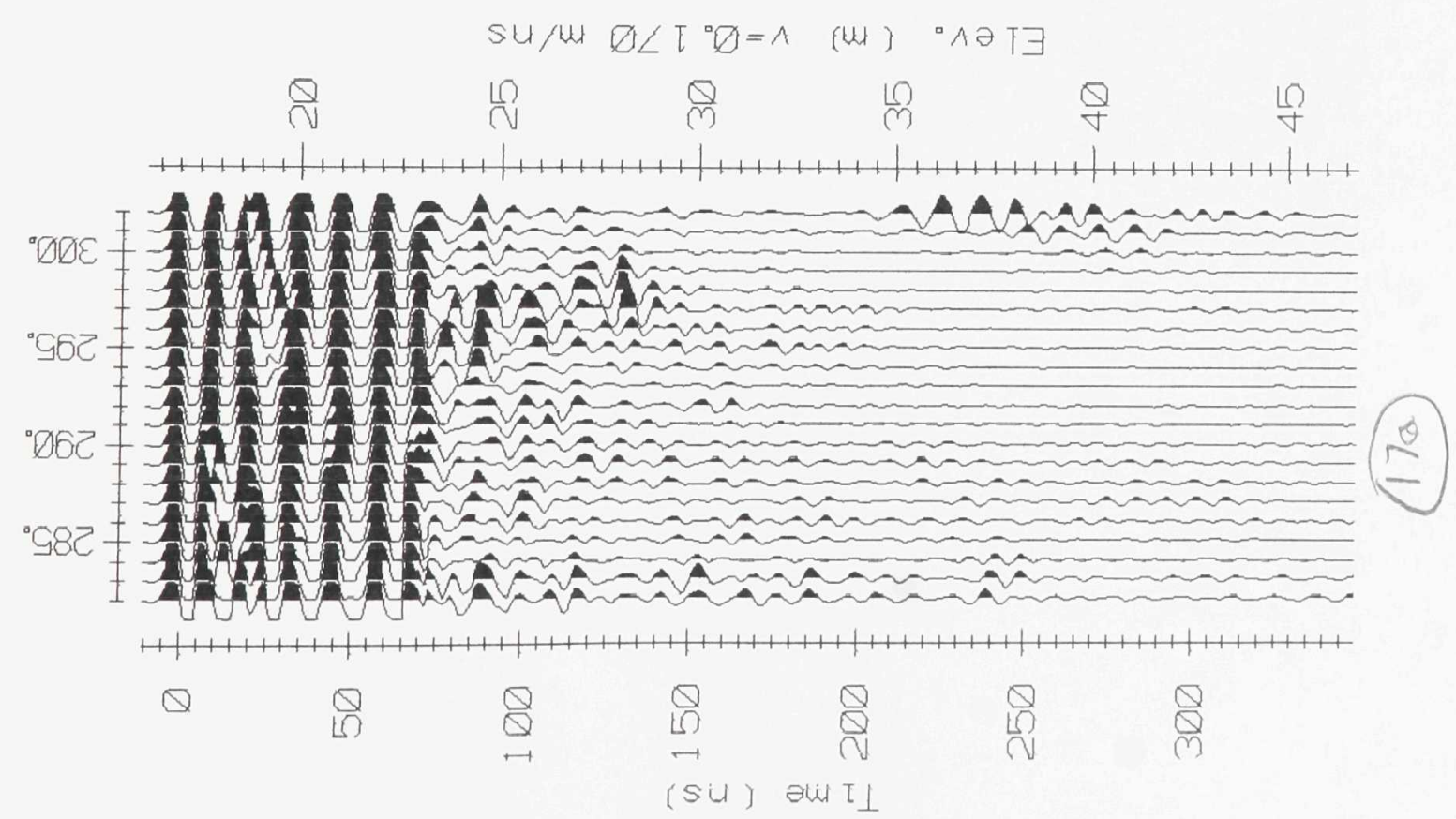




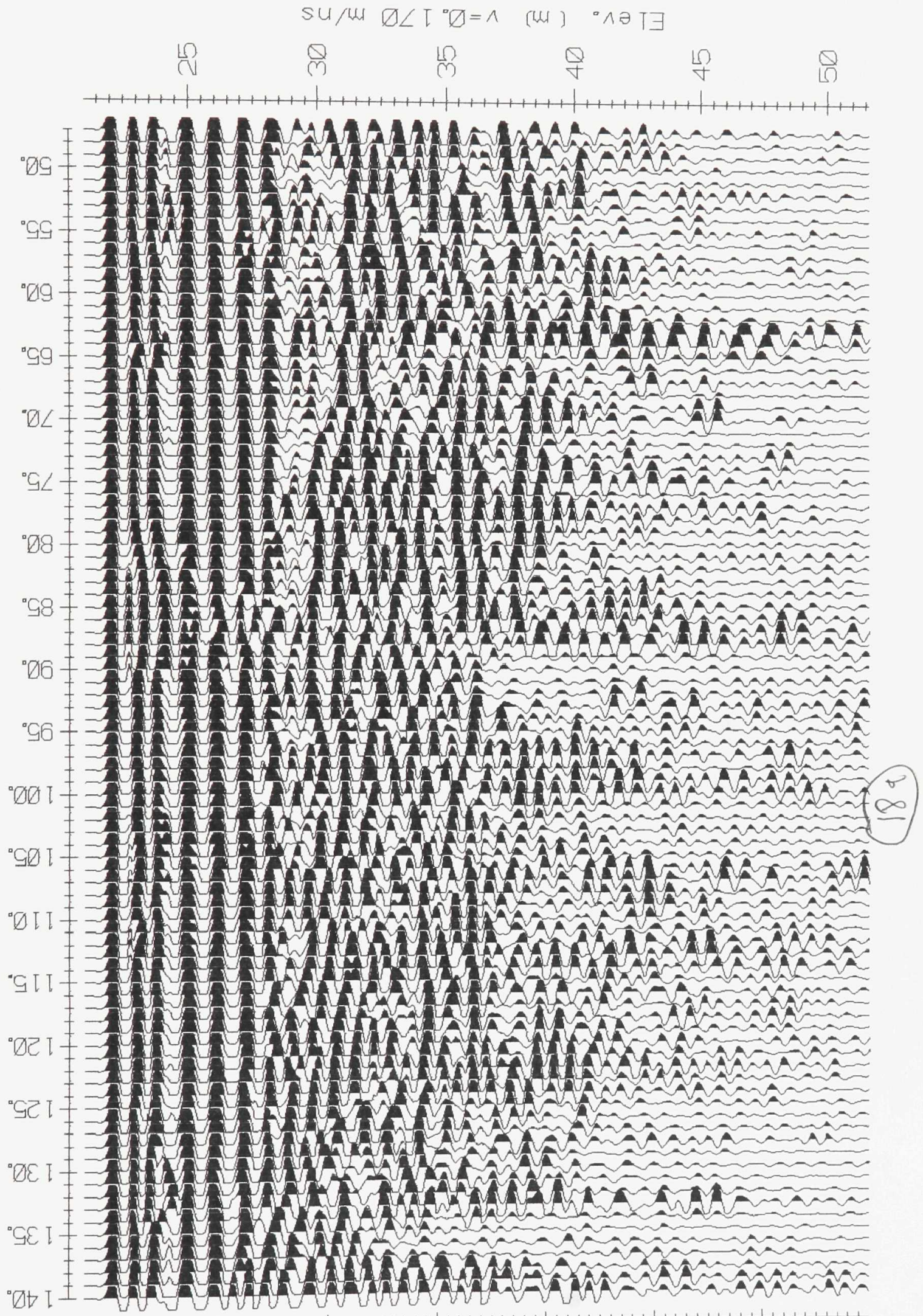


su/ut $\square \angle T{ }^{\circ} \square=\wedge$ (w) " $\wedge \partial T \exists$
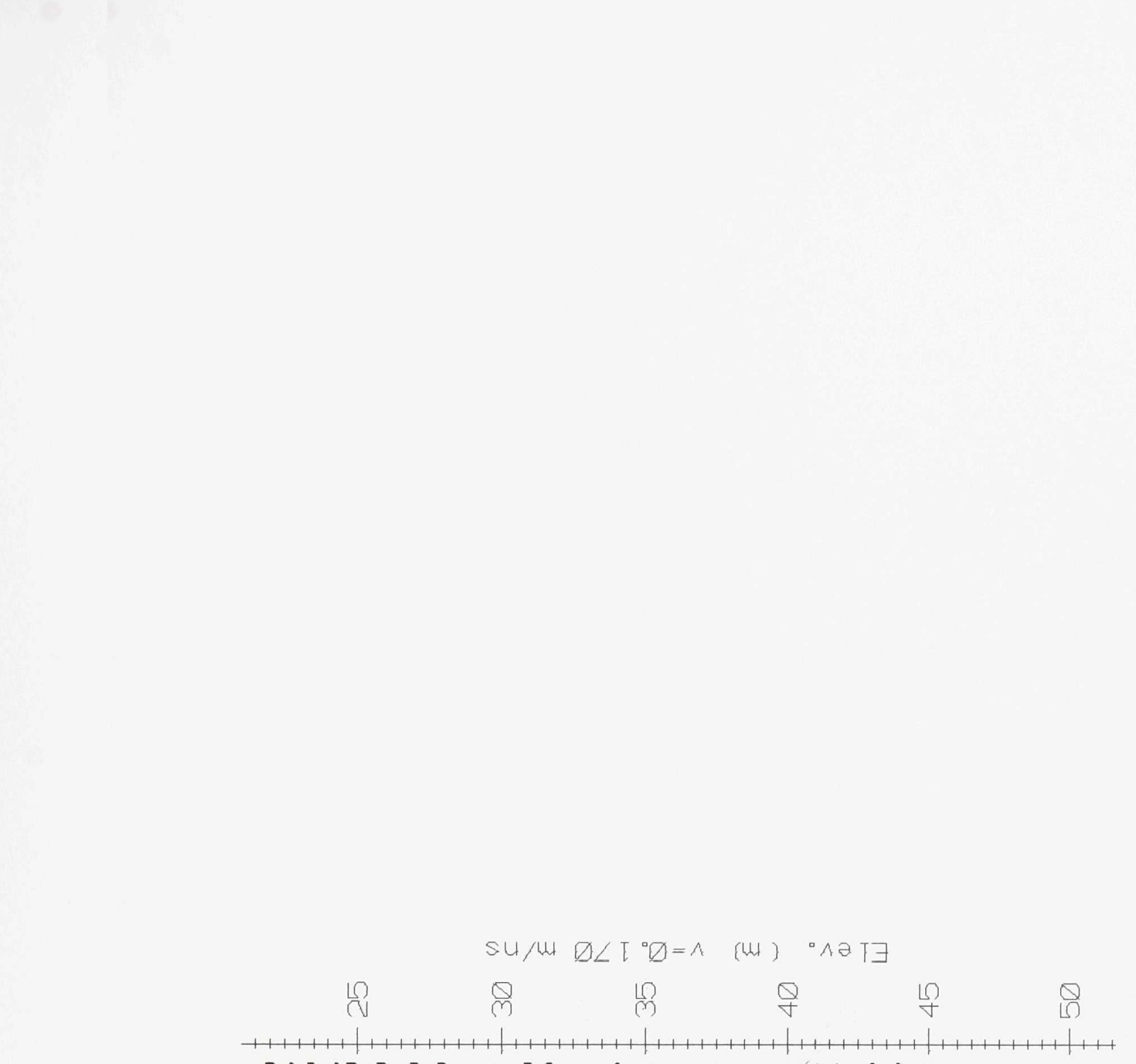

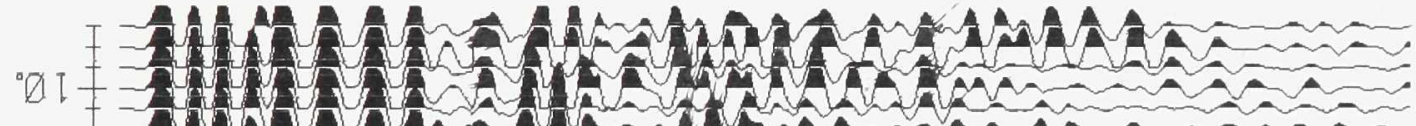

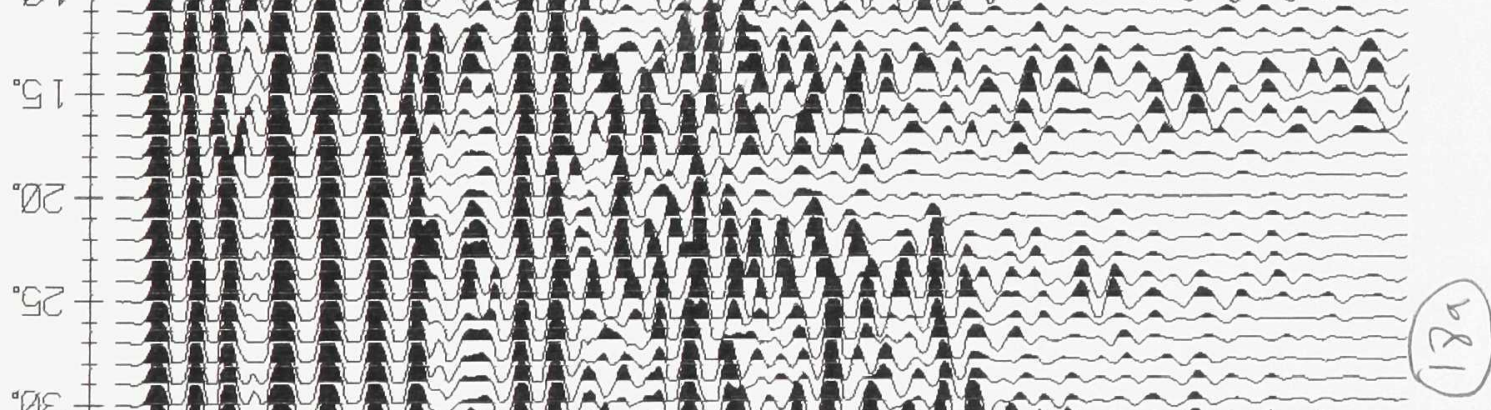

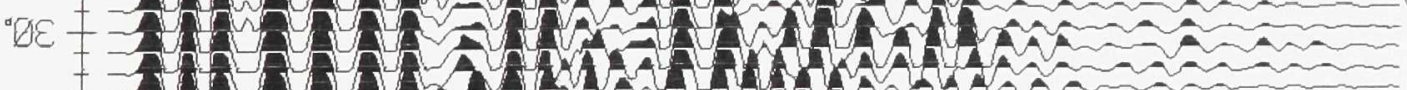

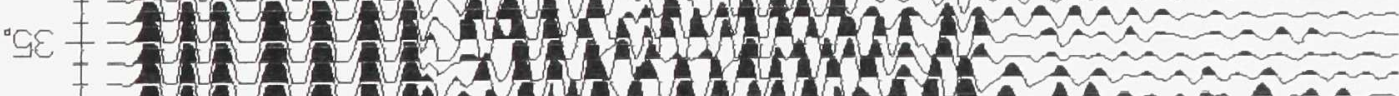

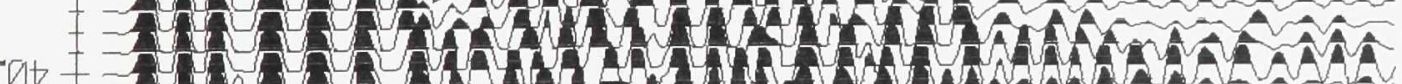

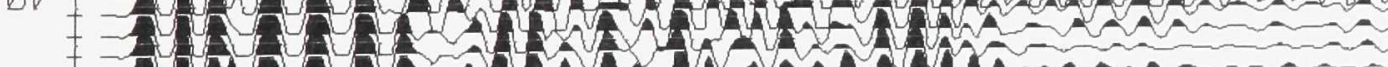

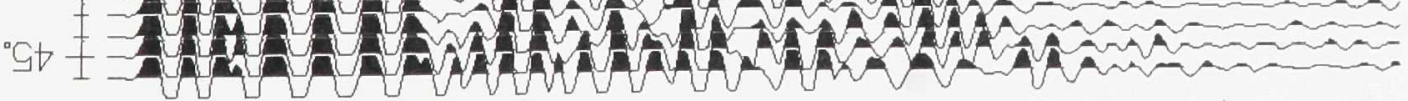

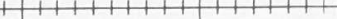

Q

Q $Q$

Q

$Q$

ति ले

su) aw $T \perp$ 


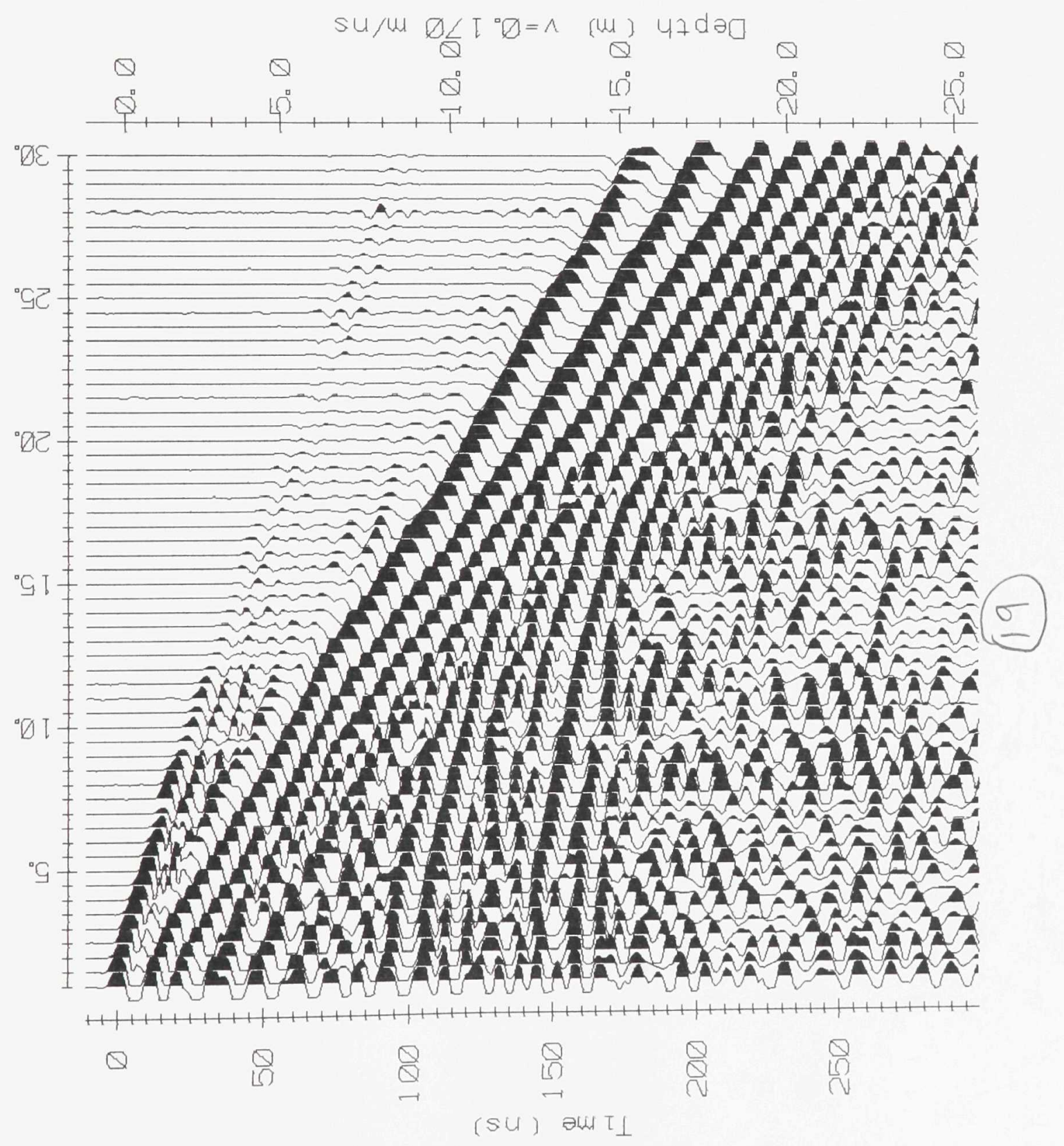




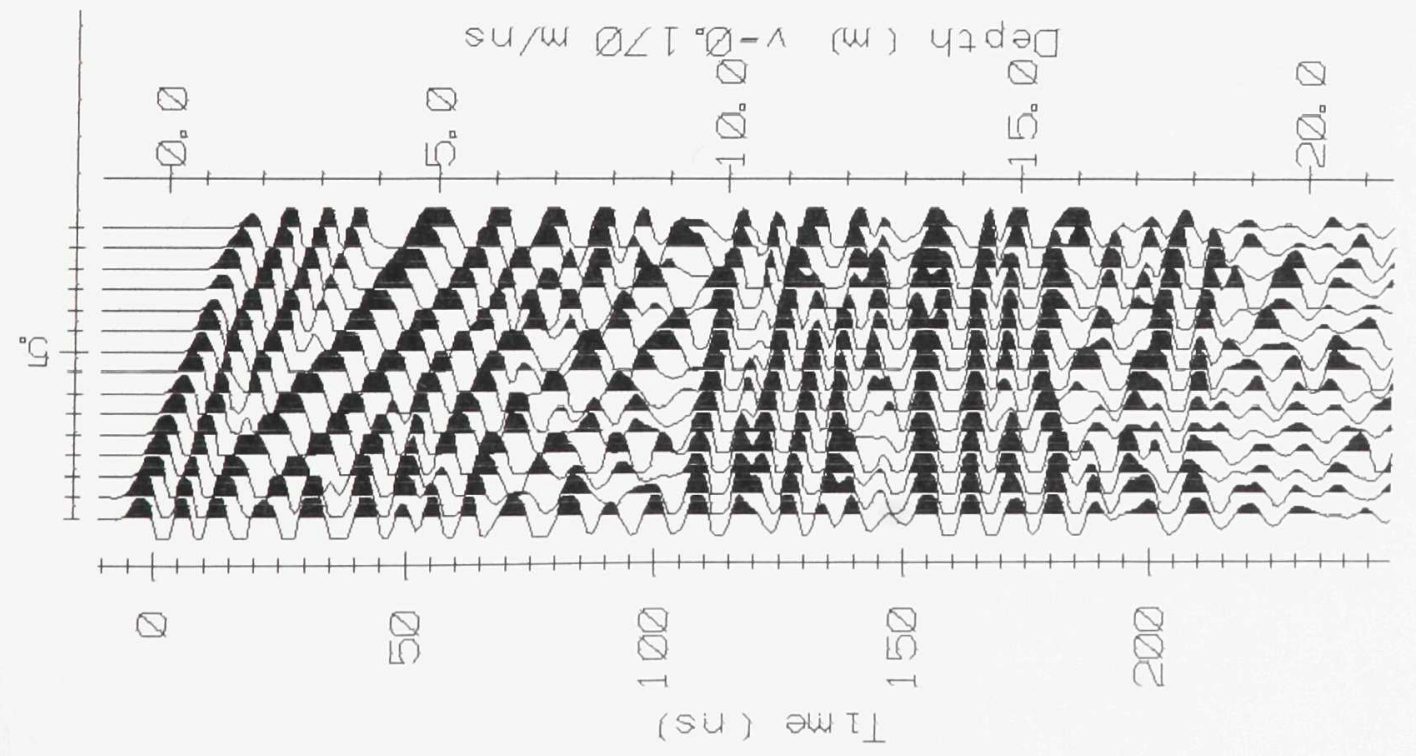




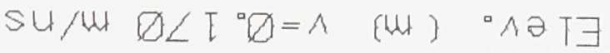

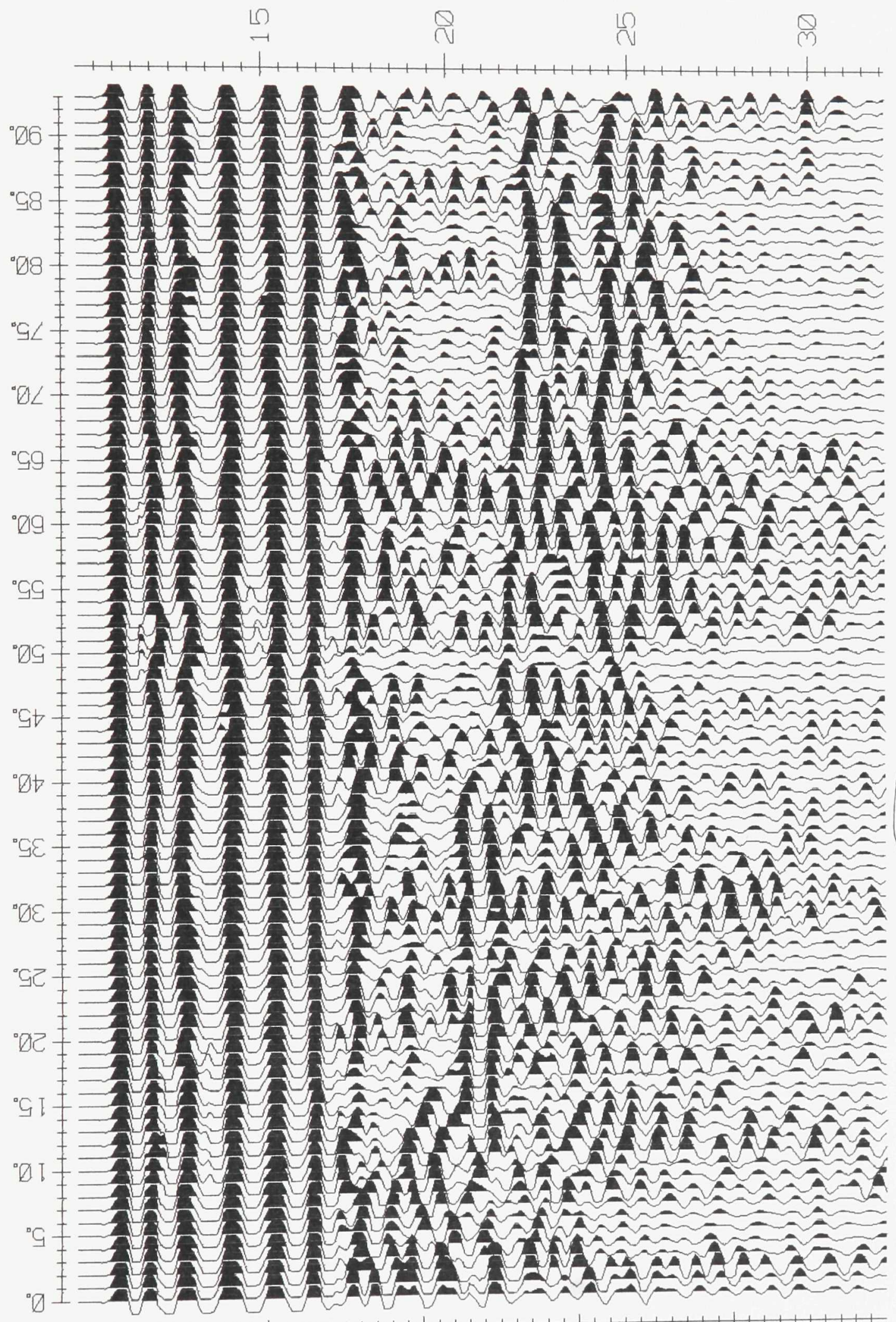


๒

${ }^{\circ} 981-$

\section{9}

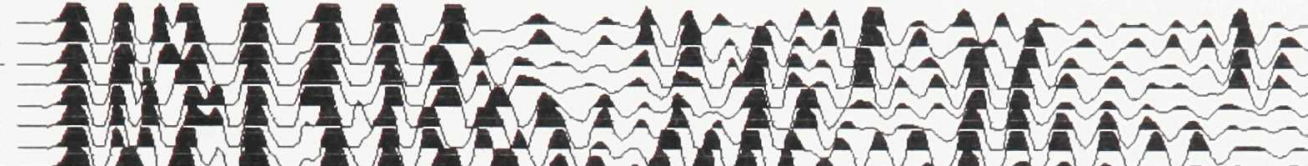

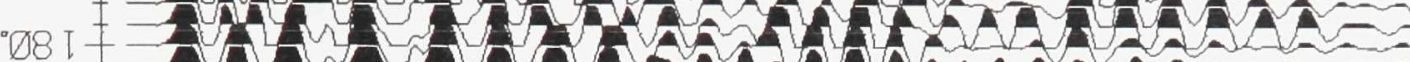

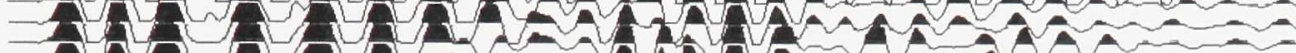

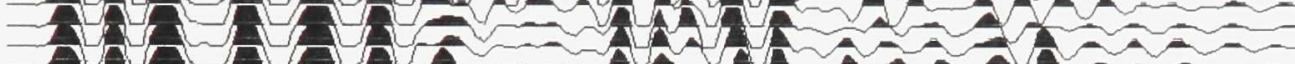

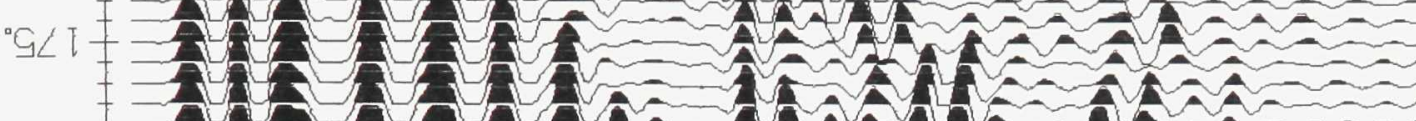

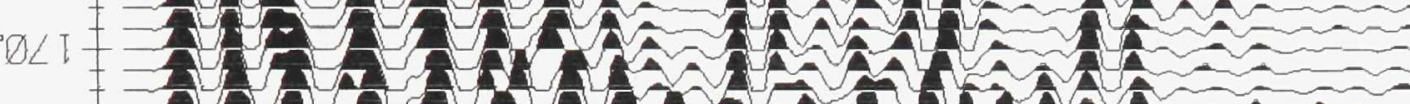

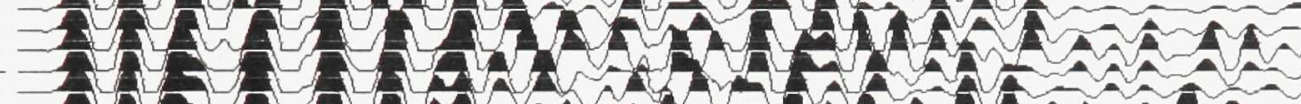

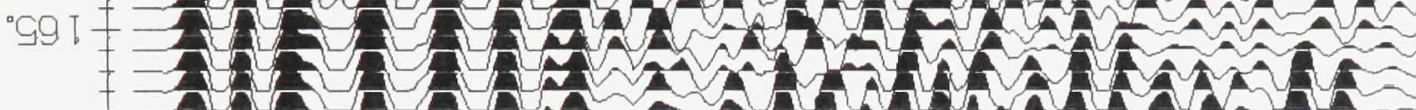

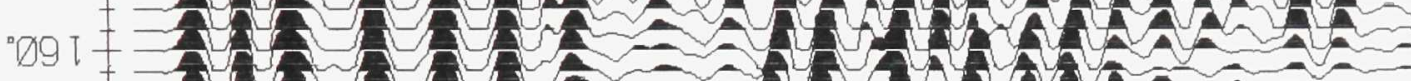

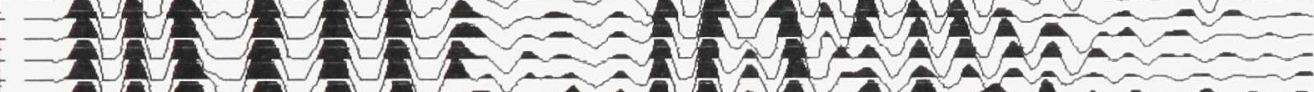

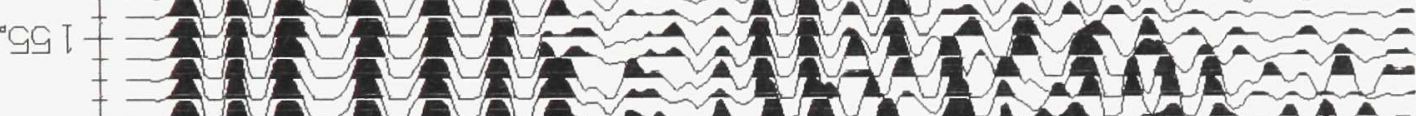

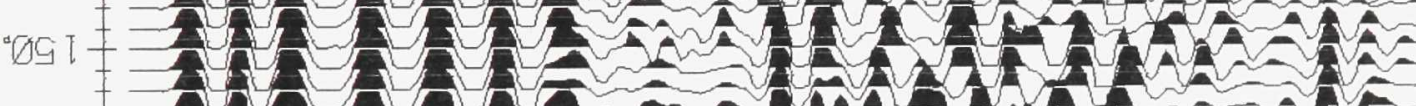

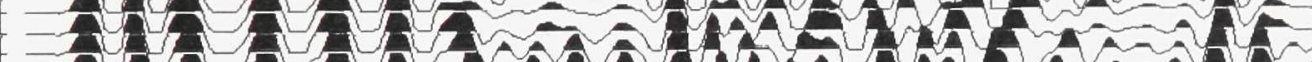
$9 t i=2$, A

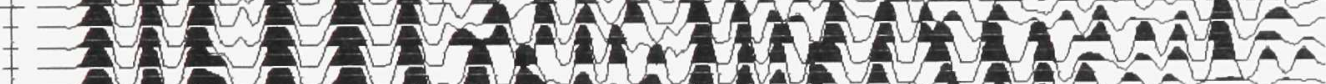

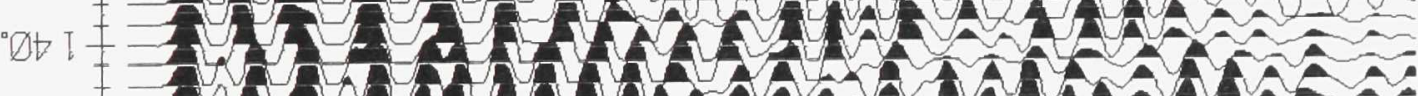

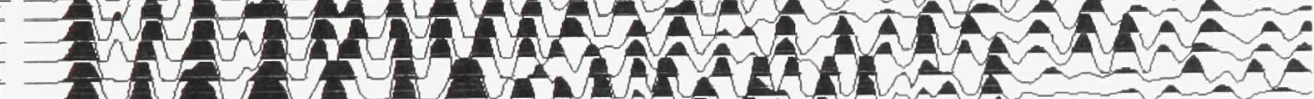
"GEI II

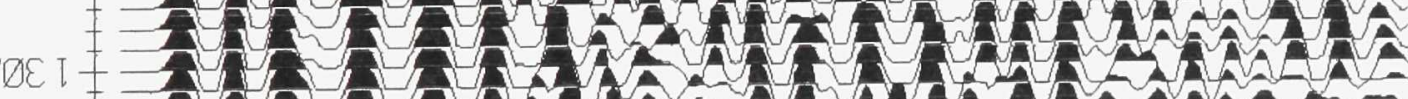

- IV R R

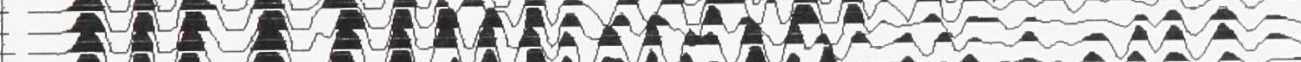
$=3$ IU

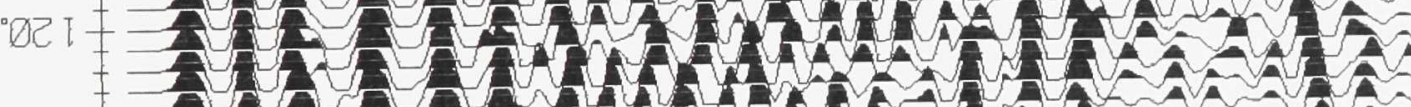

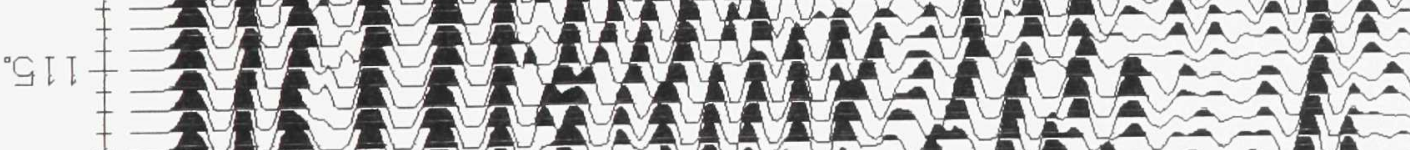

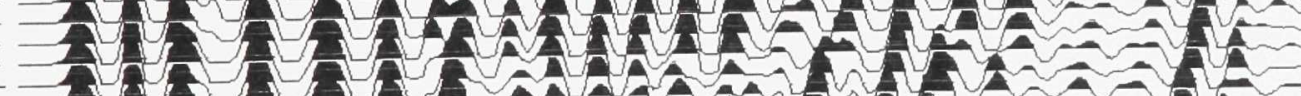

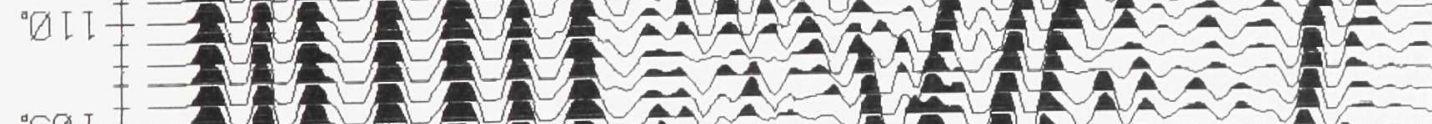
$901=\Rightarrow$ I $\Rightarrow$ A

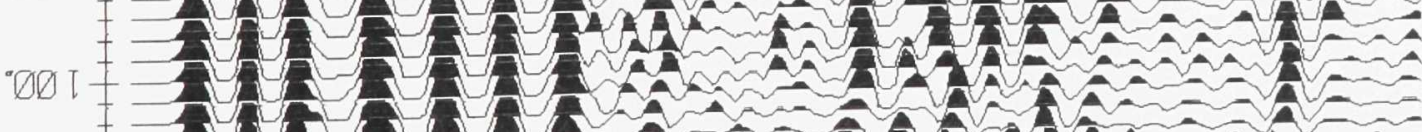
'96 = =2

Q

[O)

$Q$

Q 


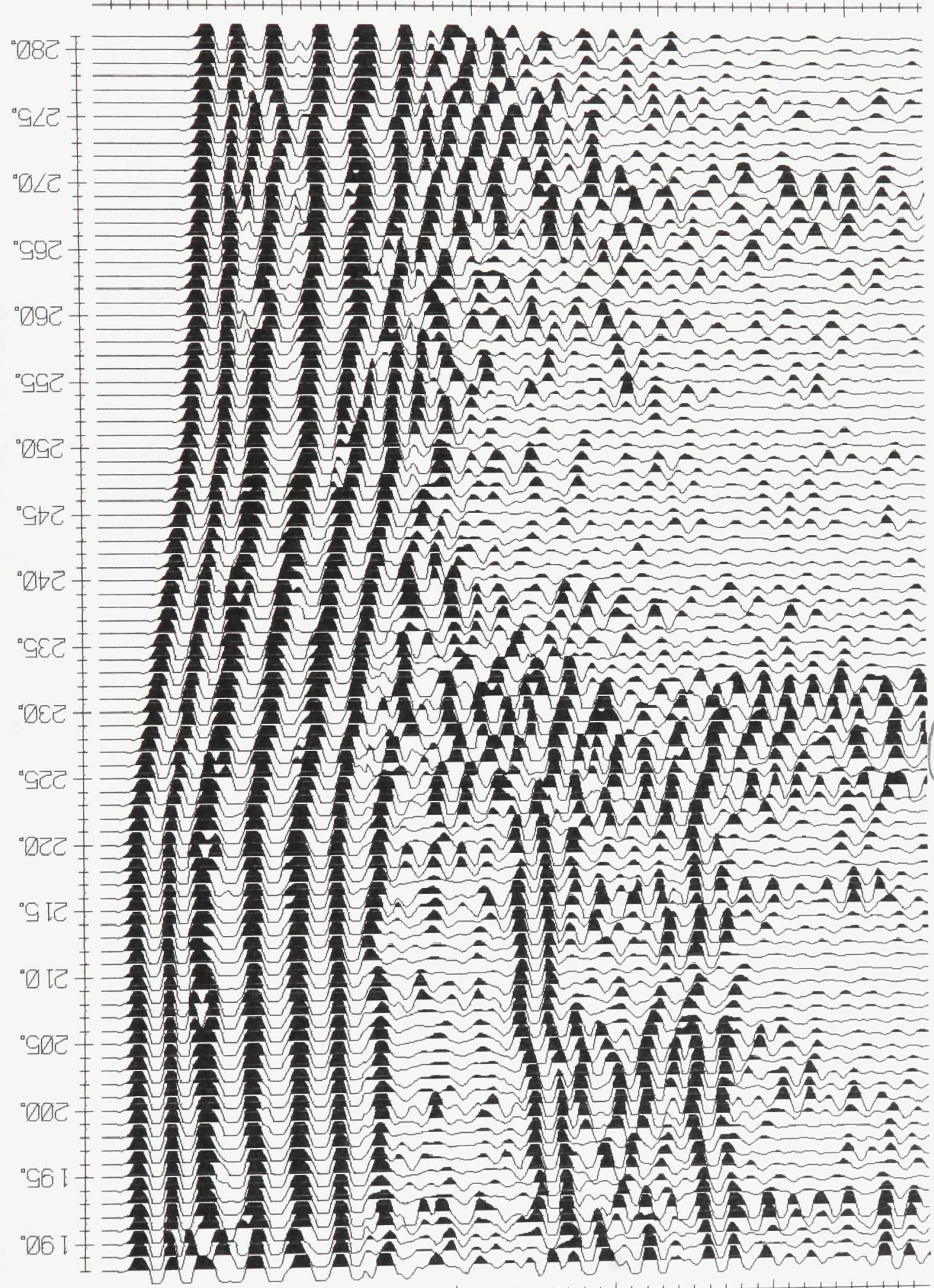

Q

Q

$Q$

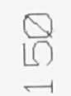


SU/M $\varnothing \angle I{ }^{\circ} \oslash=\wedge \quad$ (U) ${ }^{\circ} \wedge \partial T \exists$

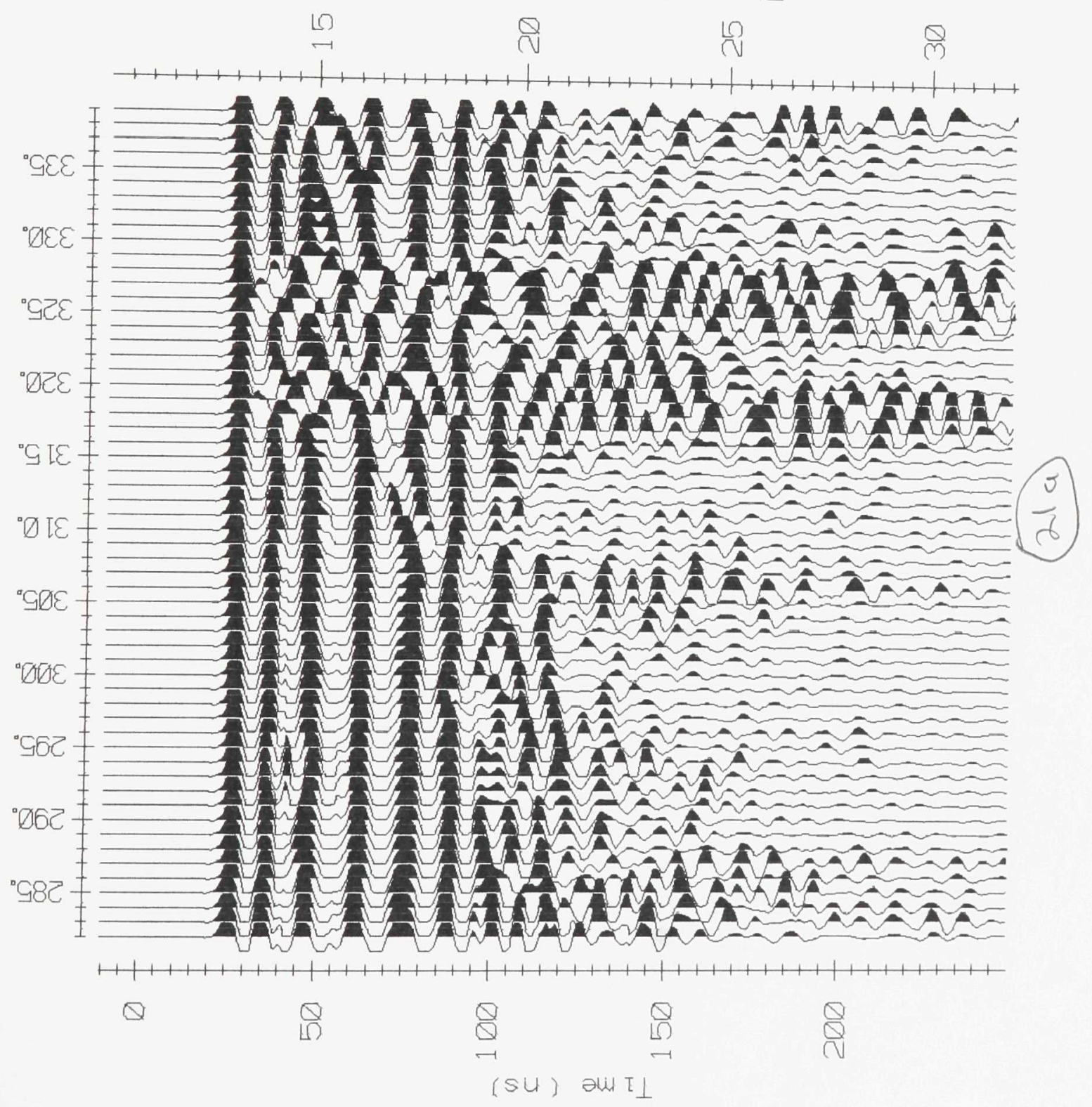


sufu $\varnothing \angle[\square=\wedge \quad(W) \cdot \wedge \partial T \exists$

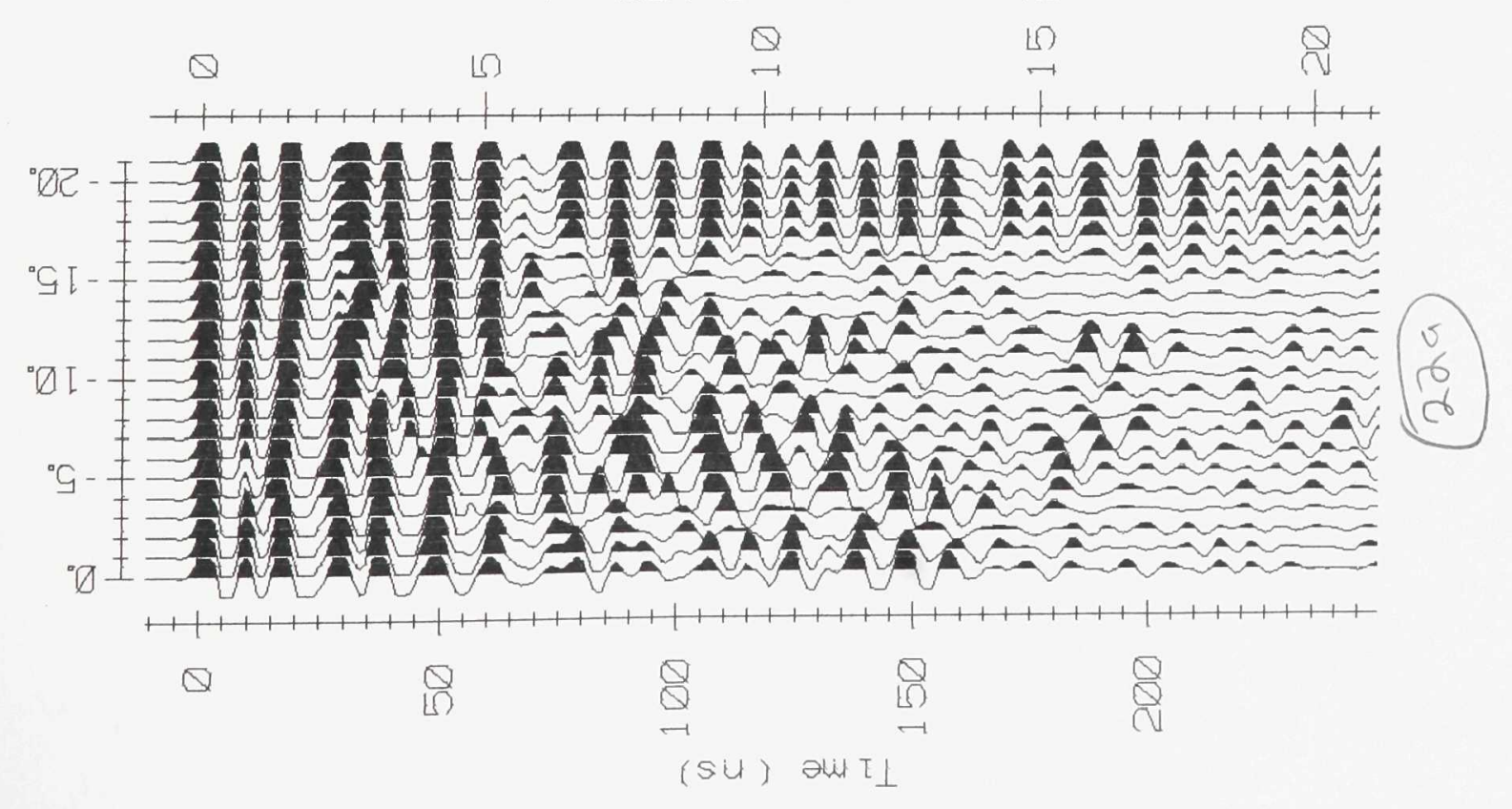



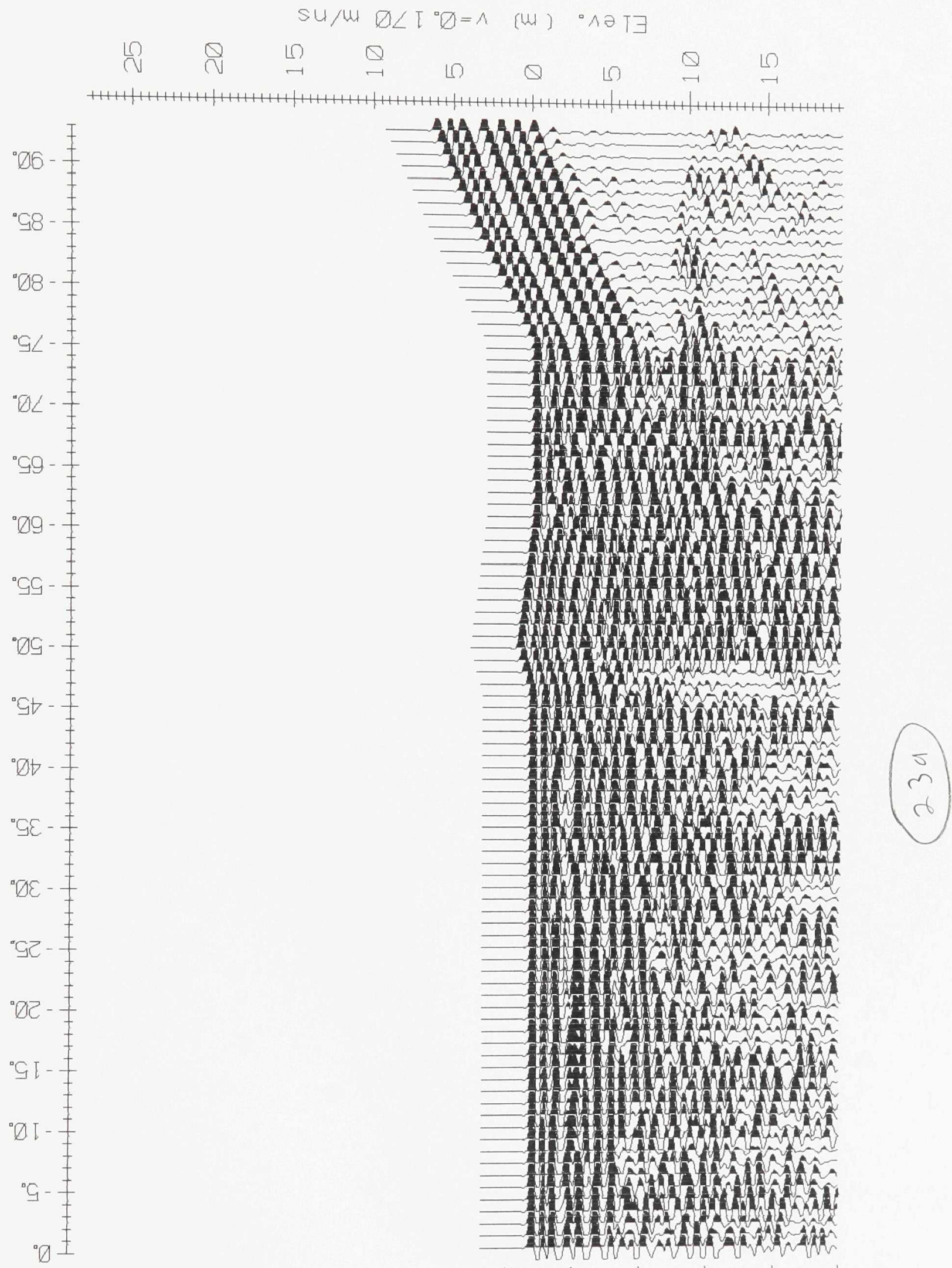

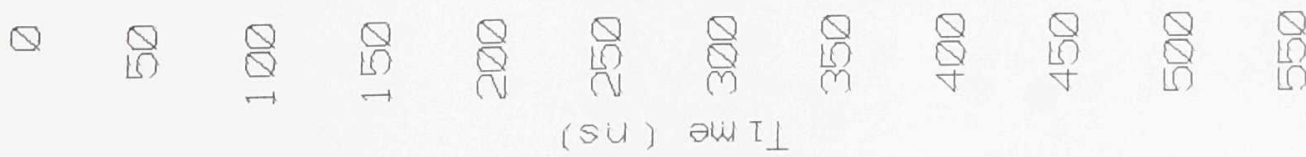


su/M $D \angle T \cdot D=\wedge \quad[M] \cdot \wedge \ni T \exists$

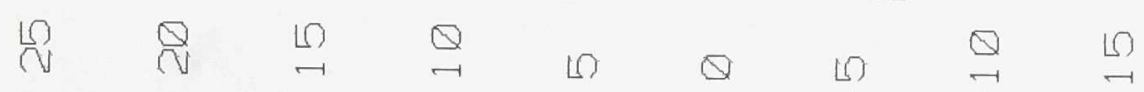
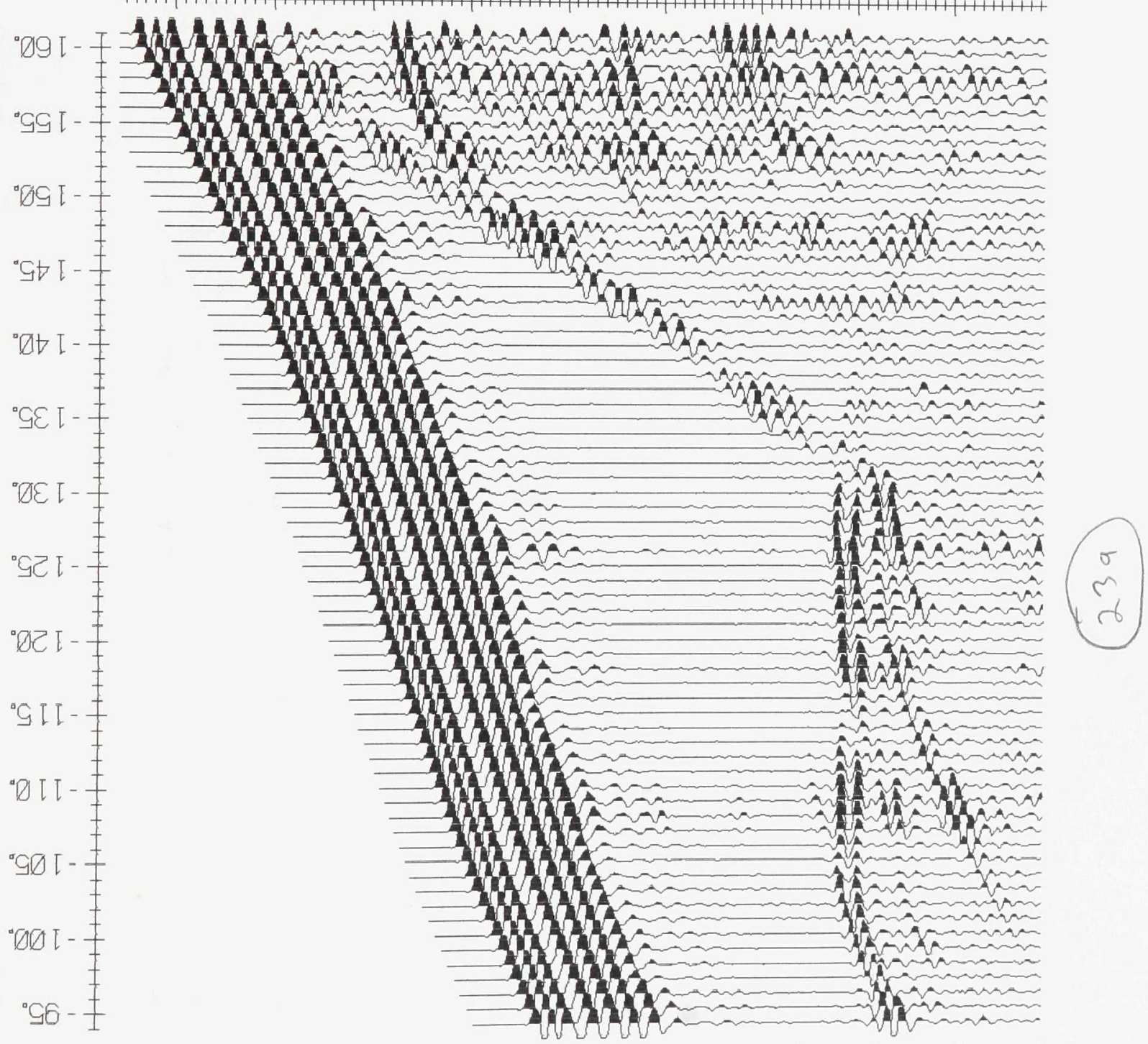

H1111111111111111111111111+111111111111111411111111111111111111111111111111111111111111114

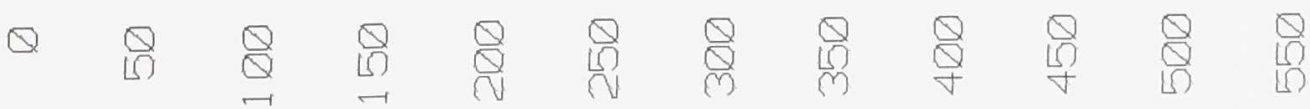

(su) DW IL 
su/M $\varnothing \angle I D=\wedge$ (w) $47 d \partial \square$

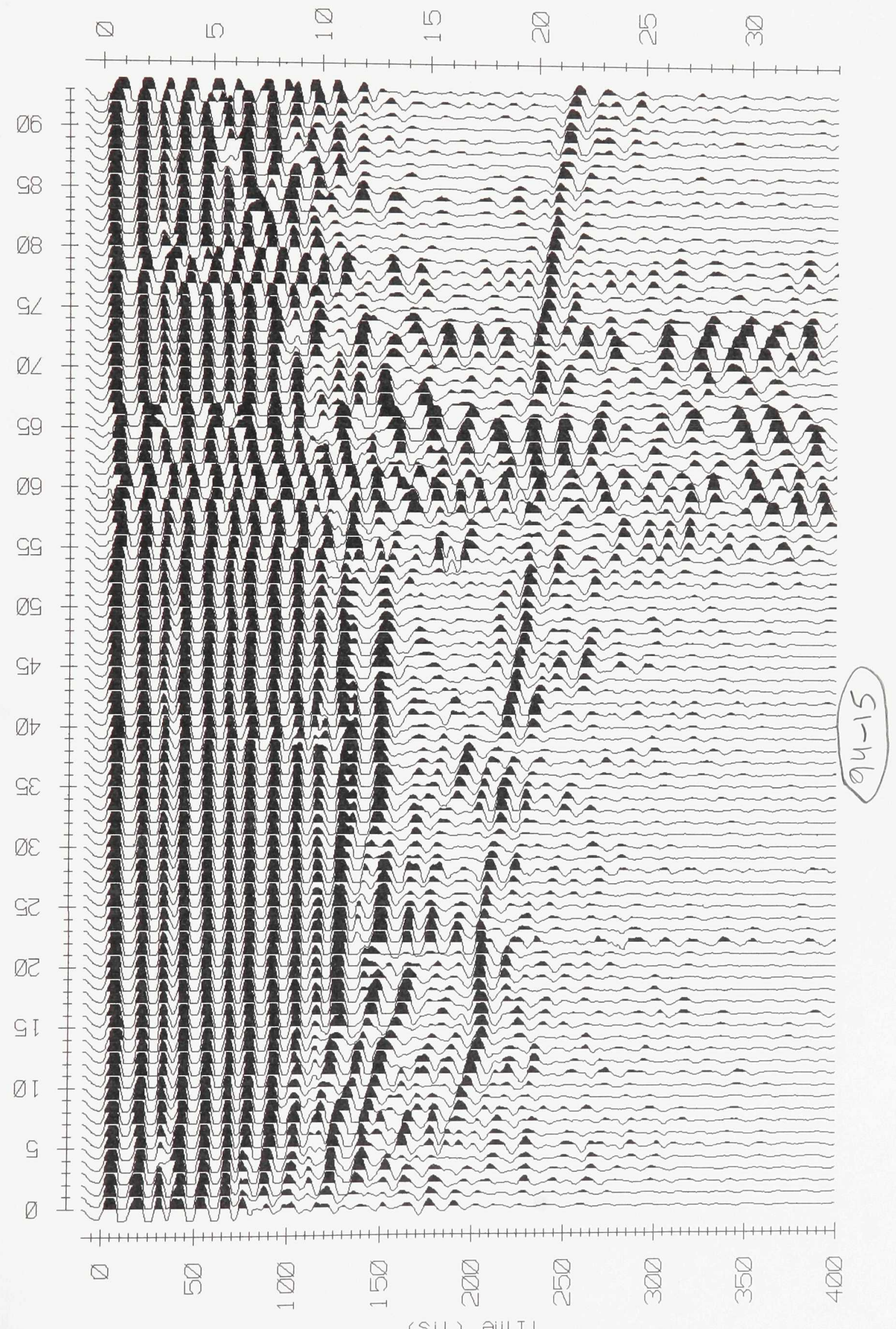


su/m $\varnothing \angle I^{\circ} \not=\wedge$ (w) 47d

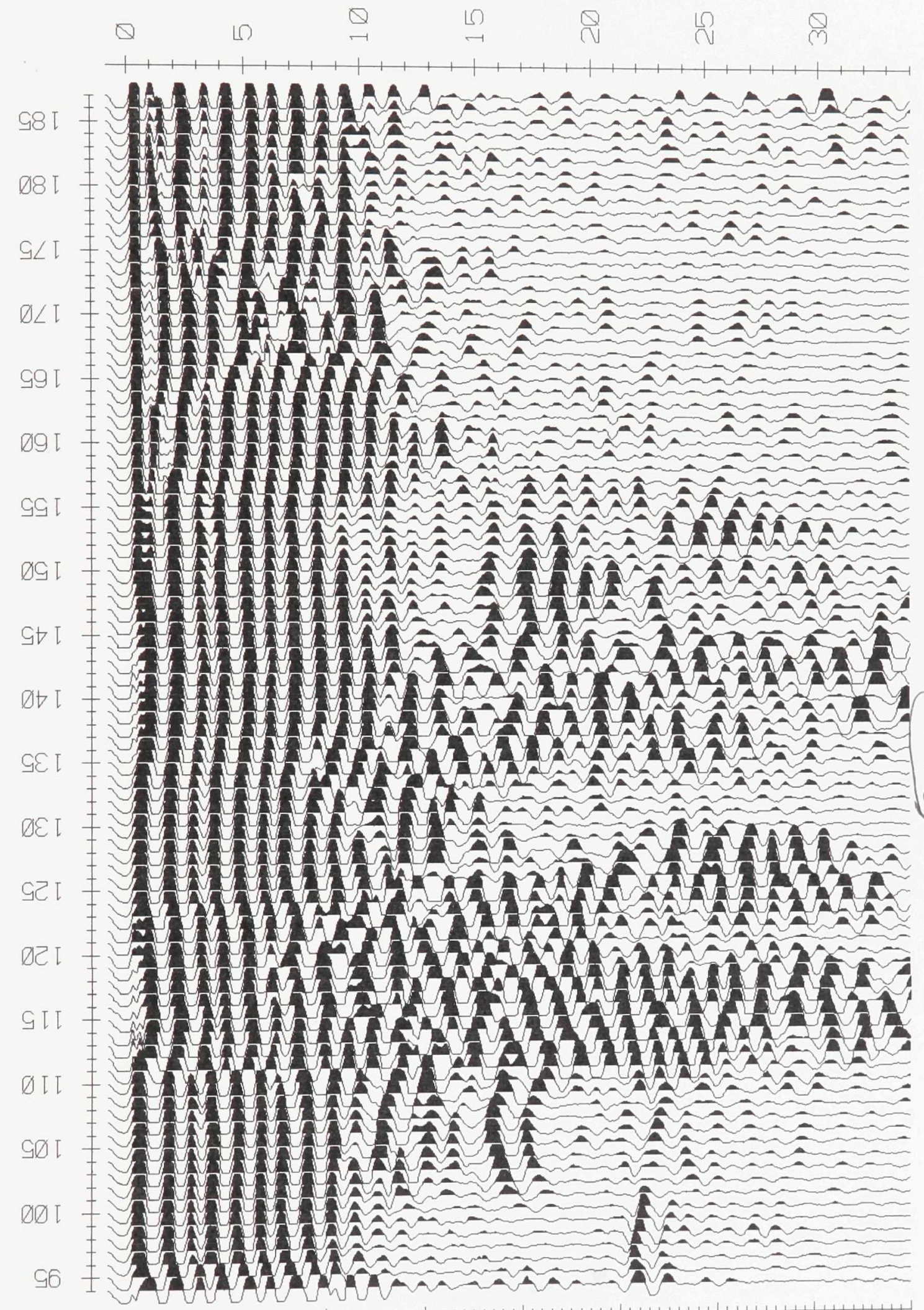


su/w $\varnothing \angle I^{\circ} \varnothing=\wedge \quad$ (w) $47 d \partial \square$

$Q$

เ

$\underset{\square}{\square}$

ڤ)

욤

召

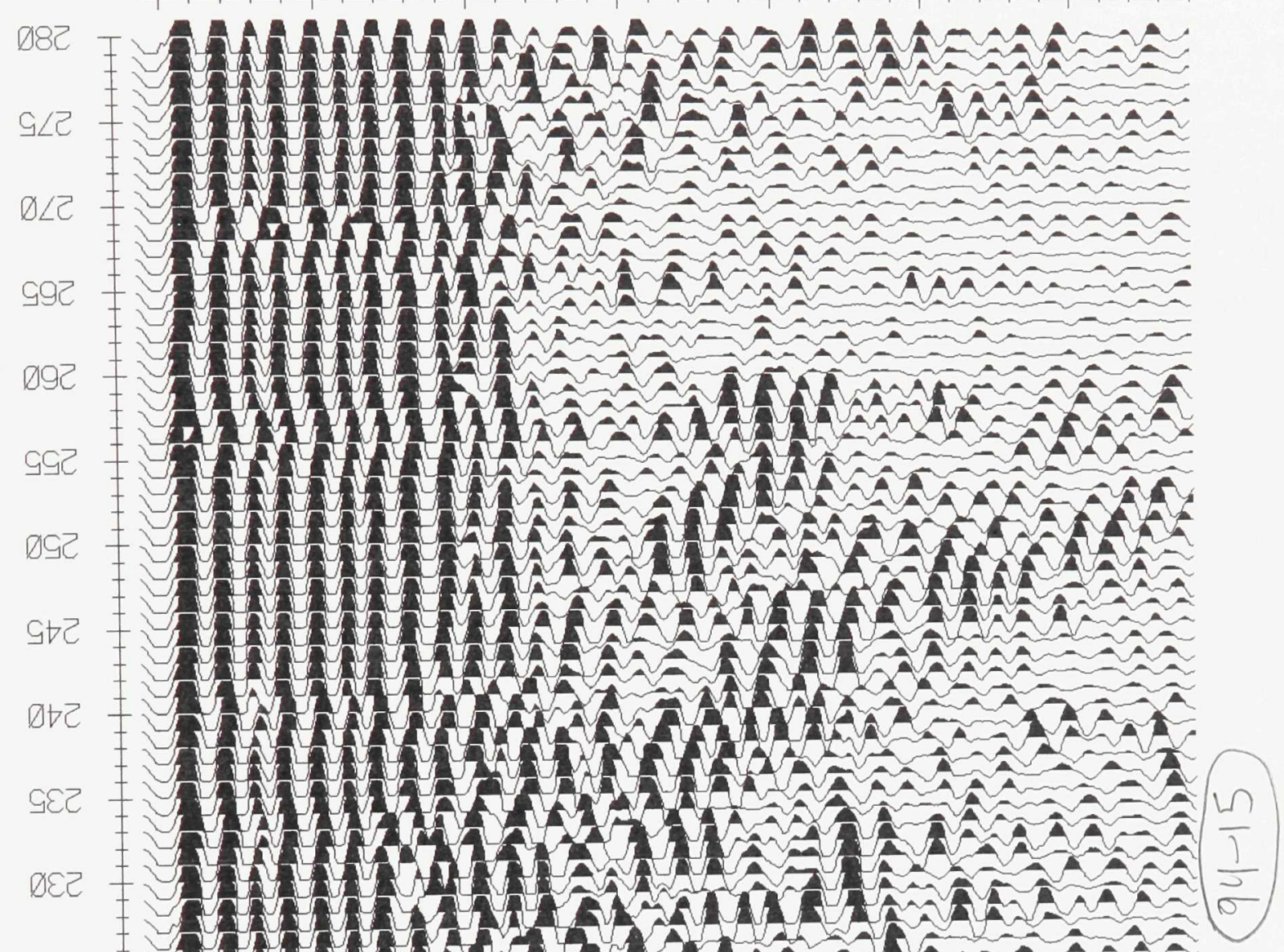

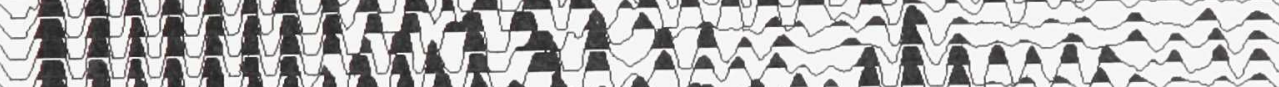

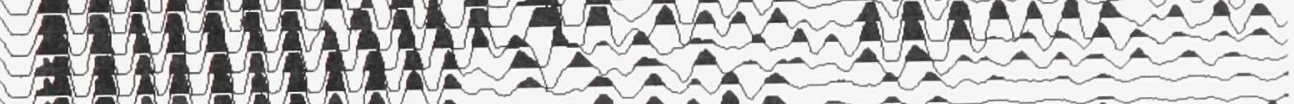

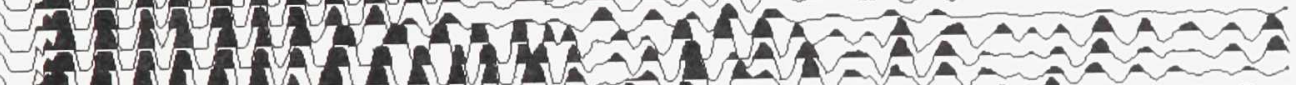

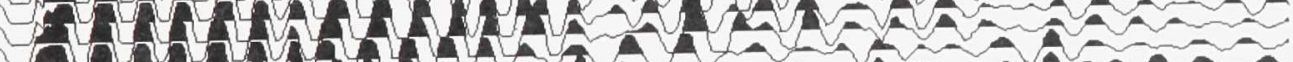

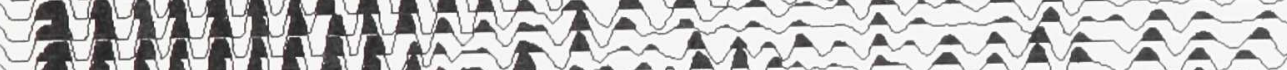

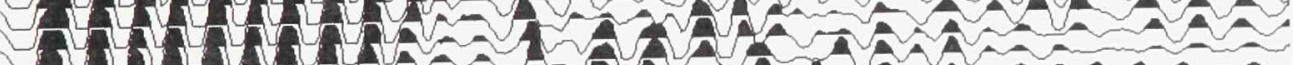

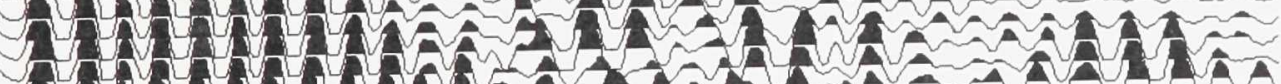

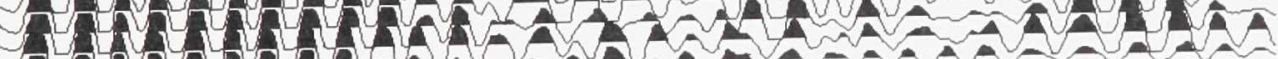

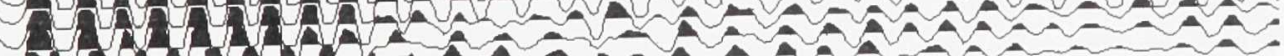
INARA 1 - $=2-2=2$

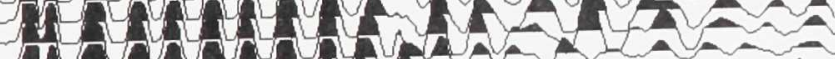

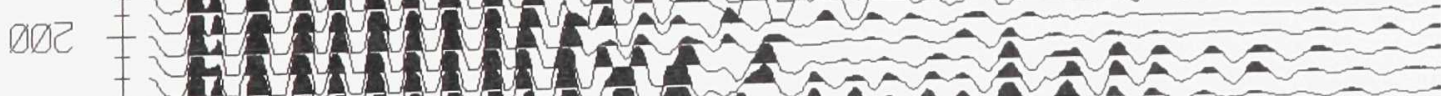
7 I U S

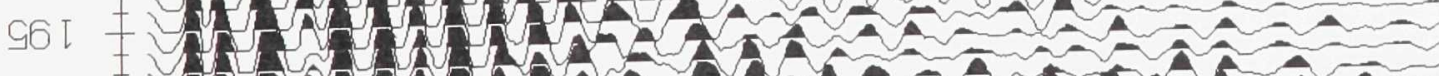
WHNAN

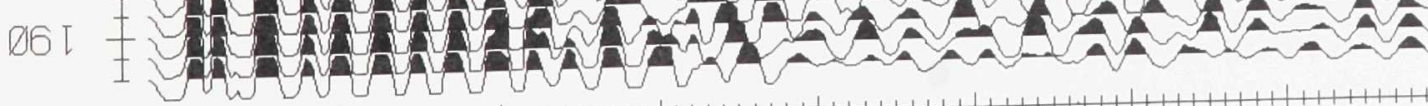

Q ڤ 용 Q

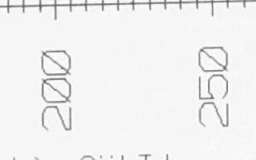




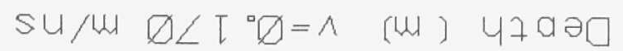

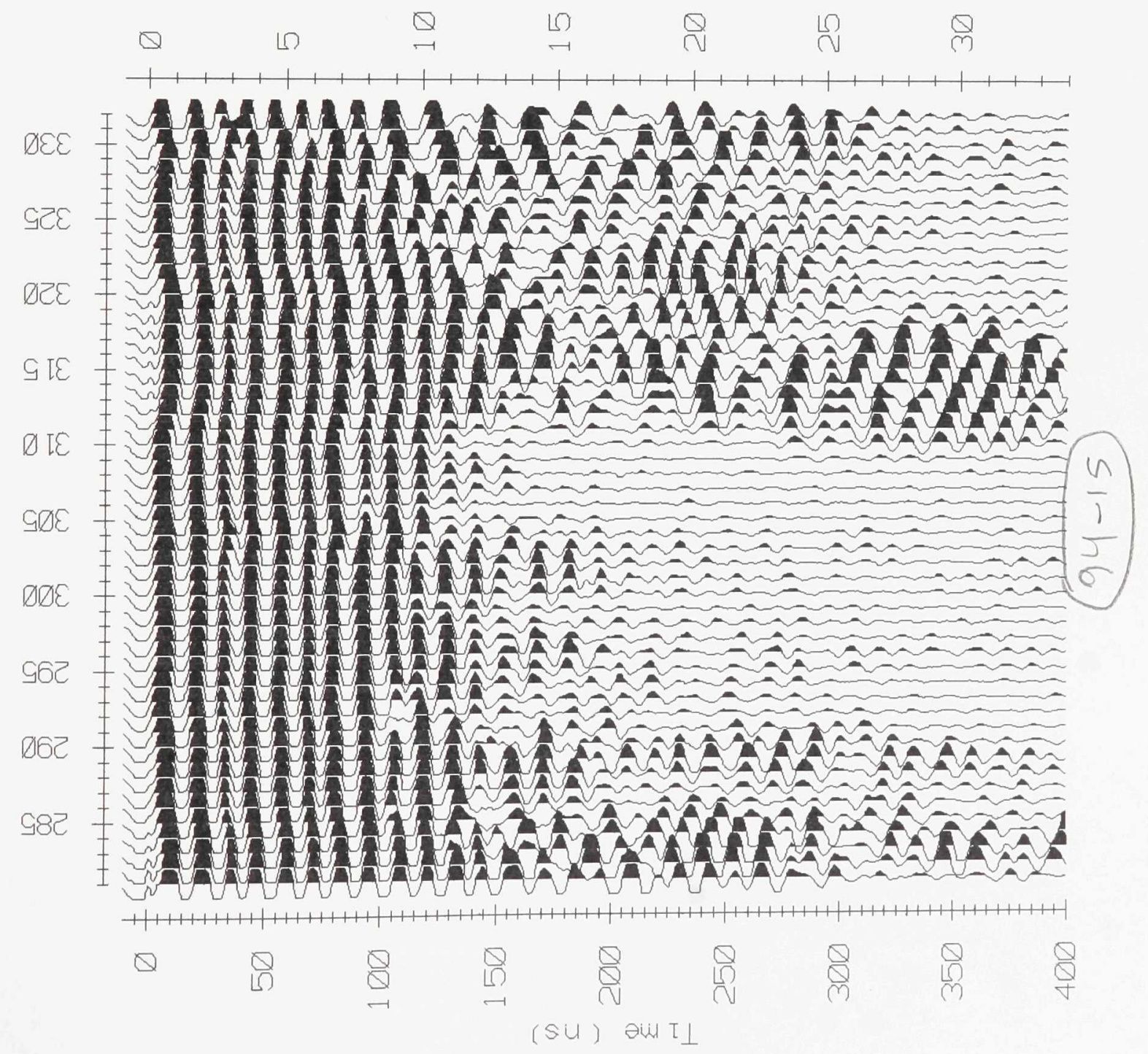




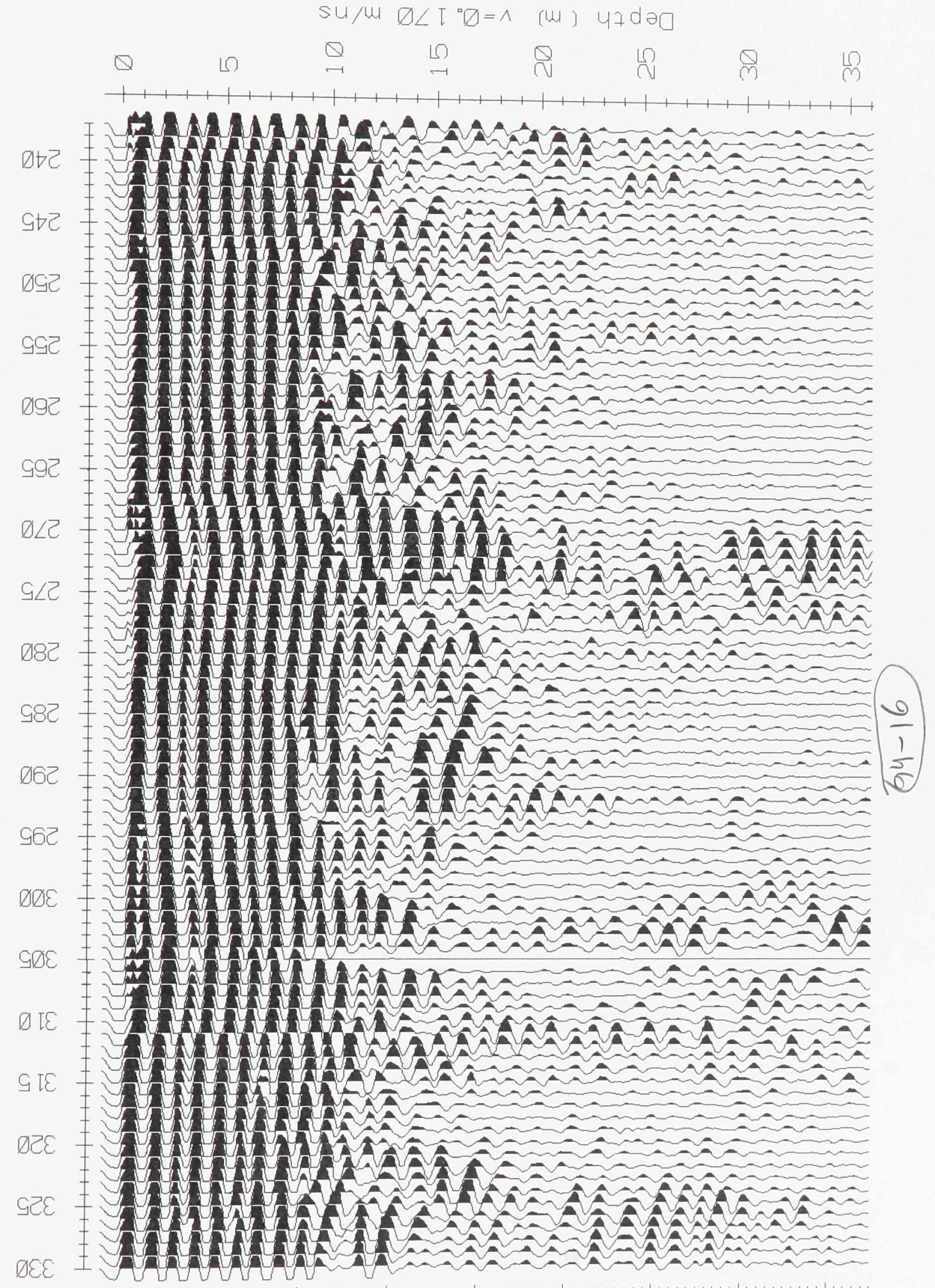


su/w $\square \angle T^{\circ} \varnothing=\wedge$ (w) 47da

$Q$

เ)

$Q$

(5)

Q

只

(n)

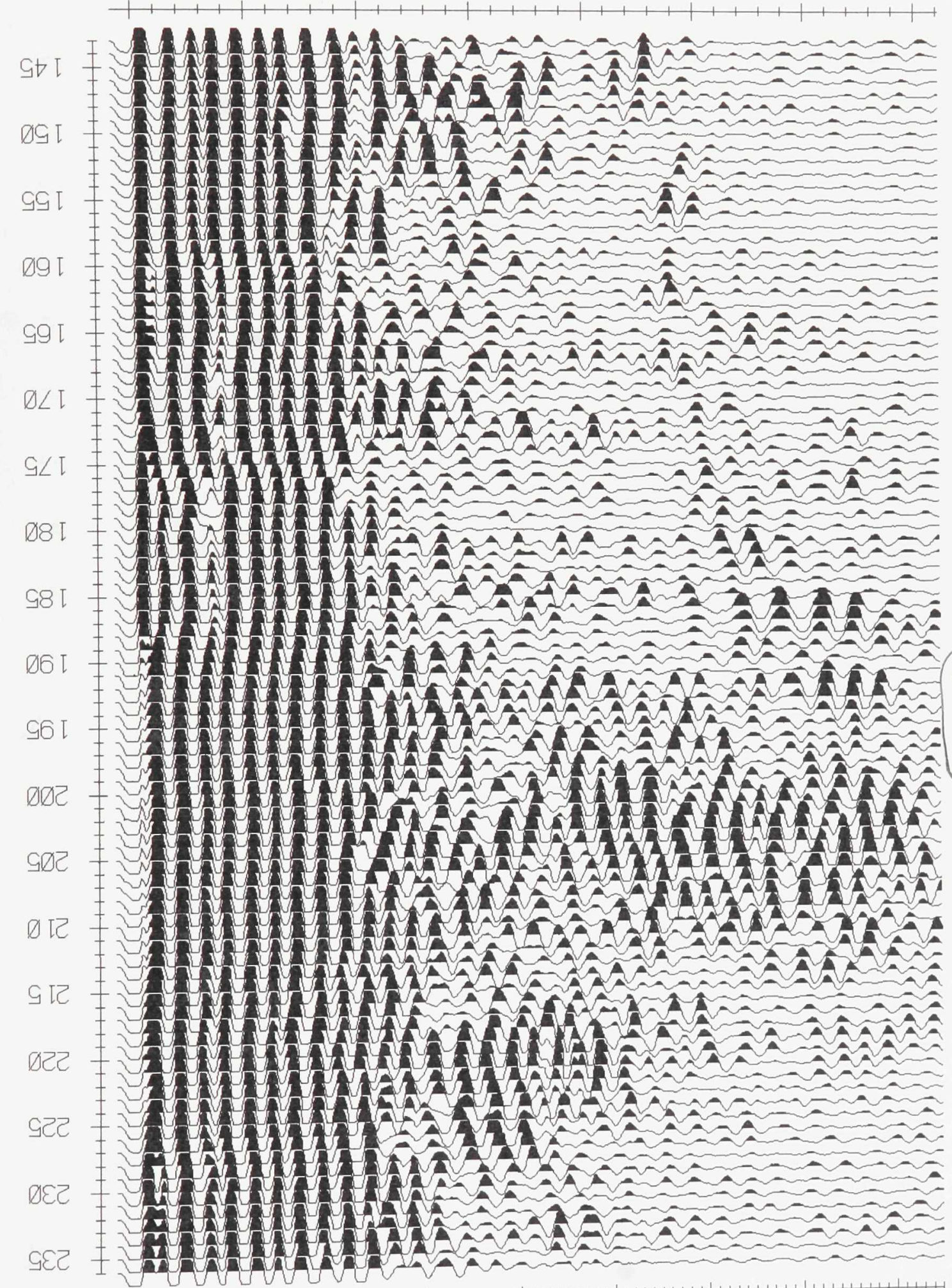

$\otimes$

Q

8

Q

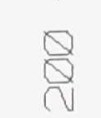




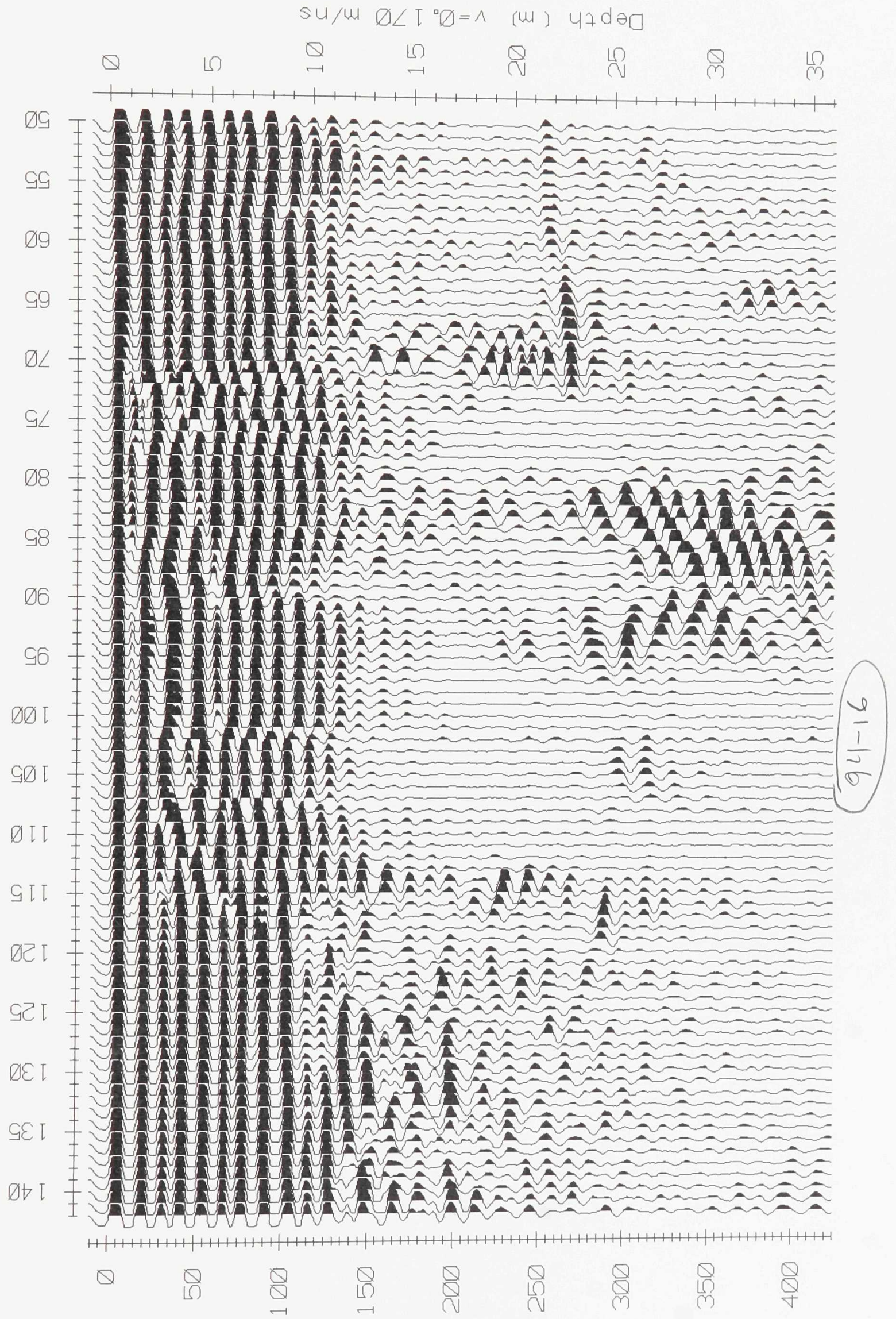


su/m $\varnothing \angle I D D=\wedge$ (w) $47 d \partial \square$

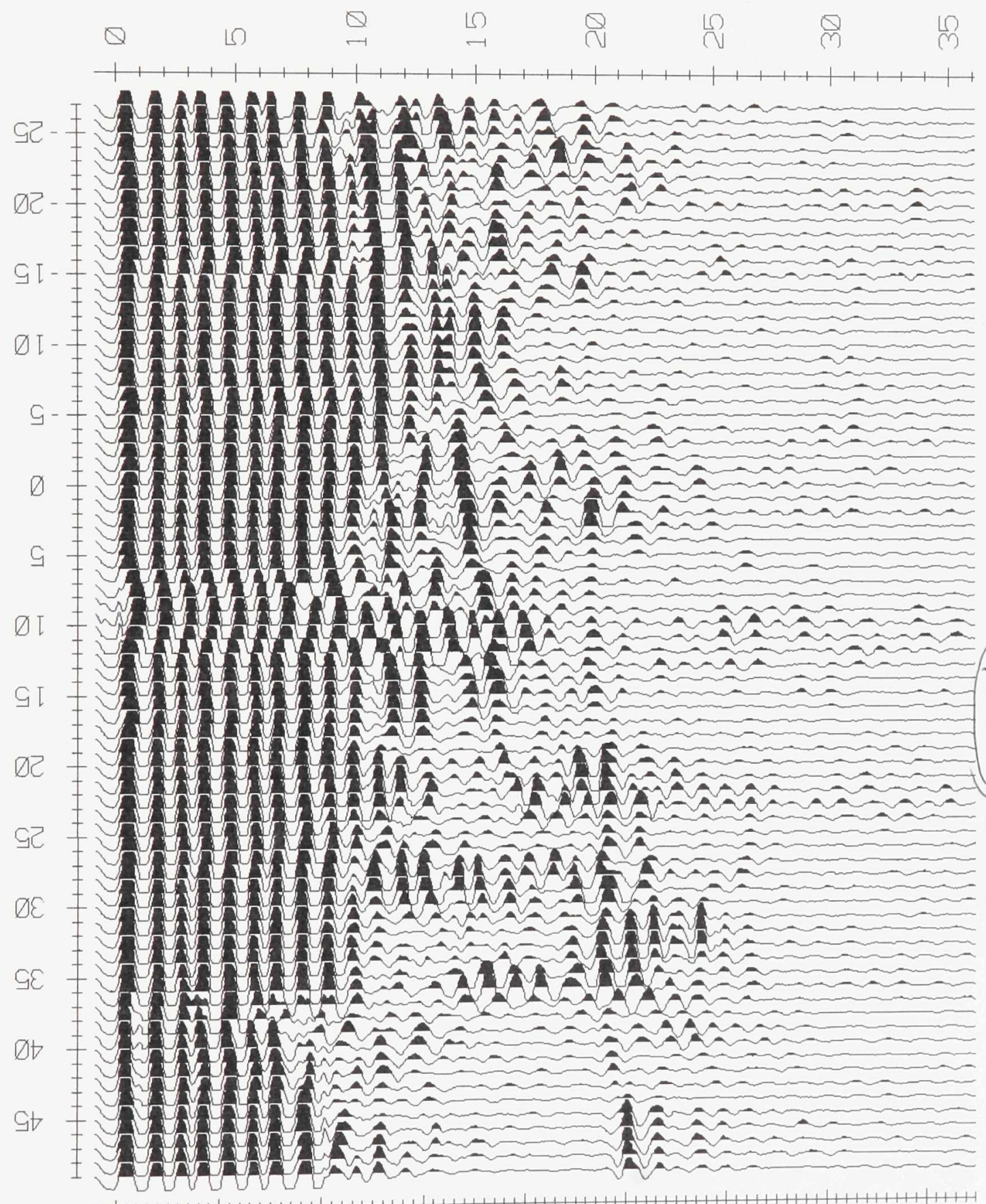

Q

ถ

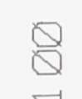

$\underset{\square}{\square}$

$\otimes$

ก

8

Q 


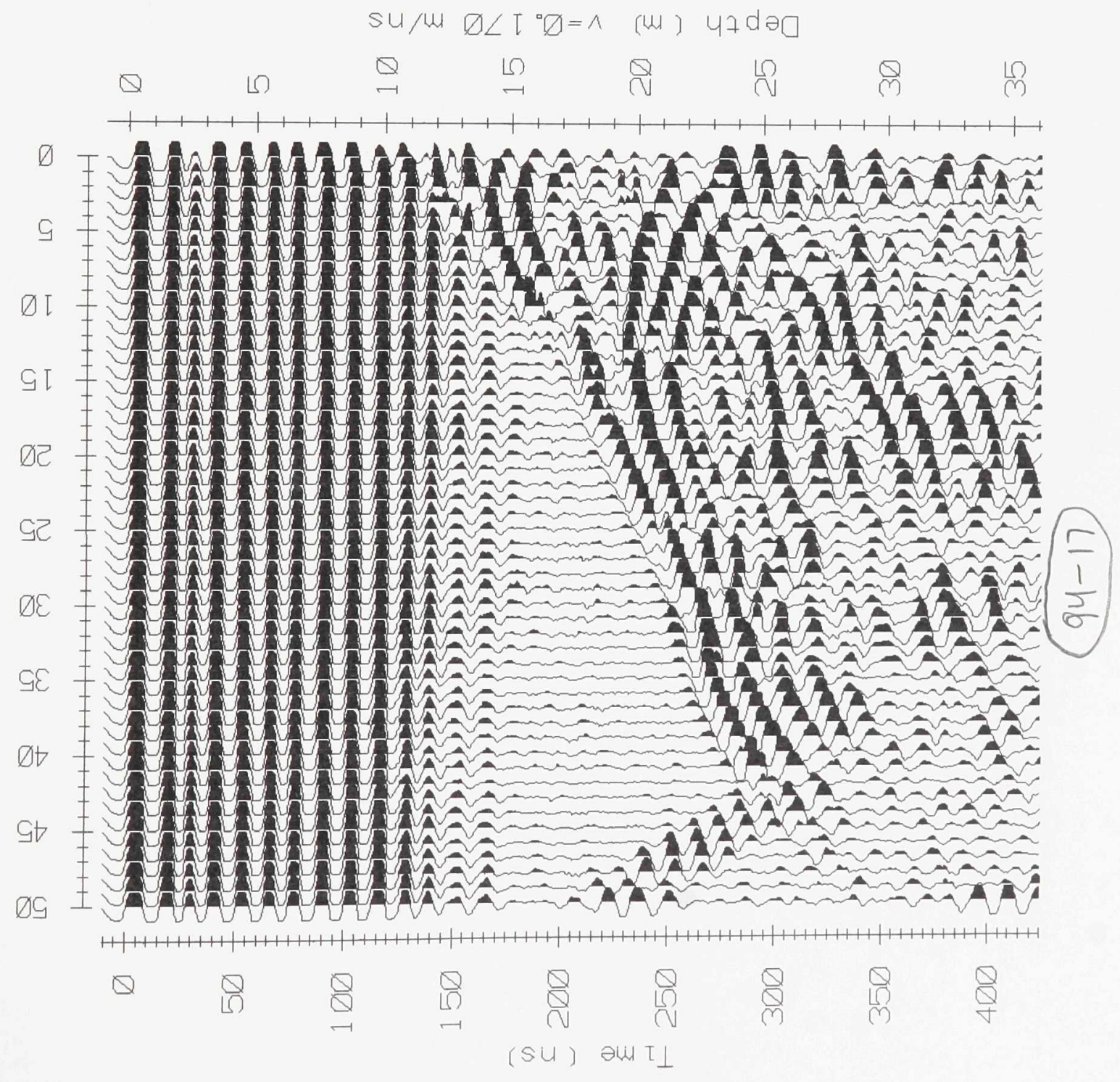




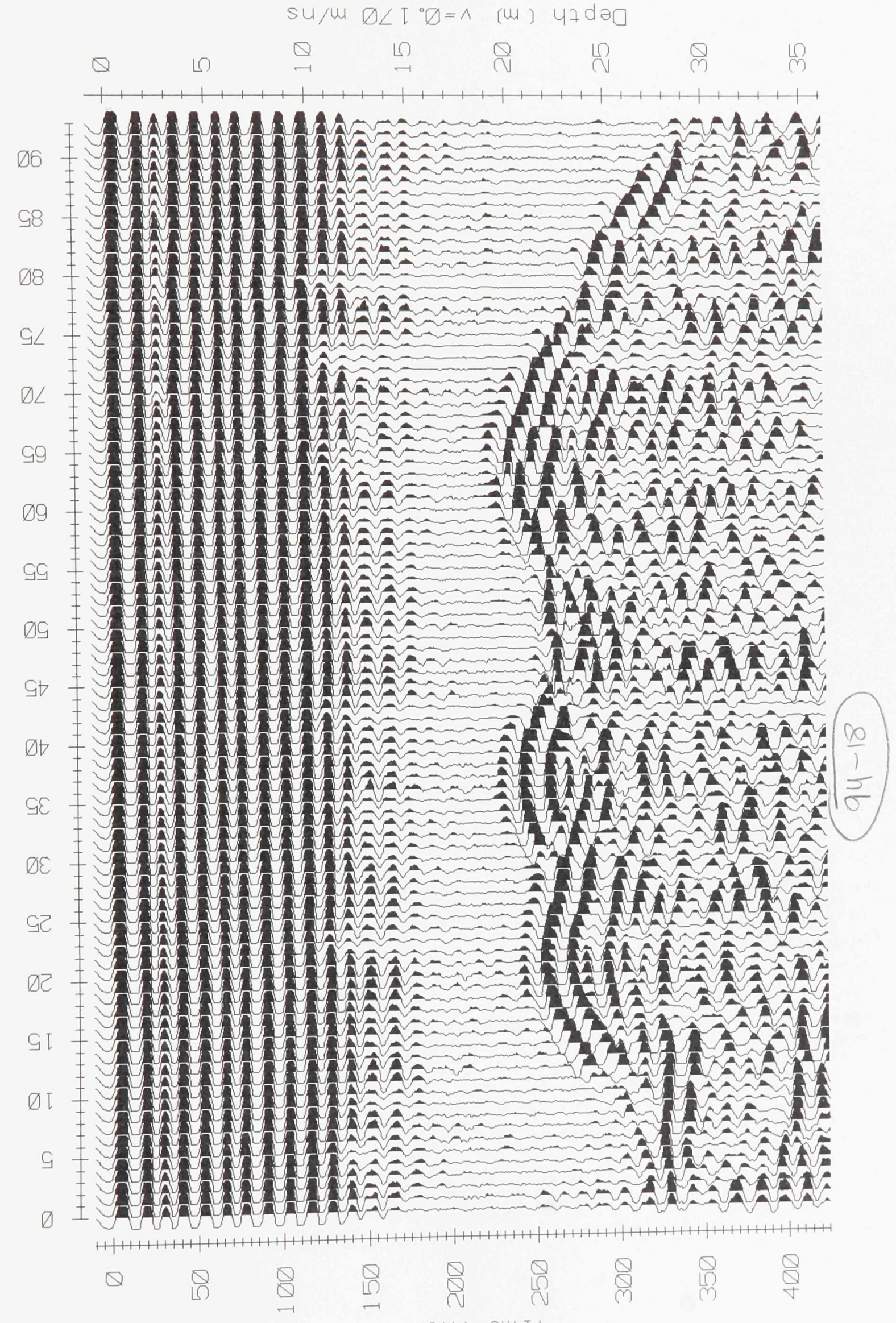


su/w $\varnothing \angle I^{\circ} \varnothing=\wedge$ (w) $47 d \partial \square$

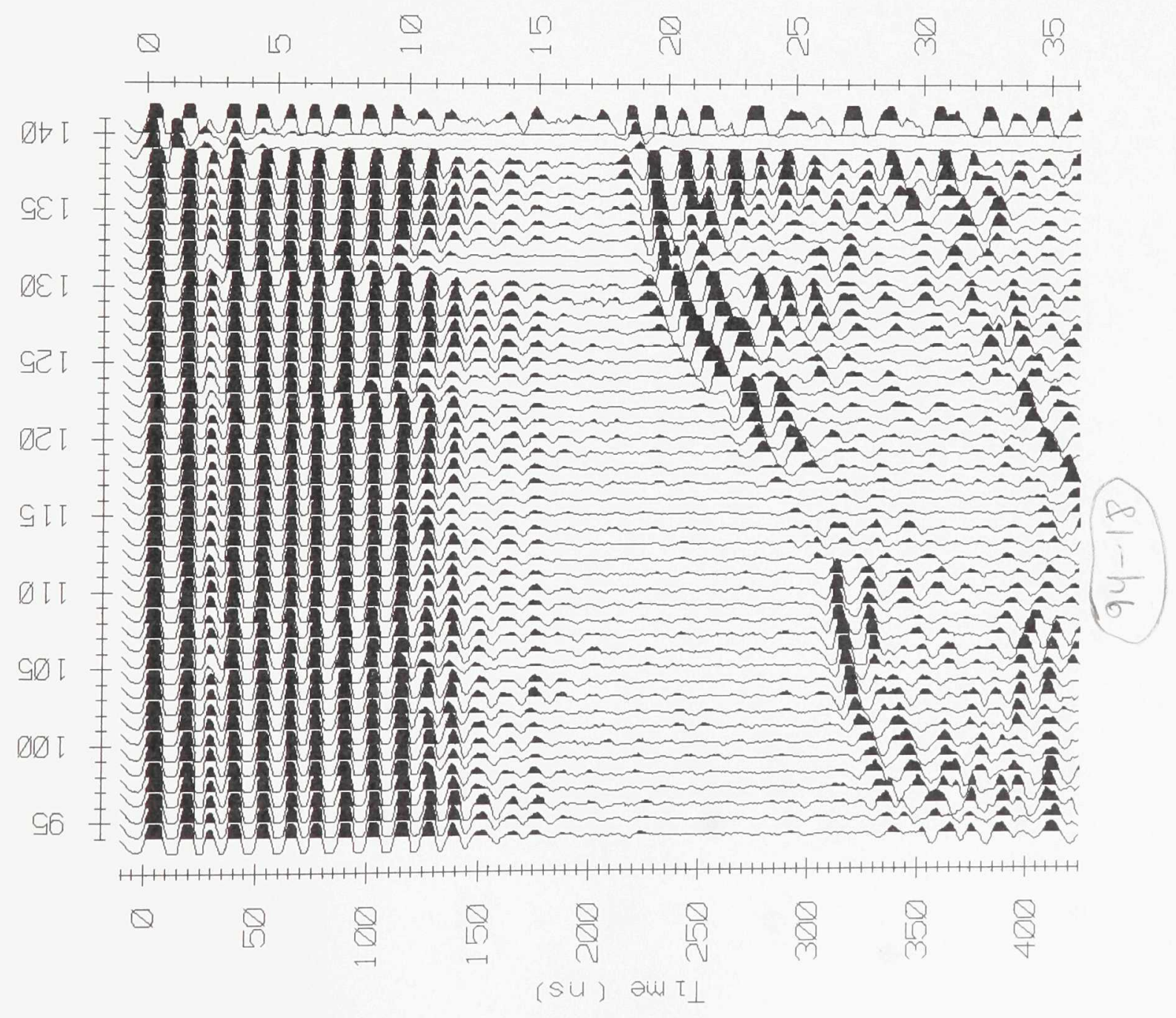


235

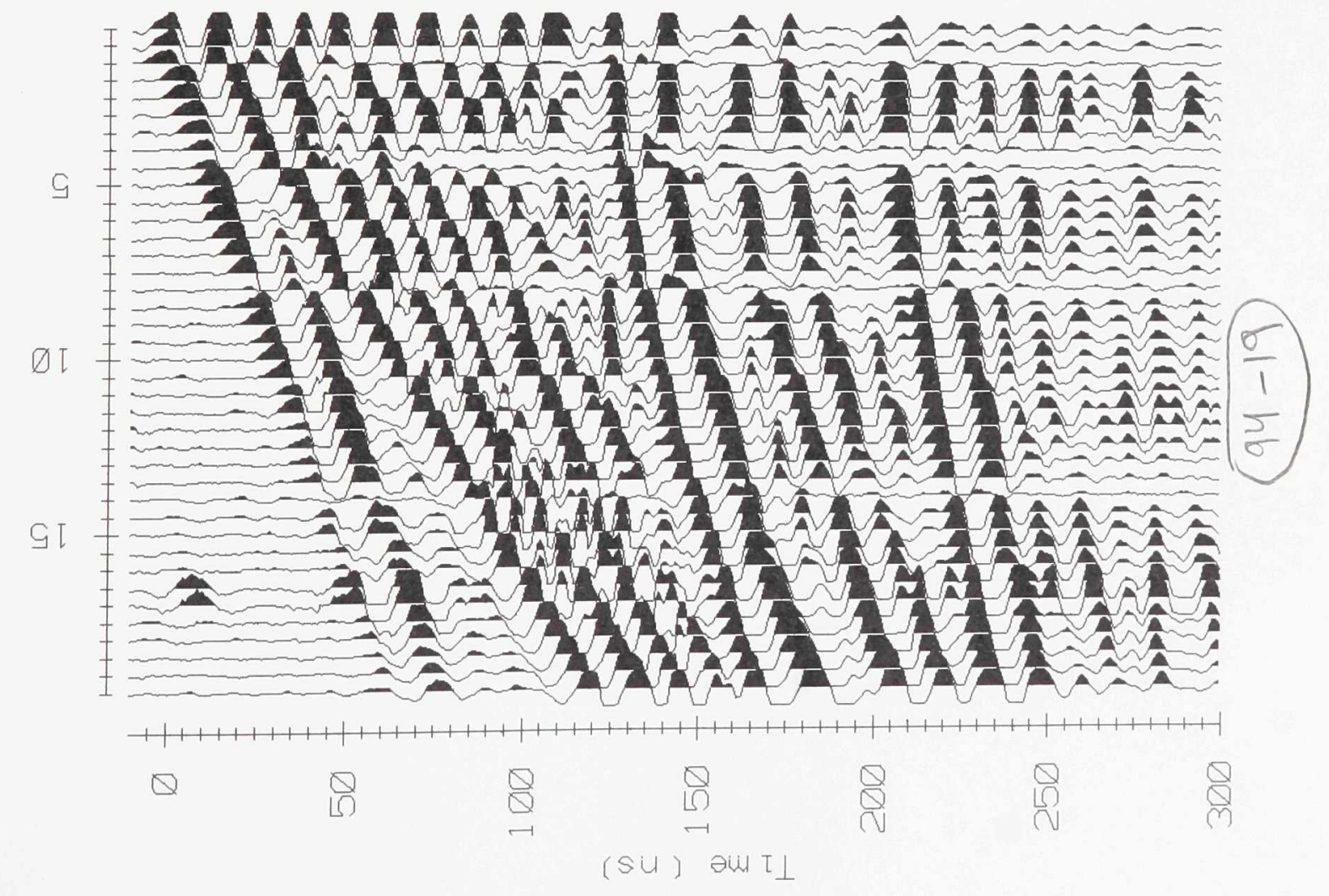


236

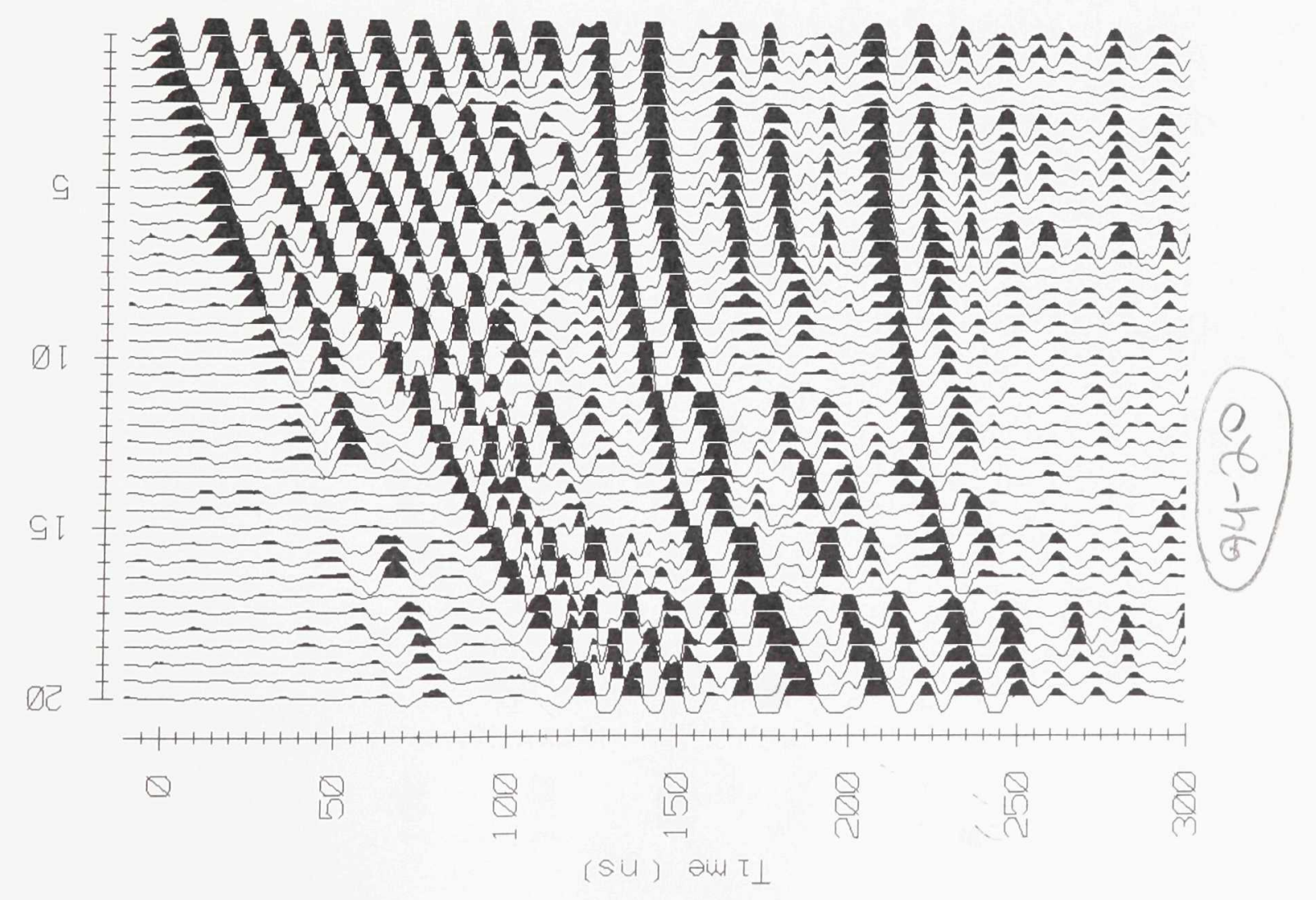


<smiles>[AlH]</smiles> 


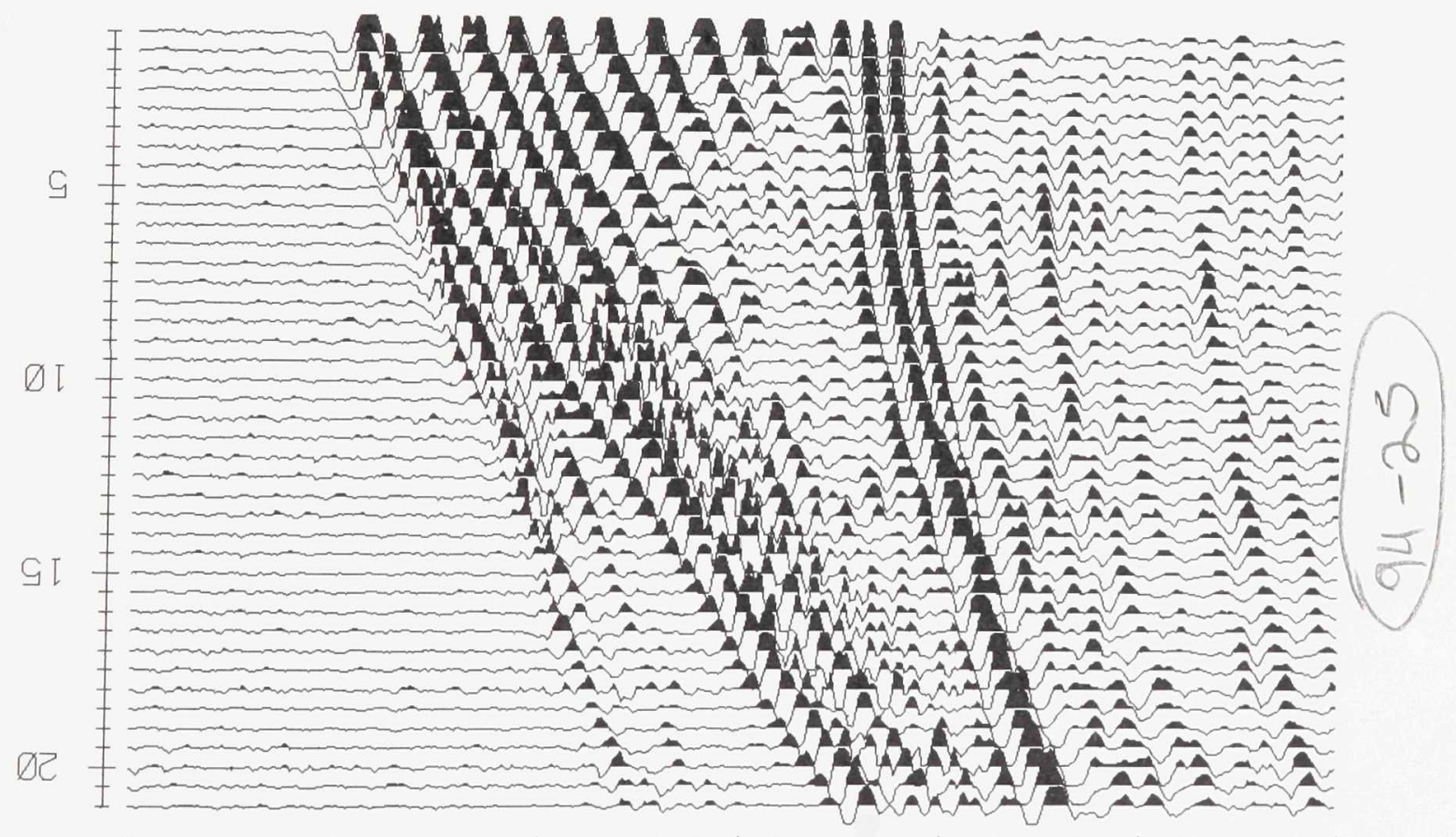

Q

$\frac{Q}{N}$

员

ल

品

$Q$

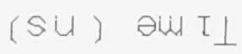


su/w $\varnothing \angle I^{\circ} \not D=\wedge$ (w) $47 d \theta \square$

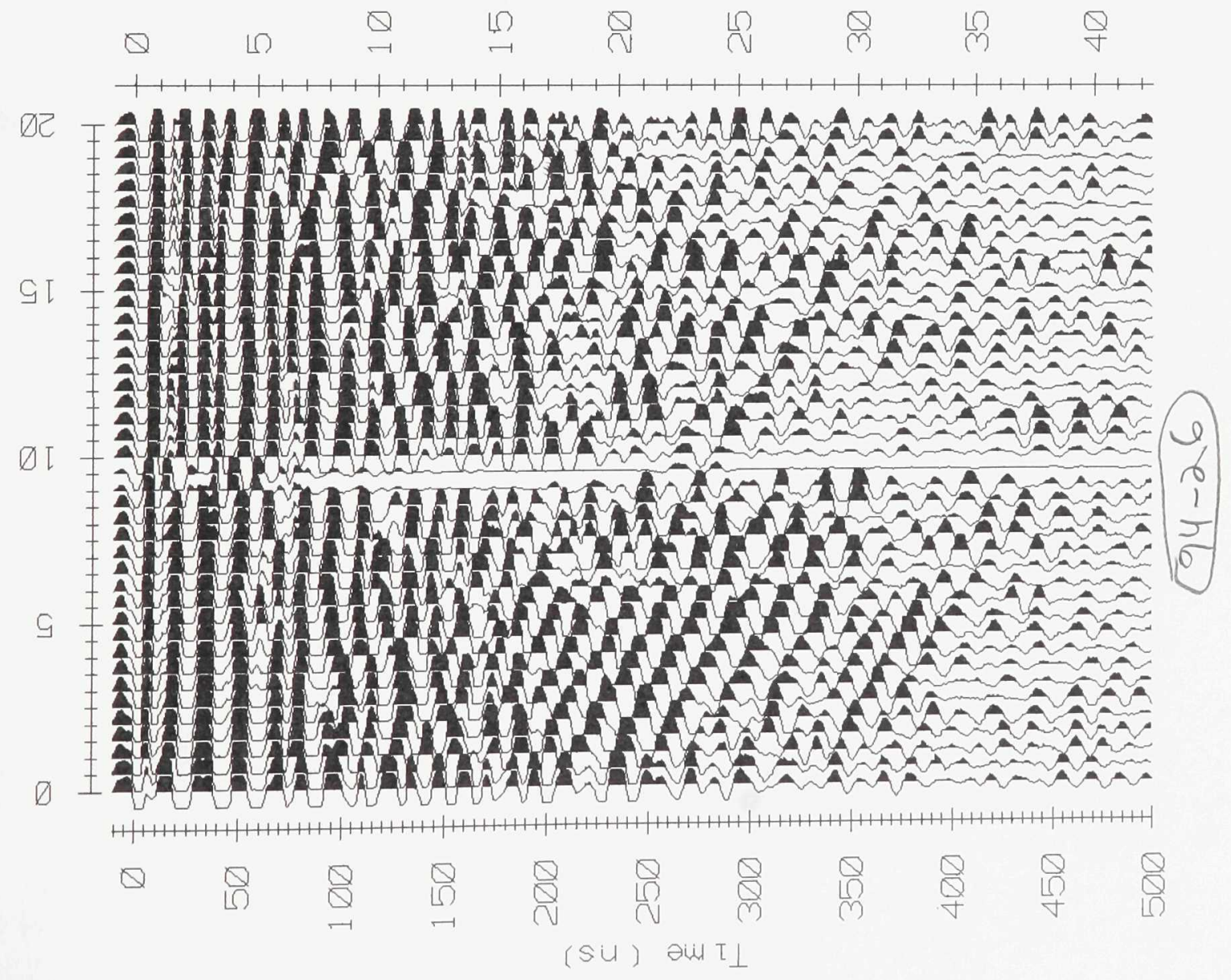


su/m $\varnothing \angle T^{\circ} \not D=\wedge$ (w) पzd

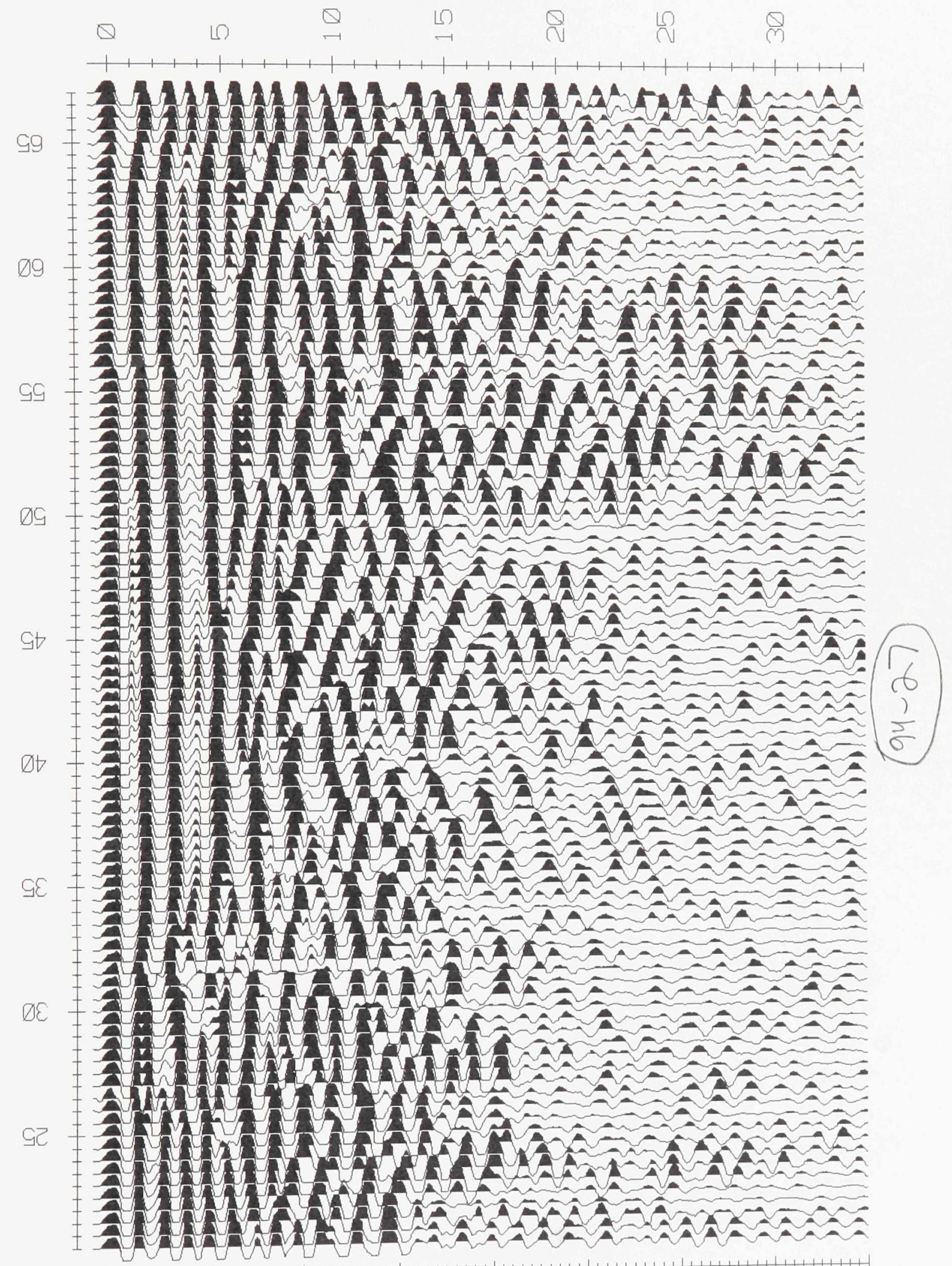

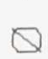

ถ)
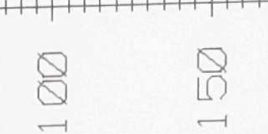


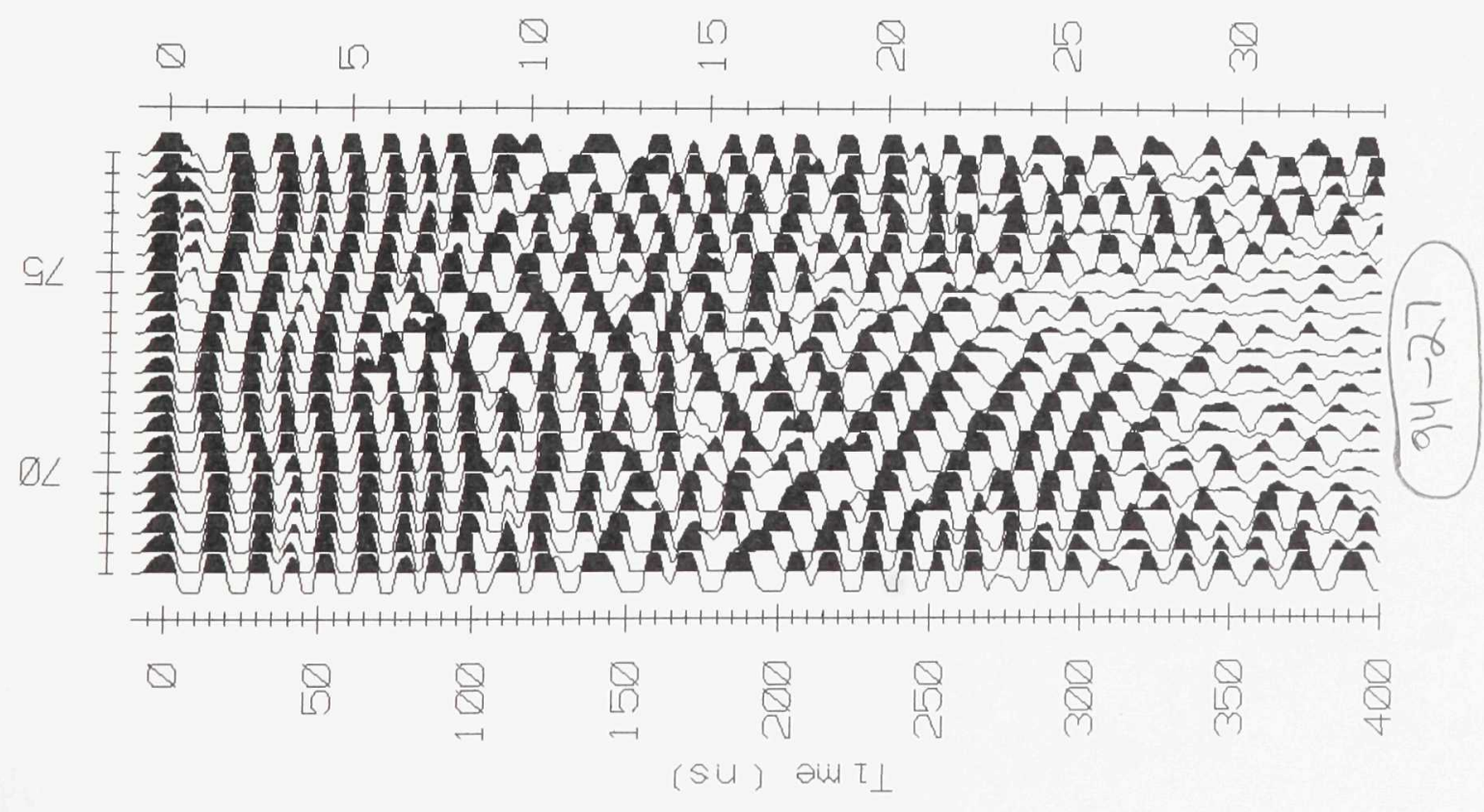




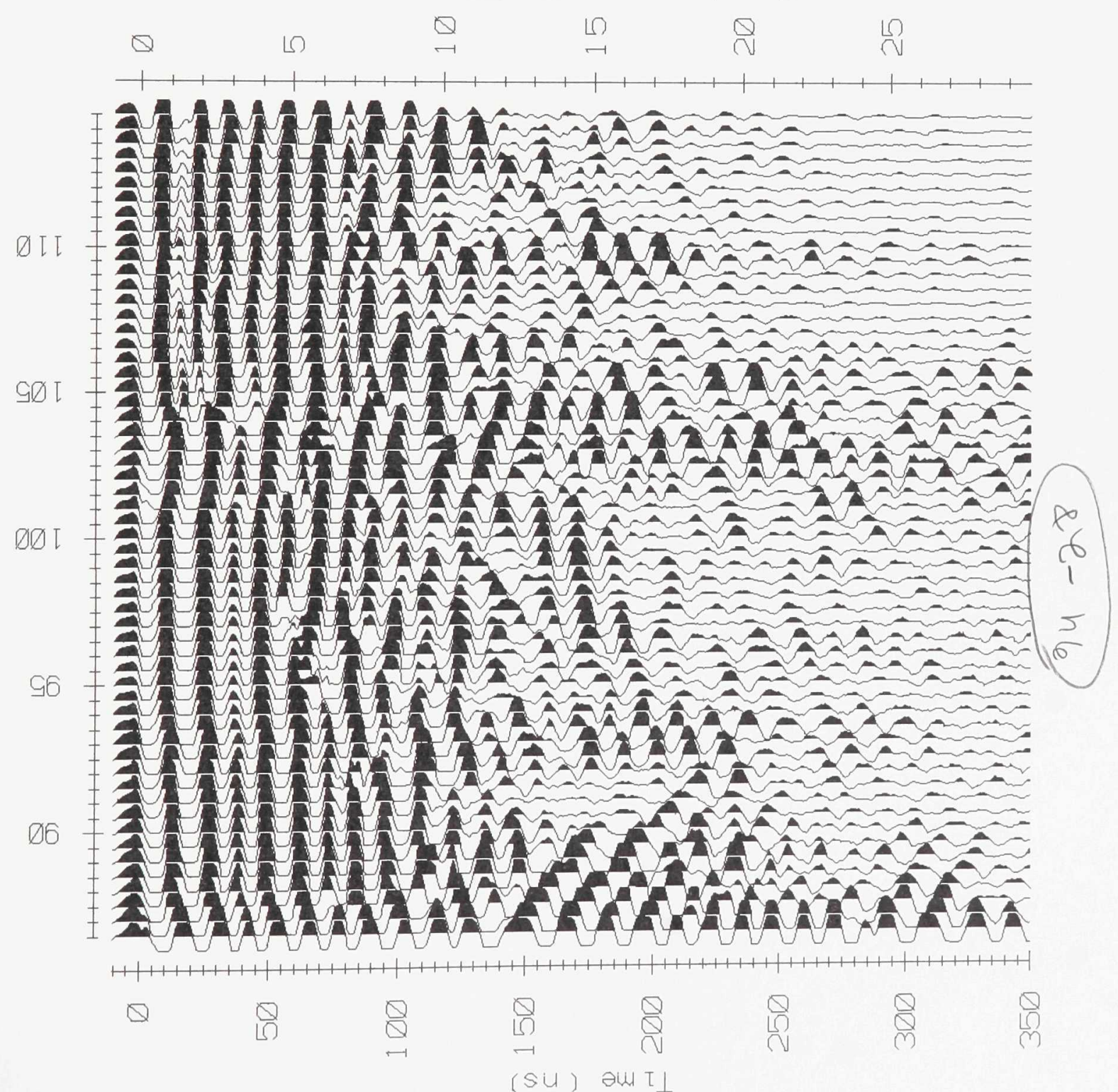


Appendix D:

Stagnation Glacier area GPR profiles 


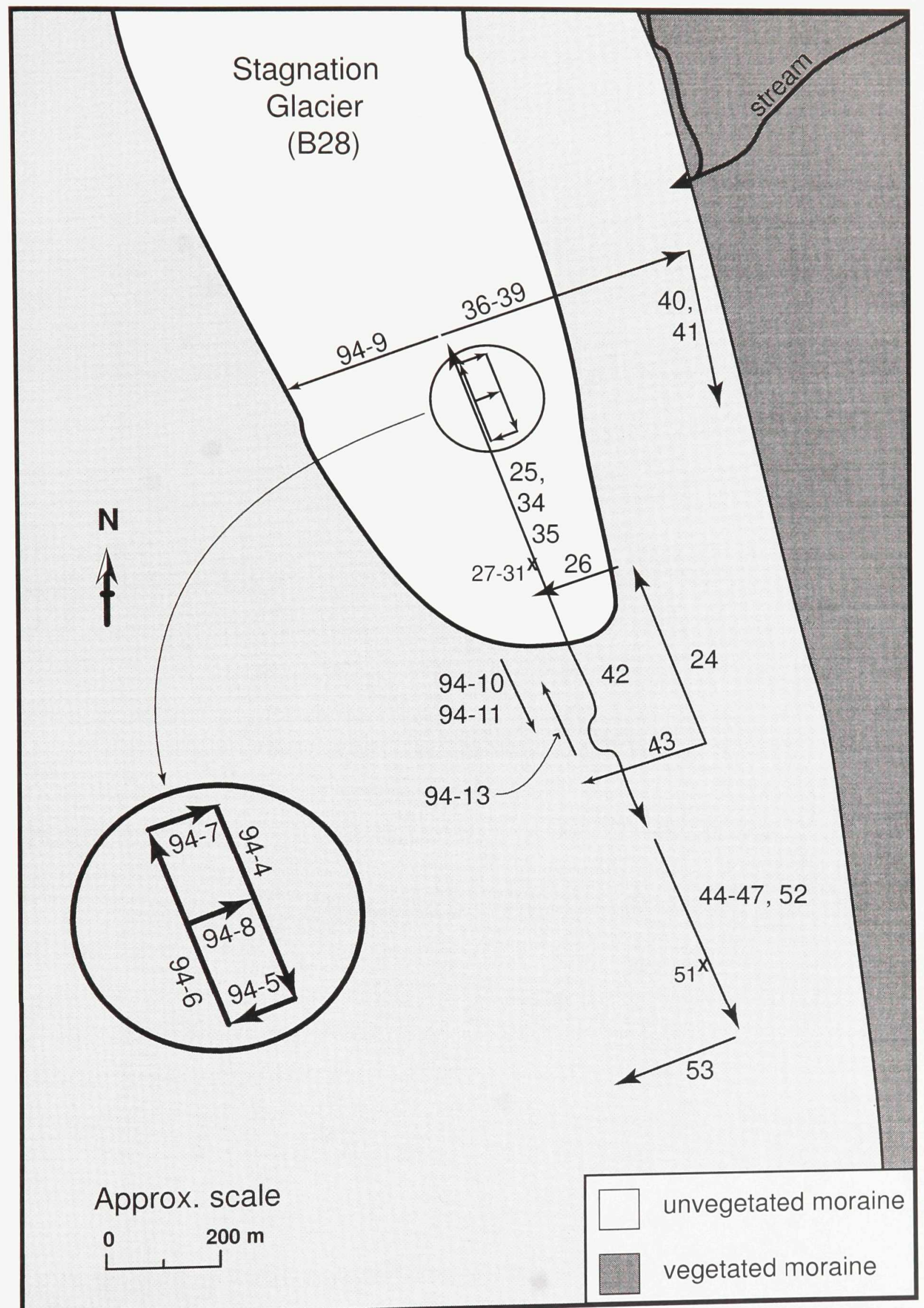

GPR profile locations. Arrows indicate direction of profile. Numbers indicate the file number. Velocity profile mid points are indicated by an "X". Some files may also end with the letter "a" indicating some modifications have been made (eg. polarity reversal or trace deletion). 


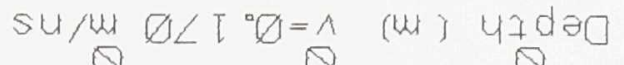
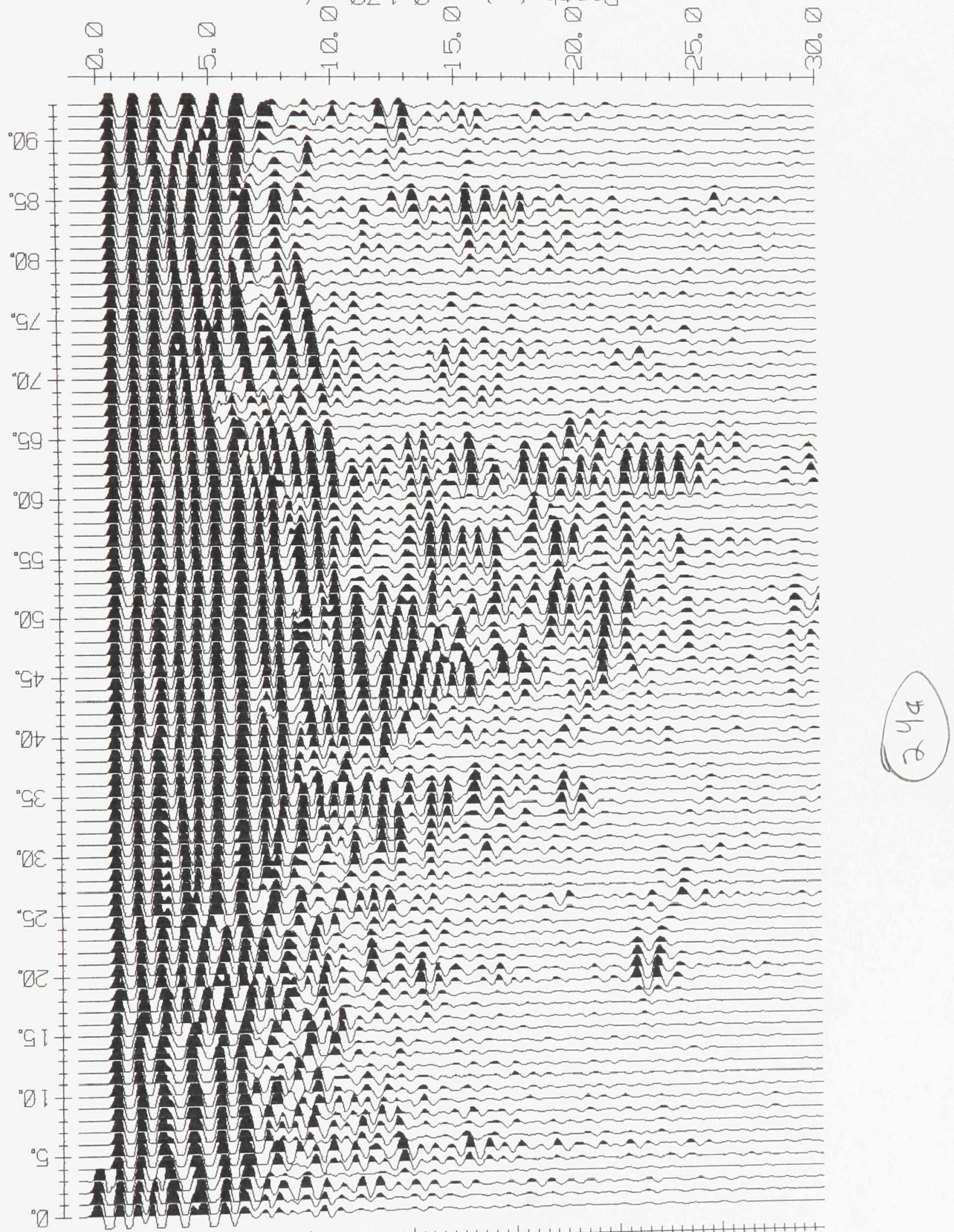

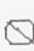

$\mathbb{Q}$

$Q$

Q

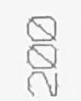

Q 


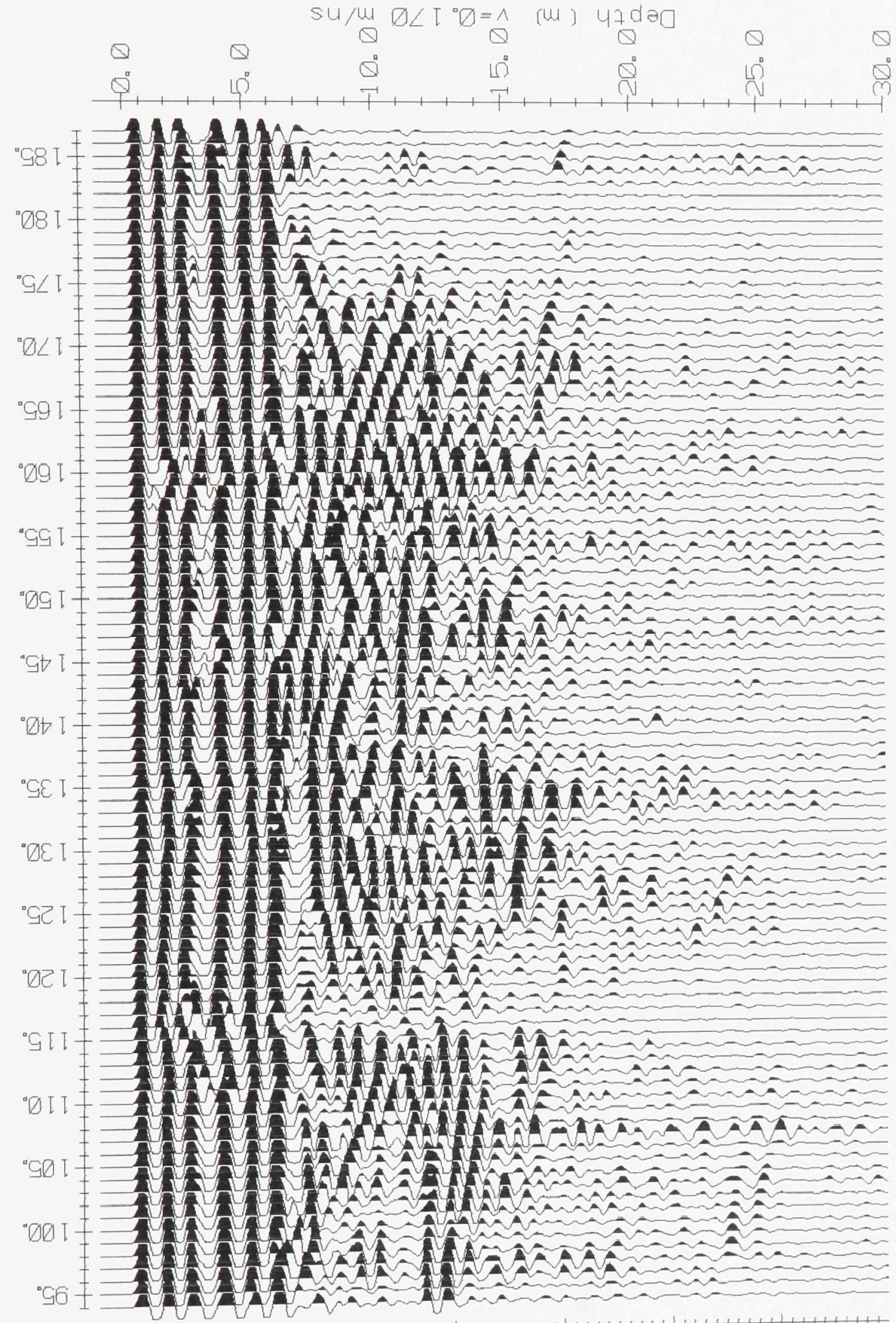




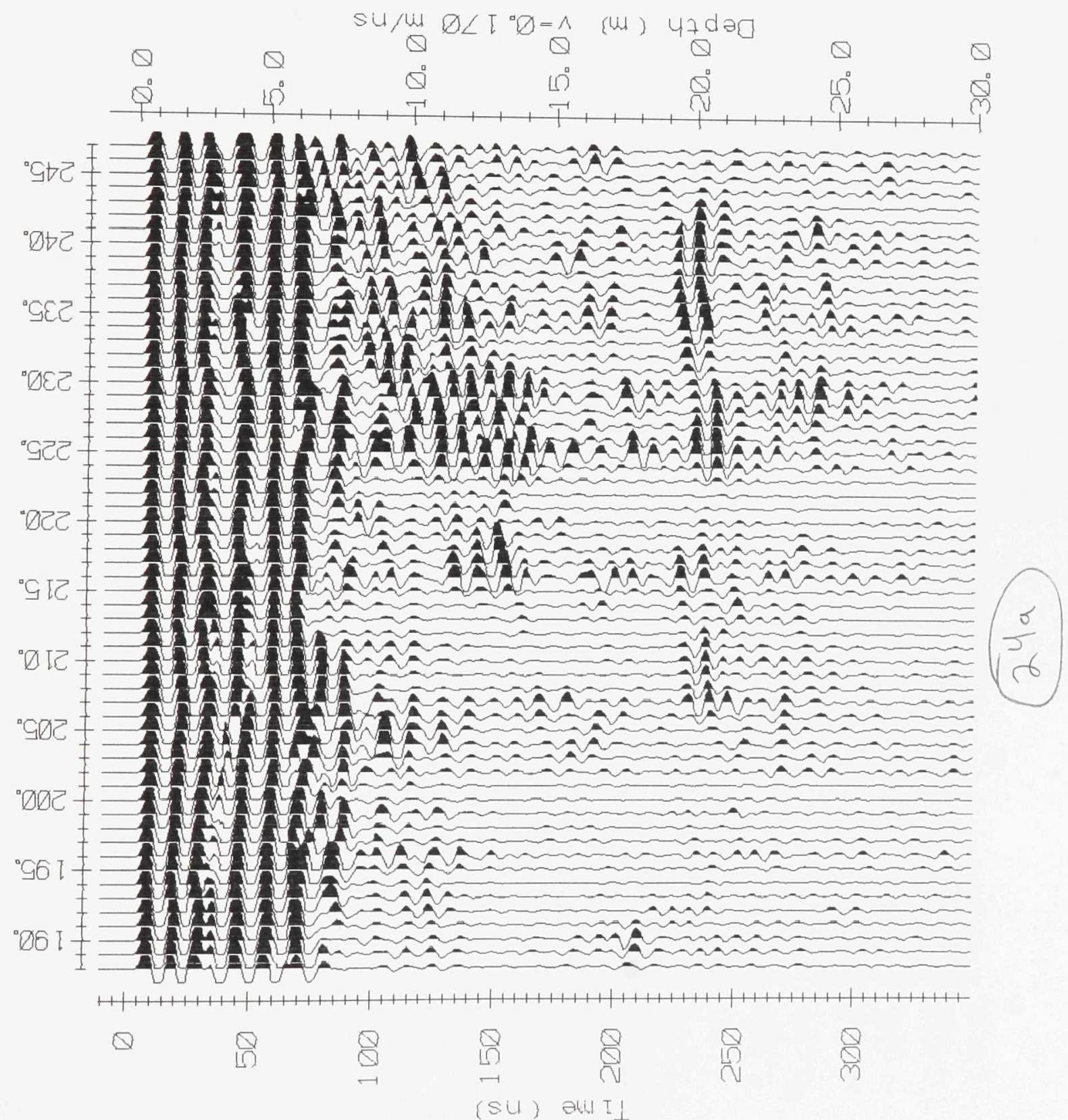




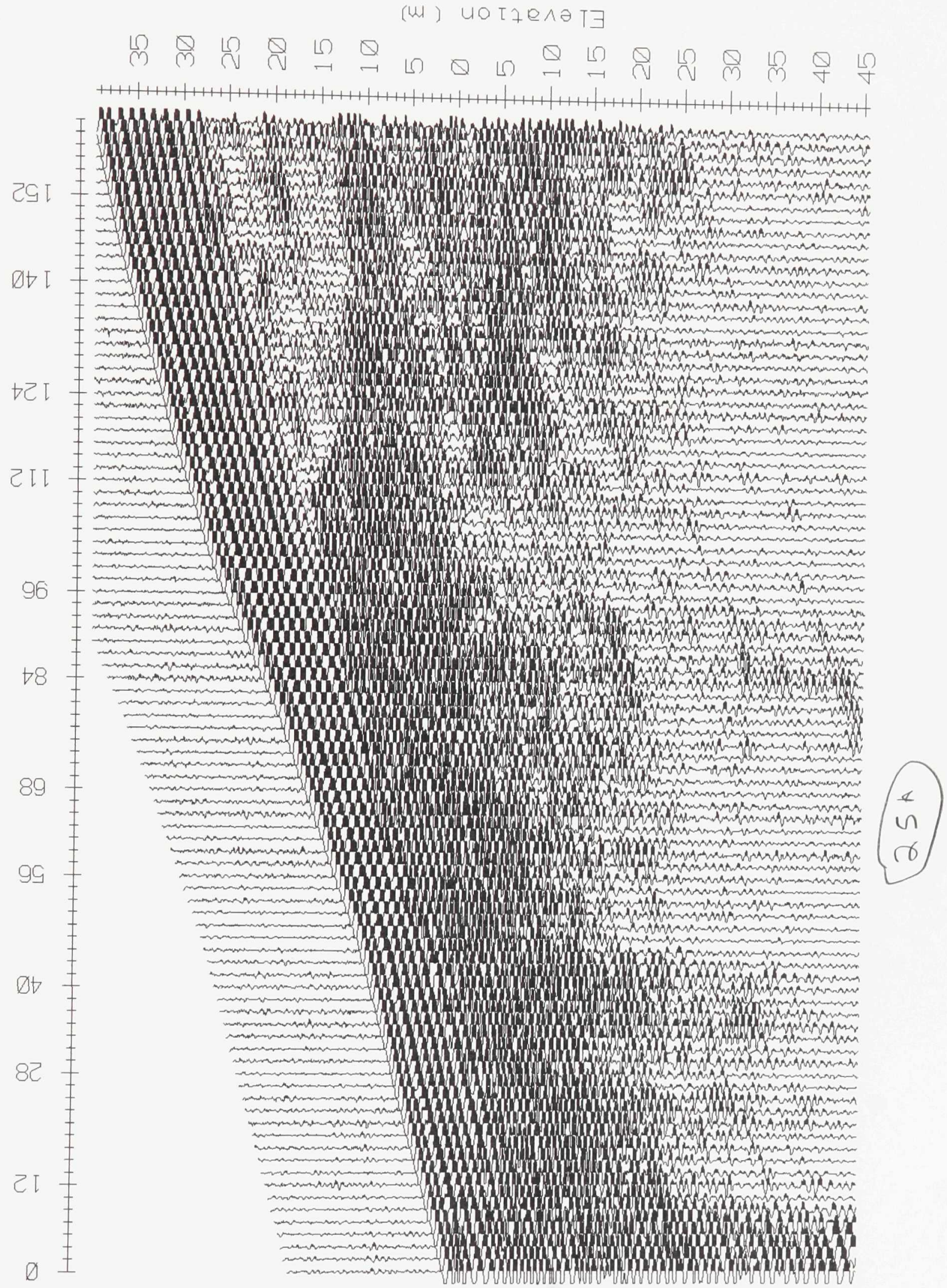

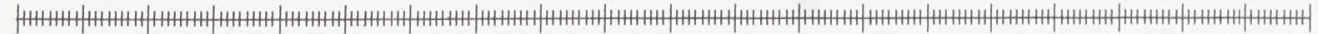

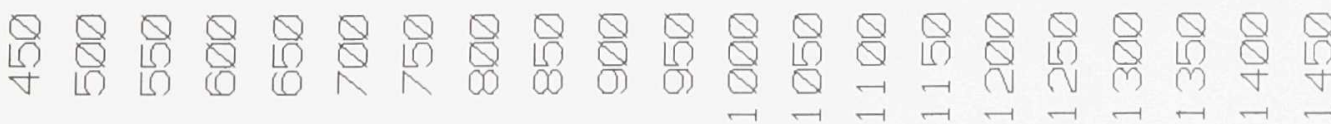




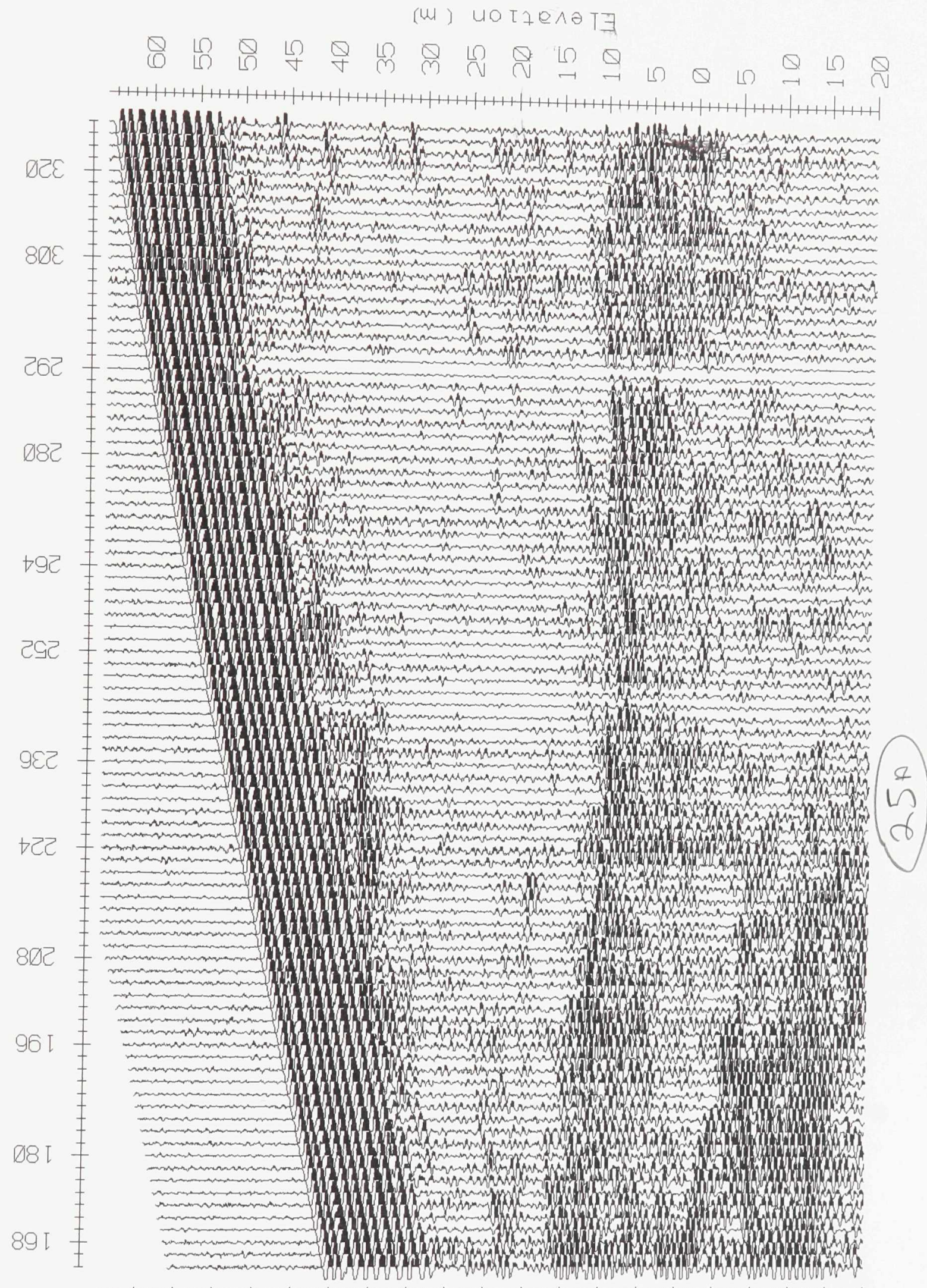

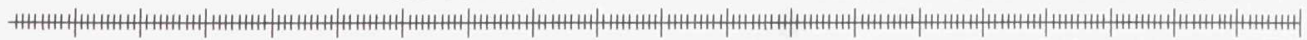

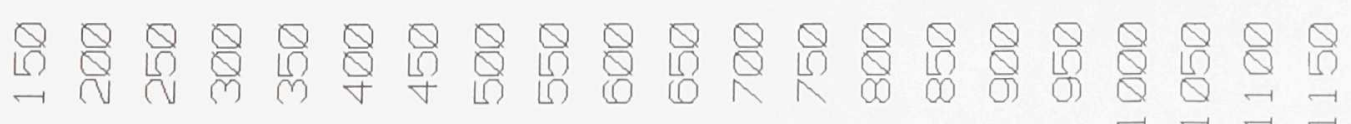




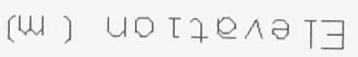

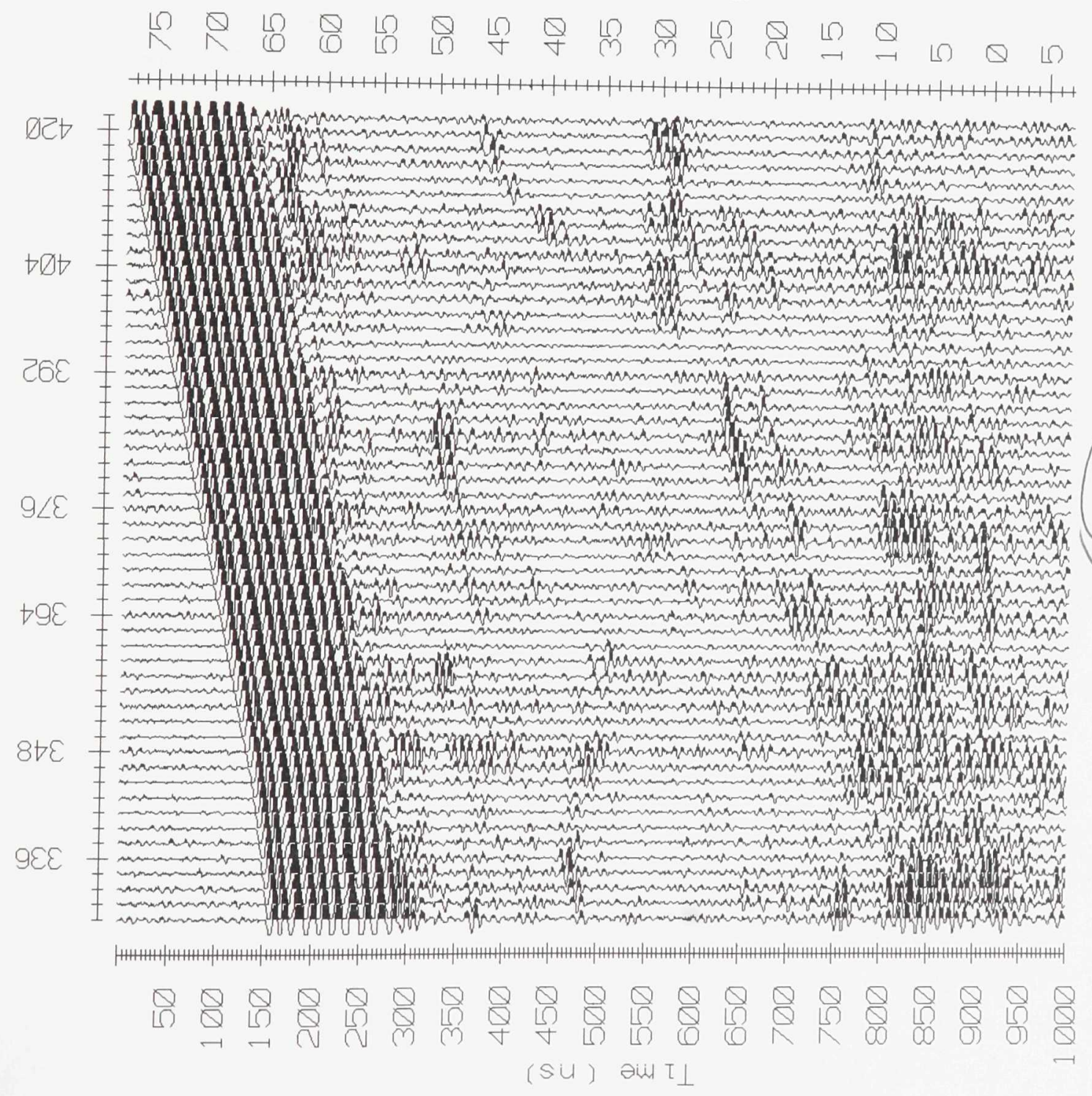



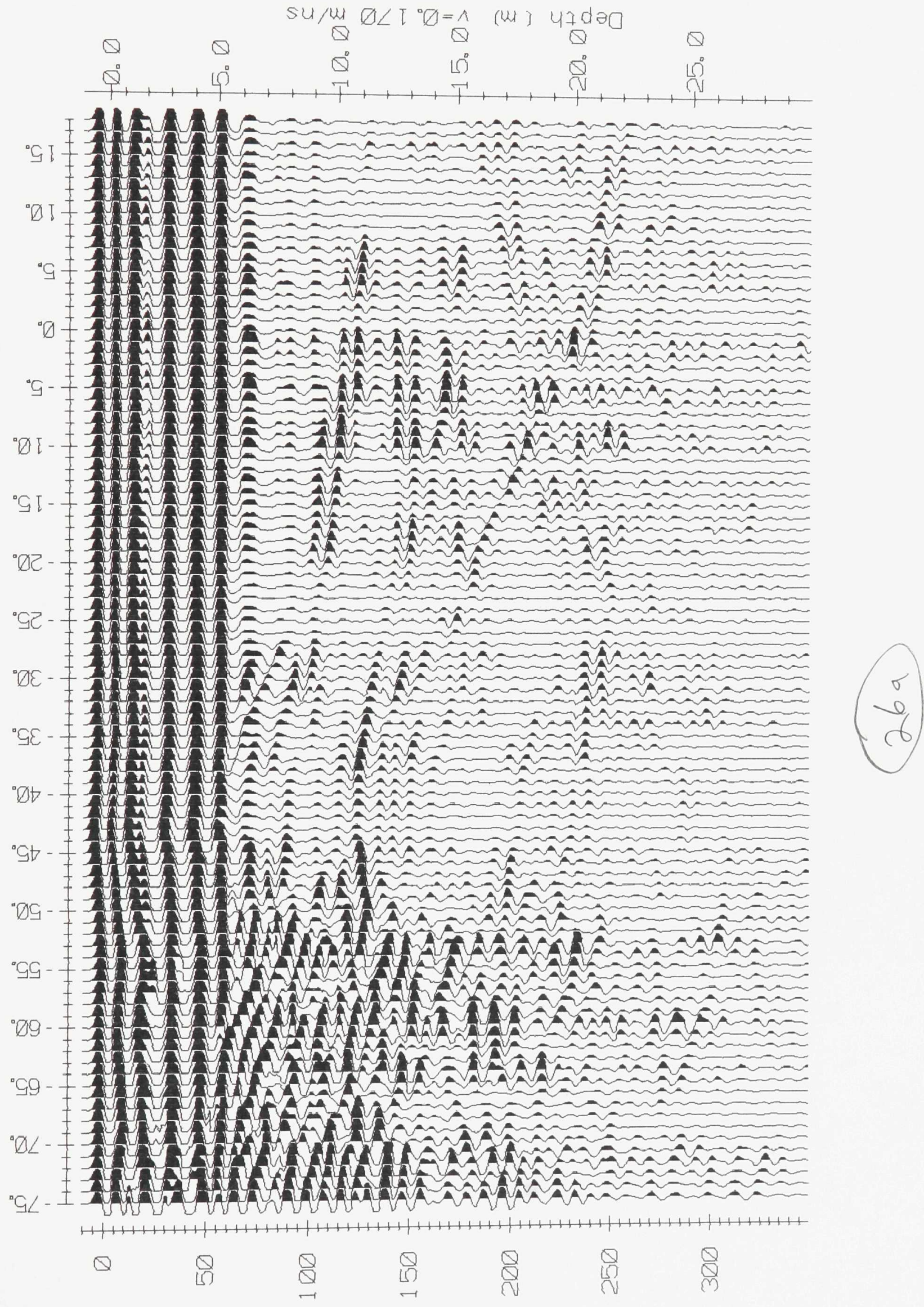

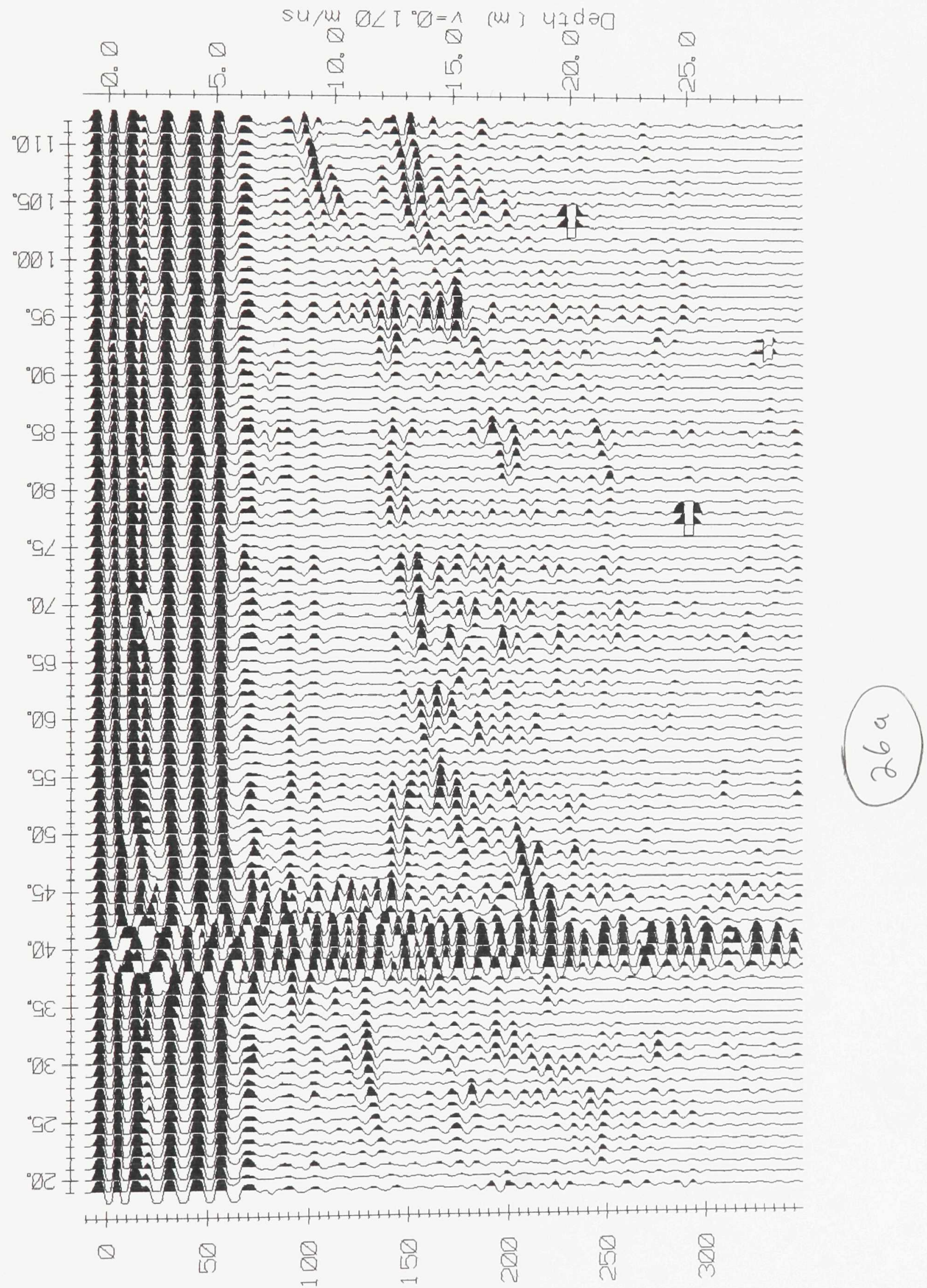


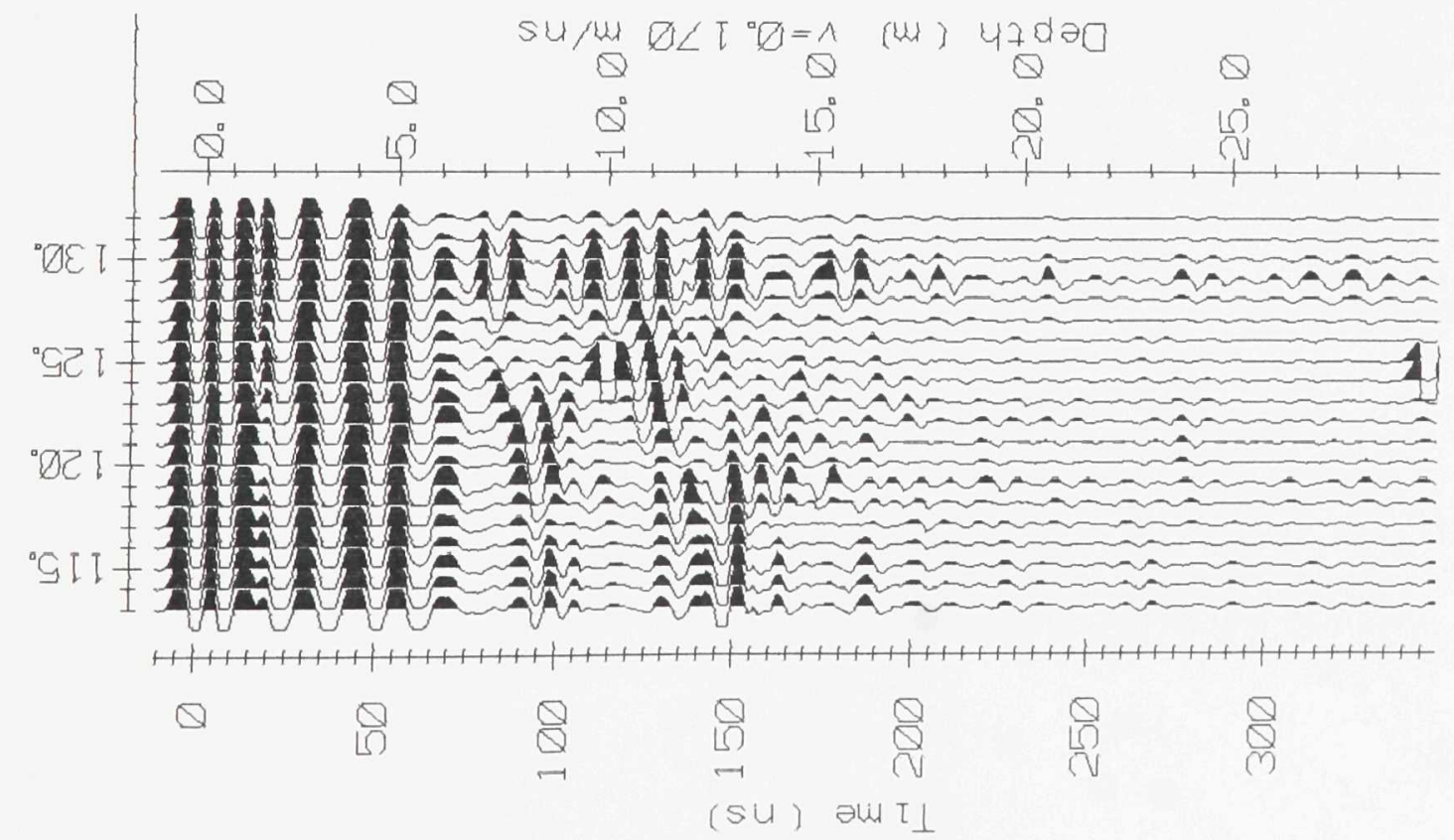




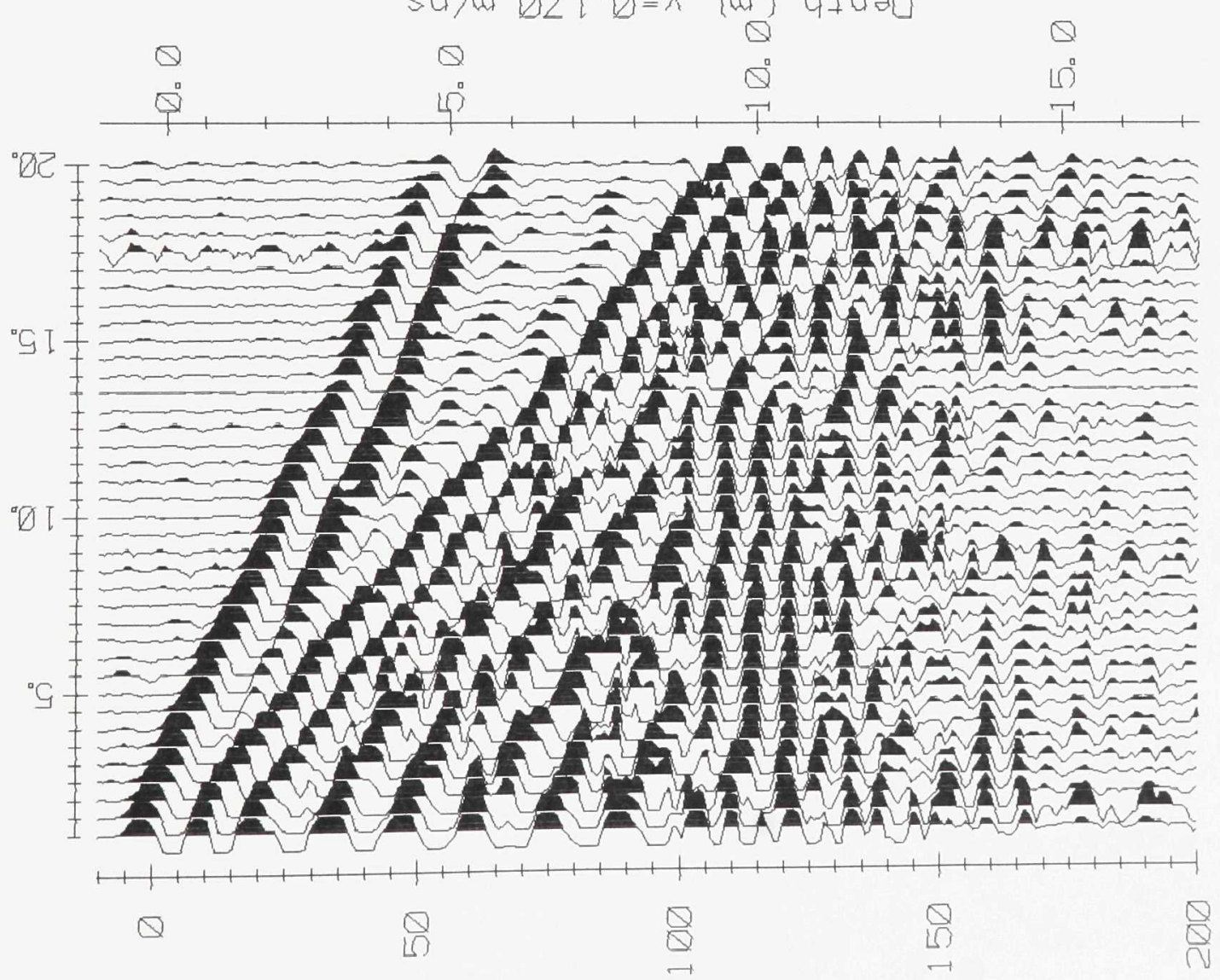



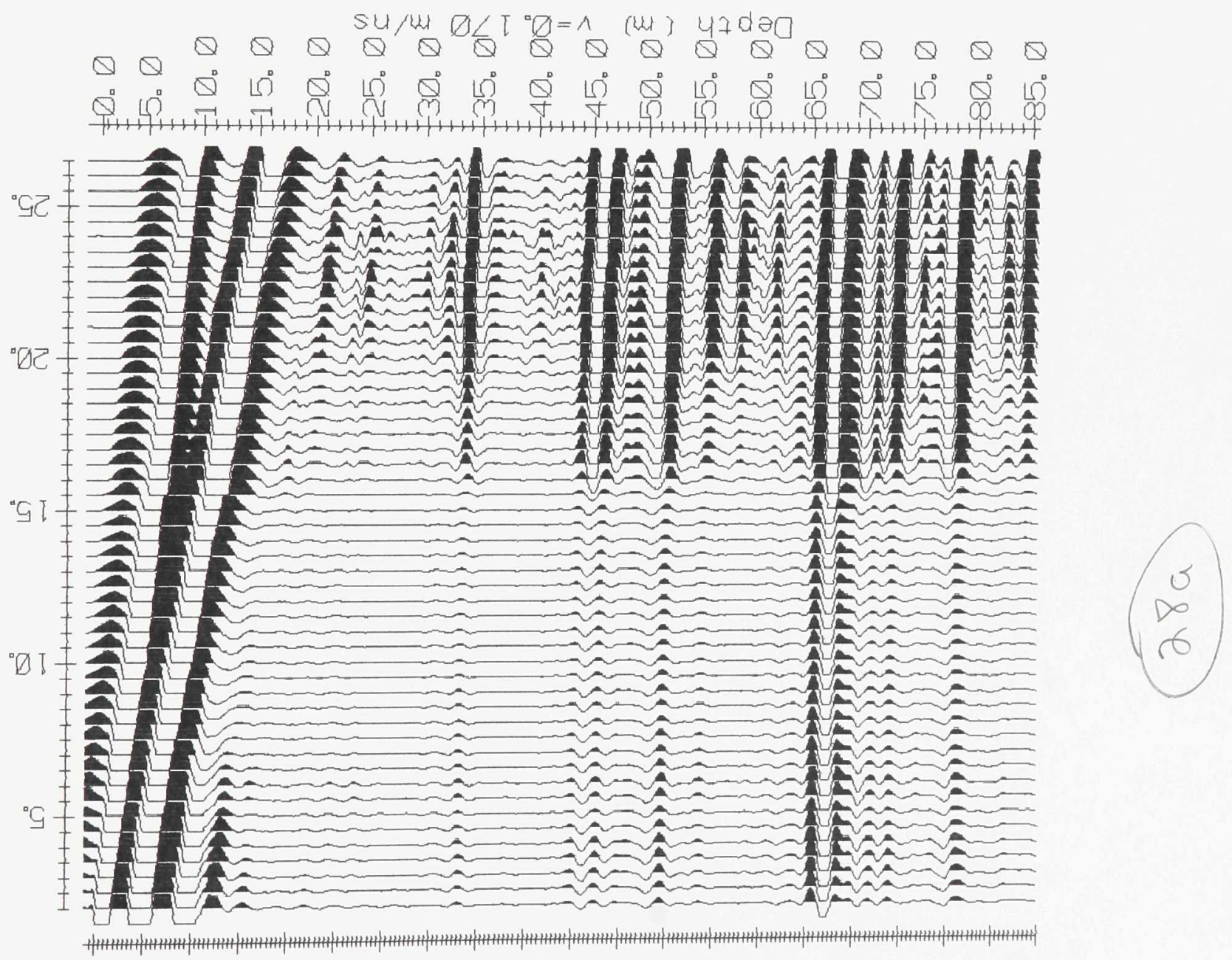

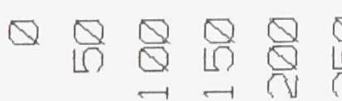
8

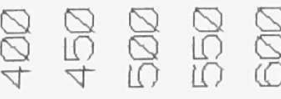
एव $ه$ म
के एत
की ब

$$
\text { (su) aw IL }
$$


Su/M $\triangle \angle T \nabla=\wedge$ (w) $47 d \partial \square$
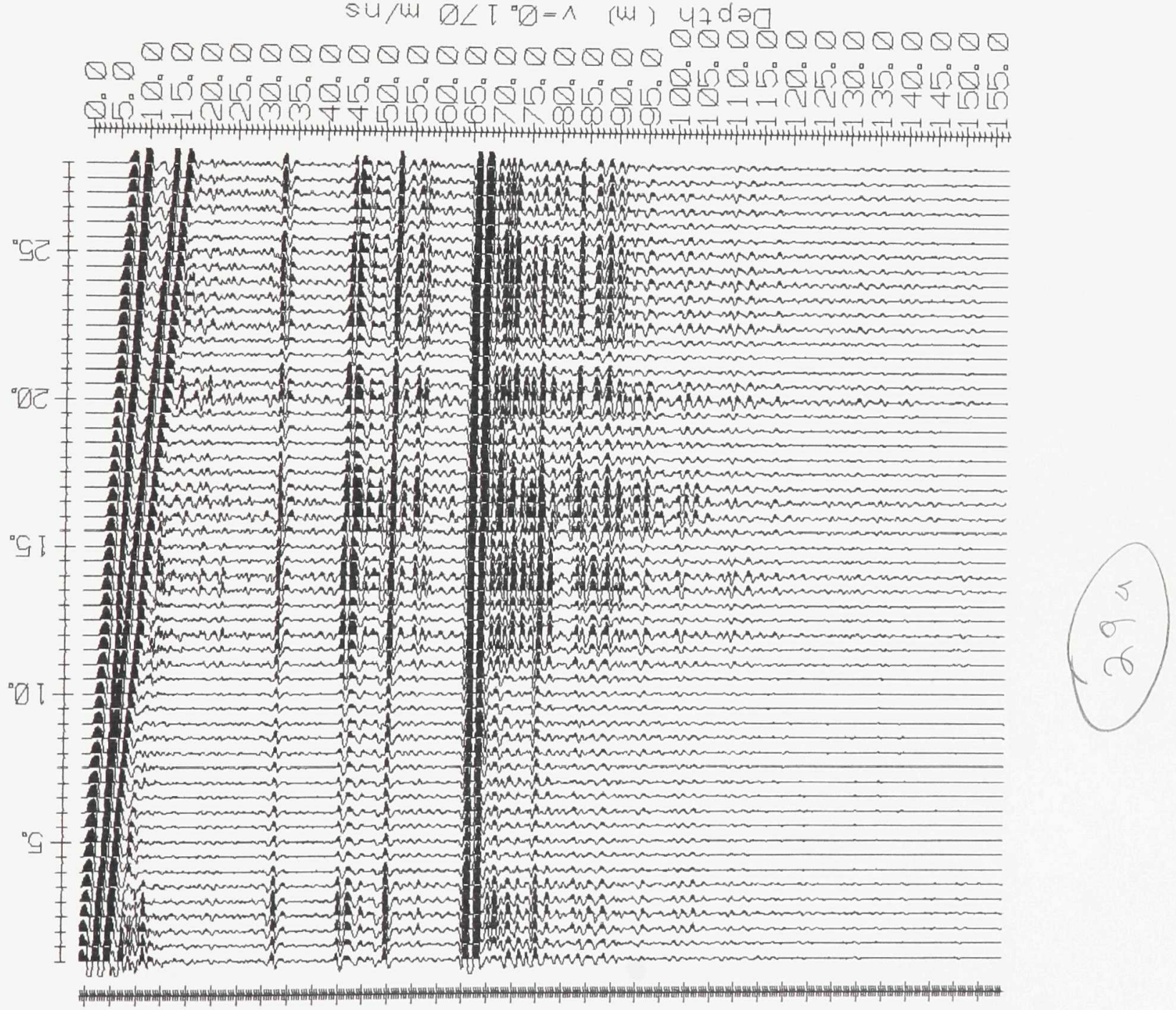

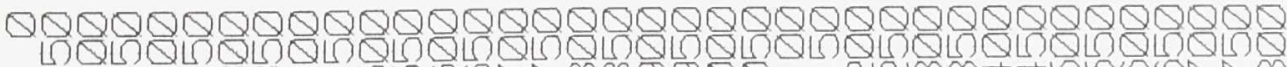

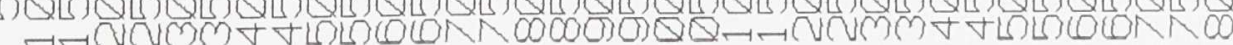


Vilime 

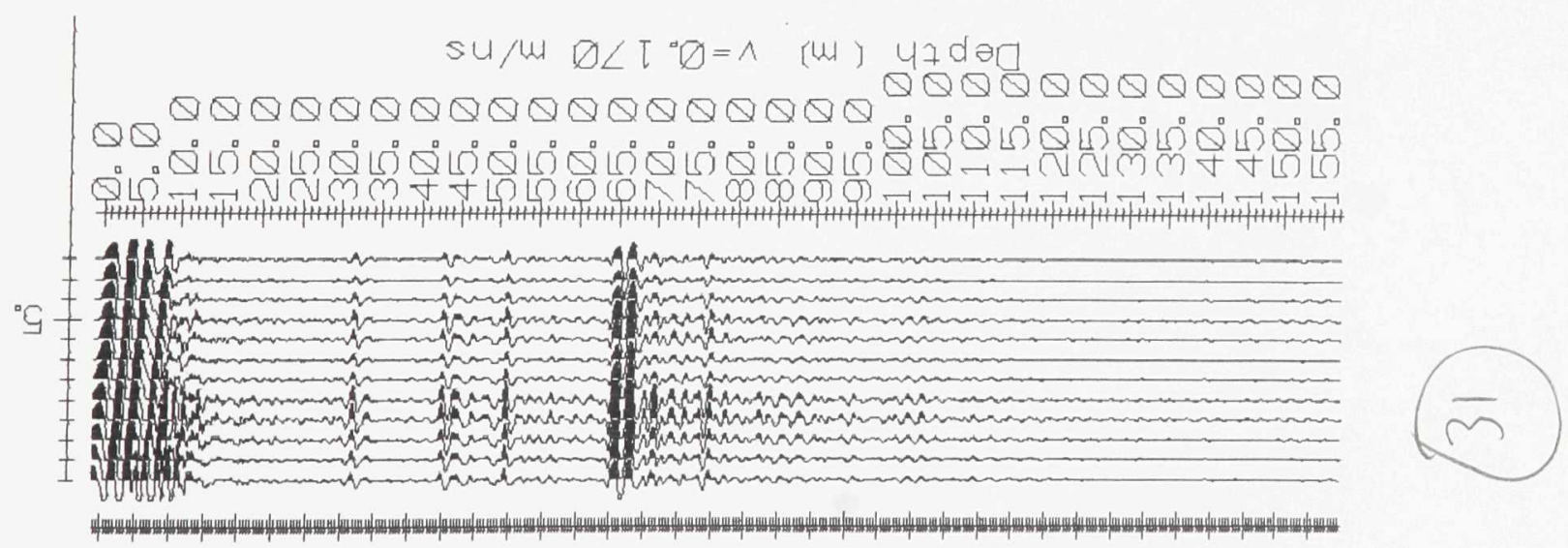

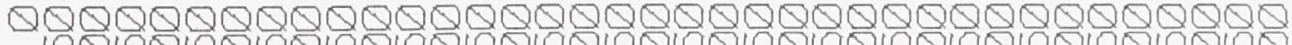

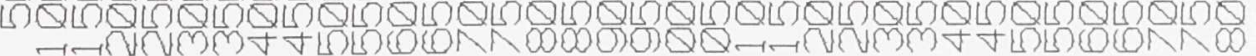

$$
\text { (SU) owi } I_{\perp}
$$




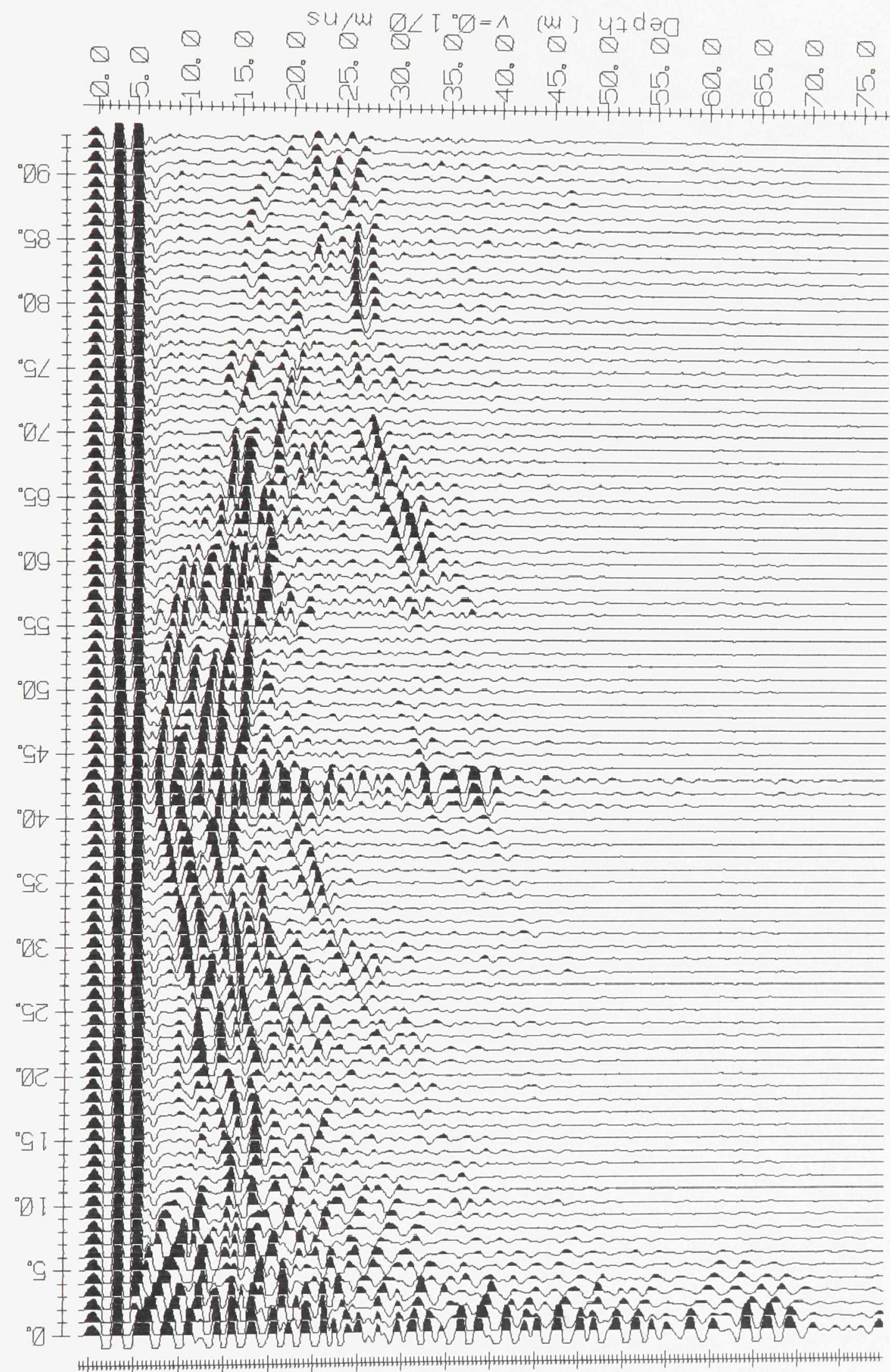

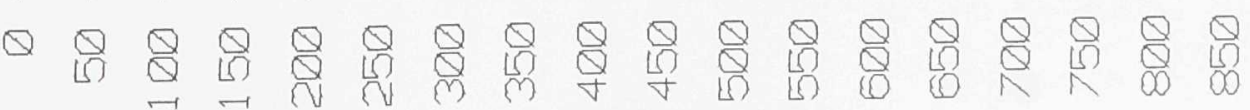




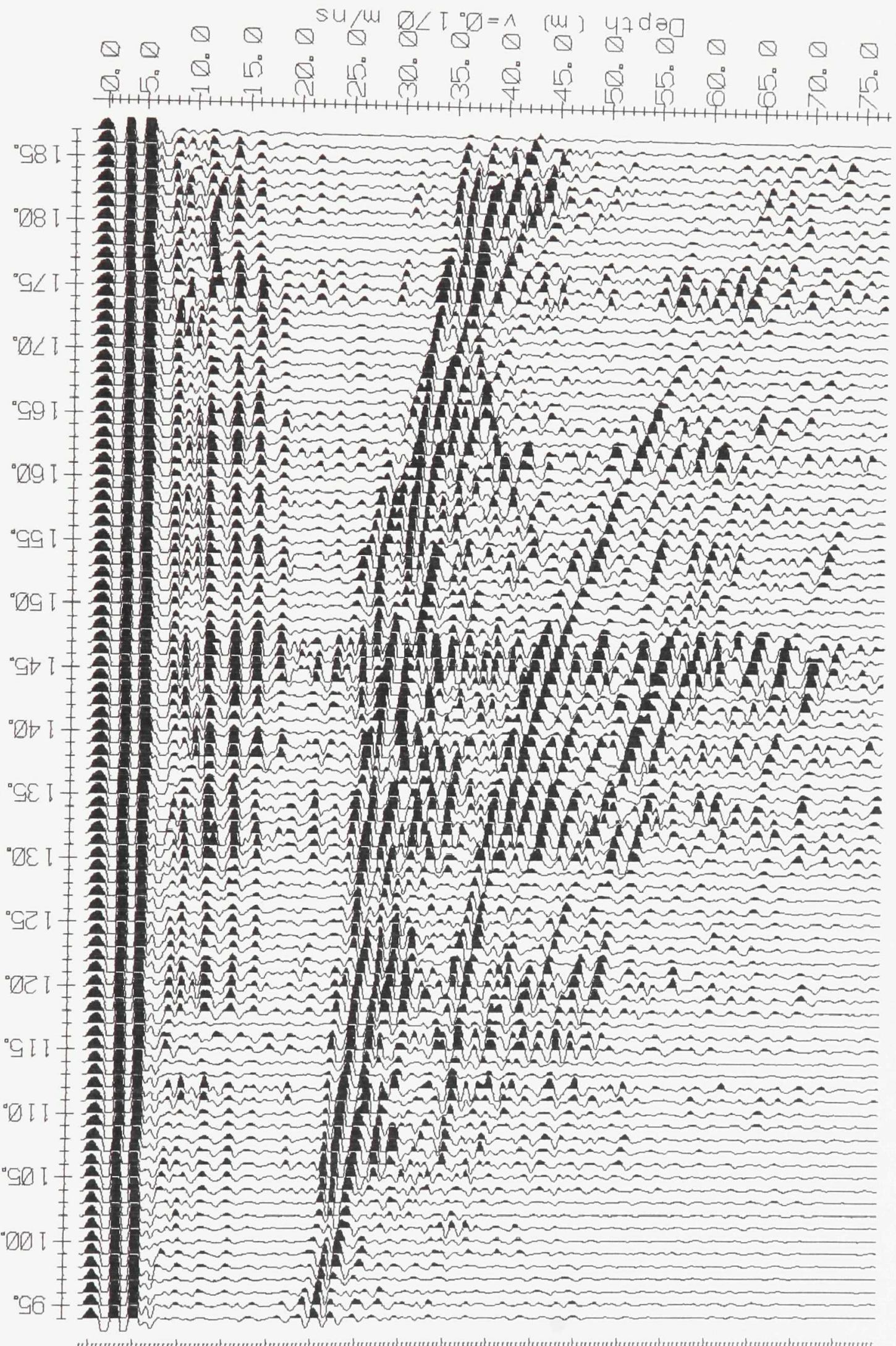



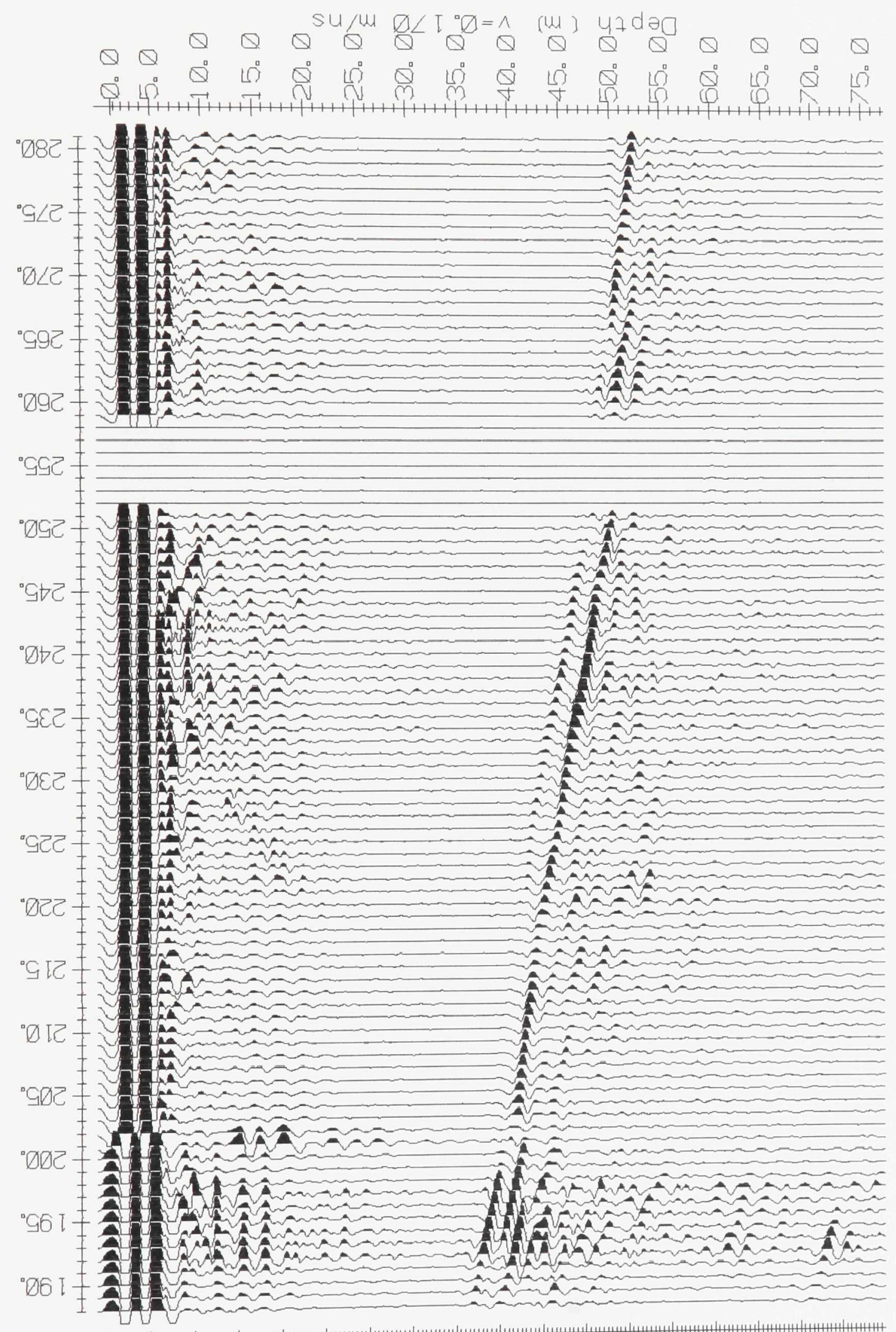

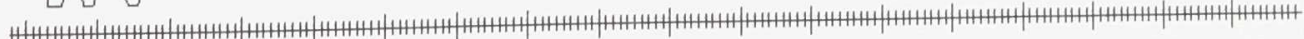
Q
Q
बे एि ले
ल
$\frac{\nabla}{\square}$
Q
8

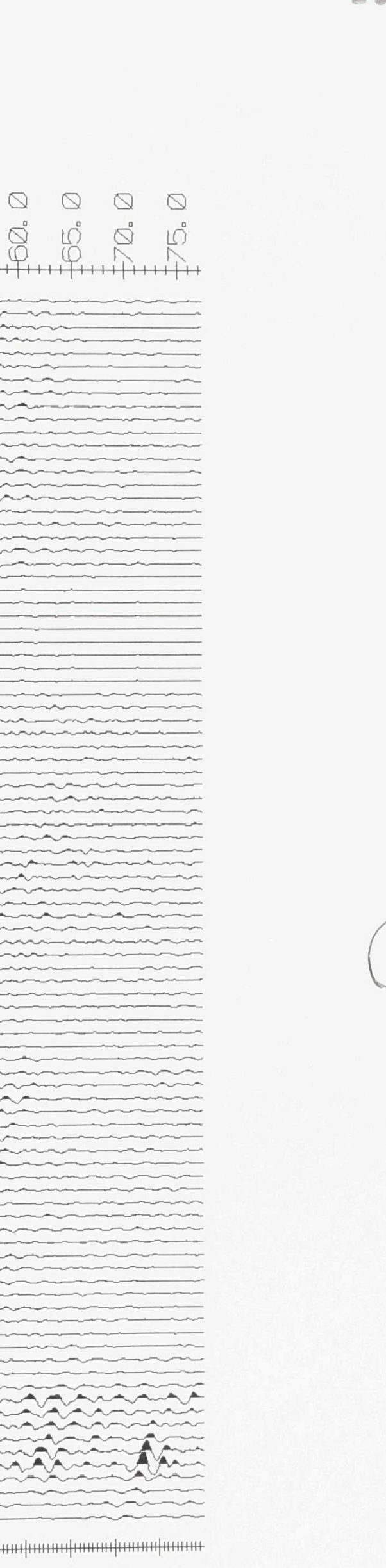




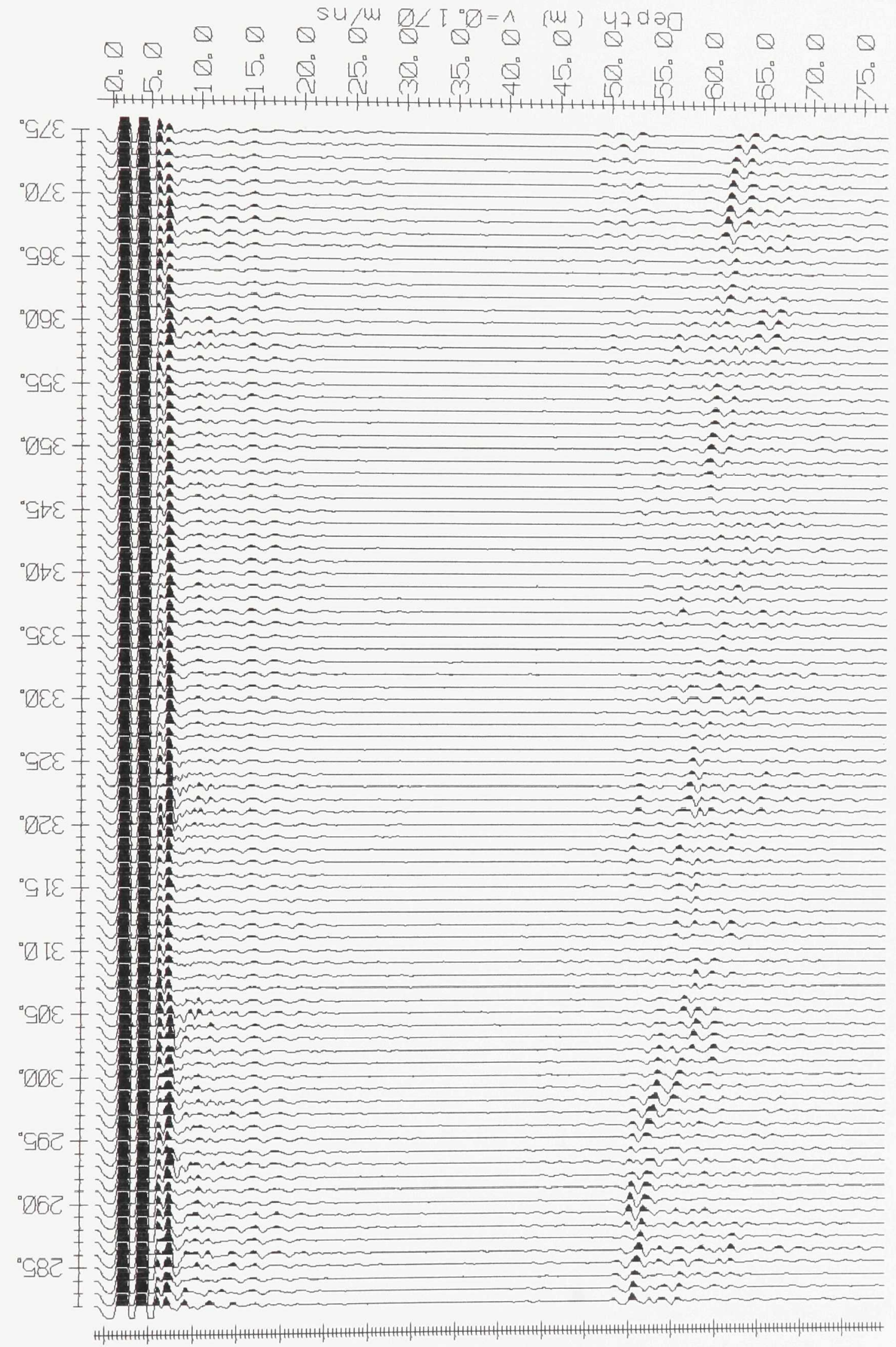
$Q \underset{\square}{Q} \boxminus$
Q
员
Q
Q
$Q$
(1)
$Q$
$\begin{array}{llll}Q & Q & Q \\ N & Q & 0\end{array}$
(si) ) aw $\tau \perp$ 


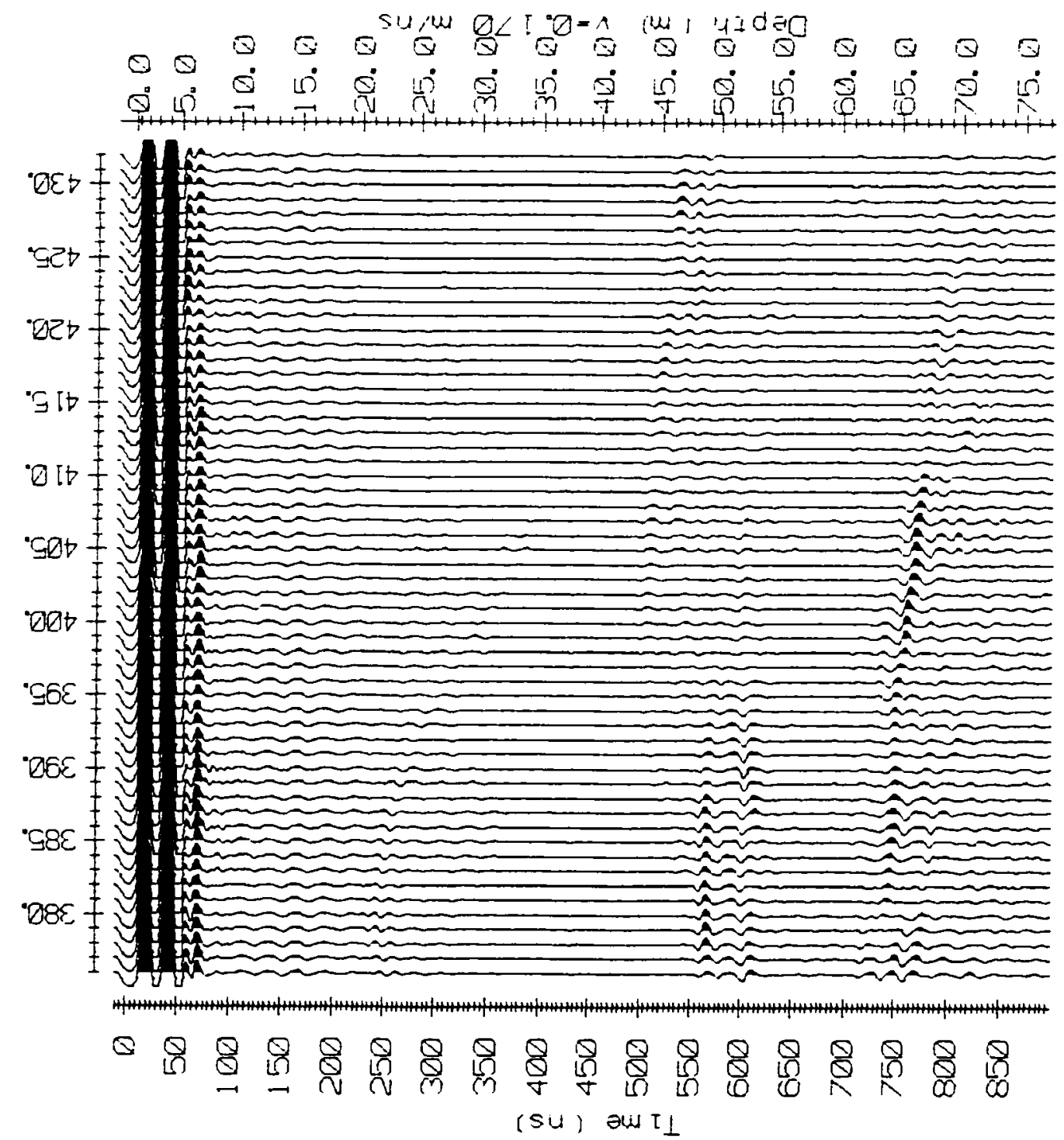



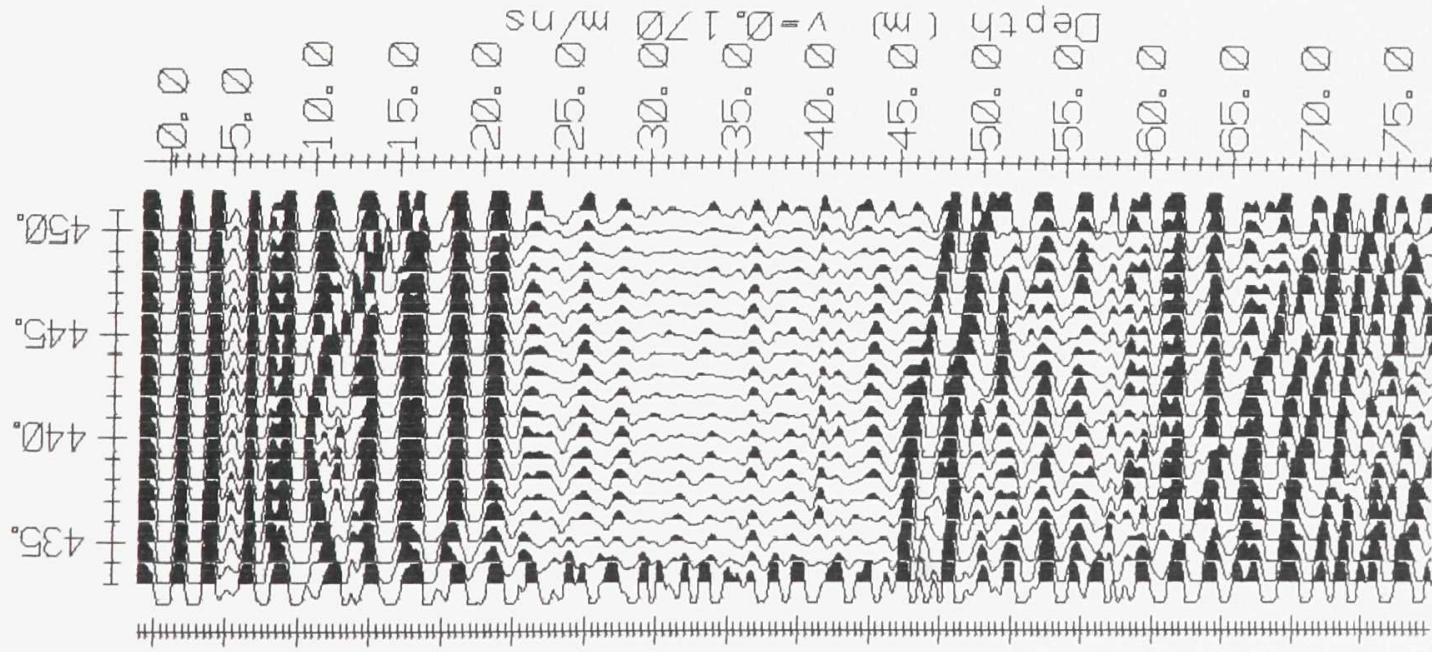
$Q \mathbb{Q} \otimes \mathbb{\Omega}$
Q
Q

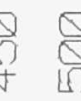

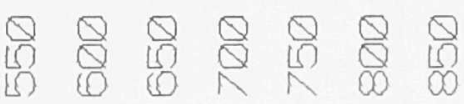

$$
\text { (su) əu IL }
$$


su/w $\not \subset \angle[\varnothing-\wedge$ (w) 47dəa

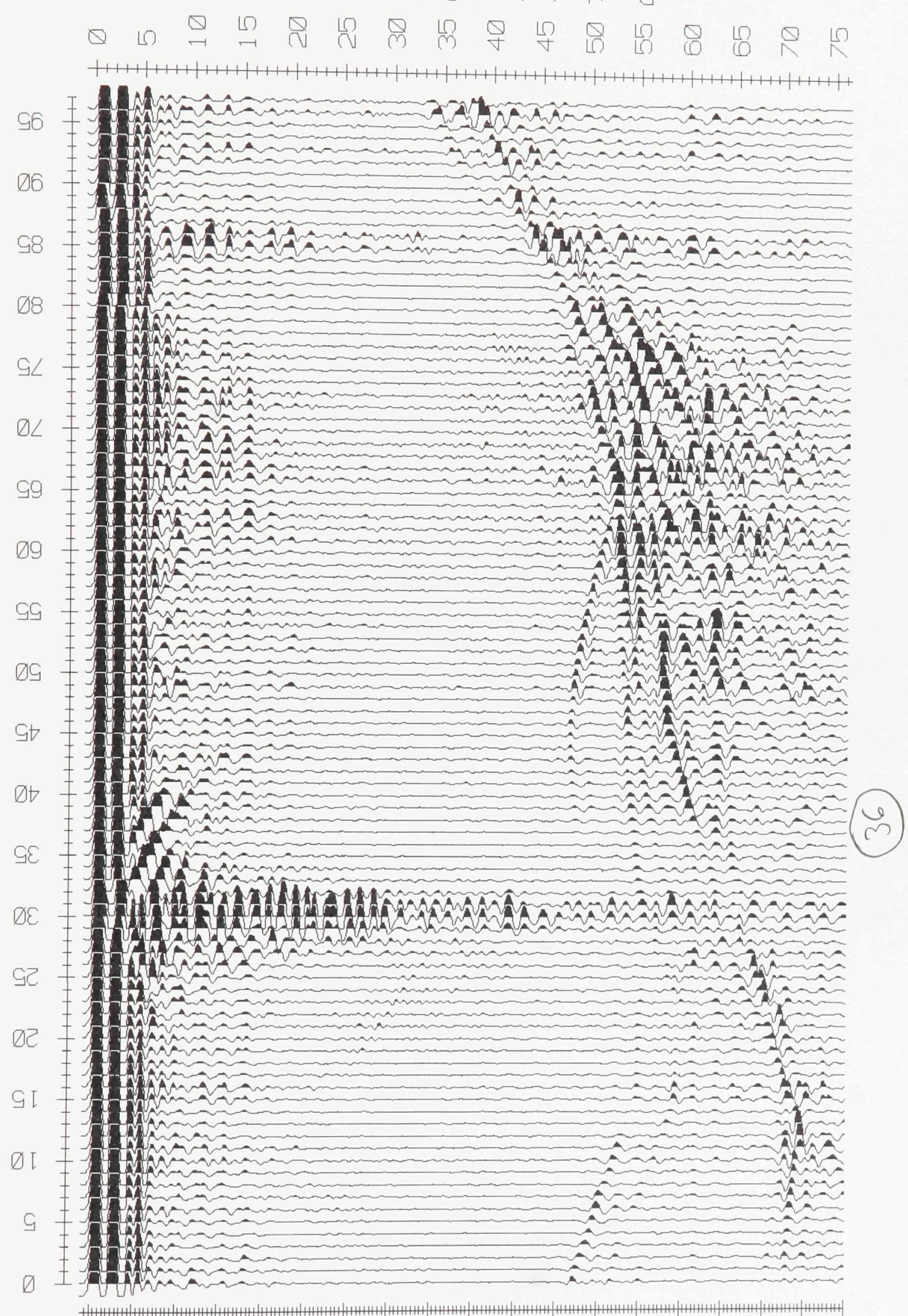

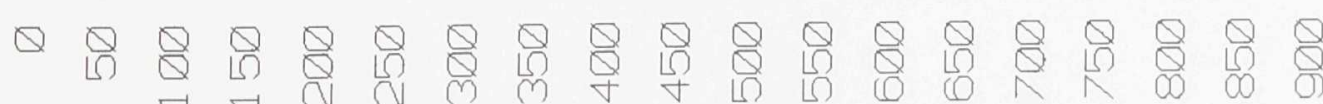




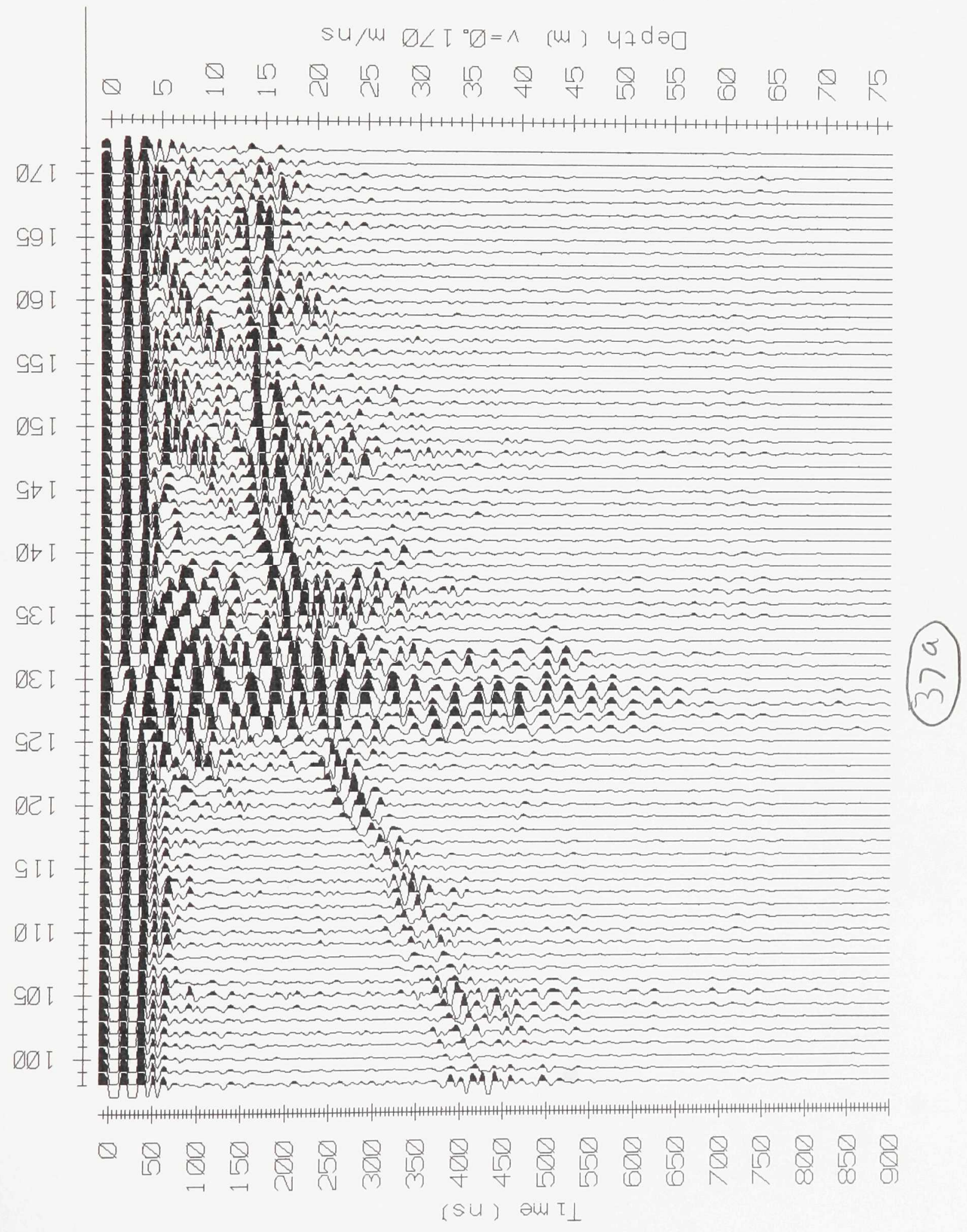


su/w $\varnothing \angle \tau^{\circ} \not d=\wedge$ (w) 47dəa

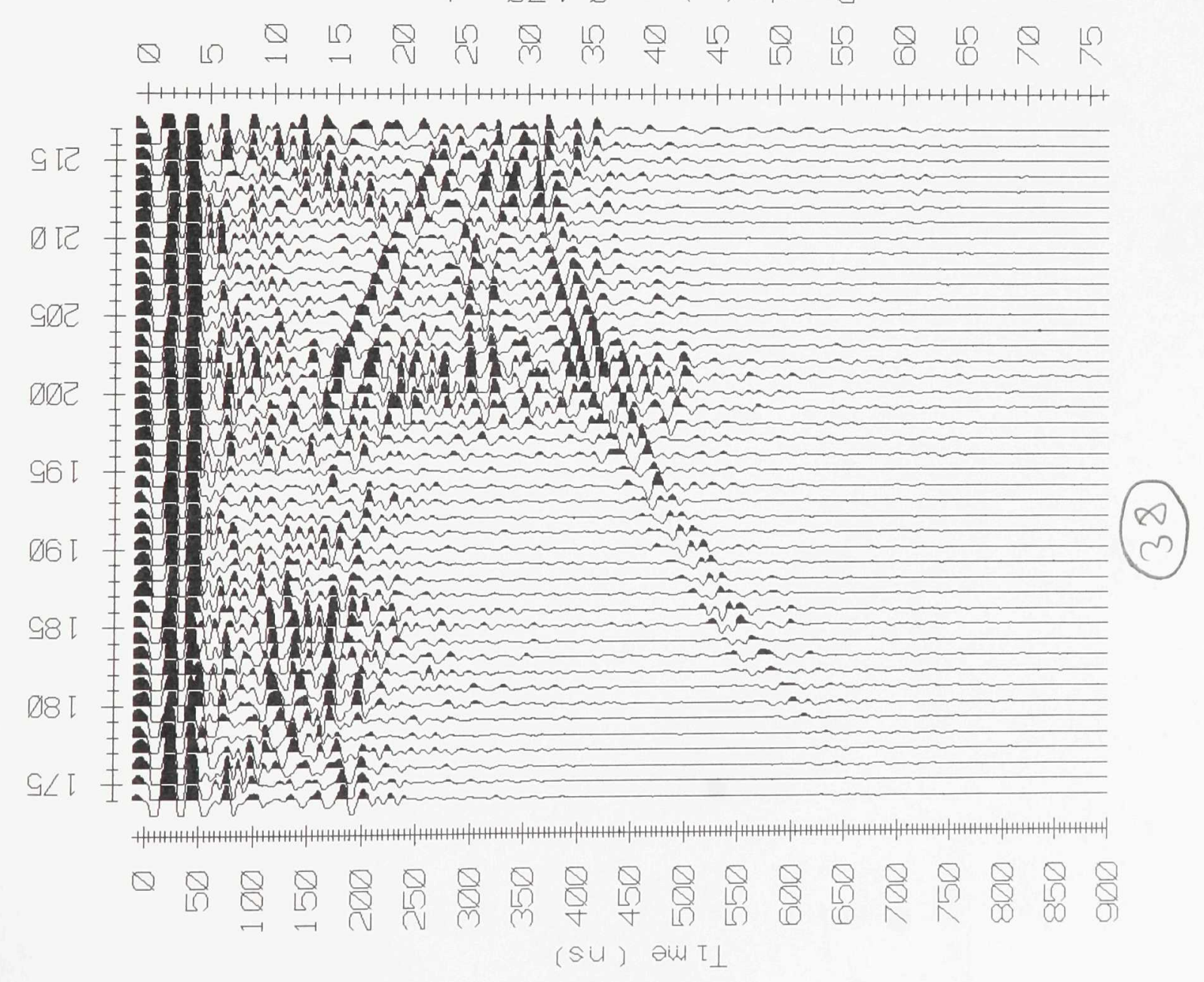




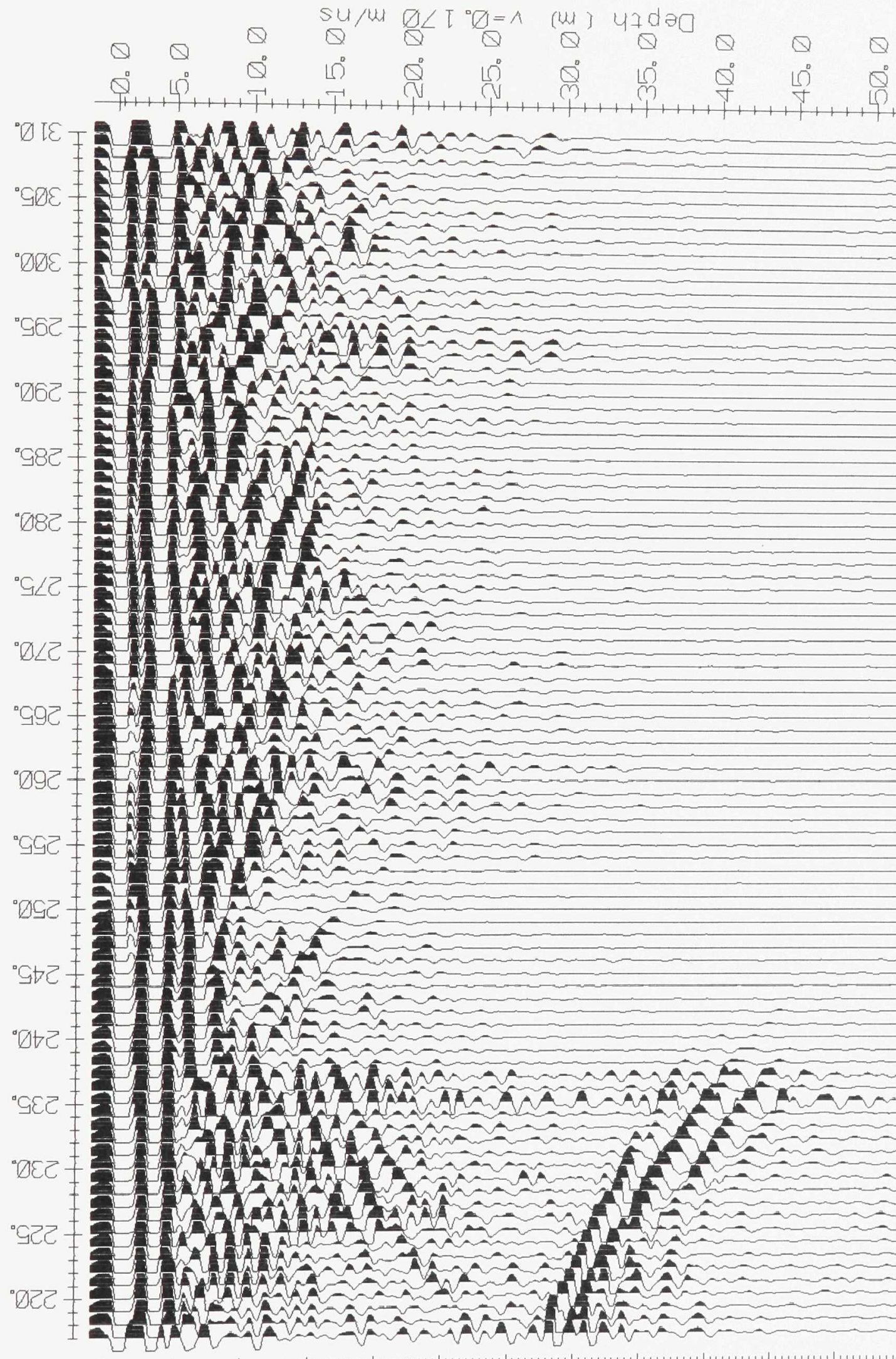

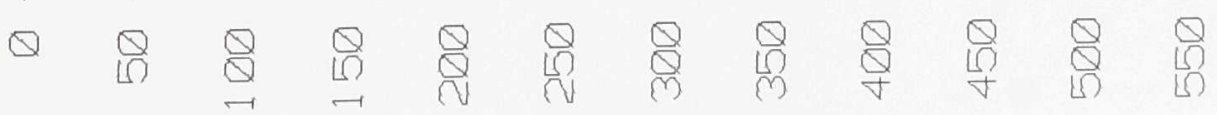



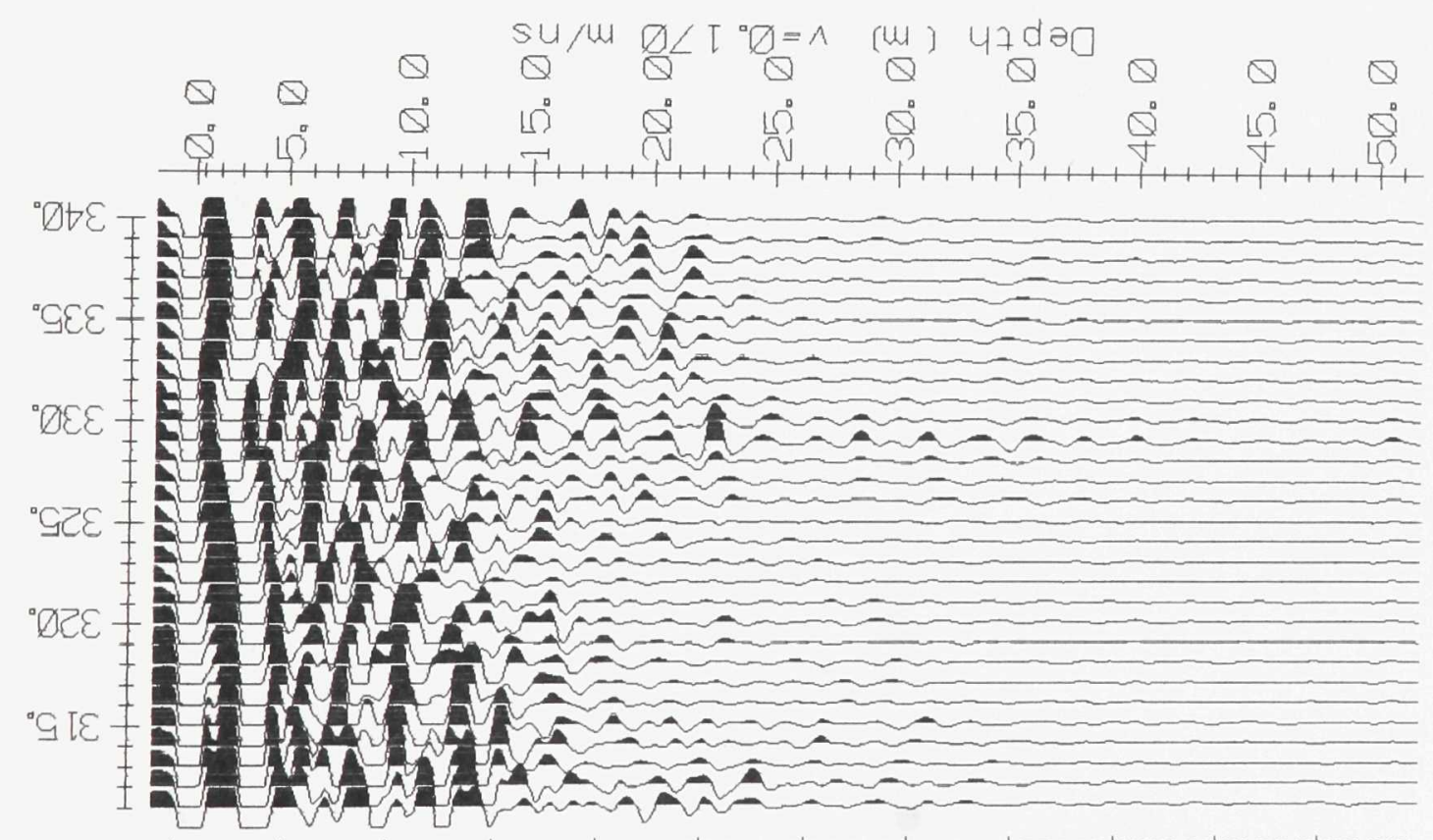

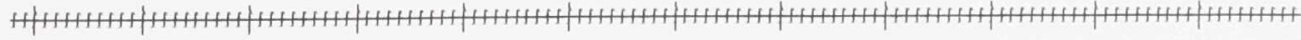

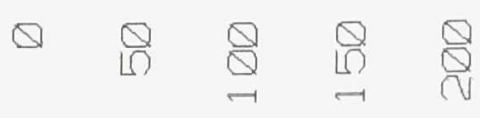
付
Q

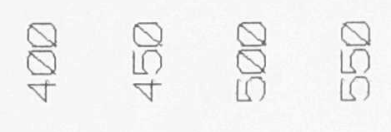
(su) aw IL 

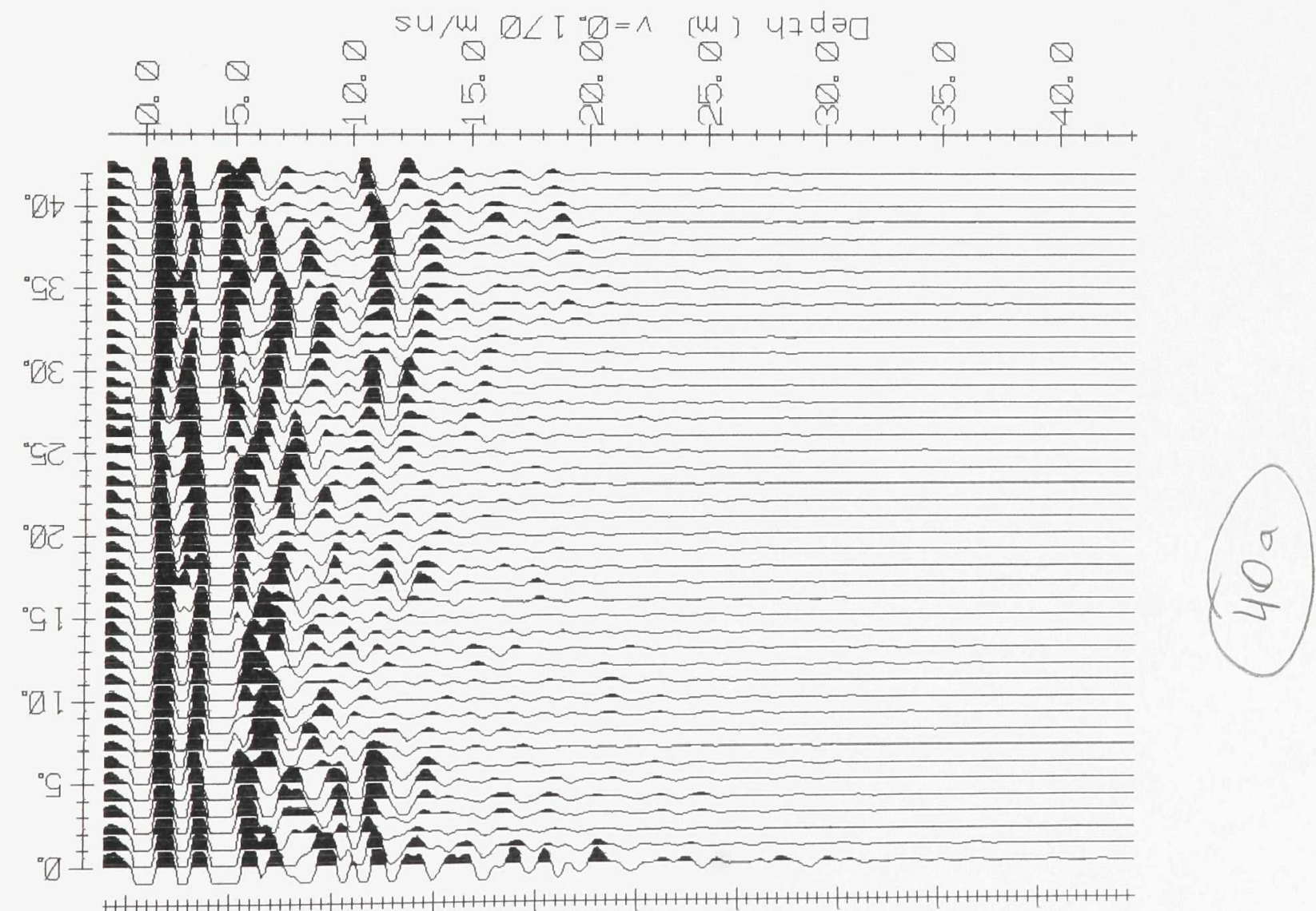
$\Delta$
ए)
Q थि
ले
ए $\quad$ Q 


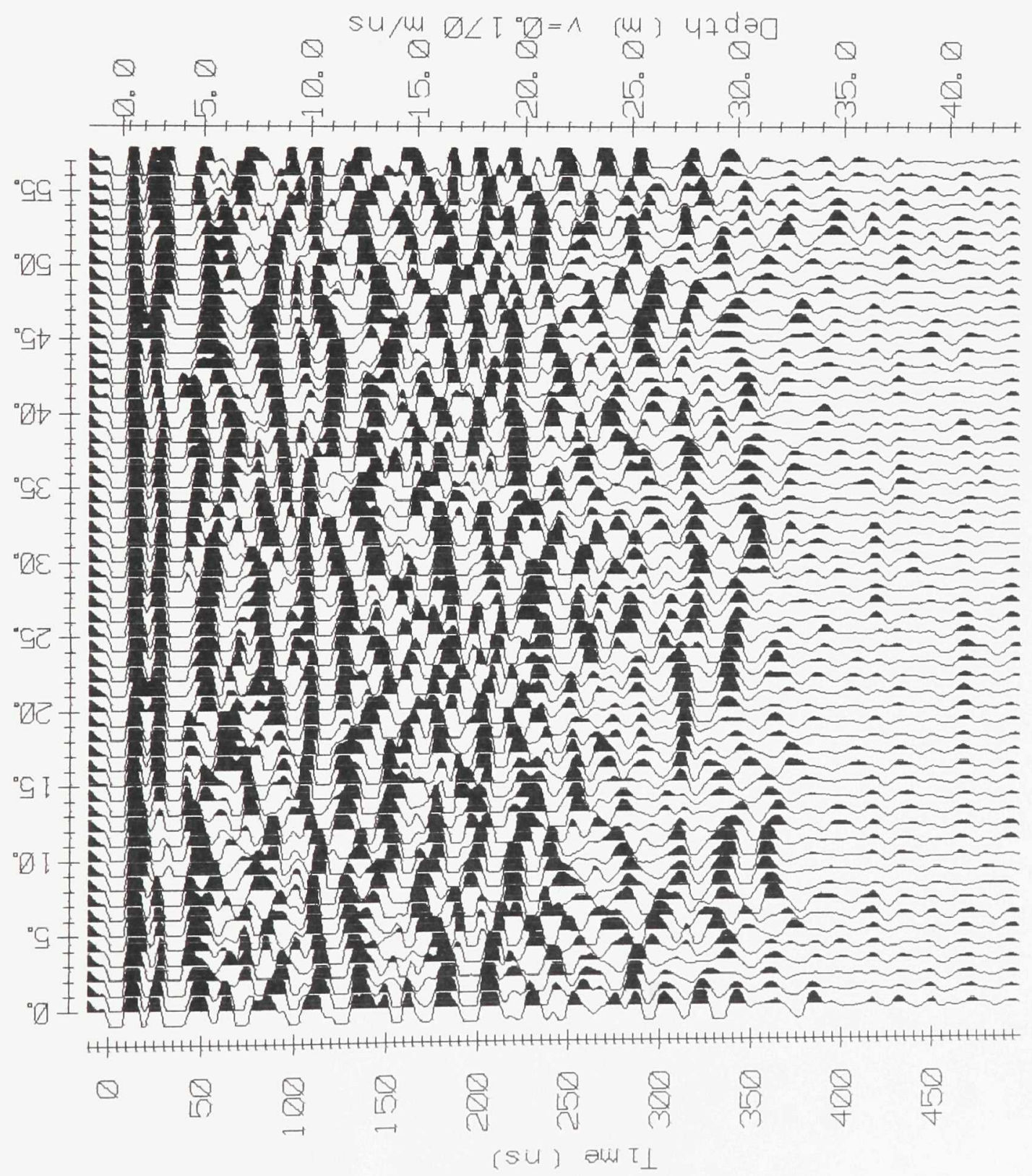


SU/M $\square \angle I{ }^{\circ} \varnothing=\wedge$ (W) ' $\left.\wedge \partial\right\rceil \exists$

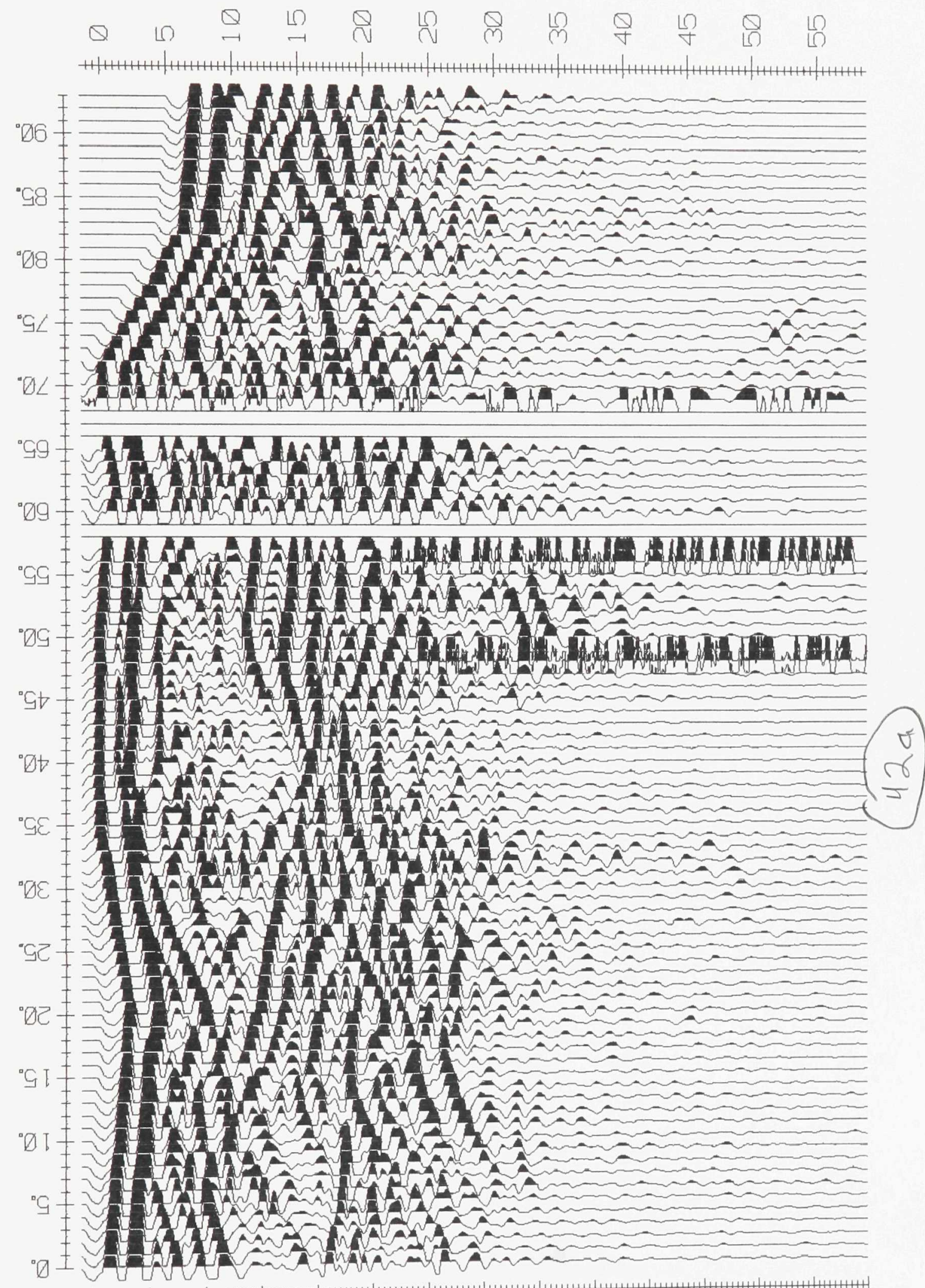

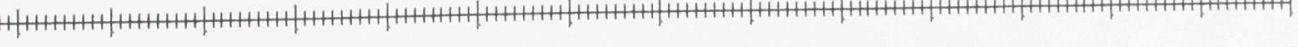

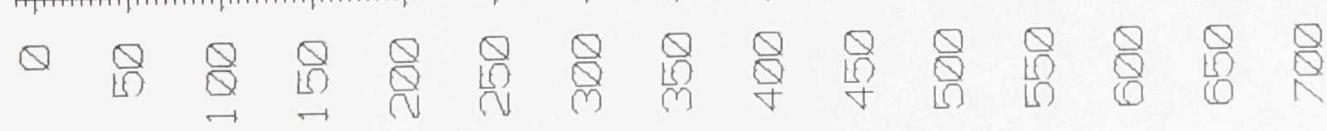




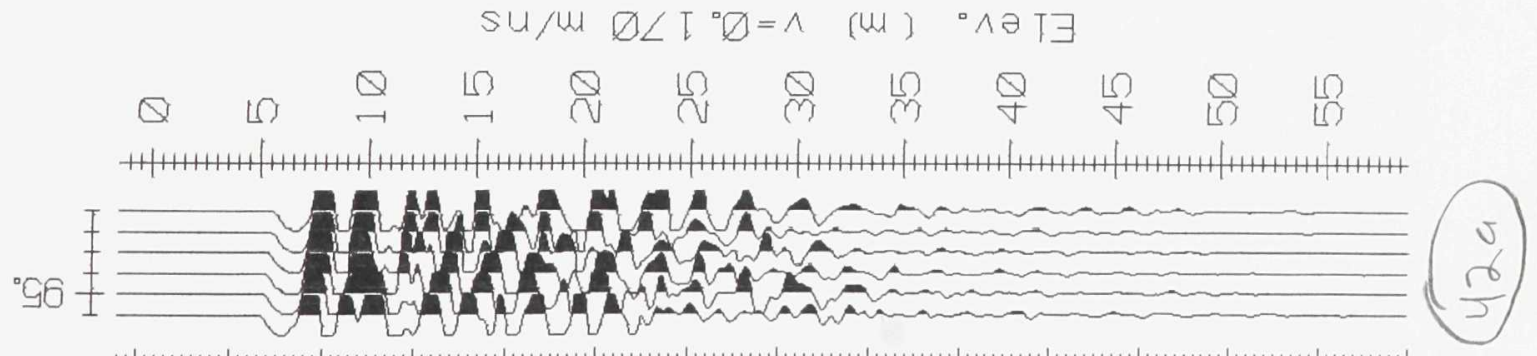

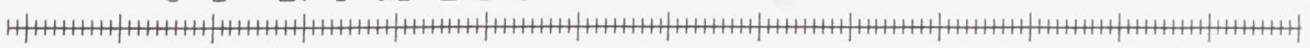
$Q \quad Q \quad Q \quad Q$
$\underset{Q}{Q}$
กิ
ले लि ब
$\frac{Q}{\square}$
$\stackrel{Q}{Q} \quad \mathbb{Q} \quad \mathbb{Q} \quad \mathbb{Q}$
(su) ow IL 


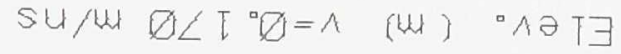

$Q$ ए म

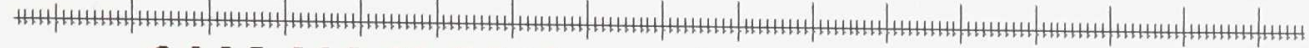

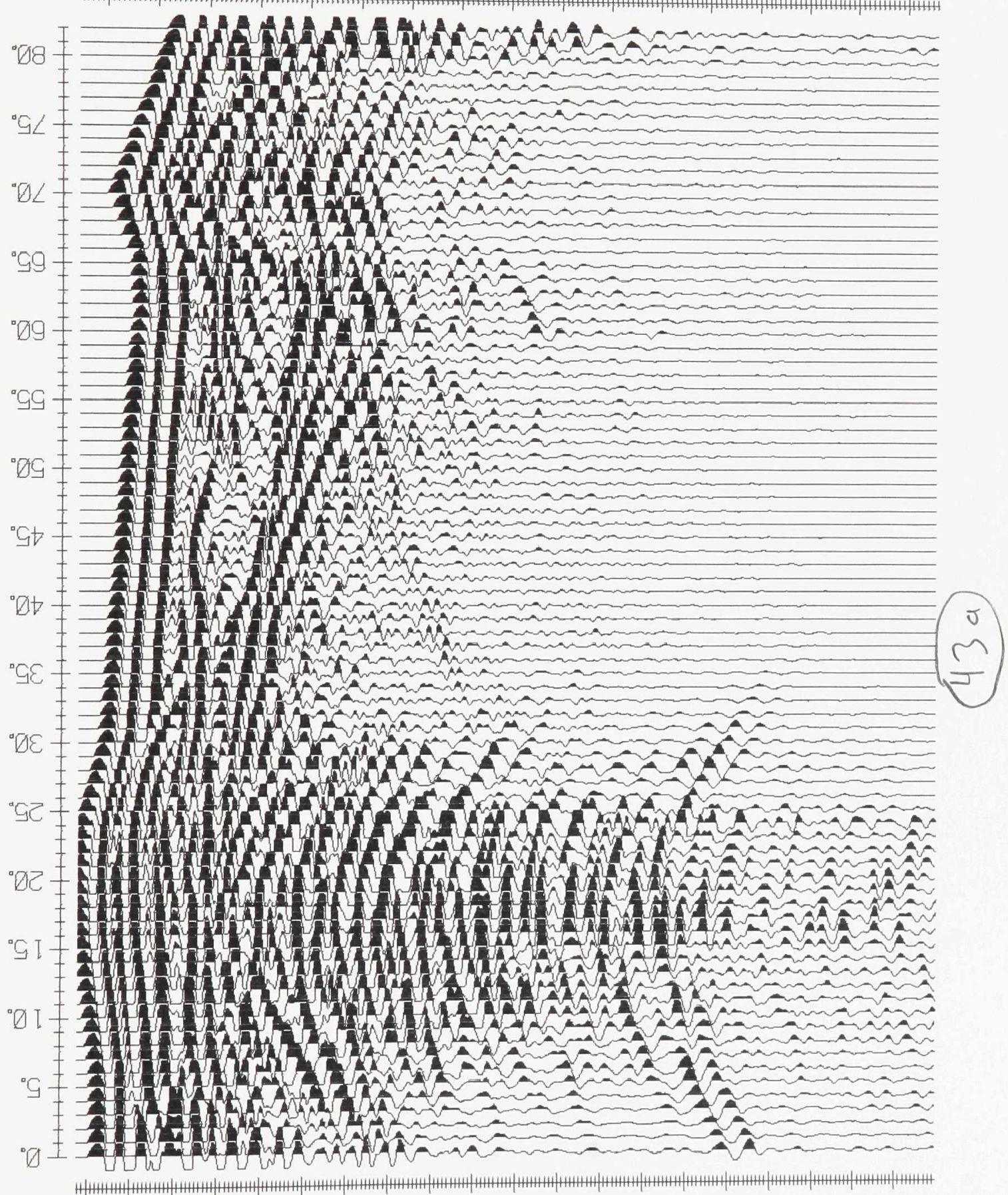

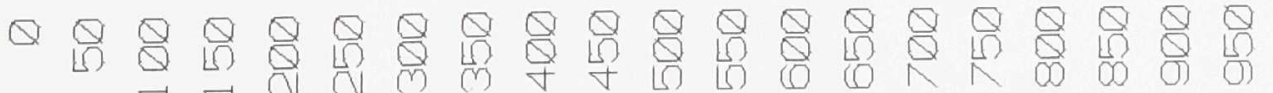




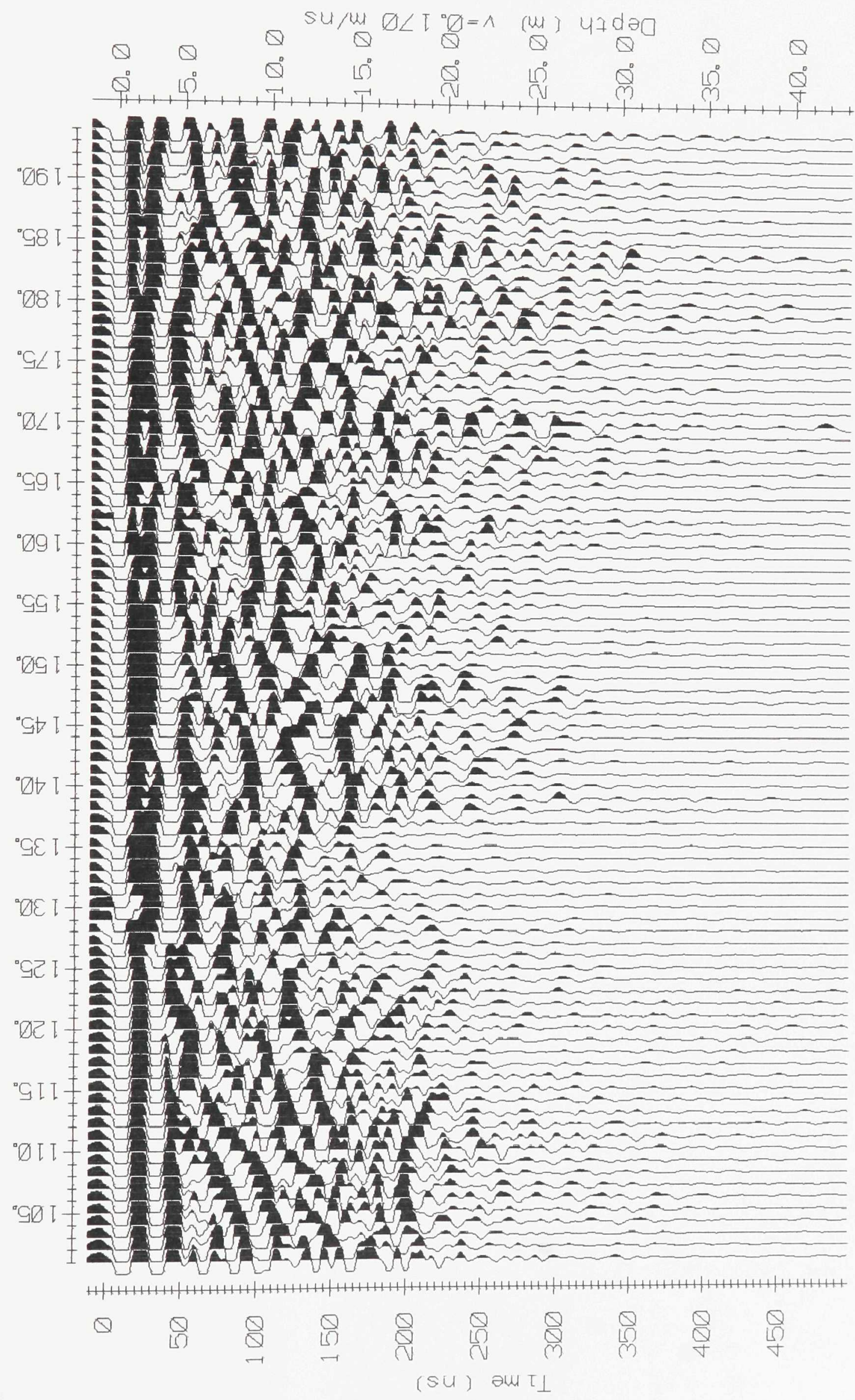




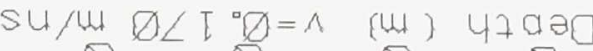

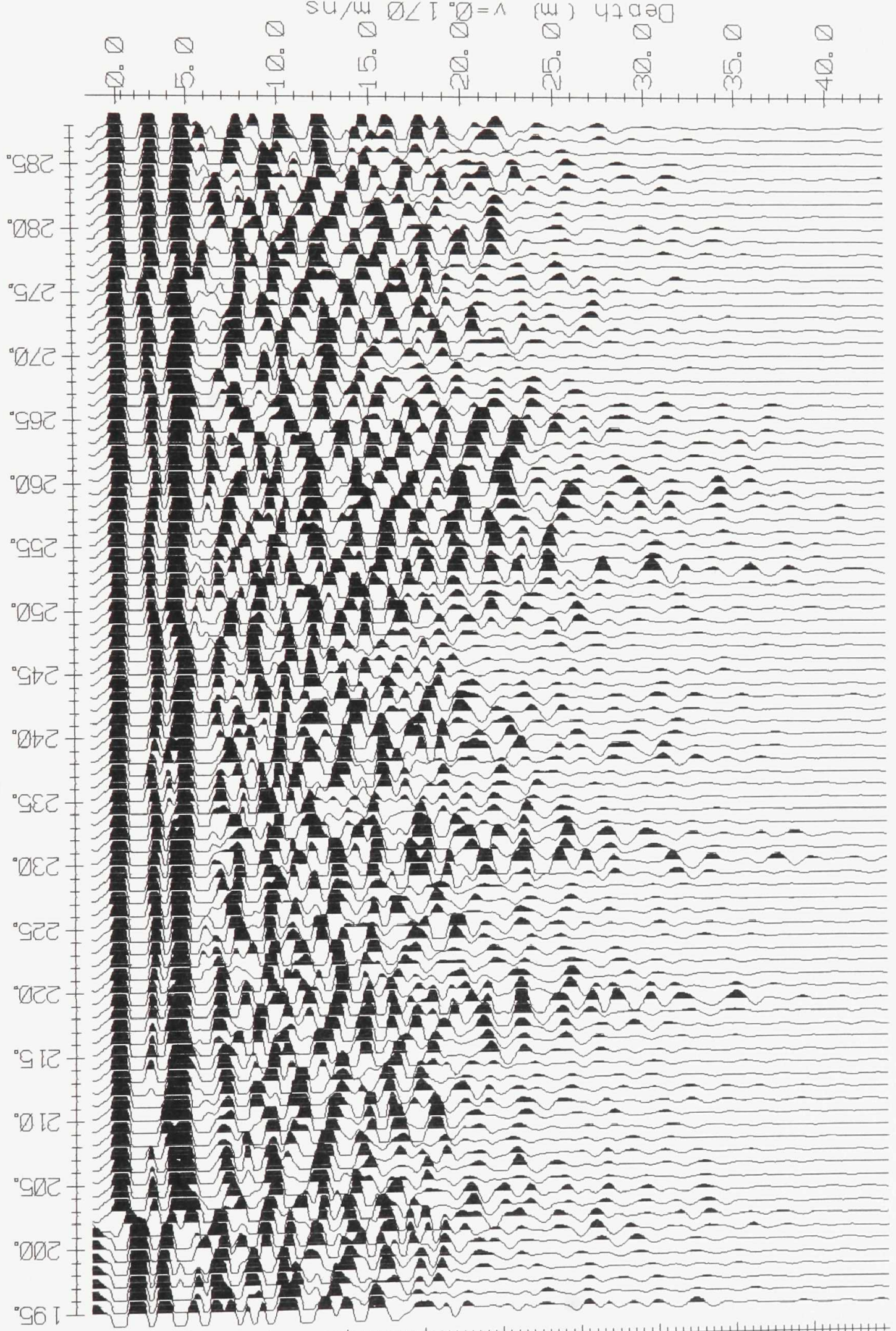




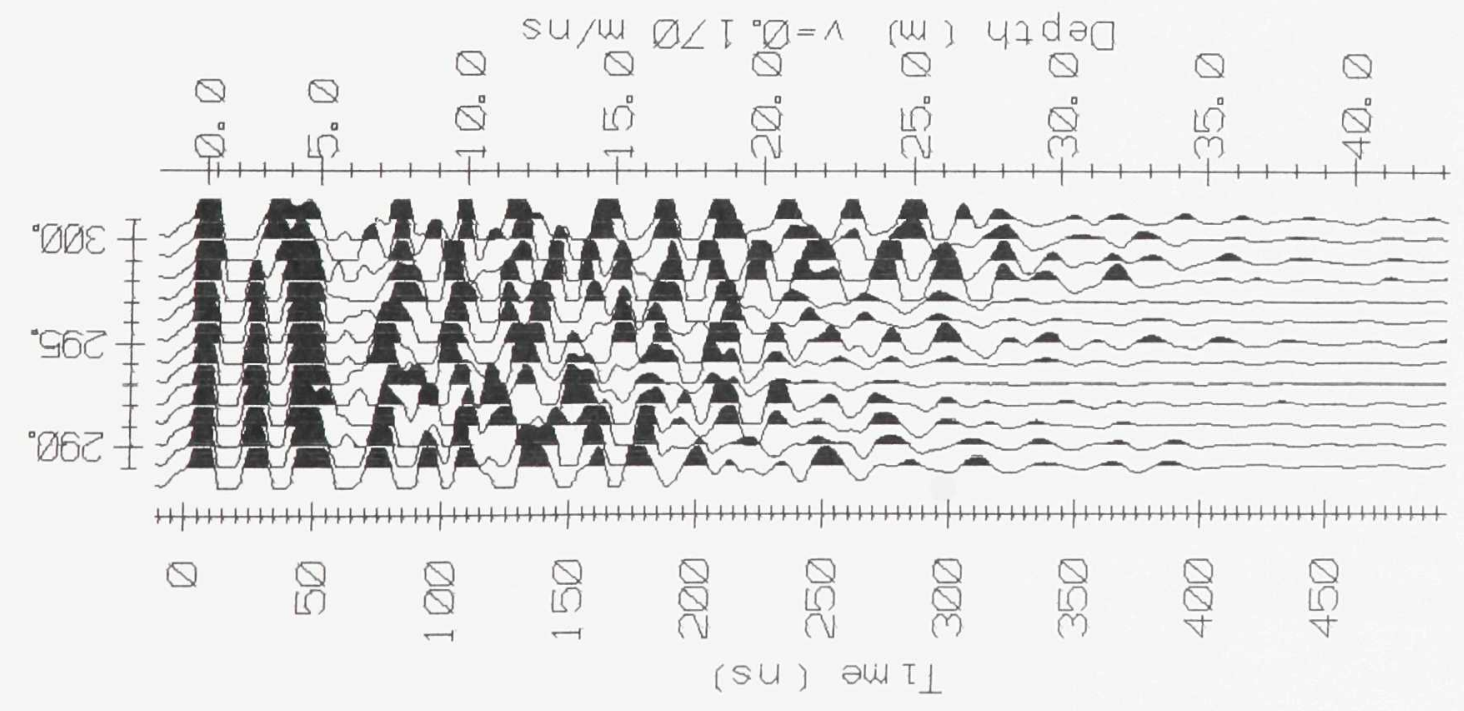




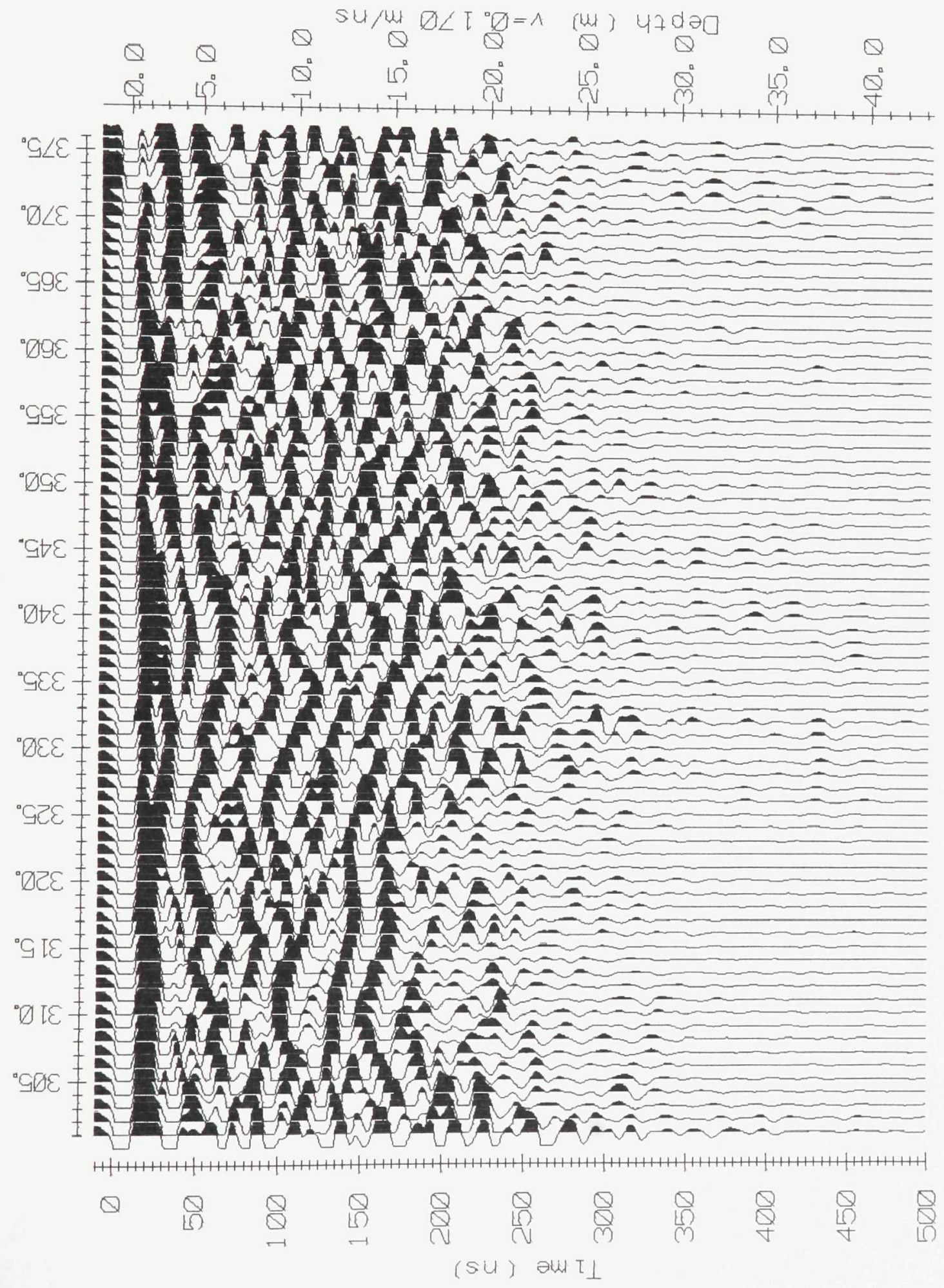



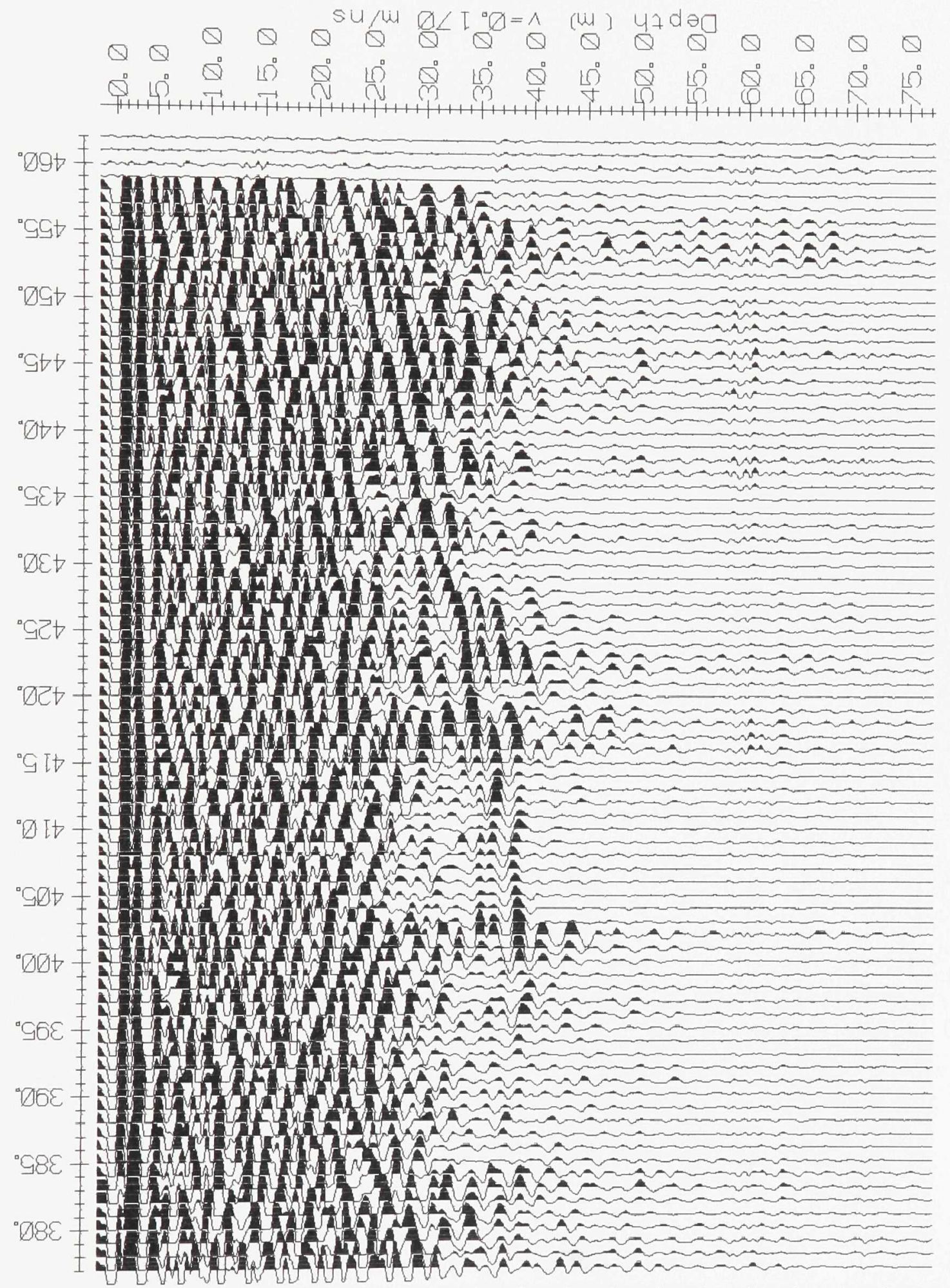

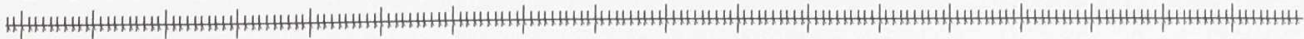

$Q$
$\square$ 


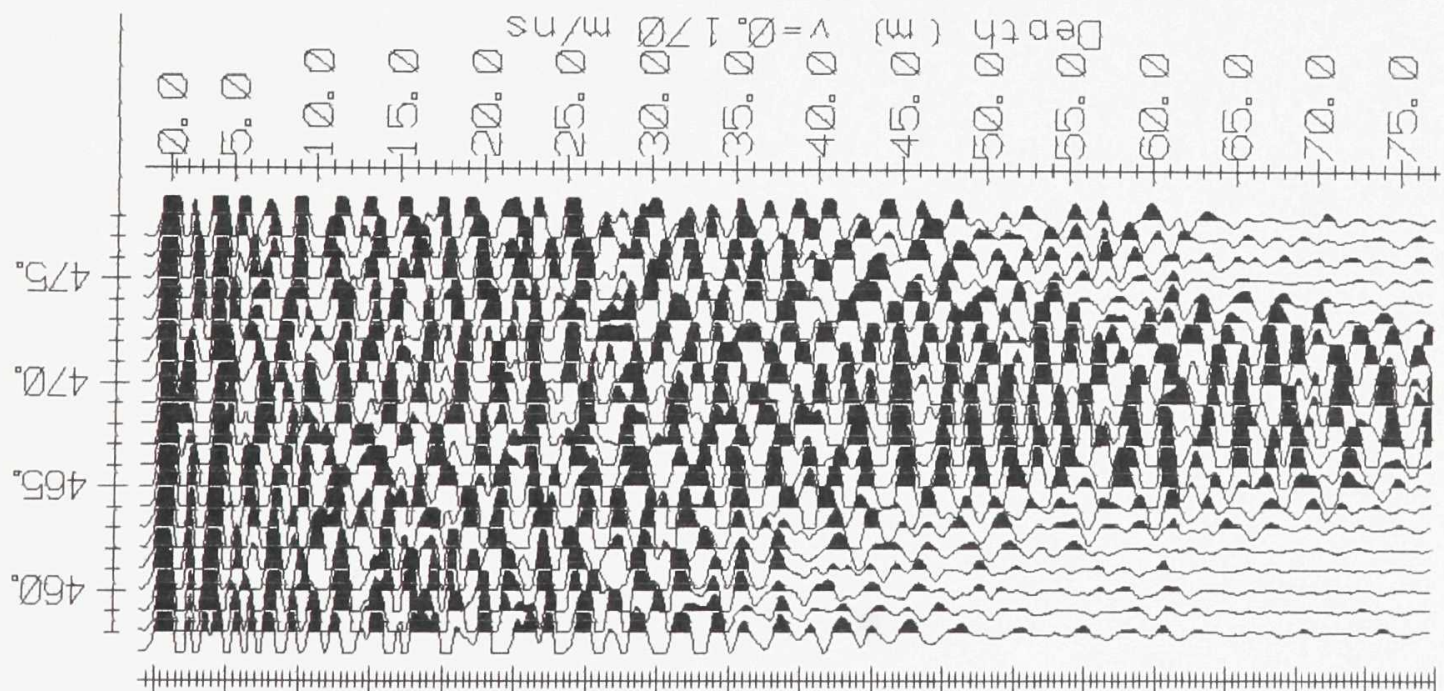

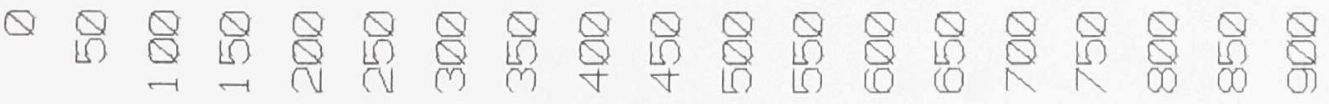 [SU] aw II 


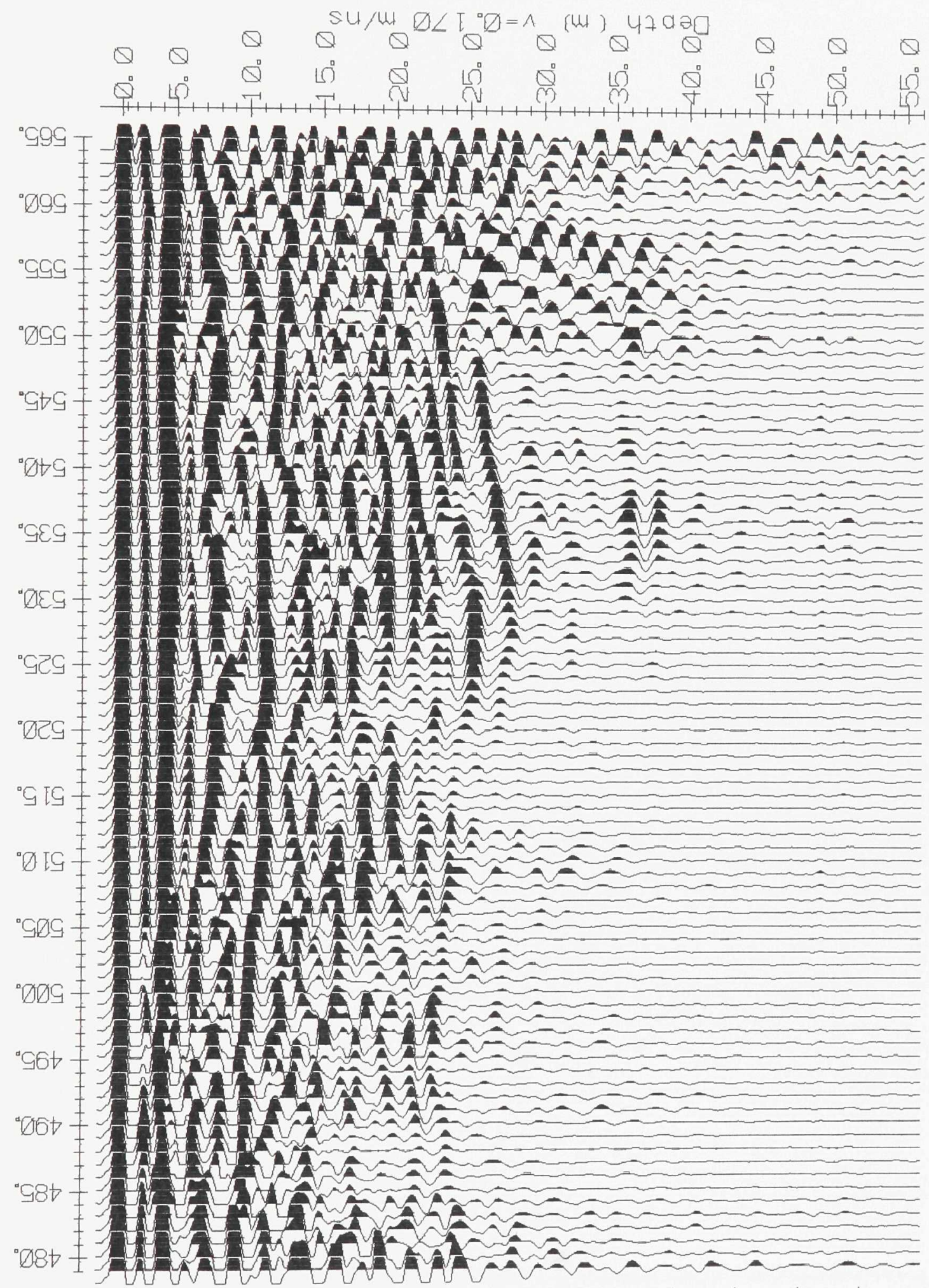

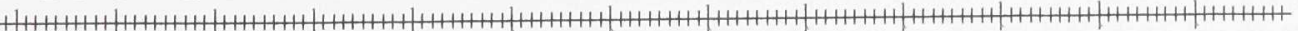

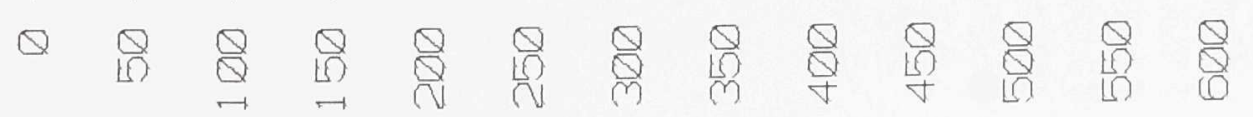




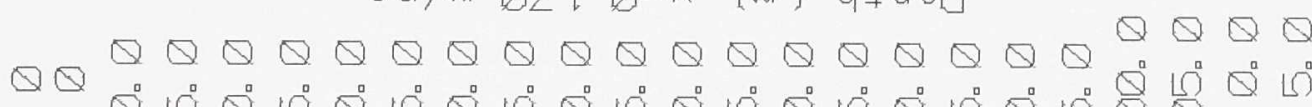

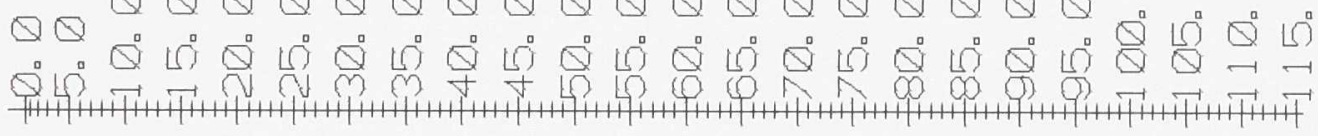

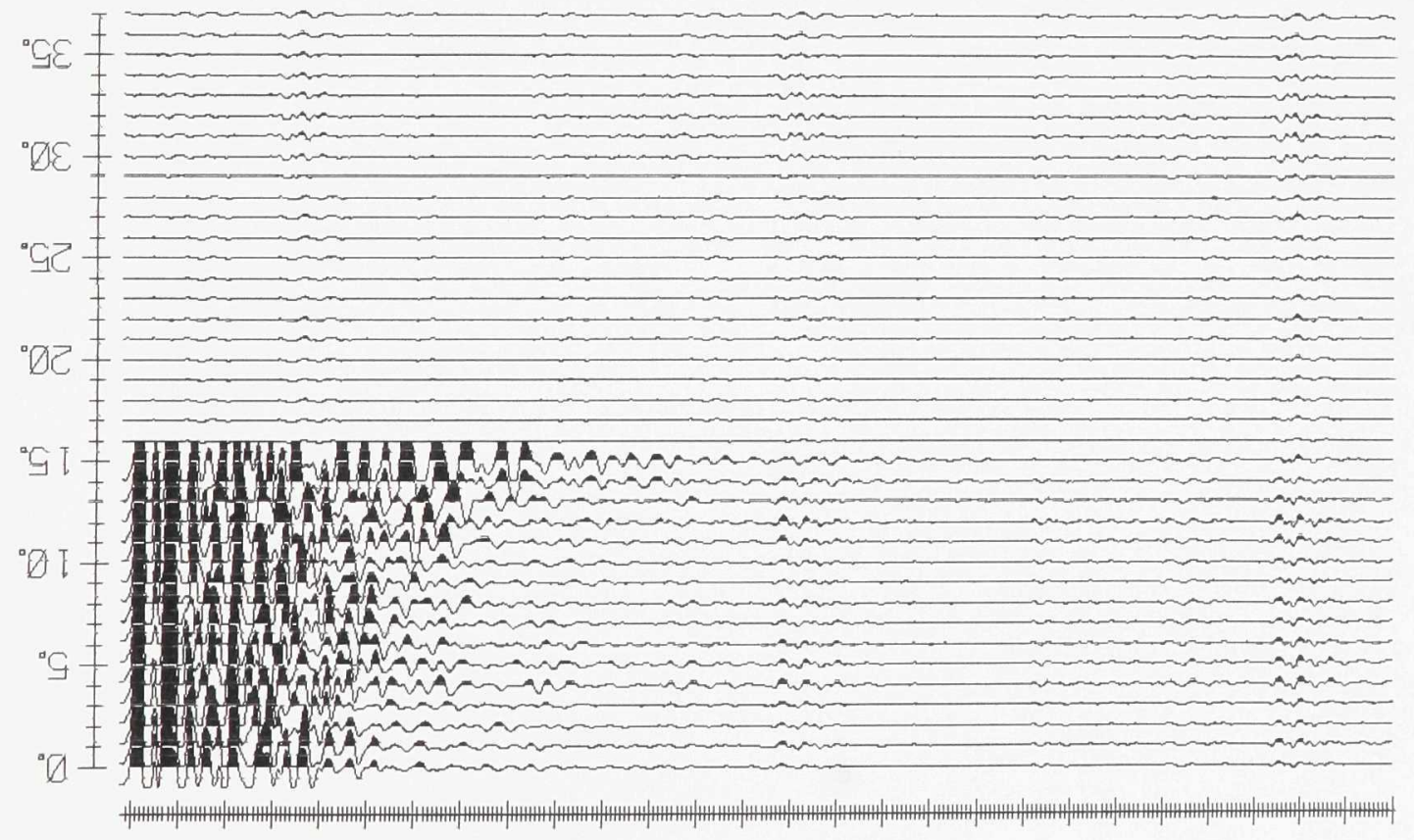

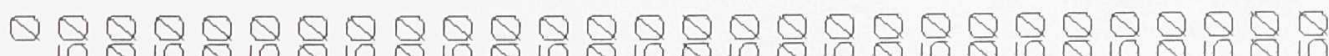
फल 
su/m $\varnothing 2 I^{\circ} \not=\wedge$ (w) $47 \mathrm{~d} \partial \mathrm{a}$

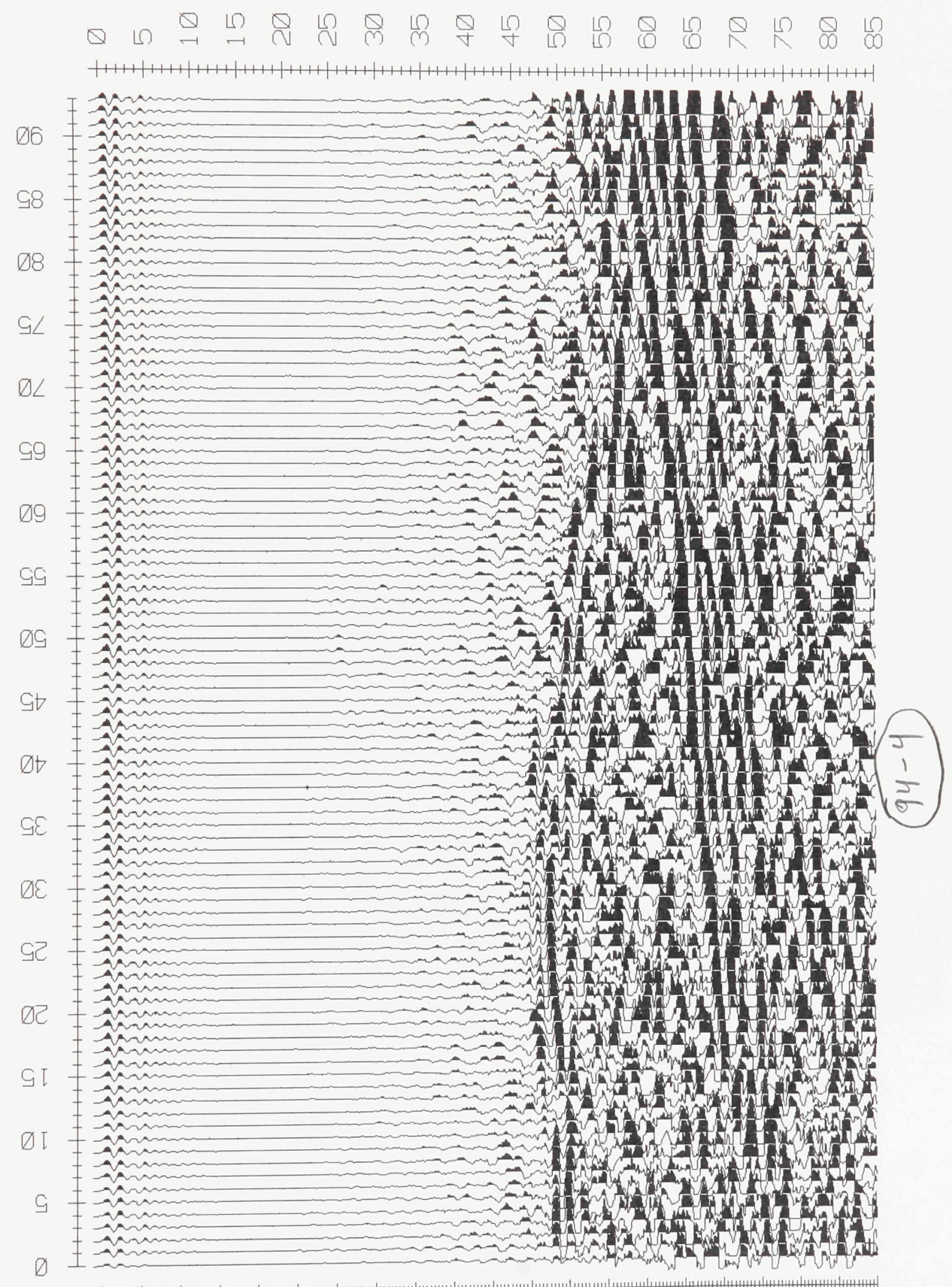

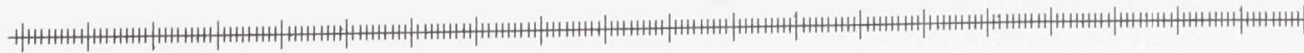

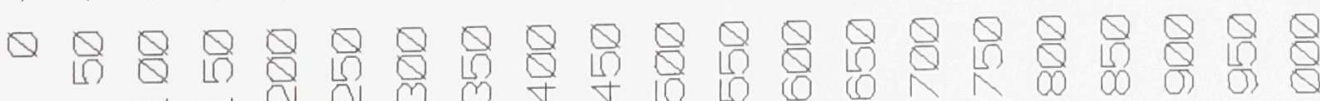




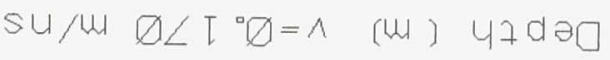

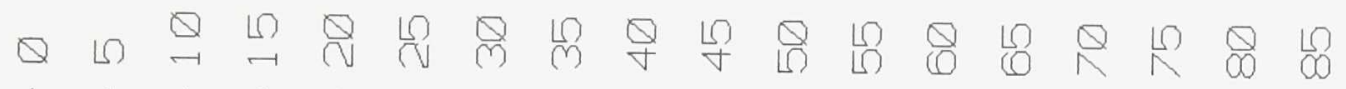

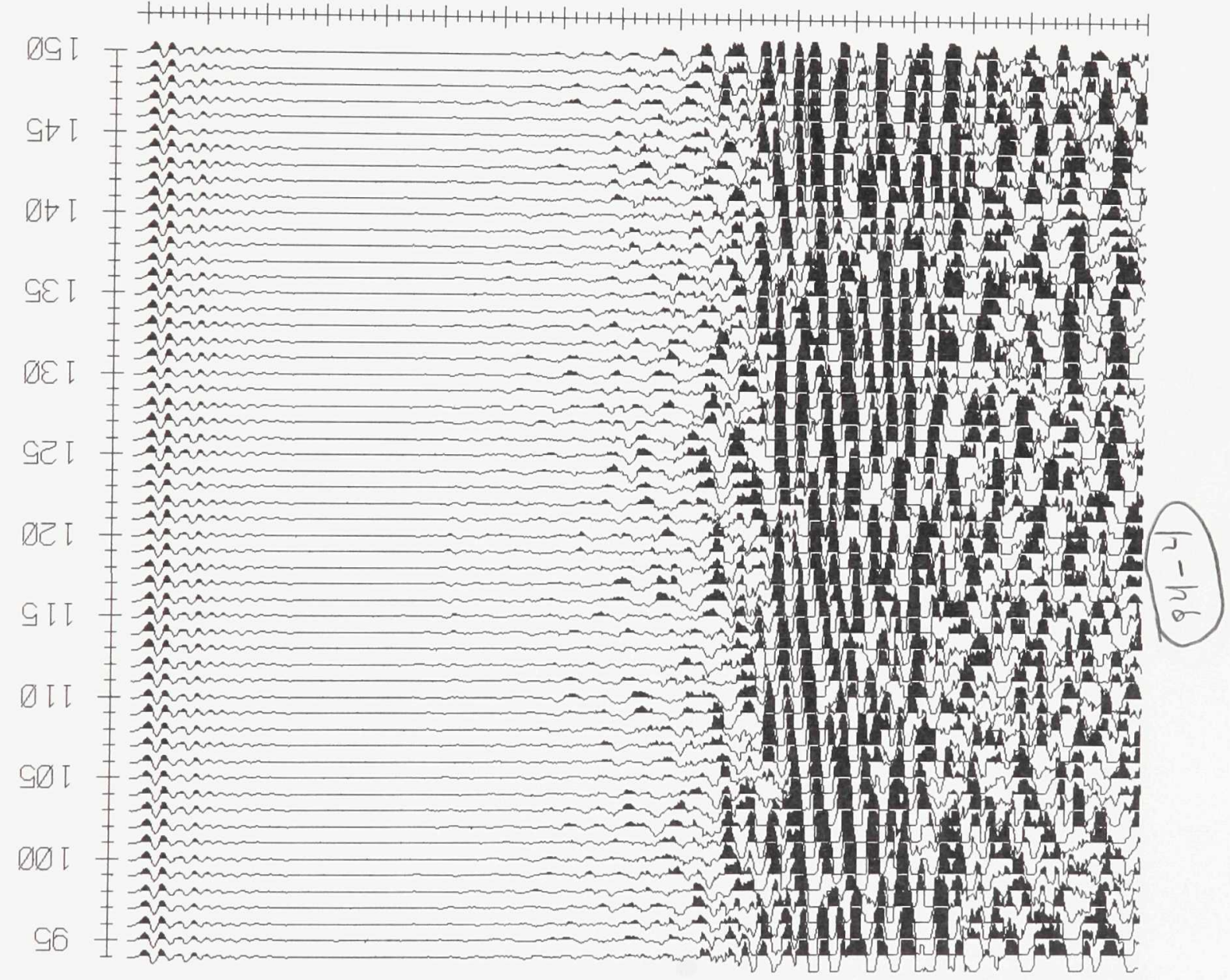

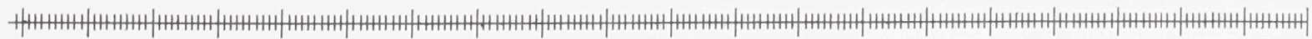
$Q$

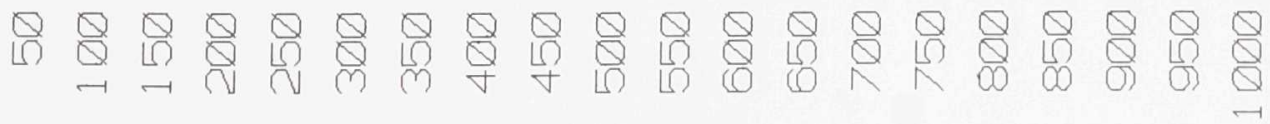



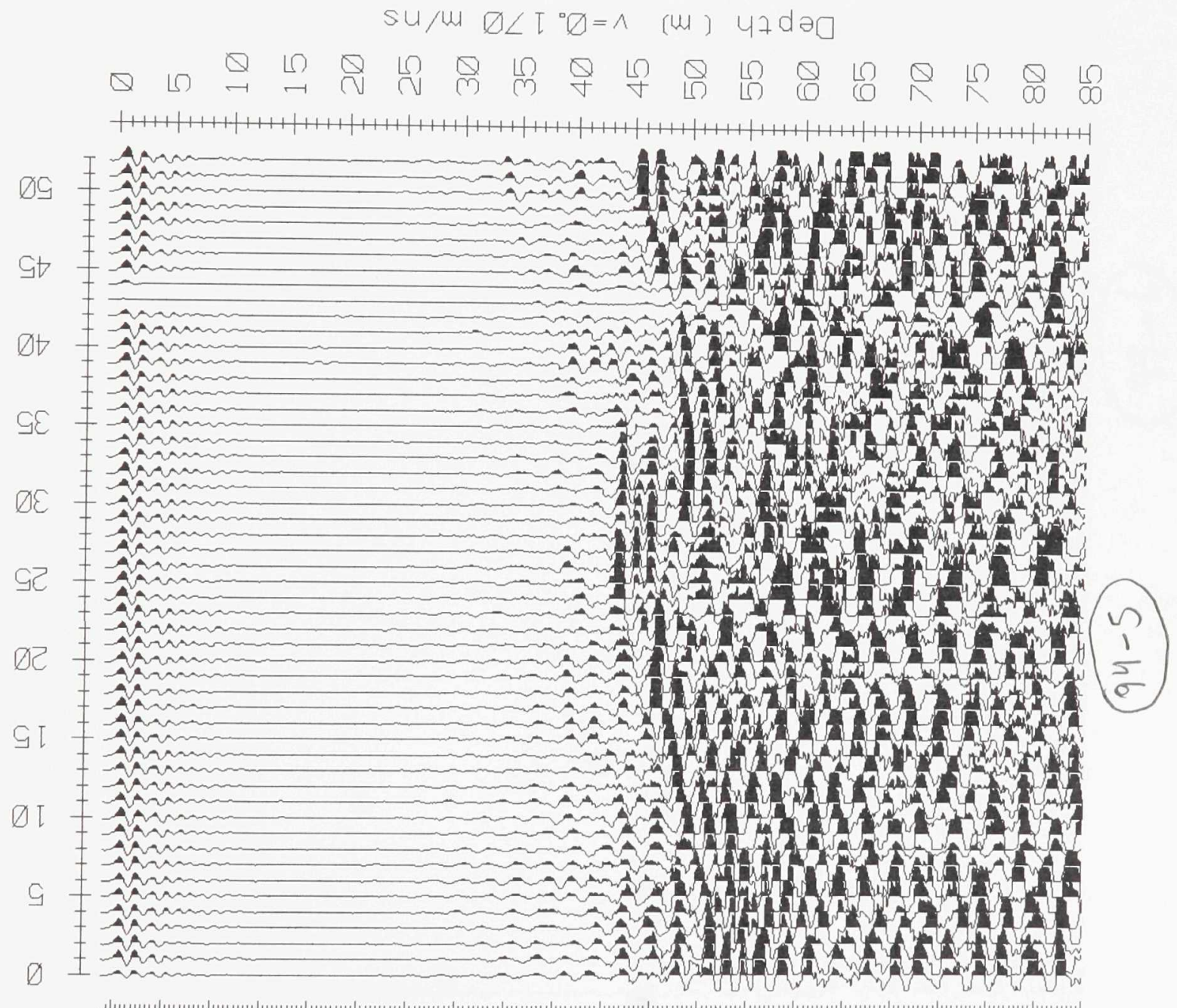

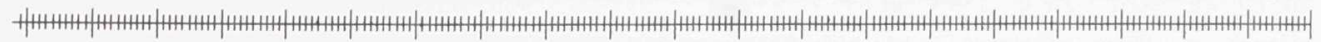

$Q$
$\square$ 


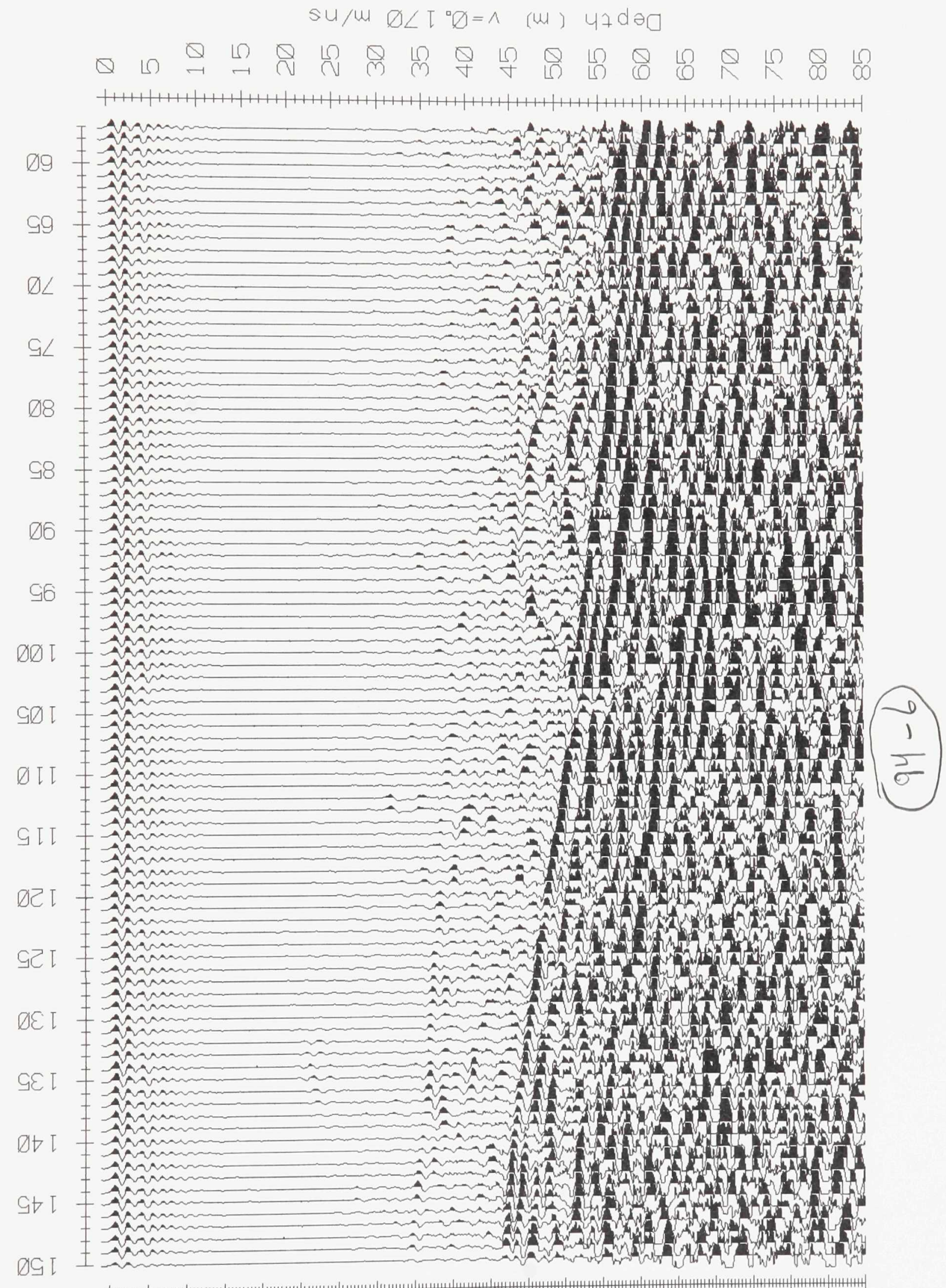

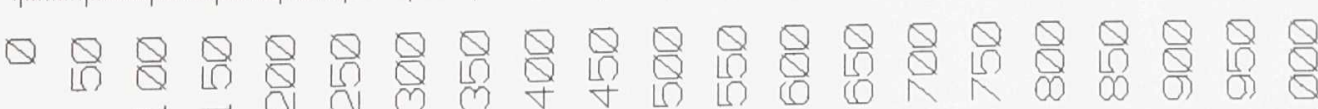




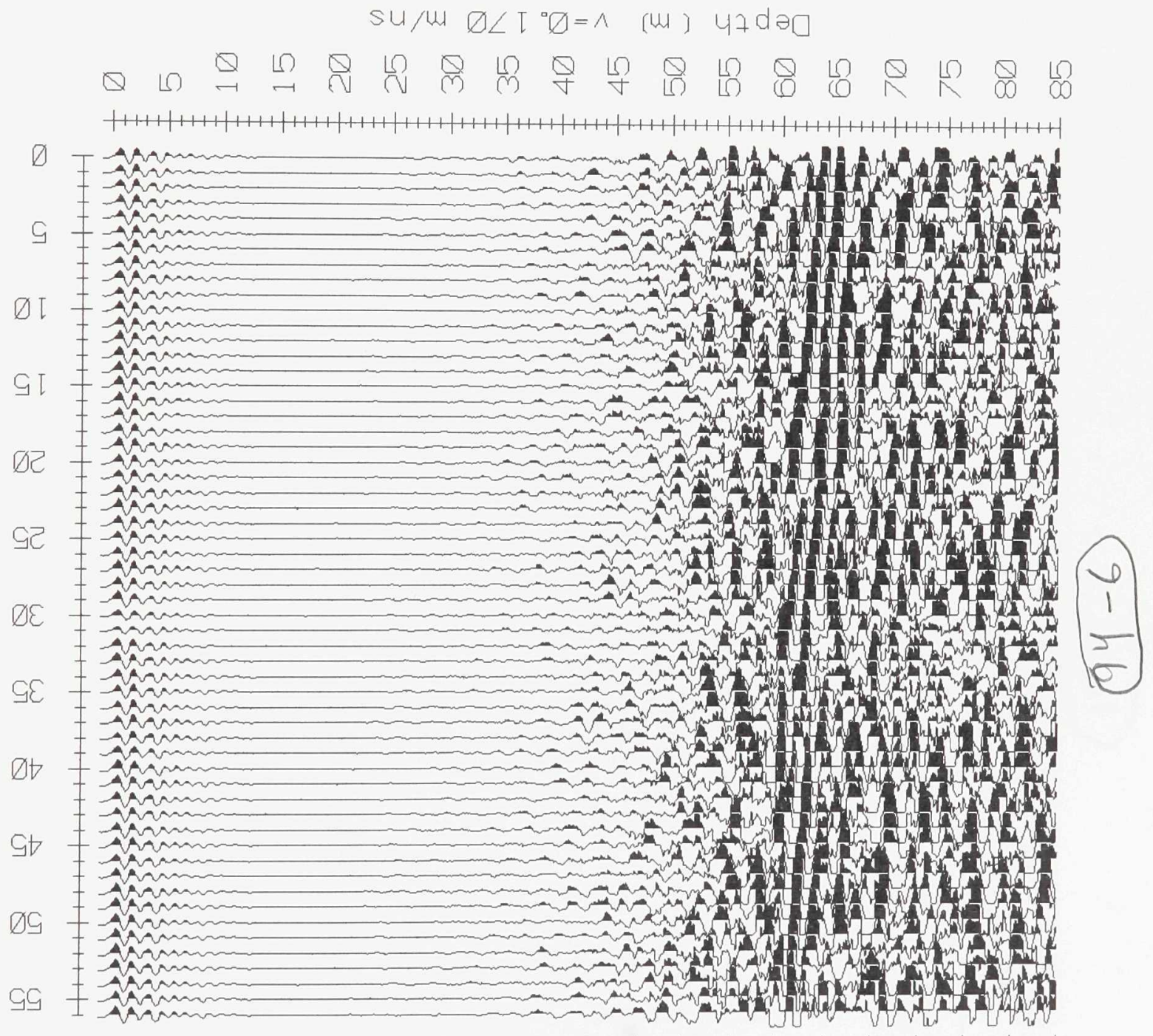

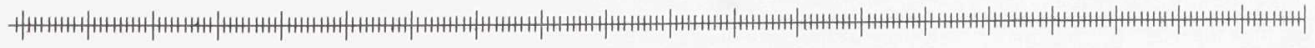

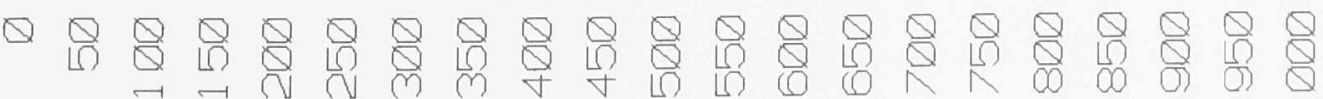




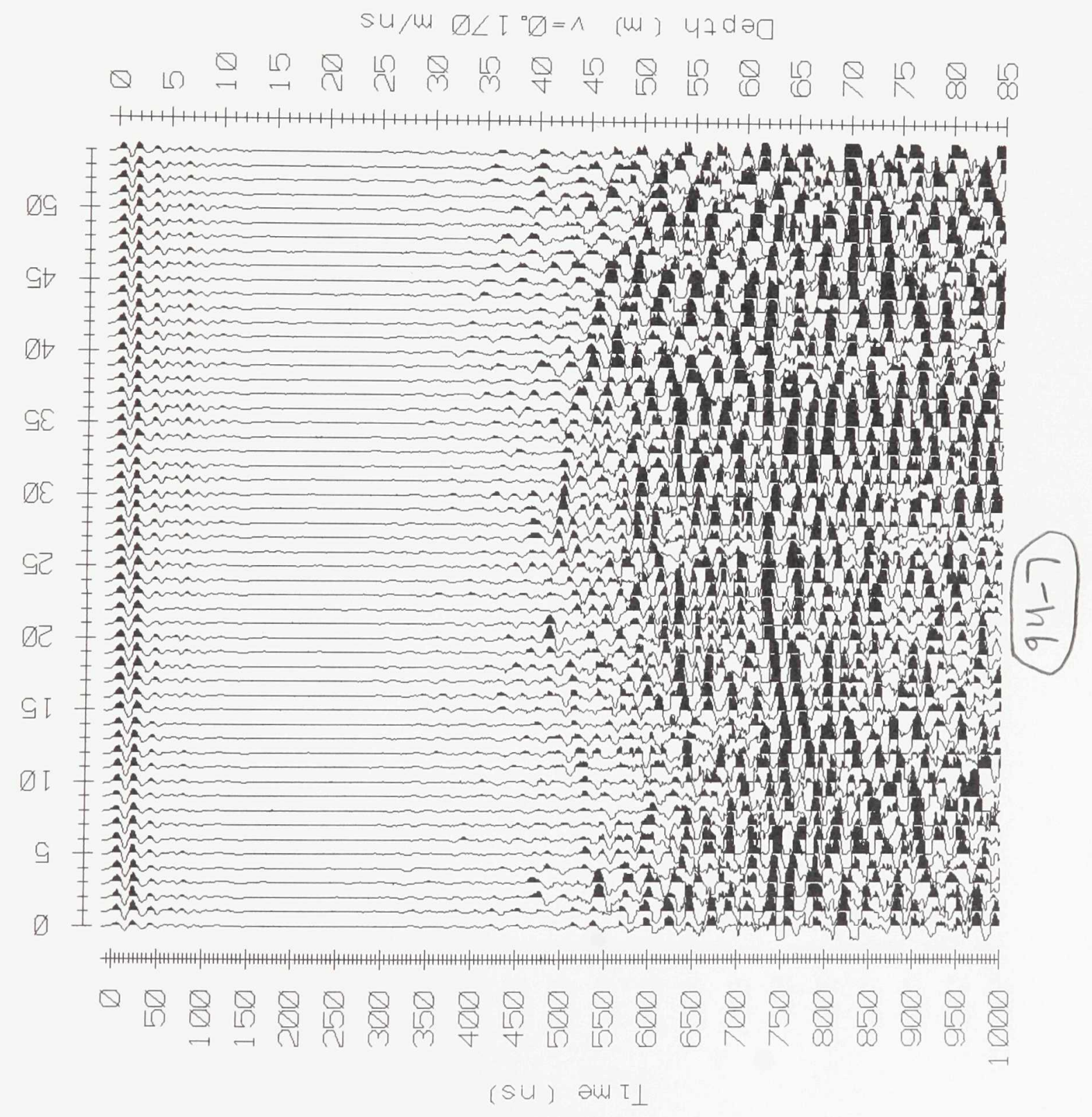


su/m $\square \angle I^{\circ} D=\wedge$ (m) 47də]

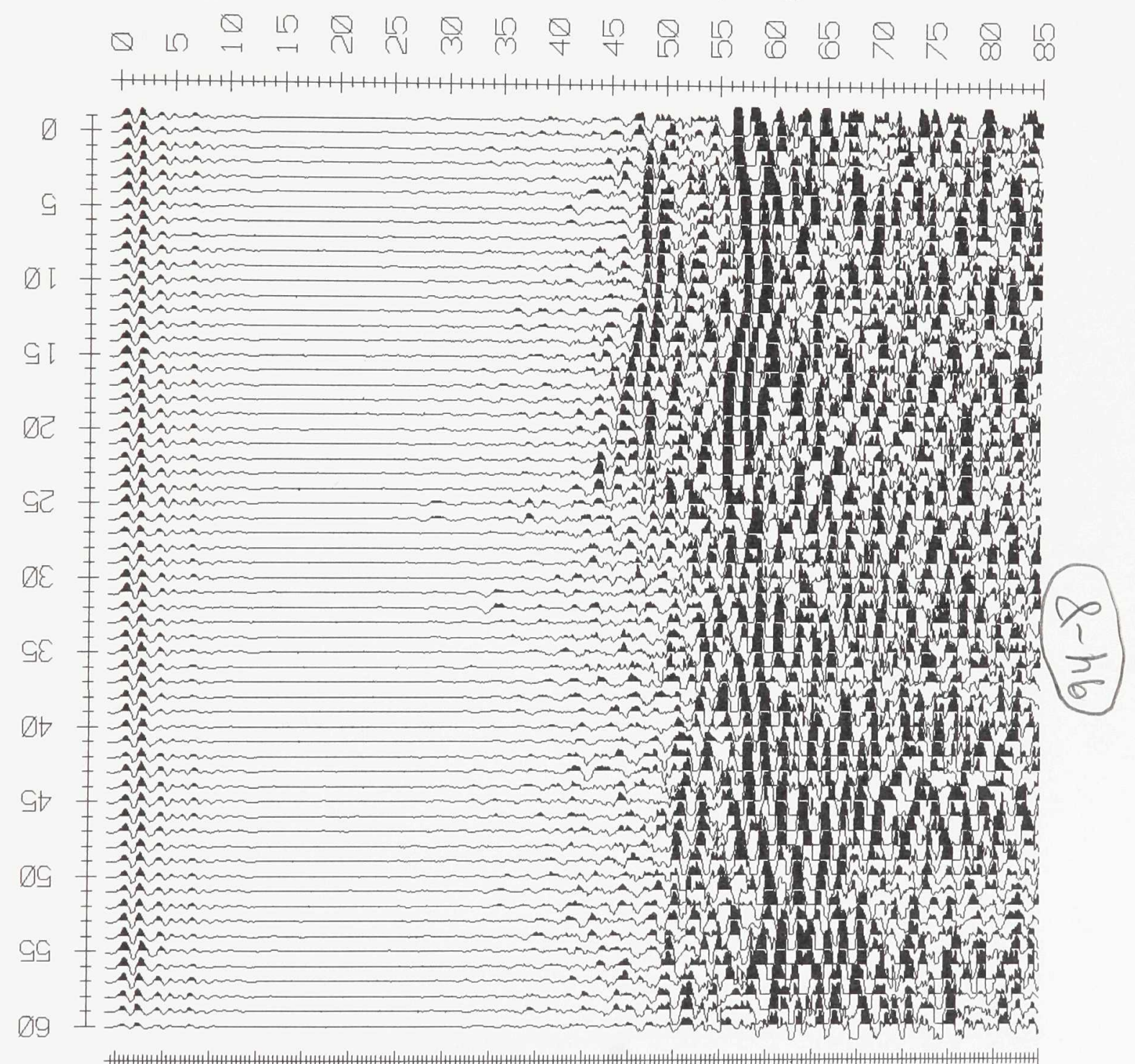

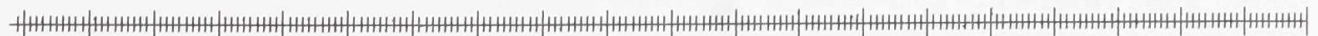
$Q$

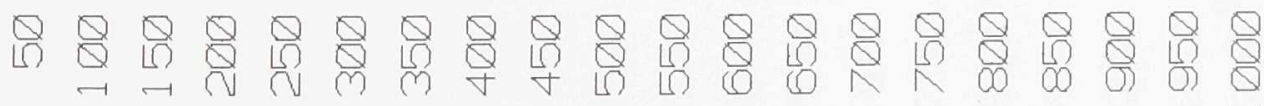




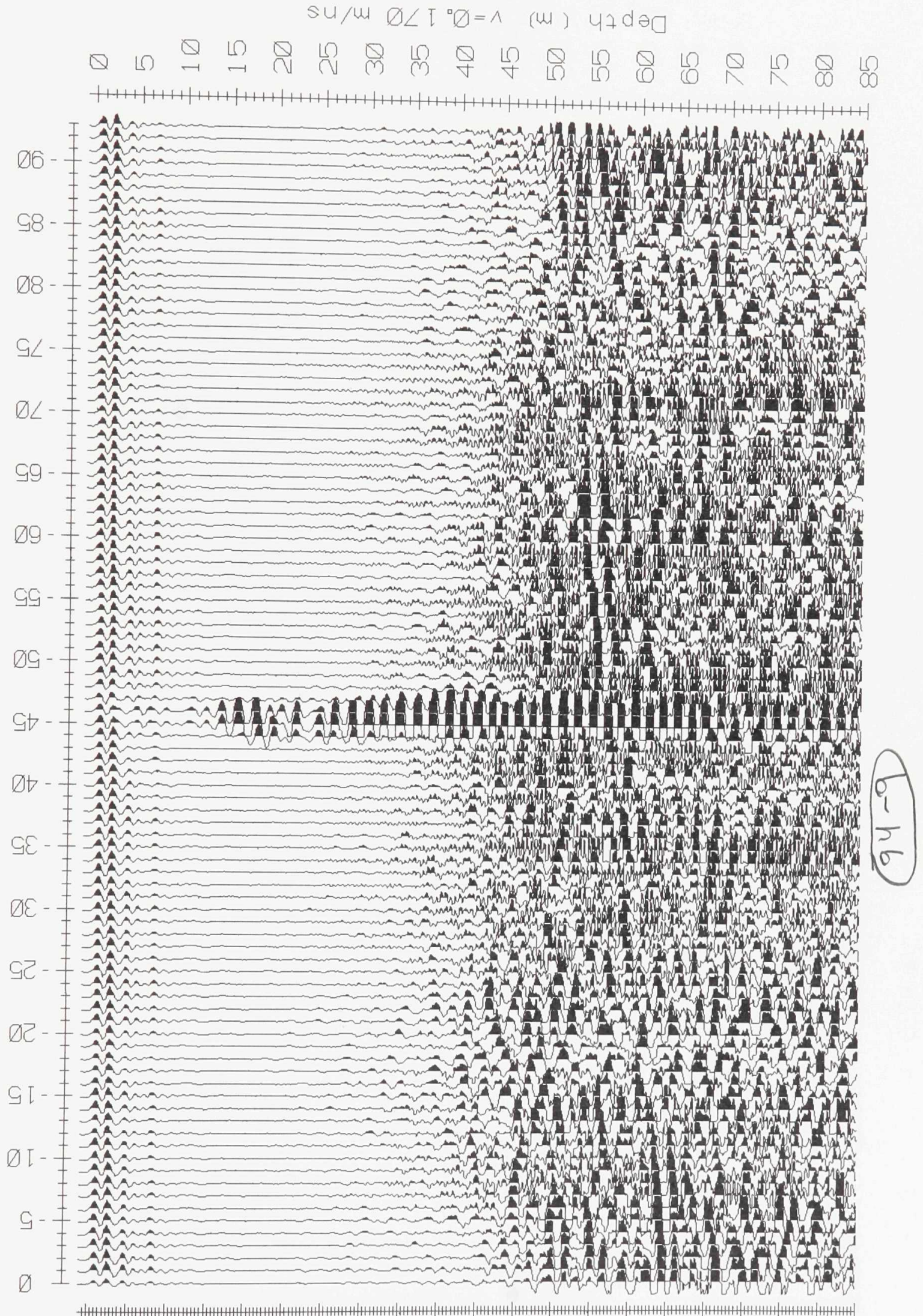

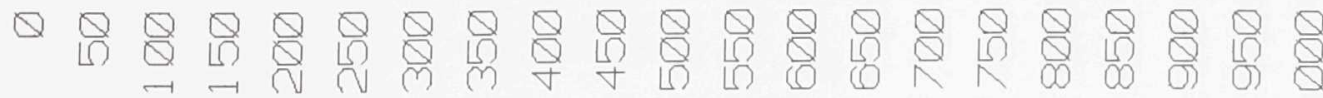




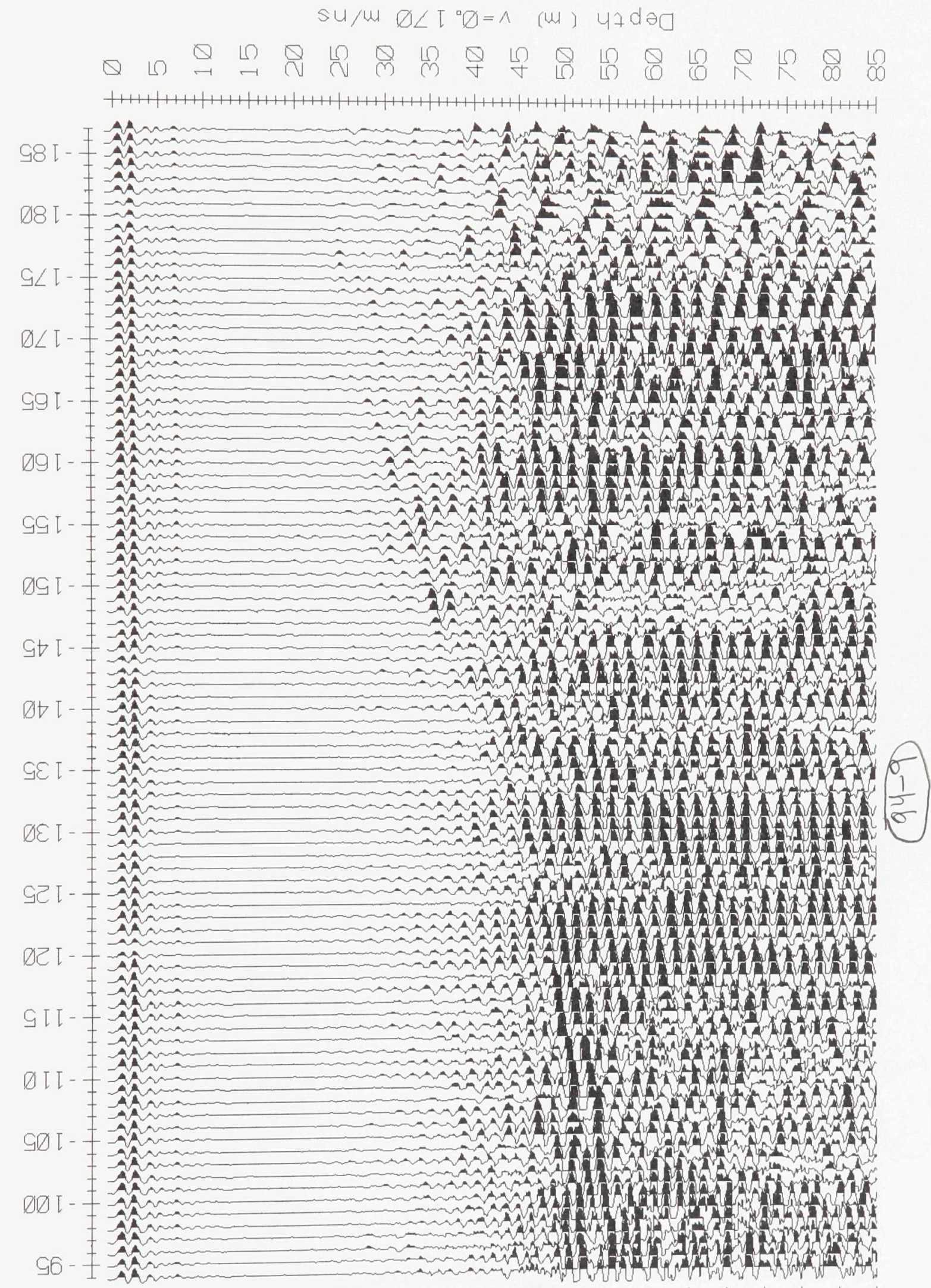

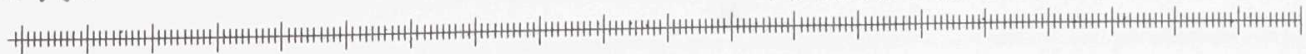

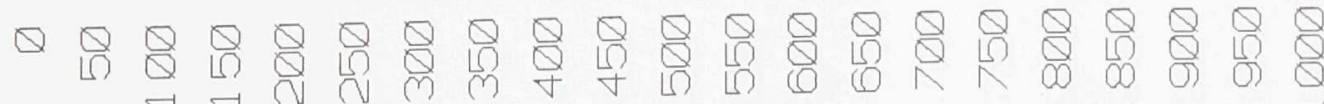


$s u / M \quad \varnothing \angle[D=\wedge \quad$ (W) $47 d \partial \square$

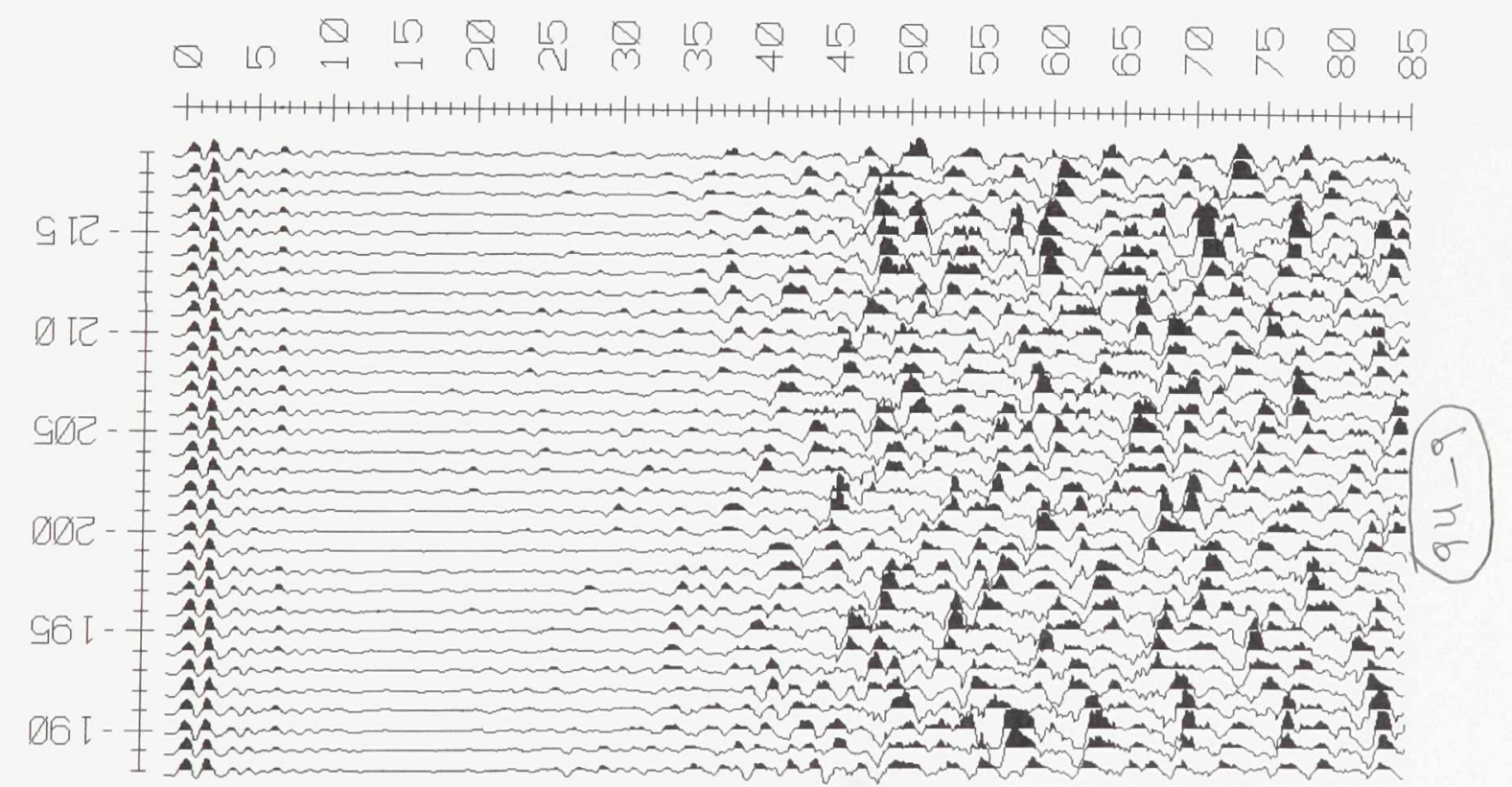

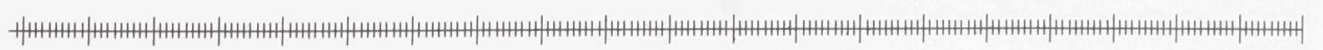

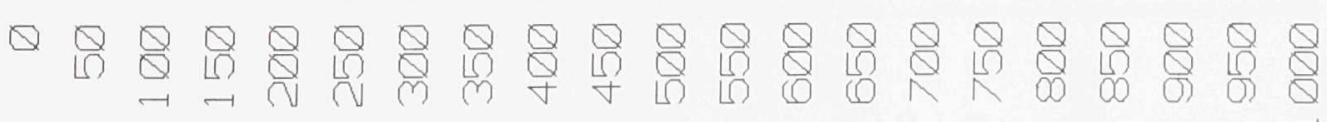


su/m $D \angle T^{\circ} D=\wedge$ (m) 47da

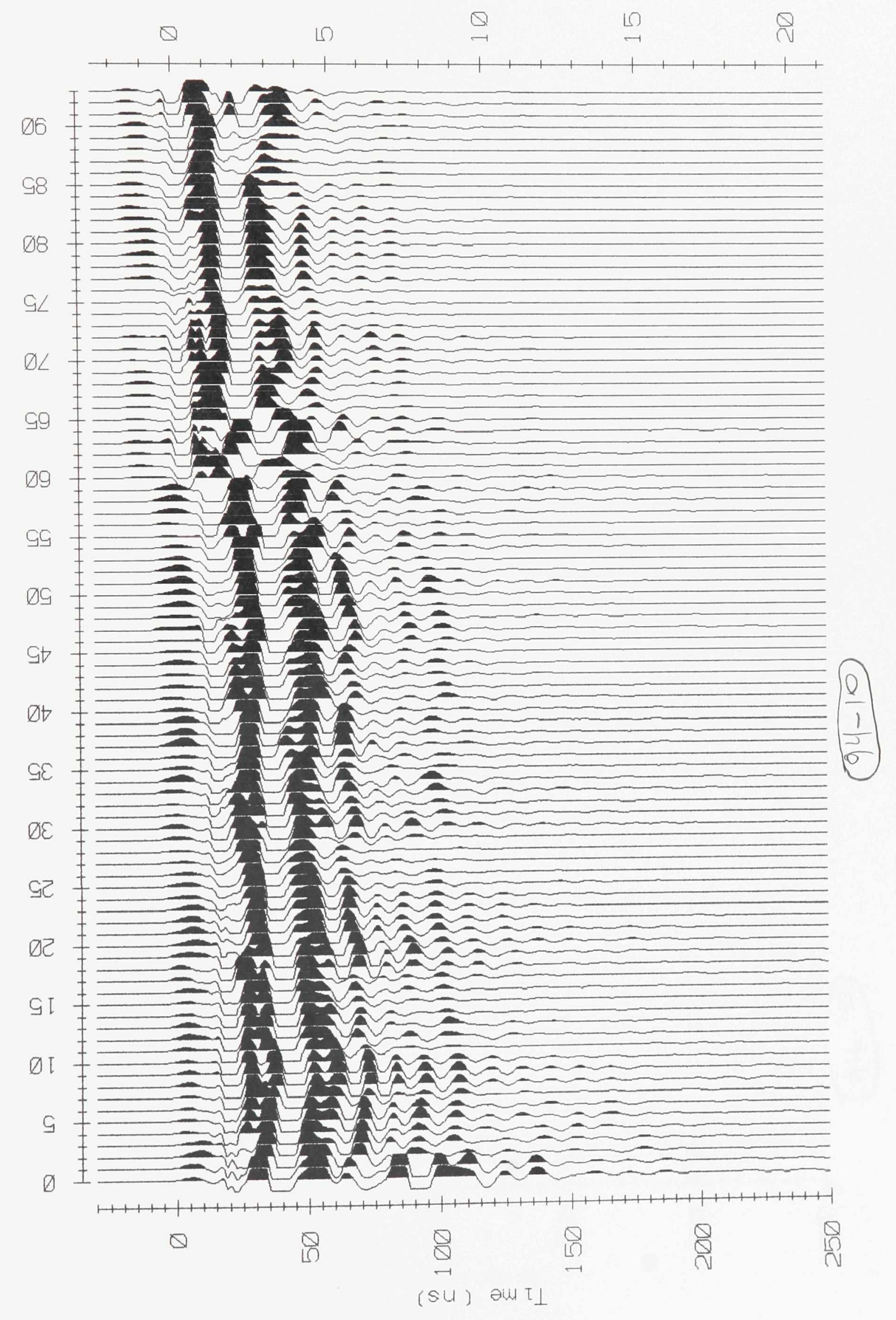


su/M $\varnothing \angle T^{\circ} \varnothing=\wedge$ (w) $47 d \partial \square$

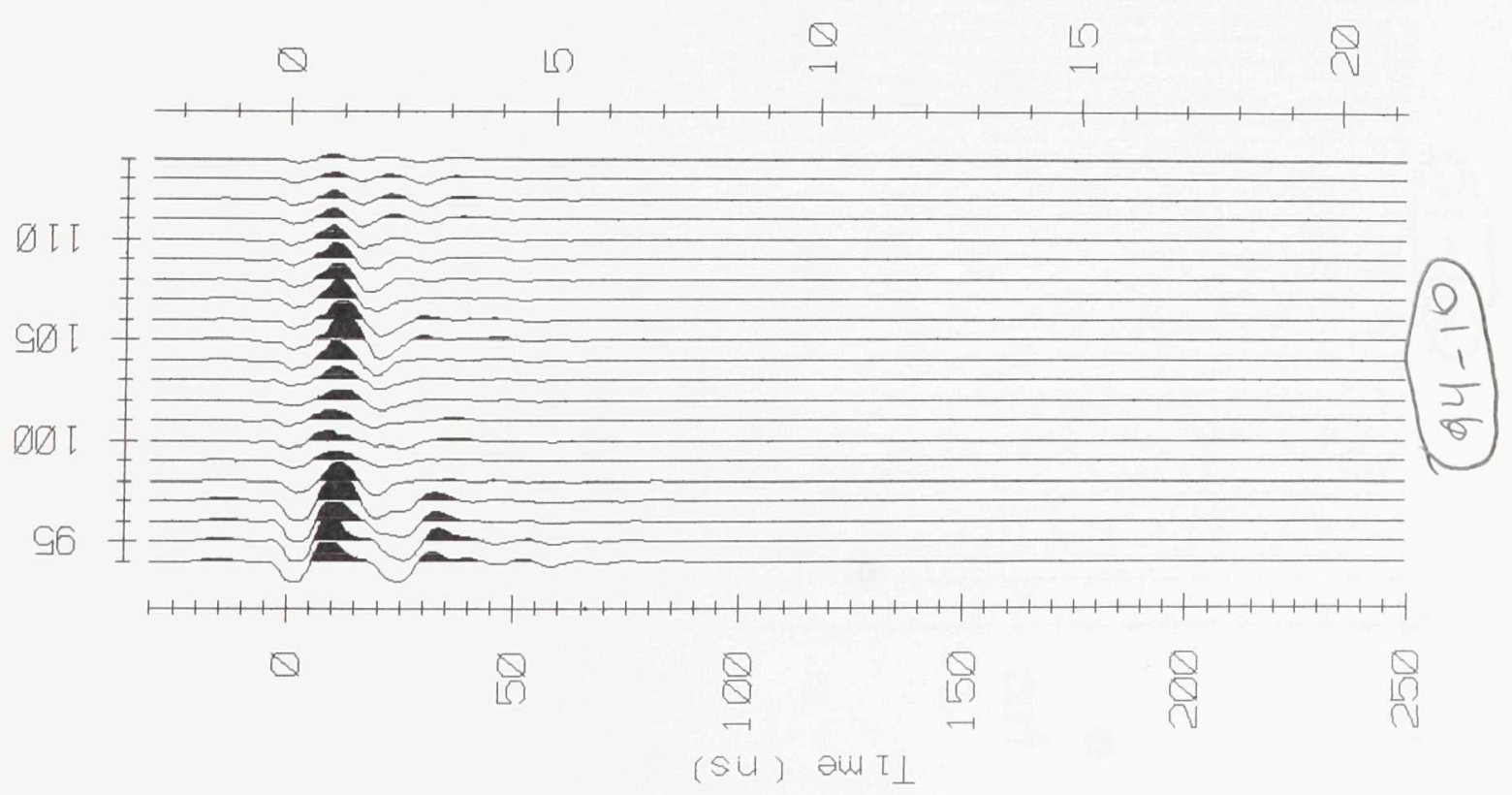


su/M $\varnothing \angle I^{\circ} D=\wedge$ (W) $47 d \partial \square$

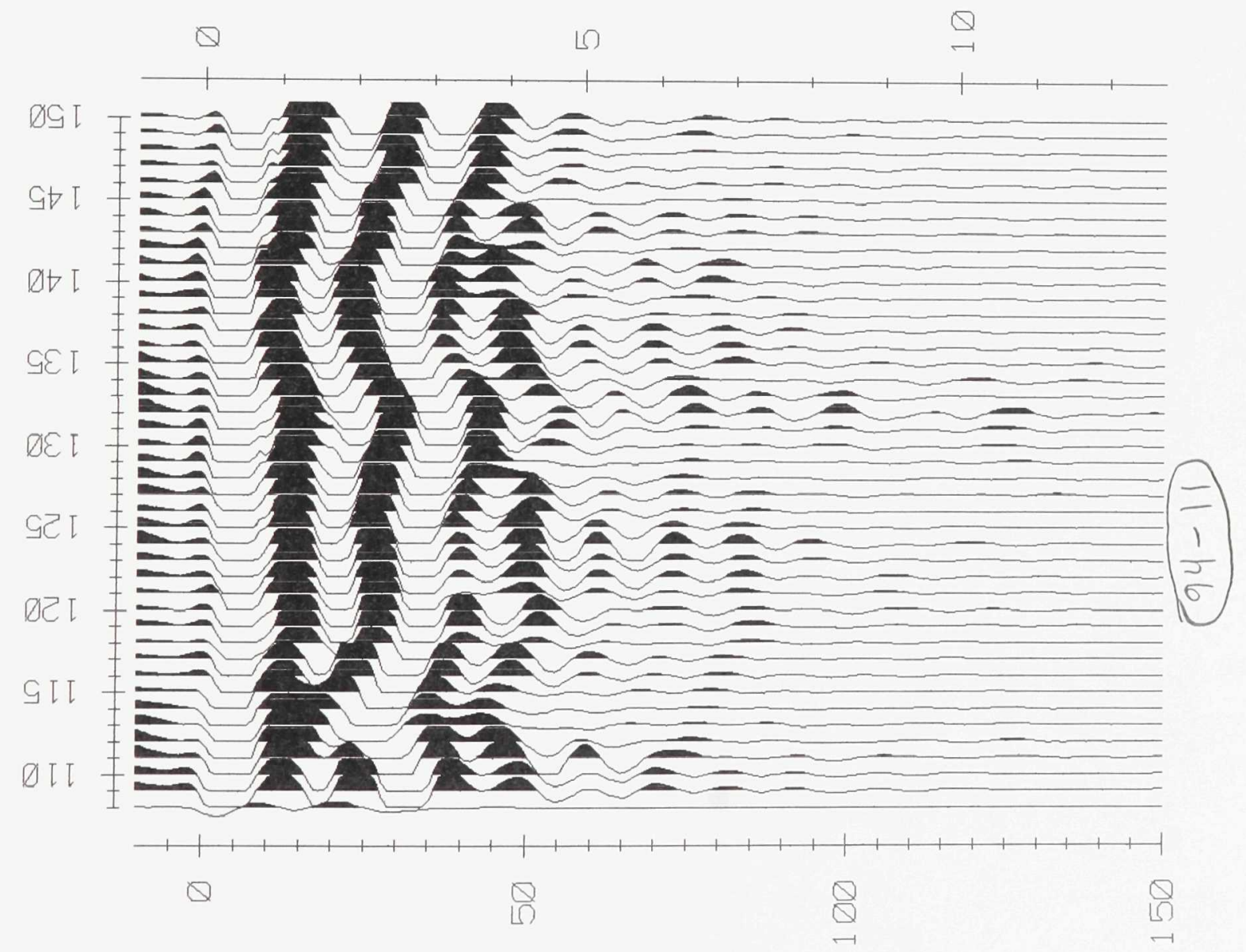

(su) Diut $I \perp$ 
su/m $\varnothing \angle I^{\circ} \varnothing=\wedge$ (w) $47 d \partial \square$

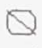

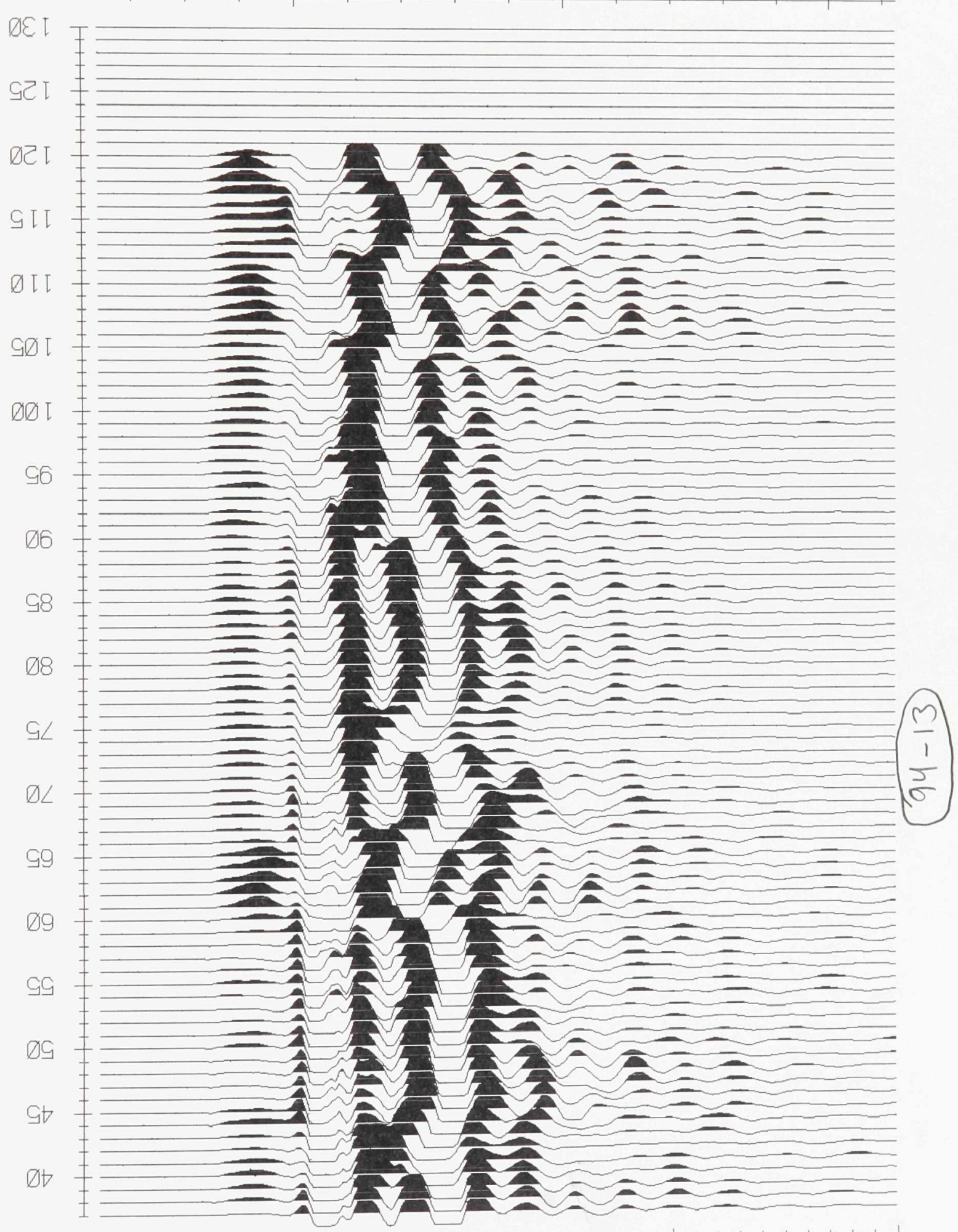

Q

ए)

Q

Q

(su) ais $I \perp$ 


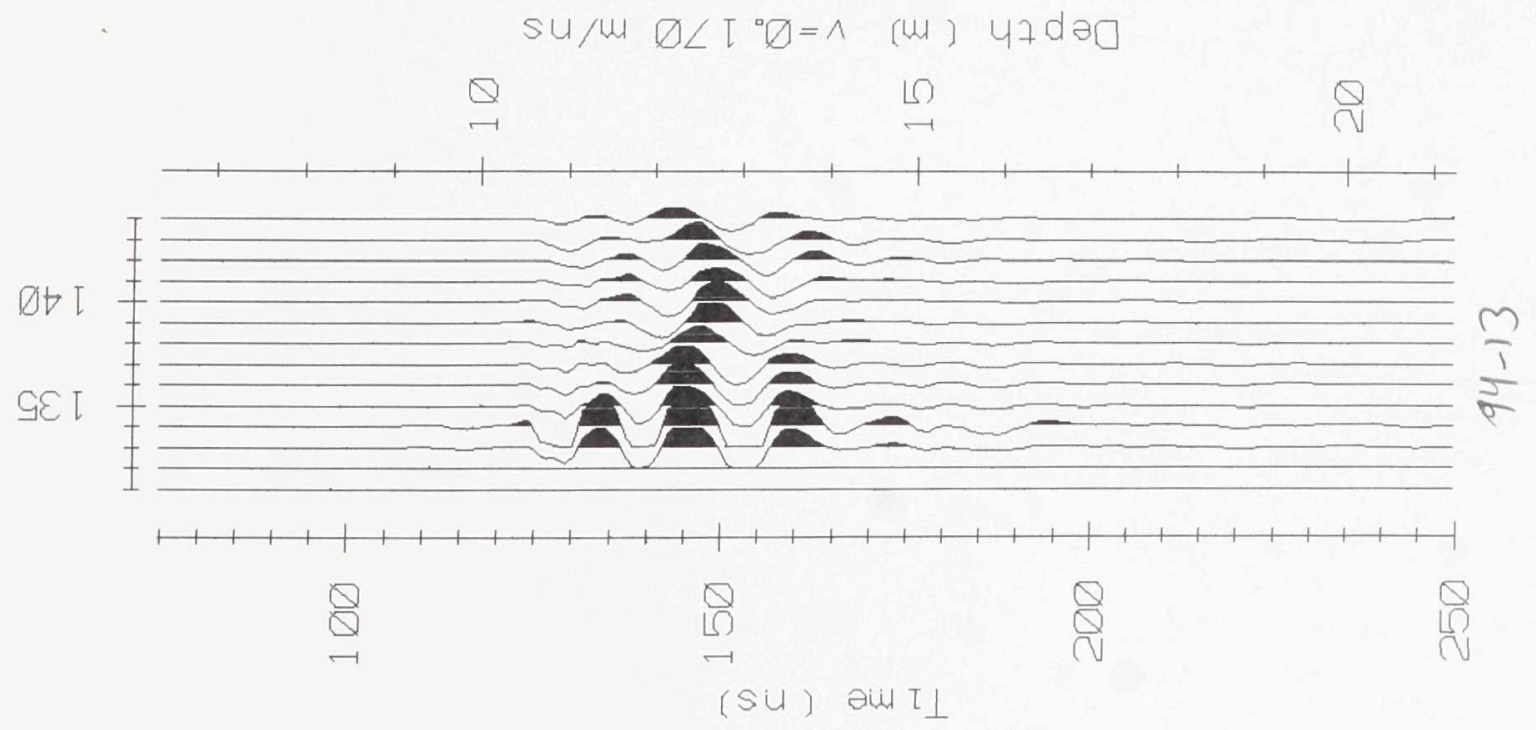


Appendix E:

Peninsula Point GPR profiles 


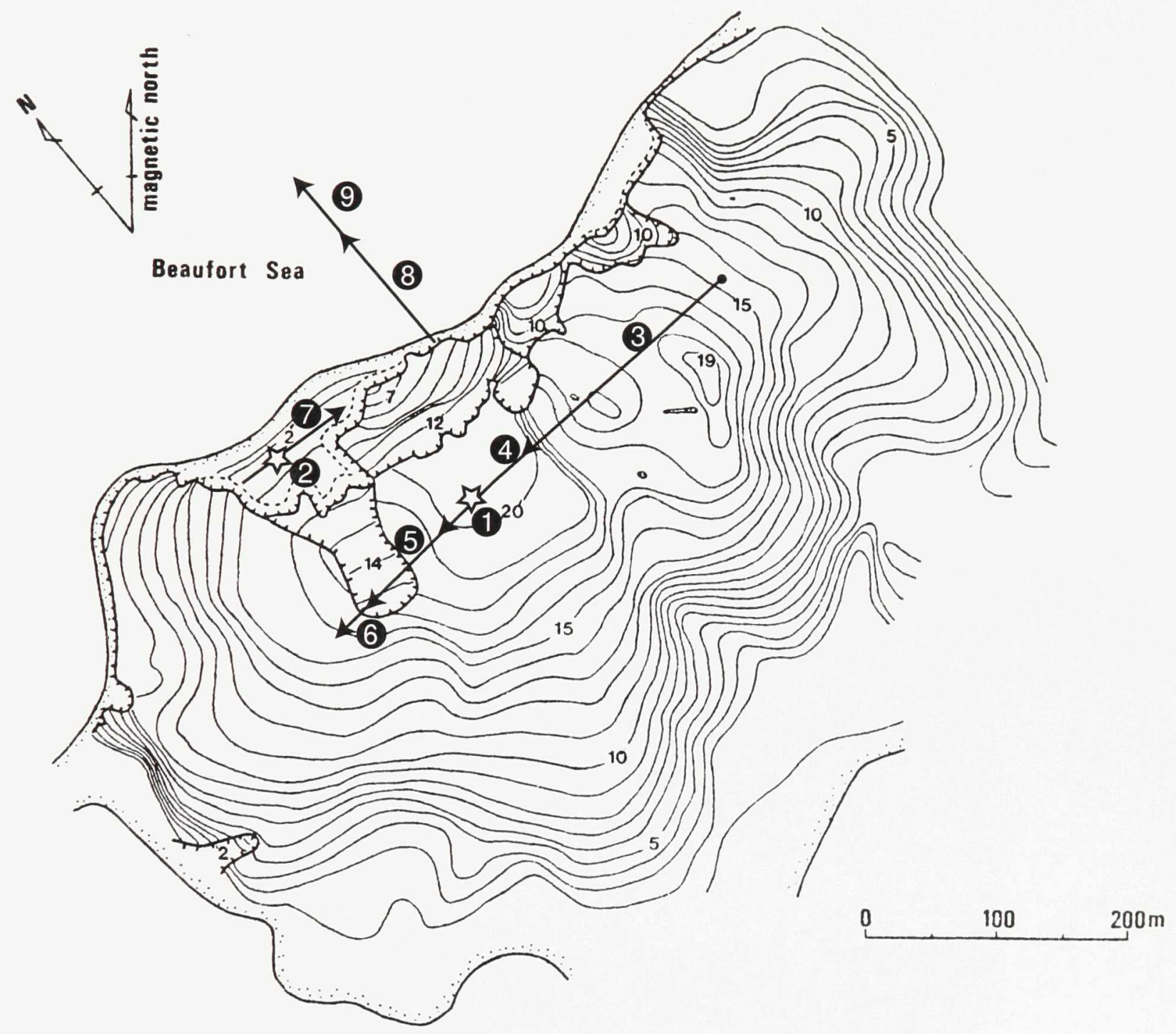

GPR profile locations. Arrows indicate direction of profile. Numbers in black circles relate to the profile number. Stars indicate the centre point of a CMP. The lines only indicate the approximate location of the profiles as they were run in different years and the headwall and general shape of the point changed rapidly. The data in profile 3 were collected in Sept. 1987, profiles 1, 2, 4, 5, 6, and 7 were collected in July 1988, and profiles 8 and 9 were collected in April 1990. 


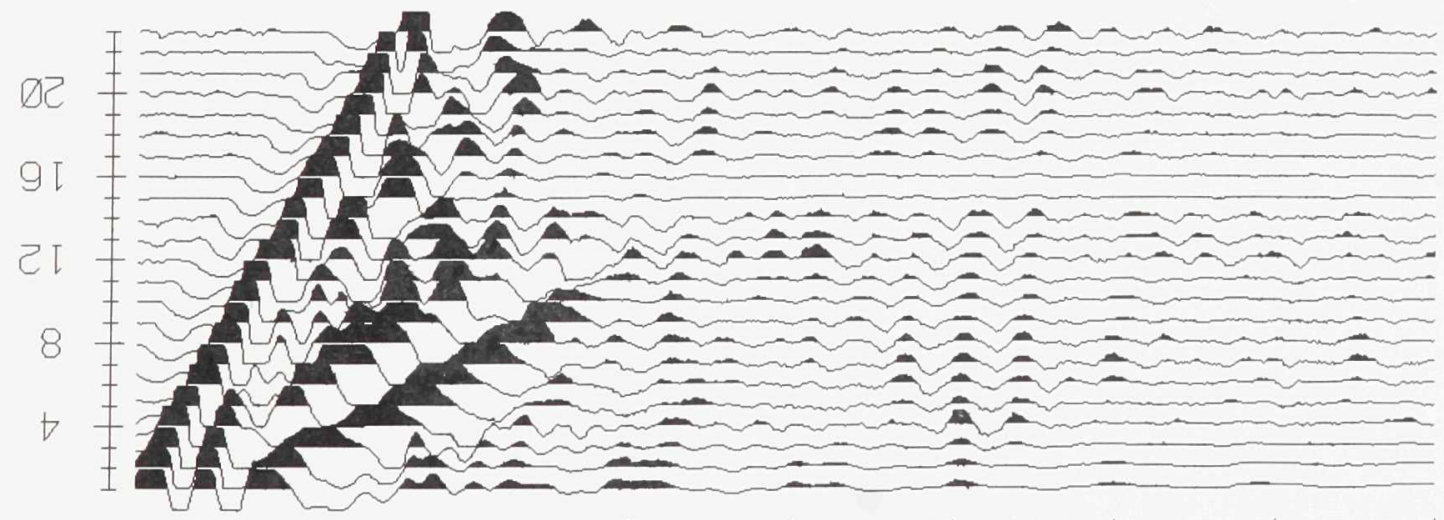
$|11111111| 111111111|11111111+1+111111|+11111111|11111111| 111111111+1111111+1$
ถึ)

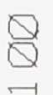
Q
$\mathbb{Q}$
ก
ले
लि $\quad \nabla$

(su) ais $I \perp$ 


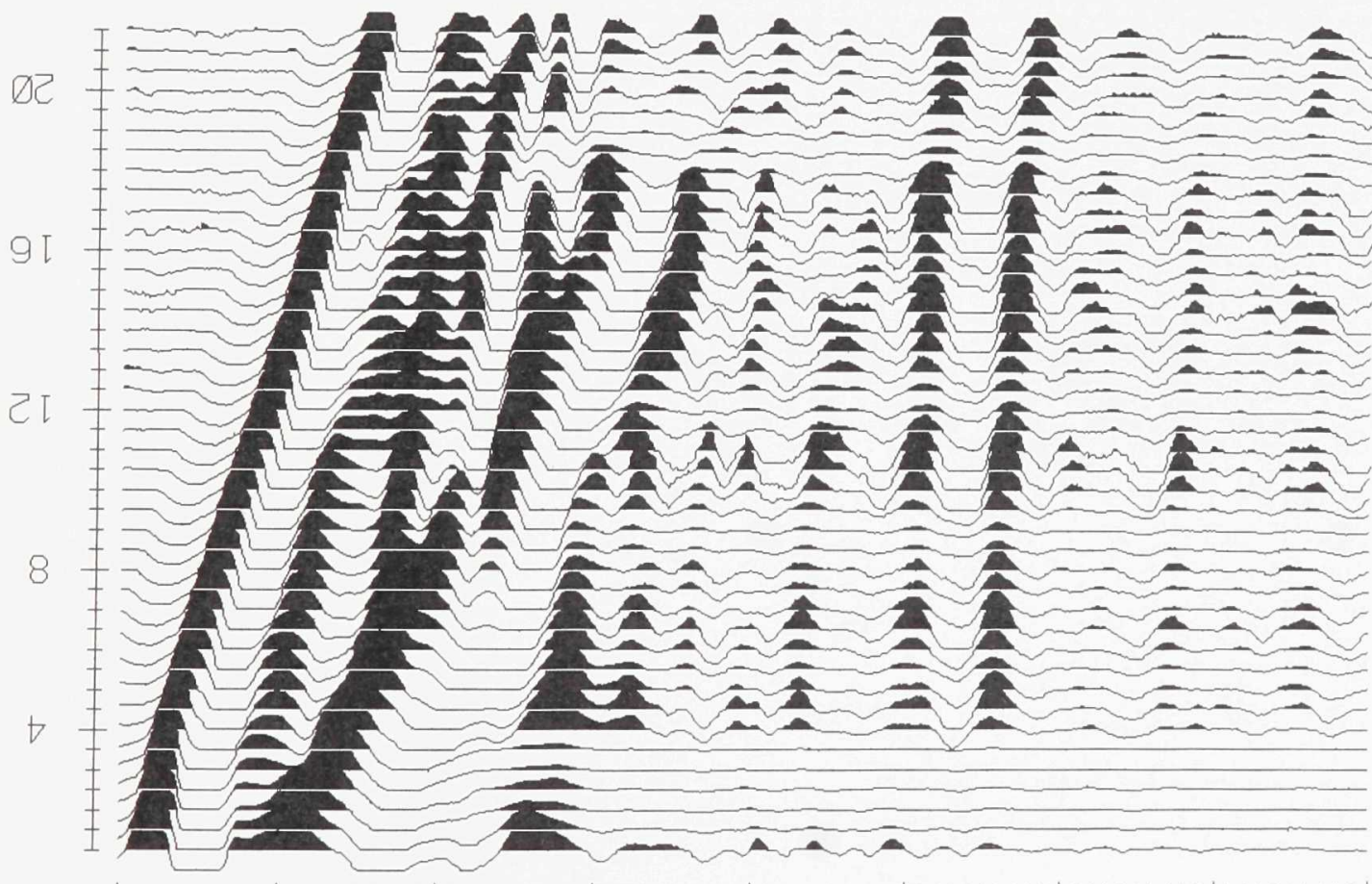

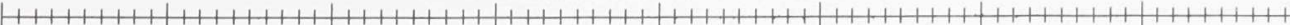

Q 


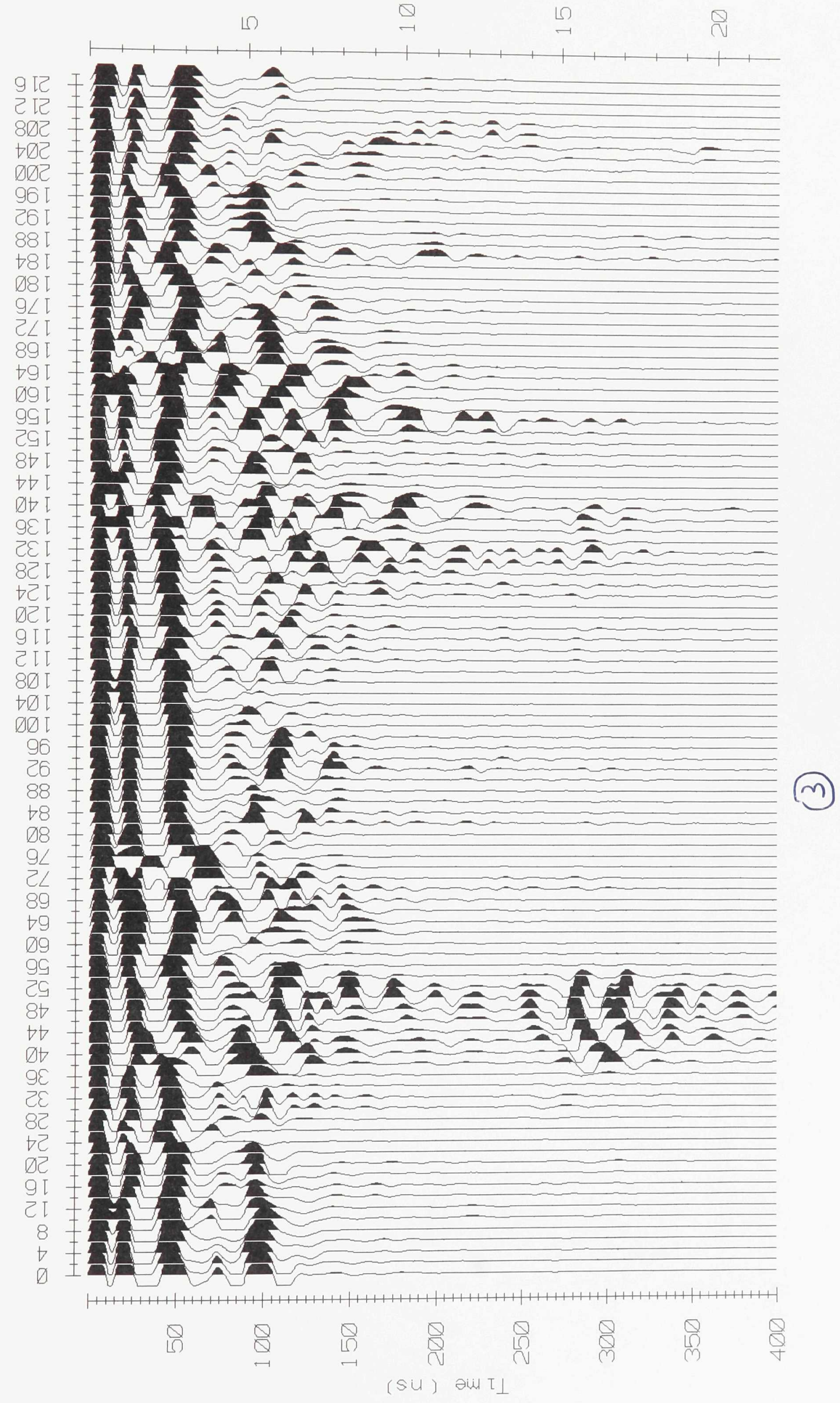


su/M ØI[ $\varnothing=\wedge \quad(m) 47 d \partial]$

เ)

Q

เ)

Q

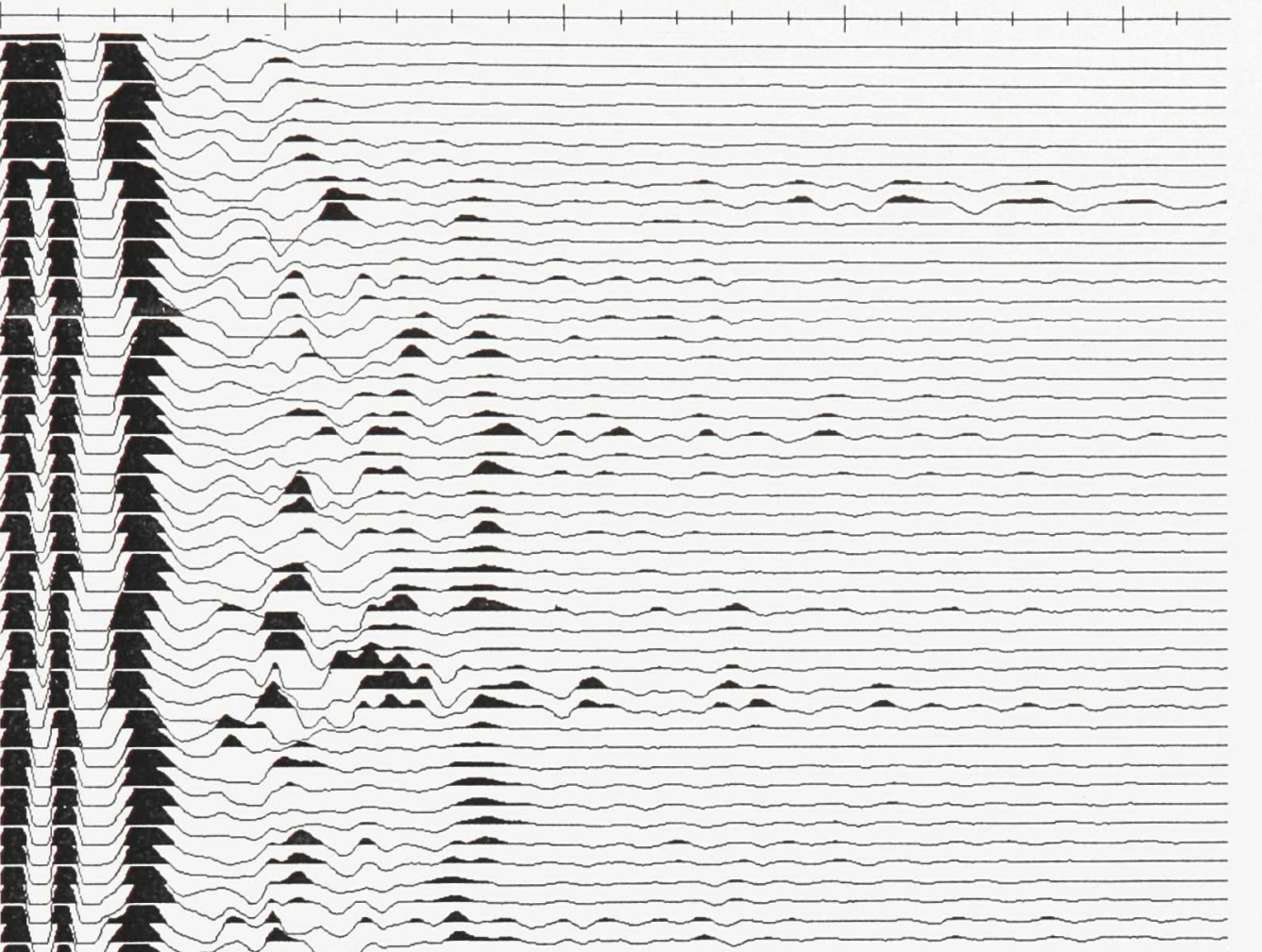

(])

S $2=1$

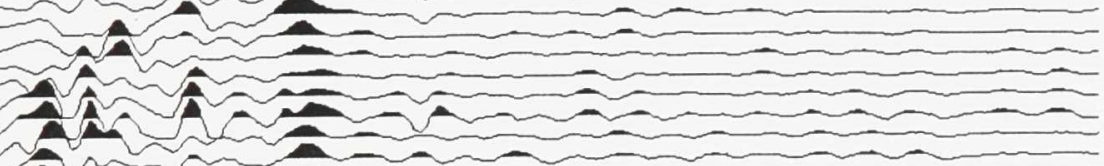

12

-

$992=2,12$

292

8†ट

$\nabla \nabla 2$

Ø๐2

$9 \varepsilon 2$

$2 \varepsilon 2$

822

$\forall 22$

๑टट

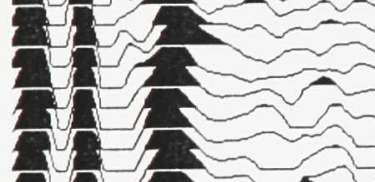

$$
\text { - }
$$

$\mathrm{CHC}_{2}$ 
30

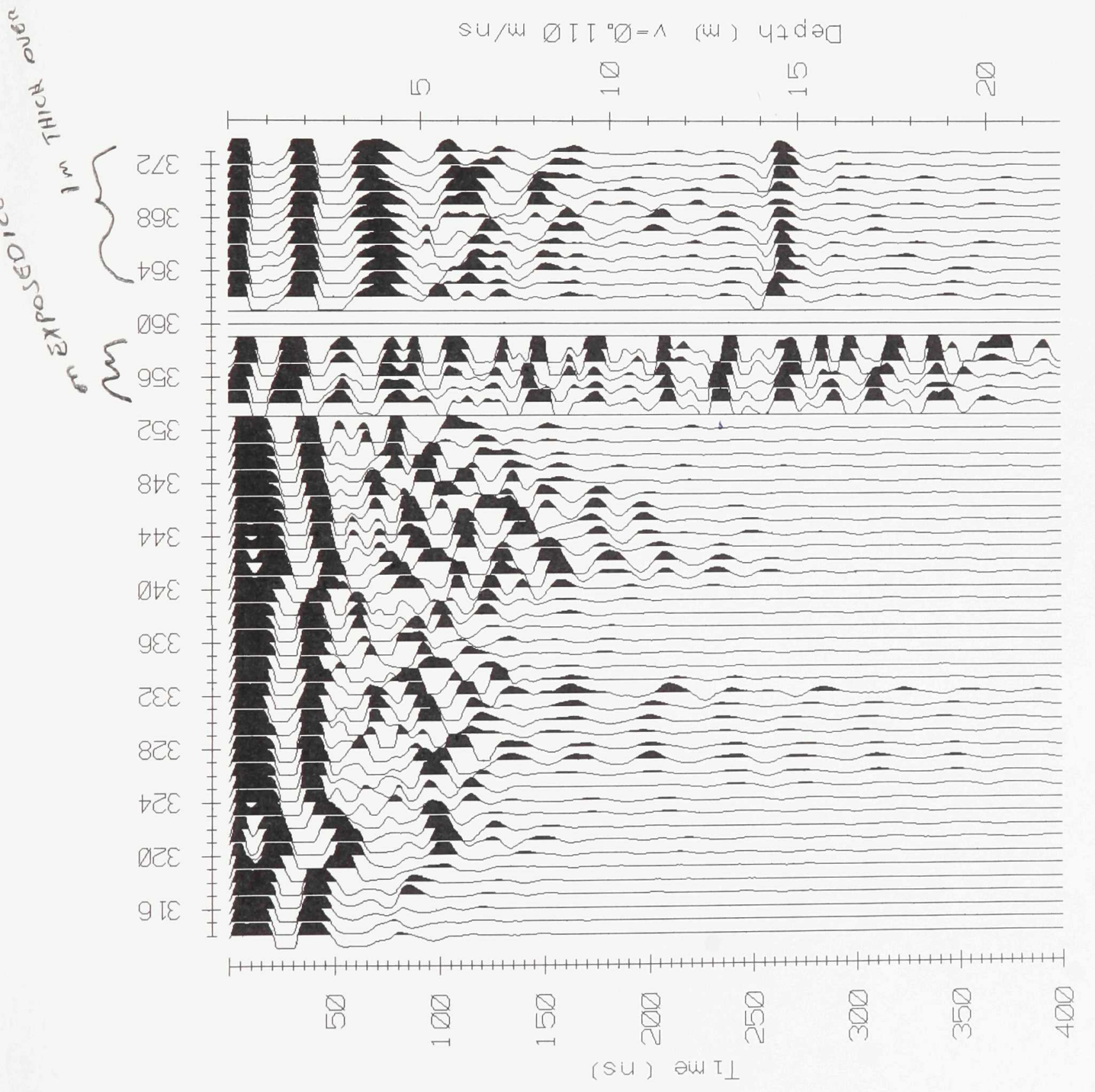

(1) 


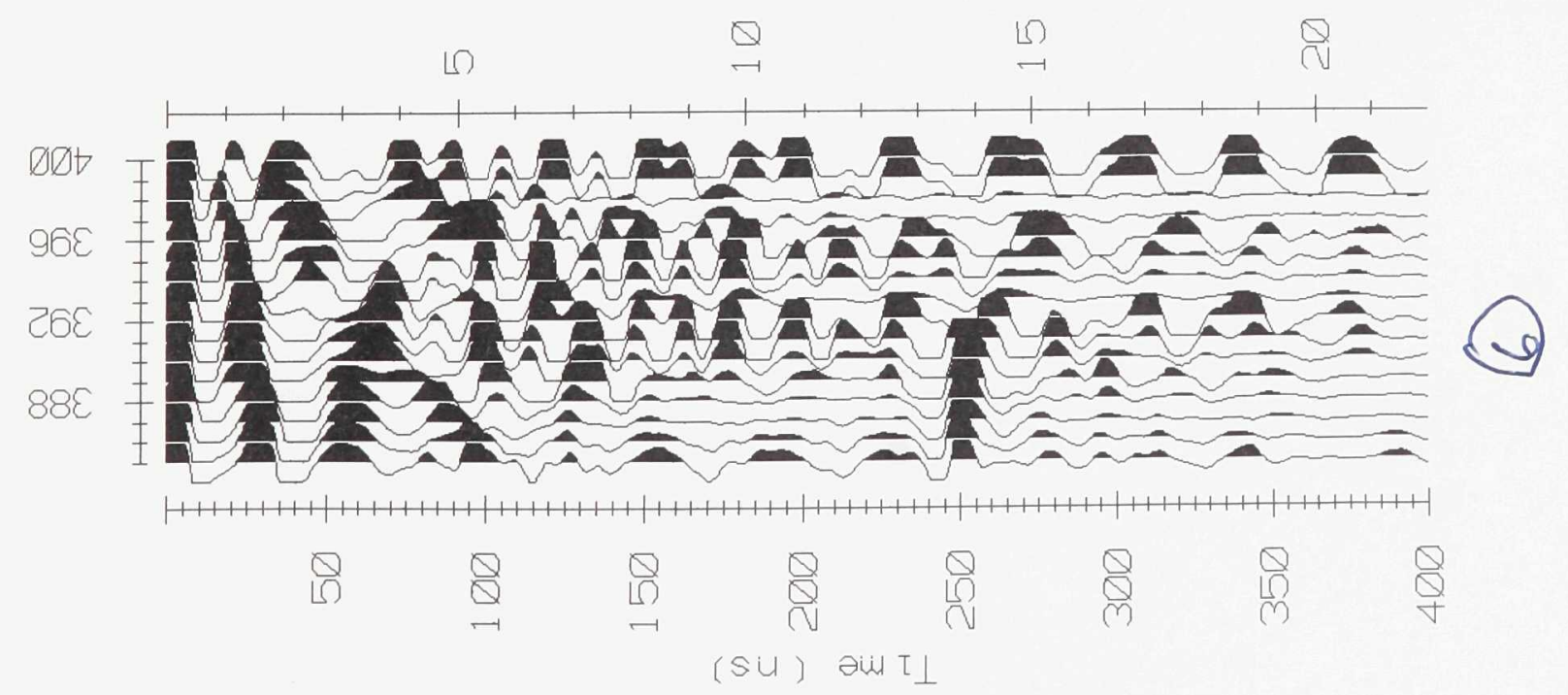


$\mathbb{H}$ 
เ)
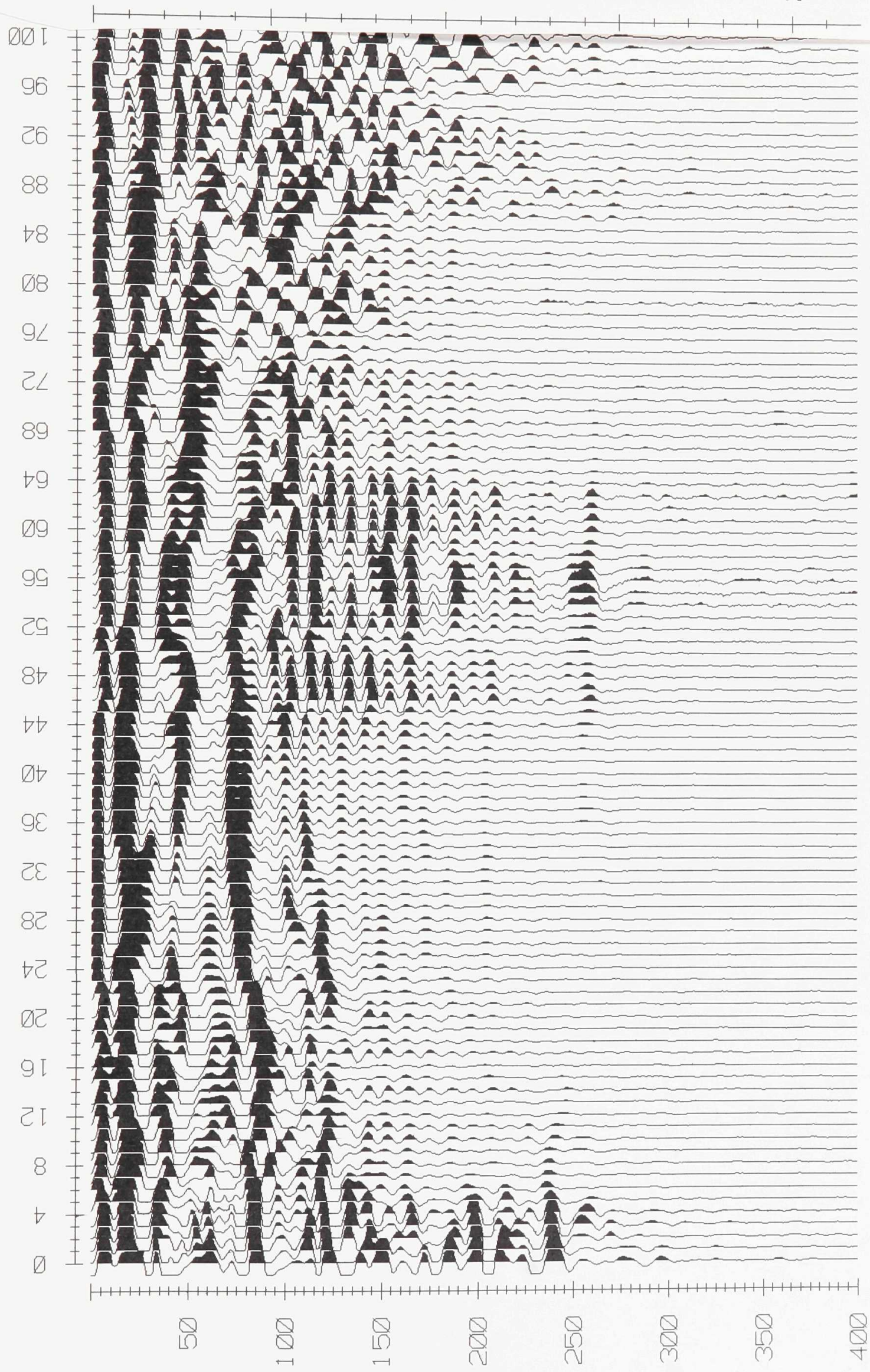
